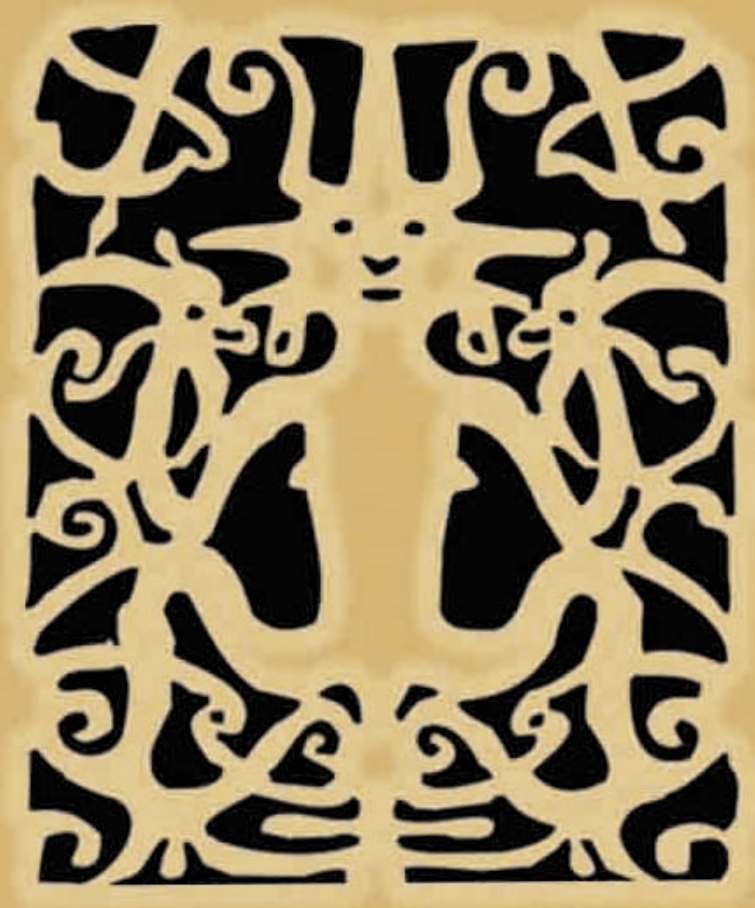

\title{
Social Science Research and
}

Conservation Mlanagement

in the linterior of Bomeo

Unravelling past and present interactions of people and forests

Editors

Cristina Eghenter

Bernard Sellato

G. Simon Devung 


\section{Social Science Research and Conservation Management in the Interior of Borneo}

Unravelling past and present interactions of people and forests

Editors

Cristina Eghenter

Bernard Sellato

G. Simon Devung 
(c) 2003 by CIFOR, WWF Indonesia,

UNESCO and Ford Foundation

All rights reserved. Published in 2003

Printed by Indonesia Printer, Indonesia

WWF Indonesia holds the copyright to

the research upon which this book is based.

The book has been published with financial support from UNESCO through its MAB Programme. The authors are responsible for the choice and the presentation of the facts contained in this book and for the opinions expressed therein, which are not necessarily those of UNESCO and do not commit the organisation.

\section{ISBN 979-3361-02-6}

The Center for International Forestry Research (CIFOR) was established in 1993 as part of the Consultative Group on International Agricultural Research (CGIAR) in response to global concerns about the social, environmental and economic consequences of forest loss and degradation. CIFOR research produces knowledge and methods needed to improve the well-being of forest-dependent people and to help tropical countries manage their forests wisely for sustained benefits. This research is done in more than two dozen countries, in partnership with numerous partners. Since it was founded, CIFOR has also played a central role in influencing global and national forestry policies.

National Library of Indonesia Cataloging -in-Publication Data

Social Science Research and Conservation Management in the Interior of Borneo: Unravelling Past and Present Interactions of People and Forests/ ed. by Cristina Eghenter, Bernard Sellato and G. Simon Devung.-Bogor, Indonesia: CIFOR, 2003. p. $\mathrm{cm}$

1. Forest management 2. Nature conservation 3. Social sciences 4. Anthropology 5. Research 6. East Kalimantan 7. Indonesia I. Eghenter, C. (ed.) II. WWF Indonesia Program III. Kayan Mentarang Conservation Project

\section{Published by}

Center for International Forestry Research

Mailing address: P. O. Box 6596 J KPWB, J akarta 10065, Indonesia

Office address: JI. CIFOR, Situ Gede, Sindang Barang,

Bogor Barat 16680, Indonesia

Tel.: +62 (251) 622622; Fax: +62 (251) 622100

E-mail: cifor@cgiar.org

Web site: http:// www. cifor. cgiar.org 


\section{Contents}

Preface

ix

Foreword

$\mathrm{xi}$

Contributors' Biodata xiii

Acknowledgements $\quad x v$

Executive Summary xvii

1 Introduction 1

by Cristina Eghenter and Bernard Sellato

\section{Resource management and traditional knowledge}

2. Biodiversity and traditional knowledge: Rice varieties among the Leppo' Ké of Apau Ping

by Indah Setyawati

3 Making a swidden: Social and technological aspects of Leppo' Ké agricultural practices

by Herculanus Bahari Sindju

4. Management, processing, and uses of rattan in Long Uli,

Puj ungan Subdistrict

65

by Martua Thomas Sirait

5. Eaglewood and forest product management and trade in the Bahau River region

by Blaj an Konradus

Traditional institutions and land tenure in a changing society

6. Traditional property rights over land among the Kenyah of Pujungan Subdistrict by S. J acobus E. Frans L.

7. Patterns of traditional land control among three Kenyah groups by Angguk Lamis, Concordius Kanyan and Y. Paulus Bunde 
8. Traditional forest use and management among the Kenyah of the Upper Bahau Area

by $\mathrm{G}$. Simon Devung

Recovering the past (in non-literate societies): Implications for development

9 A history of the Kenyah Leppo' Ké and Nyibun in Puj ungan

Subdistrict

by $\mathrm{Nj}$ au Anau

10. A history of the Kenyah Leppo' Tau in Kayan Hulu Subdistrict, Apau Kayan

by Liman Lawai

11. Archaeological surveys and research in four subdistricts of interior East Kalimantan

by Karina Arifin and Bernard Sellato

Research output back to local communities: Strengthening cultural identity and traditional rights?

12. Kenyah Bakung oral literature: An introduction by C. Yus Ngabut

13. Folk songs of the Kenyah Leppo' Ma' ut: A study of text and music by Daniel Lawing 


\section{List of tables}

Table 2.1 Farmers' sources of rice seeds 38

Table 2.2 Quality of non-kin from whom varieties were received 38

Table 2.3 Average number of rice varieties known according

to farmers' age 40

Table 3.1 Land use, by percentage (1979-1993) 54

Table 3.2 Rice yields, by percentage (1979-1993) 60

Table 3.3 Farming rituals and the melaki ceremony 61

Table 4.1 Analysis of three plots (I-II-III, 0.4 ha) of wild rattan 70

$\begin{array}{lll}\text { Table } 4.2 & \text { Analysis of a plot of planted rattan } & 71\end{array}$

Table 5.1 Prices (in Rp/ kg) per grade category in 1993

Table 5.2 Local eaglewood collectors in Pujungan Subdistrict 92

Table 6.1 Types of rights in Kenyah society in Pujungan Subdistrict 111

Table 7.1 Type of land cleared for farming in Long Apan Baru 120

Table 7.2 Owned and borrowed farm land (1984-1993)

in Long Apan Baru 121

Table 7.3 Total number of farm land plots owned per family in Apau Ping 126

Table 7.4 Owned and borrowed farm land (1984-1993) in Apau Ping 127

Table 8.1 Types of forest used for dry rice farming since $1990 \quad 140$

Table 8.2 Number of households owning hunting and fishing facilities 141

Table 8.3 Number of households involved in collecting forest products between two farming seasons (1994-1995) 141

Table 8.4 People (per household) involved in farming activities (1995-1996 farming season) 147

Table 9.1 Leppo' Ké and Nyibun population in Pujungan Subdistrict 154

Table 9.2 Population of the compound village of Apau Ping 154

Table 11.1 Distribution of container shapes in the upper Bahau 226

Table 13.1 Typology of Kenyah Leppo' Ma'ut songs 261

Table 13.2 Typology of Kenyah Leppo' Ma'ut instruments 269

\section{List of figures}

$\begin{array}{lll}\text { Figure } 1.1 & \text { The Island of Borneo } & 20\end{array}$

Figure 1.2 Kayan Mentarang and surrounding region 21

Figure 1.3 Ethnic groups in and around Kayan Mentarang 24

Figure 1.4 Secondary forest after swiddening by the Kenyah 30

Figure 1.5 A Kenyah swidden and field hut 30

Figure 1.6 A thatched Kenyah field hut by a swidden 30

Figure 1.7 A few such hanging rattan bridges are still in use 31

Figure 1.8 A blacksmith at work at the bellows 31

Figure 3.1 Threshing the paddy by trampling (mi'ik) 63

$\begin{array}{lll}\text { Figure } 3.2 \text { Winnowing the paddy (maping) } & 64\end{array}$ 
Figure 3.3 Storing the paddy in the barn (lepubung) 64

$\begin{array}{lll}\text { Figure } 4.1 & \text { The rattan plant and its parts } & 68\end{array}$

Figure 4.2 Proportion of young, old, dead, and harvested stems in Plots I-II-III $\quad 71$

Figure 4.3 Proportion of young, old, dead, and harvested stems in Plot IV

$\begin{array}{lll}\text { Figure 4.4 Collecting rattan in the forest } & 74\end{array}$

$\begin{array}{lll}\text { Figure } 4.5 & \text { Coils of rattan (rotan sega) } & 74\end{array}$

$\begin{array}{lll}\text { Figure } 4.6 \text { Tools for triming } & 75\end{array}$

$\begin{array}{lll}\text { Figure } 4.7 & \text { Rattan uses (1) } & 76\end{array}$

$\begin{array}{lll}\text { Figure } 4.8 & \text { Rattan uses (2) } & 79\end{array}$

$\begin{array}{lll}\text { Figure } 4.9 & \text { Rattan uses (3) } & 80\end{array}$

Figure 5.1 Class I eaglewood $\quad 85$

Figure 5.2 Class II eaglewood 85

Figure 5.3 Lower grade eaglewood 86

Figure 5.4 Collectors checking and cleaning their produce 95

Figure 5.5 The toké sorting the eaglewood into grades 96

$\begin{array}{ll}\text { Figure 6.1 Author conducting an interview in Long Ketaman } & 104\end{array}$

Figure 6.2 Old settlement site (lepu' un) at Long Ngiam 104

Figure 7.1 Mulen signs made by the Kenyah Leppo' Ma'ut 133

Figure 7.2 Mulen signs made by the Kenyah Bakung 133

Figure 9.1 A cluster of Leppo' Ké swidden fields near Apau Ping 154

Figure 9.2 Up the Bahau River with 'long-tail' engine to reach Apau Ping 156

$\begin{array}{lll}\text { Figure 9.3 Sketch map of the Apau Ping settlement in } 1992 & 157\end{array}$

Figure 9.4 Elderly Leppo' Ké informant Bilung Lerang at Long Lat (Apau Ping) 158

Figure 9.5 Migrations of the Leppo' Ké and Nyibun (1) 160

Figure 9.6 Historical settlements of the Kenyah Leppo' Ke' 161

$\begin{array}{lll}\text { Fgiure 9.7 Migrations of the Leppo' Ké (2) } & 164\end{array}$

$\begin{array}{lll}\text { Figure 9.8 Historical settlements of the Nyibun } & 166\end{array}$

$\begin{array}{lll}\text { Figure 9.9 Migrations of the Nyibun (2) } & 167\end{array}$

Figure 9.10 Nyibun informant J alung Apui at Long Aking (Long Berini) 169

Figure 9.11 Informant Oko' Ncuk Usat, with author, at Long Pengayan (Apau Ping)

171

Figure 9.12 A Leppo' Ké or Nyibun carved stone on a hill in upper Ngiam area 173

$\begin{array}{ll}\text { Figure 9.13 Stone barkcloth beaters excavated in Apau Ping } & 174\end{array}$

Figure 9.14 Author and ancient Nyibun funerary monuments at Long Lat site $\quad 174$

$\begin{array}{lll}\text { Figure 9.15 A Nyibun funerary monument in the upper Ngiam River area } & 174\end{array}$

Figure 10.1 Hydrographic map of interior northern East Kalimantan 185

Figure 10.2 Migrations of the Kenyah Leppo' Tau (1) 186

Figure 10.3 Hydrographic map of Apau Kayan 188

Figure 10.4 Migrations of the Kenyah Leppo' Tau (2) 189

Figure 11.1 Archaeological sites in Pujungan Subdistrict 202

Figure 11.2 Terminology of the stone urn-dolmen 203 
Figure 11.3 Surface finds of decorated pottery shards from Long Berini 204

Figure 11.4 Two stone bark beaters as surface finds from Long Berini 205

Figure 11.5 Surface finds from Apau Ping 205

Figure 11.6 Surface finds of decorated pottery shards from Apau Ping 205

Figure 11.7 Archaeological sites in Kerayan Subdistrict 207

Figure 11.8 Two anthropomorphic figures at Paru' Ating, Kerayan Hulu area of Kerayan Subdistrict 209

Figure 11.9 Anthropomorphic figure carved on a rock face by the river near Pa' Upan, Kerayan Subdistrict 209

Figure 11.10 Two menhirs standing in front of the village school, Tang La'an, Kerayan Subdistrict

Figure 11.11 Archaeological sites in Kayan Hulu and Kayan Hilir Subdistricts, Apo Kayan

Figure 11.12 A basalt tool found at Long Ampung, Kayan Hulu Subdistrict

Figure 11.13 A basalt tool found in Mentarang Subdistrict

Figure 11.14 Stone trough at Mudung Kerica, near Long Uro', Kayan Hulu Subdistrict

Figure 11.15 Stone trough at J uman Nawang, near Long Nawang, Kayan Hulu Subdistrict

Figure 11.16 Stone trough at J uman Nawang, near Long Nawang, Kayan Hulu Subdistrict

Figure 11.17 Rectangular stone trough at Batu Tukung, near Lidung Payau, Kayan Hulu Subdistrict

Figure 11.18 Rectangular stone vat at Batu Tukung, near Lidung Payau, Kayan Hulu Subdistrict 214

Figure 11.19 Large stone container with carved pillar at Data Kanuyang, Kayan Hilir Subdistrict

Figure 11.20 Anthropomorphic figure carved on a standing stone; Long Sungan, near Lidung Payau, Kayan Hulu Subdistrict

Figure 11.21 Carved stone pillars at Long Sungan, near Lidung Payau, Kayan Hulu Subdistrict

Figure 11.22 Carved stone pillar at Sawa' Angen, near Lidung Payau, Kayan Hulu Subdistrict

Figure 11.23 Anthropomorphic figure carved on a standing pillar at Long Poh, Kayan Hilir Subdistrict

Figure 11.24 Batu Kalung, a large carved boulder, some way off Long Uro', Kayan Hulu Subdistrict

Figure 11.25 Graveyard sites inventoried and test pits in Pujungan Subdistrict

Figure 11.26 Typology of stone containers 
Figure 11.32 Ovoid stone container in Ka' Tempu (No. 50) 223

Figure 11.33 Carved stone urn in Long Pulung, upper Bahau 224

Figure 11.34 Stone monuments in Long Beraa (No.3) 225

Figure 11.35 Skulls and bones from grave No. 3 in Long Beraa 225

$\begin{array}{lll}\text { Figure } 11.36 & \text { Pottery Terminology } & 228\end{array}$

$\begin{array}{ll}\text { Figure 11.37 } & \text { Ridges in earthenware (Apau Ping): } \\ & \text { (a to e) test pit III Lot 2; (f-g) test pit III Lot } 4\end{array}$

Figure 11.38 Ridges in earthenware from Apau Ping: test pit III Lot 3229

Figure 11.39 Rims in earthenware from Apau Ping: test pit III Lot 12230

Figure 11.40 Rims in earthenware from Apau Ping: test pit III Lot $2 \quad 230$

Figure 11.41 Pattern made by thin string wrapped around a paddle 231

Figure 11.42 Pattern made by thick string wrapped around a paddle 231

Figure 11.43 Terminology of the adze 232

Figure 11.44 Typology of stone adzes from the upper Bahau, type A 233

Figure 11.45 Typology of stone adzes from the upper Bahau, type B 234

Figure 11.46 Typology of stone adzes of the upper Bahau, $\mathrm{C}$ to $\mathrm{H} \quad 235$

Figure 11.47 Stone gouge from the upper Bahau 236

Figure 11.48 Stone pounder from the upper Bahau 236

Figure 12.1 Pui PeAnye' Usat singing a tekena' in the usual lying position 245

Figure 12.2 A singer performing and recording a tiang or kendau song 246

Figure 12.3 An elderly Bakung chief, PeNcuk, in his warrior's attire, now used in dancing 251

Figure 12.4 A Bakung girl in dancing attire, ready to perform 251

Figure 13.1 Oko' Dan Lawing performing the belian kenai ndok song 260

Figure 13.2 Oko' J angin performing the belian suket song 262

Figure 13.3 Oko' Awing Lawing performing the silun ketena' song 264

Figure 13.4 A typical, comfortable posture for listening to a ketena' epic song 265

Figure 13.5 Oko' Asong performing the menjaeng song 265

Figure 13.6 Woman performing traditional dance in Long Alango 266

Figure 13.7 Man performing traditional dance in Long Alango 266

Figure 13.8 Author and friend in traditional Leppo' Ma'ut costume 266

Figure 13.9 Parts of the sambi' lute (viewed from the front) 270

Figure 13.10 Young man playing the sambi' at Long Alango 270

Figure 13.11 Recording Bakung lute music in Long Aran, $1992 \quad 270$

Figure 13.12 An example of sambi' tuning 271

$\begin{array}{lll}\text { Figure 13.13 Parts of the lutung zither } & 271\end{array}$

Figure 13.14 A lutung zither, played by a Bakung woman at Long Aran 272

Figure 13.15 Short (a) and long (b) odeng talang jaran jew's harp 272

Figure 13.16 The pentatonic geng galeng xylophone 273

Figure 13.17 Leppo' Ma'ut musician Oko' Wak playing the geng galeng 273 


\section{Preface}

UNESCO's Programme on Man and the Biosphere (MAB) develops the basis, within the natural and the social sciences, for the sustainable use and conservation of biological diversity, and for the improvement of the relationship between people and their environment globally. The MAB Programme encourages interdisciplinary research, demonstration and training in natural resource management. MAB contributes thus not only to better understanding of the environment, including global change, but to greater involvement of science and scientists in policy development concerning the wise use of biological diversity.

Current and future MAB is focusing on new approaches, such as the Ecosystem Approach adopted by Convention on Biological Diversity (CBD), for facilitating sustainable development. By taking advantage of the transdisciplinary and cross-cultural opportunities of UNESCO's mandate in the fields of education, science, culture and communication. MAB is promoting both scientific research and information gathering, as well as linking with traditional knowledge about resource use. It serves to help implement Agenda 21 and related Conventions, in particular CBD.

During the last three decades UNESCO has supported and collaborated with the Indonesian National MAB Committee in the implementation of the MAB Programme. Establishment of Biosphere Reserves that represent both biological and cultural diversity, expert training and research on interaction between people and forests integrating social and natural sciences in its approach, were among the main past activities. One example was the training course in 1992 at the Kayan Mentarang National Park on research on ecology and conservation covering also ethnobotany and the production of the video films on 'the Last Traditional Potter of Borneo' in 1997. The training and the film production constituted part of the WWF Indonesia project on Culture and Nature Conservation. UNESCO encouraged the publication of Kebudayan dan Pelestarian Alam, an Indonesian version of the book on Culture and Nature Conservation. It is therefore very appropriate for UNESCO to support with CIFOR, WWF, the Ford Foundation and the MacArthur Foundation the publication of the present book on Social Science Research and Conservation Management in the Interior of Borneo: Unraveling Past and Present Interactions of People and Forests. 
The research approach adopted in the WWF project focusing on the interrelationship between people and the natural environment of the Kayan Mentarang has proved successful for integrating socio-cultural components into conservation management of the National Park. It will be a very valuable reference for those managing Biosphere Reserves and other conservation areas in Indonesia and in Southeast Asia, and contribute to the conservation efforts at a global scale. We congratulate the editors for their excellent work in the preparation of this book and believe this publication will contribute to better integration of social and natural sciences for sustainable management of protected areas.

Ecology-MAB Section, UNESCO Office, Jakarta

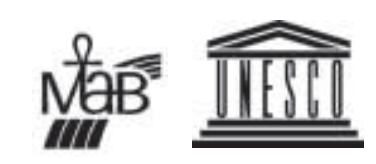




\section{Foreword}

From the vantage point of early 2003 , it is difficult to conjure the intellectual and political atmosphere within which the ideas that eventually led to the Culture \& Conservation Program were nurtured. In the late 1980s in Indonesia, the Suharto regime was firmly in control-and indeed was the darling of the international donor community-and all decisions about forest management and nature conservation were centralised in the Ministry of Forestry in Jakarta. Landscapes to be managed for production and those to be managed for protection of nature were demarcated with strict boundaries, at least in official policy and on paper. Discussions about indigenous peoples' resource rights were conducted sotto voce, if at all, when representatives of the regime were nearby.

Yet within this confined space, a number of creative individuals coming from very different backgrounds and institutions began imagining a different world. Their intuition told them that there was a confluence of interest between those concerned about threats to the ecological wealth of Indonesia's forests, and those concerned about threats to the cultural diversity and integrity of the peoples who inhabited those forests -threats that included misguided attempts to 'develop' the people and 'protect' the forests, for example, through resettlement.

More specifically, there was an intuition that efforts to document the oral histories and contemporary natural resource management practices of forest-dwelling communities could serve three mutually-reinforcing purposes. First, documentation of the histories of those communities could substantiate their claims to land and resources based on long-term residence and management, especially if accompanied by maps that could compete for legitimacy with those drawn by officials in J akarta and in provincial capitals. While such claims might not receive a fair hearing in the political climate of 15 years ago, there was a hope that some day, that climate would change.

Second, a better understanding of how forest-dwelling communities had traditionally managed natural resources-and had adapted those systems in response to dynamic pressures over the years-would provide insights into how those systems might be articulated with nature conservation approaches being promoted by various outside interests, in a way that served both community and conservation interests.

Third, translation of the rich cultural heritage of forest-dwelling communities into forms accessible to outsiders would be a scientific, spiritual and aesthetic gift to 
the rest of the world. That gift would in turn give voice to the communities themselves, and broaden the constituency for protecting those communities from thoughtless disruption of the social and ecological systems that had generated such cultural riches.

With the 1990s now come and gone, we live in a world in which much of what was once intuition has achieved the status of conventional wisdom. Everyone now 'knows' about the interdependence of ecological and cultural diversity. We all understand the linkages between natural resources management and social justice. We appreciate the value of local knowledge, and mapping techniques are a common arrow in the quiver of strategies to secure recognition of land rights. And the idea of anthropologists and conservationists working together on the same team is hardly novel.

But at the time the Cultural and Conservation Research Program was initiated, these ideas were not yet conventional wisdom. We all owe a debt of gratitude to Bernard Sellato as well as Tim J essup, Alan Feinstein and other individuals from the World Wide Fund for Nature (WWF) Indonesia and the Ford Foundation who were willing to reach across institutional and disciplinary interests to find common cause. We are also indebted to the many young (Indonesian and foreign) researchers where were willing to take the risk of investing their early careers in a research program of as yet unproven viability, including the Dayak researchers who took upon the task of looking scientifically at their own history and traditions. And we are certainly indebted to the communities in Kayan Mentarang whose welcome and knowledge were essential if the research were to have any meaning at all, whether to scholars or practitioners.

Indeed, an underappreciated value of the Culture \& Conservation Program has been its demonstration of the feasibility of the approach and the utility of its outcome, despite the many challenges along the way. It has made a significant contribution to the broad acceptance of the importance of integrating cultural and ecological values in the landscape, and the value of integrating social science research into conservation efforts.

Despite the progress in loosening intellectual constraints, the political urgency of applying these approaches has increased rather than diminished in the intervening years. In the late 1990s, dramatic political and economic dislocations in Indonesia have certainly opened up new opportunities to pursue community-based management of natural resources, but they have also intensified internal and external threats to sustainability. I hope that this English, abridged edition of Social Science Research and Conservation Management in the Interior of Borneo inspires a new generation of researchers and practitioners to build on the many insights that have blossomed from a few seeds of intuition when the research effort was first conceived.

Frances Seymour Washington, D.C. March 20, 2003 


\section{Contributors' Biodata}

Angguk Lamis was born in 1953 in Tamiang Layang, Central Kalimantan; after taking a law degree, he now teaches law at Palangkaraya University, Central Kalimantan.

Herculanus Bahari Sindju was born in 1952 in Pahauman, West Kalimantan; he received a B.A. in Education (Yogyakarta, 1982) and now teaches at FKIP (Teacher's College), Tanjungpura University, Pontianak, West Kalimantan.

Blajan Konradus, born in 1961 in Flores, holds a B.A. (1986) from Cendana University (Kupang, West Timor) and an M.A. in Anthropology from Universitas Indonesia (J akarta, 1994). He now teaches at Cendana University.

Yohanes Paulus Bunde, born in 1965 in Belimbis, West Kalimantan, holds a law degree from Tanjungpura University, Pontianak, West Kalimantan (1991); he is currently with the Bela Banua Talino Institute, Pontianak.

Daniel Lawing, born in 1964 in Long Alango, East Kalimantan, has a B.A. in Education (Samarinda, East Kalimantan, 1994); now a school teacher in the upper Bahau, he continues to collect oral literature and music.

Cristina Eghenter, born in Trento, Italy, did fieldwork in Apo Kayan (1991-93) and took her Ph.D. in Ecological Anthropology, Rutgers University (1995); she was C\&C field director (1995-97) and Community Development Program coordinator on the Kayan Mentarang Project (1996-99). Part of the work on this book was carried out while she was a European Science Foundation fellow at the Centre for South-East Asian Studies, Hull University.

Indah Setyawati, born in 1966 in Bandung, West Java, earned a B.A. in Anthropology (Universitas Indonesia, Jakarta, 1991) and an M.A. in Ecological Anthropology (Rutgers University, 1995); she is now a consultant in Timor.

S. J acobus E. Frans L., born in 1945 in Sarawak, holds a B. A. in English (1977) and a Law degree (Tanjungpura University, Pontianak, 1983); he coordinated C\&C law studies, and after working at the Governor's Office in Pontianak, he became District Head of Kapuas Hulu, West Kalimantan.

Concordius Kanyan, born in 1964 at Sungai Utik, West Kalimantan, holds a law degree (1991) from Tanjungpura University, Pontianak; he now works with the Bakermas Kita Foundation in Pontianak. 
Karina Arifin, born in 1959 in J akarta, holds a B.A. in Archaeology from Universitas Indonesia, Jakarta, and an M.A. in Archaeology from the Australian National University, Canberra (1990). After teaching archaeology at Universitas Indonesia, she is now taking her Ph.D. at ANU.

Liman Lawai, born in 1964 in Nawang Baru, Apau Kayan, East Kalimantan, holds a B.A. in Education (Samarinda, 1993). A C\&C researcher since 1993, he joined KMCP's Community Development team in 1997.

Njau Anau was born in 1967 in Long Alango, East Kalimantan; he holds a B. A. in History (Samarinda, 1992). After researching with C\&C in 1991-92, he joined KMCP's Community Development team in 1993. In 1999 he joined the Center for International Forestry Research's (CIFOR) field team in Malinau, after which he became a government employee of the District of Malinau in 2002.

Bernard Sellato, born in 1951, has been working in and on Borneo for thirty years. He has an M.Sc. in Geology (1973) and a Ph.D. in Anthropology and History (Paris, 1987). He was C\&C co-director (1990-1995) and program coordinator (1996-97), and he now heads the Institute of Research on Southeast Asia in Marseilles.

G. Simon Devung, born in 1945 in Tering Lama, East Kalimantan, holds an M. A. (IKIP Sanata Dharma, Samarinda, 1974) and a postgraduate degree (IKIP Bandung, 1983), both in Social Education, and an M. A. in Anthropology (Universitas Indonesia, 1995); he taught Culture and Social Sciences at Mulawarman University, Samarinda. Having been $C \& C$ co-director, then Director of the KRC in Samarinda, he is currently Director of the Center for Social Forestry, Mulawarman University, and is taking his Ph.D.

Martua T. Sirait, born in 1965 in Braunschweig, Germany, holds a degree in Forestry (Samarinda, 1990) and an M.Sc. in Applied Sociology and Anthropology (Ateneo de Manila University, 1996); he joined C\&C in 1991 and, later, KMCP's Community Mapping. Based in Bogor, he now works in the International Centre for Research on Agroforestry (ICRAF)/ World Agroforestry Centre, assisting the Ministry of Forestry to shape sustainable community forestry policies.

Yus Ngabut, born in 1948 in Balawa, Central Kalimantan, holds a M.A. in Education (Teacher's College, Malang, East Java, 1991) and now teaches English at Palangkaraya University, Central Kalimantan.

Some of the contributors could not be contacted regarding an update of their biodata by the time of the completion of the book manuscript. The editors extend their profound apologies to the contributors for erroneous, incomplete, or outdated data. 


\section{Acknowledgements}

The editors of this volume, in the name of all the participants in the Culture \& Conservation $(C \& C)$ Program over the course of the years, wish here to extend their heartfelt thanks to all the people of the Kayan Mentarang National Park area and surrounding regions for their hospitality and generosity toward researchers and visitors to their villages, as well as for their invaluable assistance to these visitors' work. No doubt the C\&C research would not have been successful, nor the present book have been published, without this assistance and their patience. We all shall keep a lasting and moving memory of this warm, unselfish hospitality that the people of Kalimantan have demonstrated to us whenever we resided with them, and we also wish to extend our profound apologies to them for any blunders and misunderstandings that may have inconvenienced them.

We have been very lucky to benefit from the assistance of so many people that it is now difficult to name them all, and for this, too, we apologise to them. We only shall list here the names of their villages: Apau Ping, Long Berini, Long Kemuat, Long Alango, Long Tebulo, Long Uli, Long Peliran, Long Bena, Long Belaka, Long Pujungan, Long Jelet, Long Pua, Long Apan Baru, Long Nawang, Nawang Baru, Long Temunyat, Long Uro, Lidung Payau, Data Dian, Long Metun, Sungai Anei, Miau Baru, Sajau Metun, Sajau Pura, Kelubir, Naha Aya', Long Peso', Berayang, Mara Satu, Antutan, Teras Baru, Teras Nawang, J elerai Selor, Long Tunggu, Long Bang, Long Bawan, Long Rungan, Long Layu, Tang La'an, Long Api, Kuala Belawit, Long Midan, Terang Baru, Malinau, Long Loreh, Gong Solok, Paya Seturan, Langap, and Respen Sembuak. We wish to thank very warmly all village heads, customary chiefs, community leaders, village ladies, and the five-year old children who helped collect stone tools under Apau Ping houses.

Thanks to the invaluable support of the great adat chiefs of Pujungan, Hulu Bahau, Apau Kayan, Krayan Hulu, Krayan Tengah, Krayan Hilir, Krayan Darat, Mentarang, Tubu, and Lumbis Hulu, C\&C's activities and the purposes of its research program were better understood and well received in their respective customary territories. We also benefited from the precious help of many research assistants who, for two months or several years, participated in our activities. May they all find here the expression of our deep gratitude. 
It is our hope that this book serves to strengthen feelings of cultural pride and identity among the people of the region. May it help, just a little, the people of Kalimantan fashion for themselves a brighter future. It is also hoped that it will encourage vocations among the local residents, especially community leaders and former research assistants, to investigate and record themselves the wealth of their own cultural and historical heritage. And we would be happy if it draws additional national and international attention to and recognition of Kalimantan cultures.

Finally, we would like to express our profound gratitude to all agencies of the provincial government of East Kalimantan, the district governments of Bulungan, Malinau, and Nunukan, and the many subdistrict governments concerned; the Ministry of Forestry and the Directorate General of PHPA; the Indonesian Institute of Science (LIPI); The Ford Foundation, C\&C's friendly, steady, and consistent supporter since 1990, and Alan Feinstein, Frances Seymour, Chip Fay, Mary Zurbuchen, J ennifer Lindsay, Suzanne Siskel, and Philip Yampolsky; UNESCO, Malcolm Hadley (Paris) and Philippe Delanghe and Han Qunli (J akarta), for their interest in C\&C since 1993, then in this book; CIFOR, Carol Colfer, Gideon Suharyanto, Sally Wellesley, Dina Hubudin, Norman Macdonald, Kuswata Kartawinata, and Lini Wollenberg for their support to the publication project and their instrumental role in its realisation; Michael Dove and Tri Nugroho, for their critical evaluation of our work and their precious suggestions; the Yayasan WWF Indonesia and Agus Purnomo, for permission; and DANIDA (Danish International Development Agency). 


\section{Executive Summary}

This volume presents a selection of the work carried out under the Culture \& Conservation Research Program, a program funded by the Ford Foundation as part of the Kayan Mentarang Conservation Project of WWF Indonesia in East Kalimantan, Indonesian Borneo.

It addresses two major methodological and epistemological issues that are currently debated in both academic circles and conservation organisations. Firstly, the role of social science research, and more specifically anthropology, in promoting and protecting the social, cultural, and economic interests of forest-dependent people living at the margins. The program's experience offers a privileged perspective from which to assess the contribution of social science research towards the achievement of the integrated objectives of conservation and social justice. Secondly, the ways in which conservation NGOs have contributed to the creation and maintenance of unproven assumptions concerning the natural environment and indigenous people, and sometimes made those assumptions ready-made formulas for the management of conservation projects.

As the outcome of a unique interdisciplinary engagement in central Borneo that lasted for over six years (1991-97), this volume offers a rare and comprehensive picture of the people and the environment of this region. Based on original ethnographic, ecological, and historical data, the authors make an important contribution to the understanding of past and present interactions between people and forests in the interior of Borneo. While this provides undoubtedly important information about the ways in which people have managed the forests of the interior, the book does not tender ready solutions, nor does it minimise the complex challenges faced in building equitable conservation management programs.

This collection also discloses the reality of a human and research experience, in which fieldwork encounters have enriched both the researchers and communities participating in the exchange. Through publication of the research results, the knowledge generated by and on the peoples of Kalimantan will acquire a new visibility. The field researchers, too, stand to gain deserved recognition in professional and scholarly circles, both nationally and internationally. 
The many aspects that have made this program an important methodological and practical experiment are reflected in this volume. The topics cover a wide range of disciplinary interests, transcending traditional headings such as anthropology, geography, archaeology, history, ethnobotany, and linguistics. The work is the result of a fruitful collaboration between outside and local experts, experienced scholars and young professionals, foreign researchers and Indonesian and Dayak scientists, who have all been able to integrate their views and insights to formulate a comprehensive body of knowledge of the interrelationships between natural and human components in the forests of the interior of Borneo over time.

The large number of social science reports makes Kayan Mentarang one of the ethnographically best known protected areas in Southeast Asia. This in itself is a significant achievement. The purpose of this book is not, however, limited to presenting a selection of this important information and data. The research program has also been a challenging process of design, implementation, and collaboration over the years. Moreover, by pointing at the interface between research work and forest management concerns, this book offers some tools for easing the antagonism between applied and scholarly research, and building much needed connections across fields of knowledge. It also prompts reflection upon ways to make social science research more practically, academically, and socially significant. 


\title{
1.
}

\section{Introduction}

\author{
Cristina Eghenter and Bernard Sellato
}

\section{THE CULTURE AND CONSERVATION RESEARCH PROGRAM}

This volume presents a selection of the work carried out under the Culture \& Conservation Research Program (henceforth, $C \& C$ ), a program funded by the Ford Foundation as part of the Kayan Mentarang Conservation Project (KMCP) of WWF Indonesia (WWF-I) in the province of East Kalimantan, Indonesian Borneo.

It addresses two maj or methodological/ epistemological issues that are currently being debated in both academic circles and conservation organisations. Firstly, the book addresses the role of social science research, and more specifically anthropology, in promoting and protecting the social, cultural, and economic interests of forest-dependent people living at the margins (see Brechin et al. 2002; Brosius 2001; Brosius, Tsing and Zerner 1998; Headland 1997; Sillitoe 1998; Wilshusen et al. 2002). The C\&C experience offers a privileged perspective from which to assess the contribution of social science research towards the achievement of the integrated objectives of conservation and social justice. Secondly, we examine the ways in which conservation NGOs have contributed to the creation and maintenance of unproven assumptions concerning the natural environment and the indigenous people, and sometimes made those assumptions ready-made formulas for the management of conservation projects (Chartier and Sellato 1998, 2002; Eghenter 2000a; Persoon and van Est 1998; Zerner 1994).

By being the outcome of a unique interdisciplinary engagement in central Borneo that lasted for over six and a half years (1991-1997), this volume offers readers a rare and comprehensive picture of the people and the environment of this region. Based on much original ethnographic, ecological, and historical data, the dedicated and concerned authors make a rare contribution to the understanding of past and present interactions between people and forests in the interior of Borneo. While this provides undoubtedly important information about the ways in which people have managed the forests of the interior, the book does not tender ready solutions, nor does it minimise the complex challenges faced in building equitable conservation management programs. 
This collection also discloses the reality of a human and research experience, in which fieldwork encounters have enriched both the researchers and communities participating in the exchange. By publishing the research results as a book, the knowledge generated by and on the peoples of Kalimantan will acquire a new visibility. The field researchers, too, stand to gain deserved recognition in professional and scholarly circles, both nationally and internationally.

The many aspects that have made the $C \& C$ research program an important methodological and practical experiment are reflected in this volume. The topics cover a wide range of disciplinary interests transcending traditional headings such as anthropology, geography, archaeology, history, ethnobotany, and linguistics. The work is the result of a fruitful collaboration between outside and local experts, experienced scholars and young professionals, foreign researchers and Indonesian and Dayak scientists, who have all been able to integrate their views and insights to formulate a comprehensive body of knowledge of the interrelationships between natural and human components in the forests of the interior of Borneo over time.

The large number of social science reports makes Kayan Mentarang one of the ethnographically best known protected areas in Southeast Asia. This in itself is a significant achievement. The purpose of this book is not, however, limited to presenting a selection of this important information and data. The research program has also been a challenging process of design, implementation, and collaboration over the years. Moreover, by pointing at the interface between research work and forest management concerns, this book offers some tools for easing the antagonism between applied and scholarly research, and building much needed connections across fields of knowledge (see Dove and Kammen 1997). It also prompts reflection upon ways to make social science research more practically, academically, and socially significant (Eghenter 1999, 2002; King 2002).

\section{C\&C in Perspective: Building Stronger Research Strategies}

The $C \& C$ program originated in a proposal to the Ford Foundation for a project on oral traditions in Kalimantan, and in a subsequent consultancy report (Sellato 1989a, 1990). The project aimed at studying all forms of oral tradition, particularly oral literature, history, and traditional legal systems, with the twofold purpose of documenting a rich corpus of oral literature and helping uphold traditional rights over land and natural resources. Eventually, it was decided to implement this project in conjunction with efforts to develop the management plan for the Kayan Mentarang conservation area (then a nature reserve) by WWF-I (J essup and Sellato 1990).

From the beginning, the $C \& C$ program focused the research on the interconnection between society and the natural environment in and around Kayan Mentarang in order to better understand the modalities of interaction of the communities with the forest around them. The main assumption was that taking into account traditional knowledge would help the planning and management of the nature reserve, and would allow for the elaboration of conservation strategies that are community-based. The success of nature conservation was seen as depending upon the preservation of indigenous cultures and, mostly, the maintenance of traditional practices of land tenure and natural resource management. More specifically, the program set out to: investigate the communities' knowledge and perceptions of, and attitudes toward, the natural environment; identify past and present interactions between people and the forest; demonstrate the existence of practices of land tenure based on traditional legal systems; and train Indonesian, particularly Dayak, researchers in field research techniques. Research activities were 
also seen as an important opportunity for motivating local people to lead conservation and development activities in their own communities.

In 1990-1992, the program staged a dozen field studies, carried out by local scholars and students after a period of interdisciplinary training bridging ecology and anthropology, the natural and social sciences. Subsequently (1993-1994), field studies were refocused on three main themes: linguistics and oral literature; land tenure and traditional legal systems; and regional history of societies and the forest, moving from a synchronic to a diachronic approach of the relationship between society and its natural environment. These were carried out by about thirty scholars and students, most of whom were Indonesian, who spent three to six months in the field (J essup and Sellato 1993; Sellato and J essup 1994).

In the last phase of the program (1995-1997), the overall scope of the C\&C program remained much the same. Nevertheless, specific efforts were made to address the issues highlighted by the program's reviewers (Dove and Tri Nugroho 1994), and aim at an output of research more directly linked to, and better integrated with, the agenda of the KMCP for enhancing conservation awareness, strengthening local institutions, and increasing community participation in the planning for the management of the National Park.

In this context, the $C \& C$ research agenda was geared towards the collection of empirical evidence so as to understand how and why people have managed natural and cultural resources, and what conditions had triggered changes in the degree and mode of their practices. Addressing the reviewers' recommendations to investigate changes in traditional management practices as they relate to changes in the context of evolving social and power relations in the communities of the interior, the research was directed at trying to determine changes in indigenous peoples' practices and their social context, and look at the extent to which these practices helped conserve resources or manage the forests to maintain biodiversity (Eghenter 1997). Recruiting and training continued to target Dayak researchers from communities in and around the Kayan Mentarang area who were concerned with both investigating local cultures and enhancing local awareness of social and environmental issues. A small team of core researchers and research assistants was formed.

\section{The Institutional Environment of $C \& C$}

A thorough understanding of the history of the $C \& C$ program requires looking at the concurrent developments that have taken place in the KMCP and in WWF-I in general. The evolution of strategies reflects reciprocal adjustments and changing forms of collaboration in what often appear as the reversed-growth traj ectories of the research program and the conservation project. The following provides a brief overview of how the two projects have coexisted and how the forms of their partnership have shifted through time.

Begun in 1990 as a collaborative effort by WWF-I, the Directorate General of Forest Protection and Nature Conservation (PHPA, now PHKA) of the Ministry of Forestry, and the Indonesian Institute of Sciences (LIPI), KMCP was hardly distinguishable from its $C \& C$ component. In the initial years of KMCP's life, its funding, management, and staff were largely drawn from $C \& C$, and the presence and activity in the field were largely those of the $C \& C$ staff.

KMCP's long-term goal was the establishment of conservation management and sustainable economic development in the Kayan Mentarang and surrounding areas. With its 1.4 million ha, the Kayan Mentarang conservation area in the far interior of East Kalimantan is the largest protected area of rainforest in Borneo and one of the largest in Southeast Asia. Extensive archaeological remains in the area are witness to a long history of human settlement. Nowadays, about 16000 Dayak people live in or near the 
reserve, depending on swidden agriculture, wet rice farming, hunting, fishing, and collecting forest products to fulfil their subsistence needs. In an effort to find viable solutions for the management of this vast conservation area, KMCP and C\&C collaborated in collecting evidence to recommend a change of status for the conservation area from strict nature reserve (cagar alam), as it had been gazetted in 1980, to national park (taman nasional). While in a nature reserve all human settlements are in principle excluded and human activities illegal, in a national park traditional residents are allowed and their 'traditional use' of natural resources permitted. It was upon the recognition of the local people's dependence on forest resources and entitlement to economic development that negotiations for a change of status were started. The results conveyed by an evaluation team sent by the Ministry of Forestry endorsed WWF-I's recommendation. The conservation area was finally designated as a National Park by a decree of the Ministry of Forestry two years later, in October 1996.

Encouraged by the positive response of PHKA, WWF-I used the concept of an Integrated Conservation and Development Project (ICDP) to develop the management of the Kayan Mentarang conservation area. In projects of this kind, the emphasis is on linking and integrating economic development with biodiversity conservation in protected areas by devising conservation measures with economic incentives for the local population (see Muul 1993, Wells 1995, Wells and Brandon 1992). With funding from the J ohn D. \& Catherine T. MacArthur Foundation and the European Commission, the KMCP project adapted the basic ICDP strategy and envisioned new directions and activities on a larger scale. A Geographic Information System (GIS) unit was set up to produce maps based on the interpretation of satellite imagery and field data. The Primary Environmental Care (PEC) program started in 1993, its purpose emphatically focused on advocacy of community rights and environmental awareness. In the meantime, several teams of $C \& C$ researchers were spending two to three months in the field for what turned out to be $C \& C^{\prime} s$ most intensive and extensive phase of data collection and field activities. By the end of 1994, the KMCP-C\&C partnership experienced a pendulum movement: KMCP was now bigger and more articulated, and research activity subsided in terms of its function. Although funds were still being used in new and experimental ways to start community mapping, much of the sense of the value of social science research for the overall KMCP was fading.

In yet another switch of fortunes, a long phase of financial uncertainty started in 1995 for KMCP, affecting its activities in severe ways, while $C \& C$ funding from the Ford Foundation continued. It was only at the end of 1996 that KMCP managed to secure important new funding from DANIDA, the Danish International Development Assistance Agency. In the context of a revived KMCP, $C \& C$, now a minor partner again and often viewed as a marginal entity, took the tricky path of trying to build a common ground and work more closely with other KMCP components. $C \& C^{\prime}$ 's final field and dissemination activities were designed to attend to KMCP's immediate concern to develop a management plan for the national park, which would draw on traditional tenure strategies and support the local people's leading role in the management of their forest and in the sustainable development of their region.

\section{An Overview of the Implementation of $C \& C$}

\section{Methodological Approach}

Since its inception, the $C \& C$ program has based its methodological approach on social science research techniques and the fieldwork experience of the anthropological tradition. Most of the data were collected during two- to three-month periods in the field and, often, repeated visits to the same communities over a period of time. This was especially feasible 
for locally recruited researchers. The strategy rested on the commonly shared opinion that one of the strengths of traditional social science research is its long-term commitment to the object and place of study, by means of which research can provide deeper and more thorough insights into local traditions, history, and practices (e.g., Sillitoe 1998, Headland 1997, Spradley 1980). Researchers were given formal training in interview techniques, surveys, and ethno-historical methods, and time was also devoted to discussions on how to develop a research plan and identify key research questions. It was deemed very important that researchers learn how to plan and manage research or a survey, formulate the significant questions to be asked, and envision the complexity of the possible linkages between events or practices and their economic, cultural, social, environmental, and historical circumstances. In addition, rapid demographic and socio-economic surveys were carried out to collect essential baseline data to better assess the overall context of the communities in and around the park.

The research stressed team work and collaboration among the researchers. This was achieved in a variety of ways: common initial training in a range of disciplines; flexible research units of two to three individuals investigating together similar topics in different locations; researchers focusing on distinct topics forming a team sharing the same field location; senior researchers guiding younger ones in joint field expeditions; numerous small-scale workshops in the field; researchers interpreting and writing up data together. The main objectives were to encourage exchange and crosschecking of information among researchers, reinforce the awareness of the degree of interconnectedness of the research topics investigated, and build team membership. Evaluation sessions on the progress made in the research were also based on the participation and input from all the team members. C\&C's culture-sensitive researchers and the remarkably open, hospitable, and friendly host communities also created a common 'team' spirit. They established and maintained long-term relations of genuine collaboration and empathy that remained a salient feature of the $C \& C$ field experience through the years in and around the Kayan Mentarang area (see Dove and Tri Nugroho 1994).

The research experience of $C \& C$ was not, however, narrowly restricted to the use of traditional social science methods. It was under this program that the first experiments with community sketch maps took place, which later became one of KMCP's trademarks (see Peluso 1995, Eghenter 2000b). These maps recorded local people's knowledge and decisions about land and resource use, as well as their claims to those resources. Informants organised in groups of men, women, and young people were directly involved in the collection, analysis, and discussion of data, and in the drawing of the maps (Sirait et al. 1994).

The significance of a diachronic perspective has long been praised as an important aspect of understanding human activities and their environmental effects (e.g., Headland 1997; Schrire 1984; Sellato 1994b, 1994c). In the context of the C\&C research, the historical contextualisation of people-forest interactions was expected to shed light on circumstances and events that might have important impact on future decisions for the management of the conservation area and the development of the surrounding region. The research perspective emphasised the study of both present and past activities in order to be able to compare events at different points in time and eventually find patterns in the ways in which people had exploited resources and responded to changing social, economic, and environmental circumstances over time.

\section{Products and Achievements}

The output of six and a half years of research, training, and dissemination activities includes several products and many achievements. Forty-two research reports were 
submitted to KMCP, covering a wide range of topics related to the Dayak communities of the interior-from swidden practices to oral literature, from traditional religions to the exploitation of forest products, from migration history to music and songs. A collection of thirty-six edited reports was released in 1995 as a set of five volumes (Sellato 1995e). Two video films were produced, the first one (1994) in collaboration with the Sejati Foundation ('Dayak and Biodiversity. Cultural Survival and Nature Conservation in Remote Interior Kalimantan'); the second one (1997) was made by Manguin and Sellato and sponsored by UNESCO ('The Last Traditional Potter of Borneo'). Finally, in 1999, a selection of twenty-five reports, abridged and further edited, was published as a large volume in Indonesian, sponsored by the Ford Foundation, UNESCO, and WWF (Eghenter and Sellato 1999).

The importance of human resource development, particularly of local people, has been emphasised since $C \& C^{\prime} s$ beginnings. Priority was given to recruiting and training Dayak researchers, initially from all over Kalimantan, then more specifically from the communities in and around the Kayan Mentarang National Park. The leading expectation was that members of the communities, by becoming active participants in the research program, could better clarify the scope and importance of in-depth, long-term studies to record local knowledge of the environment and traditional practices of management. In this way, they could also trigger the communities' interest in conducting their own documentation of their culture and history. Moreover, researchers were expected to become tomorrow's spokespersons for their communities and lead them in conservation and development initiatives for the management of the National Park. More than twenty-five community representatives were trained under the $C \& C$ program. Some of them moved on to become KMCP staff shortly after training. Others continued their involvement in research and later took on other positions within KMCP.

An opportunity was offered to about $15 C \& C$ researchers to present their findings in scholarly forums through their participation in three successive international conferences of the Borneo Research Council, respectively in Kota Kinabalu (Sabah, 1992), Pontianak (West Kalimantan, Indonesia, 1994), and Bandar Seri Begawan (Brunei Darussalam, 1996). For most of the Dayak researchers, it was their first time ever to be part of and interact with the international scientific community at large.

\section{Sustaining C\&C's Legacy}

As rightly pointed out by the reviewers of the $C \& C$ program (Dove and Tri Nugroho 1994), one of the consequences of field activities was the emergence of village-level curiosity about, and interest in, the research findings that could be exploited to help local communities develop plans to protect their biological and cultural resources. A similar concern motivated the promoters of $C \& C$ to start initiatives to further encourage the dissemination and 'socialisation' of research activities, and thus sustain the legacy of the $C \& C$ program. The Kalimantan Resource Center (KRC) was established in collaboration with a Jakarta-based organisation, the Foundation for Research and Development in Borneo (YPPB). It was intended to provide local communities and other stakeholders with useful information to enable them to take the lead in the long-term goal of the protection of the culture(s) and nature of Kalimantan. The objectives of the KRC included the creation of a library; the publication and dissemination of articles and books based on the results of field activities; the publications of papers to target scientific audiences and decision makers in both the government and private sectors; and the organisation of 
promotional activities including exhibitions, thematic workshops, and networks with research institutions, local NGOs, and government agencies.

The transition of the KRC from a $C \& C$ unit to an independent nongovernmental organisation was formally sanctioned in 2000 . The process has not been easy and has been marred by difficulties, mainly financial. The bulk of the library collection (some 1400 titles on the nature and cultures of Borneo, probably constituting the largest such library fund in Kalimantan) is currently under the temporary management of the Center for Social Forestry (CSF), Mulawarman University, Samarinda. Meanwhile, other community proposals for documentation have emerged, often stimulated by different, and new, community projects, like ecotourism.

\section{Recognising Indicators of Success}

Assessing the value of a research and training program like $C \& C$ calls for more than a long list of remarkable products, achievements, and initiatives carried out under its auspices. The interconnectedness of the priorities of the research agenda with those of the management of the conservation area requires that the research output be evaluated in terms of its contribution toward the achievements of KMCP's practical objectives. It is important to look at what themes and issues have emerged most forcefully from the reports, and at what they tell us about local management and practices, environmental knowledge, and people-forest interactions. It is necessary to assess whether the social science research that has been conducted under $\mathrm{C} \& \mathrm{C}$ has improved our understanding of the local context and ensured useful results for KMCP.

The geographical scope of the $C \& C$ research program covered the entire conservation area. Most early activities, however, focused on one area, the Pujungan subdistrict (kecamatan), regarded as a strategic area from several points of view. Its central position with regard to the National Park suggests that it will become the core area for the implementation of the management plan and the monitoring of the park. The existing number of archaeological remains and the diverse Dayak subgroups point to the significance of the area in understanding the history of Dayak people and their settlement of this and other parts of the interior. Contrary to areas like Apau Kayan and Krayan, the Pujungan subdistrict is also more easily accessible by river, which makes it the natural entrance point to the National Park.

\section{Highlights from the Field}

The chapters in this volume-a narrow selection from the original research reportshighlight the main attitudes and traditions in forest management among the people living in and around the Kayan Mentarang conservation area.

First, it was established that the communities are still what is usually called 'traditional communities' (masyarakat adat), largely regulated by customary law in the conduct of their daily affairs and the management of natural resources (chapter by J acobus Frans). This was a major point made with regard to both KMCP's longterm goals of involving these communities in conservation efforts and seeking official recognition for claims on traditional land and resources. The role of traditional institutions, presently reflected in institutions like the customary council (lembaga adat) and the customary chief (kepala adat), is key to understanding the communities' views of rights and the way they deliberate on issues of forest management and social responsibilities. 
Several chapters point to various aspects of what is usually referred to as an 'indigenous management system,' or the ability of local people to use, alter, regulate, and restore land and other natural resources in their environment. With a distinct emphasis, Bahari describes the stages of traditional swidden farming in the upper Bahau area and shows how farmers make their decisions on the basis of criteria rooted in their long experience of local environmental conditions (chapter by Herculanus Bahari Sindju). Adding to the growing body of literature on the environmentally sustainable function of shifting cultivation in tropical forests under stable conditions (e.g., Brookfield et al. 1995; Dove 1985a, 1988a; Colfer 1993; Conklin 1957; Jessup 1981), this research provides important evidence that local people's agricultural practices are not intrinsically destructive of the environment but rather draw on knowledge and understanding of the dynamics of that environment.

The role of the forest as provider of goods that can be eaten or used in various other ways, as well as traded out, is socially and legally reinforced by the concept that the forest must be protected from overexploitation by individuals from within and, especially, from outside that community. In all the traditional communities along the Pujungan and Bahau rivers, specific regulations exist that restrict access to the forest and regulate the exploitation of its most valuable products (chapters by Blaj an Konradus, Simon Devung, Martua Sirait, and Angguk Lamis et al.). Reserving part of forest in the village territory for harvesting products when in need or under other specific circumstances is a common strategy adopted also in other communities of the national park, and elsewhere in Borneo (e.g., Wadley et al. 1997; Eghenter 2000a).

The wide range of forest plants and crop varieties exploited suggests a high degree of biodiversity that has been managed and intentionally maintained for centuries (chapters by Martua Sirait, and Indah Setyawati). The Dayak are also keen collectors of seeds. The connection between local environmental knowledge and customary regulations also becomes apparent in the discussion of collective and individual rights and practices of forest exploitation (chapters by Angguk Lamis et al., and Simon Devung). As we would expect in all communities, there are episodes of non-adherence to common rules, yet the overall conformity of behaviour indicates a high degree of social cohesion and the community's vital dependence on the forest for its wellbeing (chapter by Simon Devung).

The definitive archaeological and historical evidence of the long presence of Dayak people in the Kayan Mentarang area (chapters by Njau Anau, Liman Lawai, and Karina Arifin and Bernard Sellato) reminds us that these peoples' practices and interactions with the forest also have a long history. Past attitudes toward the environment are reflected in the oral literature (chapter by Yus Ngabut) and the importance of natural resources is embedded in their artistic traditions (chapter by Daniel Lawing). Recent changes and adjustments brought about by new economic opportunities are also depicted (chapter by Blajan Konradus). The recognition of these changes is important in that it contradicts stale formulations and stereotypical views of timeless, backward indigenous people still entertained by government officials, urban residents, and romantic environmentalists. At the same time, the awareness that economic and social changes have taken place cannot prevent us from discerning that traditional management practices still remain in place, while adjustments are being made to suit new circumstances.

The themes highlighted above represent a necessary recapitulation of the scientific contributions of the research program. However, the findings need also be examined with regard to how useful they were in KMCP's development and whether and how they 
were (or could be) used to influence decisions and design solutions for the management and economic development of the conservation area.

While this step might seem a logical and obvious one in evaluating a research program created and implemented as part of a conservation project, it is rarely taken, with the result that there is little possibility to assess the effectiveness of the role of social science research in conservation management and sustainable development (see Sillitoe 1998; Brosius 2001). What some of the reasons might be could only be speculated on. The fact that proposals and projects of this kind are only too susceptible to stringent requirements-securing funding, respecting deadlines, fitting predetermined views of what the projects are expected to produce-might just explain the paucity of objective appraisals. The persisting gap between the prevalent 'academic' voice of research and the 'practical' concerns of field projects might also account for the still scarce instances where results of research succeed in indicating solutions and developing viable alternatives.

The contributions of $C \& C$ with regard to making KMCP a more successful project can be assessed at several levels. The training and fieldwork opportunities provided staff with the knowledge of research techniques and the analytical skills that have been brought to bear in the ways these staff successfully fulfil new responsibilities in WWF-I projects and elsewhere. The opportunity to interact with the communities during long stays in the field also enabled them to become more open-minded and gain a better sense of how to encourage community participation.

\section{Findings that Make a Difference}

Information collected in the field was instrumental in providing the crucial evidence and formulating the recommendation for the change of status from strict nature reserve to national park. The historical and archaeological data undoubtedly showed that the communities of the park have long been residents of the area and could not be forced out without raising sensitive issues of human rights abuse. Not only have Kenyah, Punan, Saben, Ngorek, and other Dayak communities settled the area for centuries, they have also maintained its forests and developed management systems. The argument that the communities themselves could prove to be the best chance for the sustainable and continued management of the Kayan Mentarang conservation area, particularly the idea that the communities' actual presence and strong cultural identity could contribute to deterring or minimising the risk of encroachment by outside parties (Sellato 1992a), relies on the interpretation of the research findings.

The extensive documentation on land tenure systems and regulations for the exploitation of forest resources helped bring the issue of customary rights to the attention of government officials in the Bulungan district (kabupaten) and the Ministry of Forestry. Future negotiations for the official recognition of traditional systems and regulations like tana' ulen and the definition of their role in the management of the national park will depend on the accuracy and inclusiveness of the research findings. The data collected also provided a basis for structuring and developing a program aimed at strengthening local institutions. The realisation of the prominent role of customary institutions in the management of forest resources requires that these institutions become the privileged interlocutors and partners in planning for the management of the conservation area.

The presence of the researchers in the communities generated village-level discussions on conservation and the future of the area. In some cases, like in the customary territory 
of the upper Bahau, the outcome was a resolution to more tightly enforce traditional regulations and exclude outsiders from the exploitation of forest products on village land. Research activities also inspired local interest in documenting historical, cultural, and artistic heritage. So far, this interest was the motive for community representatives to join KMCP and work in the midst of their own communities on behalf of the conservation project. In the future, the conservation of cultural and natural resources in the area will require a role shift whereby community representatives take the lead in the management of the national park on behalf of their communities. Their new roles will draw vitality from a stronger sense of ethnic identity and pride in their cultural heritage.

\section{Challenges to Conservation Management}

As mentioned in the section above, the output of $C \& C^{\prime} s$ research activities served the conservation management objectives of KMCP in direct ways that, in turn, raised the level of participation in and support for KMCP among local people and government officials.

Research findings, however, also brought to light the multiple aspects and complexities of the social, environmental, political, and historical context within which the viability of KMCP is ultimately tested. Dayak village communities are increasingly heterogeneous in their ethnic and socio-professional composition. This type of information becomes extremely valuable for conservation and development projects when consistently linked to difficulties that may be encountered in the implementation of activities. Limited access to information, the resilience of stereotyped views, and preference for quick results might encourage park managers to regard forest-dwelling communities as homogeneous entities in relatively uncomplicated situations, and to adopt common solutions for the whole conservation area. Although this might be easier and less time consuming, the chances of success are slim, insofar as they rest on the incongruity of the project's views with the reality of the communities (see Dove 1992). On the contrary, acknowledging the complexity and diversity of the social and economic context will lead to designing flexible and locally appropriate measures of conservation, and thus ultimately will enhance the project's sustainability in the long term.

Several of the $C \& C$ reports focusing on history point to the reality of overlapping territorial claims caused by long histories of migrations. Recent experiences with KMCP's community mapping underscored the need to take into consideration historical factors before finalising territorial maps and settling boundary issues between old and new settlements. Similarly, the initial focus on the interactions between people and forest inside the conservation area proved too narrow when research findings indicated the significant impact of people who had moved out of the park area but go back for the purpose of collecting forest products. The line between insiders and outsiders thus becomes inevitably blurred.

Communities of the interior are part of far-reaching trade networks in forest products such as eaglewood or incense wood (gaharu). The control of the trade might be in the hands of outsiders, but the local people's growing debt with these merchants, as well as their desire to purchase consumer goods and build new houses, leads them to adopt collecting practices that are unsustainable. The presence of large teams of collectors from as far away as J ava, Central Kalimantan, and Sulawesi (Celebes) created a situation of competition where customary rules were easily disregarded and considerations for short-term economic gain prevailed. The presence of these outsiders, who sometimes 
gain local residency by marrying into the village, brings new social and religious challenges to the communities. Such residents of a different religious denomination and ethnic background, in growing numbers, may embolden themselves to resist rulings by their hosts' customary council and, when convenient, challenge the validity of customary law as conflicting with the national law (Sellato 2001; Eghenter 2000c; Wadley n.d.).

Discriminations that rock the social fabric of the village communities do not, however, always originate from the outside. The customary law is the law of the aristocratic category that has maintained economic and social supremacy, unchallenged until very recently, within Kenyah and Kayan communities. New developments, education, and the Christian faith are eroding the old privileges of the higher strata and providing more opportunities for educated and enterprising individuals to climb to power.

\section{The Pioneering Role of $\mathrm{C} \& \mathrm{C}$}

If the product-i.e., the reports, information, data-elaborated by the $C \& C$ program now remains as its most tangible contribution, the mere existence of the program was important for KMCP in other ways. As mentioned earlier, in KMCP's early stages, $C \& C$ contributed to its physical establishment and presence by training staff, and providing labour and other resources. In addition, $C \& C$ helped establish the name of KMCP, especially with the communities of the park. It was $C \& C$ researchers who first visited the communities and explained the idea of a nature reserve. During their stay, researchers took time to discuss the plans for conservation and sustainable development in the area. In many villages, particularly outside the park boundaries, the first and only time KMCP staff visited was on the occasion of $C \& C$ research activities. Researchers were often asked to convey to WWF-I the local people's concerns about their rights and the current or potential conflicts with neighbouring or encroaching outside companies.

KMCP's image was largely shaped through the contacts and interactions of $C \& C$ researchers. By establishing lasting bonds with the communities, $C \& C$ unwittingly found itself in the position of spokesperson for the larger KMCP. In this role, C\&C opened the way to other KMCP activities and promoted the gradual embracing by local communities of KMCP's conservation and development objectives (Eghenter 1997).

\section{Lessons from the C\&C Experience: Improving the Dialogue between Social Science Research and Conservation Management}

Since the 1980s, in conservation and protected area management circles, there has been an increasing emphasis on the need to balance conservation priorities with the development needs of the communities living in and around the conservation area. The neglect of resident people in conservation areas, which had long characterised the approach of governments and organisations alike, was being replaced by the realisation that virtually all wilderness areas had been modified or managed by humans in one way or another. Changes in the criteria for defining protected areas now included the protection of landscapes reflecting a history of human interaction with the environment, as well as the need to maintain the 'traditional' ways of human communities (Pimbert and Pretty 1994). The ecological evidence for the positive impact of traditional human activities in some areas justified the participation of resident communities in the protection, management, and restoration of the environment (Pimbert and Pretty 1994; Headland 1997). The necessity of involving local communities, 
however, was less of an absolute technical requirement for the management of the conservation areas than it was contingent upon the consideration of both pragmatic and social justice concerns (see Orlove and Brush 1996; Wells 1995). On the one hand, the realisation that the economic benefit of biodiversity conservation did not, for the most part, reach local people living in and around the conservation area required that other economic incentives be created to reduce local pressure on natural resources and the potential loss of biodiversity (Wells 1995). On the other hand, the recognition of the rightfulness of local peoples' claims to the land, based on a long history of settlement in the protected area, discredited initiatives of strict enforcement of protection measures, such as denying them access to the exploitation of natural resources.

It was also becoming evident that local people, precisely because of their longterm residence in the area, could become assets in management and conservation efforts. They possessed a wealth of knowledge about the natural environment that could be used to design more effective conservation management strategies involving, rather than excluding, local communities. Social science research could play an important role by providing insights into local practices and beliefs, and their wider social and political context. Researchers, particularly anthropologists, have ever since been documenting indigenous knowledge and management systems in wilderness areas to attest to the conservation ethic held by local people and to the sustainability of their traditional practices (e.g., McNeely and Pitt 1985; Poffenberger 1990; Redford and Padoch 1992; Brush and Stabinsky 1995; Padoch and Peluso 1996; Sponsel et al. 1996; Wadley et al. 1997).

The general outlook of integrated conservation and development projects (or ICDPs, of which KMCP was an adjusted model) more specifically assumes that effective management of natural resources and their sustainable use over time need to incorporate traditional management practices and involve local people from the planning phase on. This approach also stresses the development of buffer zones outside protected areas to reduce pressure on resources within the protected area by providing alternative economic options. The partnership between $C \& C$ and KMCP was built upon the recognition that social science can make a significant contribution to the design of conservation and sustainable development strategies. As stated in $C \& C^{\prime}$ 's last proposal to the Ford Foundation, the activities under the auspices of the $C \& C$ program were intended 'to document and support traditional rights of tenure and local resource management, including zonation; to strengthen the ethnic and cultural identity of Dayak people; to provide training and field experience for young scientists from Kalimantan; to contribute to our knowledge of the cultural history and the forest ecology of the region' ( $\mathrm{J}$ essup and Sellato 1995). Moreover, it was expected that the results of research activities would enable KMCP to design better management strategies. The research would directly support efforts to manage the conservation area by providing information for designing conservation strategies that involve local communities and maintain indigenous management practices (Sellato 1994a, 1996a; WWF-I and WWF-D 1996).

\section{Reasons for a Research Program}

The brief evaluation of the usefulness of the outcome of $C \& C$ presented above allows for a re-interpretation of statements contained in the WWF-I proposal in light of what actually happened. While there is little doubt that $C \& C$ helped train researchers, contributed to improving our knowledge of the cultural and environmental history of the region, generated local interest in research and other KMCP activities, and 
documented forms of local resource management, it remains unclear whether $C \& C$ did or did not enable KMCP to design better management strategies. The uncertainty has less to do with the quality of the data collected than with current thinking in many conservation organisations. Wells convincingly argued that several 'unproven and optimistic assumptions' are often made in ICDP projects with regard to biodiversity conservation and sustainable economic development, despite the fact that results have for the most part fallen short of expectations (Wells 1995: 322323). Similarly, there seems to exist a sequence of causally related assumptions on the 'presumed' key role of local people in sustainable management of protected areas: indigenous people are good conservationists, hence they would make good managers of the conservation area, hence it is important to study them. In these terms, the protected area management's prevailing position of blaming local residents for destroying the environment in the past can easily turn into the opposite, yet equally simplistic position-if unsupported by hard evidence-of praising local residents as the natural managers of biodiversity.

How should a research program fit into this framework? Must it set out to prove that local people are good managers of the environment or, rather, turn such a premise into a working hypothesis that could or could not be borne out in the final results? What lessons can be drawn from the $C \& C$ experience?

Research can and should be effectively used as a means to critically question and test key assumptions implicit in the project's objectives. Reflecting on epistemological issues, Dove maintains that social sciences are in a position to address questions transcending boundaries between disciplines by problemising other fields (Dove and Kammen 1997: 99). Then, problemising or questioning premises or unproven assumptions made in the field of biodiversity conservation and sustainable development is a task that research programs like $C \& C$ can and must undertake. Such assumptions may have arisen because of political reasons or financial considerations; sometimes, they may be ideas taken for granted and recycled in unassuming ways within the common discourse currently prevailing in conservation circles. According to Ingerson, for example, the view that traditional knowledge and practices of people in a conservation area are keys to the sustainable management of that area might have been encouraged by anthropologists and advocates themselves, who have made use of romanticised notions of forest peoples as defenders of the environment to prompt governments and international foundations to fund projects for the participation of people in protected area management (Ingerson 1997; Conklin and Graham 1995).

By testing the basic assumptions implicit in the project's statements of intent, the research program would be able to provide illuminating evidence on, for example, when and under what circumstances indigenous practices are sustainable. Qualified evidence to the contrary and conflicting findings need not be ignored, but must be carefully appraised by conservation managers in order to modify strategies and make them more effective (see Sponsel 1997). Although the C\&C program did not initially set out to test the validity of certain premises professed in KMCP's proposal, successive developments encouraged reflection on how this and future research programs could best fulfil this purpose.

The results of the $C \& C$ research preclude making simplistic and sweeping statements in support of regarding local communities as the best possible conservationists. While there is strong evidence of the existence of forms of indigenous forest management and traditional regulation of resource use, there is 
also evidence of overexploitation of protected species, motivated by the desire to make economic profits in a competitive situation. The evidence relating to the circumstances and reasons for the existence or absence of sustainable traditional management of the environment is still incomplete. This shortcoming is due primarily to KMCP's inability (or reluctance) to question its own key assumptions in conservation area management and to assign to the research program the task of testing them (see Sellato 1999). The absence of a clear, 'assumptions testing' agenda for the research program ipso facto hampered efforts at finding the best possible ways to integrate research in the planning for conservation management.

\section{A Need for Better Connections}

Indeed, C\&C's research did not go without difficulties. Moreover, ambiguities concerning the criteria and modalities of research in the context of a conservation and development project have arisen throughout the three phases of $C \& C$. These became even more apparent when local communities raised occasional questions concerning the value of research activities and the practical relevance of the results with regard to their immediate needs (Eghenter 1999a).

Difficulties point to a deficient mode of collaboration between research $(C \& C)$ and project (KMCP) staff, who failed to develop a common language and framework of reference. While anthropologists and other researchers working in conservation and development projects must ask themselves what (and how) social science research can contribute to conservation, conservation and park management specialists also need to think about how and why they make use of social science studies in order to better meet the needs of a national park and the people in it (Eghenter 1999a). From the planning phase, the $C \& C$ experience lacked the concerted efforts that would have resulted in clear objectives for collaboration and reciprocal expectations. After the initial focus on documenting the social, historical, economic, and ecological context of the communities in the conservation area, the $C \& C$ research team was often alone in trying to define the research objectives of subsequent phases and formulate hypotheses, with both their field data and KMCP's priorities in mind (see Pelkey 1995).

There was exchange and communication, particularly in the beginning, but this could have been more effectively sustained by means of common discussions, internal evaluation of the usefulness of research findings, and definition of crucial issues in management, in order to open the way for adjustments of research modalities to fit KMCP's priorities and changes in management criteria following the research findings. As a result, some of the research output failed to prove of direct significance to KMCP for the drafting of conservation policies.

At yet another level, improved communication was also played out in language and mode of expression. It is important to point out that some of the reports, although informative, were by and large embedded in a scholarly mode of writing too distant from the practical and analytical emphasis favoured by proj ect managers. This problem is not uncommon. As noted by Sillitoe (1998) in discussing the use of indigenous knowledge, the esoteric accounts of local views conveyed by anthropologists and the scientific language of development and other technical advisors are far apart. Some knowledge of technical issues of conservation and development together with an appropriate research design can dramatically improve the degree of cooperation and understanding between social science researchers and conservation specialists. 


\section{The Holistic View of Interdisciplinarity}

The co-incidence and co-dependence of people and forests in this part of interior Kalimantan require that conservation efforts be based on the recognition of the importance of the human as well as natural components of the environment. From the point of view of a research program, this translates into the need for an interdisciplinary approach, whereby issues are investigated from a multiplicity of perspectives and promote a tighter coordination of research components (see Vayda 1997). Sillitoe (1998: 231) contends that 'interdisciplinary work will be central to methodological advances in this development research'. The need to procure results that are relevant to the project and provide integrated solutions to management and development issues requires a research design based on a stronger multidisciplinary and interdisciplinary perspective. Topics need not be guided by traditional disciplinary distinctions but, rather, investigated in ways that explicitly address, although they are not constrained by, the concerns of the project.

For example, research to address the issue of the use of indigenous management practices for the management of the conservation area starts by investigating existing practices of resource use and regulations. It then asks specific questions to determine their relevance and suitability as conservation measures, such as: Has traditional restricted access had a positive effect on the level of biodiversity? Does the practice in place account for the sustainable use of resources or do other economic and demographic factors account for it? Has the practice been socially and economically beneficial to the entire community? The choice of research methods and approaches will depend on criteria of appropriateness and inclusiveness, i.e., the ability to deliver all the relevant evidence to answer the questions at point. In this case, biological surveys, inventories of forest products, analysis of local institutions, and the history of forest practices may all be important to gain an understanding of the biological and social sustainability of indigenous management practices in a national park (see Eghenter 2000a).

The exchange of ideas and open discussion across disciplinary boundaries is often limited by the researchers' fear of having to make concessions on the theoretical and methodological standards of their individual discipline or field, and thus lower the absolute scientific value of their product. This is one of the many problems that often prevent interdisciplinary work from being more than a sound principle and reasonable approach (see Sillitoe 1998).

From its onset, $C \& C$ exhibited a clear interdisciplinary aspiration. The research program evolved by pursuing interconnected topics and themes about the complex mosaic of peoples and environment in the interior of Kalimantan. It identified topics for further interdisciplinary research and built on these possibilities within the limits of its strong social science denominator. A better coordination with KMCP's biology conservation side would have promoted the integration of more biological and ecological input to the research plan.

Ironically, it is precisely truly interdisciplinary research that would secure the holistic approach that is so often claimed by the social sciences and the discipline of anthropology in particular. The integration of results from various perspectives, like linguistics and geology, or ethnobotany and history, can further our understanding of local communities as part of their natural, social, and historical environment and make sure that strategies of conservation and sustainable development acknowledge these connections. 


\section{The Local Identity of Social Science Research}

\section{The Native Social Scientist}

Social scientists involved in participatory rural appraisal (PRA) activities insist that one of the contrasting views in PRA and traditional social science research is the active role accorded to local people in the research process. On the one hand, anthropologists and other social science researchers conduct research, for the most part, about local people, and sometimes, on behalf of local people; on the other hand, PRA practitioners claim that 'poor people are creative and capable, and can and should do much of their own investigation, analysis, and planning' (Chambers 1994: 954). What follows from this premise is the resolve to transfer expertise and give local people the opportunity to become researchers in their own right. It does not follow, however, that all the people have or can acquire the skills to become researchers, as it is often implied, nor that they already possess the knowledge of the causes of developmental problems, and the potential solutions (Pelkey 1995).

$C \& C^{\prime} s$ efforts to hire and train local researchers proved correct in the sense that it stimulated interest in local cultures and provided young, educated Dayak with an opportunity to know more about their own history and cultural heritage. The experience also exposed the need to expand training sessions with special workshops for improving written communication and style, which would enable Dayak researchers to upgrade their contributions to national and international standards. $C \& C$ research activities that initially saw a mix of foreign, Indonesian, and Dayak researchers became towards the end of the program the monopoly of local social scientists, native to the communities that they were now studying. What were the advantages and shortcomings of this strategy?

Sillitoe asserts that employing nationals from the region of the project can prove cost and time efficient, as they would be able to conduct the research more quickly (1998: 235). This is also an important (and attractive) consideration for project planners and managers. The facility with the language and the lack of cultural shock allow the local researchers to immediately focus on key questions of interest to the research. The familiarity with members of their community can also increase acceptance of research and informants' goodwill, and promote support within the community. Employing local researchers has, however, some drawbacks, of which we need to be aware. Sillitoe points to epistemological concerns, such as the elimination of the 'distance' of the researcher, one of the basic tenets of traditional fieldwork. He also argues that subjective factors, such as 'losing face', can constrain the effectiveness of the role of researchers in their own communities. Along similar lines, it is important to note that local researchers face another set of challenges, precisely by being 'insiders' and, thus, socially positioned within their own communities. In the $C \& C$ experience, the example of ethno-historical research, more than any other, brought the issue of self-censorship to light. The information on particular events would not be recorded nor discussed because it might have exposed the 'darker' side of the community, or stirred emotions about tragic past events still alive in the community's collective memory. Several attempts at discussing ways to separate the issues of researching from writing and returning results only partially succeeded in convincing some of the staff that their work as researchers did not necessarily undermine their social positions as members of their communities. Moreover, their own informants were also concerned about stories that might reflect unfavourably on other communities. They sometimes chose not to tell the entire story and share their knowledge. 
Researchers who are at the same time members of a community have personal interests and carry social responsibilities that might bias the research results or the way they go about doing research. While the research period spent in the community might be just a temporary occupation, social membership of the native social scientist is probably permanent, and the stakes inevitably higher. The recognition of the limits of 'native' researchers requires some adjustments to avoid invalidating the entire research effort. In the $C \& C$ experience, team work, frequent stages in the field in different communities, progress evaluation, topic selection, and comparative focus helped local researchers strive for a more objective investigation without affecting their social positions.

With differing levels of awareness, the tendency among social scientists, including native researchers, doing work in conservation areas is to be 'involved in both protected area and agricultural resource conservation as researchers on indigenous knowledge and management, as practitioners in managing conservation programs, and as advocates for indigenous peoples' rights' (Orlove and Brush 1996: 330). This was true of the expectation of both KMCP and $C \& C$ with regard to the contribution of local researchers. The moral underpinnings of doing research on sensitive issues like land tenure rights in a country where traditional community rights are still largely unrecognised become part of the research framework. Whereas the combination of research and community advocacy might turn uneasy at times, timing and methodological rigor become of the essence. If, on the one hand, an advocacy campaign being carried out at the same time as social science research can hinder objectivity and bias the scientific results to fit the immediate objectives of the campaign, on the other hand, the impact of an advocacy campaign that builds upon unprejudiced social science research findings can prove more effective in the long term. For example, the eagerness of KMCP's staff, researchers, and activists to prove that traditional management systems were the best model for conservation solutions in the protected area had them overlook the nature of the system and ignore aspects of it that were socially and economically discriminating. Initially, they presented a biased version of the facts to government officials. Years later, KMCP is discussing with local communities alternative solutions of joint management that build on the knowledge of traditional systems but explore other arrangements that can alter past inequities (see Eghenter 2000a).

\section{Devolution and Restitution}

As stressed above, the $C \& C$ research activities were for the most part conducted by local researchers and scholars. This in itself does not necessarily make a research activity locally valuable or locally based. A program like $C \& C$, built on the premise of using research to help design management and sustainable development strategies for the Kayan Mentarang conservation area, needs to confront questions such as: Are the results available locally? Have communities used them to plan for the future development of their area? Has the research contributed to a better awareness of the significance of preserving cultural and natural resources locally? Are more local people interested in conducting research?

By deciding to return the results of the research to the communities and find ways to better disseminate them, $C \& C$ was concerned with creating a local identity for research, which could maintain its legacy and sustain local interest and cultural identity in the long term. Too often, researchers remain blissfully unconcerned about their responsibility with regard to returning the output of their research and/ or to the long- 
term aftermath of both their activities and presence in the field. There are questions, however, as to the ways and modes of our 'restitutions'. It is important to think in terms of the media selected for returning the information collected, and of their possible effects on the community. Martin poignantly asks whether the written words of a Western literate tradition are necessarily the best mode (1997: 1-2) and the answer is a qualified 'no' when dealing with communities where information exchange is still largely based on oral transmission. However, initiatives like the Kalimantan Resource Center, discussions about community museums, and even published volumes like our 1999 book and the present one provide alternative forms of returning results and making the research legacy more locally and community based.

The Kalimantan Resource Center is expected to become an independent entity managed by local people. When this happens-and we already mentioned the existing difficulties-it will be one case of a successful transition and devolution of responsibilities from an international project to a local nongovernmental organisation. What about this book, our 1999 book, and other texts recently published by the Kalimantan Resource Center? Will anybody in the communities read them? In local social circles, increasingly influenced by the church, government schools, and television, the permanency of a written text is valued, as well as the realisation that this might be the only way traditional knowledge will be transmitted to the younger generations. A book can also become a powerful weapon when dealing with the bureaucratic mindset of government officials, who all too often regard spoken words and oral traditions as transient and short-lived. And it is a book that can also be read outside the local communities, so that local voices can be heard nationally and internationally.

\section{Post Scriptum: An update on important steps towards collaborative management of Kayan Mentarang National Park}

When the introduction for the edited volume Kebudayaan dan Pelestarian Alam (1999) was written in the summer of 1998, the WWF Kayan Mentarang was still in the midst of lobbying with the Ministry of Forestry for the recognition of indigenous people's rights to manage the park and its resources. The data from the Culture \& Conservation Research Program and the community mapping program provided the main evidence that the conservation area was first and foremost a tanah adat, lands historically and continuously claimed and managed by the communities. The efforts of the communities, the customary leaders, and WWF to obtain a community-based management for the park had been inexhaustible, yet the goal seemed still so far away, almost unattainable.

In addition to mapping all traditional land, WWF together with the communities and local government had tried to seek recognition for tana' ulen, a traditional system of forest management and protection common in Kenyah communities. Although the status of tana' ulen has undergone several changes with regard to its meaning and function, the issue of tana' ulen remained a way to raise awareness on tenure and management rights of indigenous people in the national park area. Moreover, it proved that local communities had the experience and knowledge to manage the forest sustainably.

Fundamental social and political changes occurred in Indonesia 1998-1999. As part of the reform movement that was triggered by the new political climate, a new Forestry law was issued (UU No 41/1999) and the law on decentralisation and regional autonomy was promulgated (UU No 22/ 1999). Both laws set a new stage with regard 
to both conservation policy and the rights of indigenous communities. The District of Bulungan was also divided into three new districts to reflect the growing population of the area: the new districts of Nunukan, Malinau and Bulungan. Most of the national park now falls into the district of Malinau. Under these circumstances, new models of national park management could be designed to accommodate the aspirations of indigenous people and engage the new districts.

In April 2002, the Ministry of Forestry issued a decree sanctioning the collaborative management for the Kayan Mentarang National Park. Policies concerning the management of the conservation area will be decided by a Policy Board (DPK), which includes representatives of the Central Government (Agency for Forest Protection and Nature Conservation), of the Provincial and District governments, and of the local communities through FoMMA (Alliance of the Indigenous People of the Kayan Mentarang National Park). In many ways, this innovative management model, which is being applied for the first time in Indonesia, responds to an important recommendation based on the findings of the Culture $\&$ Conservation Research Program: sustainability of any conservation program is contingent on the degree to which the complexity and diversity of the social and economic context are recognised and flexible and locally appropriate measures of conservation are adopted. The unique circumstances of the Kayan Mentarang National Park are the historical and cultural heritage of the Dayak people who have been living and managing the forest for centuries.

\section{LAND AND PEOPLE: AN INTRODUCTION TO KAYAN MENTARANG}

The pages below constitute a brief introductory basis to the set of twelve chapters of this book. Reflecting the research upon which it is based, the chapters mainly focus on the Kenyah people, particularly the Kenyah of Pujungan subdistrict.

Each of these chapters should be viewed as one facet of a complex prism: the prism itself allows for a multidimensional approach to Kenyah society, its modes of interaction with its natural environment, and the history of this interaction; each facet offers insights into one or several interdependent aspects of these questions; and each is illuminated by a number of other facets of the prism. To some extent -and this is, indeed, the way both the research and the present book were conceived-the book should be read in its entirety and no single chapter should be read or used separately from the whole, as none is totally self-explanatory or self-contained as an independent article should be.

Needless to say, this set of chapters does not cover all aspects of Kenyah society or its interactions with its environment. For various reasons, certain aspects of Kenyah life-such as fishing or gardening, house building or river navigation-while relevant, are not dealt with in this book. Be it as it is, with its incompleteness and flaws, we believe that the picture offered by this book is significant enough to allow for a better understanding of the current situation, by all parties concerned and for all purposes contemplated.

\section{The Environment}

The Kayan Mentarang National Park includes the headwaters of the Kayan and Mentarang rivers and their tributaries, in the Malinau and Nunukan (Bulungan) districts of the province of East Kalimantan, and borders the two Malaysian states of Sarawak and Sabah between $2^{\circ} \mathrm{N}$ and $4^{\circ} 30^{\prime} \mathrm{N}$ (see Figures 1.1 and 1.2). Ranging in elevation from 
about $200 \mathrm{~m}$ to about $2500 \mathrm{~m}$ asl, it contains lowland valleys, montane plateaus (at about 800-1000 m elevation), and steep mountainous massifs shaped from various sedimentary and volcanic formations. The wet tropical climate, with no sharp seasonality, ensures an average annual rainfall of about $4000 \mathrm{~mm}$.

Figure 1.1 The Island of Borneo

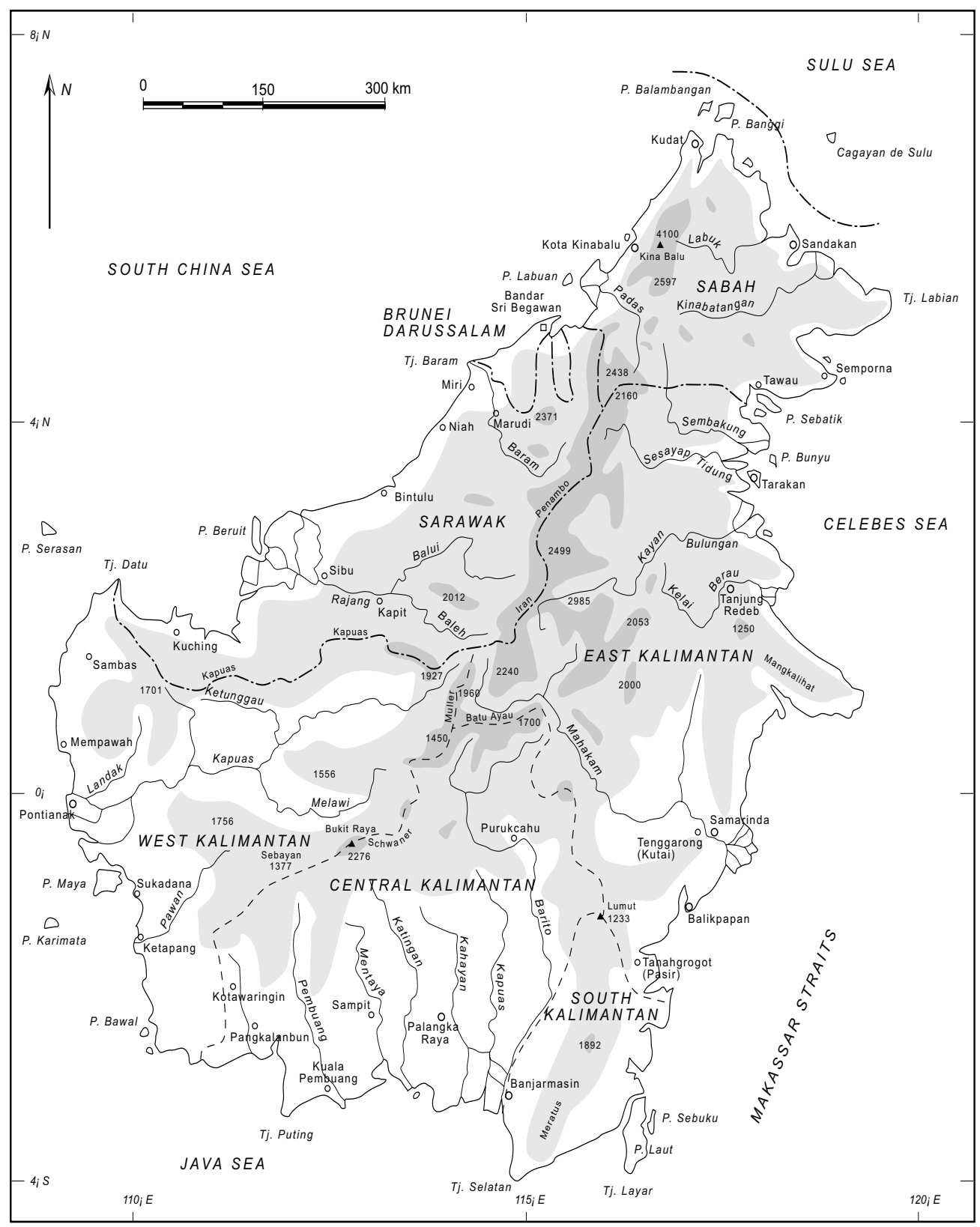


Figure 1.2 Kayan Mentarang and surrounding region

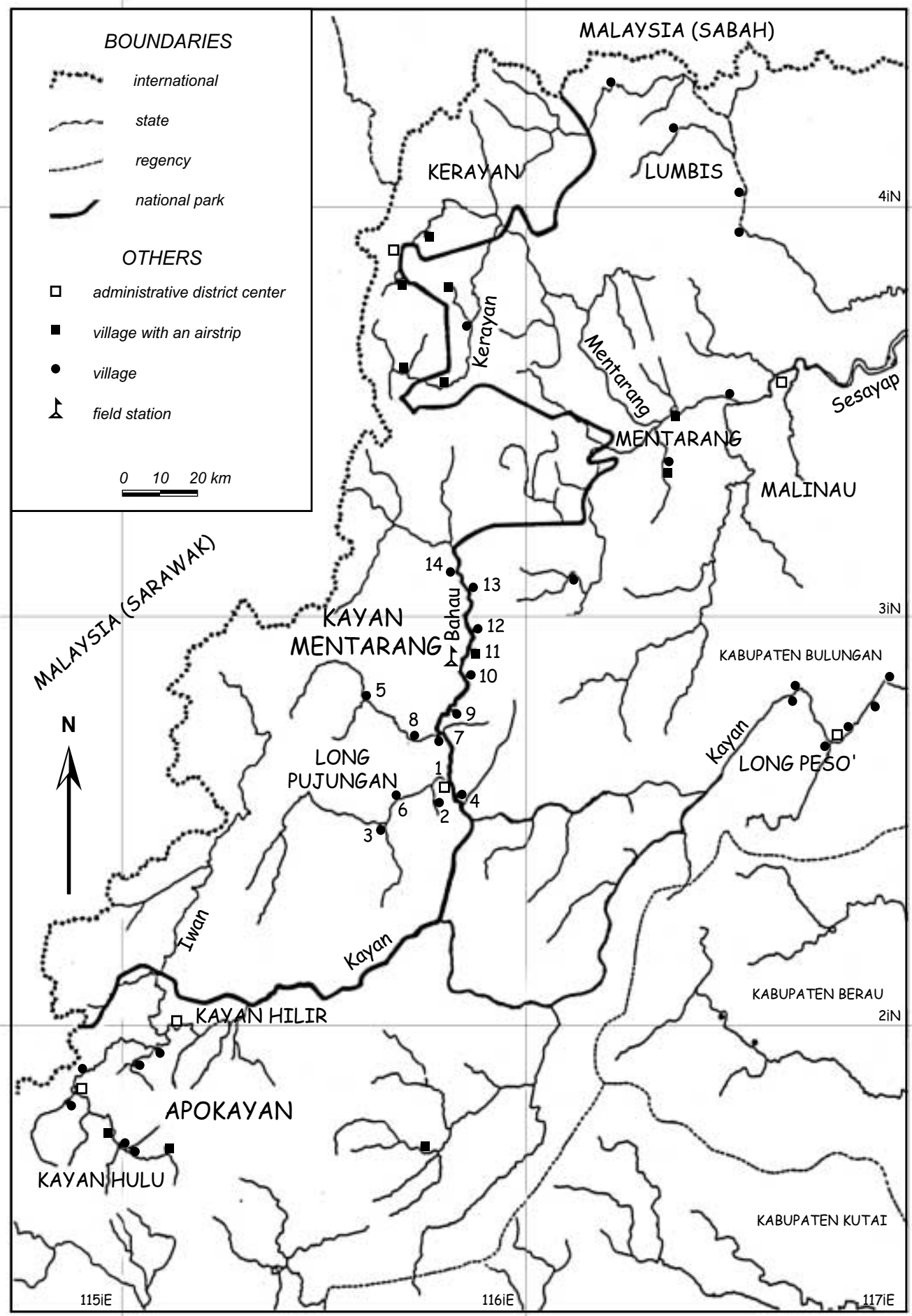


The vegetation is varied, with much variation due to local factors (geologic substratum, slope, microclimates). The main types are the mixed dipterocarp forest (from the lowlands to about $1000 \mathrm{~m}$ asl), the Fagaceae-Myrtaceae forest (or 'oak forest'), the Agathis forest, the heath forest (kerangas), the sub-montane and montane forest (above $1000 \mathrm{~m}$ ), as well as confined swamp forest, and a particular moss forest at high altitudes (above 1,500 m). Most, if not all, of these forests have undergone, since long ago, some degree of change due to human interference. Diverse types of 'secondary' forest are present. In fact, there is a continuum in botanical composition and distribution from village space, old swidden fields, and human-made agroforests (the human sphere) to what is usually called climax or 'primary' forest. As it is now commonly acknowledged, local people, through their utilisation of the forest and their management of its resources, actually made it what it is.

For the record, the flora reportedly includes about 500 species of orchids and at least twenty-five species of rattan. As for the fauna, it includes about 250 species of birds (recorded), of which seven species of hornbills; and 96 species of mammals (excluding bats), including eight species of primates and various endemic species (Soedjito and Kartawinata 1994; WWF-I 2000; Wulffraat and Samsu 2000).

The Kayan Mentarang forest is rich in products of economic importance, either to the local people or the outside markets, or both. Besides timber (mainly dipterocarps), useful palms are plentiful (rattans and sago), and for over 200 species of plants some local medicinal use has been recorded. While some non-timber forest products, such as eaglewood (incense wood or aloeswood, gaharu), resins (damar), and illipe nut (tengkawang) have long been collected for trade, over 100 species of wild fruits are known as edible by the local people. In one survey, an astonishing $86 \%$ of 383 plant taxa recorded were reported to have some use (Puri 1998; see also Puri 2001, Uluk et al. 2001, and Wollenberg, et al. 2001). This knowledge of forest resources and their uses extends to the fauna: apart from the famous bearded pig (Sus barbatus), over 45 animal species are hunted and consumed, and this does not include fish.

\section{Population and Transportation}

Kayan Mentarang National Park lies across five subdistricts (kecamatan) of the two districts (kabupaten) of Malinau and Nunukan (Bulungan), principally Pujungan, Kerayan, and also Kayan Hilir, Mentarang, and Lumbis (see Figure 1.2). In each subdistrict village, the administration, police, and army are represented, elementary and junior high schools are available, and a doctor is in residence at a small hospital (puskesmas).

The area within, and in the immediate vicinity of, the park is home to about 16 000 people. In 1997, Pujungan subdistrict had 3106 souls, Kerayan 9000, Kayan Hilir 1364, Mentarang 4995, Lumbis 7382. Population density (per sq. km) ranges from 0.1 (Kayan Hilir) and 0.3 (Pujungan) to about 2.8 (Kerayan and Lumbis). Most of the communities in or near the park are 'traditional' communities or masyarakat adat, with populations ranging from 50 to 500 people.

Transportation is mainly by river from coastal towns to Pujungan, Mentarang, and Lumbis, but Kayan Hilir and Kerayan are now only reached by air. Air service also reaches several villages of the upper Bahau River area (Pujungan). Most recently, the Malinau district government has made and agreement with MAF for subsidised flights to all subdistrict villages.

River transport is by powerful longboat along the rivers' middle courses and by small canoe with a long-tail engine (ketinting) in their upper reaches, but sudden 
changes in water height and river depth, as well as a number of dangerous rapids, considerably hamper navigation. Communication on foot-and now, locally, by motorcycle-is common in Kerayan, where rivers are not navigable. Difficult traditional footpaths across water divides connect the different interior subdistricts.

\section{Ethnic Groups and History}

The hinterland region of what used to be Bulungan District and it is now Malinau and Nunukan districts has a long and complex history (see Figure 1.3). The reconstruction offered below remains sketchy, pending a more thorough study of the historical data gathered (see Sellato 2000 for additional discussion).

The Apau Kayan and Bahau-Pujungan regions likely were inhabited by a set of culturally related peoples, which we have called Ngorek. These Ngorek probably were part of a wider ethno-cultural entity including the groups now living in Kerayan and adjacent areas. All these groups are known, throughout the region, for their secondary burial practices and related megalithic monuments. It is fairly possible that they were mainly horticulturalists with a subsistence based on tubers, and with no iron tools, as the presence of stone tools attest (Sellato 1995c).

Presumably in the $17^{\text {th }}$ century or earlier, new groups entered East Kalimantan from Sarawak through the Iwan River. Moving down the Iwan River, they found good lands in the Apau Kayan Plateau. These groups, known as Modang and Kayan, dedicated rice swiddeners mastering the technology of iron, were socially stratified and militarily aggressive.

During the first half of the $18^{\text {th }}$ century, Kenyah groups-probably nomadic groups from Sarawak that had more or less switched to rice farming under their neighbours' influence-moved over into the Iwan (see Whittier 1973, Rousseau 1990). There, they differentiated into a number of named groups, some of which moved down towards the Apau Kayan and others over into the Pujungan River drainage.

Around the middle of the $18^{\text {th }}$ century, the Kayan and Modang from Apau Kayan and their Kenyah allies massively attacked the Ngorek from the southwest and took over the Pujungan and middle Bahau, enslaving some, vassalising others, and chasing away the rest. Runaway Ngorek groups found refuge on the upper Baram and on the upper reaches of the Bahau.

The second half of the $18^{\text {th }}$ century saw a large-scale split of the Kayan and Modang groups, who started moving out of the Apau Kayan and Bahau areas (only one Kayan group now remains in Apau Kayan) and leaving particular Kenyah groups, like the Leppo' Timai in the Apau Kayan and the Uma' Alim in the Pujungan, in charge of their respective region. The Kenyah soon occupied the vacant territories and pushed away remaining Ngorek groups.

More Kenyah groups, the Leppo' Ké and the Leppo' Ma'ut, moved into the Lurah and, later, overland to the upper Bahau. Those were at war with the Kenyah of the Pujungan River. Ngorek groups scattered away to neighbouring regions, where their descendants still live, most now known under other ethnonyms, like the Merap of the Malinau and the Tembau of the Tubu. Sections of Ngorek populations remaining in the region, like the Pua' and the Nyibun, were culturally assimilated by their successive overlords.

In the course of the following 100 years, more Kenyah groups (e.g., Uma' Kulit and Uma' Baka') moved in and out of the Bahau River system; some, like the Badeng, remained. The Dutch first surveyed the region in 1900-1905 but administrative control 
Figure 1.3 Ethnic groups in and around Kayan Mentarang

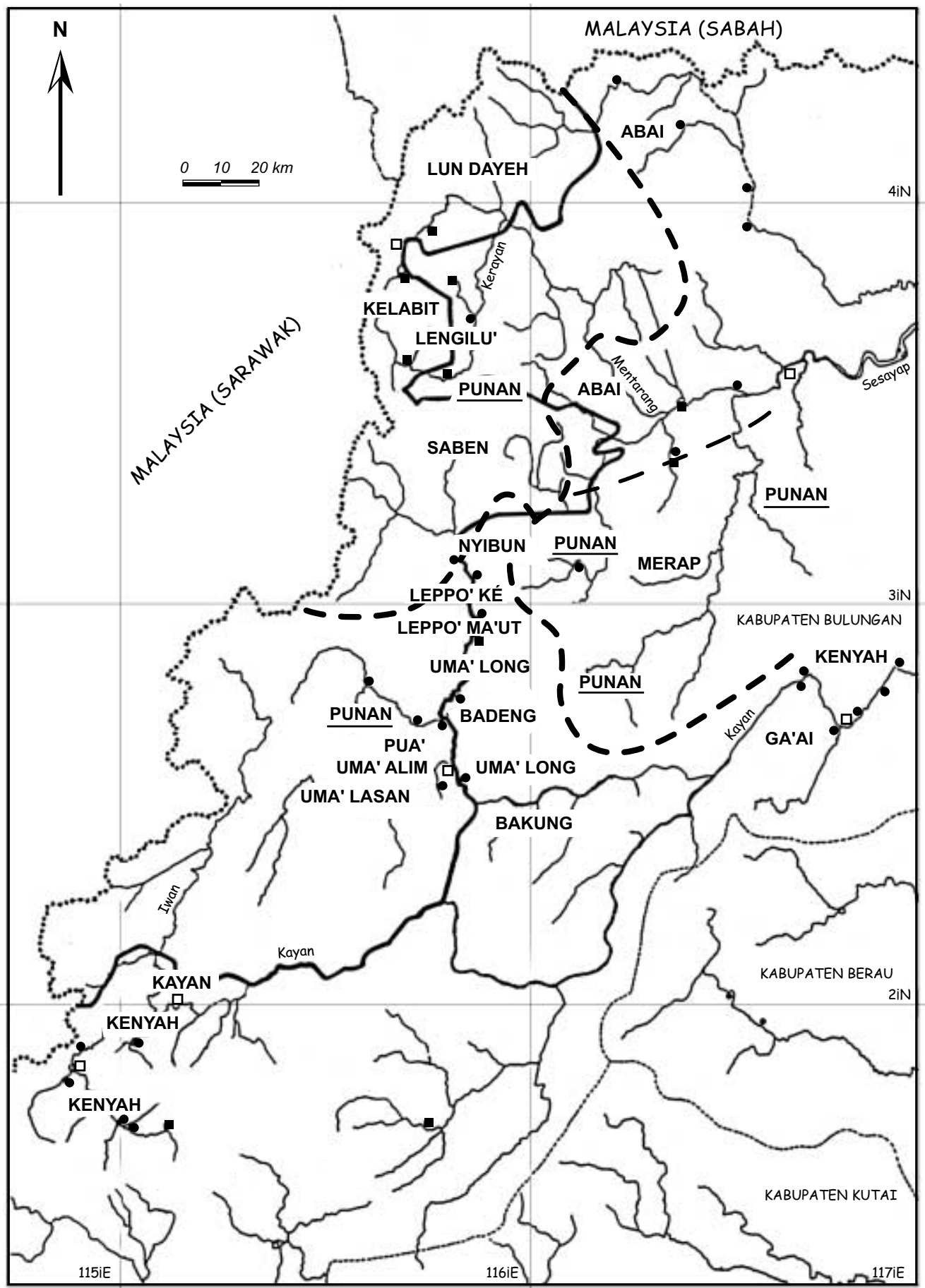


was only truly achieved around 1925-30, halting warfare and headhunting. Massive migration out of the Apau Kayan and the Bahau started in the 1960s to Sarawak, the Mahakam, the Malinau River, and the coastal regions (see below; and Eghenter 1999b, 2001).

The Kerayan and Mentarang areas are populated by groups now collectively known as Lun Dayeh. These groups probably originated from the region downstream of Malinau town, where they lived close to the Tidung people. These swidden farmers were attacked, presumably in the $17^{\text {th }}$ century, by Moslem sea raiders (Bugis or Tausug), who took control of the local river trade (see Sather 1972). While the Tidung converted to Islam, the Lun Dayeh moved upriver. Some went up the Mentarang River, while others settled the Kerayan Tengah region, and others yet entered the Kerayan Hulu area.

Pressed from the east, the groups of Kerayan Tengah soon spread to the western part of the plateau, then a large lake complex (see LeBar 1970, Schneeberger 1979), and allegedly uninhabited. At some point in the course of their migrations, these groups, later called Lun Baa' ('people of the swamps'), started growing wet rice. Some eventually moved into the Kelabit Plateau of Sarawak, and later to several other river drainages there, but were kept in check by Kayan and Kenyah groups (see Harrisson 1959c). Another group, the Lengilu', lived along the Kerayan River near the limit of Mentarang subdistrict. From there, they entered Kerayan Tengah and Kerayan Hulu.

Part of the groups of the Mentarang moved up the Kerayan, then entered the Kemaloh and the Lutut river drainages (see also Harrisson 1959c, LeBar 1972). Others entered the Kerayan Tengah area, and some probably went as far as Kerayan Hulu. Later, from the Kemaloh, some moved west and into the upper Padas River of Sabah, while others went up the Lutut and across into the Limbang and Trusan rivers of Sarawak.

The Malinau drainage was, in a remote past, inhabited by numerous nomadic bands of Punan and by the powerful Berusu'. The Merap group, fleeing the Bahau, allied with the Punan and took over the whole Malinau River drainage from the Berusu', who withdrew to the Sekatak and Bengalun Rivers. Later on, large groups of Pua' and Kenyah from the Bahau settled in Merap territory, where they are now quite prominent.

The upper Tubu was long the territory of nomadic Punan Tubu groups until runaway Ngorek groups from the Bahau settled there, like the Tembau (or Milau). A large part of the Punan Tubu subsequently took up agriculture, as well as some other cultural features. Some have recently moved into the middle Malinau drainage. In the lower Tubu drainage, as well as in other parts of Mentarang subdistrict and in Lumbis subdistrict, the Tebilun (a.k.a. Abai or Tinggalan), a group affiliated to the Murut family of Sabah, remain the dominant group, although several important communities of upriver Lun Dayeh (from Kerayan and the upper Mentarang) have now settled in the lower Mentarang and near Malinau town.

\section{Languages}

In the Pujungan subdistrict and in Apau Kayan, the ethno-linguistic situation is rather uncomplicated. At the time of their first visit, the Dutch (van Walchren 1907, Fischer and Gramberg 1910) found that each village and its precisely, de jure bounded territory were home to a distinct, named Kenyah subgroup (e.g., Leppo' Ké, Uma' Alim) speaking a unique isolect referred to by the same name (see Rousseau 1990). As a rule, indeed, each named Kenyah group has a dialect of its own, internally homogeneous 
and externally distinctive. Exceptions are Leppu' Ndang, which is giving way to Oma' Long (or Uma Long), and Nyibun, which is becoming extinct. All these dialects are mutually intelligible.

Whereas Blust (1972) included Kenyah languages in a North Sarawak Group, Hudson (1978: 28-32) classified them as a subgroup of his Kayan-Kenyah Group (which also includes the Kayanic subgroup). Early C\&C surveys (Sellato 1995b) and later dialectology studies (Soriente 1999) in the Pujungan subdistrict distinguished two groups, one including Leppu' Ndang, Bakung, Leppo' Ma' ut, Leppo' Ké, and Badeng, all closely related to the Leppo' Tau, Leppo' Bem, and Leppo' Tukung dialects of Apau Kayan; and another including Oma' Long, Uma' Alim, and Uma' Lasan. For a more elaborate reconstruction of the history of Kenyah (and Kayan) languages, see Soriente (2002).

From the start, the Pua' and Nyibun isolects were set apart. Pua' is a Kayanic language, related to the Kayan Uma Lekan language of Apau Kayan. As for Nyibun, although it is lexically a Kenyah dialect, its phonology places it in an intermediate position between Kayanic and Kenyah(ic), and close to Kenyah Uma' Timai of the Mahakam and the so-called Leppo' Pu'un isolects of Sarawak.

Non-Kenyah languages include Penan Benalui and Saben. The Penan Benalui (or Menalui) came to the Bahau region from the upper Balui in Sarawak around 1900, following the Kenyah Badeng's migration route. They split into two groups-on the Aran River and on the Lurah-but always remained closely associated with the Badeng. These Penan are generally multilingual. Their language is undergoing rapid assimilation by the Badeng dialect through a situation of bilingualism among the younger generation. The Saben appear to have come from the upper Kerayan around 1800 as two distinct groups: the Saben proper and another group that later split to become known as the Selio' (or Serio') and the Merau Kalun. Among the Pujungan's few remaining Saben (at Apau Ping), only seven are native speakers. Saben is a member of Hudson's Apo Duat Group.

In Kerayan subdistrict, today's extremely perplexing situation reflects a long history of intense ethnic and linguistic interaction related to small-scale and short distance movements, as well as a marked degree of instability of ethno-linguistic entities through time, especially in recent decades. It appears difficult today to elicit clear ethnonyms and isolect names, match them, locate the corresponding actual groups, and retrace their migration histories. Kerayan subdistrict comprises four customary areas, Kerayan Darat in the West, Kerayan Hilir in the North and Northeast, Kerayan Tengah in the East, and Kerayan Hulu in the South (see Sellato 1997c).

All these entities have been labelled Southern Murut or Kelabitic Murut (e.g., LeBar 1972), Lun Dayeh (Crain 1970, 1978), or more recently Lun Bawang (Ipoi 1989). They reportedly number 25000 in Kalimantan (Kerayan, Mentarang, Lumbis, and Malinau subdistricts), 10000 in Sarawak, 2000 in Sabah, and less than 1500 in Brunei. All these groups' tongues belong to the Apo Duat Group (Hudson 1978). It was proposed (Sellato, in press 1) to distinguish in Kerayan subdistrict, on the basis of both historical and preliminary linguistic data, four subgroups: Kelabitic, covering Kerayan Darat, the Pa' Padi (River), and part of Kerayan Hulu; Kemaloh, more or less equivalent to Hudson's Sesayap-Trusan subgroup, in Kerayan Hilir and Mentarang subdistrict; Lengilu', in Kerayan Tengah and Kerayan Hulu; and Saben, in Kerayan Hulu. Ongoing linguistic studies, particularly by Beatrice Clayre, are progressively illuminating the situation and are bound to alter the groupings above. A few minor ethno-linguistic entities, such as the Milau and Tembau, still retain an ambiguous status. Finally, one small group (70 people) of formerly nomadic and linguistically unrelated Punan Tubu (from the Tubu River) now lives in Kerayan Hulu. 


\section{The Kenyah of Pujungan Subdistrict}

Pujungan subdistrict (one of Kalimantan's largest subdistricts, approximately 8500 $\mathrm{km}^{2}$ ) comprises 21 government-designated villages (desa) distributed in 16 locations, of which three are hamlets of precarious permanence (numbers 1 to 14 below refer to Figure 1.2). It should be stressed that the spatial distribution of villages may change at any time, to the effect that the validity of the information in the paragraphs below has only a limited lifetime.

The subdistrict's chief village, Long Pujungan (1) includes two desa, Desa Long Pujungan proper, with a population of Kenyah Uma' Alim and Uma' Lasan, and Desa Long Sa' an, a group of Kenyah Oma' Long from the upper Pujungan River.

In the lower course of the Bahau, including the Pujungan and Lurah rivers, the following settlements are found: Long Ketaman (2) is populated by Uma' Alim; Long J elet (Desa Long Mesahan, 3), by Uma' Lasan. Long Aran (or Long Apan Baru, 4) has a population of Kenyah Bakung recently arrived from the Apau Kayan via the Lurah River. Long Peleran (7) comprises two groups of Kenyah Badeng, of which one came recently from Long Bena', and a small group of Penan. At Long Bena' (5), only a few families of Badeng remain. At Long Uli (9), two groups coexist, the Kenyah Oma' Long and the Kenyah Leppu' Ndang, both from the Lurah area. In the Lurah River, the hamlet of Long Belaka (8) is home to a dozen families of Penan. Another group of Penan, registered as Desa Long Sungai Ma' ut, has unpredictable whereabouts from one year to the next. Yet another group, which used to reside in the upper Aran River but later moved to the main Bahau River near Long Han, is now settled at Long Lame, next to Long Apan Baru. All these Penan groups, known as Penan Benalui, may still be viewed as semisettled nomads. Finally, a small community of Pua', a non-Kenyah group, still resides at Long Pua' (6), after most of the village's population moved to other regions.

In the upper half of the Bahau River drainage, the village of Apau Ping (14) comprises four desa, three of Kenyah Leppo' Ké (Desa Long Lat, Long Pengayan, and Apau Ping proper) and a couple of families of Saben or Berau (Desa Long Tua), a group affiliated to the Lun Dayeh of Kerayan subdistrict.

Part of the Leppo' Ké have moved downstream to Long Tebulo (10), others to the Malinau drainage. Long Alango (11) is a large village of Kenyah Leppo' Ma'ut, and two other desa, Long Kemuat (12) and Long Berini (13) are also home to Leppo' Ma' ut communities. Desa Long Aking, now located at Long Berini, is a village of Nyibun, a non-Kenyah group that has long been associated with the Leppo' Ké. Some Nyibun families are also found at Long Kemuat.

Altogether, population figures per ethnic group are, grossly, as follows: Uma' Alim (140), Uma' Lasan (300), Oma' Long (140), Leppu' Ndang (90), Pua' (60), Bakung (340), Leppo' Ma'ut (580), Leppo' Ké (440), Badeng (160), and Nyibun (140). The Penan Benalui, scattered in the Lurah and middle Bahau, now total between 250 and 300, and the Saben, only some 20. These figures, computed from 1993 Subdistrict Office data, may not accurately account for actual resident populations, as scores of registered residents are really living outside the subdistrict (Sellato 1995a). For most of these groups, the people living in the subdistrict are residual populations. Total population dropped from about 10000 at the turn of the century (Sellato in press 1) to about 7000 in 1965 (Rudes 1965), to the current 3000-in Apau Kayan, it dropped from about 20000 in 1900 to 12000 in 1971, to less than 6000 in 1994 (Nieuwenhuis 1904-07, von Franz 1988, Eghenter 1995).

This situation is typical of depopulating upriver regions throughout East Kalimantan in the last few decades (J essup 1981, Guerreiro and Sellato 1984, Sellato in press). 
Outmigration is generally the result of a pursuit of better living conditions, focused on the access to cheaper trade goods and better education and health facilities, but locally the lack of swidden farming land also has been an important factor (J essup 1981). Large numbers of former Pujungan residents are now found in Malinau subdistrict, in the lower Kayan River region (Long Peso' and Tanj ung Palas subdistricts), in the Sajau River drainage, in Berau District, and in the upper Baram River in Sarawak.

The Puj ungan subdistrict is divided into two customary areas (wilayah adat), one called Wilayah Adat Pujungan, comprising the villages numbered 1 to 9 , that is, the Pujungan and Lurah rivers and a large section of the Bahau; and the Wilayah Adat Hulu Bahau, comprising villages 10 to 14, covering the whole upper Bahau drainage. For the former, a customary chief (kepala adat besar) resides at Long Pujungan; for the latter, the chief is at Long Alango. Historically, the Uma' Alim were the prominent group in the Pujungan customary area, and the Uma' Lasan, Oma' Long, Leppu' Ndang, Badeng, Bakung, and Pua' were their allies. In the Hulu Bahau, the customary leaders were traditionally from the Leppo' Ma' ut. As for the Penan Benalui, relative newcomers, they were historically, and remain, associated with the Badeng.

\section{Subsistence Activities}

Pujungan subdistrict consists almost exclusively of rugged and rather infertile geologic terrain-Cretaceous to Eocene sandstones and claystones, intruded by Miocene basic volcanic rocks locally forming peaks over $2500 \mathrm{~m}$. Rushing streams have cut through the volcanites, leaving plateaus overlooking the valleys. Relatively fertile claystone is scarce except in the upper courses of the Bahau, Lurah, and Pujungan rivers. The Bahau River flows swiftly from about $600 \mathrm{~m}$ at Apau Ping to about $200 \mathrm{~m}$ at Long Aran.

The Kenyah, now dedicated rice-swiddeners, farm the slopes of the narrow valleys of the Bahau and its main tributaries (on swidden farming in Borneo, see, e.g., Freeman 1955, Chin 1985, Dove 1985a, Colfer 1993). Overall, Kenyah farmers stick to the patches of claystone, which have long been under cultivation. Thirty to 50 varieties of paddy are known, up to 12 of which are sticky rice. Kenyah swiddening (uma) makes repeated use of the same plots of land, which are left to fallow over long periods (bekan or jekau), and very little climax forest (mba') is felled. An average family (five to six persons) farms a 2-4 ha swidden and has been using about 40 ha of land under rotating cultivation in the course of the last two decades. Ad hoc or permanent cooperative groups (senguyun) start work in May with the clearing of the undergrowth, then the burning of the field (in two stages) in August, followed by sowing, and paddy is harvested in J anuary to March.

Some irrigated rice fields are found, but only four villages seem to have appropriate flat lands, and wet-rice farming, restricted to these narrow areas, is generally carried out alongside swidden farming. How and when some Kenyah groups first learnt swamp farming is not quite clear (see Sellato 1997c), but irrigation and terracing techniques were only introduced to farmers around 1950 (e.g., in Long Alango). Work in the wet fields (peng or mbang) is scheduled to accommodate the priorities of swidden farming. A field apparently remains under cultivation no longer than three consecutive years and is then left fallow for several years, thus participating in a rotating wet-rice farming system. Recent droughts several years on end probably accounted for a dramatic increase of wet field acreage to reduce the risk of famine in case of failure of the hill-rice crop. 
In the upper Bahau, self-sufficiency in food seems to be consistently achieved. This case compares favourably with cases in other regions of Borneo, where at least half of the households cannot meet their needs (e.g., Dove 1993). No reliable data are available on yields in Puj ungan, but in Apau Kayan, a figure of over one metric ton per hectare has been put forth (J essup 1992). The Kenyah, however, still maintain the habit of occasionally mixing boiled taro or cassava with their rice. Taro and cassava, both widely cultivated, may thus play an important role in their self-sufficiency.

Hunting is an important subsistence activity, which takes numerous forms, including unusual ones (Puri 1997). Local patches of grasslands were deliberately maintained by firing for the purpose of hunting deer (Nazir 1997). Until recently restricted to local consumption, meat, particularly of wild boar and deer, has now become a trade product, due to the improvement of river transportation. Fishing is performed in various ways, including the use of different types of nets (thrownet, jala; and castnet, pukat) and traps. A traditional form of fishing using tuba poison, meant to procure important quantities of food for a religious festival and celebration, involve the whole village. The Penan also consume dozens of small animals, usually caught by hand and ranging from palm maggots, locusts, and river snails to crabs, frogs, and lizards.

The Kenyah maintain fruit orchards and vegetable gardens. While cassava and sugarcane are planted either in or around rice swiddens, either during the rice crop or after the harvest, taro is planted in specific damp spots or on dykes around wet paddies. Vegetable gardens are usually located near the village-or even around the house-or near the swidden. Fruit trees are kept near or in the village, as well as in old and current swidden locations. Gardens may include over 100 plant taxa, of which about 40 are trees. Those include fruit trees for home consumption, such as species belonging to the genera Durio, Nephelium, Lansium, Mangifera, and Artocarpus, as well as cash crops, such as coffee and cocoa. Various species of banana play an important role as food. Some medicinal plants are also grown in gardens. Food gathering, a women's chore, takes place in gardens, but also in secondary forest, where scores of edible plant parts (from about 80 taxa) are collected. Only a few such plant parts are also locally traded in small quantities (e.g., the bekkay leaves used as a relish).

The traditional subsistence activities of the Penan Benalui hunter-gatherers include the processing of edible starch, the sago (from several species of palms, principally Arenga undulatifolia and Eugeissona utilis), which is consumed in a variety of recipes. About 200 plant taxa comprising edible parts-fruit, root or tuber, buds, leafs, shootsare also used, as well as some ferns and mushrooms. The Penan clean and maintain wild sago palm groves for their recurrent use. In times of famine, the Kenyah also resort to the carbohydrates of wild sago.

Non-timber forest products are collected by Kenyah and Penan alike for local use, as is the case for rattans of various species, and also for trade. Widely traded items include certain species of rattans and eaglewood (gaharu; see Sellato 2002, Momberg et al. 2000, Wollenberg 2001)). A maritime trade (for instance, with China) in certain forest products goes back at least one millennium, relayed by petty coastal trading polities, such as the kingdom (later, sultanate) of Bulungan or that of Tidung on the Sesayap (Sellato 2001). Cinnamon, a traditional non-timber forest product (NTFP) in the upper Bahau, is now being planted. Local trade used to be controlled by a handful of merchants based in downstream towns, but local traders are increasingly becoming important players at local level as middlemen. The villagers have also been facing much competition from teams of outside NTFP collectors sponsored by traders based in Samarinda, Tanjung Selor, or Tarakan, or by large companies. 
Figure 1.4 Secondary forest after swiddening by the Kenyah

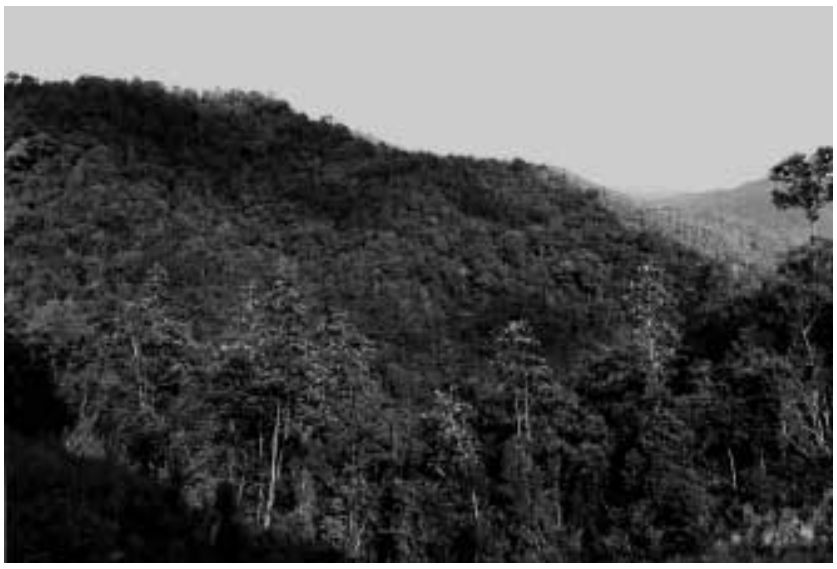

Figure 1.5 A Kenyah swidden and field hut

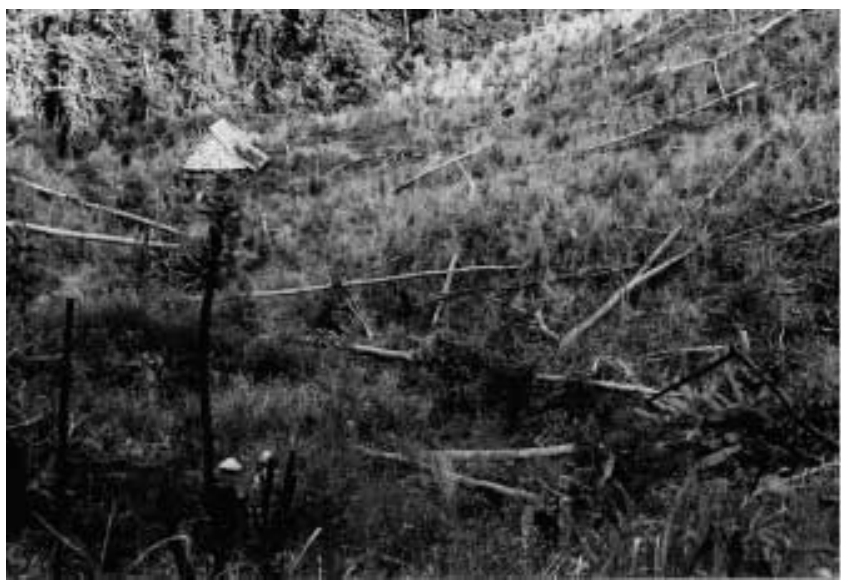

Figure 1.6 A thatched Kenyah field hut by a swidden

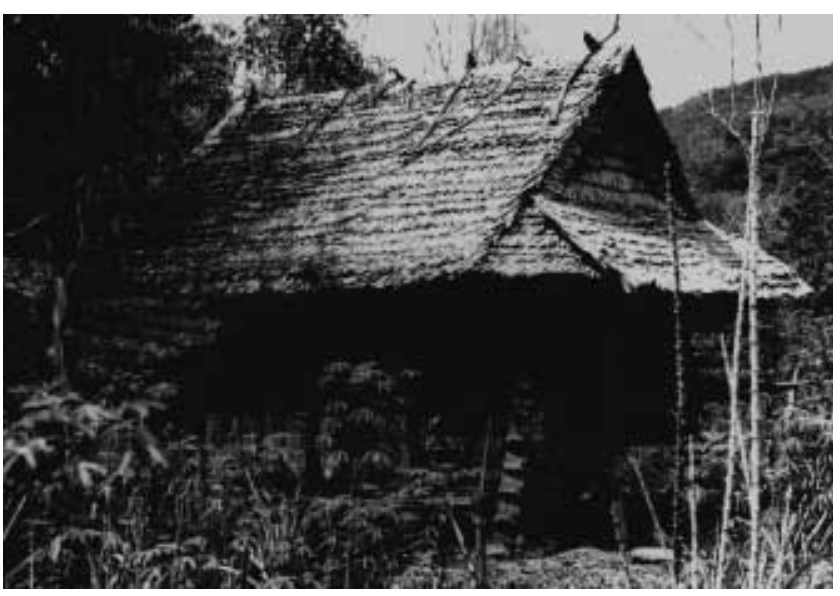


Figure 1.7 A few such hanging rattan bridges are still in use

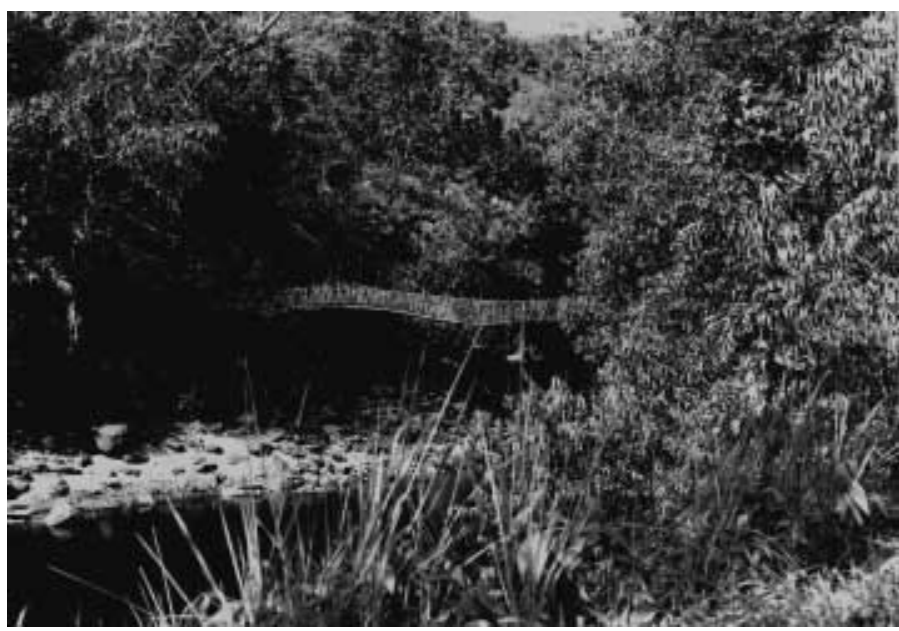

Figure 1.8 A blacksmith at work at the bellows

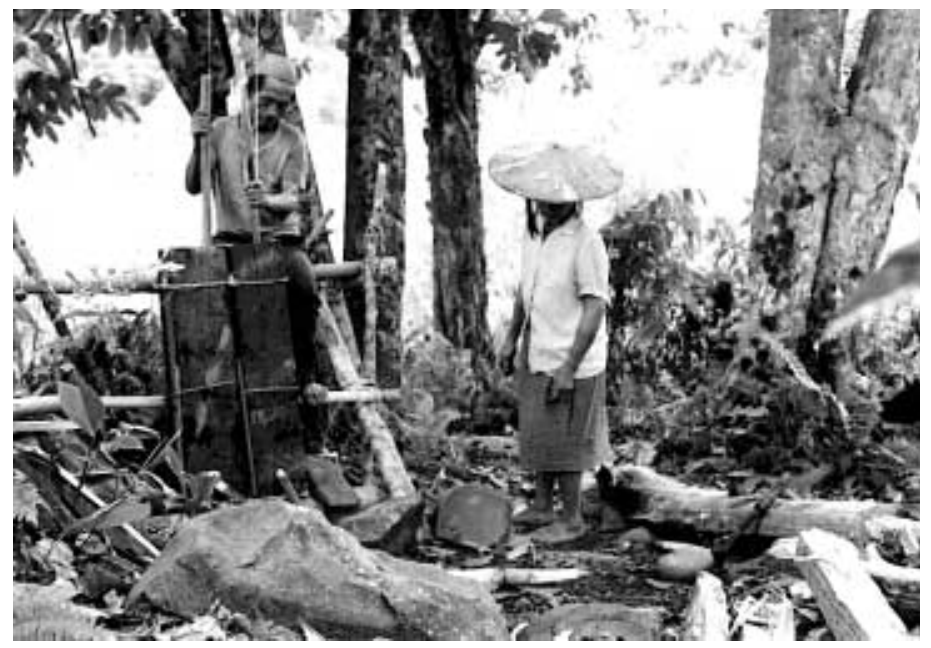

\section{Kenyah Society}

In Pujungan subdistrict, Kenyah society traditionally was stratified into aristocrats (paren), commoners (panyen), and slaves (kula'; see Whittier 1978a; Rousseau 1990). In this system, similar to that of the Kayan and seemingly derived from it, the crucial premise is the paren's divine mythical origin and therefore distinct nature, which entails a prevailing stratum endogamy and very low vertical social mobility, occurring through marriage only. In olden times, social ascription was very strict, and commonersnot to mention slaves-belonged to a given paren family, who often ruled heavy-handedly and would not allow them to leave the village. Therefore, village endogamy was the norm. High paren families, conversely, tended to weave an exogamic regional network of aristocratic alliances with other groups (see Rousseau 1990). 
Although the 'ethnographic' situation described above has undergone dramatic changes in recent decades, the Kenyah community to a large extent remains a political, economic, social, and ritual entity (see Rousseau 1990, Sellato 1987). It owns a territory that is jurally defined and precisely bounded through treaties with its neighbours. Visà-vis these neighbours, the community acts as a political unit under the leadership of its high paren. Subsistence economic activities are coordinated at village level, and so, in the past, were trading expeditions (peselai). Each and every individual formally (i.e., ritually) belongs to a village (leppo'), formerly also to a longhouse (uma'), and to a household (amin, a stem family, the minimal unit)-all of which are perpetual residential units. Each household has ritual rights and duties and must be represented in village-level religious activities. In all respects, Kenyah communities form bounded entities. However, some degree of fluidity is allowed in the composition of agricultural work groups.

In the past, minor groups under enemy threat had to request protection from a stronger group and accept its tutelage. When a village was defeated in war, its people were divided among the victors' aristocratic families and became their commoners. With the opening of formal relations with the coastal sultanates and, later, the Dutch administration, the then prominent groups were confirmed in their superior position, their high paren officially becoming regional leaders.

After Dutch rule abolished slavery, the ruling stratum found itself economically diminished. Then, the Indonesian administration and a massive conversion to Christianity dramatically changed the longhouse social environment. In the modern context, and particularly after the splits and outmigrations that occurred in the 1960s and later, the remaining communities no longer strongly display traditional societal features. Traditional social relations, particularly the stratification system, and family structures have also been heavily influenced and disrupted by education in downstream towns, the search for jobs abroad, and the increased intermingling of villagers with outsiders. To a certain extent, new structures sponsored by the Church have replaced traditional ones.

A 1991 survey (Sellato 1995a) reveals that, while village endogamy remains the norm $(75 \%$ to $85 \%)$, other features have dramatically changed. With the advent of separate houses and neolocal residence, the proportion of stem families is down to between $20 \%$ and $40 \%$ and the number of individuals per household is down to between 4.4 and 6.8, varying with villages-this suggests an average of about six for the whole subdistrict. The number of children in residence per household is only three or four, with older children abroad at school or working. While uxorilocal residence was possibly the norm in the old days of the longhouses and tends to remain dominant in stem families (a young couple lives with the wife's parents), virilocality is now prominent in nuclear families (the couple's house belongs to the husband). Finally, the study suggests that the impact of education should not be overstated: in the sample villages, only between $20 \%$ and $40 \%$ of the people have received some formal primary education, and only $25 \%$ of those (i.e., $5 \%$ to $10 \%$ of the population) ever went on through some secondary education.

A Kenyah family resides partly at its village house, where its social ascription lies, and partly at its farm. Villagers split into several groups for farming activities, each group of families residing near their fields, clustered in a distinct sector of the village's territory, during periods of intensive farm work. Such a group functions as a cooperative unit based on labour exchange (senguyun) and its membership, which does not automatically follow village residential ascription or kinship, may change from one 
year to the next. In 1993, Apau Ping had five farming groups, with membership ranging from 3 to 13 families who, in olden times, would have lived together in a small longhouse. Other types of collective work groups exist, restricted to particular activities.

Altogether, despite drastic modern alterations, communities in Pujungan subdistrict have remained 'adat communities', in the sense that they still function under the traditional customary legal system, adat, as Jacobus' critical study has established (this volume). While still internally efficient, this system is confronted more and more by the national legal system during intercourse with outsiders, particularly in the context of the management and exploitation of forest resources. New notions of territoriality and communal rights over land and resources have emerged and are now being negotiated with the administration. 


\title{
2.
}

\section{Biodiversity and traditional knowledge: Rice varieties among the Leppo' Ké of Apau Ping}

\author{
Indah Setyawati
}

\section{INTRODUCTION}

It has been known for some time from agricultural and anthropological research (e.g., Freeman 1970, Sutlive 1978, Padoch 1988) that Dayak farmers identify and plant a number of varieties of rice. The importance of Borneo for collecting traditional rice varieties has been recognised by breeders (see Vaughan 1980), aware that changing economic and environmental conditions may cause loss in germplasm biodiversity, especially in genetic resource areas like Asia and Africa (Richards 1992a, Oka 1988). National and international institutions-like the International Rice Research Institute (IRRI) in the Philippines, the Centre for Research and Development of Coarse Grains, Pulses, Roots and Tuber Crops (ESCAP CGPRT Centre) in Bogor, and botanical gardens in many countries-have established seed gene banks to conserve and develop rice germplasm. In situ conservation, however, is still needed for seed production, since complex in situ environments cannot be replicated in screenhouses, and maintaining ex situ genetic populations is costly, as Vaughan and Chang (1992) noted. In situ environments are subject to dynamic changes-occurrence of new pests and diseases, natural crosspollination between cultivated and wild varieties-causing new stresses that might produce a new strain as a prolongation of natural evolution whereas 'ex situ conservation essentially freezes germplasm at one point' (Vaughan and Chang 1992: 372).

Some recent studies have found that farmers maintain genetic diversity of rice varieties to match local environmental conditions (Watson 1984, Fuj isaka 1987, Damus 1992, 1995). Others have focused on farmers' practices in plant breeding, their experiments related to varietal changes, their reasons for abandoning or choosing varieties, and their means of obtaining new varieties (Lambert 1985, Richards 1986, Fujisaka et al. 1992). Studies of farmers' knowledge and use of varieties have been carried out worldwide and with respect to other crops-like beans in Central Africa 
(Voss 1992, Sperling 1992), potatoes in Peru (Prain et al. 1992), or maize in Mexico (Bellon 1991). Such studies, unfortunately, rarely go below the level of the local community as a whole. While they generally mention the total number of rice varieties known to the community, they fail to provide a breakdown of the number of varieties that each individual farmer actually plants (e.g., Watson 1984, Widjaja and J essup 1986, Fuj isaka et al. 1992, Damus 1995). As far as I know, this is also true of studies on other crops (e.g., Bellon 1991, Voss 1992).

To better understand farmers' roles in in situ conservation of agro-ecosystems, we need descriptions of intracommunity dynamics (see Vaughan and Chang 1992), i.e., individual farmers' agricultural practices and interactions with one another with regard to these practices. Research, then, should focus not only on what biodiversity and what knowledge of it are present, but also on how that diversity, and knowledge of it, is generated and maintained (McCay and Vayda 1992, citing Vayda 1992). Richards, investigating the sources and dissemination patterns of the local knowledge of rice varieties in Sierra Leone, found that each farmer actually planted from four to six varieties, while between 40 and 50 were known to the community as a whole (Richards 1992b), and similar figures were put forth by A. Endre Nyerges (pers. comm. 1993) among another farming group of Sierra Leone. This raises another question not answered by previous research: do farmers have the opportunity to try other varieties present in the village and, if so, how?

The research on which this contribution is based was carried out for seven weeks in 1993 among the Kenyah Leppo' Ké community of Apau Ping on the upper Bahau River (Long Pujungan District). It focused on a few specific questions, in some ways similar to Richards' (1986): Why do farmers select and maintain certain rice varieties, and abandon others? Do some farmers take care to maintain certain varieties abandoned by most other farmers? Are any traditional practices effective for the conservation of biodiversity? And how are the knowledge of varieties and the seeds themselves disseminated? I also attempted to understand the mechanisms operating among farmers in the acquisition and maintenance of rice varieties (see Vayda 1992)-a question that, as far as I know, Richards and others did not address.

\section{RESEARCH METHODS}

For reasons of time constraints and availability of information, this research was meant to be a follow-up to Damus' 1991 research (Damus 1995), in the same village of Apau Ping, the last village on the upper Bahau, populated by the Leppo' Ké group of the Kenyah (250 persons; Sellato 1995a). In J uly 1993, there were 50 households, almost all full-time farmers. The hilly environment makes swidden rice cultivation the main farming method, sometimes combined with wet-rice farming. Swiddens are generally moved to different sites every year in order to get the best possible harvest.

Instead of focusing on the community's general agricultural knowledge, I focused on individuals' knowledge and behaviour in farming activities and on eliciting explanations for the occurrence of genetic diversity in rice varieties and the dynamics of farmers' knowledge of rice. Quantitative data from questionnaires was combined with depth-interview data from selected informants. As a sample, I took the 42 households for which farming was the main livelihood and which had made swiddens in the previous two years.

Questionnaires were mostly short (two to five questions), devised from time to time in the field to obtain a larger picture of certain phenomena recorded in case studies. 
One such questionnaire was meant to determine the number (and names) of the rice varieties that each household had and to collect data on whether some farmers had changed some of their varieties within the previous two years. In those cases, I used the whole sample of 42 households. For other questions-such as why farmers changed their varieties, or how they learn about varieties-I randomly chose households (about 22 out of 42) to provide case studies, ranging from those with the smallest number to those with the highest number of varieties. For in-depth interviews, I used randomly chosen informants, mostly women, since most tasks in farming are handled by women, who thus know more about this subject than men.

Following advice from Chang et al. (1972), I also collected seed samples of 35 of the existing varieties. Three more varieties mentioned were unavailable, as the seed stock was just enough for planting needs-this occurs in the case of a new variety just brought from another village, or of a poor harvest from the last planting season. Specimens were sent to the ESCAP CGPRT Centre in Bogor for identification, from which some will be sent to the gene bank at IRRI. With these samples, I could learn how to identify varieties and informants could demonstrate their capability for, and methods of, identification. I could also observe their behaviour towards the seed samples, which triggered their interest in varieties with which they were not well acquainted. I also drew sketch maps of Apau Ping house and granary locations, in order to check a possible link between house or granary proximity and seed exchange.

\section{RICE VARIETIES}

Damus in 1991 found 31 varieties. I recorded 38, but could obtain samples of only 35. Farmers classify rice varieties into two categories: non-glutinous rice, padai nyain (25 varieties), and glutinous, padai pulut (10 varieties). Most varieties (23) are for upland farming and can be planted in various topographic conditions ${ }^{1}$, six can be planted only in wetland or swamp areas, and six more in either wetland or upland areas. Pending identification, it remains unclear whether any are indigenous varieties.

The remoteness of Apau Ping does not keep farmers from bringing new seeds from other areas, to which trips are often made. In the past, migrations and headhunting and forest product collecting expeditions to distant regions must have provided occasions for the spread of varieties. Freeman (1970: 190) mentioned that he 'encountered a number of cases of [Iban] men having collected seed on their travels (bejalai)', and 11 of my 42 respondents brought in rice seeds from outside to be planted in their fields. Twenty-five varieties were thus brought in, six of them never before planted in the village. Bringing in new varieties may add to farmers' knowledge, but it also has contributed to the replacement of 'old' varieties which then might have become rare.

In each planting season, most farmers (32) plant at least one variety different from the previous season. This variety may be a new one for the whole village or new only to a given farmer. There may be considerable variation in the varieties planted

\footnotetext{
${ }^{1}$ Farmers distinguish at least five kinds of farming land according to topography (see, e.g., Bahari in this volume and Syahirsyah in Eghenter and Sellato 1999): 1) tana' bila', very steep, usually cannot be planted at all; 2) tana' miang, sloping but less steep, is the most commonly used for planting rice; glutinous varieties grow well on the slightly less sloped tana' miang pejalai, rare around Apau Ping; 3 ) tana' leka, a flat away from streams, can be planted in virtually all upland rice varieties; 4) tana' apau, a hilltop flat, can easily go dry during droughts and, according to farmers, is a risky bet; 5) tana' bawang, a wet or swampy area near rivers, is used for wet-rice varieties.
} 
from one year to the next, and farmers offer various reasons, from the need for a certain variety for a special occasion (e. g. , a wedding ceremony) to the disappointment experienced with a particular variety (more about this later).

\section{SOURCES AND EXCHANGE OF RICE VARIETIES}

Investigation into how the seeds of varieties planted the previous year were obtained yielded information not only on sources of seed, but also on relationships among the partners in the exchange of knowledge and seeds, and on the circumstances promoting exchanges. Data obtained from each of the 42 households identified 202 transfers of rice seeds, showing that the most common sources of seed were households having kin ties (consanguineal or affinal) with respondents (59.9\% of cases). Some informants mentioned that women moving from one household to another upon marriage often bring along rice varieties, a finding similar to that of other researchers (Boster 1986, Richards 1992b). Other sources of seeds are neighbours within the village $(33.7 \%$ of cases) or non-kin friends in other villages (two to five hours away by canoe; $1.98 \%$ ). Most $(55.9 \%)$ of those neighbours attend the same church as the respondents (see Tables 2.1 and 2.2). Farmers may also obtain seeds from coworkers in the same cooperative senguyun group (8 cases from 22 groups $^{2}$ ).

Table 2.1 Farmers' sources of rice seeds

\begin{tabular}{|c|c|c|}
\hline Sources & $\%$ & $N=202=100 \%$ \\
\hline \multicolumn{3}{|l|}{ Within Apau Ping } \\
\hline - Relatives & $53.5 \%$ & $(108)$ \\
\hline - Non Relatives & $33.7 \%$ & $(68)$ \\
\hline \multicolumn{3}{|c|}{ Outside Apau Ping within the Bahau area } \\
\hline - Relatives & $6.64 \%$ & (13) \\
\hline - Non Relatives & $1.98 \%$ & $(4)$ \\
\hline \multicolumn{3}{|c|}{ From travels to other areas } \\
\hline - Sarawak & $3.98 \%$ & (8) \\
\hline - Malinau & $0.49 \%$ & (1) \\
\hline
\end{tabular}

Table 2.2 Quality of non-kin from whom varieties were received

\begin{tabular}{lcc}
\hline Quality & $\%$ & $\mathbf{N}=\mathbf{6 8}=\mathbf{1 0 0 \%}$ \\
\hline - Member of same senguyun group & $29.2 \%$ & $(14)^{*}$ \\
- Member of same church & $55.9 \%$ & $(38)$ \\
- Member of same social stratum & $45.5 \%$ & $(20)^{* *}$ \\
\hline
\end{tabular}

Notes:

* The sample here is 48 rather than 68 cases; I eliminated some respondents from consideration because they did not have permanent senguyun group memberships.

** The sample here is 44; I eliminated some respondents with special positions (nurse, teachers, and priest) who were not born into any of the four established groups.

\footnotetext{
${ }^{2}$ A senguyun group consists of farmers cooperating during the planting season (Galvin 1975), each in turn obtaining a full day of help from other members without paying for anything more than food and drink. Membership in a particular senguyun group continues from year to year.
} 
Practical considerations in the exchange of seeds, such as the closeness of the granaries or houses, were also investigated. Of 22 cases of neighbours as sources of seeds, 16 cases involved neighbours with granaries in the same area as the respondents, a situation providing extra opportunities, since farmers with neighbouring granaries do not necessarily have neighbouring rice fields ${ }^{3}$. Activities like drying the grain or pounding it, done mostly by the granaries, offer farmers the possibility of learning about and examining one another's varieties. Therefore, kinship, friendship, neighbourliness (maybe especially among farmers with neighbouring houses or granaries), and membership in community groups (church or senguyun) play a role in the transmission of knowledge and seeds.

Traditional forms of social organisation are still relevant to people's life in Apau Ping, where two strata are found: the aristocrats (paren, 24 households) and the commoners (panyen, 18). Earlier studies of Kenyah society in the Bahau and elsewhere (Conley 1973; Galvin 1975; Whittier 1978a; Sellato 1995a), as well as the persistence of senguyun activities, suggest that Apau Ping farmers are still influenced by social stratification, although both church and government are said to disapprove of it. But the data shows that, in 68 cases of seed transfers to non-relatives within Apau Ping, 25 farmers (10 paren and 15 panyen) were the recipients and, therefore, that social stratification is not a significant factor.

\section{KNOWLEDGE OF RICE VARIETIES}

The existence of various means of acquisition and dissemination of the knowledge of rice varieties does not, however, entail the acquaintance of all the farmers with all existing varieties. In fact, no single farmer (in a sample of 20 ) was able to recognise all 35 varieties. Informants were able to identify between 5 and 16 of the 35 varieties collected (average was 9.71 , and median was 10 ). If the sample is representative, then the average farmer knows only $28 \%$ of the locally existing varieties.

\section{Age and Expertise}

Ethnographic studies have shown that older members of society are often more knowledgeable in particular domains of expertise than younger ones (J ohannes 1981, Borofsky 1987). I found no evidence that this was true of knowledge of rice in Apau Ping. The farmers who identified most varieties were a 30-year-old woman (16 varieties) and a 47-year-old woman (15 varieties). The nine farmers who were between 30 and 49 years old were more knowledgeable than either the six younger ones or the five older ones (see Table 2.3). They had more experience than the younger ones and were free of certain problems affecting the older ones. The oldest farmers (aged between 60 and 75 years) seemed to have the most difficulty in identifying rice varieties from my seed samples, because of poor eyesight or failing memory about the shapes and colours of seeds planted long ago. They often limit their use of varieties because

\footnotetext{
${ }^{3}$ Apau Ping farms, in any given year, are grouped into several clusters located in different areas of the village's territory. An individual farmer can choose among those clusters, each consisting of the adjacent swiddens of several farmers. Practical reasons for this system are an easier cooperative work organization for clearing, burning, and fencing the swiddens (to protect the crop against animal pests), and security (if farmers have to work late or spend the night at the swiddens).
} 
they no longer feel strong enough. They might have scored better by seeing the actual rice plants in the fields.

Table 2.3 Average number of rice varieties known according to farmers' age

\begin{tabular}{ccc}
\hline Age & $\begin{array}{c}\text { Average number } \\
\text { of varieties known }\end{array}$ & $\begin{array}{c}\text { Number } \\
\text { of respondents }\end{array}$ \\
\hline $19-29$ & 8.10 & 6 \\
$30-39$ & 11.40 & 5 \\
$40-49$ & 11.75 & 4 \\
$50-59$ & 9.00 & 2 \\
$60-69$ & 7.50 & 2 \\
$70-79$ & 7.00 & 1 \\
$19-79$ & 9.63 & 20 (total) \\
\hline
\end{tabular}

Another problem might come from the seed samples themselves, many of which might have been varieties that were 'new' to older informants, while varieties known by older informants no longer existed in Apau Ping. It would be useful to have historical information about all the varieties ever planted in Apau Ping. A relevant article (Colson 1979) stressed the importance of the time dimension with respect to knowledge. In the case of famine, occurring at long intervals, knowledge of appropriate food-collecting strategies may be limited to older members of a society, because only they have previously experienced famine (on knowledge of migration, see Eghenter in Eghenter and Sellato 1999). But for annual events like rice planting, older people do not necessarily know more than younger ones. Indeed, they likely know less if the event's features change from one year to the next and if their participation becomes less active. This may explain the situation of knowledge of rice varieties in Apau Ping.

The number of varieties known to an informant does not reflect the number of varieties which she has ever planted, as knowledge may also come from helping others in planting or harvesting. Senguyun activity contributes to the flow of information about varieties. That harvesting groups may have a different membership than planting groups means that different farmers have opportunities to learn about one another's varieties. The observations that farmers make at harvest time mainly focus on the condition of harvests. One farmer's good harvest of a particular variety can motivate others to find out more about it. As previous research in J ava (Setyawati 1991) has led me to expect, farmers like to observe their neighbours' crops from the time the seed is planted, monitoring a new variety's growth, its yield, then its taste. If a variety looks green and healthy (as indicated by high tillering) and then yields a good harvest, they will inquire about it. If they are satisfied with their observations, they might ask the owner of the field to lend them a few tins of seeds of that variety to be planted in their own fields the next season.

\section{Selection of Seeds}

All respondents stated that they make plans well in advance about the varieties to be planted next season. If they plan to plant the same variety again, an appropriate quantity of seed of that variety has to be set aside from their own harvest. If they want to try another variety for the first time, they must ask another farmer to set aside some seed for them. If they wait until after such a new variety has been harvested 
(for example, to evaluate its yield) to express their interest, they may fail to secure seed from its owner. These seeds are always carefully selected. Ideally, they should be fully ripe (as shown by the plant's yellow, dry panicles and leaves) and come from healthy plants standing upright, with long panicles and fully ripe spikelets attached to them, and no signs of disease or insect attack on either the plants or grains.

Most farmers stated that they take seed grains from plants in the centre of their fields, a practice reported by Richards (1992b) in Sierra Leone, where farmers explain it as a way of getting pure seed since seeds from plants at the margins of plots might have been crosspollinated by other varieties nearby. In Apau Ping, however, the only reason proffered is that the field centre is usually less disturbed by monkeys and other pests from the forest although, farmers also stated, it might suffer from insect or bird attacks or from strong winds. In cases of such damage, seeds are selected from any plants that look good by the criteria above, regardless of their location.

To identify varieties from seeds, farmers combine several criteria. They observe the size of the grain and its shape (categorised as 'thin', 'full', 'straight', or 'slightly curved'); the colour of the husk (bright yellow, dusty yellow, blackish or reddish) and of the glumes (red, white, black, patchy red or patchy black); the colour of the grain's end which, in some varieties, is different (like black or white); and certain signs, like the awns in the spikelets or the shape of the sheath on the spikelet. In fact, they tend to name varieties after some special feature of the grains. Finally, they taste the raw grain to check whether it comes from a variety of glutinous rice-said to smell good and taste slightly sticky-or non-glutinous rice. I also observed farmers distinguishing between varieties by comparing the appearance of the grain.

Almost all respondents were women who knew more about rice varieties than anybody else in their household and were responsible, year after year, for deciding which varieties would be planted. If no elderly woman (the household head's wife or mother) is present, the oldest daughter or even a granddaughter will bear this responsibility. The men's opinion about the taste of cooked rice, however, may influence the women's decision. One informant stated that, because her husband cared about taste, the two of them looked for new varieties whenever she or he had an opportunity to visit other villages.

\section{Selection of Swidden Location}

Of thirteen women interviewed on their role in the selection of sites for swiddens, six said that they usually take the initiative in proposing a field location to their husbands (or, in the case of a widow, to her son); two informants said that they consider and decide on locations together with their husbands; two more said that they only choose the site of the small garden (keli'it) close to the village where they plant such crops as onions and chilli peppers and a small quantity of certain rice varieties, while their husbands select the sites of the main swidden fields; and three said that they always let their husbands decide the location of rice fields. When they propose sites, women usually just refer to some recognised locale-'the Mela'ing River,' 'the Sekakan River'-rather than to a more particular site in the locale. Men go in groups to inspect locales, which may include those suggested by their wives. Usually only a few locations are selected each year. Then, individual men, heeding or not their wives' suggestions, choose one among the selected locations and join other farmers who want to farm in that location.

The ten women who either proposed locations to, or discussed them with, their husbands gave various reasons for doing so. Some said that they wanted to have their 
field near those of certain good friends or relatives. Others, that they had certain concerns at the time. For example, one suggested the Sekakan River area because she wanted their swidden near their wet rice field and that area was the only place where she thought she could plant wet rice; having both fields near each other would make it easier for her to care for the crops during the whole rice cycle. Another said that she wanted her swidden close to the village because she and her husband were then busy building a new house.

Farmers follow certain rules in planting different rice varieties. They plant them according to the time that each needs to mature-most need about six months, but some might need only about four to five months. The slower varieties (usually the non-glutinous ones) are planted first, in the centre of the field, and the faster-growing (glutinous) ones later, at the edges. One farmer believes that the glutinous varieties should never be planted in the middle of the field because their fast growth would so 'embarrass' plants of non-glutinous varieties as to make them yield poorly. But, as most farmers explained, it is easier to harvest the faster varieties from the edges of a plot.

\section{REASONS FOR PLANTING DIFFERENT VARIETIES}

Like in other parts of the world, traditional farmers in Apau Ping, for various reasons, plant a number of rice varieties. In two planting seasons (1992-93 and 1993-94), the number of varieties planted (or to be planted) ranged from 2 to 11 . For the 42 households that farmed in 1992-93, the average number of varieties planted was 4.72-a figure similar to those other researchers found in Africa. For the 1993-94 planting season, the average number that farmers planned to plant was 4.09, a lower figure due to some farmers not yet having made up their minds and others still trying to borrow seeds.

\section{Rice Varieties and Soil Conditions}

Some researchers (e.g., Richards 1992a, Damus 1995) stated that farmers plant different varieties in order to match different soil conditions encountered from year to year as the locations of the fields are shifted. This reason, however, was not mentioned by my informants, who stated that they wanted variety in taste-to keep them from getting bored with their food-and needed different kinds of rice for ceremonial and household consumption. Rice from glutinous varieties is also needed for special occasions, like for lunches offered by farmers to their senguyun teams, and for making rice beer and various food preparations, important in any ritual celebration. Rice from the glutinous padai pulut among variety is the only rice that a woman having just given birth may eat (gifts of this rice are made by family and neighbours), and it is also recommended to breast-feeding mothers. Moreover, rice is often cooked with taro in Apau Ping households and only certain varieties taste good with taro, so farmers try to grow at least some of those varieties.

The notion of matching rice varieties with particular soil conditions was dismissed by my informants. They pointed out that they must collect and set aside their seed at harvest time, long before they even know where they will farm in the next season, and months before they can check the soil of their plots. They also believe that all upland varieties grow well enough in any plot as long as it has black soil (tana' saleng) which, according to Syahirsyah (in Eghenter and Sellato 1999), contains enough humus 
(see also Fujisaka 1986, 1987). The responses to questionnaires relative to the 199293 and 1993-94 seasons show that farmers in most cases plant different varieties in the same soil type or plant the same variety in different soil types. However, they do know that certain varieties should be planted only in wetland and others only in upland, and that some varieties can be planted in either wetland or upland but that most of them grow better in wetland (where they are usually planted).

When land at a given farming location is divided up, individual farmers might not be able to make their fields entirely in the best soils that the location offers. In this case, they plant their favourite varieties-usually non-glutinous varieties yielding well and, in effect, their staple food-in the best soil available, while other varieties are planted in whatever other soils are available. On the relation of farmers' knowledge of crop varieties to their knowledge of soil conditions, the following points should be noted. First, some statements by earlier researchers are ambiguous: do farmers really try to match a particular variety to a soil type, or do they simply recognise different varieties for wetland and upland (e.g., Damus 1995)? Reports from elsewhere (e.g., Johnson 1974, Fujisaka 1986, Voss 1992) mention that farmers match soil types to their cultivars, by actually planting different crops (or crop mixtures) in different kinds of soils, rather than matching different varieties of a single crop to particular soil types. More focused and detailed research to clarify these matters is needed.

Secondly, if farmers do plant different varieties in different soil types, do they do it with the intention of acting on their knowledge of how different varieties are suited to different soils (or vice versa)? Actually there are two questions: Do the farmers have the knowledge? And are they acting on the basis of it? They might well plant different varieties in different soils regardless of whether their knowledge is sufficient. Uncertainty about environmental conditions in their fields from year to year might encourage them to try several varieties and change the combination of varieties with only the hope (rather than experience-based knowledge) that some will yield well and be well suited to soil conditions in that particular year and in those particular sites. Among the Kantu' of West Kalimantan, unpredictability of the specific soil conditions is why some villagers use augurs to select swidden sites (Dove 1993). Apau Ping farmers have given up augury, but may have other ways of dealing with this uncertainty, including planting several varieties without specific and detailed knowledge of the conditions for which they are best suited. We may also ask just how the farmers act and with what intentions. Do they look for the soils to match preselected varieties, or for varieties to match preselected soil types? In reality, they do not completely preselect either. A clarification of their aims regarding preselection and of the constraints on actually achieving these aims is needed, as well as on how hard they try. Besides, at particular times or in particular contexts, soil types may be less important than other factors, e.g., land slope or water resources.

Thirdly, if it could be shown that Apau Ping farmers know about planting certain varieties in particular soil types but are kept by the unavailability of certain seeds or soils from applying their knowledge, we might still say (see J ohnson 1974 about Brazilian sharecroppers) that they have 'rules' about what to plant where. But having rules in agriculture is not enough and farmers, for various reasons, do not always follow them, as J ohnson found. The types of data gathered in Apau Ping in 1993 do not allow for answering these questions, and long-term research and direct observation in the fields are needed (see Bloch 1991 and Vayda 1992 on the need for participant observation). The complex knowledge connections that people make in their minds in response to 
external stimuli just cannot be described adequately in words such as are used in interviews. We need, as much as possible, to see our subjects in action, repeatedly, in similar but not identical contexts, to begin to understand the knowledge that they are drawing on and combining as bases for context-dependent action.

\section{Experience and Experimentation}

Sustained observation and participation can also keep researchers from misinterpreting what they see and are told. Experts sometimes start by observing what farmers do in their fields with their crops, then try to build models to explain what farmers do-and why-as if they were following predetermined designs (see Richards 1989). What an expert sees during any given period of observation, however, is a complex 'performance' by the farmers, based on years of experience, varying from year to year and from place to place, and depending on a particular sequence of conditions. No simple, complete, and neat design can be inferred from farmers' actions during a limited period and then used to predict or explain their actions at future times or in other places.

My data on two planting seasons hints at the farmers' strong tendency to change varieties from year to year. Several reasons were stated. Some farmers did not like something about a variety they planted earlier and wanted to replace it with a new one. Others were curious about new varieties that neighbours were talking about, and wanted to try them: e.g., a variety brought back from Malaysia, padai Mayun, that smells and tastes very good; a variety with long panicles (allegedly indicating high productivity), which does not quickly become 'overripe'4; a variety called padai Mahak, the grains of which are easy to separate from the panicles by the usual method of trampling. One farmer accidentally found a new variety and was curious to know its taste.

Farmers' interest in and curiosity about new rice varieties are displayed in their planting experiments. New varieties are usually planted by the edges of the fields or near the huts, and in the best soil in the swidden sites-a procedure common among rice farmers in other places (see Lambert 1985, Richards 1986, Fujisaka et al. 1992). One informant experimented for two successive years with a variety-found in a piece of sackcloth obtained from a Punan family in Long Bena-that she called padai kapit because the sepals in its spikelets grow very long, like two wings (kapit). Curious about their unusual appearance, she multiplied the three grains she had found by planting them in flat land (considered among the best for rice) and in the best soil available in her successive swiddens and, after three seasons, was still saving all the seeds (about four and a half cups) for planting, putting off cooking them to discover the taste. She said that she would plant this variety repeatedly until some day she could taste it and see whether she likes it.

\section{MAINTENANCE AND ABANDONMENT OF VARIETIES}

As noted above, one reason why farmers change rice varieties and try new oneswhich usually means abandoning some varieties-is dissatisfaction with some characteristic of varieties from their last harvest.

\footnotetext{
${ }^{4}$ According to one farmer, in order to ensure the good preservation of stored grain, the rice plants should not be left in the fields for too long after they are ready to harvest lest, she says, their seed become 'overripe', empty, and decayed.
} 


\section{Taste, Droughts, and Good Matches}

Taste characteristics are important. Some farmers no longer want to plant padai pulut among because, they say, it tastes 'bitter'. Others do not want to plant padai kalun because the leftover cooked rice hardens so quickly as to become inedible. One said that she does not like to plant wetland rice, simply because she and her family like the taste of upland rice better. A few stated that they would not plant padai Mahak because its small grain is hard to separate from the husk-a factor probably accounting for the disappearance of the padai Tamen Ba' un, recorded by Damus in 1991 but not found in 1993, when it was still remembered by some farmers but no longer owned or planted. Farmers also abandon varieties if they have had unpleasant experiences due to their physical characteristics. The padai pulut among and padai pulut pute', among others, have spikelets with long awns that chafe the farmer's skin when harvesting and hurt her soles when trampling it. One farmer said that she no longer wants to plant padai imban because its short panicles do not produce enough grains and she had difficulty cutting them.

Farmers are also concerned with the ability of a variety to cope with a drought occurring in the middle of the growing period. A variety known from experience to easily wilt in drought is hardly considered for planting again. A variety maturing so quickly that the grains easily become overripe or too old in the fields before farmers can finish bringing in the harvest will also be readily abandoned. Farmers also have no predilection for fast-ripening varieties, because of the extra time required to harvest varieties ripening at different times, and because different maturation times in the same field are believed to damage the whole harvest since the ripe grains attract pests that also damage the other varieties while they are still growing or later when they ripen.

Almost all informants have abandoned certain varieties due to harvest failure. Many would not plant any variety that has resulted in a bad harvest. Harvest failure is viewed as the sign of a 'wrong match' between a variety and a farmer, who would never get a good harvest from that variety and should look for another that 'matches' her better. Some farmers needed only a single harvest failure to decide that a variety was a wrong match, while a few waited for two seasons before making a decision. Farmers strongly believe that a variety consistently giving them good harvests must be well matched with their personalities and that they should hold on to it. A few said that they keep experimenting with new varieties to find some that suit their personalities and therefore consistently produce good harvests.

\section{Introduction and Extinction}

These beliefs might relate to the relatively high flow of new varieties that farmers brought in from outside the village. In 1991 Damus recorded 31 varieties and in 1993 I found 38, hinting at a substantial increase. Three of those found in 1991 (padai melien, padai Tamen Ba'un, and padai Ubung Kirip) could no longer be found in 1993. Two more (padai bura bala and padai ibet), not recorded in 1991, were mentioned in 1993 by a few informants. So the actual number of varieties introduced in two years is at least 10. From 11 respondents (out of 42) who introduced seeds, I recorded as many as 20 introduced varieties that they were planting. Although not all are new varieties for Apau Ping farmers and no data is available on just when each of them was actually brought to Apau Ping, this clearly is a high number for a village with only 42 farming households and, from the number of varieties introduced in two years, we can get a rough idea of the extent of varietal change, with extant varieties being 
continually challenged by new varieties brought from outside in the hope that they have superior characteristics. Then, any variety with characteristics regarded as less attractive than those of a new variety can easily be swept aside.

The 1993 data allows for the identification of only five of the varieties that have disappeared, and annual local extinction rates cannot be calculated with confidence. Some 'old' varieties clearly do win out over new ones because of superior characteristics, since farmers stated that their favourite two varieties, padai pute' and padai nyelung membat, well suited to local conditions, have already been planted for a long timealthough whether they are 'indigenous' cannot yet be established. Most farmers plant at least one of them as their staple, because they produce more than other varieties, can be planted in virtually any kind of soil, and are drought-resistant. They are said to produce best when planted in the sloping sites common in swidden locations.

These two varieties, despite their superior characteristics, do not satisfy the taste requirements of some farmers who, to improve the taste of the cooked rice, mix their grains with those of other varieties known for their good 'aroma', such as the padai sabun (reminiscent of the smell of soap). To get both a good harvest and good-tasting rice, these farmers mix seeds of padai pute' and padai sabun together in their swiddens, and some who said that they plant padai pute' were actually planting this mixture. However, this may not be intentional, since they might have obtained seed from other farmers who had mixed the varieties in their fields and could no longer keep them separate. The practice of mixing seeds of two different varieties is common among Apau Ping farmers, although most do this when seeds of a particular variety are in too short a supply for family consumption. I was unable to find varieties other than padai pute' and padai sabun that were mixed before planting.

\section{Environmental Constraints and Seed Custody}

Other factors contributing to the disappearance of some varieties relate to new environmental constraints. Some farmers said that they stopped planting two varieties of wetland rice simply because there were no longer enough wetland areas. One said that the only conveniently located flat land, which used to be a wetland rice area, has been turned into an airstrip. Other circumstances leading to the local extinction of a variety include harvest failure (especially when only one or two farmers have planted it), a long drought, or so much rain that rice cannot be planted on time, any of which may force farmers to eat their seed stocks-all the seeds of the now-extinct padai ibet are said to have been consumed during a long drought.

Most farmers' granaries have a separate container for each variety of rice intended for planting. Granaries are designed to protect the seeds from mice, but cannot protect them from humidity, which would lessen their quality if kept for more than one year. Therefore, farmers must replant all their seeds each year to get new ones for the following year. If farmers stopped planting a particular variety or if its harvest fails, its disappearance is the likely course. But some farmers do make an effort to plant certain varieties each year just to keep them from becoming extinct. Others simply keep distributing seeds of that variety to different farmers interested in planting them, in order to reduce the risk of local extinction because of harvest failure in just one or two swiddens.

Yet other farmers look for 'custodians' for seeds of particular varieties. One farmer, planning to stay away from the village for a year and wanting to maintain one particular wetland variety that she had obtained from her parents and that nobody 
else in Apau Ping had, asked another farmer to plant it for her, just enough to renew the seeds for the next season, so that she would have 'live seeds' when she returns. She said that, on several occasions, she had to ask other farmers to plant it for her because she had no suitable swampy land available. Another year, a farmer who had access to a swampy area borrowed seeds of that variety from her, but she would make sure to get her seeds back. So, a rare variety might be planted by different farmers in successive years.

As can be seen from the descriptions above, many factors affect the occurrence and loss of rice varieties. Apau Ping farmers themselves, with their ideas and intentions, are the main agents in selecting and maintaining a rice variety. Although environmental conditions certainly influence their decisions about planting that variety or not, I regard attention to farmers' individual experiences with different varieties as the key to understanding the fate of those varieties in Apau Ping.

\section{CONCLUDING REMARKS}

I have described various ways and reasons for Apau Ping farmers to acquire and spread knowledge and seeds of rice varieties. In order to secure food supply in an uncertain farming environment-unpredictable weather, variable soil fertility and other soil properties-farmers need sufficient agricultural knowledge, not only of land or soil conditions, but also of varieties that can be planted under such conditions. That planting several varieties contributes to curbing the risk of total harvest failure accounts for the high number of varieties present. However, in selecting varieties, most farmers ponder subjective factors, like personal taste, along with more objective ones, like easy milling.

Farmers construct their individual knowledge by way of experimentation, exchange of information, and careful observation of one another's crops, carried out on almost all occasions, most of which are culturally or socially provided for them to gain and transmit this knowledge of varieties. As this knowledge is subject to change, not all farmers within a village have the same knowledge and information, and their individual curiosity and capability, related to age and farming experience, in updating their knowledge becomes important.

Some researchers have suggested making farmers agents in local germplasm conservation (Vaughan and Chang 1992). In fact, that farmers have such great interest in looking at, experimenting with, and adopting new rice varieties might work against conserving 'local, rare, and indigenous' varieties. Although many factors, including natural selection, are involved, the farmers' possible bias in favour of new varieties should be taken into account in planning programs for germplasm conservation and, while they certainly should participate in such programs, there should also be a monitoring of local varieties by rice experts or breeders.

There is no doubt that farming experience and experimentation are sources for the farmers' knowledge of existing varieties and provide bases for our explanations of what they do in their fields. However, most of what they do is not just part of a fixed plan or design, but rather action is continually adjusted to particular, changing environmental conditions and may be performed in such an ad hoc, chance, or opportunistic fashion that we can find no simple general explanations of observed practices.

The data presented here comes mostly from interviews and it is clear that further studies to procure observational data are needed for discerning what farmers 
really do in their fields as compared to what they say in interviews. To get a clear understanding of their knowledge of rice varieties as well as other agricultural matters, direct observation during an entire annual farming cycle is critical (see Vayda 1993). The participant observation method provides researchers with opportunities to see more in context how farmers put their knowledge into practice. A perception of the context of each activity is critical to understanding how and in what kinds of situations farmers adjust their practices to cope with the various problems that they face. Direct observation will also allow for a better comprehension of how farmers interact with the environment and apply their knowledge to interpret what they see in their fields. 


\title{
3.
}

\section{Making a swidden: Social and technological aspects of Leppo' Ké agricultural practices}

\author{
Herculanus Bahari Sindju
}

\section{INTRODUCTION}

This contribution focuses on the practices of land preparation and utilisation for swidden farming by the Kenyah of the Apau Ping area. It is especially aimed at understanding: 1) their methods of selecting farming land; 2) their ways of preparing the land before sowing; 3 ) the land acreage needed by each farming family; 4) rice productivity in relation to a family's yearly needs, and the use of the land both during and after the farming year; 5) the special forms of work organisation and the techniques for efficient use of human resources; 6) particular cultural traditions in the preparation of the swiddens. The research, carried out from 6 J uly to 18 October 1993, used a participatory approach with regard to agricultural and social activities. Participant observation techniques were used, as well as interviews with 47 of the village's 48 heads (kepala keluarga) of farming families, and also with several informants specifically connected with the topic of the research. This research can be described as population research, using a total sample.

Apau Ping is the last settlement on the upper Bahau River, famous for its rapids. It is located at an altitude of $600-700 \mathrm{~m}$ asl. The region consists of hills wedging in small valleys and forming small rivers, so that there are no extensive flatlands, even along the main Bahau River. Apau Ping is close to the border with Sarawak (only a three-day walk away). The settlement of Apau Ping consists of four villages (desa): Apau Ping proper, Long Pengayan, Long Lat (all three of the Kenyah Leppo' Ké), and Long Tua (a very small Saben group). 
Every village is headed by its own village chief (kepala desa), assisted by his staff. The two ethnic groups, however, have been living peacefully side by side for a long time, as is obvious from the ongoing process of socialisation. Geographically and socially, they truly have become one community, not only in the settlement itself, but also in the farming areas. According to information obtained from the village chiefs, the government supported the relocation of the four formerly widely scattered villages to the site of Apau Ping to increase the efficiency of social development (on the history of the Kenyah Leppo' Ké, see Njau, this volume; and Njau 1995). A group led by Njuk Anye', Bilung Usat, Lerang Bilung, and Njau Bilung moved from Ka Buang (Leppo' Ké) to Apau Ping in about 1962 and formed the village (desa) of Apau Ping. The group of Liling Liran, Bilung Lerang, and Njuk Usat from the village of Long Pengayan (Leppo' Ké) joined in 1982. The group of Laden, Lawing Usan, and Darius Irang from the village of Long Tua (Saben group) also joined Apau Ping in 1982. Finally, the group of Bilung Lerang and Lawai Bilong from Long Lian (a breakaway from the village of Long Lat, Leppo' Ké) joined Apau Ping in 1983.

In 1993, this area had a population of 289 people, with 102 of them residing in desa Apau Ping, 144 in Long Pengayan, 25 in Long Lat, and 18 in Long Tua. Ethnically, 247 belonged to the Kenyah Leppo' Ké and 15 were Saben. During the 1993-94 farming year, the farming population of Apau Ping consisted of 48 heads of families, of which 44 were active farmers, with a labour force of 150. Among the remainder were two inactive family heads (elderly people with no offspring), one family head engaged in trade, and one who was on a long journey (peselai) elsewhere. The workforce was composed of all age groups, including children of elementary school (SD) age who took part in clearing and sowing and could also assist with weeding after coming home from school. The children had a rather high economic value in the family, but this was detrimental to their studies, for example during the sowing season when their labour, especially that of the girls, was fully used, so that school could not operate for a period of two weeks.

\section{LAND CLASSIFICATION ACCORDING TO LOCAL KNOWLEDGE}

The people of Apau Ping have studied and analysed the conditions of their lands for generations, and thus have acquired a valuable body of knowledge to be passed on to the next generation. Land is classified according to stages of plant growth, soil characteristics, and topography, similar in that to the land classification of the Dayak Kanayatn of West Kalimantan (see Bahari 1993: 14).

\section{According to Plant Succession}

The bekan jami are former swiddens that have been left fallow for approximately one year since the last harvest (ma'jau) and still display dried paddy stalks (jami). This type of land is dominated by low-growing plants or grasses (aka ceng and udu' kapen), which will only later be mixed with small pioneer plants such as udu' belenda (elephant grass), mbong, balang iap, jelupang, and japa (for Latin names, see Syahirsyah 1995 and Eghenter and Sellato 1999). In the bekan ca'lem, abandoned for two to six years after the harvest, woody plants are found. The pioneering plants have already disappeared as the fields were increasingly colonised by taller plants. In the bekan bu'et (or jekau bu' et; bu'et, short), the lower plants have increasingly disappeared (except for several hygrophilic plants, such as udu' salasui), as the woody plants have grown, and the vegetation is now dominated by shrub and plants of about $4 \mathrm{~m}$ high and with a trunk diameter of $10-15 \mathrm{~cm}$. 
The jekau mbau (mbau, high) is dominated by tall trees with a trunk diameter of $16-25 \mathrm{~cm}$. Shrub is almost entirely absent, except in clearings of the canopy where the lower levels of vegetation are relatively exposed. The land is already covered with a rather thick layer of deposits formed at least by the plants of the first two stages, i.e., pioneer and shrub plants, and even by plants of the third stage. The jekau mukun (mukun $=$ old) is already a secondary forest, with tree trunks over $25 \mathrm{~cm}$ in diameter and over twenty years of age. In many respects, the land has now become jungle, differing from it only in tree size and age. The mba' is land that has never been farmed, the primary forest that has remained untouched by human hands.

\section{According to Soil Characteristics}

The people of Apau Ping classify their lands according to the colour of the soils and the structure of their sand contents into several types with different levels of fertility (Damus 1995). Based on soil colour, four types are known: tana' bala, red and rather fertile; tana' da' payau, reddish-brown like deer blood; tana' bila', yellow; and tana' saleng, black. Oko' Uray Njuk J alung Ungau (60 years old) recognises four subtypes of tana' saleng: the common tana' saleng, found in the jekau bu' et; tana' saleng sepit, a sticky black soil found in the jekau mbau; tana' ait saleng, containing fine sand and found in the jekau mukun; and tana' membo, found in mba' land. The black colour is specific to humus-rich soils, and thus tana' saleng is known to be fertile, but its level of fertility varies according to the land's succession stage. In fields around the village, which have been repeatedly farmed as keli' it (small swiddens), the soil is generally yellow, red, or blood red and is of the red and yellow podzolic type which is not very fertile (Ardans 1993: 4). According to informants, a soil originally classified as tana' saleng changes colour over years of use and becomes red and yellow.

The people are also familiar with soil classification according to the type of sand: tana' ait memut contains fine sand; tana' ait metan contains packed sand; and tana' ait mebo has scattered sand and is known to be rather fertile (regarding levels of acidity and the soil's organic content, see Syahirsyah 1995). In addition, there is a type of soil, tana' ngelaa, which has a high sand content and cannot clump. Other types of soil based on texture are also known: tana' sepit contains a high level of clay and can be clumped without breaking; and tana' la'e is a yellow soil mixed with compact soil.

\section{According to Topography}

The people of Apau Ping distinguish land according to altitude and slope, for both lands that can and cannot be used for farming: tana' leka are flatlands on a river bank, rarely found; tana' bawang are flatlands with a high level of moisture, at the foot of hills or the mouths of small rivers, similar to marshes with mud deposition and permanent water seepage, and fertile for farming; tana' miang, the prevalent type found in the Apau Ping area, are hill slopes with an incline of $10^{\circ}$ to $40^{\circ}$. Two subtypes of tana' miang, based on land morphology, are known: tana' tenjalun straddles both flanks of a valley between two hills; and tana' kelepek covers both sides of the same hill. There are also pejalai, with a slope of less than $10^{\circ}$; tana' bilah, with a slope in excess of $40^{\circ}$, often found on passes between hills and not good for farming; tana' apau, flatlands on top or on the sides of hills, which can still be farmed; and tana' tuan, lands formed by old landslides. 
Evaluating the fertility according to the topography is closely tied to the succession stage of the vegetation and the colour of the soil. Since the presence of water also plays a role, however, the morphological types considered the most suitable for swiddens are tana' bawang, tana' tenjalun, and tana' kelepek, as compared to tana' apau and tana' bilah.

\section{According to Other Characteristics}

Other classifications of lands are based on features such as the plant species present, animal activity, or the level of moisture. For example, tana' nyala is a red and yellow soil covered by a layer of fern roots about $10 \mathrm{~cm}$ thick; tana' mettan is exhausted soil, with a very reduced level of fertility due to repeated use; tana' ngelu' bo is a crumbly soil containing the remains of decomposed plants or animals, with granules and a raised surface with cavities; tana' u'dip refers to soil heaped up as a result of animal activity, such as mounds made by termites or white ants; tana' lanut is a muddy soil but without the presence of surface water; tana' mbeng denotes land that is wet as a result of human intervention, whether intentional, such as in wet rice fields, or unintentional, such as land at the edge of an artificial pool or fountain; tana' betak-betak is soil with a cracked surface due to drought. This soil classification is based on physical characteristics, organic content, and level of fertility (see Syahirsyah 1995).

\section{SELECTION OF LAND}

In order to meet their various needs, the people farm two types of swidden fields, a main field (uma) and a smaller field (keli'it). The same practice is also common in Apo Kayan (J essup 1992: 4). In Apau Ping, the uma is of large dimensions and is established on fertile secondary forest land. It is planted with rice together with vegetables and corn. The keli'it, on the other hand, is a secondary field, located close to the village. It is established on land of younger growth or bekan jami and planted with sticky rice, secondary crops, corn, and cassava. The decision to make a keli'it is usually linked to the family's schedule of festivities which require sticky rice in rather large amounts. The following data refers to the primary fields (uma).

Through the experience of centuries, the people of Apau Ping have developed a system of swidden farming that fits their needs, the demands of their life, and the local environment. Modern needs for education, health, and social and religious life today limit the distance the fields may be from the village. In 1993, the most distant fields were no more than a 90-minute walk from Apau Ping. It is no longer necessary for the farmer to spend the night at the fields, except at times when the work is very intensive, as during weeding (but the children can still go to school). This type of adaptation resembles the farming practice known as lumma' umma (shifting cultivation) among the Dayak Kayan of Kapuas Hulu, in West Kalimantan (Mering 1988: 17).

To guarantee the success of their farming activities, the Kenyah Leppo' Ké of Apau Ping prepare their farming land very carefully. The selection of the land takes into account the type of land and the rotation of the field being considered for use.

\section{Selection Procedure}

Because farming activities involve cooperative work groups, the selection of land cannot be done individually. It considers not only soil fertility but also the efforts needed for pest prevention, and thus habits developed which by now have become 
standard procedure. This procedure starts from the initiative of one person, and is based on his experience or knowledge of an area visited while hunting. Bathing in the river, doing voluntary work, or walking to church constitute opportunities for him to informally convey his suggestion to a neighbour, a relative, or a close friend. In this way a group is formed that will then go and study the feasibility of the location. If it is considered suitable, the location and boundaries of the fields for the various members of the group are established. This stage is very important if this land is forested with large trees, as is the case with primary forest (mba') or the old secondary forest left by the Kenyah Leppo' Ma' ut, who long ago occupied the Apau Ping area.

\section{Basis for Selection}

To evaluate the level of fertility of the land, the farmers check the abundance of plants with straight stems or trunks. The straighter the vegetation, the greater the fertility of the soil, because weeds are rather sparse, so people tend to select land with big trees (mba', jekau mukun, or jekau mbau). Next, a check is made of certain types of plants used as indicators of fertility. This is considered very important at this stage for land covered with small secondary forest (bekan jami, bekan ca'lem, or jekau bu'et). If there are any indications of low fertility, the process may be stopped, as occurred with the family of J along Nyuk ( 70 years old). In addition, black soil is first choice, followed by tana' bala and tana' ait mebo. Fields with many stones at the surface are not selected. In the middle of abandoned fields (bekan), one can see small areas of primary forest (mba') left over because the presence of many large stones or an accumulation of small stones on the surface made farming impossible. Lands located on hills or mountain slopes can still be farmed, whereas lands at higher elevations are beyond the physical reach of the farmers. As for slope, farmers tend to select lands with a slope of less than $40^{\circ}$.

The distance of the farm site to the village is also a determining factor. If it is not too far away, it can be reached without requiring an overnight stay. In the 1993-94 farming year, the most distant field was about 90 minutes on foot from the village. In the 1994-95 farming year, the lands in the upper reaches of the same river may not be farmed again, because the distance as well as the altitude render this area beyond farming feasibility. This is, for instance, the case with the field of Apui Njuk's family. Selecting a new field close to the field of the preceding year (bekan jami) is very practical, making the preparation of the new field easier. The hut built the preceding year can still be used, and the foodstuff available in the bekan jami (e.g., vegetables, fruits such as papaya and bananas, hot peppers, cassava leaves, taro, and sugarcane) can easily be resorted to while working in the new field.

The number of farmers joining in one farming site is also carefully considered, because it has a bearing on the problem of pest control-especially deer (Cervus unicolor), barking deer (Muntiacus muntjak), and wild oxen (Bos sundaicus). In the case of large farming groups, prevention is easier and can reduce the risk of loss. In the 1993-94 farming year, the farmers of Apau Ping were distributed among five farming sites, with a membership ranging from three to thirteen family heads. There were also six family heads whose fields were separate, although not too far from one of the existing farming sites. 


\section{Types of Land Used}

The types of land used were the result of the selection described in detail above. In Apau Ping, in the 1993-94 farming year, of 43 farming families, $4.7 \%$ chose land covered with mba', $55.8 \%$ chose jekau mukun, $2.3 \%$ chose jekau mbau, $30.2 \%$ chose jekau bu' et, $2.3 \%$ chose bekan ca'lem, and $4.7 \%$ selected bekan jami. For topography, $20.9 \%$ chose tana' apau, $76.7 \%$ chose tana' miang, and $2.4 \%$ chose tana' leka. For soils, 83. $7 \%$ chose tana' saleng, $13.9 \%$ tana' bila', and $2.4 \%$ tana' bala. Thus, the first choice was for land covered with vegetation of the jekau mukun type, with a tana' miang slope and a tana' saleng soil. For land use statistics for the period 1979-1993, see Table 3.1. The jekau mukun land is similar to the Iahan jaroung of the Dayak Kantu' in West Kalimantan, which is preferred because the forest does not have underbrush or thickets (see Dove 1988b: 49).

Table 3.1 Land use, by percentage (1979-1993)

\begin{tabular}{lrrrrrrrr}
\hline \multirow{2}{*}{ Year } & \multicolumn{5}{c}{ Succession Stages } & \multicolumn{2}{c}{$\begin{array}{c}\text { Number of } \\
\text { Farmers }\end{array}$} \\
\cline { 2 - 6 } & Mba' & \multicolumn{3}{c}{ Jekau } & & \multicolumn{2}{c}{ Bekan } & \\
\cline { 3 - 6 } \cline { 5 - 6 } & & mukun & mbau & bu'et & ca'lem & jami & \\
\hline 1979 & 12.5 & 83.3 & - & 4.2 & - & - & 24 \\
1980 & 7.4 & 88.9 & - & - & - & 3.7 & 27 \\
1981 & 7.1 & 85.7 & - & 3.6 & - & 3.6 & 28 \\
1982 & 3.2 & 74.1 & - & 13.0 & 3.2 & 6.5 & 31 \\
1983 & - & 78.8 & 3.0 & 15.2 & 3.0 & - & 33 \\
1984 & - & 63.7 & - & 21.2 & 3.0 & 12.1 & 33 \\
1985 & 2.9 & 80.0 & - & 14.2 & - & 2.9 & 35 \\
1986 & 5.5 & 52.7 & - & 13.8 & 2.8 & 22.2 & 36 \\
1987 & 8.4 & 66.7 & 2.8 & 13.8 & 2.8 & 5.5 & 36 \\
1988 & - & 67.5 & - & 12.5 & 5.0 & 15.0 & 40 \\
1989 & - & 51.2 & 4.9 & 24.4 & 2.4 & 17.1 & 41 \\
1990 & - & 52.2 & 2.3 & 20.5 & 2.3 & 22.7 & 44 \\
1991 & 4.5 & 59.1 & - & 13.6 & 2.3 & 20.5 & 44 \\
1992 & 4.5 & 70.5 & - & 20.5 & 4.5 & - & 44 \\
1993 & 4.7 & 55.8 & 2.3 & 30.2 & 2.3 & 4.7 & 43 \\
\hline
\end{tabular}

\section{WORK ORGANISATION}

The people of Apau Ping have an organisation to operate and utilise manpower for farming activities. This organisation is aimed at mobilising manpower from the land preparation stage until the harvest. The activities connected to this organisation are known as senguyun and mepo.

\section{Senguyun}

Senguyun has approximately the same meaning as the Indonesian gotong-royong (cooperative work) or the balale of the Dayak Kanayatn of West Kalimantan (Bahari 1993: 16). There are two types of senguyun, the permanent and the incidental. The permanent senguyun is practiced for sowing (nu'gan) and involves several families (not individuals) who are permanent members. The days for each family's turn at 
sowing are set by tradition. For the paren (nobility) families, it is always Monday, Wednesday, and Friday, while for the panyen (ordinary people) it is Tuesday, Thursday, and Saturday. The senguyun activities are regulated through an official meeting led by the paren bio' (or kepala adat besar, the high customary chief), which discusses and determines first, the appropriate starting time for sowing; second, which families are ready to plant in the first and second weeks; and third, which families are members of which senguyun group according to long-standing custom.

Incidental senguyun is used for certain farming stages other than sowing. The membership of these groups is determined informally, as when meeting in the street, visiting, bathing in the river, or doing voluntary work. The groups are set up to deal with certain seasonal tasks requiring important manpower, such as clearing undergrowth, felling trees, harvesting, and building boats. Membership is individualfor example, one family member, regardless of age or sex-and is not binding. For example, someone can participate in a group for only one work rotation, and can then stop and join another senguyun group with other members who may be more appropriate for the type of work that has to be done. In this way, an incidental senguyun group can simply disband, but on the other hand it can also aggregate more members.

The members of the senguyun groups traditionally adhered to a certain work pattern. This is evident in the food that is provided when one type of work is being done. In principle, every senguyun member who goes to work brings along his or her own lunch (rice and side dish). Yet the 'host' family must prepare food (rice, vegetables, and meat or fish) for the senguyun members working for them. For this, the host has made arrangements for the preparation of the food. There is also a sexual division of labour: at clearing or felling time, the men are responsible for sharpening the tools (machetes or adzes) used by the female members of the senguyun group; or, at sowing time, the men dibble holes in the soil for the women to drop the seeds.

\section{Mepo}

Another type of work organisation, mepo, is, like the senguyun, also an effort to mobilise manpower, but it tends to be more of a purely social work group and emerges spontaneously to assist a person or family thought to be in need of help in completing his or her farm work. The mepo members do not expect compensation in any form; moreover, they bring their own equipment and food provisions without expecting these to be provided by the 'host'. The membership of the mepo group is not based on family ties. Of 18 people who participated in a mepo group on 12 and 16 July 1993, only three happened to be related to the family assisted. The involvement of villagers in mepo is truly based on humanitarian considerations and solidarity with those thought to be unable to carry out their own tasks (especially farm work).

There are two forms of mepo: mepo leto balu, intended to help a widow (see Meyer in Eghenter and Sellato 1999); and mepo kelunan sakit, intended to help an individual or a family that is ill. In the 1993-94 farming year, mepo was organised three times. The first was a mepo kelunan sakit in the fields of Oko' Irang's family in early June of 1994. According to him, his fields were entirely worked by his fellow villagers without his having to pay anything. The second was a mepo leto balu in the fields of the widow Buring Lawing on July 12, 1993, to complete the cutting of the remaining tree branches (miting) prior to burning. The third was a mepo kelunan sakit in Oko' Liling Liran's field, to assist with the clearing and felling that remained unfinished after he had fallen ill. 


\section{Other Forms of Cooperation}

A mobilisation of labour similar to mepo also occurs under pressing conditions and if many people are needed, as for harvesting, or carrying rice or construction materials. A family in need of help asks for it through the person in charge of managing cooperative activities, formerly the church board, but now occasionally also the board of the youth organisation (Karang Taruna), and they contribute a fee of Rp. 5000 to 10000 . To mobilise the villagers, the manager then goes round the village entreating participation (pekasat) or he makes an announcement in church. This differs from mepo in that this assistance must be compensated, and in that it is performed at the initiative of the family requesting it. In mepo, the assistance is the result of the initiative of the villagers who have noticed the circumstances of a needy family.

Furthermore, every farming family head (kepala keluarga) in Apau Ping is obliged to work for the paren bio' (today the village head, kepala desa). Formerly this obligation was binding, and the villagers had to cultivate as large a field as the paren bio' wanted. Nevertheless, for some years the obligation of the villagers has now been limited to working for one day only for their kepala desa.

\section{PREPARATION OF THE FIELD}

After a plot of land has been chosen, it has to be cleared, trees have to be felled and their branches cut off, and then the field has to be burned. In scheduling these activities in the farming cycle, people observe the position of the sun and the phases of the moon.

\section{Using the Natural Cycles}

There are two techniques using the natural cycles known to the people of Apau Ping, one being the observation of a shadow cast by the sun, and the other, that of the moon's shape. The former makes use of a wooden staff pitched in the ground permanently at a specially chosen place. The length of the staff's shadow is measured and its shifts observed. This technique can also use the pillar of a rice barn, as was done by the family of Oko' Bilung Lerang ( 75 years old). In the course of many years of observation and record, certain shadow lengths have been linked to certain features or events relevant to the harvest secured. The experience thus obtained allows, through the measurement of that shadow, for the determination of auspicious days for starting farming work. In the second technique, the shape of the moon is observed at night, and farming activities are only carried out when the shape of the moon is appropriate. For example, the right time for sowing has come when the moon takes the shape of the belekueng (the beak of the hornbill bird) or the lu'ung payang (the payang fruit), but the best time is when the moon is shaped like a chicken egg (tilu' manuk; see Damus 1995).

Traditionally, the observation of the shadow made by the sun and the shape of the moon is used in determining the most favourable days for beginning any farming activity, for not any day can be used. Today, for many farming activities, people no longer follow these traditional requirements. For example, because it has now become customary to celebrate the anniversary of the proclamation of Indonesian independence on August 17 in the capital of the district, the sowing in the fields must be finished by that date, as was the case in 1993. 


\section{Clearing (Melidik)}

This activity (melidik) involves clearing away the underbrush of the areas to be turned into farmland with a machete (baing). The time for beginning this activity depends on the type of forest growing on the land selected. For fields with tall vegetation, such as jekau mukun and mba', clearing is usually carried out in early May so that the grass and the small wood cleared can dry for long enough to make burning easy. For fields established in young secondary forest (jekau bu'et and bekan ca'lem), it is carried out in the first part of J une, and for bekan jami, only in the middle of J uly, as was the case with the church fields of the GKII congregation and the fields of the PKK (women's organisation) in 1993.

\section{Felling Trees (Nepeng) and Cutting Branches (Miting)}

The next step is the cutting down of trees (nepeng) using a variety of equipment. For small trees, it is enough to use a machete (baing), while for larger trees, the axe (asay), adze (asay peta'), and occasionally-if available-chain saws are used. In the 1993-94 farming year, however, there were no farmers left who used an adze for felling trees. Some traditional tools are made by local blacksmiths. At present, there are still four smiths producing large machetes: Liling Liran (63 years old), Bilung Liran (50), Aran Lenggang (48), and Ging Bareng (43). The making of one machete requires one to two days. Axes and chain saws are obtained from coastal traders and from Sarawak. The people of Apau Ping started to use chain saws in 1970, the produce of their salaried work in Malaysia. Today almost all families have a chain saw and about 10 family heads have more than one. The felling of trees is combined with the cutting of the large branches once they have been felled. This is done to accelerate the drying process so that the burning of the fields will be more thorough.

\section{Burning (Nutung and Mekuk)}

The field is now left for a certain period of time so that the fallen trees will dry out. In mba' and jekau mukun, 1.5 to 2 months are needed; in bekan ca'lem and jekau bu' et, 1 to 1.5 months; and in bekan jami, 1 to 2 weeks only. The drying out is very important and its duration is carefully monitored, because if it is not dry enough, the burning (nutung) will not be thorough. However, the weather also has an influence on this process. Certain methods are used to ensure that burning is successful. First, the wind direction is observed. If the wind blows to the north, the burning must start from the south and the wind will fan the fire, which will burn the branches and twigs and proceed northward rapidly. If there is no wind, the best place for starting the burning is in the lower part of a sloping field, or by lighting fires all around the field (this is used for leka and apau fields). The instrument used for burning, sulo' bulo', is made of a length of bamboo of which the upper joint, filled with kerosene, is equipped with a wick, so that it can burn for a long time, usually long enough complete the burning of the field. If the burning is incomplete, the unburned plant or tree remnants are gathered in several piles and are burned once again. This second burning is called mekuk.

\section{Making a Field Hut (Lepau)}

To support the logistics of the farming activities, a lepau (hut or shed) is needed to provide shade and a place to cook, eat, and rest, and to spend the night if necessary 
(e.g., while weeding or guarding the fields against pests). Construction of the lepau is usually started before sowing and continued after sowing. The lepau around Apau Ping has a more or less standard pattern, with two floors. The lower floor is used for resting in the shade, cooking, and eating, while the upper floor is used as a sleeping area for the family. During the harvest, the lepau is used also as a temporary rice storage barn, after the rice has been dried and before it is carried to the village for storage in the permanent barn.

\section{Sowing (Nu'gan)}

The equipment needed for sowing consists of a tu'gan (dibbling stick), which is a piece of wood with a piece of iron at its end, and a pasan or karien, or seed container, a type of basket with a neck that is tied to the waist. The people of Apau Ping use two types of sun hats, the common sa' ung, made of pandanus leaf and used by the panyen, and the sa' ung seling, made of plaited bamboo with very artistic designs and used by the paren.

Burak, a type of rice beer, and a'dut, a food made from sticky rice, are traditionally provided at sowing time. The people of Apau Ping and other villages in the upper Bahau are familiar with two types of burak. One, burak ubi, made from fermented cassava, is usually present at feasts or parties (naming ceremonies, weddings, welcome parties for guests, and even Christmas and New Year); the other, burak ketan, made from fermented sticky rice (padi pulut), is prepared for consumption during the sowing in the fields. After the cassava or sticky rice has fermented (tapai), it is mixed with boiled water that has been left to cool, and then offered immediately without being pressed.

For consumption at sowing time, every family prepares burak. Burak ubi is prepared several weeks before sowing, while burak ketan is made about three nights before sowing. When the day comes, the old people collect the bamboo pipes used for drinking burak and the leaves to wrap food. Meanwhile, the children (especially the girls) do the cooking; then the food is carried to the fields for those working there. In addition, a family which is about to sow prepares traditional foods such as chicken porridge and a' dut. A' dut is made from sticky rice (a kind of filled rice roll), wrapped in leaves, and then boiled. When resting during the sowing, burak ketan is offered as a thirst-quencher and, in the evening, the family whose field has been sown offers burak ubi to those who participated in the sowing. This is not just a statement of thanks by the host, it also provides an occasion for friendly social ising between villagers and between members of the same work group (senguyun).

\section{LAND USE AND PRODUCTIVITY}

The people of Apau Ping do not in fact evaluate their work productivity quantitatively as is customary in the world of agribusiness, but they only classify the output of their labour into 'a lot' or 'little', into 'insufficient', 'enough', or 'more than needed', based on their families' needs. In order to produce food in sufficient quantity and quality, land is used as efficiently as possible, for example through the practice of dual cropping before or when sowing rice, and the planting of vegetables and fruits after the rice harvest.

The rice productivity is closely tied to the fertility of the land, which in turn is closely related to the stage of forest succession. The soil in former fields must be given the time to recover its fertility. Through experience, the people have discovered 
and maintained a system of rotation for working their swiddens with a certain periodicity, which is considered the most appropriate farming method for local conditions and the most profitable economically. According to Mubyarto, this method of earning a living is suitable for the local ecology and thus does not harm the existing agro-ecosystem (Mubyarto 1992: 15).

\section{Rotation of Fields}

Observation of the history of family farming among the people of Apau Ping has not yet provided a clear pattern of rotation. As noted above, the first group of Leppo' Ké settled in Apau Ping in 1962; other groups did not join until 1982-83; and by 1993-94, the Leppo' Ké had not yet completed the re-opening of the old fields left by the Leppo' Ma'ut, who had long occupied the area previously. Nevertheless, between 1979 and 1993, the percentage of farmers farming jekau bu' et fields (which have been left fallow for about 7 years) rose rather remarkably from $4.2 \%$ to $30.2 \%$ (see Table 3.1 ), while the re-opening of jekau mukun (more than 20 years fallow) has declined (from $83.3 \%$ to $55.8 \%$ ). It is worth noting that, in the last few years, only an average of $4.5 \%$ of the farming families have opened primary forest.

\section{Land Use during the Farming Year}

Swidden fields are the primary source for meeting the nutritional needs of vegetable origin for the people of Apau Ping. In fact, their fields are not only planted with rice, but also with other crops such as corn, sorghum, millet, beans, amaranth, mustard greens, cucumber, squash, and watermelon, which are normally sown before the rice. When the burning of the rice fields is completed, the women sow corn over almost the entire field, rather far apart so that it does not interfere with the growth of the rice. The parts of the fields in which the burning was very successful are sown with various vegetables and watermelon, whose shoots will already be visible when the rice is sown. The rice is sown all at once. By working in senguyun groups, it is possible to sow any one field in one day, so that the time elapsed between the first sown and last sown of the villagers' fields is not too long. In the 1993-94 farming year, the sowing went on for about two weeks (from 23 August to 4 September 1993), interrupted by Sunday breaks.

The varieties of rice planted vary considerably according to need and the type of land (see Damus 1995). According to information from village notables and traders, the Apau Ping area is in fact self-sufficient in rice, and has even managed to produce surpluses, as for example in the 1960s, when the area was able to supply rice for military operations during the Confrontation with Malaysia. In the 1992-93 farming year, 36 of 43 farm families interviewed stated that they produced enough rice for their needs, four that they produced more than needed, and three that their rice production was insufficient (see Table 3.2). Failures are in large part the result of prolonged dry spells, and in part attributable to pests, especially wild oxen, monkeys, wild pigs, and sparrows. Wild oxen and deer are the most feared pests, to the point that there is a taboo on bringing deer or wild ox meat to the fields during the sowing season.

\section{Land Use after the Harvest}

Almost all farmers continue to use their fields after the rice harvest by planting various types of crops, such as fruits (papaya, banana, watermelon), tubers (cassava, sweet potato, and taro), vegetables (onion, hot peppers, tomato, eggplant), and sugarcane. 
Table 3.2 Rice yields, by percentage (1979-1993)

\begin{tabular}{lrccc}
\hline Year & \multicolumn{3}{c}{ Yield in relation to needs } & \multirow{2}{*}{$\begin{array}{c}\text { Number of } \\
\text { Farmers }\end{array}$} \\
\cline { 2 - 4 } & Too Low & Enough & Surplus & \\
\hline $1978-79$ & 5.0 & 90.0 & 5.0 & 20 \\
$1979-80$ & - & 95.8 & 4.2 & 24 \\
$1980-81$ & - & 96.3 & 3.7 & 27 \\
$1981-82$ & 3.5 & 94.5 & - & 28 \\
$1982-83$ & 3.2 & 93.6 & 3.2 & 31 \\
$1983-84$ & 12.2 & 84.8 & 3.0 & 33 \\
$1984-85$ & 12.2 & 84.8 & 3.0 & 33 \\
$1985-86$ & 11.4 & 88.6 & - & 35 \\
$1986-87$ & 5.5 & 91.7 & 2.8 & 36 \\
$1987-88$ & 1.8 & 98.2 & - & 36 \\
$1988-89$ & 5.0 & 90.0 & 5.0 & 40 \\
$1989-90$ & 9.7 & 90.3 & - & 41 \\
$1990-91$ & 18.2 & 79.5 & 2.3 & 44 \\
$1991-92$ & 11.3 & 86.4 & 2.3 & 44 \\
$1992-93$ & 6.8 & 84.1 & 9.1 & 44 \\
\hline
\end{tabular}

Among all these, cassava and taro are given precedence. Cassava is planted in greater quantities than taro, because the type of land suitable for taro is generally limited. There is a close relationship between the two types of plants and cultural traditions. Besides the custom of offering burak at various types of festivities, there are local dishes known as ma' upa', consisting of pieces of taro mixed with rice, and luko upa', which is ma' upa' cooked in bamboo tubes.

In the Apau Ping area, plantation crops such as rubber, commonly found among the Dayak of West Kalimantan, are absent. Every family, however, plants fruits such as ta' ap (unidentified), isau (Euporia longana), and rambutan (Nephelium spp.), although not in significant quantities and not as trade commodities. Other perennial plantation crops, such as coffee and cinnamon, are better known, but only planted in small gardens around the village by a few families. Actually, coffee was once planted by all the people rather extensively, but failed because the plants were not properly cared for.

\section{THE TRADITIONAL MELAKI CEREMONY}

Various matters related to the cultural tradition of the people of Apau Ping have been mentioned above. The Kenyah Leppo' Ké also had a tradition inspired by ancestral beliefs and known as melaki, which has faded away since the people converted to Christianity and today it is almost extinct, so that the young generation no longer know the melaki ceremony at all. According to informants, it was last held by the family of Oko' Bilung Lerang in 1983.

The name melaki is derived from pelaki, the Brahminy kite, and to the calling of the kite in a ceremony aimed at asking the Almighty (J elong Peselong or Bilung Nyelong) for good fortune, life force, health, and a long life. The Leppo' Ké believed that the kite had a bali, i.e., a spirit, which could give clues to the humans regarding the intentions of J elong Peselong. According to elderly informants, the melaki ceremony 
was not only carried out within the framework of agricultural activities but also at times of birth feasts, and at times of epidemics (see Table 3.3). The frequency and the scheduling of this ceremony differed between the Leppo' Ké from the village of Ka Buang and those from the village of Long Lat, who now live together in Apau Ping.

Table 3.3 Farming rituals and the melaki ceremony

\begin{tabular}{|c|c|c|c|c|}
\hline \multirow{2}{*}{$\begin{array}{l}\text { Name of } \\
\text { Ritual }\end{array}$} & \multicolumn{4}{|c|}{ Organisation of the Ritual } \\
\hline & Time & Participants & Leader & Place \\
\hline \multirow[t]{4}{*}{$\begin{array}{l}\text { MELAKI } \\
\text { (for farming) }\end{array}$} & $\begin{array}{l}\text { 1. Before } \\
\text { clearing }{ }^{1}\end{array}$ & All villagers & $\begin{array}{l}\text { Village } \\
\text { elders }\end{array}$ & $\begin{array}{l}\text { Hill near } \\
\text { village }\end{array}$ \\
\hline & 2. Before sowing & Paren family & Family el ders & Idem \\
\hline & $\begin{array}{l}\text { 3. While } \\
\text { weeding }\end{array}$ & All villagers & $\begin{array}{l}\text { Village elders } \\
\text { and paren bio' }\end{array}$ & $\begin{array}{l}\text { One of the } \\
\text { swiddens }\end{array}$ \\
\hline & $\begin{array}{l}\text { 4. If there } \\
\text { are pests }\end{array}$ & Idem & Idem & Idem \\
\hline NGELEPON & $\begin{array}{l}\text { Before } \\
\text { harvest }^{1}\end{array}$ & Idem & $\begin{array}{l}\text { Adat } \\
\text { leader }^{2}\end{array}$ & $\begin{array}{l}\text { Hill near } \\
\text { village }\end{array}$ \\
\hline UMAN MA' & First morning & Idem & Family & From house \\
\hline $\mathrm{MA}^{\prime} \mathrm{DING}^{3}$ & $\begin{array}{l}\text { when new rice } \\
\text { is cooked }\end{array}$ & & elders & to house \\
\hline $\begin{array}{l}\text { MELAKI (for } \\
\text { birth ritual) }\end{array}$ & $\begin{array}{l}\text { 12th day } \\
\text { after birth }\end{array}$ & $\begin{array}{l}\text { Paren } \\
\text { families }\end{array}$ & $\begin{array}{l}\text { Panyen } \\
\text { elders }\end{array}$ & Idem \\
\hline $\begin{array}{l}\text { MELAKI (for } \\
\text { epidemics) }\end{array}$ & $\begin{array}{l}\text { If there is } \\
\text { an epidemic }\end{array}$ & All villagers & $\begin{array}{l}\text { Adat } \\
\text { leader }\end{array}$ & Idem \\
\hline
\end{tabular}

Notes:

1 Known among the Kenyah Leppo' Ké from desa Ka' Buang.

2 The villagers send a delegate to the man chosen, to request his willingness to become the ritual leader for these ceremonies, and offer him a machete, a sword, and glass beads as a sign of their trust. After the harvest, each family head surrenders one can of paddy $(15 \mathrm{~kg})$ to this leader as an expression of thanks.

3 Same as above, except that the leader does not receive a gift of paddy as is the case with the ngelepon ceremony.

The holding of the melaki ceremony required several types of paraphernalia: 1) a fibre taken from the stem of a Zingiberaceae (nyanding), split in two; 2) a piece of wood about 1.5 to 2 handspans long, stuck into the ground and split in the middle to accommodate the nyanding; 3) unung, a branch or twig about 1 to $1.5 \mathrm{~m}$ long with two leaves as large as a thumb, stuck into the ground; 4) a piece of bamboo about 1.5 handspans long, for placing offerings during the ceremony; 5) machetes made of bamboo, sharpened and stuck into the ground, four to the right to symbolise good forces and two to the left to symbolise evil forces.

Facing uphill, the leader of the ceremony begins by calling the bali pelaki by uttering a prayer known as ngelepon bali. Offerings in the form of ma' luko (rice cooked in bamboo), jakan (sugarcane juice), and sam can (pork fat still attached to the skin) are placed on the bamboo stuck in the ground. In the meantime, the bamboo tubes which have been used to cook the rice (bulo' luko) are split and stuck into the ground to the right and left of the unung. The remaining ma' luko is distributed among the participants and the leader of the ceremony, so they all eat a little of it. 
They then request what they desire, according to the purpose of this ceremony. As soon as the ngelepon bali prayer is finished, the leader of the ceremony and the other participants anxiously wait for the coming of the kite. They observe the direction of its flight and its behaviour and discuss the meaning contained in these, because they are believed to indicate the wishes of the Almighty, J elong Peselong (or Bilong Nyelong).

The interpretation is as follows: If when it first appears, the kite flies from right to left three times in a row or more (the more the better), this is a sign that the Almighty, through the bali pelaki, has bestowed life force, health, and long life. If the bird arrives from the left to the right, this is a sign of the good intentions of J elong Peselong, who is willing to grant good fortune and meet the request of the supplicants. If these signs do not appear, it means the request has not been bestowed, and the ceremony has to be repeated four days later. If the ceremony is successful, the rest of the rice is carried home and, upon arriving at the village, is distributed with calls of 'Ma'! Ma'!', which means: 'Rice, rice!' Those who hear this come to take it and taste a little of it, so that they too will be given life by J elong Peselong.

Then a chicken is sacrificed, its blood rubbed on the arms of all those present, and the meat cooked for chicken porridge and then consumed collectively. The ceremony continues with circling the longhouse in procession while splattering water left and right of the house and on the top of the stairs with a machete (baing). This is the sign that the participants may now go down to the river to bathe. In the case of a melaki ceremony held to heal a sick person, the patient is sprinkled with jakan (sugarcane juice) also by using a machete. After bathing, a village council or meeting may be held if necessary.

In addition to melaki, there are two other farming ceremonies, ngelepon (prior to the harvest) and eating the new rice (uman ma' ma' ding; when the harvest begins). The ngelepon ceremony simply consists of saying a prayer and requires no paraphernalia such as is used in the melaki ceremony. Eating the new rice is a joyful ceremony. A family cooking the new rice for the first time must carry three packages of rice complete with side dish to their relatives and neighbours, and the children of the families receiving the rice must mark the face of the one who brought it with soot.

\section{SUGGESTIONS}

In the traditional farming of Apau Ping, land use patterns allow for a long period of time between the first opening of a plot of land and the next phase of farming. This period can last up to 30 years, which is sufficient for the cultivation of one generation of plantation crops. Since Apau Ping has a lot of vacant land, it is very possible to establish smallholding rubber plantations. This suggestion, in line with ideas of land management for the twenty-first century-which anticipate agricultural systems conceived by taking into account the advantages as well as the weaknesses of systems used and applied to this day (Sutarman 1993: 22)-can be applied in stages by the farming community. On the basis of the experience of the case of the Dayak of West Kalimantan, smallholding rubber estates and plantations of forest products seem appropriate for development in Apau Ping. Other industrial plantations cannot be carried out on a large scale in the conservation area.

The switch from rice to rubber can bring several benefits. First, rubber becomes productive after at most 8 years, and it can thus be economically profitable for 12 to 22 years for its planter. Second, planting former rice swiddens with perennial crops like rubber contributes to conserving the forest in the form of agroforestry 
(see Mubyarto 1992: 4). Third, the planting of rubber can also be beneficial-like in West Kalimantan, where it has been known since 1905-by contributing to the emergence of a clarification of individual land rights (Sapardi 1992: 79). Fourth, by the time the rubber plantation needs to be rejuvenated, the land can again be used for rice, so that its fertility can be maintained by combining the advantages and weaknesses of the agro-ecosystem with the regeneration of the natural ecosystem. In this way, the people can be permitted to continue their traditional practices in or around the protected areas and they can be made partners in the activities of nature conservation in their region (Mackinnon and Mackinnon 1990: 114).

Besides rubber, forest products such as cinnamon and illipe (tengkawang, Dipterocarpaceae), as well as incense wood (gaharu), can also be planted as long-term perennial crops and grown on former swidden fields during the fallow period. To increase the economic value of the villagers' enterprises, special attention should be given them by the government in the form of development projects capable of breaking down the isolation of the region, one of the primary causes of its poverty and backwardness. In the case of Apau Ping, priority must be given to the development of infrastructures and to the creation of transportation and communications facilities.

Figure 3.1 Threshing the paddy by trampling (mi'ik)

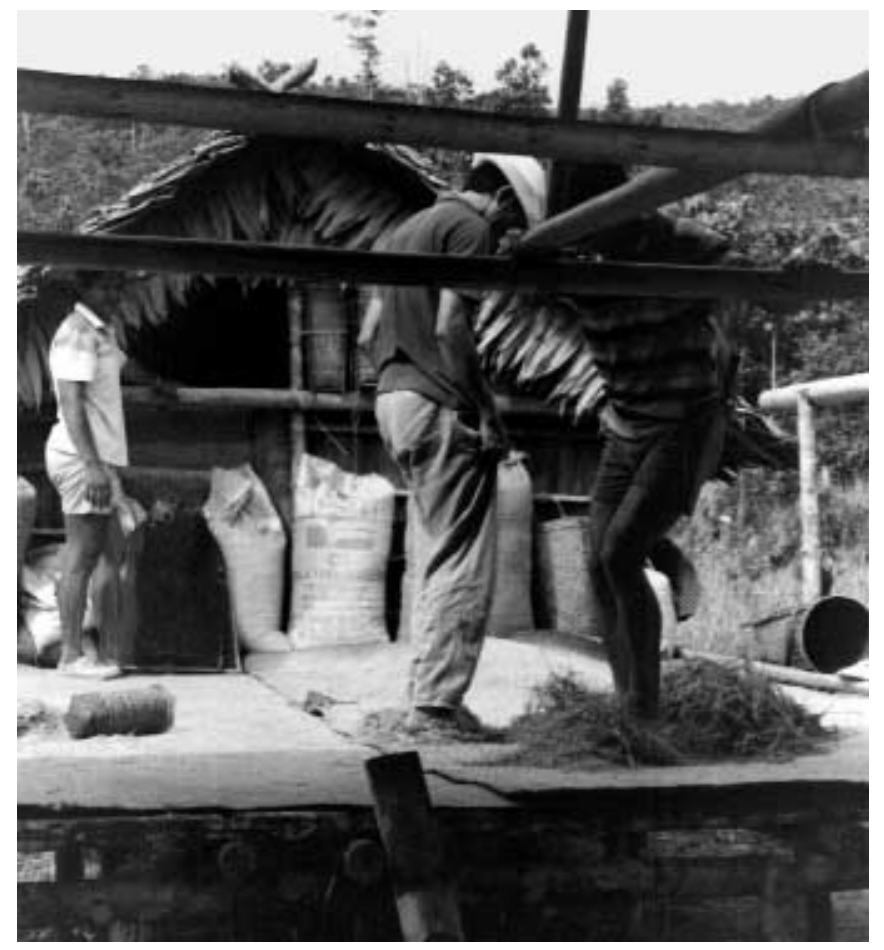


Figure 3.2 Winnowing the paddy (maping)

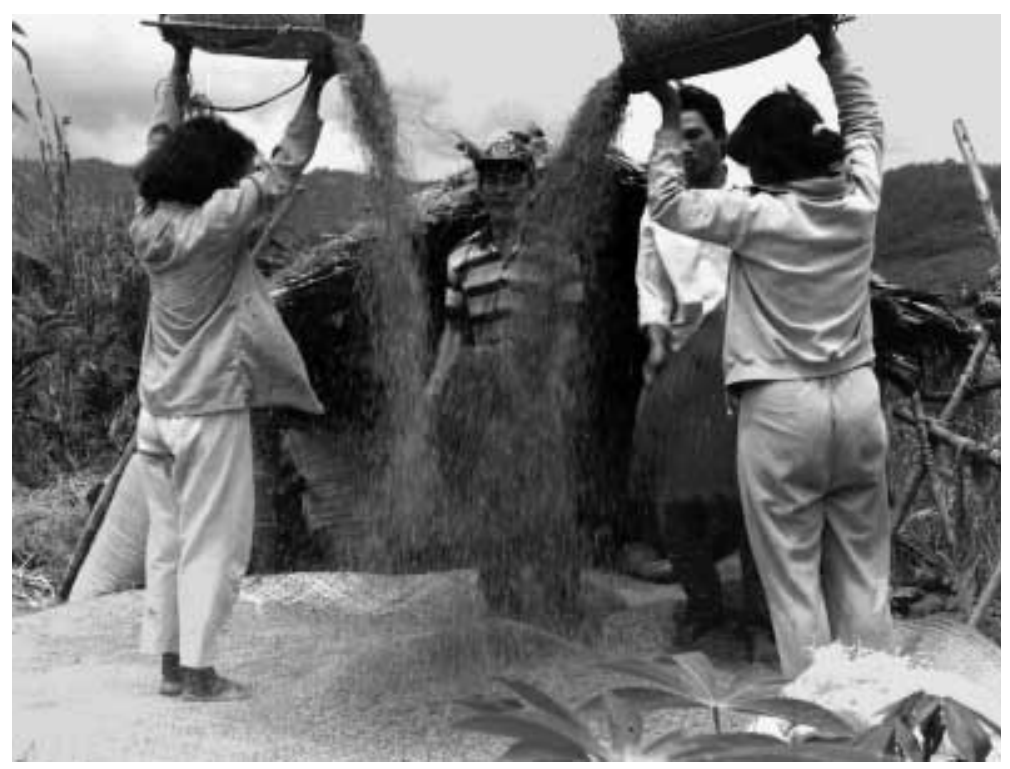

Figure 3.3 Storing the paddy in the barn (lepubung)

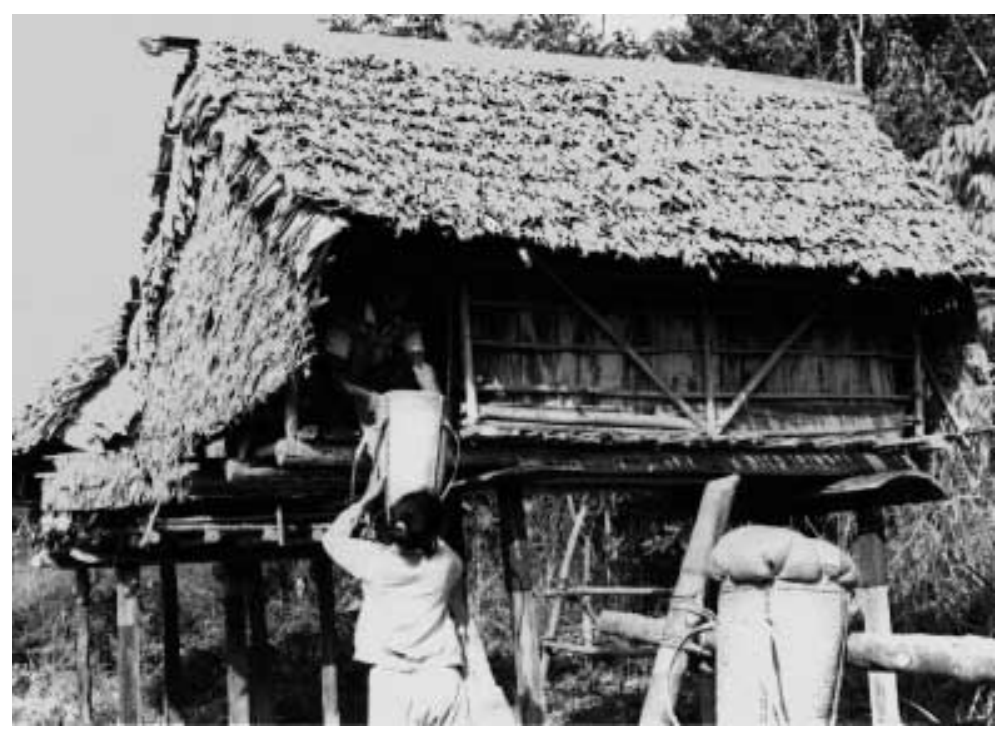


4.

\title{
Management, processing, and uses of rattan in Long Uli, Pujungan Subdistrict
}

\author{
Martua Thomas Sirait
}

\section{INTRODUCTION}

The village of Long Uli is located on the banks of the Bahau River. Its inhabitants are members of the Kenyah Oma' Long (or Uma Long), the Kenyah Leppo' Ndang (or Leppo' Ntang) and there are a few families of Punan Benalui who use the forest resources in the area to make a living. Rattan, collected for sale as well as for everyday use, is one of the most important forest resources. Both raw and woven rattan are very valuable, for exchange, sale, and use, which makes it one of the economic mainstays of the community. The marketing of unprocessed rattan and woven rattan involves various social groups (village elders, local and outside rattan collectors, intermediary traders and shops).

\section{History of the Village of Long Uli}

The Oma' Long people now living in Long Uli formerly lived on the plateau of Apau Urung, between the upper Lurah and Pujungan rivers. In 1932, under the leadership of Imung Alang (the father of the present village head of Long Uli), they moved together with the Leppo' Ndang to Long Lurah. In Long Lurah, Imung Alang met with Tumai Bilung, leader of the Kenyah Badeng at Long Peliran (the grandfather of the village head of Long Peliran at the time this research was conducted). Tumai Bilung presented a jar to Imung Alang with the words 'Let our two groups live together, raise children and grandchildren and farm until only the red stones are left on this land.' In return 
Imung Alang gave a gong to Tumai Bilung. The two groups also established separate customary forest lands (tana' ulen) ${ }^{1}$ : the Belaka River area (tributary of the Lurah River) became the Ulen Alo Belaka of the Badeng, and the Lutung River became the Ulen Alo Lutung of the Oma' Long. In this way, the two groups lived together for eight years.

Because of rapid population growth and limited availability of farming lands, which led to frequent conflicts between Badeng and Oma' Long villagers, the Oma' Long slowly moved their fields upstream (to today's Long Uli), while they continued to farm together with the Badeng for two or three years at the initial site. Over time, the Oma' Long farmed farther and farther into the Long Benato area, until they eventually moved there (1940). At Long Benato, Tigang Imung (son of Imung Alang) became their leader but because he was still too young, his uncle, Bit Irang, replaced him. After Bit Irang's death, he was succeeded by Imang Bilung. In 1948, the chief Arang (leader of the Leppo' Tau on the Baram River in Malaysia) came to the Bahau River to make peace with Apuy $\mathrm{Njau}$ (Great Adat Chief of Hulu Bahau) and Angit Ingan (Great Adat Chief of Pujungan). This visit was followed by a visit of six people from Long Benato to the Baram River, and since then a flow of Indonesian labour to Marudi, Bario, and Miri (via Batu Kalong) started. Many young people from the subdistrict of Pujungan went to work to Malaysia, as they do presently. One year after the end of the period of confrontation with Malaysia (1963-65), the borders were reopened and have remained open until now.

Around 1950, a serious epidemic ravaged the Long Benato and the villages of the upper Bahau, spreading quickly and leaving many dead. All the Oma' Long from Long Benato moved to Long Uli under the leadership of Imang Bilung. Because Imang Bilung had no children, his nephew, Ngang Dieng, was appointed village leader. In 1967, part of the Oma' Long, under the leadership of Imang Bilung, moved from Long Uli to Bhayangkara, where they joined a group of Kayan; another group moved to Malinau to establish their own village, Batu Kajang. At Long Uli, Terang Udau was chosen as village head and was eventually succeeded by Aran Imung, who still holds the position today.

\section{History of the Tana' Ulen}

After the Lutung River area became the sungai ulen or tana' ulen of the Oma' Long, it was considered forbidden territory and could no longer be freely entered by their own people or people from other villages. Tana' ulen is the prohibited lands (ulen = prohibition) of the village. At that time, the paren (nobility) still had a strong influence over the panyen (ordinary people) and the kula' (slaves), as well as over people coming from other villages, so that the management of the tana' ulen of the village in practice was still controlled by the paren. The function of the tana' ulen is to ensure that fish, animals, and forest products remain available for festivities and construction needs of the villagers. Under certain circumstances and for special reasons, a time was set for collecting forest products from the tana' ulen, which is known as buka ulen. Anyone

\footnotetext{
1 Ulen means 'property' or 'the right [of someone]', hence 'prohibition' for others. By marking something, or placing a sign of ownership on it, anyone can molen (or impose ulen on) that object, thus forbidding others to use it. For example, to open a swidden field this year, the farmer surveys the field's location in a new forest area and sets up a sign (a branch or wooden post) at the border of that field. Because of this sign, other people cannot legitimately use that location for farming. Someone can also molen a certain tree to be used for building or for a boat, by marking it by wrapping something around it or tying a piece of rattan around it. Molen such as this can only be used outside the tana' ulen or sungai ulen of the village.
} 
planning to enter the tana' ulen to collect forest products or to fish had to obtain permission from the paren of the village.

At that time, non-timber forest products (NTFP), for sale or for domestic use, were not harvested in the tana' ulen but in the communally owned forest of the village. Because of the pressing demand for NTFPs and of the large number of outside collectors, the tana' ulen was turned from a forest preserve intended to meet village needs into a source of cash income for the village or the village treasury. Every person who came to ngusa (collect forest products) had to obtain permission from the village head to buka ulen or enter the tana' ulen. Usually, buka ulen was allowed on condition of product sharing (or pancang) and the use of non-destructive methods of harvesting (rattan or other forest resources).

Pancang is the payment of a fee for the right to take away the forest product harvested; the amount is set at a meeting of the village elders. According to informants, a large-scale buka ulen was staged in 1991 to harvest meranti timber (Shorea spp.) using the banjir kap method, i.e., felling trees and waiting for floods to wash the logs downriver. The village elders of Long Uli also set the fees for all teams of rattan collectors in the tana' ulen, in accordance with the tariff in effect at Long Pujungan (the residence of the great adat chief), i.e., Rp. $50 / \mathrm{kg}$ for the village and $\mathrm{Rp} .50 / \mathrm{kg}$ for the adat chief. The fees so collected for the tana' ulen of the Lutung River were intended for the village and the church treasury, and the fees for the tana' ulen of the Tela'o River, for the village orphans.

\section{Research Methodology}

Two extended orientation periods (J une to J uly 1992 and October 1991 to February 1992), meant to gain familiarity with the problem, preceded the research in Long Uli and field surveys of promising areas for rattan (a two-month period, May to J une 1992). The rattan areas considered promising for the research were the two tana' ulen areas of the village of Long Uli, i.e., the Lutung River area (Left Lutung, Right Lutung, and Ping rivers) and the Tela'o River area (Tela'o, Batu Bala, and Tuan rivers).

Since knowledge of the problem was still inadequate, the research was exploratory in nature and expected to allow for a more refined formulation of the problem and the emergence of new ideas regarding the phenomena faced. Three data collection techniques were used. First, measurements in the rattan areas by using sample plots to determine the varieties and the percentages of old (=mature), young, and dead plants and what had been harvested. Second, open-ended interviews giving the respondents room to express their views freely and enabling the researcher to ask more penetrating questions on a variety of matters. Third, involvement of the respondents in data collection by, for example, accompanying the researcher in the field to demonstrate methods, write them up, and describe them and clarify special terminology in the local language, so that people could gain a sense of involvement in the research process and of ownership over its results.

\section{RATTAN IN THE VILLAGE OF LONG ULI}

The following description presents the various types of rattan, natural and cultivated, found in Long Uli, as well as the results of the survey in the sample plots. 


\section{Diversity of Rattan Types}

The area of the village of Long Uli, especially its two tana' ulen mentioned above, is an area of great potential for rattan. In a 0.4 ha plot, seventy clumps were found ( $n=70$ ), representing approximately ten types (taxa) of local rattan (including uvey seka, uvey semole, uvey ayeng, uvey beloko, uvey tebongen, uvey bala mata, uvey bulu isau, and uvey seringan) belonging to five genera: Calamus, Daemonorops, Korthalsia, Plectocomiopsis, and Ceratolobus. All rattans belong to the Palmae family (subfamily Lepidocaryoideae).

The people of Long Uli distinguish types of rattan in different ways (see Figure 4.1). Types that have many uses are better known than those that are seldom used, and the characteristics of each type, described by analogy with other, local features, contribute to the vernacular names of particular types of rattan.

Uvey seka (Calamus caesius*) ${ }^{2}$ is recognised by the underside of its leaves, which is white, and by the silica layer on its stems (putik). It is sold unprocessed and used for many types of weavings.
Figure 4.1 The rattan plant and its parts. A: ocrea (pa uvey); B: 'knee' (lep); C: flagellum (kesavi); D: fruit (beva); E: flower (pie); F: shoot (belukuk); G: roots (aga); H: stem thorns (soek); I: stem (eneng); J : leaf (daen); K: nervure (daeng); L: internode (va); M: node (boge).

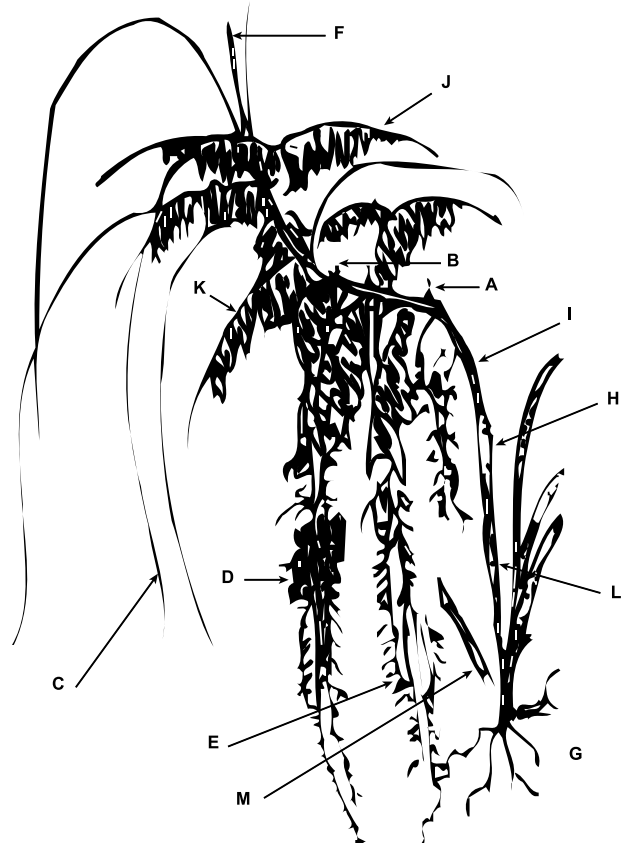

Uvey katap (Calamus pogonacanthus?) is named for the fact that it grows together with uvey seka and for the shape of its leaves and the size of its stems that resemble (katap) uvey seka. The back of its leaves is not white and its stems are not covered with a silica layer. It is only used for tying.

Uvey semole (Calamus pseudoulur*, Daemonorops didymophylla) has bigger stems, Ionger leaves and smaller buds than uvey seka. It is used for coarse weavings.

Uvey timay (Calamus javensis, Calamus spp.) derives its name (timay, small) from the size of its stems. Several types of rattan are referred to as uvey timay; among them, uvey abun (abun, clouds) grows only in the highlands, which from below often look as if they are wrapped in clouds. The people of Long Uli equate uvey abun with uvey timay. It is used for weaving without being first split or trimmed.

Uvey bulu isau (Calamus muricatus*) is so named because the thorns of its branches resemble the skin of the isau fruit (Dimocarpus longan). It is only used for tying.

Uvey tebongan (Calamus ornatus*) has only one, large stem. It is used for making brooms and other utensils because it is too stiff for weaving.

2 The sign * indicates types of rattan that have already been matched with samples in the Herbarium Bogoriense. 
Uvey ilem (Calamus pilosellus*) is used to make the frame of sa' ung hats and of kiba carrying baskets. It is often used together with uvey timay and is even stronger than the latter.

Uvey sanam (Ceratolobus concolor*, Korthalsia ferox*, K. hispida, and K. rostrata) often has ants' nests (sanam) at its ocrea, and all types that have ants' nests are referred to as uvey sanam. It is only used for tying.

Uvey bala mata (Daemonorops histrix var. exulaus*) is characterised by its red (bala)coloured thorns (mata). It is only used for tying.

Uvey pait (Plectocomiopsis geminiflora*) is distinguished by its bitter (pait) fruits, which despite their taste, can be used as vegetables. It has only one stem, light green in colour, and small thorns. This type of rattan is used to make frames for kiba, taven, and koo vadei (see below).

Uvey beloko has shafts nearly the size of the those of uvey semole but stronger. It is used for tying boats and for sturdy weaving.

Uvey baya (Calamus blumea/tomentosu?) has bark showing the colour and the patterns of crocodile (baya) skin. It is used for tying.

Uvey kelasi (Daemonorops atra*) grows short and always has fruit. Its stems have long yellow thorns the colour of the skin of the kelasi monkey (red leaf monkey, Presbytis rubicunda). This type of rattan is not used.

Uvey seringan (Daemonorops sabut*) has thorns perpendicular to the stem and is used to make frames for taven, kiba, and others.

Uvey lanya (Daemonorops fissa) is also used for making frames for taven, kiba, and others.

\section{Natural Rattan}

Plot I (in Lalut Isau) and Plot II (on the Batu Bala River), located west of the village of Long Uli, covered 0.4 ha $(400 \mathrm{~m} \times 10 \mathrm{~m})$ each, and their vegetation represented the natural rattan of the sungai ulen of Long Uli (Tela'o, Batu Bala, and Tuan rivers). The sungai ulen has the following boundaries: along the Bahau River, it borders on jekau (secondary growth on former rice fields); upstream, it is bordered by the Tela'o River, from Lepau Batu (the Batu River) to Apau (the highlands); downstream, by the Tuan River, from Lalut Dian to the highlands. The vegetation near the sungai ulen of the Tela'0, Batu Bala, and Tuan rivers begins with young jekau for about $400 \mathrm{~m}$ from the banks of the Bahau; deeper into the sungai ulen, there is primary forest (mba'); then, on the modong ang (ridge between two valleys) on the upper Batu Bala and upper Lalut Isau rivers, there is ten namam (open fern forest), followed by ten sang (palm forest), and ten uvey (rattan forest). Plot III, measuring $63 \times 63 \mathrm{~m}(0.4 \mathrm{ha})$, is located in the sungai ulen of the Lutung River, at Lalut Pekelem in the Left Lutung River, not far from its confluence with the Lutung River, and it is estimated that the rattan forest there has already been exploited too far. The plot contains pulung mba', a mix of forest and fruit gardens. It is unclear whether the rattan was planted or grew naturally and was later cultivated (Table 4.1 and Figure 4.2).

The natural rattan vegetation in all three plots has been analysed using local terminology for young rattan stems (mengeg) and old (mature) rattan stems (mugeng), and also considering rattan stems al ready harvested (as indicated by the stumps 


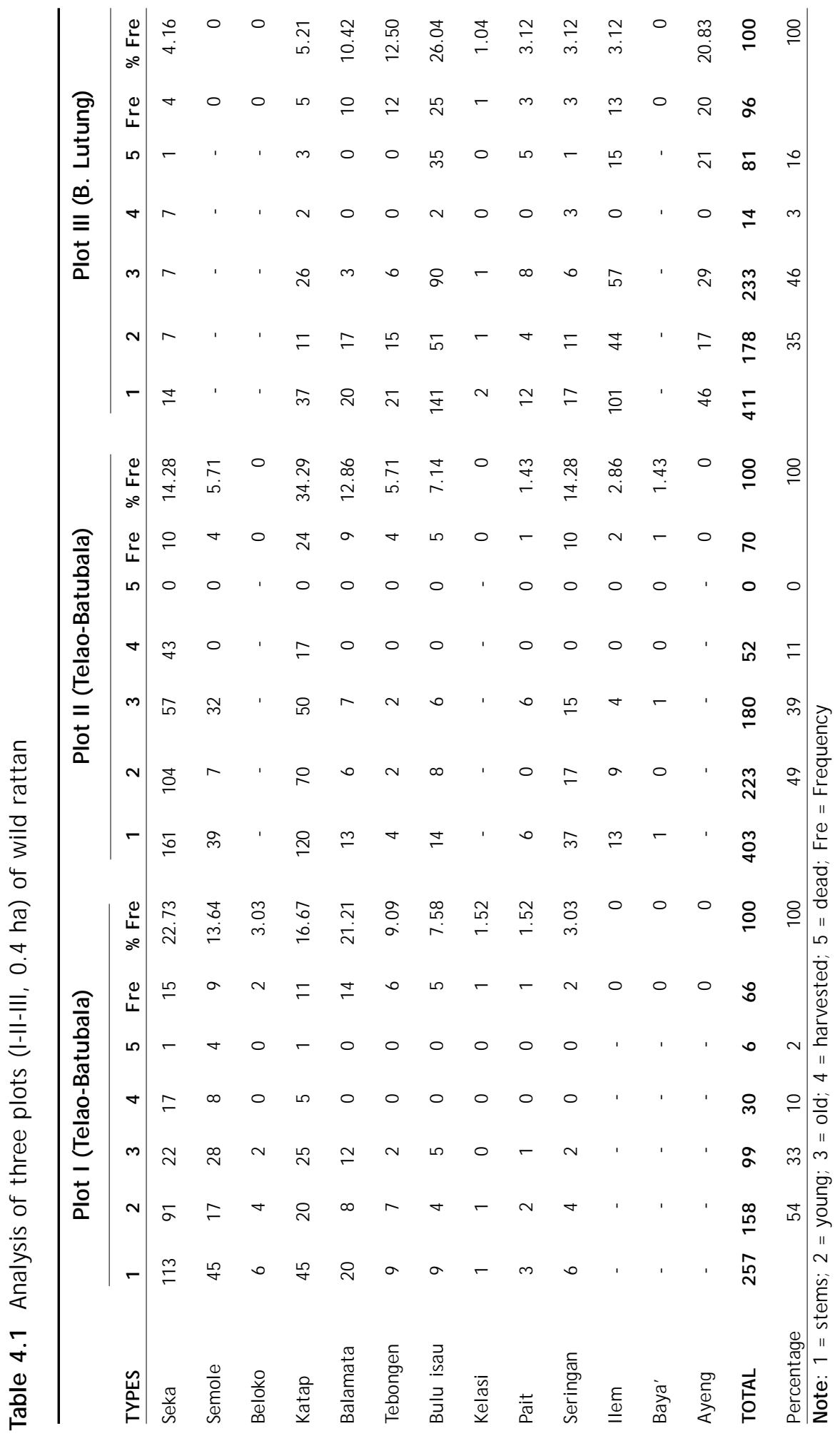


Figure 4.2 Proportion of young, old, dead, and harvested stems in Plots I-II-III

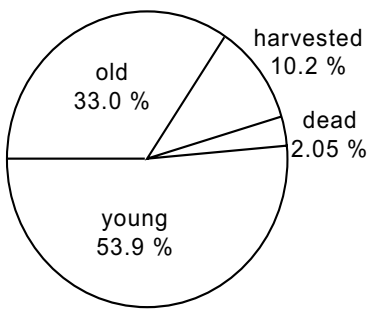

|

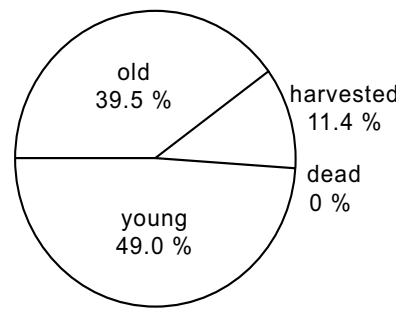

II

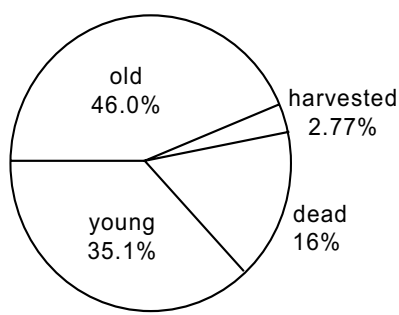

III

remaining after cutting) and those that have simply died off. This analysis revealed the existence of ten different types of rattan in Plots I, II, and III, consisting of 13 local varieties belonging to five genera (Calamus, Ceratolobus, Korthalsia, Plectocomiopsis, and Daemonorops).

In Plots I and II, sufficient amount of mature rattan was available for harvesting (about 35\%). The rattan types were generally commercial varieties and had many uses (uvey seka, uvey semole). In Plot I and II, about $11 \%$ of the rattan had already been harvested, without visible effect of the harvest on either the young stems or the dead ones. In Plot III, many mature stems were found (46\%), but they included types that are not particularly used. There was also a substantial percentage of dead or harvested stems $(18 \%)$, the result of excessive and improper harvesting which cut the stems too close to the ground so that the rattan began to rot, which spread to the roots. According to information obtained, several years ago Plot III was known as a promising plot for uvey seka.

\section{Cultivated Rattan}

Several families have begun to plant rattan, specifically uvey seka (Calamus caesius) in their fields and gardens to guarantee sustainable production. In light of the people's efforts to improve their economic situation and raise their welfare level, an effort to protect sustainable production is needed. This effort relates to patterns of land ownership-this concerns farm lands (bekan and jekau), gardens, pulung (graveyards), and tana' ulen. There should be further efforts, which already have been undertaken or can be undertaken by both the local people and government to improve the local economy in the forest-product sector, and especially with regard to rattan. One sungai ulen (Tela'o River) is located in the Kayan Mentarang nature reserve; the second one (Lutung River) is included in a forest concession belonging to the Sarana Tri Karya timber company (Roda Mas Group) (Table 4.2 and Figure 4.3).

Table 4.2 Analysis of a plot of planted rattan (Plot IV at Long Sebung, $0.25 \mathrm{ha}$ )

\begin{tabular}{lrrrcccc}
\hline Rattan Types & Stems & Young & Old & Harvested & Dead & Frequency & \% Freq. \\
\hline Seka & 457 & 239 & 218 & 127 & 8 & 14 & 52 \\
Semole & 41 & 26 & 15 & 9 & 0 & 9 & 33 \\
Tebongen & 3 & 3 & 0 & 0 & 0 & 2 & 7 \\
Balamata & 4 & 2 & 2 & 0 & 0 & 2 & 7 \\
TOTAL & $\mathbf{5 0 5}$ & $\mathbf{2 7 0}$ & $\mathbf{2 3 5}$ & $\mathbf{1 3 6}$ & $\mathbf{8}$ & $\mathbf{2 7}$ & $\mathbf{1 0 0}$ \\
Percentage & & 42 & 36 & 21 & 1 & & \\
\hline
\end{tabular}


Figure 4.3 Proportion of young, old, dead, and harvested stems in Plot IV

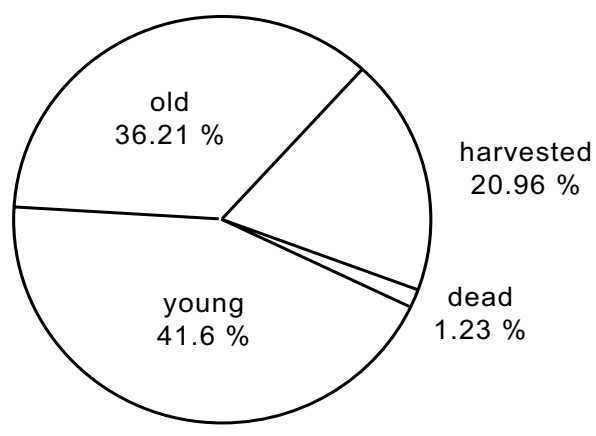

Cultivated rattan is planted in the gardens, in former swiddens and in other areas that are not going to be farmed. The types of rattan planted are limited to those varieties that have many uses, such as uvey seka and uvey semole. These usually grow together with sang (a type of palm, Licuala sp., used for making sunhats), talang (a type of palm, Arenga undulatifolia, which has edible shoots and leaf stems that can be used for roofing), as well as other types of rattan that are cultivated in rattan gardens. Plot IV was a rattan plantation belonging to Lidem

Luat's family. It covered 0.25 ha $(250 \mathrm{~m} \times 10 \mathrm{~m})$ on the banks of the Bahau River at Long Sebung. This plantation was first planted with uvey seka and uvey semole by Idi Aluy, Lidem Luat's grandmother, in the 1960s. In 1986, it was planted again with the same types of rattan by Luat Apuy, the father of Lidem Luat.

In Plot IV, the percentage of dead (8\%) and live (77\%) plants was fairly good, even though it has already been harvested (21\%), and the percentage of mature stems ready for harvest (37\%) was good. Field observation showed that the harvested rattan had not been cut too close to the base, so that there was no rot. It could be concluded that the rattan gardens were better managed than the natural rattan groves.

\section{THE MANAGEMENT OF RATTAN BY LOCAL PEOPLE}

Every social group has its own techniques for managing natural resources in order to sustain life and, further, to improve its quality. Nature provides a livelihood, and social groups regulate control over the lands they occupy, for their own people, as well as for outsiders, who pay fees in cash or in kind (see Soerjono 1985). These customary or adat rights and the use and management of local resources must be studied in greater depth in order to support the future development of the local people's economy.

\section{Permits}

Permits are regulated in the village (desa) and the requirements depend on need, whether the collection is for commercial purposes or for domestic use. To enter the tana' ulen area, a collector must obtain permission from the village head (kepala desa) and follow the rules regarding rattan harvesting techniques. If the rattan collected is intended for sale, the collector must pay a tax to the village treasury. If it is intended for domestic use, it is enough to obtain permission from the village head. To collect rattan from private gardens, either for sale or domestic use, it is also necessary to obtain permission from the owner and to set terms for compensation to the owner. The actual harvesting of the product is done only by the owner of the garden. Villagers can collect rattan freely in the communally owned forest of their village without permission from or notification to the village head, either for sale or domestic use. 
Collectors other than villagers, either people from neighbouring villages or outsiders from downstream regions, must first report to the village head.

\section{Rattan Work Groups}

Rattan collecting groups each consist of four to five of the village's young men; the group is coordinated by a group leader, usually the oldest among them. If they intend to be absent for over one week, those who already have families will leave rice provisions (or money) for as long as they will be gone. Each individual's work equipment consists of a kiba (carrying basket), pet (sleeping mat), keloma (blanket), ntelu (a pillow made from kapok, kapuk saleng), baing and elang (machete and knife), batu tenap (sharpening stone), losan batung (tobacco container), malat batung (or mece, batung ketib, matches), jemo (tow for making a fire, from the birai plant), jako (tobacco), da' un jako (cigarette wrapper).

The equipment of the group includes a sengau (tarpaulin), keleput (blowgun), keleput langan (darts), salo (dart poison), and piping (dart fliers). If they do not have a blowgun, they bring along a selapeng kiep (or senjata dorlok, a homemade gun) or a keleber (an $8 \mathrm{~mm}$ rifle and bullets), or a bujak (hunting spear); they also carry a buan lenya (lantern), telang lenya (kerosene), kere (kettle), and parei (cooking pot). The food supplies that they bring along are baa (rice), gola (sugar), kupi (coffee), osen (salt), bicing (monosodium glutamate), telesi babui (lard), and siei (smoked pork).

Usually part of this equipment is borrowed, while the food supplies are obtained on credit from the store or the rattan trader, so that the output of the harvest cannot be sold to anyone else. On the occasion of rattan harvesting of this kind, intermediary dealers in the village try to coordinate 'rattan expeditions', provide for all the group's needs and buy the rattan harvested at cheaper prices (e.g., Rp. 650/ kg while the price is Rp. $800 / \mathrm{kg}$ in Long Pujungan).

\section{Harvesting and Transporting Rattan}

The rattan, usually uvey seka, is harvested by pulling down a mature rattan stem and cutting it. The signs that a stem is mature are: peeling bark, a yellowish colour, and a clearly visible silica layer (putik). The harvested rattan is more than 3 depa (=depo or repo, approximately $1.70 \mathrm{~m}$ ) long, the tip is cut off (if necessary, someone will climb up), then the base is cut approximately one depa from the ground and is stuck into the ground again. According to reports and observation, cutting the stem so high above the ground prevents rotting of the stem to spread to the roots. The cut rattan is gathered and tied into a coil of thirty lengths, each 3 depa long and weighing 4 to $5 \mathrm{~kg}$ (Figures 4.4 and 4.5).

The coils are dragged or carried to camp and piled together near the hut. Usually 50-60 coils are considered enough. The rattan is then carried to the village in stages, over land or by river. If this is done by land, the rattan is dried, so that it is lighter to carry, and a carrier (ee) is made, which can be carried by anyone. If transport is by river, the rattan is also dried, so that it can float in the water-it should be able to stay afloat for at least three days. Then it is rolled up and made into a raft (akit Uma' Baka) to float alongside the boat. If the duration of the trip exceeds three days, the raft is taken apart after three days and the rattan left to dry for a day or two, until it can float again, and then the trip is resumed. 
Figure 4.4a Harvesting the rattan

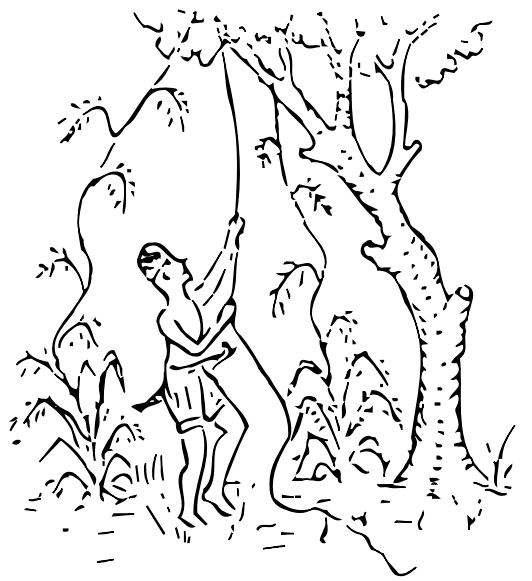

Figure 4.4c Carrying the rattan

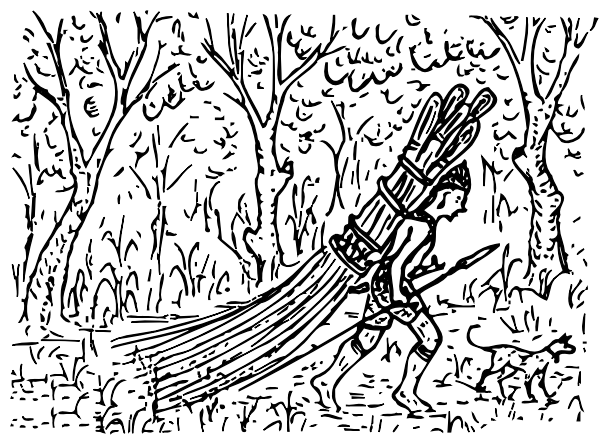

Figure 4.4b Tying up the rattan in bundles

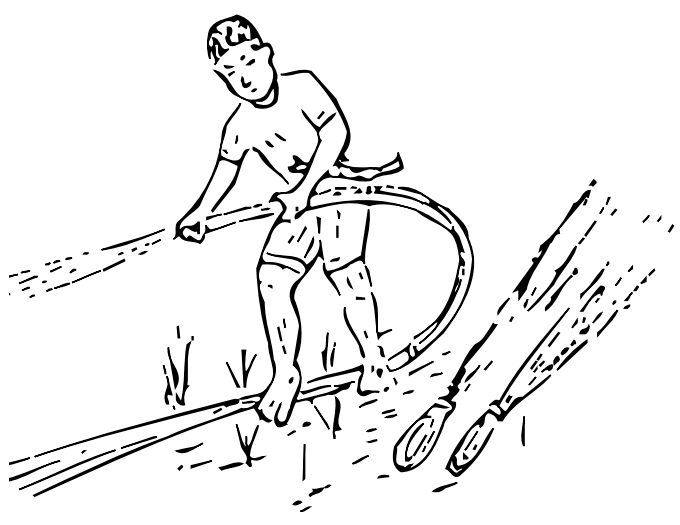

Figure 4.4d Hauling the rattan

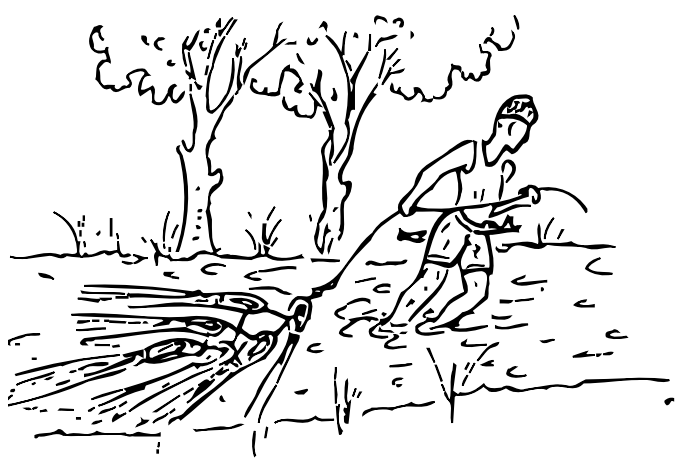

Figure 4.5 Coils of rattan (rotan sega)

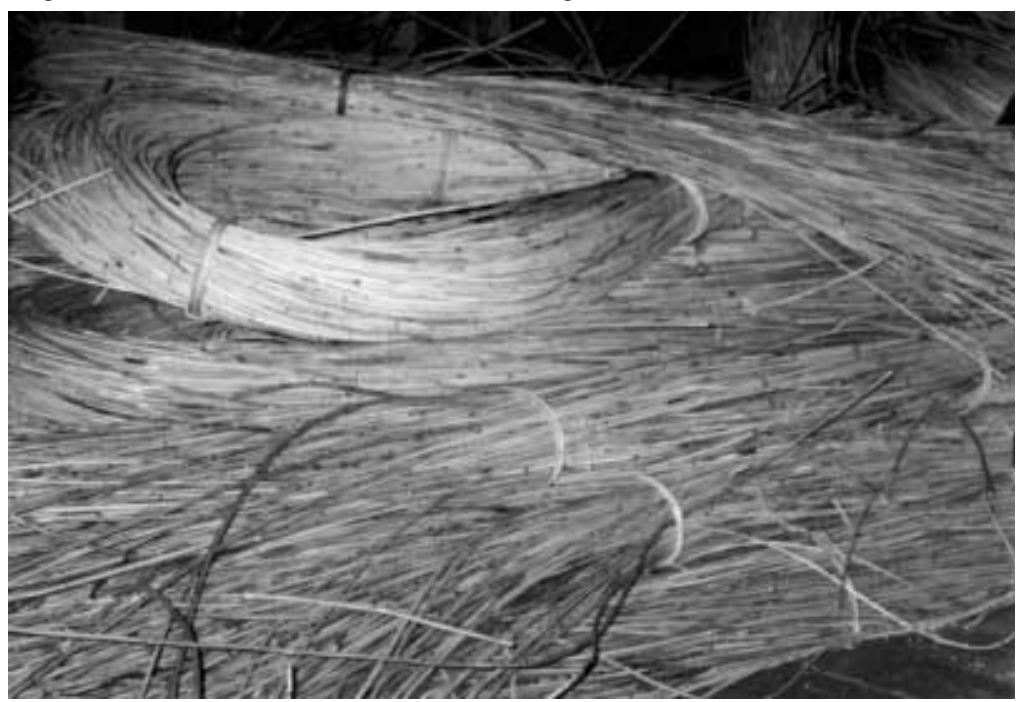




\section{Use and Preparation of Rattan}

The rattan harvested can be sold or be intended for domestic use.

\section{For Sale}

To be sold unprocessed, the coils must be completely dry; that is, until there is no more rattan that is green in colour (bileng) or that is green and yellow (korap), which can lower its quality. After drying, it is tied again into coils. With a row boat (alut) or a ketinting (small motor boat) rented from its owner or from the village, the rattan is then transported to the subdistrict capital at Long Puj ungan, where shop owners Moming or Obet will buy it at a price of Rp. $800 / \mathrm{kg}$ (as of May 1992). All the work described above is carried out by men. Some intermediary buyers go to the villages themselves to buy rattan at lower prices. They also must pay fees for the tana' ulen to the village if this has not yet been done by the harvesting group when they entered the tana' ulen. The money from the sale of the rattan is used to pay off the credit for the goods obtained before departure. The rest is divided among the members of the harvesting group, who use it to buy daily necessities (soap, sugar, oil, cigarettes, clothing), and any amount left is saved.

\section{For Domestic Use}

Rattan is woven into useful tools and utensils, and it is also used for tying, or the fruits and shoots are harvested for food. This type of work is done by men as well as women.

If it is woven into useful items, the rattan is cut up (mutun) on the basis of the item to be manufactured and it is dried (ngetow) for one day. In the case of uvey seka, the silica layer (putik) is removed (mutik), and the rattan is then cut according to the required measurements. Generally, uvey seka is split into four strands and uvey semole is split into six strands. Rattan that has not yet been split on a given day is left to soak in water, so that it is easily split the next day. Then the rattan is trimmed and calibrated using two iron blades (elang venet) set in a piece of wood (Figure 4.6).

Figure 4.6a Elang venet

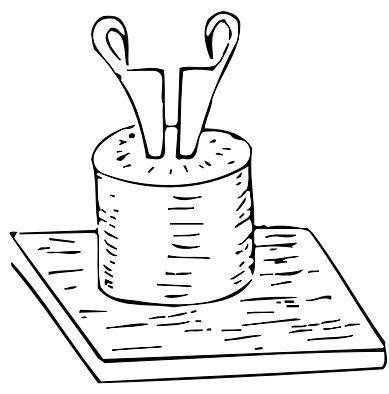

Figure 4.6b Elang venet used in a different position

Figure 4.6c A tool to trim rattan strands

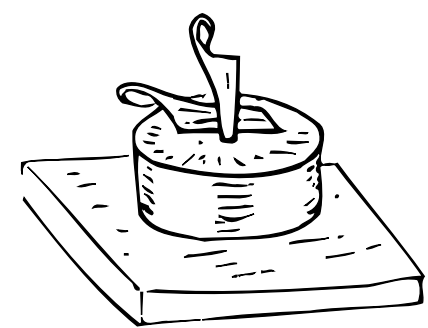


The rattan is woven (manyan) into a variety of utensils: Kiba, a type of carrying basket or backpack, comes in two different forms according to whether it is for use by men, or by women (kiba leto); belanyit, also a type of carrying basket, can be of three different types: with loose weave, tight weave, or patterned weave; ingen, a basket for carrying foodstuff; ingen biyen is a large basket used for carrying paddy ears to the field hut, and ingen tesek, manufactured to fit their owners' backs, are used for carrying threshed paddy to their houses; bening, used for carrying small children, are beautifully decorated to indicate the child's social status; abut, a large rice container. lye, a shoulder strap for the kiba, belanyit, or bening; pet, sleeping mats; pet lampit, floor mats for the living room; tayang uvey, mats for drying rice; badang, a small rice container to be taken along on a trip; terezen, a container for paddy seed while planting (nugan); boeing paen, a container for keeping the betel nut equipment; kereben, a container, usually tied to the head, for keeping the catch while fishing with a scoop; sengep sang, a container to store a roll of sewn sang leaves (Licuala sp.) used as a tarp; sa'ung, a broad sun hat, worn when working, and made of sang leaves on a rattan frame; tapung beloko, a war helmet, decorated with the feathers of the kuwai bird (Argusianus argus), is frequently used today as an accessory for dancing; tabit, a sitting mat, was used in the past when loincloths were still in use, but today only an accessory when dancing; poaen, a cage: either a chicken coop (poaen za), or bird cage (poaen sui) for the popular kekeng (parakeets, Bloriculus gal gulus) or the yellow crowned bulbul (Pycnonotus zeylanicus) (Figure 4.7).

Figure 4.7a Kiba (left) and kiba leto (right)
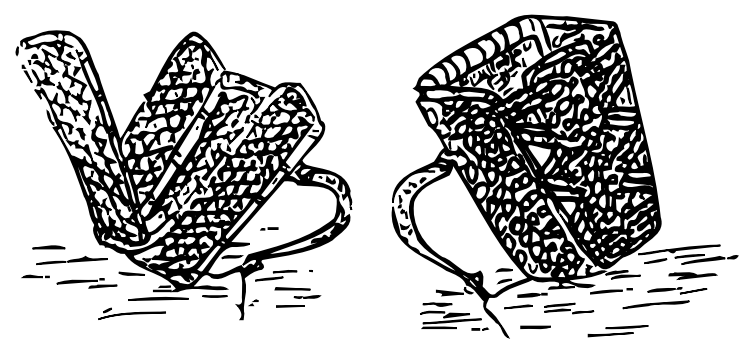

Figure 4.7b Belanyit (left) and belanyit kalong (right)
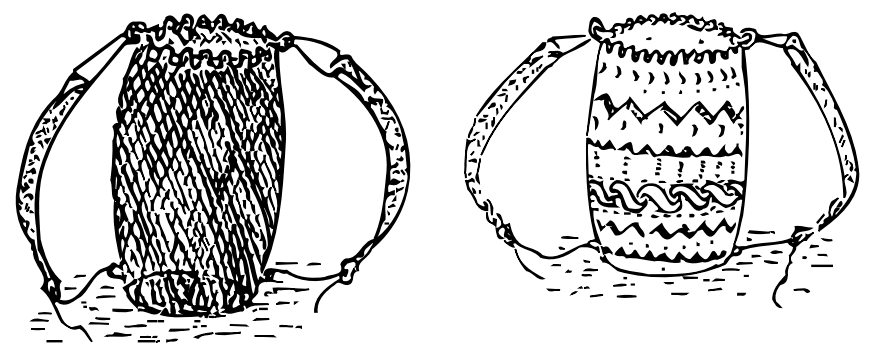

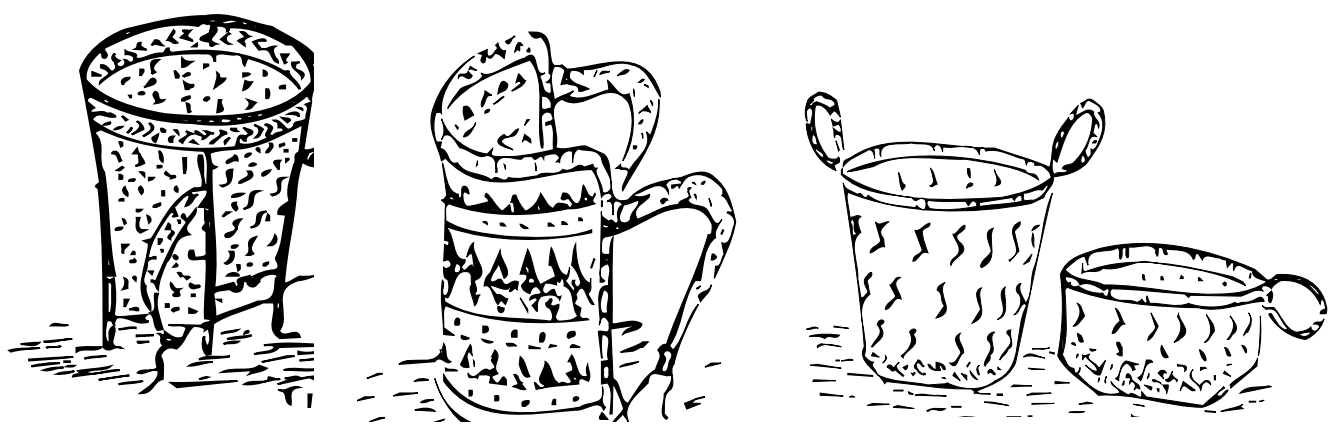

Figure 4.7f Lye

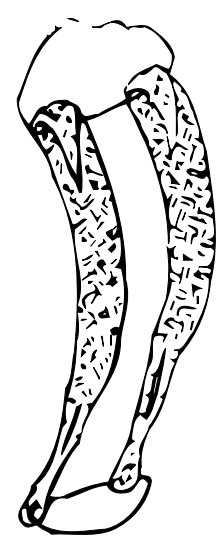

Figure $\mathbf{4 . 7 g}$. Pet

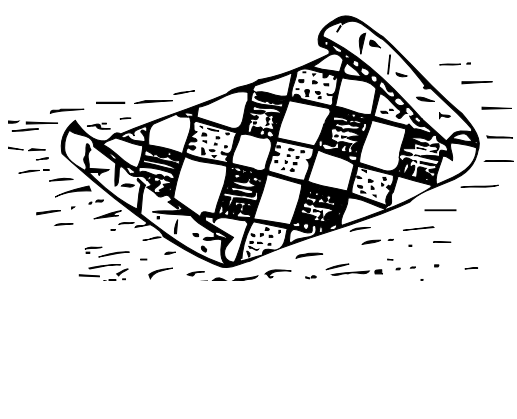

Figure 4.7h Pet lampit
Figure 4.7i Tayang uvey

Figure 4.7j Badang

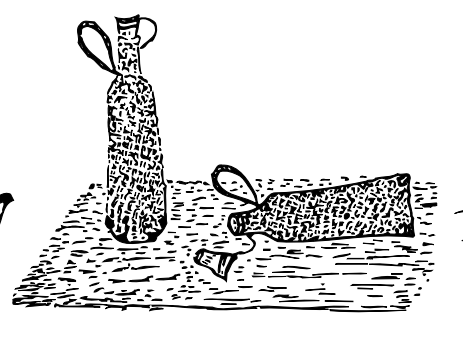

Figure 4.7k Terezen

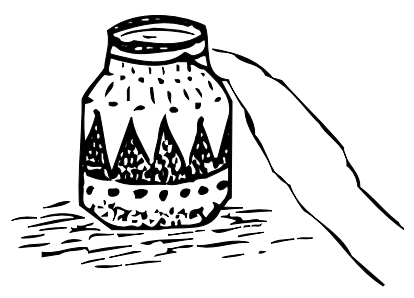


Figure 4.7I Boeing paen

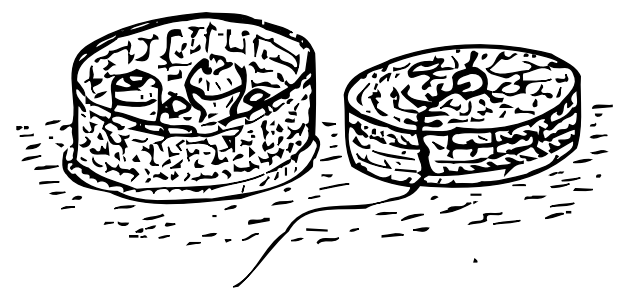

Figure $4.7 \mathrm{~m}$ Kereben

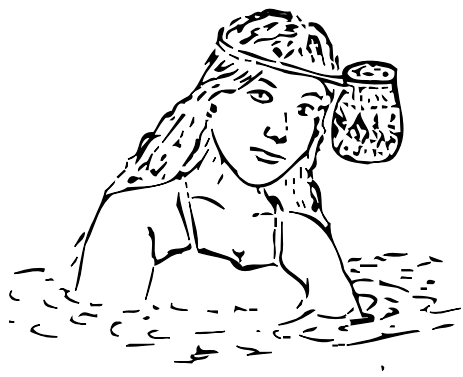

Figure 4.7n Sengep sang

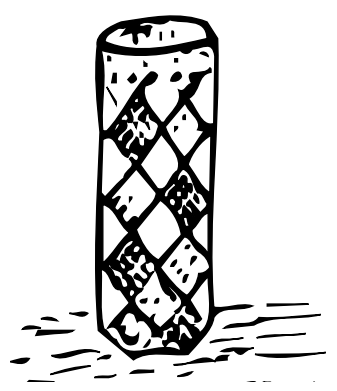

Figure 4.70 Sa'ung

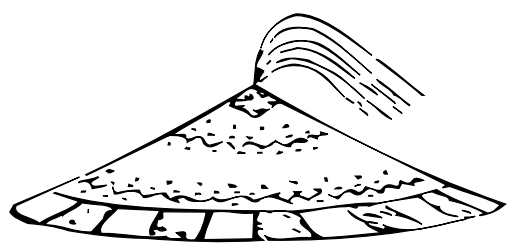

Figure 4.7p Tapung beloko

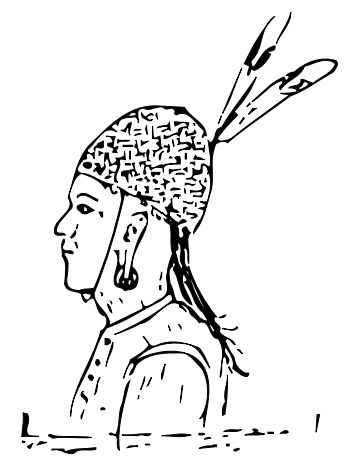

Figure 4.7q Tabit

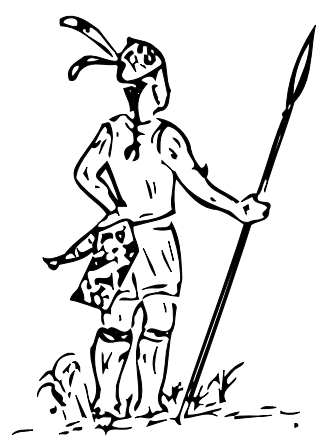

Figure 4.7r Poaen za

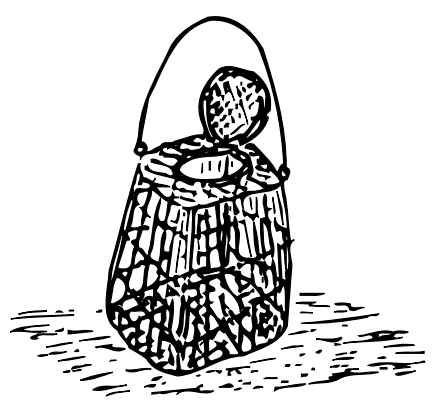

Figure 4.7s Poaen sui

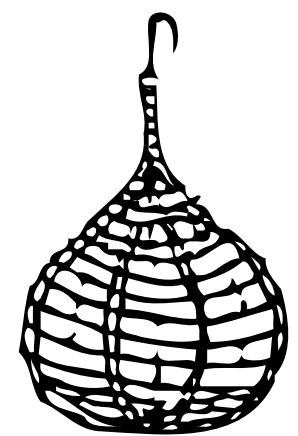


Rattan is also worked into tools: atip, tongs for picking up coals and charcoal in the kitchen; kelawit, a hook to pull down brush while clearing the fields; koo vadei, a sieve to thresh paddy; taven is used for sifting or winnowing rice (husked or unhusked) and other materials; jagap, a rake for brush and small trees after mekup (cutting up wood remains after the burning of the fields); pa uvey, a broom of palm leaf spines for leaves and other dirt; sekep is a fishing scoop; kuas cat, used like an ordinary painting brush and made from fine-fibred rattan (Figure 4.8).

Figure 4.8a Atip

Figure 4.8b Kelawit

Figure 4.8c Koo vadey

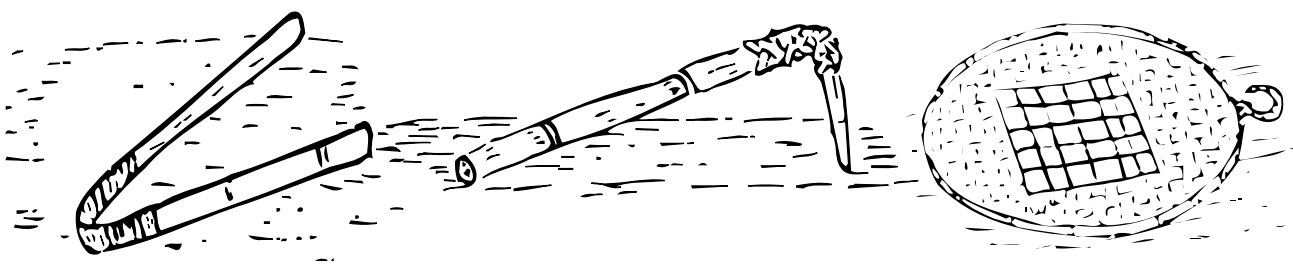

Figure 4.8d Taven

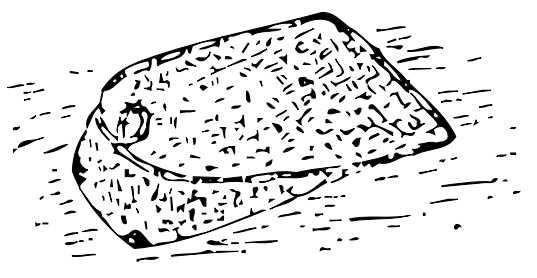

Figure 4.8e J agap

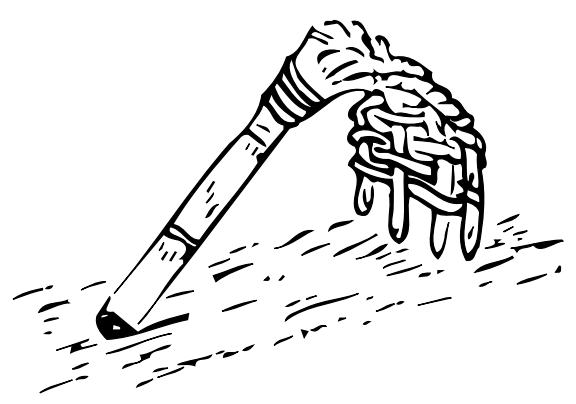

Figure 4.8f $\mathrm{Pa}$ uvey

Figure $\mathbf{4 . 8 g}$ Sekep

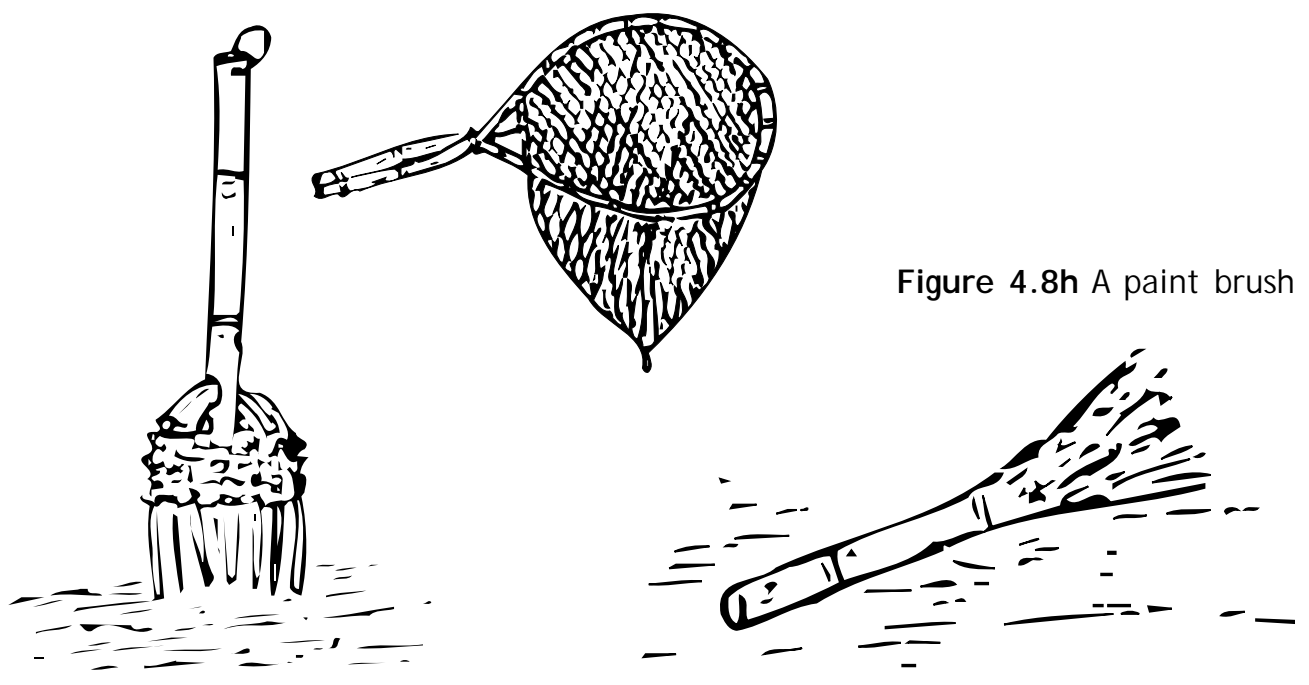


As a tying material (seli), rattan is used to attach iron blades to their handles or shafts: spears (bujak), adzes (bikung), machetes (bazang), axes (asai). Seli kelorang forms a casing for earthenware pots (kuden tana'); seli kepang secures the wooden shingles, usually made from benatu wood, to the roof; and seli lepau fastens the structure of a hut. Rattan also serves to tether a canoe (alut) and, in the old times, before iron nails were available, to fasten its side boards. And a rattan rope also serves for drying clothes (akui galen) (Figures 4.9).

Figure 4.9a Seli: bujak, bikung, bazang, asai
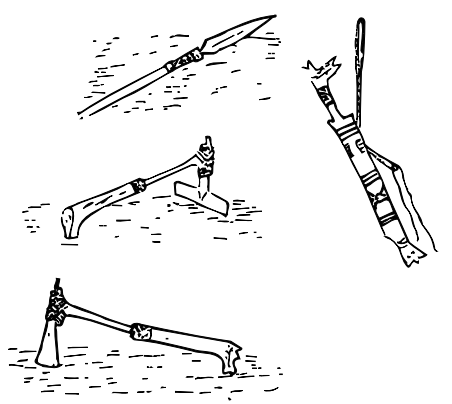

Figure 4.9d Seli lepau

Figure $4.9 \mathrm{e}$ A canoe rope
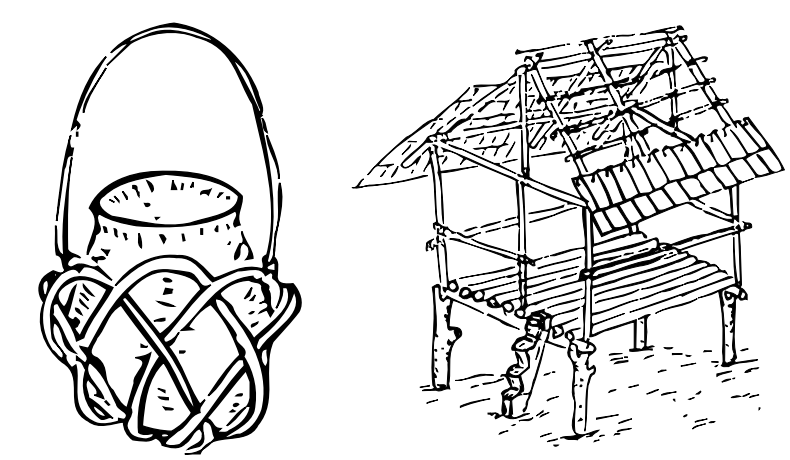

Figure 4.9b Seli kelorang

Figure 4.9c Seli kepang

Figure 4.9f Akui galen
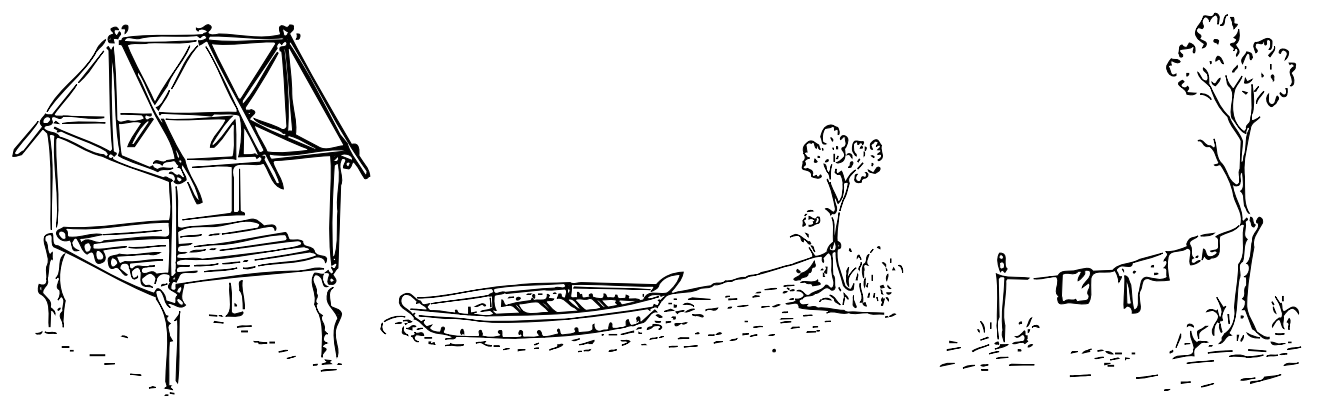

Rattan, finally, can also be consumed: the fruits of uvey bala mata are used in place of areca nuts for betel; the shoots of uvey pait are used as vegetables; and uvey lanya is boiled and drunk as a poison antidote.

\section{The Rattan Trading Network}

Among the non-wood forest products only uvey seka (Calamus caesius) can be marketed in raw form. The other types of rattan are used for daily needs (Puri et al. 1991). However, knowledge of rattan's regenerative capacity, its harvesting techniques, and its management is not yet widespread among the people (J essup and Peluso 1986). 
The first group in the NTFP (non-timber forest products) trading network comprises the rattan collectors from among the farming people. Usually, the people in the villages, specifically the Kenyah, try to find spare time for collecting rattan (or other NTFPs, such as the incense wood, gaharu; see Blajan Konradus in this volume) after weeding, after harvesting, and on other occasions. This work is adjusted to the farming schedule, because every family member has responsibilities in the family's farm work. Usually, no one spends more than one month at a time in the forest.

Another group engaged in rattan collecting includes the Punan Benalui, who live at Long Uli and nearby villages (Long Peliran and Long Bena), and the Punan from the Malinau and the Tubu rivers. They usually make swiddens but do not tend them properly. Thus, they have comparatively more free time than the Kenyah who tend their fields more intensively. The Punan generally are less familiar with market prices for NTFPs and tend to trade them in the nearest village for their daily necessities, such as sugar, rice, salt, clothing, or machetes.

Other rattan collectors are those coming from downstream areas (usually from the villages of Long Lian, Long Peso', Long Bia, and Bhayangkara). These groups can work for months in the forest, because they usually are not farmers. Thus all their necessities are purchased with the money they receive from the sale of the NTFP. They are coordinated by traders keeping shops in villages or by intermediary river traders. Those come with either their own boats or rented boats and carry away large quantities of product.

In Pujungan subdistrict, it is indeed difficult to distinguish between intermediary village traders, village store traders, intermediary river traders, or boat traders, such as described by De Beer and McDermott (1989). In this area, the existence of a cluster of several trading individuals or families linked to an NTFP trading network extending from upstream to downriver is very clear. Regarding the NTFP trading networks, especially concerning incense wood, see Blajan's chapter. 


\title{
5. \\ Eaglewood and forest product management and trade in the Bahau River region
}

\author{
Blajan Konradus
}

\section{INTRODUCTION}

The highly effective forest management institutions formerly used by all Kenyah people are no longer strictly enforced today, even though the Kenyah have lived in close interaction with the forest for centuries. Factors much touted as the primary causes of this change are economic pressures and market demands for forest products which continue to force people to collect forest products in disregard for their traditional management rules. These pressures and demands also seem to have caused a shift in the values relating to the tana' ulen leppo' (village forest preserves). These areas that formerly served social and economic functions nowadays retain only an economic function (see the chapter by Jacobus et al. and other writings in this book).

In fact, the forest products used by the people are non-timber forest products (NTFP), such as incense wood or eaglewood (gaharu), cinnamon bark, rattan, and ketipai (Palaquium quercifolium), while timber products tend to be exploited by big business through their forest concessions (HPH). If we compare environmental damage, it is obvious that the effects of the NTFP business are much less significant than those of the logging activities. Nevertheless, the expansion of the NTFP business (maximalisation) has had some harmful effects and has brought about a change in the overall patterns of forest management. This article focuses on the effects of the maximalisation of the NTFP business, especially in the growing eaglewood marketing network, on forest management patterns in the Bahau River region. These effects are 
viewed from a sociological perspective, and with regard to the sustainability of the potential of the resource, and with concern for the economic life of the local society.

The subdistrict (kecamatan) of Puj ungan contains various types of forested lands, including lowland dipterocarp forest, submontane forest, heath forest (kerangas), and secondary forest. Farming is the primary economic occupation of the inhabitants. In the spare time between their farm work, they gather non-timber forest products (NTFP) for sale. The most sought after of these products is eaglewood, and in the last few years, it has been extensively collected by the people. The area covered by this research, carried out from July to October 1993, includes the entire subdistrict of Puj ungan. The primary observation point, however, was the village of Long Pujungan, the subdistrict capital, which serves as a trading centre providing food and medicine needed by the people and by the NTFP collectors. This village also serves as the operational base for the NTFP dealers, and as a NTFP trading centre for the entire district. Non-timber forest products are carried from here to Long Peso', Tanjung Selor, or even Tarakan.

\section{Eaglewood and its Marketing}

The eaglewood (Aquilaria beccariana van Tiegh, as well as several other species and genera) that is traded is a part of the tree that has been damaged or infected (by a type of fungus), so that a resin fills the holes or pores of the wood. These heavy, resin-filled parts of the tree are collected. Eaglewood is used as raw material for perfumes and, as dust or powder, is used for the manufacture of incense sticks and the like for religious purposes in the People's Republic of China, India, Saudi Arabia, Singapore, and Thailand.

The Kenyah language recognises three types of eaglewood trees (sekkau); these are sekkau tengun ('mountain-horn' eaglewood), sekkau baya' ('crocodile' eaglewood), and sekkau nyibung, all of which have different characteristics. The sekkau tengun tree has soft wood, and may grow as tall as a coconut palm and reach a circumference of 1 to $1.5 \mathrm{~m}$. It is found in coastal areas and along rivers, but not at high altitudes. The sekkau baya' tree is a hardwood with many knots and it may reach a circumference of 25 to $30 \mathrm{~cm}$. The valuable resin is found in the trunk, and only rarely in the branches. This tree, which is not very high, usually grows along rivers, on hillsides, and in stony areas. The sekkau nyibung is a tall and broad tree, but with few branches. Its dark resin (if present at all) is very abundant, in the trunk as well as in the branches. The tree's circumference can reach $50 \mathrm{~cm}$ to $1 \mathrm{~m}$.

\section{Quality Classification}

Eaglewood quality varies widely. No less than five levels (generally six) of quality are known, and they are often divided again into a number of subclasses: super (super buku and super biasa); teri (teri A and teri B), class I (IA and IB), class II (IIA and IIB), class III (IIIA and IIIB), class IV (pelagon or long adau). The characteristics of these various categories are as follows:

- Super: the pieces of eaglewood are small, round, dense, and shiny; wood fibres are not straight; there are no holes; and weight varies between 100 to $300 \mathrm{gr}$ per piece; in super buku, the resin content exceeds $90 \%$ and the material is completely black; in super biasa, the resin content is below $90 \%$ and the material is reddish black. 
- Teri: in this category, the material comes in small, knotty pieces of less than $100 \mathrm{gr}$; it comprises Teri A (or teri kacang): round, nutlike shapes, entirely black; and Teri B (or teri tebu): thin like sugarcane skin, mixed black and light brown.

- Class I (see Fig. 5.1): in this category, pieces are solid, without holes, and heavier than $300 \mathrm{gr}$; it comprises Class IA: entirely black, ; and Class IB: mixed black (95\%) and dark brown (5\%).

- Class II (see Fig. 5.2): pieces are dense but contain holes; Class IIA: black (85\%) and dark brown (15\%) alternating; and Class IIB: mixed black (50\%) and brown (50\%) alternating.

- Class III (see Fig. 5.3): pieces are bigger, showing traces of axe cuts, dark lines circling the light brown wood that is less dense and has a high water content; it comprises Class IIIA: weight between 3 and $4 \mathrm{~kg}$ per piece; and Class IIIB: weight between 5 and $6 \mathrm{~kg}$ per piece.
Figure 5.1 Class I eaglewood

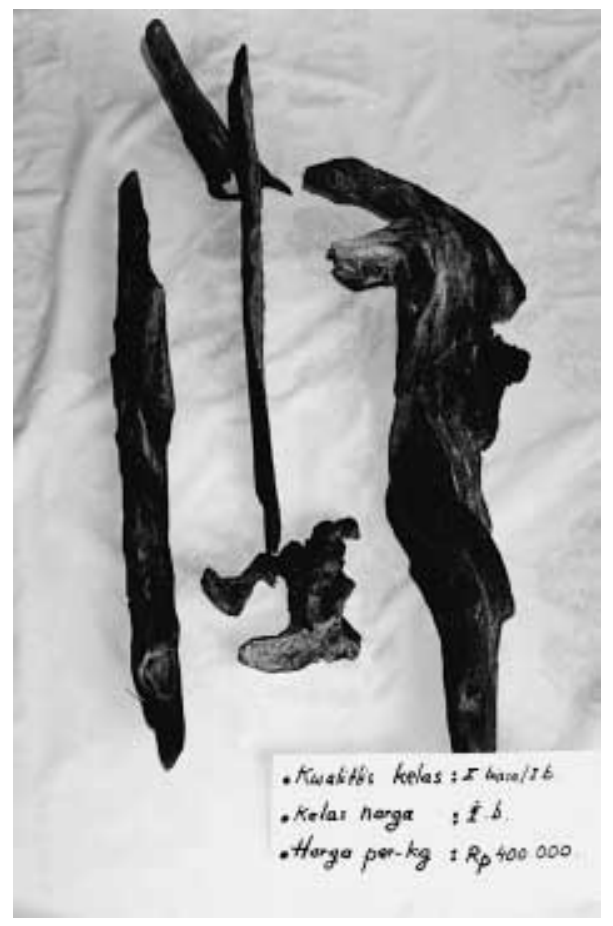

Figure 5.2 Class II eaglewood

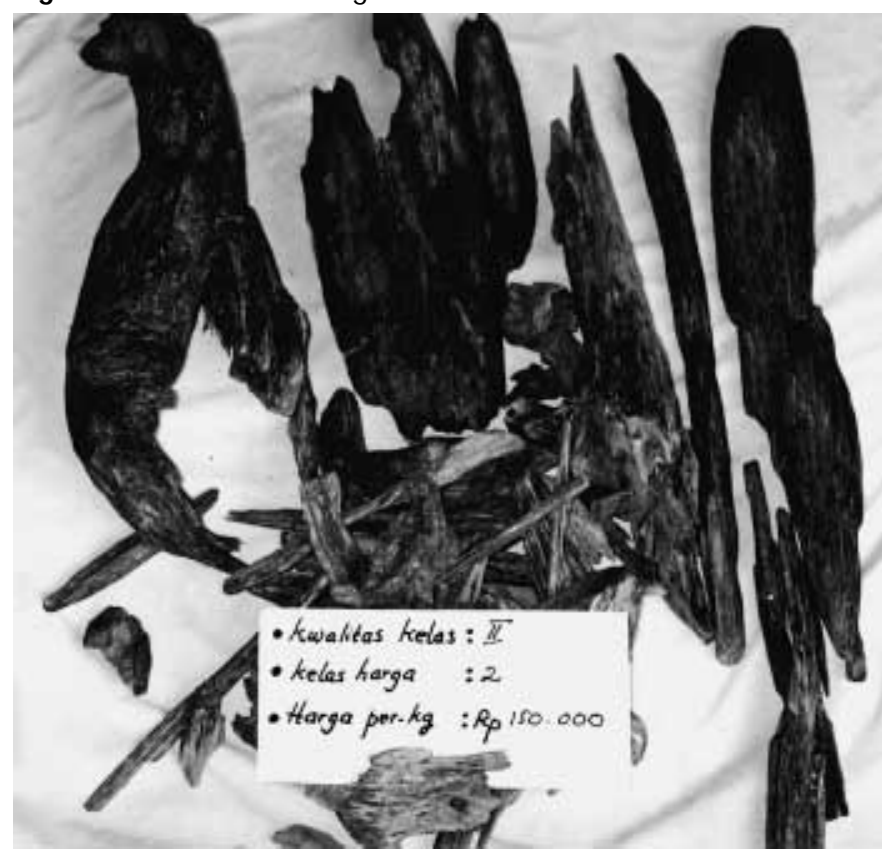


Figure 5.3 Lower grade eaglewood

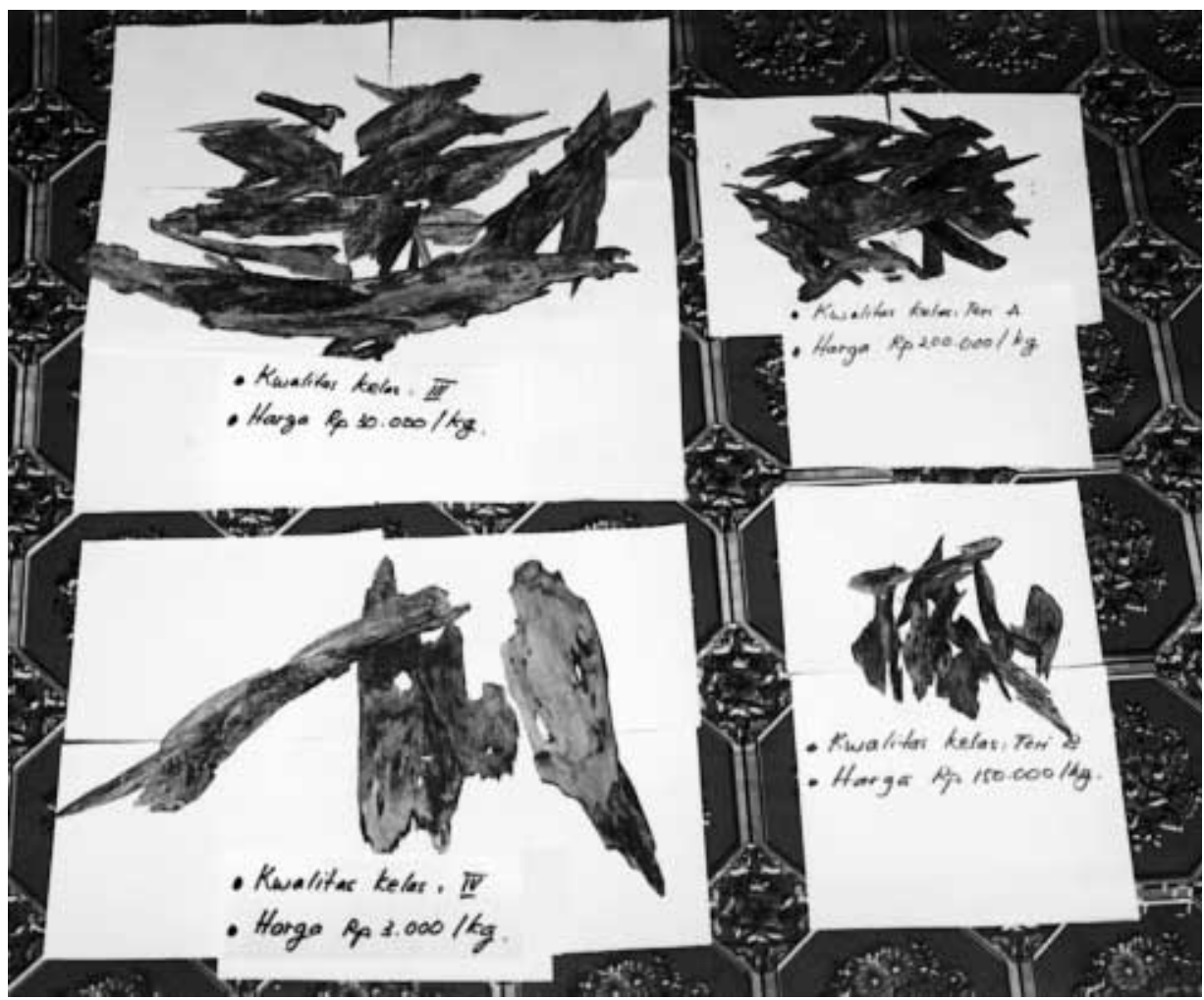

- Class IV (or long adau): it comprises Class IVA (or adau berbaju): weight up to 20 $\mathrm{kg}$ per piece; thick brown lines surround a large part of the wood so that it seems 'dressed' (berbaju); rather high water content, rather low resin content (15\%); shrinks easily; and Class IVB: (or 'regular'): wood without a 'dress' (without brown lines); weight 20-25 kg per piece; high water content, and shrinks easily; light brown mixed with white.

\section{Price of Eaglewood}

The eaglewood classifications used in the subdistrict of Pujungan and its environs as far as Tanjung Selor (the capital of the district) are marked by a lack of standardisation in quality and terminology. Dealers tend to devise their own criteria in order to procure the largest possible profits. For example, the division of the kelas super into super buku and super biasa is only used by a few dealers who have been operating on the upper Bahau for a long time. The coming of eaglewood traders (toké) from outside the subdistrict has led to greater variation in the classification, and at the same time has contributed to decreasing standardisation of prices. Four businessmen in the Long Pujungan area separately admitted that traders tend to elaborate the quality classifications in order to manipulate prices. One trader, in fact, not only uses the general system of classification, but he has also devised another system of eaglewood classification based on classes and price grades (see Table 5.1). 
Faced with these matters an eaglewood seller commented: 'It seems that prices have dropped in 1993. There are too many categories and groups. There are super, IIA, IIB, III, IV, Category IV or long adau. I have noticed that this is one way used by the dealers to confuse the eaglewood sellers so that they themselves can make more money. Actually, eaglewood only consists of at most five or four classes: super, I, II, III, and IV. The creation of seven classes is only an attempt to manipulate the prices to make the highest possible profits. That is why these games are played. Many people already know that prices are higher, so to counter this, dealers have devised many categories. When they sell downriver, however, they lump the various categories together again.'

\section{Market Conditions}

Hunting for eaglewood in the spare time between farming activities is not new to the Kenyah. Yet, recently, the eaglewood-hunting schedule has undergone radical changes. In the 1970s, the eaglewood business was viewed as a side activity and the people used their free time from farm work-such as between planting and weeding, or the period after harvesting and before looking for a new farming site. In the 1980s the eaglewood business increased rapidly and the collectors entered the forest more and more frequently, especially if the price rose dramatically, which usually occurred during the Haj season in May and J une. The sudden jump in prices not only induced local people to rush to the forest but also attracted eaglewood collectors from outside the subdistrict. The latter came in large groups in longboats. Some even came from Malinau by airplane. Others reportedly were flown into the Apau Kayan area with large helicopters by companies from Samarinda (see WWF and PHPA 1995).

The search for eaglewood has continued to expand into the 1990s and now is carried out throughout the year. This is made possible by the 'note system' (credit): the collectors receive cash and supplies (fuel, food, and medicines) from dealers or businessmen (toké, usually of Chinese descent) on the basis of a note (credit). The eaglewood they find is later bought by this same toké, who then subtracts the collector's credit. The rise and fall of the market price also influences the intensity of the search. The effects of the international political situation (especially as they relate to the eaglewood-importing countries) and of relations between Indonesia and those countries are felt even in Long Puj ungan. In 1991, during the Gulf War, dealers could not ship their eaglewood to Saudi Arabia and many potential pilgrims did not make the Haj pilgrimage to Mecca. As a result, the eaglewood price fell drastically (by as much as $40 \%$ ).

\section{FOREST PRODUCT MANAGEMENT}

This section describes the forest product management system that has been in force for a long time. The term tana' ulen has been mentioned earlier. In the Kenyah language, ulen means 'prohibition', and the term mulen means to 'reserve' or 'supply' by restricting access. Tana' ulen leppo' contains the meaning 'village land which has been reserved, protected, or even managed for the interests of the villagers, by prohibiting all forms of interference from people of any other village.' The history of the formation of tana' ulen leppo' in the subdistrict of Pujungan is inseparable from the traditional social structure of the Kenyah, which consisted of paren (nobility), panyen (ordinary people), and kula' (slaves). 


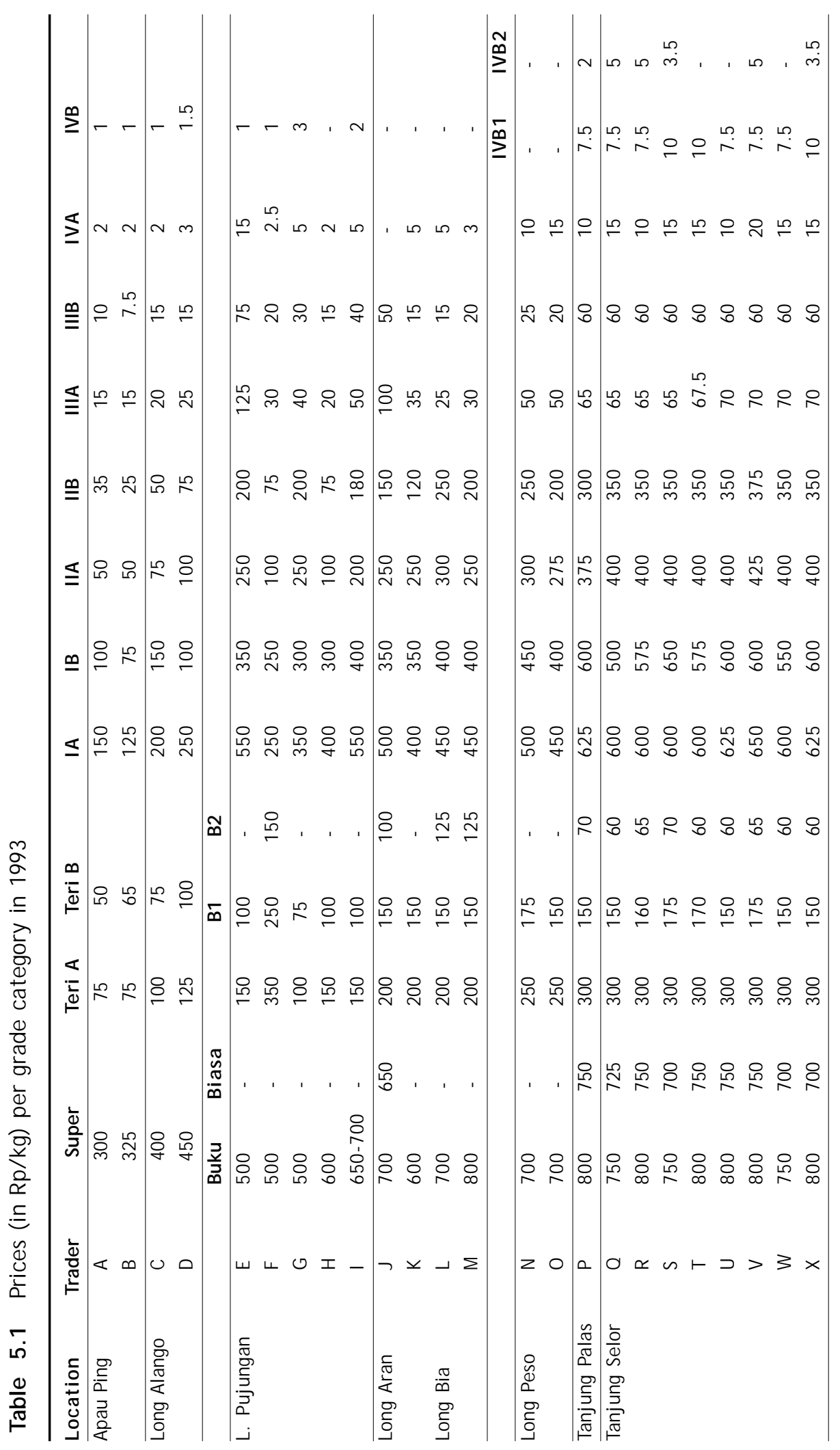




\section{Tana' Ulen in the Past}

In the past, the tana' ulen was land allocated to the paren who held power in the village, and it was a reserve of natural resources that could be harvested from time to time for the benefit of the paren. At times, as occurred in the village of Long Berini, the paren awarded a piece of tana' ulen as a sign of respect to a war leader who returned victoriously. The management of the tana' ulen by and for the paren with the labour of the panyen was based on a number of considerations. First, only the paren were permitted to build houses of hard wood. In fact, it was believed that only the paren were able to handle the bali (spirits) that inhabited hardwood trees. The panyen thus were only allowed to use soft wood or bamboo. The tana' ulen was located in forest areas with an abundance of hardwood, which could only be harvested for the benefit of the paren. Second, the paren were responsible for entertaining guests to the village, while the panyen hunted, fished, and harvested vegetables in the tana' ulen for these feasts.

During the 1963-1964 Confrontation between Malaysia and Indonesia, the management practices relating to the tana' ulen changed drastically. The soldiers of the Indonesian Army who were assigned to the border area together with some local people often entered the tana' ulen of the upper Bahau (where observation posts had been established) to hunt or look for food. The paren could not object because they were afraid of the armed soldiers. Gradually, the collection of forest products in the tana' ulen came to be viewed as normal by the people, and the rules for managing the tana' ulen were increasingly ignored. In the early 1960s, the tana' ulen finally changed status and became village-rather than paren-owned and referred to as tana' ulen leppo'. This change was subsequently reinforced by a decree of the provincial government of East Kalimantan in 1967 that further eroded traditional controls over land. The tana' ulen leppo' then was protected and carefully managed for the common interest of all villagers, because it served as a source of supplies and a reserve for meeting the villagers' needs for natural resources, such as construction materials, foodstuffs, and economically valuable non-timber forest products.

\section{Tana' Ulen Leppo'}

The management of the tana' ulen leppo' by the village is guided by a number of rules that are strictly adhered to by all villagers. Forest products are collected at certain times, referred to as buka ulen, which do not follow the calendar as does the farming cycle. The collection is specifically intended to benefit the village, as for example, in the case of construction wood for a church or a meeting hall (BPU, Balai Pertemuan Umum). Some villages have allowed exceptions for those of their citizens who needed construction wood for building houses or making boats with the provision that they obtain permission from the village head. The same applies to the collection of rattan, eaglewood, and cinnamon by the villagers for sale to the toké (trader-dealer), an activity that is organised by the village head together with the local government apparatus. The buka ulen activities are planned in a village meeting, from the beginning to the sale to the levying of a fee to be paid by the toké.

The meeting of village leaders and adat elders discusses the location, types of non-timber products to be harvested, and the number of days needed for buka ulen. If the market price of NTFP rises, a meeting on buka ulen is held by the village. The money obtained through buka ulen is used to support village activities. At the time of buka ulen, all citizens have the right to enter the tana' ulen to ngusa. They can sell their harvest directly to the toké, the purchasing or collecting dealer. Demands for 
fees for the village treasury (kas desa) are handled directly by the village leadership, who contact the toké. People from other villages who wish to ngusa must pay a tax of $20 \%$ of the revenues obtained from the sale of their products to the toké. This tax is used as follows: $10 \%$ to the village treasury and $10 \%$ to the families of the paren for their service in creating the tana' ulen leppo' of the village.

Certain very strict prohibitions exist: villagers may not go ngusa (here, harvest NTFPs) in the tana' ulen outside the time of buka ulen; people from other villages may not enter without permission from the village head or leaders, at the time of buka ulen and at any other time; cutting young rattan or felling young cinnamon trees is strictly forbidden. Violations of the rules of tana' ulen leppo' meet with sanctions that are appropriate to the type of violation and take the form of fines paid to the village. Every individual who violates the rules is fined a machete, which will be used in other activities for the benefit of the village, or will be sold and the money added to the village funds. Violations by outsiders are more heavily punished. The same is true for violations by the paren, and village leaders, because they come from families that sponsored the creation of the tana' ulen leppo', that is, a group that should serve as a model for other villagers.

From 1969 to the 1970s the rules for managing the tana' ulen leppo' became more and more relaxed in the Bahau River area. A local adat figure took the opportunity to relax the rules for all villagers, allowing them to take hardwood for building houses and making boats. This attitude, backed by considerations of equality of all citizens (including the non-paren), has elicited favourable as well as unfavourable reactions among the paren of several other villages.

\section{Tana' Ulen at Present}

Since 1978, the condition of the tana' ulen in the subdistrict of Pujungan has given increasing cause for concern. Heavy market demands have enticed many collectors of NTFP (primarily eaglewood) from downriver to the area. These do not only come to ngusa in the open forest belonging to the villages of the subdistrict, but they also trespass into various tana' ulen leppo' areas. The large number of outside collectors puts pressure on the local people to collect eaglewood themselves, not only in the open forest but also in the tana' ulen leppo' of their own village, without heeding their management rules. The tana' ulen leppo', which initially had social and economic functions, shifted more and more to only an economic function. Tana' ulen leppo' is promoted as a promising area for forest products and a source of cash income for the village through fees.

The fees charged to outside eaglewood collectors are Rp. 5000 per individual and Rp. 50000 per group. This tariff applies to NTFP collectors who ngusa in the open forest of the village, while for collecting in the tana' ulen leppo' they are charged Rp. 50000 per person. The amount of the fee varies among villages. In practice, many types of transgressions are common. For example, outsiders who, in fact, make up several groups, only pay Rp. 50000 posing as one group for one entry into the tana' ulen leppo'.

Trespassing on the open forests and the tana' ulen leppo' by groups of outside eaglewood collectors, now a frequent occurrence, results from collusion between outside traders and local leaders through rather large payments for lining the latter's pockets. In 1992-1993, there were also several cases of trespassing on the tana' ulen leppo' of a particular village by eaglewood collectors from other villages who were sponsored by 
an eaglewood dealer. In addition, there are many cases of villagers entering the tana' ulen leppo' of their own village without authorisation.

As a result of these unauthorised entries, the potential for NTFPs, especially of eaglewood, in various tana' ulen leppo' in the subdistrict of Pujungan has already declined. Of the subdistrict's 21 villages, only the village of Long Pujungan proper has begun to revive the management rules for its tana' ulen leppo'. In 1990 the village established a Tana' Ulen Committee, charged with helping the villagers and the village leadership in monitoring the condition of the tana' ulen leppo' as a whole, with regard to both land conditions and the resources growing on it. The responsibilities of the Committee include taking action against violators of the tana' ulen leppo' management rules, both fellow villagers and outsiders; setting the time for buka ulen in cooperation with village leaders and adat elders; collecting the fees for forest products (timber and non-timber) from the dealers (toké) who purchase or collect them from the local people; and reporting to the people in a village meeting at the end of the year.

\section{EAGLEWOOD IN THE SOCIAL, ECONOMIC, AND CULTURAL FRAMEWORK}

The economic life of the people of the subdistrict of Pujungan is supported by the agricultural sector, including cash crops, animal husbandry, and the trade in forest products. The people's primary enterprise is farming, specifically rice growing in dry and wet fields, as well as secondary crops, reinforced to a limited extent by commodities such as coconuts, cloves, coffee, pepper, and cocoa. The crops grown are consumed by the people themselves, because of the lack of markets. Thus, even the coffee and the cocoa, which for several years were promoted by the government, are not bought by traders. The problems faced are difficulties of transportation to marketing centres and lack of technical guidance from the government, so that the harvest from perennial plants only remains a promise but does not yet produce money. Pig and goat farming is for local consumption and poultry (chickens and ducks) is sold to visitors only occasionally and in small quantities. The produce of game hunting (wild pigs, deer, and others) and the fish catch usually are also intended only for local consumption, except for those that are routinely sent from the village of Long Pujungan to the toké in Long Peso'. This actually has greater potential for generating cash income than livestock cultivation.

\section{Eaglewood Collectors and their Organisation}

Under these conditions, it is reasonable that forest products have become a major source, relied on for meeting daily needs. Local people practise shifting cultivation agriculturalists and traditionally have collected eaglewood in their free time between farming activities. For some Kenyah people, however, these activities have now become a permanent full-time profession. Thus the people of the subdistrict of Pujungan (see Table 5.2) must be distinguished between professional eaglewood collectors, who collect throughout the year and do not farm, and occasional eaglewood collectors, who only collect in their spare time between other activities, such as farming, teaching, or office work (civil servants).

In addition, a number of outside eaglewood collectors, usually professionals, are operating in the subdistrict. Some of them have come from the downstream areas of the Kayan River (hundreds of people), and some have come by plane from the districts of Lumbis (30 people) and Malinau (25 people). It is difficult to determine their numbers 
Table 5.2 Local eaglewood collectors in Pujungan Subdistrict

\begin{tabular}{lccc}
\hline Village (Desa) & \multicolumn{2}{c}{ Numbers of Collectors } & Total \\
\cline { 2 - 3 } & Active & Occasional & \\
\hline Long Puj ungan & 25 & 5 & 30 \\
Long Sa'an & 10 & 2 & 12 \\
Long Ketaman & 20 & 3 & 23 \\
Long Pua' & 1 & - & 1 \\
Long J elet & 12 & 1 & 13 \\
Long Apan Baru & 20 & 3 & 23 \\
Long Lame & 15 & - & 15 \\
Long Pelian & 20 & 2 & 22 \\
Long Belaka & 26 & 2 & 28 \\
Long S. Bawang & 12 & - & 12 \\
Long Bena & 10 & - & 10 \\
Long Uli & 12 & 2 & 14 \\
Long Tebulo & 10 & 1 & 11 \\
Long Alango & 26 & 7 & 33 \\
Long Lat & 2 & - & 2 \\
Long Berini & 10 & 1 & 11 \\
Long Aking & 5 & - & 5 \\
Long Atua & 1 & - & 1 \\
Long Pengayan & 11 & 1 & 12 \\
Long Tua & 1 & - & 1 \\
Apau Ping & 10 & - & 10 \\
Total & $\mathbf{2 5 9}$ & $\mathbf{3 0}$ & $\mathbf{2 8 9}$ \\
\hline
\end{tabular}

with any precision. They are employed by several toké and have a rather complex work coordination and strategy. Overall-and seen from several angles (such as capital, organisation, numbers)-the eaglewood collection in the subdistrict of Pujungan is dominated by professional collectors from outside.

The local people can only enjoy the forest products as a source of boards (for construction) and food. With regard to income generation, however, they do not benefit significantly from NTFPs (such as eaglewood, rattan, and cinnamon) with a high economic value. Even though nowadays, a large-scale business in NTFPs has developed (especially in eaglewood), the eaglewood collectors among the local people are not yet able to enjoy to the fullest the results of this growth, because they are faced with problems of capital, which eventually also afflict the outlet organisation.

A KUD (Koperasi Unit Desa or village cooperative) managed by the subdistrict only sells a few staple products that are daily necessities. The people are not yet organised or given training on the role of the KUD in supporting the village economy, and they see the KUD only as a small shop. To enable the people to benefit directly from the existence of a KUD, it would be better to transform the KUD into a venue for business of the local people by establishing a management system and setting quality and price standards in a situation of open information. 


\section{Social and Cultural Factors}

The socio-cultural background plays an important role in eaglewood-collecting activities at the subdistrict level. The domination of these activities by professional collectors from downriver areas often causes problems. For example, in several villages, such as Long Apan Baru and Long Ketaman, a dilemma developed between economic competition and feelings of village cohesion when it became known that a group of people of the same ethnic group from Long Peso' had come to the village to look for eaglewood in the forest around the village. The news forced local villagers to rush to the forest to ngusa before the eaglewood on their own village lands was finished by the outside collectors.

Farming activities are only undertaken by women and old people, while the men who are still strong collect eaglewood. The sex ratio is no longer balanced because many young men go to school in the towns or go to Sarawak to earn their living. This means that the farm work is neglected and does not produce optimal results. Furthermore, communication is obstructed by the long distances between the villages and the subdistrict capital; transportation is difficult and expensive, especially to the market centre at Tanjung Selor; much time, energy, and money are required. Thus, in general, the socio-economic condition of the people may be described as worrying.

Male workers who live in the villages are gradually shifting from farming to eaglewood collecting, not only because eaglewood guarantees tempting money, but also because the local institutions are increasingly weakening, especially those related to forest management rules. Today, the traditional social groupings no longer officially exist among the Kenyah, yet the village heads throughout the subdistrict continue to be members of the paren class, who still are very influential in various economic matters, such as determining the location of fields, managing the tana' ulen leppo', and regulating the collection of forest products, both in the interest of various villagers and in the common interest. Usually the panyen agree to the wishes of the paren in matters relating to the interests of the village.

\section{Ceremonies, Prohibitions, Taboos}

The Kenyah and the Punan of the subdistrict of Pujungan generally are familiar with a variety of ceremonies and taboos related to the collection of eaglewood. Yet, only a small number of the people, especially the occasional collectors of eaglewood, still observe them, while the others simply are of the opinion that the eaglewood business is not exempt from fate-good luck or bad luck. Therefore, the eaglewood collection methods differ greatly among collectors, individually as well as by groups.

The melewa (Kenyah) or tapo (Punan) ceremony is held, among other occasions, before departing to collect for eaglewood. The leader of the ceremony and the participants who will go to the forest wear black shirts and pants. A cock is killed, a wooden stick sharpened and its tip split (ngelebu), and a chicken feather is then slipped into the split tip. A prayer is uttered (Punan Benalui): 'Go, wood, ask him for eaglewood, he the god of the land, the god of the mountain, the god of the tana' ulen, the god of hills, the god of mountains, the god of water, the god of springs. When you come back looking for an offering, I will give you wood shavings, I remind you, so that one or two of the trees that I will fell have something [eaglewood] in them. I give this to the tapo [the split wooden stick] because I ask to become rich, I ask for good luck, for prosperity, I ask for eaglewood, I ask it of you, I, a lowly human, a poor man, without money, without ringgit, without even one. I only give you this pure white chicken, this rooster, 
this chicken for help.' The base of the wooden stick is thereupon stuck into the ground and only then may the eaglewood collectors depart for the forest.

A group of Kenyah in the subdistrict of Pujungan still believe in and adhere to various taboos. The night preceding their departure, eaglewood collectors are prohibited from associating with women, from using coarse language or scolding, because looking for eaglewood is considered a sacred task that tests one's fate in the forest. If the house is dirty, the eaglewood collector may not sweep it, because garbage in the house must be left scattered like the eaglewood is expected to be found scattered in the forest. There is also a belief that all plans are known to the gods who bring good or bad fortune, and if some member of a group is prevented from departing on the set day the entire group must abandon their plan and make a new plan for another day so that the god does not abandon his readiness to protect the group.

If some object has been left behind in the village and this is only discovered when the group is approaching the forest, it is forbidden to go back for it and the trip must be continued. It is believed that good luck has followed the collectors since they left the village, and if anyone returns, the good luck also will go back and will not accompany them further. In collecting for eaglewood, the members of a group must go in the same direction, they cannot disperse in opposite directions. It is also advisable to look for eaglewood from downriver going upriver, because the hoped-for good luck is believed to follow the course of the river. It is prohibited to catch fish in the river with tuba poison, because the tuba root, which smells rather sharp, might annoy the accompanying gods, angering them so that they will bring disaster down on the collectors. If the collectors find high quality eaglewood, they must remain quiet; it is forbidden to brag, because the gods who have accompanied them from the beginning do not like conceit in men.

\section{EAGLEWOOD COLLECTING PRACTICES}

The people downriver who have long gathered eaglewood and traded it via middlemen have extensive experience in the eaglewood business. Even though the Kenyah have been farmers since the old days and have collected eaglewood only in their free time, there have also been a few Kenyah in the subdistrict of Puj ungan who have traditional knowledge of the physical characteristics of eaglewood, because they have been familiar with the eaglewood trade since their youth. These characteristics can serve as a guide to determine whether a tree trunk is already old or still young, and contains eaglewood or not.

\section{Selecting an Eaglewood Tree}

The first step is to determine the type of eaglewood (sekkau tengun, sekkau baya', or sekkau nyibung), according to the characteristics discussed earlier. The chances of finding eaglewood and the possible amounts of eaglewood differ among the various species.

The eaglewood tree that can be expected to contain the sought-for substance is usually relatively old and has the following characteristics: the trunk is dark brown, with black lines and moss, and its leaves are dark green or yellowish (if the tree is sick and almost dead). This type of tree shows traces of machete or axe cuts, broken and dead (dry) branches due to high winds, and holes made by black ants. A young tree usually has light green leaves, whitish bark, and white wood. Tree height and trunk 
size do not warrant the presence or absence of eaglewood, because they depend on soil conditions.

To determine whether the tree contains eaglewood, the tree trunk can be cleared of bark for a length of one meter. The presence of broken fibres in the tree bark indicates that eaglewood is present and the tree can be cut down at once. If the fibres of the trunk bark are strong and unbroken, on the other hand, it is clear that no eaglewood is present, and the tree need not be felled. This method is only used by a group of eaglewood collectors from the village of Long Uli. Another method often used is as follows: A cut is made into the tree trunk to a depth of half its diameter. This is best done from the direction opposite to that in which it leans so that the pith is encountered quickly and the tree does not topple. If the pith is damaged or thick and black, eaglewood is present, and the tree can be cut down.

Yet, the traditional knowledge of these characteristics or indications of type, age, and presence of eaglewood in a tree, in fact, is rarely used in making the selection. This is due to the nature of the eaglewood collectors who allow themselves to depend more on fate, and therefore often hesitate to take decisions about whether to fell a tree or not. Thus, even though the indications based on his knowledge are sufficiently clear, a collector who cuts into a tree and does not find eaglewood does not immediately abandon the tree. He still fells the tree, because he wants to search for eaglewood in the branches and twigs, because it is just possible that fate may smile upon him and he may find eaglewood there. This has the result that thousands of eaglewood trees are felled, of which only a small number will bring profit to the collector.

Furthermore, if he does in fact find eaglewood, the black parts of the wood are taken and carried to the hut, and there shaped and separated into black, brown, and white pieces (see Figure 5.4). This process can also be carried out at home. After carrying home his eaglewood, the collector's next step is to sort the pieces according to class or quality for marketing. This sorting is not final, and the classifications are necessarily changed when the produce is sold to the dealer (see Figure 5.5), a resourceful speculator who bargains and manipulates the grades and the prices, in the end significantly defrauding the eaglewood collector.

Figure 5.4 Collectors checking and cleaning their produce

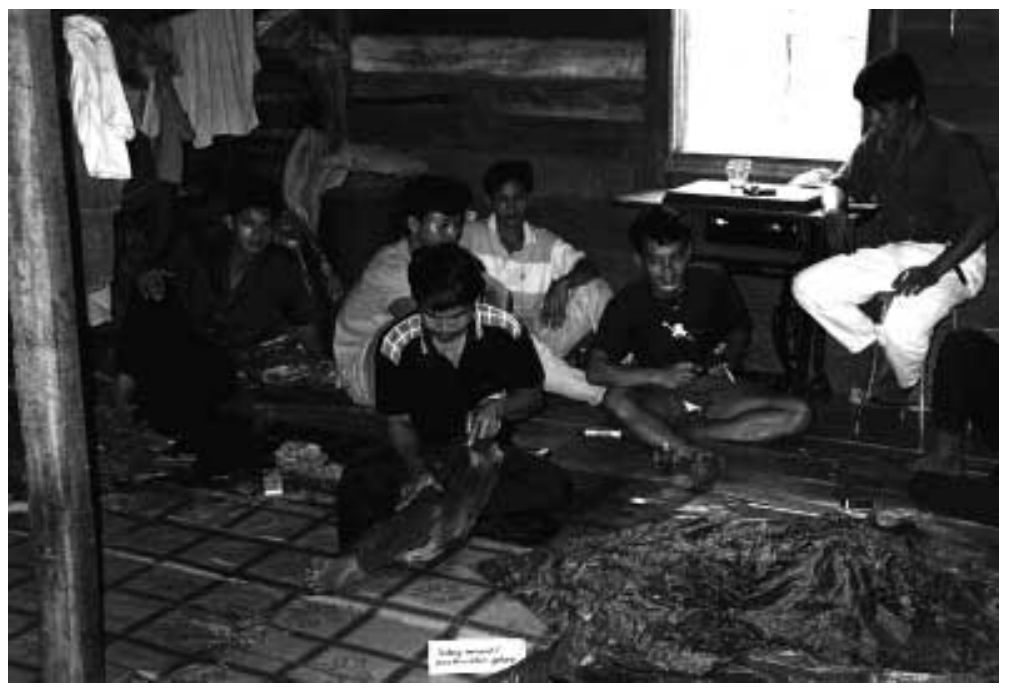


Figure 5.5 The toké sorting the eaglewood into grades

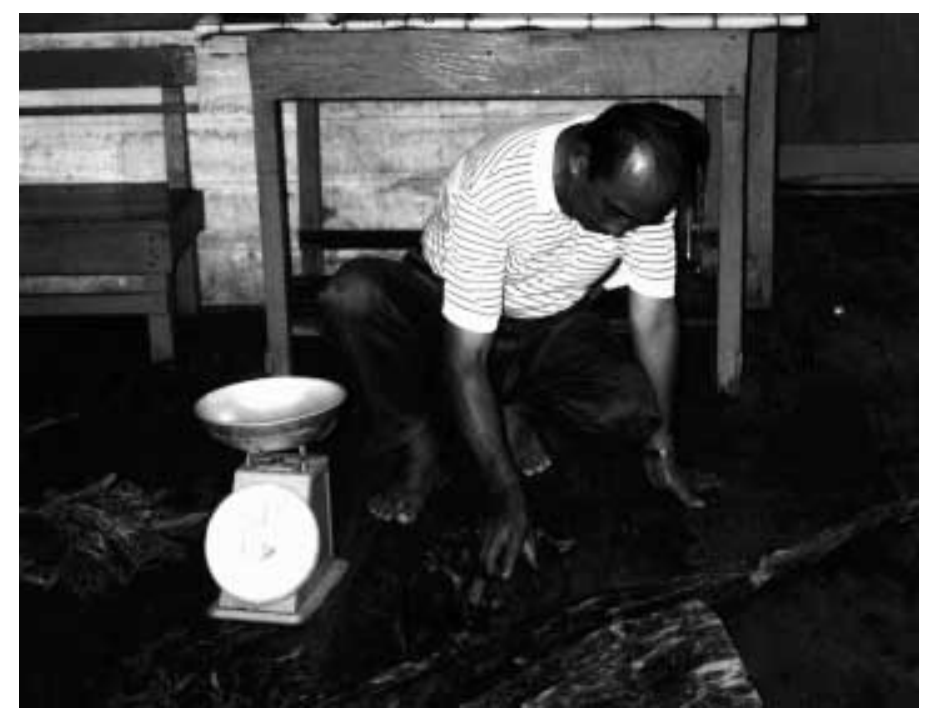

\section{Tactics of the Professional Collectors}

The coming of professional collectors from outside has unsettled the people of the subdistrict of Pujungan. In order to confound the villagers whose forests they are about to enter, and to avoid taxes or fees levied by the village involved, the professional collectors attempt to find an indirect route going several tens of kilometres upstream. First, they enter the forest of another village in the downstream area of the subdistrict, then they walk through the forests of several other villages in the subdistrict and they only stop to ngusa eaglewood when they reach the forest area of the intended village.

For example, in J une 1993, a group of eaglewood collectors from the subdistrict of Long Peso' wanted to ngusa in the Buing River area, which is part of the tana' ulen leppo' of the village of Long Ketaman. To deceive the villagers of Long Ketaman, they entered from the Puling River, which is the tana' ulen leppo' of the village of Long Apan Baru, and then walked through the forest along the Puling River, past the forests of Long Puj ungan village, until they arrived at the Buing River, which they then followed upstream.

In a similar manner, in July 1993, a 30-man group from the subdistrict of Lumbis walked through the forest lands of Long Peliran village and through the Aran River area in the territory of Long Apan Baru village, and finally entered the tana' ulen leppo' of the village of Long Pujungan in the Ahan River area. After ngusa there for one week, they were discovered and arrested by the people of Long Pujungan.

\section{Disappearance of Eaglewood Trees}

Observation on the Panen River, near Long Pujungan village, indicates that every day for every eaglewood collector, only 15 trees are cut part way or perforated, while 20 trees are cut down or fall down. In fact, not all the trees that are felled provide the hoped-for results. In the Panen River area, a number of trees with traces of machete and axe cuts can be seen. Some still stand firm, others are leaning from the effects of high winds, and many more eaglewood trees have been cut down. 
It is difficult to calculate with precision the number of trees that have been felled by eaglewood collectors throughout the subdistrict of Pujungan. Yet, on the basis of data on the number of collectors and the frequency of their activities while in the forest, the number of trees cut can be estimated at between 250000 and 750000 per year. This means that the eaglewood tree is in the process of disappearing.

\section{THE ROLE OF TRADERS IN THE EAGLEWOOD MARKETING NETWORK}

It is not easy to become a dealer or a trader in forest products in the interior of Kalimantan. To succeed in this profession, it is not enough to rely on capital and other facilities, such as storage houses for forest products and manpower trained in marketing. A man must also have the 'soul of a trader', that is, the will, the spirit, and the determination to work hard, and the courage to take risks-nonmaterial types of capital. Another equally important factor is skill in maintaining relations with other traders, workers (labour), the government, and the social environment in the business area.

\section{Authorisation}

The tricks of the dealers and traders in forest products have a significant effect on the local institutions that regulate the management of forests and forest products in this area. Generally, the greatest emphasis is placed on the trade negotiations, at district level, with the Tripika (including the subdistrict head, the local chief of police, and the local military commander). The subdistrict leadership issues licenses to anyone for carrying business in eaglewood anywhere in the Pujungan Subdistrict area. This means that adat figures and informal leaders do not play a significant role in forest product management activities. Some adat figures not only fail to act firmly against violators of forest resource management rules in their area, but they themselves are responsible for the violation of those rules.

For example, a well-known individual, $X$, from village $Z$ granted permission to a professional collecting group from outside to do business in eaglewood in the forest area of the village of $Z$, both in the open forest and in the tana' ulen leppo'. In addition to the fees, this group also paid the party who gave permission a certain amount of money that subsequently was not surrendered to the village treasury. When this was discovered, extended unrest among the people of the village of $Z$ developed and finally ended in popular indifference toward $X$ and his leadership. As a protest and because of their need for cash, the people of $Z$ then consciously and intentionally began trespassing on the tana' ulen leppo', in disregard of the forest management rules.

The attitude displayed by $X$ is also viewed as destructive of earlier patterns of social life. As a result, the enforcement of forest management rules is increasingly slack, and many of the rules have stopped functioning altogether. A further result is the growing weakness of the role played by adat institutions in village society in the subdistrict of Pujungan.

\section{Eaglewood Marketing Channels}

The influence of traders on the Kenyah's forest management strategy and activities is apparent in the intensity and the frequency of eaglewood business activities. Initially, eaglewood for marketing purposes was only attractive to a small number of traders from downriver areas, who purchased and stored the eaglewood in Long Pujungan and in Long Bia (subdistrict of Long Peso') prior to export. 
Recently, the eaglewood business in the subdistrict of Pujungan has become much more lively and has attracted a number of outside traders who go directly to the villages to buy eaglewood. They not only wait for the villagers to sell their eaglewood harvest, but they also send out tens of groups to collect for eaglewood. These groups are in and out of the forest for weeks at a time, and even for as long as two to three months.

Eaglewood collectors are operating from Long Bia, Long Peso', and Long Bang (subdistrict of Long Peso'). In Tanjung Palas there is also a large-scale trader, while Tanjung Selor (capital of the district of Bulungan) has not less than seven, some of them of Chinese descent and others of Arab descent. The marketing network in the lower Kayan River area, too, is linked to a large-scale eaglewood exporter in Tarakan. Cooperation between traders from the subdistrict of Pujungan thus extends as far as Tarakan and forms an intricate eaglewood-trading network.

\section{Labour and the Credit System}

For a better understanding of this network stretching from the village to the marketing centre, it is necessary to describe the organisation of eaglewood collecting, that is, the expeditions that are arranged by dealers and the form of the dealers' relations with the workers, both outside and inside the subdistrict of Pujungan. One trick that traders use in order to employ as many eaglewood collectors as possible is to give them loans of goods and supplies on the basis of what are generally known as bon or 'notes' (i.e., credit). The collectors are expected to repay these loans in the form of eaglewood after their return from their expeditions. The debts, however, can only rarely be paid promptly, and thus the collectors are tied to the trader by these debts and forced to continue to collect eaglewood for that trader. In this way, the dealer attempts to obtain a labour monopoly on as many local workers as possible.

A 'general' (or group) note covers the needs of a group for food, medicine, kerosene, gasoline, cigarettes, batteries, raincoats, shoes, and alcoholic beverages (whiskey), as well as essential cash. The amount of the notes varies with the needs of the groups and the length of time that they plan to be in the forest. It can total as much as Rp 2 million for one entry by the group into the forest. Cash is also provided individually on a personal note, in amounts between Rp. 50000 and Rp. 500 000. Prices of goods provided on the basis of a note, either personal or group, usually are higher than they would be if the goods were paid in cash-sometimes as much as double.

In addition to providing the supplies for entering the forest, traders also accept personal notes for other goods. For example, while the eaglewood collector is in the forest, his family (wife, children, or parents) may pick up daily necessities on the basis of a note to enable them to surmount any cash shortage and make ends meet. Household goods, such as pressure lamps, boat engines, or even bicycles, radios, and cassette players, as well as televisions, may also be obtained on the basis of a note. The note system thus is already commonly accepted among eaglewood collectors.

In the subdistrict of Pujungan, the system of paying off notes to the trader with eaglewood leaves many eaglewood collectors' families trapped in their debts. If they cannot pay their debts, the goods that they have obtained must be returned. The case of a group of eaglewood collectors of the Punan Benalui sufficiently demonstrates the pressures and the dependence resulting from the note system. Unable to pay off their debt with eaglewood, they were forced by trader $Y$ in Long Puj ungan to return the five boat engines previously provided by him. 


\section{Relations with the Eaglewood Collectors}

Because of the existing note system, work relations between the trader and the eaglewood collectors resemble a patron-client relationship, in which the eaglewood collector is in a weak position, because he is resigned and forced to do whatever the trader wants. Caught up in the note system, he is forced to go to the forest repeatedly just to enable himself to pay off his debts. Thus, the frequency of expeditions is closely related to the note system. Farm work is necessarily neglected, resulting in declining harvests. The health of families also does not receive adequate attention because the responsibility for caring for the family is left only to the wife.

The tricks of the traders in maintaining relations with eaglewood collectors are also apparent in their efforts to transport them to and from the forest in longboats. Two stopover posts (in Long Pujungan and Long Apan Baru) have been established by traders from the subdistrict of Long Peso' as locations for local dealers who serve as an extension of the traders' reach. These posts function to meet the needs of the traders' employees from downriver who are operating in the subdistrict of Pujungan. If they run short of supplies, fall ill, or have an accident, the toké in that post will take care of everything. The posts are also used to arrange the transmission and receipt of information relating to the movement of eaglewood collecting groups.

The dealers also attempt to create a moral dependence on the part of the eaglewood collectors by establishing informal associations of an incidental nature. For example, during the commemoration of the anniversary of Indonesian independence on 17 August 1993, eaglewood collectors who worked for toké Z formed a sports team. All their expenses of registration, uniforms, and shoes, as well as a number of prizes for the teams, were paid by $Z$.

\section{EFFECTS OF THE EAGLEWOOD MARKETING NETWORK}

Even though there have been shifts in values and changes in rules, the forest management practices used by the Kenyah in the subdistrict of Pujungan in their tana' ulen leppo' bear proof that the rural people in the interior of East Kalimantan have local institutions that since the old days have played a role in the preservation of forest resources. This is in line with the statement of Poffenberger et al. (1990) and of Alcorn et al. (1990) that fundamentally the rural people have long carried out traditional conservation activities. The practices for managing the tana' ulen leppo', including the management of eaglewood, have been heavily influenced by the traditional social cultural background, among others, the social structure, the traditions and customs, and the belief system of the past (see Cernea 1988 and McKinnon and McKinnon 1990). The Kenyah's management of the forest generally and of eaglewood in particular represents a means of adapting to the forest environment.

As a system, human ecology has several component parts, such as the natural environment, humans interacting with the environment, and the methods-or the culture-of that interaction. In the management of eaglewood, the environmental component is the forest, with its promise of both timber and non-timber resources. To obtain the necessities of life, the people use their environment according to their local knowledge of existing forest resources, and they also manage the forest according to their local customs and belief systems. The efforts to manage the forest resources are an adaptation strategy of the local people to enable them to live by using the resources in their local environment. 
Changes in rules and shifts in values that now affect the management of the tana' ulen leppo' are the result of intervention by outside forces, that is, the eaglewood marketing network. In fact, the Kenyah since long ago have had contact with outside parties through the forest product trading network. This contact became more intensive and easier at the beginning of the 20th century as a result of the military expeditions of the Dutch government, which succeeded in pacifying the interior by reducing the interethnic fighting and weakening the headhunting tradition. Later, as the value of money became known-it was used for commodities that could not be produced by the people themselves, such as salt, sugar, tobacco, clothing, and others-in village life, the isolation of the interior region decreased steadily and a new way of life began.

As mentioned earlier, the eaglewood business initially was a side occupation for the farmers, undertaken in spare time between their farm work. Nevertheless, in response to high prices and growing market demands, these activities were pursued more and more intensively so that they became a basic source of livelihood for the local inhabitants. Dealers from downriver areas not only maintained local trading channels, but also sent in hundreds of eaglewood collectors from downriver. The changes in the eaglewood management practices in the end had their own impact on various aspects of community life, including sociological, economic, and ecological aspects.

\section{Sociological Aspects}

Initially the management of eaglewood followed the management practices used for the tana' ulen, which later changed into tana' ulen leppo'. Nevertheless, in fact, at present the devices used by traders to obtain eaglewood are not limited to trade relations with sellers. The field situation shows that cooperation between dealers and the subdistrict leadership, the police (POLSEK), and the military (Koramil) is diversifying into the eaglewood trade. The same type of cooperation has spread to village leadership and the adat leadership, as well as to informal community leaders such as elementary school principals. This has resulted in blocking the channels by which the people can pass up information regarding problems that they face in the fight over forest resources-such as eaglewood-which occur because of competition by the eaglewood collectors from outside.

At the village level, certain well-known leaders and adat leaders are in collusion with the traders, for example, in the issuing of permits. In addition, complaints by the people to the subdistrict leadership regarding violations by the outside eaglewood collectors are ignored. In fact, according to district leaders, eaglewood grows on its own in the forest, and everyone is free to deal in it. The people, who are facing economic pressure and are in need of cash, become irritated and restless because their complaints are ineffective, while the outside eaglewood collectors continue to come. In part to deal with their irritation, the local people, who in fact clearly understand the rules for managing the tana' ulen leppo', now intentionally violate these rules by ngusa eaglewood not only in the open forest but also in their tana' ulen leppo'. The function of the tana' ulen leppo', which formerly was social as well as economic, thereby has contracted to an economic function only, because the tana' ulen leppo' is promoted as a source of fees for the village treasury without regard for the future potential of its natural resources.

The sociological impact of the eaglewood trade network thus is evident in the vanishing authority of and respect for some of the adat notables as individuals fully responsible for maintaining social order, and in the growing weakness of the role of local institutions in forest management. Another sociological impact is seen in the 
labour problem. Because of the appearance of hundreds of eaglewood collectors from outside the subdistrict, competition for work among local collectors and newcomers has developed. Because they feel that the forest and its products-which it has always been their right to work-have been taken over by outsiders, many young people have dropped out of school and have gone to Sarawak to find work. This has had a demographic impact, leaving an imbalance in the demographic ratio between men and women. There are many women without husbands (spinsters), as well as many balu ('widows') who live alone, not because their husbands are dead, but because they went to Sarawak, married again there, and never returned (see Meyer in Eghenter and Sellato 1999).

\section{Economic Impact}

The area of the subdistrict of Pujungan holds great promise for eaglewood if it is managed well, but that potential is not of much significance for the life of the local population. The emergence of an eaglewood-marketing network has created labour problems and led to emigration to Sarawak. As a result, the productive labour available for farming is declining steadily. Many farming families consist only of father, mother, and daughters. They work increasingly smaller fields, so that the harvests continue to decline every planting season. Data obtained from the subdistrict office in Long Pujungan shows that in 1992 the farmed area amounted to about 128 ha with an average production of only $240 \mathrm{~kg}$ per ha. These figures really give cause for worry.

The most outstanding aspect of the economic impact is the indebtedness of the local eaglewood collectors, caught in a cycle of debts and repayments as a result of the note system of the dealers. Seen from the point of view of employment, the recruitment of local farmers to collect eaglewood is something positive, because it can help to reduce unemployment. If researched more thoroughly, however, the mechanism of giving and returning notes is very deleterious to the economic situation of the eaglewood collectors. The note system that has thrown many eaglewood collectors' families into debt also has shaped the work relationship between traders and eaglewood collectors until it resembles a patron-client relationship in which the client finds himself in a weak position and is forced to follow the wishes of the trader. Thus, the local eaglewood collectors are under increasing economic pressure; and as the number of notes continues to increase, their debts keep swelling, but their farming activities are more and more neglected.

Another factor that worsens the economic situation of the households of eaglewood collectors is the fluctuation in the market price of eaglewood and the lack of standardisation of eaglewood quality. In this area, the traders' tendency to determine themselves the quality of the eaglewood that they are buying has resulted in frequent cheating of the local eaglewood collectors. In the end, the benefits of eaglewood, which has significant potential on the export market, are not enjoyed by its original owners. In the writer's opinion, the emergence of the eaglewood marketing network in the subdistrict of Pujungan economically has not helped to raise the standard of living of the local people, but in fact, has tended to impoverish them.

\section{Ecological Impact}

The entanglement of the eaglewood collectors in the note system has forced them to enter the forest repeatedly and exploit the eaglewood business to the fullest. These activities have of course been affected by economic pressures, as well as by the weakening of the traditional social forces in the form of adat institutions and 
management rules for the tana' ulen leppo'. Ecologically, the large-scale eaglewood business with its limited, economic orientation is very dangerous. In agreement with Bennett's (1976) opinion, it may be said that the Kenyah in the subdistrict of Pujungan are experiencing an ecological transition in their interaction with the forest environment, as demonstrated in their harvesting of eaglewood.

Initially, the harvesting of eaglewood was based on the Kenyah's local knowledge and regulations. This included the manner of distinguishing eaglewood trees that were still young from those that were already old, and adherence to prohibitions of gathering eaglewood in the tana' ulen leppo'. In the end, however, the appearance of outside eaglewood collectors and the emergence of a eaglewood-trading network in this area brought many changes. Pushed by the desire for cash to pay off their notes and to meet various other necessities of life, the Kenyah became overexploitative in their eaglewood collecting activities. Not only did they no longer apply their traditional knowledge, but they even intentionally ignored the rules for managing the tana' ulen leppo'.

Furthermore, the ecological transition that the Kenyah are experiencing is also evident in the imbalance between the availability of the eaglewood resource and the population needing it, that is, the local eaglewood traders and the outside collectors who are routinely imported in large numbers by the dealers.

\section{CONCLUSION}

The benefits of the eaglewood forest product should be very marked in the economic life of the local people, but the existence of the note system has thrown the eaglewood collectors generally into debt, and the effects of the note system have tended to impoverish the local population.

At present, the principle of 'indiscriminate felling' that is influenced by a belief in fate, and the demands for paying off their notes have caused the eaglewood collectors to lose their ecological wisdom. This is highly damaging to the environment and to efforts to preserve nature, and is a threat to the very existence of the eaglewood resource.

The potential of the eaglewood resource in the subdistrict of Pujungan can no longer be fully controlled through the management rules of the tana' ulen leppo' of the local people, but tends to be controlled more by the marketing networks.

The appearance of eaglewood collectors from outside the subdistrict of Pujungan as part of a long chain of the networks of traders has a potential for conflict which significantly unsettles the local people.

Among the various deviations from or violations of the eaglewood management rules, some are committed by village leaders and adat leaders in collusion with traders and the members of the Tripika. This has caused a decline in the status of those figures and has weakened the functioning and the role of the local institutions in maintaining the eaglewood management regulations.

The involvement of members of the local Tripika in the diversification of business into the eaglewood trade has complicated the eaglewood trade and has worsened the economic condition of the people and the condition of the forest, especially with regard to the potential of the eaglewood resource.

The market situation in this area is not advantageous to the local eaglewood collectors because the market price is manipulated by the local traders in cooperation with dealers from outside the subdistrict. 


\title{
6.
}

\section{Traditional property rights over land among the Kenyah of Pujungan Subdistrict}

\author{
S. J acobus E. Frans L.
}

\section{INTRODUCTION}

The research into customary law conducted in the subdistrict of Pujungan in 1991 has its starting point in a question that all indigenous Dayak people of Kalimantan have often been asking lately: 'Is it true that land ownership based on customary or adat law can be recognised?' Today the easy answer is: 'Yes, it can be accepted if there is evidence.' In light of administrative practices dealing with land titles that have been in use so far, the formal judicial meaning intended by the term 'proof' or 'evidence' tends to be the land certificate issued by the Office for Land Affairs (known as Kantor Badan Pertanahan Nasional).

If this is really true, has all the land of Kalimantan already been certified as evidence of ownership of the land? The answer that we give will remain full of question marks unless some wise efforts are made to harmonise views of what 'is' and what 'should be.' Thus, the attempt to reconcile fact and theory, beginning with Articles 5, 2, 3 and 4 of Law No. 5 of 1960 on Basic Agrarian Regulations (UUPA), and Law No. 56 of 1960 on Determining the Area of Agricultural Land, requires focused research in order to answer the above question.

The Pujungan Subdistrict comprises two customary territories, the Pujungan Customary Land and the Hulu Bahau Customary Land. The inhabitants are for the most part from several Kenyah subgroups, as well as related groups such as the Punan, Pua', Nyibun, and Saben. Every customary territory consists of a number of smaller 
territories (village level). The writer carried out field research in both areas in 1991 and returned in 1993 as a field research coordinator. He focused on the general aspects of traditional land ownership. In the meantime, the writer's three colleagues, during their field work in 1993, looked at several specific aspects of traditional land ownership in three different Kenyah subgroups (see Angguk Lamis, Concordius Kanyan, and Y. Paulus Bunde, in this volume).

The research focus for this paper is the issue of land tenure among the Kenyah of the Pujungan Subdistrict. The research approach combined description and analysis to be able to clearly illustrate the facts at the time of the research as well as at the time of drawing the conclusions. As a sample, the writer selected six of the nine villages in the Hulu Bahau Customary Land, and an additional sample of four of the 12 villages in the Pujungan Customary Land. The author discussed directly with the people, traditional leaders, and customary chiefs from both customary territories by means of interviews; the author also visited the various locations in the field. In addition, the author used indirect communication techniques such as questionnaires (Figures 6.1 and 6.2).

Figure 6.1 Author conducting an interview in Long Ketaman

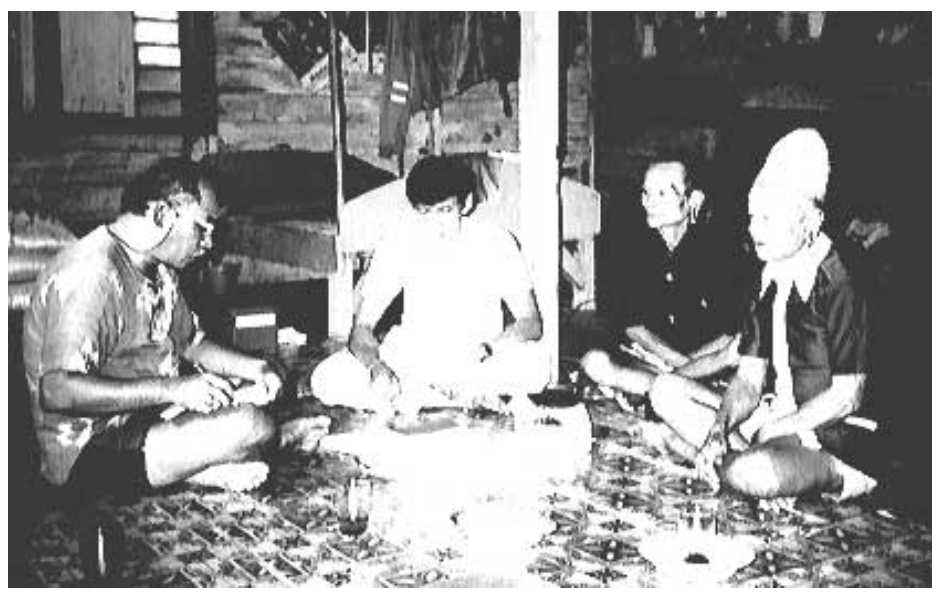

Figure 6.2 Old settlement site (lepu'un) at Long Ngiam

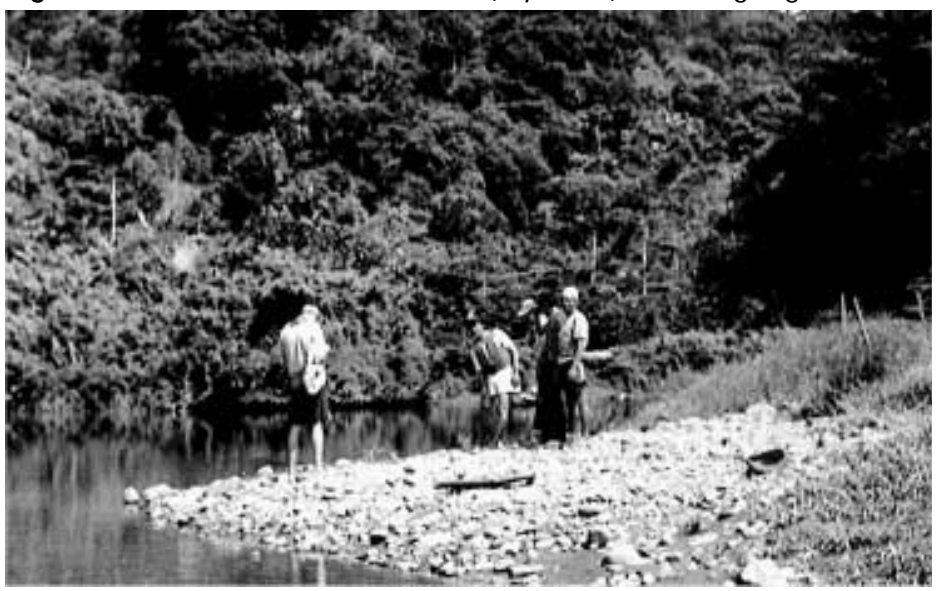




\section{SOCIAL STRUCTURE AND THE PLACE OF TRADITIONAL (ADAT) LAW}

The Kenyah of Puj ungan no longer live in longhouses, once the traditional living arrangements in the community. Nevertheless, the communal attitude present in the stratified social structure (see Liman Lawai in this volume), which has begun to disappear, remains evident in legal matters, such as marriages or violations of social norms of decency and good manners. Stratification in social life and social relations, however, does not appear to be an obstacle because, in relative terms, the Kenyah legal system no longer distinguishes between social classes.

Generally, Kenyah society was divided into three social levels, the paren (or nobility), the panyen (ordinary people), and the kulak or kula' (slaves). This was the case among the Kenyah Uma' Alim and the Kenyah Badeng. Yet, in several subgroups there were differences in the terminology of social classes and subclasses. For example, in the Hulu Bahau area, the Kenyah Leppo' Ké differentiated between datau pekukuk (original paren) and datau pebese (mother was paren and father panyen); and among the panyen they distinguished panyen tiga (well-known ordinary people) and panyen uma' or kelunan kadu (ordinary people). In the Pujungan area, the Kenyah Uma' Lasan differentiated between paren pu'ub (original nobility) and paren ma'ding (mother paren and father panyen), while the Kenyah Leppo' Ndang used the terms paren lai (da tau) and paren (tau). The Kenyah Bakung recognise paren pu'un (original nobility) and paren ma' ding (mother paren, father panyen), while they distinguish among panyen tiga (well-known ordinary people), panyen (ordinary people) and panyen ja' at (lowranking people).

In addition to social classes, the Kenyah also have customary or adat institutions divided into three levels, with related functionaries. In the Hulu Bahau area, the first level is the kepala adat bio' (or great customary chief) of Hulu Bahau; the second level is the kepala leppo' (or village chief); and with regard to the third level, the Kenyah Leppo' Ké and Leppo' Ma'ut recognise the pengela ta' adat or the pengukun (elders and well-known figures). The entire adat structure is referred to as penteneng adat leppo'. In the Puj ungan area, the first level is known as kepala adat bizu by the Uma' Lasan and Uma' Alim, and kepala adat bio' by the Leppo' Ndang, Bakung, and Badeng, that is, the Great Customary Chief of Pujungan. The second level is referred to as pengohon adat by the Uma Lasan and Uma Alim; tu' a leppo' by the Badeng; or tu'a-tu'a bio' by the Bakung. The third level is known as perava adat among the Uma' Lasan and Uma' Alim; tu'a uma' among the Leppo' Ndang; or tu'a penguma among the Badeng. The elders or other well-known figures are called pengelata adat by the Leppo' Ndang, or tu'a-tu'a penguma by the Badeng.

Adat functionaries have legal control of a specific area where they carry out the duties that derive from their position. The great customary chief, as head of an ethnic group and highest customary chief within a certain customary territory, maintains control of the ulen leppo', or the territory of a group that includes one or more villages (in line with Law No. 5 of 1979 on Village Government). For example, the Great Customary Chief of Pujungan covers 12 villages and the Great Customary Chief of Hulu Bahau covers 9 villages. The kepala leppo', tu'a leppo', tu'a uma', pengohon adat, tu'a adat, and perava adat, who ex officio assist the great customary chief, have legal authority over an area as extensive as their respective village territory within the customary territory. The pengelata adat or pengukun adat are the local adat officers who assist the village chief in upholding and applying local customary regulations. 
This general picture describing the social structure and the hierarchical levels of adat functionaries, as part of cultural history, reinforces the evidence that the Kenyah of Long Pujungan are an indigenous and customary law-based society.

\section{RECOGNITION OF TRADITIONAL INSTITUTIONS IN THE NATIONAL LAW}

According to Law No. 5 of 1979 on Village Government, customary institutions are equivalent or at the same level as the kepala desa or village chief. They are both part of the Lembaga Musyawarah Desa (LMD) or village council, which is headed by the village chief.

The existence of traditional or community institutions is defined in Article 17 of Law No. 5 of 1979 as follows: '(1) The village council is a venue for consultation/ discussion. Its members include village chiefs, the leaders of community institutions, elders and well-known figures in the same village.'

Law No. 5 of 1979 is very basic, because a large portion of the Indonesian people live in rural areas and their daily life, work and social interactions follow customary norms and moral norms known as adat-istiadat (traditions and customs). For this reason, adat and community institutions are highly effective for implementing village government if both can work together and are in harmony. In traditional societies, specifically among the Kenyah, these conditions still prevail.

In the meantime, Hilman Hadikusuma (1987) stated that 'allowing customary figures to participate does not mean to revive feudalism; respecting existing customary law will instead ease the way to development.' (quoted in Abdurrahman 1990: 35). This is especially the case if leaders and notables are part, as they should be, of these institutions, because a large part of the society, in fact, still values their customary institutions. Especially in rural areas far from easy reach of transportation and communications, adat institutions and adat notables play a very important role in creating and preserving a sense of security and order, and even of justice among the people.

This existence of adat institutions, customary laws and customs, and the traditions of a society based on law is in line with the philosophical bases or foundations expressed in:

1. The preamble 'Taking into account' of Law No. 5 of 1979, paragraph b, which states:

'b. whereas in line with the nature of the Unitary State of the Republic of Indonesia, the position of the Village Government has been made uniform as far as possible, by paying attention to the uniformity of village conditions and the integration of existing traditions and customs in order to strengthen the Village Government and enable it to mobilise the people for development and provide a broader and more effective village administration.'

2. The preamble 'Considering' of the Decree of the Minister of Home Affairs (PERMENDAGRI) No. 11 of 1984 regarding Guidance and Development of Traditions and Customs at the village level:

'a. whereas Law No. 5 of 1979 on Village Government only regulates aspects of Government while continuing to recognise the unity of the society based on law, on customs and traditions, and on persisting traditions as long as they support development and national security;

b. whereas traditions and customs that have grown and developed through centuries of history have made a valuable contribution to the continuation of social life, 
the struggle for independence, and the development of the Nation, the Region, and the Village.'

3. In the preamble 'Considering' of the Decree of the Minister of Home Affairs No. 17, 1989 regarding the Guidance and Development of Adat Institutions at Village Level:

'a. whereas Law No. 5 of 1979 on Village Government continues to recognise social unity including the unity of the society based on law, customs and traditions and existing traditions as long as they support the continuation of development and national security;

b. whereas customs and traditions are a set of values, norms and social beliefs that have grown since the beginning together with the development of rural population, are known, internalised, and practiced by the villagers concerned so that the traditions and customs that have been institutionalised within an adat institution can become more effective;

c. whereas the customs and traditions that have taken root and can support the continuation of development and national security shall be preserved, nurtured, and developed continuously;

d. whereas the goals and purpose of the 'Guidance and Development of Adat Institutions' are to enhance the role and function of Adat Institutions and preserve the traditions and customs (adat istiadat) within the Village.'

4. Paragraphs of Regulation of the Minister of Home Affairs No. 11, 1984:

Article 1 (paragraphs $d$ and e):

'd. Customs and traditions are habits that are alive and maintained in daily social interaction in line with Pancasila.

e. Guidance and development include all activities carried out in an effort to nurture and promote customs and traditions that support the continuation of development and national security, and do not conflict with the public interest and existing laws and regulations.'

Article 2:

'Nurturing and promoting traditions and customs are aimed at enabling these traditions and customs to promote and support the continuing development of national security within the concept of the Archipelago.'

Article 3:

'The nurturing and development of customs and traditions must be aimed at the promotion of national stability, in ideology, politics, economics and social-cultural matters as well as in the field of defence and security, and must support the smooth progress of the implementation of government, development, and social duties.'

Article 4:

'In an effort to preserve regional culture and enrich the national cultural heritage, government apparatus at all levels must nurture and develop customs and traditions which are alive and useful in development.'

Article 5:

'The head of the district as well as village chiefs and their officers are charged with nurturing and developing the traditions and customs that are alive among the people of their areas.' 
5. The First Edict of Instruction of the Minister of Home Affairs No. 17 of 1989: Determine regional regulations regarding guidance and development of adat institutions at village level as a guide to implementing Ministerial Instruction No. 11 of 1984 which regulates the following matters:

a. Undertake the inventory of existing adat institutions at village level and the reorganisation of the position, role, and function of existing adat institutions, making them more effective in the support of government, development and public life.

b. Regulate the naming and organisational structure of existing adat institutions alive in each area.

c. Regulate the inventory of financial resources and wealth of adat institutions which are used in support of the activities of these Institutions in the interests of implementing government, development, and social guidance.

d. Regulate the mechanisms that provide guidance and development for adat institutions in line with the conditions in various areas.

e. Determine the role and function of adat institutions in line with the goals and purposes which are expected to be achieved.'

For this reason, if good and harmonious cooperation exists between these two institutions, progress in village development will be easy to attain.

\section{THE LEGAL BASIS OF CONTROL FOR OWNERSHIP}

In 1945, when the Indonesian nation proclaimed its independence, which legally and constitutionally was reiterated on 18 August 1945, it stated that the territory of the Unitary State of the Republic of Indonesia covers the former colonial territory of the Dutch Indies from Sabang at the northernmost tip of Sumatra to Merauke in the easternmost part of West Papua.

According to theory, a state is sovereign if it controls people and territory, including land, sea, and air. For the Unitary State of the Republic of Indonesia, this matter was regulated in Article 33, Paragraph (3), of the Constitution of 1945, which states: 'The land and the water and the natural wealth contained in them is controlled by the state to be used for the maximum prosperity of the people.' The meaning of 'controlled by the state' does not signify that the state is the absolute owner of the land and the soil in the sense an individual can with ease buy and sell or change the status of land they own. In this connection, control as intended in Article 2, Paragraph (2), of Law No. 5 of 1960 on Basic Agrarian Regulations (UUPA) suggests that the state has the authority to (a) regulate and arrange the purpose, use, availability, and management of the land, the water, and space; (b) determine and regulate legal relations between people and land, water, and space; and (c) determine and regulate legal relations between people and legal activities regarding land, water, and space.

Authority that is based on the state's right to control as intended in Article 2, Paragraph (2) of Law No. 2 of 1960 is used to achieve overall prosperity of the people in the sense of nation, welfare, and liberty in the society and under the law of an Indonesia that is sovereign, just, and prosperous. The authority of the state is not an authority founded on the right of individual ownership. Viewing state authority as identical to individual ownership would result in a general view that sees everything within the borders of the Republic of Indonesia as belonging to the state. This would mean that the state through its administrators would be free to do anything. 
Here, the meaning of 'own' related to the meaning of region and the concept of archipelago in the general sense of the national administrative law is in fact that way. Ownership in the general sense, however, is not limited to land, water, and space but, individually, the citizens of the Republic of Indonesia, with all their property, also belong to the Unitary State of the Republic of Indonesia. On the other hand, however, if the view arises from civil law, the resulting meaning will be that found in Article 2, Paragraph (2) of Law No. 5 of 1960, which takes Article 33, Paragraph (3) of the Constitution of 1945 as its conceptual basis: 'It is clear that the state does not own, but controls.'

For this reason, land ownership among the Kenyah people, which is based on control because of discovery, control because of purchase, or control because of exchange is in line with the theory of territorial control by the state. If land ownership based on control of a region, area, or site that is judicially under adat law, then among the Kenyah this has generally been the case since long before Law No. 5 of 1960-the Basic Agrarian Law (Undang-Undang Pokok Agraria or UUPA)-went into effect, even long before the proclamation of Indonesian independence, and even before the occupation by Japan and by the Dutch, because the Dayak ethnic groups have been living on the island of Kalimantan since about 3000 to 1500 BC (Coomans 1987).

Customary law, an oral tradition that regulates control over land, is still recognised and the articles in the 1960 Basic Agrarian Law reflect the fact that customary law is one of the primary sources for the compilation of the regulations of territorial law in particular. Etymologically, the words of hak ulayat can be taken to mean: 1) hak is right/ claim in the sense of control; 2) ulayat is territory; so 3) hak ulayat is control/ right over territory. So, in relation to ownership over certain pieces of land, hak ulayat refers to the territory in which one society exerts control over land in accordance with customary law.

The literal meaning of the word ulayat originates in the Minangkabau language, and clearly, as such, is not found in the Kenyah languages. Nevertheless, the meaning of tanah hak ulayat in relation to land ownership according to traditional law is found in the Kenyah expression tana' ulen leppo'. It is the right to control land, or the right to a common territory controlled by a Kenyah ethnic group according to customary law, in both the broad and narrow senses. In the narrow sense, tana' ulen is limited to a certain area, as, for example, in ulen rattan, ulen timber, and others. In the broad sense, however, it comprises the entire area or territory of a Kenyah ethnic group, as, for example, in tana' ulen leppo' Kenyah Leppo' Ké, tana' ulen leppo' Kenyah Uma' Lasan, and so on.

On this basis, then, it may be concluded that among the Kenyah ethnic group, hak ulayat is the right of ulen leppo', or the territory controlled by common or shared rights of a social group in accordance with the customary law of that particular Kenyah group. It includes land, water, air, and the objects and creatures in or on it. The use of the term ulen leppo' is in line with the meaning of hak ulayat, which is referred to as '... other such laws' as found in Article 3 of Law No. 5 of 1960, which states that: ' ... the implementation of the hak ulayat and other such laws in traditional societies as long they still exist must proceed in such a way ...'

Therefore, if the patterns of land control according to traditional law as discussed above are connected to Article 4 of Law No. 5 of 1960, based on the state's right to control, then the rights over land that may be given to individuals or legal entities are differentiated as follows: a) right of ownership, right of use for construction, right of usage, right to rent, right to open land, right to collect forest products; b) right to 
pawn, right of sharecropping, right of tenancy, and right to rent agricultural land, which are temporary in nature and can be later defined according to law; and c) the right to control, which is public in nature and usually referred to as hak ulayat or other such rights found in societies adhering to traditional or customary law.

The reference to hak ulayat and other such rights in Article 3 of Law No. 5 of 1960 is a consequence of the variety of adat laws and of traditions and customs found among the various Indonesian ethnic groups that use different terms to refer to these laws and traditions. For example, in Ambon they are referred to as patuanan, in South Sulawesi as limpo, in Buru as nuru, in Java as wewengkon, in Bali as prabumian, and so on. In West Kalimantan, however, the hak ulayat and Other Such Rights are referred to by the term panyampeto or pawatasan (J acobus 1988). In East Kalimantan, the Kenyah ethnic group uses the term ulen. This term, as explained above, is obtained from or has developed from the type of control that is based on discovery, conquest, or gift, as well as purchase or exchange.

As determined in Article 2, Paragraph (2) of Law No. 5 of 1960, the right to control of an adat community - a society united by adherence to adat law-is in line with or is an indirect extension of the authority of the state's right to control. After independence, adat law was recognised as an existing form of law that was native to and valid on Indonesian soil together with the Indonesian nation, as long as its implementation did not conflict with the Constitution of 1945, as included in Article II of the Regulations for Transfer of the Constitution of 1945, especially regarding land, which were further implemented through Articles 5, 56, and 58 of Law No. 5 of 1960.

In this connection, a professor of traditional law from the University of J ember is of the opinion 'that ... traditional law is the manifestation of Pancasila in matters of law, in legal terms, that Pancasila is, among others, the source (welbron) and Adat Law is the mark (kenbron) of Pancasila in legal matters, because a nation or society with a Pancasila identity gives rise to, develops, applies, and maintains Pancasila law, which is commonly referred to as Adat Law.' (Abdurrachman 1990:38).

Matters relating to land ownership and control in Kenyah society in the subdistrict of Pujungan, especially as they concern agricultural lands, are protected not only by the regulations of Law No. 5 of 1960, but also by Law No. 5 Prp. of 1960 regarding the regulation of agricultural land area (confirmed 29 December 1960). It sets maximum limits for such areas according to the following criteria: (1) not densely populated, maximum area 15 ha for wet rice fields and 20 ha for dry fields; (2) densely populated: a) not-so-densely populated, 10 ha for wet rice fields and 12 ha for dry fields; (b) rather densely populated: 7.5 ha for wet rice fields and 9 ha for dry fields; and (c) very densely populated: 5 ha for wet rice fields and 6 ha for dry fields. The population density is determined as follows: (1) not densely populated: 50 people per $\mathrm{km}^{2}$; (2a) not-so-densely populated: 51-250 people per $\mathrm{km}^{2}$; (2b) rather densely populated: $251-400$ people per $\mathrm{km}^{2}$; (2c) very densely populated: 401 or more people per $\mathrm{km}^{2}$.

\section{TRADITIONAL LAND OWNERSHIP RIGHTS}

As is true generally in Kalimantan, the Dayak ethnic groups of East Kalimantan still depend for their livelihood on nature, and work the land by farming, hunting, fishing in rivers, and gathering forest products in a traditional manner. Since their move hundreds of years ago from the Belujo River in Sarawak via the Kayan River, they have opened and worked the forest in one location after another, in one settlement area 


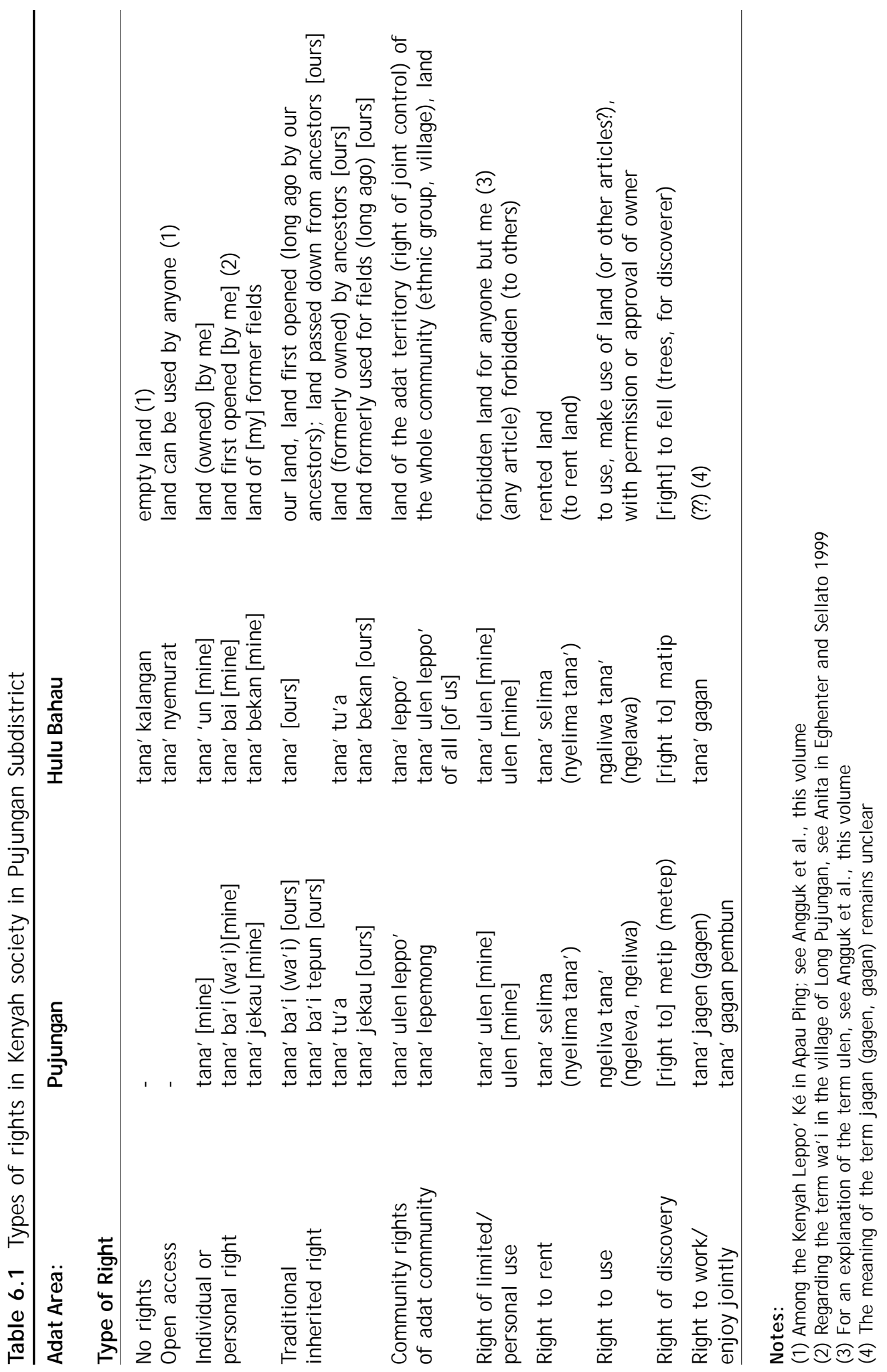


after another, according to need, ever since ancestral times and from generation to generation (see Njau Anau's and Liman Lawai's contributions to this volume) (Table 6.1).

In addition to having to open new forest to meet their need for agricultural land through a recycling system, they occasionally exchanged land with, borrowed land from, and/ or lent land to the citizens of other Kenyah groups. For example, the Kenyah Leppo' Ké in Apau Ping borrowed or exchanged the use of land with the Kenyah Leppo' Ma' ut at Long Berini (see Njau Anau in this volume); or the Kenyah Uma' Lasan borrowed or exchanged land use with the Kenyah Uma' Alim. In this way, this habitual custom developed and was handed down through the generations, especially among those who lived in nearby areas or who had social or kinship relations.

Over time, these activities of borrowing to use or exchanging use became customary, and one side might even voluntarily offer its ulen as fields to be worked by another party, as described above. For example, the ulen leppo' that the Kenyah Leppo' Ma' ut abandoned in Apau Ping when they moved was subsequently and is today occupied by the Kenyah Leppo' Ké and the Saben (or Berau). This legal event, in fact, was recognised by the Leppo' Ma'ut who today live at Long Alango, Long Kemuat, and Long Berini. These activities are approved by the traditional law of the Kenyah ethnic group in the subdistrict of Pujungan, both in the adat area of Hulu Bahau and in the adat area of Long Pujungan. In line with agreements concluded, for example, after the forest was opened, it was worked over generations and planted with crops to meet daily needs, based on the condition of the land and in accordance to a system of recycling.

In the same way, the ulen leppo' of a Kenyah ethnic group that, for some reason, migrated to another area could be surrendered to a related or neighbouring Kenyah group on the basis of a joint agreement. Through other means of land acquisition, such as exchange, various types of rights held by one party developed (even though actual land sale seldom occurred).

In line with the legal theories advanced above, both according to adat law and according to the Indonesian national laws that regulate land matters, specifically the 1960 Basic Agrarian Law, the ownership of land by the Kenyah ethnic group in the subdistrict of Pujungan is well founded. This is in line with the legal theory advanced by Iman Sudiyat (1982: 9), which states that the right to own land can be obtained by: '1) opening land/jungle; 2) inheriting land; 3) acquiring land because of purchase, trade, or as a gift; 4) expiration (verjaring).' This theory can be demonstrated in Article 4 of Law No. 5 of 1960, in combination with Article 2, as suggested by Parlindungan (1991: 38): '4) the state's right to control can be delegated to autonomous areas and adat societies as long as it is necessary and not in conflict with the national interest according to the stipulations of Government Regulations.'

In the meantime, with regard to rights obtained according to traditional law (hak ulayat), Parlindungan also states (1991: 45): 'The article by article elucidation of the UUPA notes that the right to open land and the right to use forest products are rights originating in traditional (adat) law. For this reason, the UUPA applies nationwide and the adat law only applies within the various adat environments and must be controlled by government regulations, so that the regulation in Article 46 can apply nationally and so that every Indonesian citizen, without discrimination as to sex, region, original citizenship, or descent, can open land and use forest products, with protection given to weak economic groups (Article 1 of UUPA) and preserving the hak ulayat (traditional land rights) of the adat societies.'

This analysis does not conflict with observations on the history of the Kenyah in the subdistrict of Pujungan, which consists of two adat areas, the Hulu Bahau area 
and the Long Pujungan area, as illustrated through the lepu'un (former settlement sites) or even through sites left by earlier generations, because, as the UUPA states, the authority that they hold is obtained from the state (Hak Ulayat Negara). For this reason and on the basis of the above-mentioned facts, various types of land ownership rights have developed among the Kenyah, in both the Hulu Bahau and the Long Puj ungan adat areas.

\section{GENERAL CONCLUSION}

If we look only briefly at the Kenyah societies found in those two adat areas, Long Pujungan and Hulu Bahau, which include a total of nine ethnic groups who lived as neighbours and even mixed with other Dayak groups, it is, in fact, rather difficult to determine the relationships to the land that these societies have controlled until today.

\section{The Kenyah are an Adat Society}

According to research results discussed earlier, both based on direct personal observation and on information or explanations obtained from informants and a number of respondents, matters relating to control and ownership of land are based on the traditional or adat law of the Kenyah in the subdistrict of Pujungan. In line with the statement ubi jus ubi societas (where there is law, there is a society), it becomes clear that the Kenyah are a society based on traditional law.

The truth of this statement can be demonstrated. It is shown in the social life of the Kenyah, where adat law still occupies the highest place in dealing with social conflicts among the people and even with other people outside their own adat legal unit. Therefore, traditional rights of land ownership among the Kenyah certainly were in existence long before Law No. 5 of 1960 on Basic Agrarian Regulations (UUPA).

Nevertheless, in the meantime, people are mistaken in contrasting the adat law with laws based on the teachings of the Protestant church followed by the majority of the Kenyah. Yet, if faced with a conflict or dispute over land, or with some other civil conflict, the Kenyah will settle it through consultation of the adat leaders. Examples are the conference of the adat leaders on 10 November 1991 between the Kenyah Uma' Long and the Kenyah Leppo' Ndang (or Ntang) who lived at Long Uli, and the Kenyah Badeng, held at Long Peliran; or the conference of the Adat Court on 2 November 1991 regarding the delinquency of elementary school students suspected of stealing sugarcane from their teacher, which was held in Apau Ping.

With this exception, in the application of adat sanctions, they are familiar with the exchange value of objects as fines, including gongs, ceramics, or large jars, mats for drying rice, beads, plaited floor mats, ba'ing (a type of sword), obo ba'ing (an unused machete), and domestic animals such as chickens and pigs. Additional evidence is found in the decision of the adat conference held between adat notables, civil servants, and the people of Long Alango in the adat area of Hulu Bahau on 5 May 1987.

\section{Land as a Source of Livelihood}

Land is a valuable possession. Not only is its significance inseparable from the life of the Kenyah ethnic group, but for generations it has definitely had strategic and vital significance for them. The life and death of Kenyah communities is heavily dependent on their land use policies. How could it be otherwise, since the Kenyah's primary and 
most important sources of livelihood are farming, hunting, fishing, and gathering forest products. The cultivation of land generally is still done in a traditional manner. This applies to both farming patterns as well as the management and conservation of land. Although a small number of people are attempting to apply new agricultural technology with a simple form and modest absorptive capacity, they are not yet able to influence the traditional methods of the majority.

Traditional planting patterns, land management, and crop care not only require labour and time but also relatively extensive field surfaces. For example, whereas in flat land at the edge of rivers, which contain humus and mud deposits from flooding, the fields are rather small, in highlands or hilly areas, which represent the general situation along the Bahau River and its tributaries, dry (swidden) fields are generally much larger.

Limited land availability-in view of land use needs and population growth with its steadily growing requirements-tends to push the Kenyah of a given village to open new lands, while control over lands owned through the generations has been decreasing. In the meantime, river traffic has gradually reached almost all Kenyah settlements. The opening of communication lines has gradually opened their areas to outsiders, bringing those outsiders increasingly close to their settlements. The coming of these outsiders, either as individuals or in groups, will nevertheless bring about another set of problems for the Kenyah in the subdistrict of Pujungan.

\section{The Problem of Written Evidence}

The reasons for establishing or developing ulen, either as ulen leppo' or as individually owned ulen, based on adat law, left the individual rights that developed without written evidence. The Kenyah have never known written evidence. In Indonesia, documentary evidence or formal legal transcripts of land rights only became known during the colonial period, and concerned particularly lands granted under Western law, or earlier, by kings during the feudal age or by the autonomous regional governments (sultanates). Only in recent times have they followed the 1960 Basic Agrarian Law (UUPA).

Yet, control and ownership of land based on adat law existed long before all these regulations or rules came into effect. This is often insufficiently realised by the local communities, because their settlements are isolated, transportation is difficult, and they can neither read nor write. All these are obstacles that from the beginning, since the arrival of the Kenyah in the subdistrict of Pujungan, have prevented them from owning certificates as written proof of their control over land.

\section{Expected Developments}

A feeling of unease or anxiety haunts or unsettles all Kenyah citizens, both those who still live around the ulen leppo' of their early settlements and those who, for whatever reason or in whatever pursuit, have moved to urban areas. They are haunted by the threat of loss and disappearance of their traditional lands, which they have held for generations, especially since efforts have been made by certain parties to obtain control over these adat lands, both those that are ulen in the broad sense and the ulen in the narrow sense of the term, by using the theory of domeinverklaring from Dutch colonial times. There is, then, a need for the Kenyah to prove their ownership (a contrario evidence). If they are unable to do this, the land in question is state land. 
Even though these fears are reasonable for the Kenyah in the subdistrict of Pujungan, they are unnecessary if the parties in question are in fact well-intentioned, that is, if they sincerely mean to develop the area for the sake of progress of the nation and its people, on the basis of existing laws and regulations. Article 33 of the Constitution of 1945, the 1960 Basic Agrarian Law (UUPA), Law No. 5 of 1979, Presidential Instruction No. 9 of 1973 (which establishes the meaning of the Public Interest), as well as other regulations and laws have provided guarantees of the principles of equalisation and justice.

For this reason, as among other people in East Kalimantan, a growing sense of justice based on the implementation of development to raise the standard of living of the entire society in line with the goals of the Proclamation of Independence on 17 August 1945, forms the basis for the hope and the expectations of all Kenyah people in the district of Bulungan, and specifically those in the subdistrict of Pujungan.

\section{ADDENDUM 2002}

\section{By Cristina Eghenter}

As noted in the Introduction, the new law (Law No. 22 of 1999) on regional autonomy and decentralisation came into effect in Indonesia. The law accommodates the aspirations of provinces, regencies, and districts for more autonomy and more control over budget and resources. It also sanctions a change away from the old centralistic system of the government towards more administrative and financial federalism.

This law institutes some major changes in the structure and authority of the government, including the status of pemerintahan desa, or village government, which is now gaining greater autonomy and decision-making power. Under the new system, the village head is elected by the people by a majority vote, established formally by the new Village Legislative Assembly (Badan Perwakilan Desa), and acknowledged by the district head. As a result of these changes, the old law on village government (Law No. 5 of 1979) is annulled. The protection and respect of adat-istiadat, or customary laws and traditions, becomes the prerogative of the Village Legislative Assembly.

More importantly, the regencies now have full legislative power on a variety of matters and issue decrees (Peraturan Daerah), including on the role of customary law. In 2001, the District of Malinau, which includes the subdistrict of Pujungan, passed a law on the 'Empowerment, protection, and development of customary law and customary councils.'

Although the legal and social environment in Indonesia has changed, the discussion by J acobus Frans remains relevant, particularly in connection with the function and importance of customary institutions in traditional Kenyah society. 


\title{
7. \\ Patterns of traditional land control among three Kenyah groups
}

\author{
Angguk Lamis, Paulus Bunde and Concordius Kanyan
}

\section{INTRODUCTION}

The traditional utilisation of land and natural resources is an expression of the deep relationship between humans and their environment. This relationship also determines the form of control over or ownership of land by individuals as well as by groups.

In 1991, preliminary research was carried out in the subdistrict of Pujungan by J acobus Frans (previous chapter). J acobus' research included all the Kenyah groups in this subdistrict and focused primarily on judicial aspects of adat law and their position as seen from the point of view of national law. He demonstrated that the Kenyah of the subdistrict of Pujungan form adat communities, that is, communities that are still fully regulated by local traditional law.

Later, in 1993, the present three writers carried out follow-up research over three months among three different Kenyah subgroups. Paulus Bunde stayed in the village of Long Apan Baru (in the adat area of Pujungan), whose inhabitants are Kenyah Bakung. Concordius Kanyan stayed in the compound village of Apau Ping with a population consisting mainly of Kenyah Leppo' Ké, and Angguk Lamis stayed in the village of Long Alango, whose inhabitants are Kenyah Leppo' Ma' ut. (The last two villages are located in the adat area of the Hulu Bahau.) The three writers' research focused on practical aspects and the implementation of adat law in daily life, especially with regard to rights over land and natural resources and to patterns of land control and the process of land transfer. 
Even though there is some degree of divergence in the special attention given to particular problems relating to adat law in the different villages, this three-part chapter invites comparison of similarities and differences between the three ethnic groups studied.

\section{PATTERNS OF LAND CONTROL AMONG THE KENYAH BAKUNG}

This part aims at describing and determining the land rights and the patterns of land control among the Kenyah Bakung in the village of Long Apan Baru (also known as Long Aran). The traditional village (leppo') consisted of several longhouses (uma'). The social structure of the Bakung formerly recognised three classes: the paren (nobility), the panyen (ordinary people), and the salut or kula' (slaves). Today only the first two groups are still known. Even though this social structure has increasingly faded away, these social categories still are considered in the election of the village chief and of adat leaders. This structure also continues to play a role when the people provide volunteer labour to open a rice field for the village chief. (This event is known as mabe. ) The research data were collected through interviews with each head of family who played a role in land management activities.

\section{Position and Function of Adat Institutions}

The Bakung are familiar with several levels of institutional adat leadership: the kepala adat bio' (great adat chief), tua leppo' (traditional village chief or village head), pengelata' (adat elders or social leaders), and pegawa' (lower adat leaders). These adat functionaries have authority over their respective adat law areas in accordance with their position.

The village of Long Apan Baru is part of the adat area of Pujungan, which is headed by a kepala adat bio' (from the Kenyah Uma' Alim) residing in Long Pujungan. It includes twelve villages (desa). The village of Long Apan Baru is headed by a tua' leppo' (village head) serving as leader and arbiter in dealing with the various problems encountered within the leppo' area. Formerly the tua' leppo' (also known as paren leppo'; see Ngindra in Eghenter and Sellato 1999) were the highest local nobility and considered the owners of the leppo' territory and of its people (panyen). Today the position of the tua' leppo' parallels that of the village chief, and thus it is normal that in the selection of the village chief the people always choose a member of the paren group. Traditionally, the tua' leppo' in fact was not an adat leader and, in settling problems within his territory, he was assisted by several pengelata' believed to be knowledgeable in adat matters and influential among the people. Even though longhouses no longer exist, the uma' continues to be a social unit lead by a tua' uma' (longhouse head) or a paren uma' (longhouse noble). Long Apan Baru village is thus divided into three uma', which today tend to be referred to as blok, or 'block', while the tua' uma' tends to be known as ketua blok, or block chief.

In the earlier society the pegawa' performed an important function in dealing with disputes at the uma' level, endeavouring to settle them internally. Because the problems faced today are increasingly complex, it is very difficult to find influential people who are respected and capable of taking appropriate action. As a result, the duties of the pegawa' have shifted to the tua' uma'. In addition, there is also a pelawa', an assistant to the village chief, who delivers various announcements to the public.

So far the settlement of disputes relating to adat matters still follows the old procedures. In the early stages of settling a problem affecting the village, the pegawa' 
(nowadays the tua' uma') attempts to solve it within the uma' or block. Only if this proves impossible is the problem passed on to the village chief (tua' leppo'), who is assisted by the pengelata' as legal advisor. If it still cannot be settled, the problem is passed on to the level of the kepala adat bio'. Similarly, the selection of the village chief does not entirely adhere to the regulations of Law No. 5 of 1979, particularly with regard to the criteria for the village chief's position, because the people still follow adat regulations.

Even though settlement patterns have already changed from longhouses to individual family houses, adat institutions still continue to function, showing that national law need not be applied as long as adat settlements are considered adequate for solving problems. In rural areas still far from easy communications and transportation, adat institutions and adat leaders still play a very important role in creating and perpetuating a sense of security and order, and even a sense of justice among the people.

\section{Land Rights in Land Usage}

In using land, especially agricultural land, the Bakung people generally tend to re-use former fields that they own themselves (right of ownership). Occasionally, they also can borrow lands belonging to others (right of use). Other types of land rights do not exist among the Bakung.

\section{Right of Ownership}

Article 20 of the Basic Agrarian Law (No. 5 of 1960, or UUPA) states that the right of ownership is a right that is passed down through the generations, and is the strongest and most comprehensive right that anyone may have over land. In line with this, the Bakung of Long Apan Baru use and own land according to adat, and their lands have been farmed for generations. They live off traditional shifting (swidden) agriculture, combined with hunting and gathering. The process of land ownership among the Bakung is very simple. Anyone who opens forest land and establishes a field on this land holds the rights to that land. Former fields that have reverted to forest (jekau) remain the property of the family that first opened those lands-or their descendants-and this right is recognised by other members of the community. Thus, as many as $85 \%$ of the 47 heads of farming families in Long Apan Baru each own between 6 and 20 plots of jekau land (see Bunde 1995). Proof of ownership often consists of the fruit trees planted along the boundaries of the fields.

The territory of the village of Long Apan Baru actually used to belong to the Kenyah Uma' Alim, who were its early inhabitants. The Uma' Alim were followed by the Kenyah Oma' Long. After these two groups had migrated elsewhere, the area was occupied by the Kenyah Bakung, who are still settled there today. The transfer of the rights to the territory to the Bakung did not present a problem because it was handled by the kepala adat bio' of the adat area of Pujungan. Ownership rights on former fields are annulled if the owner moves to another area and no descendant remains to inherit the lands. In practice, then, the abandoned land becomes land owned by the adat community. The Bakung have lived in the village of Long Apan Baru for thirty years, and so far not one member of the Uma' Alim or the Oma' Long, who once occupied the area made a claim to the lands they abandoned. 
Because the village territory is rather extensive, every farmer can select the type of land he wants for farming (see Table 7.1). In general, the use of secondary forest (jekau) dominates over the opening of primary forest (mba') and the use of brush land (bekan). J ekau land is considered easier to work, because its trees are rather thin (with an average diameter of $10-30 \mathrm{~cm}$ ) and not too dense, while its undergrowth is not too thick. The predominant use of jekau also is due in large part to the strategic location of the fields in valleys (leka'), on plateaus (apau), or at river confluences (long), which all had once been farmed by the Uma' Alim when they lived there. The Bakung needed but to work the lands left by the Uma' Alim.

Table 7.1 Type of land cleared for farming in Long Apan Baru ( $\mathrm{N}=47$ family heads)

\begin{tabular}{rrrrrrrrr}
\hline Year & mba' & \multicolumn{1}{c}{$\%$} & jekau & $\%$ & bekan & $\%$ & Not farming & $\%$ \\
\hline 1984 & 5 & 10.64 & 40 & 85.11 & 0 & 0 & 2 & 4.25 \\
1985 & 3 & 6.38 & 41 & 87.23 & 1 & 2.13 & 2 & 4.25 \\
1986 & 8 & 17.02 & 37 & 78.72 & 1 & 2.13 & 1 & 2.13 \\
1987 & 10 & 21.28 & 36 & 76.65 & 1 & 2.13 & 0 & 0 \\
1988 & 13 & 27.66 & 31 & 65.97 & 3 & 6.38 & 0 & 0 \\
1989 & 17 & 36.17 & 29 & 61.70 & 1 & 2.13 & 0 & 0 \\
1990 & 8 & 17.02 & 33 & 70.21 & 5 & 10.64 & 1 & 2.13 \\
1991 & 7 & 14.89 & 39 & 82.98 & 0 & 0 & 1 & 2.13 \\
1992 & 9 & 19.15 & 36 & 76.60 & 2 & 4.25 & 0 & 0 \\
1993 & 8 & 17.02 & 39 & 82.98 & 0 & 0 & 0 & 0 \\
\hline
\end{tabular}

The opening of primary forest (mba') was more significant in the years 19861989 because the people then began to use chainsaws for felling trees. They obtained these chainsaws with the income from their work as labourers in Sarawak, Malaysia. The area of primary forest opened every year is still relatively small, because in fact the felling remains difficult and very time- and labour-consuming, even though the soil of the primary forest is rather fertile. Primary forest is usually opened only to enlarge the agricultural area around existing fields. In fact, beginning in 1990, land use patterns reverted to the pre-1986 situation.

The use of brush land (bekan) for swidden fields has declined somewhat. In the Bakung language, the term bekan refers to rice fields recently abandoned, in which the rice stalks are still visible. These fields are not very fertile for farming and, if they are planted with rice, experience shows, the grass grows more thickly than the rice. The Kenyah generally use bekan land for planting secondary crops and describe these fields as kelimeng (gardens).

\section{Right of Use}

Among the Bakung, the right of use is limited to borrowing and lending land without formal agreement regarding the division of the harvest. The right to rent is also unknown, because extensive lands for farming are still available. Every farmer is free to expand the land he works according to the labour force available in his family.

In establishing swidden fields (uma'), the Bakung place great importance on togetherness and unity so that farmers of the same village join in groups at several farming locations. Farming in groups is also more effective for cooperative activities 
and in fighting off pests. The members of a group do not have to be related through kinship. In a farming group, there is always a motivator, who directs the other members and gives advice. The motivator is an influential individual, usually someone from among the paren. But often he is a member of the panyen who is believed to be experienced, especially with regard to farming matters.

The farm lands that are cultivated are generally owned personally by the farmer's family and controlled according to adat (see Table 7.2). Occasionally, however, a family lends its lands to another family. The reason for this may be that a farmer wants to join another farming group and does not own any jekau land at their location. If he also does not want to open new forest land, he can ask another person to lend him a piece of jekau land. Or a farmer (for example, the above mentioned motivator) may suggest to another family that they establish a field at a particular location and, at the same time, may offer his land to them for farming. This type of borrowing or lending occurs only rarely because almost all families have jekau land in every farming location. This lending and borrowing system is rather simple: Those interested need only inform the owner of the land. They are not asked to pay anything and, after the harvest, the rights to this land revert to its owner.

Table 7.2 Owned and borrowed farm land (1984-1993) in Long Apan Baru (N=47 family heads)

\begin{tabular}{rcccccr}
\hline Year & $\begin{array}{c}\text { Plot } \\
\text { owned }\end{array}$ & $\%$ & $\begin{array}{c}\text { Plot } \\
\text { borrowed }\end{array}$ & $\%$ & $\begin{array}{c}\text { Not } \\
\text { farming }\end{array}$ & $\%$ \\
\hline 1984 & 40 & 85.11 & 5 & 10.64 & 2 & 4.25 \\
1985 & 39 & 80.98 & 6 & 12.72 & 2 & 4.25 \\
1986 & 38 & 80.85 & 8 & 17.02 & 1 & 2.13 \\
1987 & 40 & 85.11 & 7 & 14.89 & 0 & 0 \\
1988 & 44 & 93.63 & 3 & 6.38 & 0 & 0 \\
1989 & 44 & 93.63 & 3 & 6.38 & 0 & 0 \\
1990 & 42 & 89.36 & 4 & 8.51 & 1 & 2.13 \\
1991 & 39 & 82.98 & 7 & 14.89 & 1 & 2.13 \\
1992 & 38 & 80.85 & 9 & 19.15 & 0 & 0 \\
1993 & 37 & 78.72 & 10 & 21.28 & 0 & 0 \\
\hline
\end{tabular}

Land use for purposes other than farming is nearly unknown. Secondary crops such as coffee, cocoa, and pepper are only planted around the residence for household consumption. Cash crop plantations are not found, with the exception of rattan, which is cultivated cooperatively with businessmen holding forest concessions (HPH) in the Kebun Bina Desa (a village cash crop plantation program steered by the forest concessionaire).

\section{Use of Forest Products}

In between their farming activities, the Bakung do business in forest products such as rattan, timber, and eaglewood. Timber and rattan are important necessities for construction. Timber is not only felled for personal use, but it can also be sold after it is processed into beams or boards. Rattan is traded at certain times, depending on 
the market price. In recent times, the price of rattan has tended to decline and, as a result, the people have been reluctant to do business in rattan.

Eaglewood is a forest product gathered specifically for sale. In recent times, its prices on the world market have tended to shoot up, causing a variety of problems between the Bakung and outside collectors (see Blaj an Konradus in this volume). These problems, which continue to cause confrontation between local customary law (adat) and national law, are discussed below.

\section{Within the Adat Community}

The Bakung sell the eaglewood through cukong (or toké, usually Chinese traders and financial backers) who come to the area to gather it from collectors. This means that the difference between the village price and the true market price is rather marked. In practice, all economic activities of the Bakung are controlled through complex marketing networks. The forest product management is regulated by traditional customary law (adat), because it occurs within the territory of the community. Every village has reserve lands that are referred to as village preserves and commonly known as tana' ulen, 'prohibited lands.' But the phrase tana' ulen as it is used now in the modern context in the subdistrict, is not yet universal or standardised, and some people do not even understand its meaning.

Fundamentally, ulen is a prohibition that can be applied to certain things. For example, ulen for a particular tree means that this tree is marked with a sign of prohibition known as atap, to prevent other people from cutting it down. The term ulen can also be used for a site or area in which an important event has taken place, such as a murder, a war, or some other historical event, which makes it impossible to use the site. Some of the land of the village may also be marked as ulen and the forest products found in this ulen area can only be used for the common interest and may not be exploited for personal interest. The social policies regarding the processing of forest products are contained in a decision of the LKMD (Lembaga Ketahanan Masyarakat Desa, Institute of Village Community Resilience) issued by the bupati (district head) of Bulungan.

The use of the term tana' ulen of the village treasury (tanah kas desa), or land meant to be exploited to fill the village treasury, is in fact based on a new concept. The people are still permitted to take timber, rattan, and other products in the village treasury land. Even more ironically, in Long Apan Baru, the tana' ulen of the village treasury includes lands farmed by the people and which have not yet been fully surrendered to the village. The people can still own and work these lands for their own benefit. The tana' ulen concept here is intentionally adjusted to make possible the designation of these lands as intended for the village treasury.

\section{Relations with Outsiders}

In recent days, the people have been confronted with the choice of opening up to the outside. They have to be prepared to take all the risks, especially because their source of livelihood and economy have come under pressure. The coming of companies holding HPH (Hak Pengusahaan Hutan, or timber concession) in fact can bring good fortune to some of the people, but those people who rely on traditional farming will certainly come under pressure. In fact, village regulations have tried to anticipate the effects of contact with the outside world. For example, the LKMD requires individuals or groups doing business in timber, rattan, or eaglewood on the lands of the village of Long Apan Baru to pay fees in the form of money for village development. Nevertheless, 
the funds that can be so netted are usually limited and originate from the local people themselves, and often this only benefits the cukong.

A number of cases demonstrate this. For example, the village of Long Apan Baru contains a 10 ha rattan plantation, managed by the local people together with a forest concession holder, PT Dana Mulia Bakti. The management of this plantation is hampered because the funds that are spent are not consistent with the agreed-upon rules. Initially, the funds agreed on totalled Rp. 10 million, but, in fact, only Rp. 2 million were spent, only enough for providing seedlings, cleaning the fields, and several plantings. Because of this, the rattan plantation was eventually abandoned by the people and the enterprise came to a halt because the company did not issue the remaining funds due.

Field observation leads to the conclusion that the failure of this rattan plantation business was primarily caused by inadequate coordination between the village chief, the relevant government authorities, and the timber concessionaire, culminating in failure to issue the remaining funds. Secondly, the rattan plantation that was already established was neglected and is no longer cared for because the people are not informed or aware of the importance of this plantation. And no extension worker has been made available to assist the people in their attempt at cash crop plantation.

The local people also fell timber, which is sold to interested cukong. Timber is felled by the riverside with simple technology. The price reaches Rp 30000 per $\mathrm{m}^{3}$. The cukong collect the timber from the people, float the trunks down the Bahau River, and gather them at Long Bia and Long Peso'. It appears that this unregulated exploitation of timber does not evade the grip of timber mafias, which disregard the law in order to procure a higher profit.

\section{Conclusions}

The above discussion permits several conclusions. (1) Control of land among the Bakung is always based on adat law. Land may be owned by individuals, or adat communities and institutions that play a functional role in the protection of society.

(2) In the traditional social structure of the Bakung, the paren had the primary right to land within the territory of the Ieppo', while the panyen had the right to work the land. (3) There are strong indications that the Bakung have a tolerance for patterns of land control that are governed by the adat community (pewatasan or ulen). The community rights (besikkingrecht), governing land control and use, limit individual rights. (4) At present, the right of the leppo' to exploit its territory is the same as the hak ulayat (or traditional land rights), while holders of ownership rights over land are individual members of the community. (5) The process of transferring inherited lands is always based on a feeling of togetherness, of being part of the same ethnic group, and always focuses on the majority's best interests in benefiting from a given territory. The process of land ownership, however, certainly always focuses on traditional evidence, such as the planting of one or two trees in an area once worked or farmed. (6) The use of forest products is limited to certain commodities and is temporary in nature, and still carried out in a traditional manner or with simple technology. (7) In settling disputes, the people not only continue to adhere to traditional customary regulations, but they also make decisions jointly, together with the village chief and notables. The decision is then put into writing in a 'decree' of the LKMD (Lembaga Ketahanan Masyarakat Desa) in order to regulate the use of forest resources. 


\section{PATTERNS OF LAND CONTROL AMONG THE KENYAH LEPPO' KÉ}

This part attempts to discuss the manner in which the Kenyah Leppo' Ké of Apau Ping define and confirm their land rights. The village of Apau Ping is a compound village consisting of four desa, the product of a resettlement scheme. It is located on the far upper reaches of the Bahau River. Three of the four desa are occupied by Kenyah Leppo' Ké (see Njau Anau in this volume), while the fourth is inhabited by a few remaining families of a group of Saben that has moved to Sarawak.

The residential arrangement today does not indicate clear boundaries between the desa, and these boundaries are not considered problematic by the villagers, even though they have been drawn administratively. Reinforced by intermarriages between the two ethnic groups, a gradual integration of culture and traditional customs has occurred. Many aspects of life, including farming patterns, indicate that the Saben have voluntarily and fully submitted to the adat law of the Leppo' Ké. The village of Apau Ping is part of the adat area of the upper Bahau.

Even though Apau Ping is difficult to reach from the coastal region, its inhabitants are not excessively isolated and are able to receive news from the outside world. Among other things, Apau Ping is a transit area for people travelling to Sarawak, and thus it is not surprising that its inhabitants are more familiar with cities in Sarawak (the town of Miri, for example) than with the towns of coastal East Kalimantan.

The data were gathered through interviews with well-known figures among the Leppo' Ké, and by disseminating a questionnaire to several heads of families, followed by more in-depth interviews (case studies).

\section{The Position of Adat Law}

Ties to ancestral customs, traditions, and culture are no longer very conspicuous in everyday life in Apau Ping. Yet, a very close relationship to land and surviving traditional beliefs appear when the people are about to work their land. They hold a short ceremony or prayer, as a request for advice or protection, as well as for blessings and abundance for their fields. This is a transformation from the melaki ritual (see Herculanus Bahari Sindju in this volume), which was usually held by the people before they converted to Christianity.

At present, the Leppo' Ké live in individual houses, rather than their former longhouses (uma' dado'). This reflects a change in their values. The communal values characteristic of a traditional, or adat, society persist, while individualistic values begin to be accepted. Formerly, the primary rights among the Leppo' Ké were held by the village (leppo') community, led by the paren or nobility, who played a very important role in the control over land rights.

The work in the fields was carried out by turns according to the system of cooperation in groups that is known as senguyun (see Herculanus Bahari Sindju in this volume). The membership of the senguyun nugan group (for planting purposes) was fixed since ancestral times, and may have served as the community's means of recording in memory the location of former fields. In fact, there is a general agreement on land rights, and people work their fields without challenges from the rights of others. Except in planting, the composition of the senguyun group changes every year.

The church as a social organisation is now considered as the protector of togetherness, community, and harmony among congregations. The church is also given priority in the use of lands for the interest of the congregation. Thus there are regulations regarding the existence of church fields and church land. In addition, the 
church is given a chance to use forest products from certain areas around the village. The existence of an elementary school and a public health centre (Puskesmas) in Apau Ping also plays a role in changing the way of life of the traditional society.

The traditions and customs adhered to by the Leppo' Ké not only contain sacred values, as reflected in the melaki ceremony, but they are also legal in nature and contain legal principles in the form of laws, prohibitions, and duties. The existence of legal rules within the adat provides the people with rights to prohibit access to or claim (mulen) something that is considered valuable, such as land, rivers, trees, and so on. In other words, mulen is a particular act with legal implications on the part of and for the Kenyah Leppo' Ké. It consists of placing a marker or sign on fields or objects that are to be prohibited to others.

No official process involving other villagers occurs in claiming, or mulen, a particular item, such as a tree; no announcement or other official statement is made. The sign or mark, however, is proof that the ownership of that tree must be respected and recognised by everyone. Something may be claimed or mulen (or become someone's ulen), as long as it has not yet been previously claimed as ulen by someone else. Violations of ulen trees by others are settled on the basis of traditional legal rules. These ownership patterns are effectively implemented by the people of Apau Ping.

\section{Rights to Agricultural Lands}

The Leppo' Ké have a very long history in Apau Ping, and land is truly important for them as a place to live, to farm, bury their dead, and so on. Everything that is on the land can contribute to the livelihood of every member of society who needs it. Land is sacred in nature, and the people believe that there is a power that occupies the land and can protect or damage it. The social, religious, and legal aspects that are inherent in the society's relationship with the land form the primary basis for controlling land.

The migration of social groups and their ways of life in meeting their daily needs are historical proof of the existence of close relationships between a society and the natural resources that provide their livelihood. For example, it is recognised that the individual who first opened primary forest (mba') retains the right to the fields. This right is only that of the primary user, while the holder of the highest right is the leppo' (as a social institution), and the rights of the leppo' among the Leppo' Ké is controlled by the paren who leads the leppo' in question.

\section{Land Ownership Rights}

The system of shifting agriculture is a traditional form of control over land. After the inhabitants had been resettled in Apau Ping, population pressure gradually led to problems with regard to land ownership. Fields had only been made around the settlement (with the most distant no more than a two-hour walk away) and the land available for fields growing increasingly scarce. Residents who had settled there earlier, in 1963 (the original village of Apau Ping), gradually began to feel enclosed because the three villages that joined later (1988), i.e., Long Pengayan, Long Lat, and Long Tua, had to farm within the area of the village of Apau Ping, while they continued to claim the rights to their original territories. These conditions presented opportunities for competition over land rights among residents, no longer among social groups (leppo' or desa). The shift of land rights from leppo' to individuals or families is a clear shift in values. 
It was possible to interview 39 heads of families who, from memory, could point out the locations, boundaries, and crops of every plot of land that they owned (see Table 7.3). Variation in the number of plots is closely related to the preference and capabilities of each farming family in using free lands (primary forest, mba'), which gives the opener of the land the right of ownership. Yet in the period 1984-1993, no more than three families each year opened new land in Apau Ping (see Kanyan 1995).

Table 7.3 Total number of farm land plots owned per family in Apau Ping ( $\mathrm{N}=39$ families)

\begin{tabular}{ccc}
\hline Number of plots & Number of families & \% of all families \\
\hline $6-10$ & 8 & 20.51 \\
$11-15$ & 9 & 23.08 \\
$16-20$ & 6 & 15.39 \\
$21-25$ & 8 & 20.51 \\
$26-30$ & 5 & 12.82 \\
$31-35$ & 1 & 2.56 \\
$36-40$ & 0 & 0.00 \\
$41-45$ & 2 & 5.13 \\
\hline
\end{tabular}

Eight of the 39 heads of families (20.5\%), who owned 6-10 plots of land fell into two groups: new families (newly settled in Apau Ping or newly independent married couples); and families with a greater tendency to use land covered by young secondary forest or brush land (jekau bu'et or bekan), because of a lack of available labour in their families. In the second case, the land worked was always owned land, either personally owned or owned by others. Two heads of families (5.13\%), who owned 41-45 plots of land, were elderly paren who, as leaders, had long been helped by leppo' residents with work in opening fields in primary forest. Nevertheless, because land rights only take the form of right of use, even those who have many plots of land do not become landlords as is the case in J ava, for example.

The system of farming in groups means that the status of land is not the main factor in owning land, since ownership tends to favour social aspects, as farming in groups creates opportunities for borrowing the land of others villagers (see above on the Bakung) on the condition that the land not be planted with perennials, such as cinnamon or coffee. Interviews with 45 families regarding their farming activities during the period 1984-1993 (see Table 7.4) show that, from 1984 to 1988, an average of $16 \%$ of all farming families chose to cultivate borrowed lands, because the groups from Long Pengayan, Long Lat, and Long Tua had not yet joined Apau Ping. Beginning in 1989, however, as a result of the resettlement in Apau Ping and of population growth, population density suddenly became high. Because of the general tendency to use jekau land rather than primary forest, this percentage increased sharply to 35\% in 1993.

In 1993, as many as $68 \%$ of 41 respondents in Apau Ping established wet rice fields in addition to their dry rice fields. The rights to wet rice fields are more secure than those over dry fields. The people have also begun to plant and cultivate cinnamon (85\% of 41 respondents; see Kanyan 1995), which is usually found wild in the forest and considered a forest product. If the cinnamon trees are cultivated and no longer considered a forest product, the rights to cinnamon fields are identical to the rights 
Table 7.4 Owned and borrowed farm land (1984-1993) in Apau Ping ( $\mathrm{N}=45$ families)

\begin{tabular}{lcccccc}
\hline Year & $\begin{array}{c}\text { Plot } \\
\text { owned }\end{array}$ & $\%$ & $\begin{array}{c}\text { Plot } \\
\text { borrowed }\end{array}$ & $\%$ & $\begin{array}{c}\text { Not } \\
\text { farming }\end{array}$ & $\%$ \\
\hline 1993 & 27 & 60.10 & 16 & 35.55 & 2 & 4.44 \\
1992 & 32 & 71.11 & 12 & 26.66 & 1 & 2.22 \\
1991 & 31 & 68.88 & 13 & 28.88 & 1 & 2.22 \\
1990 & 29 & 64.44 & 14 & 31.11 & 2 & 4.44 \\
1989 & 29 & 64.44 & 13 & 28.88 & 3 & 6.66 \\
1988 & 34 & 75.55 & 5 & 11.11 & 6 & 13.33 \\
1987 & 33 & 73.33 & 3 & 6.66 & 9 & 20.00 \\
1986 & 26 & 57.77 & 10 & 22.22 & 9 & 20.00 \\
1985 & 32 & 71.11 & 3 & 6.66 & 10 & 22.22 \\
1984 & 24 & 53.33 & 8 & 17.77 & 13 & 28.88 \\
\hline
\end{tabular}

over wet-rice fields or coffee plantations, and are no longer subject to the regulations regarding the harvesting of forest products (see below).

It should also be noted that, due to the switch from longhouses to individual houses, new married couples tend to establish neolocal residence, to the effect that these new families take initiatives on their own in the use of land around the settlement. This is leading toward more individualistic patterns of land use.

\section{Transfer of Land Ownership Rights}

Land rights in the Apau Ping area are generally acquired by opening plots that are still free, tana' nyemurat. These lands can be used by anyone since, as yet, no one holds any rights over them. They include lands covered by 'primary' forests that are in fact very old secondary forests-these lands were farmed by the Kenyah Leppo' Ma' ut, who moved elsewhere about one century ago. The same is true for tana' kalangan, or empty lands which have never been farmed and are not yet covered by any rights of ownership. These lands are very extensive in the area and, as a result, large land areas are not yet owned or controlled by anyone and may be used by anyone. Most farmers, however, prefer to open land covered by young secondary forest rather than primary forest (see Herculanus Bahari Sindju in this volume).

When they are ready to open rice fields, farmers first go in groups to survey the area that they will farm together, always keeping in mind the matter of the ownership of the plots. This survey results in a map showing the land ownership in that area. The farmers then hold an informal meeting. If the prospective plot of land is not yet covered by ownership rights, the farmer only needs to mention his intentions to other farmers. If the plot already has an owner, the farmer hoping to work it must determine if its owner is willing to lend it to him. On the other hand, the owner may also offer his fields to others for farming.

A formal transfer of the right of use only occurs in connection with wet-rice fields, and the length of use is determined by agreement between the owner and the user. Such transfers take place when an owner is unable to protect, maintain, or cultivate a field himself and therefore asks another to do so. A potential user may also approach 
the owner. This transfer does not involve any type of fee and the people do not know rental rights or sharecropping.

Inheritance of ownership of dry farming lands is almost unknown, since the Leppo' Ké are relatively new settlers in Apau Ping (1963 and 1988). The area available for farming is still adequate in light of the population's ability to work it, and the farmers can easily obtain land to work, either owned or borrowed. In the case of wet-rice fields, however, the transfer of rights through inheritance is prevalent. An informant from Long Pengayan village, for example, admits to inheriting land from his wife's parents.

Intervillage relations have not become tense over land ownership because of population growth, since the residents of the three villages in fact belong to the same ethnic group and many are closely related. No formal process is required if a resident of Long Pengayan opens new fields in the Apau Ping area, as long as the ownership rights of the farmer who originally opened the land are taken into account. In Apau Ping, the same is true for the rather vague boundaries between desa. Similarly, village residence is not much of a problem for the members of a senguyun group. This work institution is formed only on the basis of good social relations among fellow villagers in daily life.

\section{Tana' Ulen and the Use of Forest Products}

The concept of tana' ulen, which is of great importance for traditional societies, has undergone a shift in meaning, especially because of the boom in forest products (eaglewood) that has recently engulfed the interior of East Kalimantan and unsettled its people.

\section{Tana' Ulen}

Control over land closely tied to the collective interests of the leppo' of the Kenyah Leppo' Ké is referred to as tana' ulen, from the word tana' (land) and ulen (claim; mulen means 'to prohibit access to or to claim'). The legal meaning of tana' ulen is that of a 'land that is off-limits to other people', and 'other people' here refers to those who are not members of the family that controls or has claimed the land in question. Formerly, tana' ulen developed for a variety of social and religious reasons. For example, as a reward to a member of the paren who had bravely fought in an interethnic war, a piece of land was set aside for him. It had to be protected and respected by every resident.

Basically, it is the leppo' as a communal social unit that may claim or control land. According to the Leppo' Ké's traditional laws, the leppo' is led by the paren (nobility), and thus it seems as if only the paren have the right to control the tana' ulen. Yet, the tana' ulen may be used by the common people (panyen) at certain times (except for purposes of farming), such as ritual occasions and adat ceremonies, which are directly related to the public interest of the people of the leppo'. These occasions are restricted to members of the leppo' itself, and require the permission of the head of the leppo' involved. Even though the leppo' as a communal unit within the adat community has the right to control land, the use and ownership according to traditional law is an individual or family matter.

Among the Leppo' Ké, the territory of the Ieppo' is today better known as the village territory (wilayah desa). The village head and his staff play a significant role in 
the changes occurring in traditional land ownership, which is now undergoing a shift in judicial values and functions. In line with the changes and shifts in cultural, social, and economic values, and the social changes of the traditional society into a village society, the concept of tana' ulen has also changed. It is no longer limited to certain areas controlled by the paren, but is based on the common interest of all members of the adat community (leppo'). At present, the tana' ulen includes the entire village territory and has become the property of all villagers.

It is difficult to define the concept of tana' ulen. The history and the purpose of the creation of tana' ulen are different from those of the watas in West Kalimantan. Watas can be established for various reasons, but basically it is controlled by an adat community in the public interest. Tana' ulen, on the other hand, was initially controlled by one social group (paren) within an adat community (leppo'), primarily for the interests of the paren themselves. In addition, tana' ulen includes an overall idea of conservation, while the concept of village territory in East Kalimantan tends to have an administrative emphasis to facilitate supervision of the use of natural resources.

The setting aside of land for the village treasury, a step suggested for every village by the government, in fact is not conceptually identical with the tana' ulen. The location of the village treasury lands is determined by the availability of natural resources. While these lands as yet have not been claimed, they are located close to the settlement, so that they can be put to optimal use by the members of the society.

\section{Use of Forest Products}

The Apau Ping area still has what may be described rich in natural resources. Forest products in general are used for consumption, except for cinnamon and eaglewood, which are beginning to form the basis for large-scale business enterprises. The business in these two commodities even involves many outsiders, because their economic value is high and their marketing channels are rather simple (see Blajan Konradus in this volume).

The regulation of the use of forest products among the people of Apau Ping themselves has not given rise to any significant problems, because the lands of the four desa within the Apau Ping area are only viewed as administrative boundaries set by the government. Nevertheless, residents of village A who are planning to gather forest products on the lands of village $B$ are expected to report to the village head or his staff in village $B$. This reporting is not particularly formal and more in the nature of 'letting him know.' People from outside Apau Ping, on the other hand, who want to gather forest products on the lands of village B must officially report to the village chief or his staff in village $B$.

The regulations that become the basis for policy decisions regarding the use of forest products are always made in consultation by the four desa heads and local notables in Apau Ping. The enforcement of these regulations, however, always ran into difficulties because there were no personnel charged with the task of and responsibility for controlling the forest product collectors entering the area. The fees required from outside eaglewood collectors, that is, $10 \%$ of the income obtained, could not be levied because outsiders tended to enter and leave the area without reporting to the village chief. New rules, requiring the payment of an entry fee, were also ineffective.

Finally, regulations were made, entirely forbidding outsiders to search for eaglewood in the areas protected by the community. Only local people could go straight into the forest, and only eaglewood dealers who purchased the produce directly from these local collectors were permitted to be present. Even though these regulations appear to 
have the people's full support, they are still difficult to enforce, because, among other things, each of the four village chiefs has autonomy in setting policies regarding the use of forest products in his area, and the joint decision by the four village heads is occasionally difficult to use as a reference or control for the decisions of each village head. Furthermore, there are complicating factors within the Apau Ping community; that is, leaders who themselves violate the rules for personal profit.

\section{Conclusion}

From the above discussion of the system of shifting agriculture and land ownership patterns, the following conclusions can be drawn: (1) A social group's history in the region that it controls can be demonstrated through its land-holding patterns. The history of the Kenyah Leppo' Ké is characterised by frequent changes of settlements, as shown by the existence of a number of former settlement sites (leppu' un; see $\mathrm{Njau}$ Anau in this volume). According to tradition, the people still retain their land rights in former areas. (2) When settled in one area, the people have always established fields around their villages, and as long as they remain there they continue to control their former fields. (3) In the traditional social structure of the Kenyah Leppo' Ké, the paren were the primary holders of land rights within the territory of the leppo', while their panyen only had the right to use or work the land. (4) As a result of the development and social changes that have recently flooded the society, the leppo"s rights of control have been reduced to the same level as other traditional ownership rights. Land ownership rights are held by individuals or families. (5) The first person to open a forest area not yet controlled by others holds the right of ownership to that land. (6) Control over land is more certain if that land is worked continuously as wet rice fields or planted with perennial crops. (7). The patterns of land ownership rights among the Leppo' Ké have become more varied as the need for land became more varied and as the land available for shifting agriculture became scarcer.

\section{PATTERNS OF LAND CONTROL AMONG THE KENYAH LEPPO' MA'UT}

The village of Long Alango is located on the upper Bahau river. Its territory includes extensive and fertile lands that are very supportive of the people's agricultural activities. The inhabitants of Long Alango include Kenyah Leppo' Ma' ut and several Leppo' Ké families. Their source of livelihood generally includes dry land farming as well as wet-rice farming. There are also several civil servants (elementary school teachers and paramedics) and a preacher. In addition to farming, the people also cultivate gardens and hunt. The average educational level is elementary school. Mobility is rather high, especially among the young people, who tend to go to Sarawak to work in companies and only return home at the end of the year to visit their families.

\section{Village History and Territorial Borders}

Long Alango village, part of the Hulu Bahau adat area, is bordered upstream the Bahau River by the village of Long Kemuat, and downstream by the village of Long Tebulo. The formation of the traditional territory of a leppo' and its borders are the result of the historical development of the Leppo' Ma'ut group and the migration of its people. Until now, the transfer of territory from one village to another, as well as disputes, have been settled according to traditional law. In 1991, however, the camat (head of 
the kecamatan, or subdistrict) of Puj ungan ordered all villages to set definitive borders to be reported to the subdistrict office.

\section{Setting Borders with Long Tebulo Village}

The people of Long Tebulo village came from Long Lio' village on the upper Ngiam river (see Njau Anau in this volume). According to Apui Njuk, village head of Long Tebulo, the Long Lio' area is so isolated that it was difficult to meet daily needs for salt, clothing, and tobacco. With permission of the great adat chief of the Hulu Bahau, Dan Awan, Apui Njuk and several others from Long Lio' began to farm in the Long Tebulo area, which still had extensive unused land areas. This action was welcomed by the village chief of Long Alango and, in time, many more inhabitants of Long Lio' moved. By 1972, some of the inhabitants of Long Lio' migrated to Long Loreh (in the district of Malinau), while the remainder moved to Long Tebulo in 1973 on the suggestion of Dan Awan and Apui Njuk.

The great adat chief set the village boundaries at the Poton Loten River confluence on the left bank of the Bahau and at the Lalut Sungan confluence on the right bank of the Bahau River. In line with the orders of the camat of Puj ungan in 1991, the Long Alango village head invited the village head of Long Tebulo and his people to determine the village borders. The meeting went smoothly and the people from Long Tebulo basically gave in on everything to the people of Long Alango. The results of the meeting only reinforced the borders that had been determined long before.

\section{Setting Borders with Long Kemuat Village}

In the 1940s, several residents of Long Kemuat began to open land in the Alango River area, because the land around Long Kemuat was becoming increasingly insufficient. The great adat chief of the Hulu Bahau at that time (Apuy Njau) encouraged his people to establish wet rice in former dry rice fields near the Alango River, which has many tributaries that flow year round. Even though the wet-rice growing experiment succeeded well, the land was thought to be too far from Long Kemuat, and in 1948 the great adat chief and the village head of Long Kemuat village encouraged the people to move downstream to Long Alango. Because extensive empty and fertile lands were available, a number of Long Kemuat villagers agreed to the move and in 1952 the village of Long Alango was established. People from Long Kemuat gradually moved to Long Alango until the 1960s. Finally, only about seven heads of families had resisted the move from Long Kemuat, and the village of Long Kemuat could only could start to develop again after it received an influx of new inhabitants (1978) from Long Aking (Leppo' Ké and Nyibun people; see Njau Anau in this book).

Traditionally, the border between Long Alango and Long Kemuat did not pose a problem, because the two villages belonged to the same ethnic group. To follow the instructions of the camat, however, the head of Long Alango (Ajang Apuy) invited the head of Long Kemuat (Ingan Irang) and other notables to attend a meeting. This meeting set the boundary at the mouth of the Ilan River and the Oko' Bun Stream, calling attention first of all to the borders of the land worked by the people of the various villages: 1) dry fields and wet-rice fields worked by the people of Long Kemuat around Long Ilan and Oko' Bun Stream belonged to the people of Long Alango; 2) at present a large part of the people of Long Kemuat are newcomers from other ethnic groups, not original settlers in Long Kemuat; 3) setting village borders at the Ilan 
River does not restrict the farming activities of the people of Long Kemuat, even though their fields are located in the territory of Long Alango. This decision also took into account the responsibility of the parties in maintaining paths connecting the two villages (located at Oko' Bun Stream near the Apuy Njau air strip).

The village head of Long Kemuat, however, was not willing to sign this decision, because he considered the border at the Ilan River too close to the Long Kemuat settlement. A second meeting was held in Long Kemuat; it was attended by the village heads and the heads of the 'block' residential units of Long Alango, but it was unable to reach a decision. Only after Baya' Apuy, the elder brother of the great adat chief at the time this research was conducted and a member of the regional parliament of the kabupaten (district) of Bulungan, had explained the purpose of defining village borders did the participants of the meeting understand (although some continued to resist), and finally the village head and the notables from Long Kemuat signed the decision that was in line with the results of the earlier meeting at Long Alango.

\section{Controlling Land Rights}

The different land rights that are based on local tradition, including the ulen and the tana' ulen and rights related to farming activities (dry fields, wet-rice fields, gardens/ orchards, and home yard) are described in detail below. Ways of settling disputes over land rights at various levels in the adat structure are also described.

\section{Private Ulen}

According to the Leppo' Ma'ut, mulen is control or ownership of a particular object. For example, if someone finds in the forest a tree carrying a bee hive, or a fruit tree that has not yet been touched by human hand, he can own that tree by cleaning the ground around it and sticking a $2 \mathrm{~m}$ long piece of wood (known as cak) into the ground with its central part split in such a way as to make possible the insertion of a wood twig. The process of clearing the brush, cleaning, and sticking the cak into the ground is known as mulen. The term mulen includes the following ideas: 1) an object already has an owner; 2) the object may not be disturbed; 3 ) anyone who disturbs it accidentally or intentionally, can be charged with an offence and punished; and 4) the article may be used by others (for example, the fruit of the tree may be picked, ) but this must be done with the permission of the owner (see Figures 7.1 and 7.2).

The ownership of the tree is an example of private or personal ulen. The same applies to land. If someone opens land in the primary forest, after the harvest that land becomes the ulen of the one who opened it. Others may work the land but they need the permission of the one who first cleared the land. Nevertheless, in daily language, the owner does not need to say 'This is my tana' ulen,' but only: 'This is my land.'

\section{Tana' Ulen of Adat Communities}

Land is basic capital for meeting the necessities of daily life-for opening fields, hunting, fishing, collecting rattan, gathering wood for construction, and collecting other forest products-both for own use and for sale. The ulen land of the adat community of Long Alango has been in existence from the very beginning of the village, even since the people opened land for agriculture, and it expresses the direct and strong connection between the village society and its land, as seen from both inside 
Figure 7.1 Mulen signs made by the Kenyah Leppo' Ma'ut (by Bilung Njau)

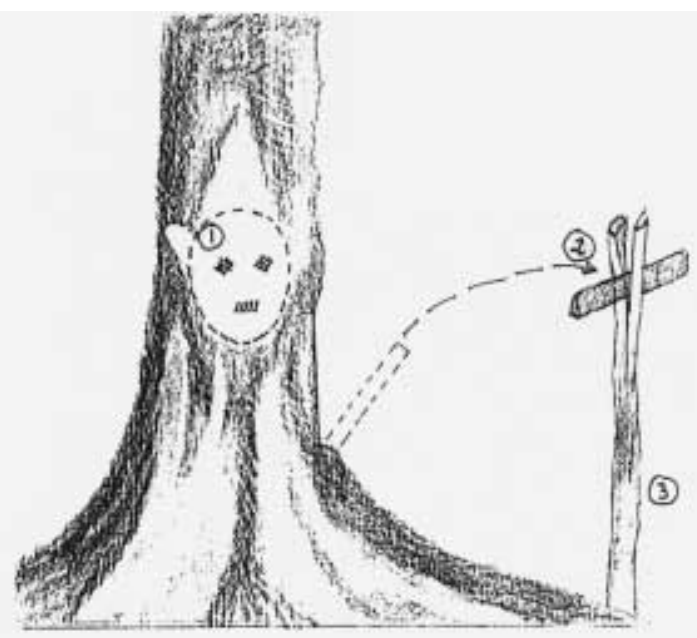

1- NYELONG : CARVING A HUMAN FACE ON THE TREE TRUNK

2- MESIP : INSERTING A BARK STRIP IN THE CEK STICK

3. CEK : A WOODEN STICK STUCK IN THE GROUND AND SPLIT AT ITS TOP

Figure 7.2 Mulen signs made by the Kenyah Bakung (by Lukas Lahang)

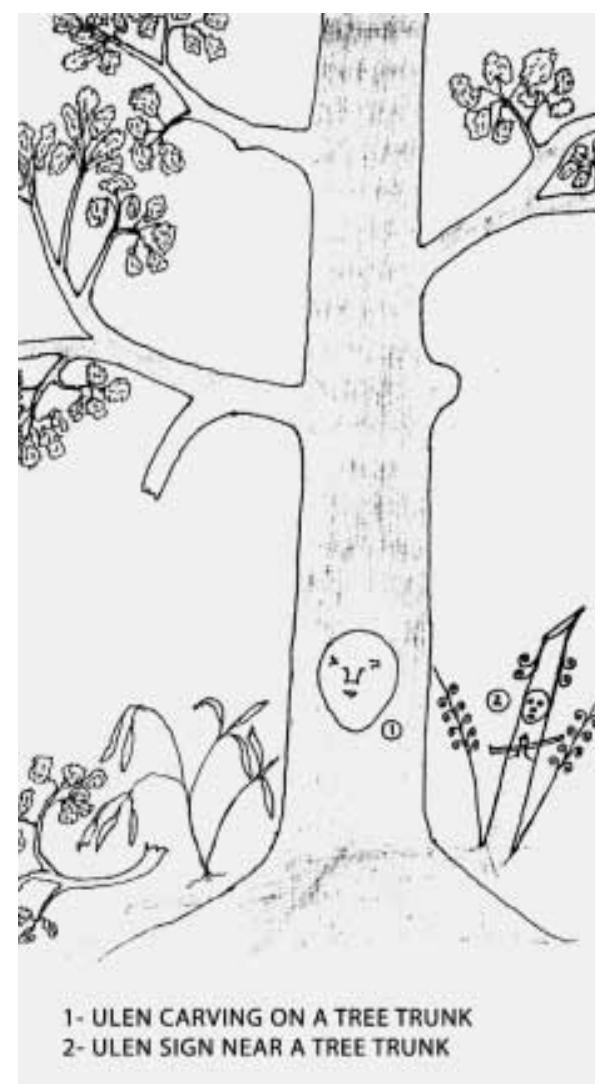


and outside the village. In this way, the natural resources in the ulen land can only be used for the interests of the villagers. The ulen concept known in the Hulu Bahau adat area is identical to the traditional ownership rights known in various other adat communities throughout Indonesia.

After the establishment of Long Alango village, two ulen areas for the village were set aside: the tana' ulen of the Nggeng River and the tana' ulen of the Pande River. Both were owned by the great adat chief of the Hulu Bahau (residing in Long Alango), who intentionally claimed (memulen) them. The products of this tana' ulen, particularly the animals hunted and fish from the rivers bordering them, can be used by all people of the village, and not only for the interest of the adat chief and his family alone. For example, if a family was unable to provide side dishes for its feasts or ceremonies by hunting around the village, they could be given permission by the adat chief to hunt in the tana' ulen. During the dry season, the adat chief could invite the people to fish together in the rivers within the ulen lands. The people could not freely hunt or fish in the ulen lands without obtaining permission. The lands were closely guarded, and anyone trespassing was charged and had to pay a fine in the form of a machete (bayeng). So, in the eyes of the people, the tana' ulen was also a place that kept available a supply of animals for hunting and of fish if they could no longer be found elsewhere.

Long ago, the adat chief declared the tana' ulen on the Pande River open to the people for hunting and fishing, on the grounds that the area was located too close to the village and game was no longer as plentiful as earlier. The meeting of the village leaders and the people, led by the village head on 5 September 1993, determined that the tana' ulen area on the Nggeng River, today the home of the WWF field station, was no longer to be monitored, on the grounds that the area produced no significant products. People from the neighbouring village were permitted to farm in the Long Alango area with the permission of the village chief. Prior to 1992, other people were allowed to enter the village area. These included eaglewood collectors from outside the district, as long as they paid an entrance fee of Rp. 50000 into the village coffers (see Blajan Konradus in this volume). It was soon realised that their actions were very damaging to the village, since eaglewood collecting was a side activity for the villagers, carried out in the free time between their farming activities (before and after harvest). Finally, as of 1992, outsiders are no longer given permission.

\section{Dry Fields}

The primary source of livelihood of the people is dry field farming and wet-rice cultivation. The dry field farming activities begin with a meeting of the farmers to discuss potential field sites or (uma). Attention is given to soil fertility, and distance from the village. Once agreement has been reached, the farmers go in a group to view the location and delineate its borders with a path. On the following days, they begin to clear the brush, both individually and in groups, taking turns (senguyun). If the site is covered with large trees (mba') or old (25-30 year-old) secondary forest (bekan mokon), the clearing activities are begun in May; if it is covered with young forest (6-15 years, bekan lawan), they are begun in J une. To facilitate pest control, the people tend to make the fields side by side (uma' kelindung) rather than separately (uma' tegen). 
If the fields are opened in primary forest (mba'), then they continue to belong to the one who opened them after the harvest, even if they are abandoned to revert to secondary forest. Anyone wanting to open lands once opened by someone else must ask permission from the first pioneer, who usually prefers that the fields are worked even if he cannot do it himself, since fields that remain fallow for long periods become the hiding places of pests, particularly in the uma' kelindung.

\section{Wet Rice Fields}

For wet rice fields the people do not open forest, but also use former fields. Their knowledge of wet-rice cultivation is said to have originated from Apuy $\mathrm{Njau}$, who had occasion to visit Java, Kuching in Sarawak, and often travelled to Long Peso', where he observed wet-rice culture. From his experience, he taught the people how to grow wet rice on former dry fields on the Alango River. The seed he used had been obtained in Long Peso'. Subsequently, local rice varieties were planted. Because the area permits it, ditches were dug to channel water from springs in the hills for irrigation, and wet-rice cultivation expanded into the area around the Ait River, Apau Arai, and Long Arai. The borders between rice fields are the dikes made by the respective owners.

From that time until today, the methods of wet-rice cultivation have not changed. First, the people clear the land to be planted of brush, and at this time the ditches and waterways are covered with stones and leaves. The dry cuttings are burned and water is channelled through the ditches. Wet-rice planting is done individually or cooperatively (senguyun). At harvest time, the water channels are closed again. The people also channel water from the field ditches with plastic pipes for household uses. Rice fields cannot be worked continuously. After 2-3 years, production will certainly decline and a farmer will open a new rice field. This move is not too difficult because former dry fields are widely available for wet-rice growing. Large numbers of farmers still prefer dry field farming to wet-rice cultivation, even though the adat chief and the village head of Long Alango, who only cultivate wet rice, obtain two abundant harvests a year.

Because wet rice fields are established on former dry fields, the farmers tend to use recently abandoned fields (bekan) that they own themselves. If a farmer plans to use a piece of bekan land belonging to someone else to grow wet rice, the adat status of that field is not very clear, because wet-rice cultivation is a relatively new phenomenon in Long Alango. It seems that the creator of the new wet rice field is in a stronger position. There is also a possibility for the plot of bekan land to simply be given by its original owner to the creator of the wet rice field, not as a loan, but to own. Dikes between wet rice fields can still be seen clearly even though the fields have not been worked for several years. Generally, land rights to wet rice fields tend to be more certain and definite, either individually or by family, than rights over dry fields.

\section{Gardens and Yards}

A garden (pola) is land that is planted with crops other than rice. In Long Alango, these activities have been side occupations carried out on the dikes between the rice fields, in the yards of houses, and in former fields. Two types of crops are planted, perennials and annual crops. Trees, for example, Lansium, rambutan, kapok, 
terap (grown for its bark and fruit), coconuts, jackfruit, and tamarind are planted dispersed and mixed in relatively small numbers, and their owners do not take care of them. Perennials planted and cared for specially are cinnamon and coffee, but not all villagers grow them. A crop planted specially is cassava, in former fields after the harvest, while bananas, papaya, and sugarcane are planted on the dikes between rice fields. Beans are planted together with the dry field rice, in small quantities. The people are not much interested in gardens beyond their own familial needs, because they are too far from markets to market their production.

It seems that rights over gardens are not known, except for perennial crops such as cinnamon, which is a commercial crop, and even this seems to be a recent development. Ownership generally relates to plants (trees) themselves, rather than to the land on which they are planted, and it is an individually or family-held right of ownership.

When they settled in Long Alango, the people still followed the old customs and traditions. The establishment of the village of Long Alango was preceded by a melaki ceremony, that is, a ceremony of calling the Brahminy kite, the messenger of the gods who can heal the sick, protect the village from all harm, and protect the fields from attacks of pests. After the ceremony was completed, the great adat chief and the village head divided the village's residential land into yards for building houses, each measuring 15 depa (a depa is the distance to which someone can spread their arms) along the road.

The boundaries of these yards were very simple, indicated only by a fruit tree, flowering plants, a ditch, a marker, or any other sign. Even though controlled by the village, the yards are individually or family owned, and recognition of this ownership takes various forms. The residents respect each other's ownership and do not bother each other, there is no involvement of the village government apparatus.

\section{Settling Land Disputes}

Disputes occur if any party feels harmed, either intentionally or otherwise, as for example in the case of $T$ and $S$, who owned fields side by side. When they had opened the primary forest, the plot border was a small creek (lalut). According to T, the border was a straight line from one end of the field to the other. According to $\mathrm{S}$, however, the border followed the bends of the small river.

The case was brought by the party that felt he had suffered a loss, that is, S, to the head of the block unit, who called both parties and other farmers. $S$ and $T$ were each given a chance to state their case and those present had a chance to respond. Then everyone conferred to arrive at a decision and $T$ was declared in the wrong. (If the decision is still a source of concern, a field review must be held.) No cost or payment was involved in settling the dispute, only food and drink were made available for the village staff who went to the field. The substance of the decision was made public only through the assigned village staff who also served as witnesses.

If disputes develop between residents of different blocks, the settlement is arranged before the heads of both blocks. If settlement is impossible, the village head calls the parties and the heads of their respective blocks to discuss the problem. This discussion is attended by the block elders and other notables. All explanations become material to be considered in joint consultation and by the great adat chief. The great adat chief attends and gives his views regarding the settlement of the dispute, so that the decision is acceptable by both sides without too much worry or waste of energy and time. 
The people adhere closely to adat law and decisions reached through consultation and discussions are considered logical. By the time the writer carried out his research, there had never been a dispute that had to be settled according to written rules and through the involvement of the government.

\section{Transfer of Land Rights}

The transfer of land ownership rights can occur in two ways: through inheritance and through sale/ purchase. Generally, inheritance is the transfer of a right from one person to his children, the heirs. There is no differentiation between biological children and adopted children. Children (anak sekeret) adopted through certain adat ceremonies have the same rights and obligations as biological children. Since the Leppo' Ma'ut have adopted Christianity, adoption of children is done through a church service led by a pastor.

An estate can be divided by its owner during his/ her lifetime. One of the children who still remains in the house is responsible for taking care of his/ her parents in old age. If both parents have passed away, the division of property is carried out by the oldest child, and attended by relatives from both the mother's and the father's side, who can provide explanations in case misunderstandings occur. Basically, the division does not distinguish between younger and older children or between sons and daughters. One of the children and his/her family, who carry on the parental home, have responsibility for taking care of and maintaining the property and the rights attached to the household and the house, the fields, heirlooms, and so on. Children who live in other villages because of marriage or who have moved for other reasons, give up their right to the inheritance to their siblings who remain in the house.

The Leppo' Ma'ut in Long Alango became familiar with the transfer of rights by sale or purchase after 1988, when some of the villagers moved to Long Belua' (also called Bhayangkara, near Tanjung Selor) to be closer to educational and market facilities. The villagers who left generally surrendered the rights to their wet rice fields and gardens to people who remained behind, receiving for them a woven mat, a wok, a machete, clothing according to the 'purchaser's' ability, as well as money. According to informants, those who received wet rice fields or gardens did so only to protect them against the demands of other parties, while the sellers preferred to sell their land rather than leave them unused. Even though simple, this transfer of ownership rights was nevertheless a sale/ purchase transaction because the land was transferred in perpetuity. Some residents transferred their land to family members or to the village without any reimbursement whatsoever; some simply left their land. Generally the buyers or the recipients of the land were people whose lands bordered directly on the lands sold/ purchased. So far, only agricultural land has been sold/ bought, while home yards, which are still fully controlled by the village, have not been sold/purchased; the owner of the yard can only sell the products of the plants. 


\section{Conclusion}

Three conclusions may be drawn regarding control over land according to the traditional adat of the Leppo' Ma'ut in Long Alango. First, the status of village land (territory) so far is fully controlled and regulated by local traditional law, especially as it relates to land ownership, land use, land borders, and transfer of land rights. Second, the tana' ulen of a village is controlled by the village. This does not mean total exclusion of others though, as outsiders may use the land with the permission of the village head. Land disputes are always settled according to traditional law, that is, in a village consultation, and the decision is always honoured by all parties involved, with the result that so far no dispute has ever come before the government officials for settlement. Third, it is time that land rights came under the regulation of written law, specifically Law No. 5 of 1960. At the very least this should be the case for the yards of houses in light of present rapid population growth, economic growth and development. 


\title{
8.
}

\section{Traditional forest use and management among the Kenyah of the Upper Bahau Area}

\author{
G. Simon Devung
}

\section{INTRODUCTION}

This contribution is a modified version of a paper presented at the Fourth Biennial International Conference of the Borneo Research Council in Bandar Seri Begawan, Brunei Darussalam, in J une 1996. It is based on fieldwork carried out in two villages, Long Tebulo and Long Uli, in the upper Bahau River area, Pujungan District.

The absence of national laws regulating activities related to the use and management of specific forest resources does not imply that there are no effective mechanisms for the same purpose at community level (Ostrom 1992: 47). A community may possess special rules and regulations, transmitted from generation to generation, or new forms of such rules and regulations modified to meet changing circumstances and needs. These I generally refer to here as 'traditional institutions' (following Davis 1949; see Alisjahbana 1974: 90). The role of traditional institutions in filling the lacunae of national law is particularly clear at the operational level, as these institutions do affect the strategies of the users, their actions, and the consequences of those actions (Ostrom 1992: 20, 47).

However, it is also worth mentioning that traditional institutions are not always effective in every traditional community, at either the individual or community level. Numerous studies in various parts of Indonesia indicate that in some communities activities related to forest resource use and management by community members generally conform to existing traditional rules and regulations (see i.a. Abdoellah et al. 
1993, Atmadja 1993, Tjitradjaja et al. 1994), as opposed to other communities where the level of conformity is somewhat poor (see Momberg 1992, Tjitradjaja 1993). It is therefore useful to try to better examine the mechanisms that cause traditional institutions to function or not; and to look more closely at the context of these mechanisms.

\section{FOREST RESOURCE USE AND MANAGEMENT}

The study of the use and management of forest resources by village communities in the upper Bahau area in Long Tebulo and Long Uli shows that the forest still represents the main source of livelihood for the local communities (Devung 1996). Long Tebulo (LT) is populated by a subgroup of Kenyah, the Leppo' Ké, while the people of Long Uli (LU) are Kenyah Oma' Long (Uma Lung) and Kenyah Leppo' Ndang.

The forest is used for various needs related to subsistence: rotational cultivation of rice in both primary and secondary forest, hunting and fishing, harvesting of fruit and plants, and gathering of building materials. The major portion of the villagers' cash income originates from commercial forest products, particularly eaglewood (or aloe wood, or incense wood, LT sekkau, LU sekkou, Indonesian gaharu; Aquilaria beccariana and A. malaccensis, Thymelaeceae, and other taxa) and, to a lesser extent, rattan (LT uway sekka, LU véy sekko; Calamus caesius, Palmae), and resin used to glue machete hilts (LT-LU ketipay; Palaquium quercifolium, Sapotaceae) as well as spice leaves (LT-LU bekkay; Pycnarrhena cauliflora, Menispermaceae) for the local market.

Considerable variation has been observed with regard to the intensity and frequency of the use of each of these resources, at both the individual and community levels. The use of primary and secondary forests for the cultivation of dry rice fields is described in Table 8.1. Field size ranges from 1.5 ha to 2 ha per household. The households not accounted for were cultivating only permanent wet rice fields that particular year (LT mpeng, LU sava).

Table 8.1 Types of forest used for dry rice farming since 1990 (number of households; households not accounted for were cultivating wet rice fields)

\begin{tabular}{lcccc}
\hline Type of forest & Long Tebulo & $\%$ & Long Uli & $\%$ \\
\hline Primary & 5 & 24 & 5 & 21 \\
Secondary & 6 & 29 & 21 & 88 \\
\hline
\end{tabular}

In hunting and fishing, variation can be seen from the amount of hunting and fishing equipment owned by each household (see Table 8.2). Hunting is performed generally once a week by those who have hunting dogs and at least twice a week by those who possess guns. Fishing is done almost every day by those who have fishing nets, either dragnets or cast nets, when river conditions allow. Besides hunting and fishing for household consumption, these are also done in connection with collective needs of the village such as the harvest festival, a wedding party, or cooperative work. The collection of commercial forest products, such as gaharu, rattan, ketipay 
resin, and bekkay leaves, also shows variation in the types of products collected, the number of households involved, and the frequency of collecting (see Table 8.3).

Table 8.2 Number of households owning hunting and fishing facilities

\begin{tabular}{lcccc}
\hline Facilities & Long Tebulo & $\%$ & Long Uli & $\%$ \\
\hline Hunting dogs & 5 & 23 & 7 & 29 \\
Hunting guns & 19 & 86 & 10 & 42 \\
Blowpipes & - & - & 3 & 13 \\
Fishing nets & 21 & 100 & 10 & 42 \\
\hline
\end{tabular}

Table 8.3 Number of households involved in collecting forest products between two farming seasons (1994-1995)

\begin{tabular}{lcccccc}
\hline Product & L. Tebulo & $\%$ & Frequency & Long Uli & $\%$ & Frequency \\
\hline Eaglewood & 13 & 59 & $1-6$ & 20 & 83 & $1-47$ \\
Rattan & - & - & - & 10 & 42 & $1-5$ \\
Ketipay & 7 & 32 & $1-3$ & - & - & - \\
Bekkay & 6 & 27 & $1-3$ & - & - & - \\
\hline
\end{tabular}

The management of forest resources by the local community is closely linked to the management of the village territory and the use of the forest within, on the basis of each area's potential and local people's use preferences. A village territory is commonly divided into several designated areas, including a settlement area (LT uku' Ieppo', LU ukhu' oma), several farming areas (LT uku' uma, LU ukhu' umu; or LT uku' mpeng, LU ukhu' sava), and a restricted forest area (LT tana' ulen, LU tana' olen). The rest, the village's open communal forest, is used for various purposes like hunting, fishing, harvesting fruit and plants, gathering building materials, and collecting commercial forest products.

The use and management of the forest by the community is based on the principles of common arrangement, cooperation, and mutual help in the social context of production, as well as sharing in the social context of consumption. Such principles can be seen clearly in the rules governing social relationships and in the regulations of activities related to resource use and management of each of the forest products. These rules and regulations vary both in content and complexity.

In the use of the forest (either primary or secondary) for agricultural purposes, there are rules about the location of the fields that will be cleared, the delineation of the boundaries between fields, and the timing of the clearing and burning of the fields. In hunting, regulations concern the prohibition of the use of bamboo spring spears (LT-LU belatik) and bamboo spiked traps (LU zhezang) in the hunting areas and around the settlement, the sharing of game meat, the organisation of hunting during the periods when wild pigs swim across the river (LT satung, LU satong) or when birds flock to the salt springs (LT sungan, LU songen). In fishing, rules and regulations 
concern the use of fish poison ( $L T$ tu'ba, $L U$ tu'bo), the designation of certain streams for daily and occasional fishing, and the sharing of fish among involved parties and with relatives and neighbours (LT ngatu, LU mate). In the harvesting of fruit and plants for consumption, regulations concern collective and private ownership of trees and plants, the harvesting, and sharing of the product. In the gathering of building materials from the forest, rules and regulations mostly relate to the establishment of collective or private ownership of the trees or plants that provide the materials. In collecting commercial forest products, rules and regulations govern the customary territory (Indonesian wilayah adat), village territory (Indonesian wilayah desa), village restricted forests (LT tana' ulen, LU tana' olen), modes of harvesting the forest products, and the dues to be paid to the village (Indonesian iuran LMD).

Some degree of variation also exists between the two communities observed, with regard to both the content and complexity of rules and regulations, for example, the sharing of wild pig meat during the pig swimming season (see below).

The common principles underlying rules and regulations govern individual and group access to each type of resource in such a way that 1 ) every individual or household has more or less the same opportunity; 2) given this opportunity, there is possibility for cooperation and mutual help, as well as a chance for every individual or household to earn a larger share than others; and 3) the surplus thus obtained can be redistributed. In this way, unhealthy competition and open conflict over resource use in the community can be minimised.

The following is an inventory of rules and regulations relative to forest use and management in the two communities at the time of my field research (Devung 1996: 128-158).

\section{Farming}

The rice fields should be located in one or another of the designated farming areas. Fields should be side by side in clusters or at least close to one another. The field boundaries as agreed upon among households should not be altered without prior common agreement. In a given cluster of fields, the clearing of the forest should be carried out more or less simultaneously. At the time of the clearing, omens should be observed and fellow villagers notified. In a given cluster, the burning of the fields should be done simultaneously.

\section{Hunting}

Bamboo spring spears are not allowed in hunting areas, around the rice fields, or near the village. In Long Uli, bamboo spiked traps may be set up along the rice field fences as long as fellow villagers are notified. In Long Tebulo, the regulation for this kind of trap is the same as for the bamboo spring spear, both are prohibited.

Some hunters are more successful than others. A successful hunter must share the meat with neighbours within a radius of two houses and with close relatives (grandparents, parents, siblings) outside of that radius.

Local people usually hunt in groups with dogs. The owner of the dog pack, whether he participates in the hunt or lets others borrow his dog pack, gets the head portion (LT tulat ulu, LU tolet ule) and the tail portion (LT tulat so'et, LU tolet pali) of the catch, then the rest is evenly shared among all the hunters of the group, including the owner of the pack. When hunting is performed using a gun, the gun owner gets the head portion 
of the catch, whether or not he participates in the hunt. If the bullets also belong to him, he also gets the tail portion. If the bullets belong to someone else, that person gets the tail portion, whether or not he participates in the hunt. The rest is then evenly shared among all hunters, including the gun owner and the bullet owner.

When a party goes hunting for the village's collective consumption (LT nyamet, LU nyaméd)-for example, for the harvest festival or a wedding-the owners of the dog pack, of the gun, and of the bullets get their shares as specified above. Other hunters get the innards (LT-LU tena'i; LT betuka', LU betukho; LT atay, LU até). Then the rest is handed over for collective consumption (LT mung kuman, LU femong omen).

During the season when wild pigs swim across the river, it is forbidden to go hunting with dogs or guns around the places where the pigs usually cross. It is also prohibited to wait for the pigs on the same bank where they descend to cross. Hunting may only be done with spears (LT buja', LU sekke') on canoes built from wood planks (LT alut, LU aled) while the wild pigs are swimming across the river. The hunters whose canoe is closest to the swimming pigs have priority over others, and thus, the opportunity to be the first to spear the pigs.

The first hunter to get a catch in the swimming-pig season must invite all household heads in the village to dinner (LT mung kuman, LU femong omen). At the dinner, a village official publicly announces the beginning of the season and reminds the villagers of the rules and regulations regarding this type of hunting activity. Every day during the pig swimming season, the catch must be gathered and shared among all participating hunters before they return home. Hunters who first stabbed and injured a pig get the head portion and the rest is evenly shared among all hunters, including those who have received the head portion. In Long Tebulo, this rule is valid for the entire pig swimming season. In Long Uli, however, it applies only to the first two weeks. During the following two weeks, the sharing is performed only among hunters at the same waiting site (ka), and afterwards, only among those on board the same canoe.

During the season when birds flock to the salt springs, the use of guns around the area is not allowed. Birds may only be caught using bird nets (LU kap sevi). The first hunters to build their huts in the vicinity of the spring have priority in setting their nets in front of their huts during the whole period. If another hunter wishes to use the hut and nets, he must notify the owner, and the catch must be evenly shared with him.

When there are two or more hunters setting their nets at the same time near the spring, all the nets should be taken down simultaneously. The hunter whose net has caught the most birds gives the signal to start taking down the nets. When all the nets have been folded, the hunters with the least catch must assist the others in picking the birds from the nets, cleaning up the surroundings, and resetting the nets. For their assistance they get a portion of the catch.

\section{Fishing}

Individual villagers are not allowed to fish using poison in the Bahau River and in rivers within the area of the restricted forest, which may be poisoned only for collective consumption. In small tributaries of the Bahau River or other small rivers outside the area of restricted forest, poisoning for individual needs is permitted. The kinds of fish poison permitted in all cases are those extracted from plant roots (LT tu' ba aka, LU tu'bo aka) or tree bark (LT sok elang, LU zak ilang). The streams where fish are known to spawn or where people usually set bamboo fish traps (ilid) may in no case be poisoned. 
A person catching a big fish or a large amount of fish must share with his neighbours and close relatives. When a group goes fishing with a casting net, the catch is shared more or less evenly among the participants, the owner of the net and the owner of the canoe, whether or not they have participated in the fishing.

In the case of fishing for the village's collective consumption, a small part of the catch is shared among the fishermen and the rest is handed over to the community.

\section{Harvesting Fruit and Plants for Consumption}

Trees and plants with edible parts-leaves, flowers, or shoots commonly used as vegetables, or fruits-growing around the village or near the rice fields may be claimed as private property by those who first found or cleared them, and may later be inherited. A claim is established by certain ownership marks: LT cek ( $L U$ ce' $^{\prime}$ ), a plain wooden stake stuck in the ground, pointing to the tree or plant; or LT tak ulu (LU ta' ule), a sign resembling a human face carved in the trunk of the tree; or prohibition marks: LT sip (LU tip), a wooden stake stuck in the ground, pointing to the tree or plant, with a prohibition symbol slipped across the split upper end of the stake.

Prohibition signs usually have four escalating levels of warning. The first level has LT da' un (LU da'eng), a fresh leaf or leafy twig, placed at the sip (slip), meaning: 'This is owned by someone!' The sign da' un (da'eng) represents the words LT i' da un (LU é'da eng), which means: 'someone owns (it)'. Thus this prohibition sign has exactly the same function as the ownership mark.

People are prohibited from taking edible parts from a tree or plant bearing such ownership marks without permission from its owners. If someone gets caught redhanded, the owner has the right to reprimand the thief on the spot, file a complaint through the elders, or prosecute through the adat court.

If the thief is unknown, the owner may place a second-level prohibition sign, using udu' ai' (Imperata cylindrica), meaning: 'Don't take it!' The sign ai' represents the word ayen which means 'don' $t$ '. If theft occurs again and the thief is still unknown, the owner may place a third-level prohibition sign, using udu' tangé (Lycopodium cernuum), meaning: 'Your bad deed makes us cry!' The sign udu' tangé represents the word nangé, 'to cry'. In case of repeated theft, the last level of prohibition signs uses puten luten (a piece of burnt firewood), meaning: 'We are now angry!' The burnt part symbolises the owner's hurt feelings.

People having collected forest vegetables or fruits in large quantities must share with their neighbours and close relatives. In case of need (a wedding party, cooperative work, or a sudden death), the owners of forest trees or plants with edible parts must allow the harvesting of these edibles for collective consumption.

\section{Gathering Building and Other Materials from the Forest}

Trees and plants commonly used for building materials or household implements which grow around the settlement, near the rice fields, or in the village's common forest may be claimed as private property by those who first found or cleared them, and they may later be inherited. Ownership marks or prohibition marks may be placed next to those trees or plants. For large trees, owners also commonly carve a sign resembling a human face (LT tak ulu, LU ta' ule) on the trunk, and recently also the initials of their name (LT tak kalung nga'dan). 
A fallen tree without ownership marks may be claimed by the person who first found it, who then must clear the ground around it and place an ownership or prohibition mark or a stick (LT sekiwat, LU sekéved) across over the trunk. A tree drifting in the river without ownership marks or the initials of the owner's name may be claimed by the person who first found and tied it up by carving his/ her ownership mark (human head or initials) on the trunk.

It is prohibited to cut any standing and fallen tree bearing ownership marks or prohibition marks without permission from the owner. In case of theft, the owner may reprimand the thief on the spot, file a complaint through the elders, or prosecute through the adat court.

\section{Collecting Commercial Forest Products}

In the Upper Bahau customary area (Wilayah Adat Hulu Bahau), to which Long Tebulo belongs, outsiders are prohibited from collecting commercial forest products, and are only allowed to purchase the products from local collectors. The villagers of Long Tebulo, like villagers of other settlements in the Upper Bahau customary area, are allowed to collect commercial forest products within the territory of any village (wilayah desa) in the Upper Bahau, as long as they have permission from the concerned village officials. Every group going on a forest expedition, whether in their own or another village's territory, must pay Rp. 2500 per collector as dues to the LMD (Lembaga Masyarakat Desa or village council).

In the Pujungan customary area (Wilayah Adat Pujungan), to which Long Uli belongs, outsiders are permitted to collect commercial forest products but need to procure permission from the district officials in Long Puj ungan. They may not, however, enter the Sungai Lutung restricted forest area of Long Uli. For each week spent in the forest, a group of outsiders must pay Rp. 50000 as LMD dues, whereas a group of local collectors must pay only Rp. 5000, whether the collecting is carried out in the village's communal forest area or in the restricted forest area of Sungai Lutung.

Small Aquilaria trees may not be cut when collecting eaglewood, and collectors are required to gouge the trunks of large trees in order to check whether they contain any gaharu resin (Indonesian isi gaharu), before cutting down the tree. Likewise, young stems may not be cut in the collection of rattan. Mature rattan stems must be cut at about $1 \mathrm{~m}$ from the ground, and the upper part of the stem must be planted back into the ground to allow it to produce new shoots. In collecting ketipay resin, small ketipay trees may only be tapped and may not be cut down. In harvesting relish leaves (bekkay), only mature leaves may be picked, while the stems may not be cut down.

\section{TRADITIONAL INSTITUTIONS AND ACTUAL PRACTICES}

In both Long Tebulo and Long Uli, traditional rules and regulations are still effectively practiced in the use and management of forest resources for subsistence needs, at community level as well as individual level. Conversely, in the use and management of forest resources for commercial purposes, particularly in the extraction of gaharu, traditional rules and regulations seem to be no longer in effect, either at individual or at community level. In the collection of rattan, in both Long Tebulo and Long Uli, some rules and regulations are still maintained and effectively used at community level, while others are already neglected. In the extraction of ketipay resin and collection of bekkay leaves in Long Tebulo, traditional rules and regulations relating to the technical 
aspects of extraction are still maintained and effectively used at community level but those concerned with the payment of the village dues are not in effect and are practically neglected.

Seen in the social context of production and consumption, compliance and incompliance between practices and traditional regulations may relate to a number of factors: 1) the relationship of the individuals involved in forest resource use and management activities; 2) the group's influence on individuals; 3) the transparency of forest resource use and management activities; and 4) the nature of control in these activities. Some of these factors play independent roles in the phenomena of compliance and incompliance, while others play interconnected roles, with somewhat different causal mechanisms and intensity. These aspects can be seen in several activities of forest resource use and management as described above.

In activities of forest resource use and management that are related to subsistence needs, the interdependency of individuals involved in the activities and the group's influence on individuals are greater, the activities undertaken are more transparent, and controlling measures can be taken directly in case of deviation. This is possible because in the social context of production there are mechanisms of cooperation and collective organisation. In the social context of consumption, there are mechanisms of mutual help and sharing. Besides, all of these activities are undertaken internally to the community. There is no interaction with other actors beyond the community members and there is no intervention of other mechanisms.

In forest resource use and management activities that are related to commercial purposes, the interdependency of individuals involved in the activities and the group's influence on individuals are somewhat loose, the activities undertaken are less transparent, and controlling measures cannot be taken directly in case of deviation. This happens because in the social context of production the mechanisms of cooperation and collective arrangement in forest resource use and management activities are limited to the work groups and do not include the entire community. The same situation also applies to the mechanism of mutual help and sharing in the social context of consumption. Besides, some of these activities are performed beyond the internal context of the community, in interaction with outside actors beyond the circle of the community.

In both the activities of forest resource use and management related to subsistence needs, and in those related to commercial purposes, the aforementioned circumstances to a certain extent are generated by one or more situational factors, such as the existing physical environment, forest resource characteristics, population numbers, economic condition, social organisation, community leadership, production (forest resource use) system, technology, and interactions with other actors.

In the use of forest for agricultural land, either for dry or wet-rice cultivation, every household needs the cooperation and the help of other households. Such a situation is caused by the shortage of labour available in each household and the limits of agricultural technology adapted to the local environmental conditions and social organisation. For example, the limited number of days without rain needed for burning the rice fields, and the traditional organisation of rice planting (LT nu' gan, LU nogen) with fixed days for planting for each household, require a strict schedule for clearing and felling trees in the rice fields. Due to shortage of labour, every household needs the cooperation and help of the other households, in the form of either labour exchange (LT senguyun, LU sengozen) or cooperative work (LT ga'gan pembun, LU jagen fempeng), to meet such an arrangement. Table 8.4 shows labour per household involved in agricultural activities in Long Tebulo and Long Uli. 
Table 8.4 People (per household) involved in farming activities (1995-1996 farming season)

\begin{tabular}{ccccr}
\hline $\begin{array}{l}\text { Number } \\
\text { of people }\end{array}$ & $\begin{array}{c}\text { Households } \\
\text { Long Tebulo }\end{array}$ & $\%$ & $\begin{array}{c}\text { Households } \\
\text { Long Uli }\end{array}$ & $\%$ \\
\hline 1 & - & - & 1 & 4 \\
2 & 7 & 34 & 7 & 29 \\
3 & 5 & 29 & 8 & 33 \\
4 & 2 & 10 & 4 & 17 \\
5 & 1 & 5 & 1 & 4 \\
6 & 1 & 5 & 1 & 4 \\
7 & 3 & 14 & 4 & 4 \\
\hline
\end{tabular}

In the social context of consumption, every household can at one time or another experience harvest failure, either because of pests, a long dry season, or river flooding. Some environmental factors, such as the elevation of the rice field or soil conditions, may cause more detrimental effects to some households' rice fields than others. In such conditions, the unlucky households normally expect to be allowed to help harvest others' rice fields (LT mettau, LU metto) and get a share of the rice for the service to make up for the shortage in meeting the needs of their annual rice consumption. It is also common that after the harvesting season the unlucky households still expect to be allowed to help pound rice for other households and receive some of the pounded rice in return for the service.

With the interdependency of households in the social context of production as well as in the social context of consumption as described above, it is understandable that rules and regulations relating to the use of forests for agricultural fields are normally adhered to. Some individual adjustments in order to conform to the rules and regulations may occur, for instance, at Long Tebulo. In the last five years, for two consecutive farming seasons, two households were late in beginning the clearing of their wet rice fields. They decided to make smaller fields, and thus managed to catch up with their fellow farmers and burn and water the fields at the same time as they did, although they knew that they would have a smaller harvest.

The decisions concerning the location of the fields, the boundaries among fields, the time to begin clearing and burning the fields are traditionally determined collectively, either in village meetings or in discussions held among households of the same cluster. In that way, group influence on individuals is greater, and conformity to what was agreed together more guaranteed (Krech et al. 1967: 506). Activities following those decisions and arrangements are also undertaken collectively, thus being more transparent, and the necessary controlling measures can also be applied directly in case of deviation.

Hunting and fishing also involve cooperation and mutual help among households. First, not all households possess hunting or fishing equipment, as shown in Table 8.1. Those that do not possess hunting or fishing equipment commonly expect to borrow it from those who own it, or to be invited to join in hunting or fishing activities. Due to a shortage of adult males in certain households, it is also common that those possessing the equipment prefer to lend it to other households or to invite members of other households to go fishing or hunting with them. The thick forest and rapid river current 
also encourage people to go together when hunting or fishing, especially if the destination is quite distant from the village, or if they go hunting and fishing at night.

In the social context of consumption, as people do not go hunting or fishing every day-or if they do, there is no guarantee that they will always be successful-people as a consequence also depend on the sharing of meat and fish by their fellow villagers. Such conditions of dependency urge people to consciously conform to the rules and regulations relating to hunting and fishing arrangements. Such arrangements are also decided collectively either at the village level or at group level, as has been described before. Group influence on individuals is therefore greater, forcing them to conform to the rules and regulations.

Deviation from rules and regulations relating to hunting and fishing arrangements is also easily found out. Most of the activities are commonly undertaken together with other people. The hunting and fishing areas are frequently visited, especially during particular seasons such as the wild pig swimming season, the salt spring bird season, or the fish spawning season. In such conditions, controlling measures can be also applied directly when necessary. For example, in the 1990 wild pig swimming season, a hunter went chasing his prey on the river bank alongside the area that is prohibited during that season. After seeing his canoe by the beach, other hunters, who arrived later to wait for the wild pigs to swim, got mad and hoisted the canoe to the top of a nearby laran tree (Dipterocarpus oblongifolia Bl.).

Those who come home from hunting or fishing with an abundant catch are also easy to notice. The boats are always parked at the bathing area by the river bank, which is commonly shared with neighbours, and the path to every house in the village is wide open. Given these conditions, the rules concerning the obligation to share meat and fish with close relatives and neighbours tend to be readily conformed to by the villagers. Individual adjustments to rules and regulations exist among the hunters in both Long Tebulo and Long Uli. If the catch is too heavy to carry home, the hunters normally leave the heads and the innards in the forest. In such a case, the owner of the hunting dogs or the gun would get the fatty skin of the catch (LT-LU nyak) instead of the head or tail portion.

In harvesting fruit and plants for consumption, although more limited, cooperation among parties involved is also frequently needed. To harvest edible parts and fruits of big and tall trees, people usually need someone to climb the trees; or if the location of the trees is quite distant from the village, they prefer to have some company. In the afternoon, in both Long Tebulo and Long Uli, one can notice groups of two or three women coming back from the adjacent forest with vegetables or fruits in their baskets (kiba).

In the social context of consumption, when someone comes from the forest with abundant vegetables or fruits, it is very common that fellow villagers ask for some. At special occasions such as funerals, weddings, or cooperative work, people also get vegetables or fruits from fellow villagers as a contribution. The obligation to share with fellow villagers is frequently stressed, particularly in the words of advice given to the bridal couple at the wedding ceremony, or as part of the advice given to new settlers in the village. At Long Tebulo, the advice concerning this obligation is: Ayen ma'em, buk uba' tareng kuman sin, kuman atuk, kuman bua', atek tareng lina ngatu maan panak, maan i'da cen a'jo' ('Don't be selfish, if you want to eat game meat, eat fish, eat fruits frequently, you must also frequently share yours with your relatives and neighbours').

The influence of the group on individuals is also great in this context. Deviation from the rules and regulations will bring blame on the offender from all parties. The 
prohibition on taking vegetables or fruits from trees having ownership marks without the owners' permission is always reiterated in the village meetings, especially when those fruits are in season, to avoid conflict and disputes among households. In Long Uli, the forefathers' advice concerning this is frequently recited by the elders in meetings: É' en vonén beva, beva kadu loung ('Don't fight over fruit trees, fruit trees have many fruits').

Taking vegetables or fruits from trees bearing ownership marks without the owners' permission is also easy to notice, as such trees are commonly close to the owner's residence or rice field. The custom of sharing, the influence of the group on the individual, and the location of the fruit trees or vegetable plants, make the rules and regulations relating to the harvesting of fruit and plants easy to conform to.

The case of gathering building materials and other plants for domestic use from the forest is more or less similar to that described for hunting and fishing, as well as for harvesting fruit and plants. In the social context of production, cooperation among fellow villagers is sometimes needed because not all households possess the necessary working equipment, such as chainsaw (sensor or shinsow) for felling trees and cutting wood, or motor boat (ketinting) for transporting materials. When traditional equipment, such as axes (LT asay, LU azé), is used for felling and cutting trees, or when a rowboat or wooden raft is used for transporting materials, even more cooperation is needed among households and may sometimes involve all the households in the village (LT ga'gan pembun, LU jagen fempeng). During my stay in the field, I had the opportunity (twice in Long Tebulo and once in Long Uli) to observe people undertaking village cooperative work, namely gathering building materials from the forest for house building. In the social context of consumption, in emergency cases, such as when someone's house or boat is washed away by a flood (e.g., on 26 April 1995), fellow villagers usually lend the spare building materials, boat keel or hull they have to the family in need.

The rules and regulations concerning the prohibition on cutting trees or plants bearing ownership marks for building materials without the owners' permission are commonly conformed to by the villagers. Besides the cooperation and the custom of sharing mentioned above, the location of such trees and plants is commonly close to the paths frequently used by the villagers. Deviations or violations are easy to notice, at least when the violators take the materials home or when they dry the materials in their open yards.

In the collection of commercial forest products, especially gaharu (eaglewood), cooperation in the social context of production is relatively limited and a considerable number of alternatives are available to the collectors. Outside collectors only need limited cooperation with local villagers during their short stay in the village. Their cooperation is often limited to the village authority (pengurus desa) and/ or the host family. If there is a problem or difficulty during their stay, they can easily move to other villages. Cooperation among the local collectors is also limited, as the collection is commonly done in small groups, or even individually, and the provisions needed for the expedition for the most part supplied by the gaharu traders (buyers) who act as their patrons.

In the social context of consumption, the sharing of products collected during the expeditions is limited to the members of the collecting group. No direct sharing with fellow villagers is expected, even if the collection is known to have been successful. This way, the rules and regulations concerning the collection of commercial forest products are perceived by people to limit rather than bring benefits. As a consequence, 
those rules and regulations tend to be neglected whenever possible. Such a tendency applies to rules and regulations concerning the areas off-limits for collection, village dues payment, and the mode of collection.

Geographical aspects and the characteristics of the resource also play an important role in the poor conformity to the rules and regulations. The vast customary areas (wilayah adat) as well as village areas (wilayah desa), and restricted forest areas (tana' ulen) allow people to encroach on these areas from various entry points, beyond the control of the local authorities and inhabitants. The gaharu trees are widely scattered and those potentially containing gaharu resin seem to grow more abundantly in remote locations that are rarely visited by the villagers in their subsistence-gathering activities. Such conditions make it difficult to secure and control the implementation of rules and regulations concerning prohibited areas or permitted modes of collection. No one is able to check who goes where, and who cuts which gaharu trees and how.

The quantity of gaharu trees encountered in a collecting trip also plays a considerable role in the compliance with rules and regulations concerning the modes of collection. The collectors both in Long Tebulo and Long Uli admitted that, if during the trip they encounter many gaharu trees, they normally leave all small trees and selectively check the big trees for gaharu resin before felling them. However, if they encounter only a few gaharu trees during the trip, they prefer to fell all the gaharu trees that they find, regardless of size or content indicators, especially when it is already late in the afternoon.

Conformity to the rules and regulations in the collection of rattan, ketipay resin, and bekkay leaves varies. In the collection of rattan, the rule concerning the obligation to cut only mature stems is usually complied with, as the collectors realise that rattan with mature stems weighs more and does not break easily. The rule concerning the obligation to plant the upper end of the stem back into the ground, however, is hardly conformed to, as it is quite time consuming and hard to do in the midst of thorny clumps, especially when large-scale collecting is taking place.

In the collection of the ketipay resin and bekkay relish, rules relating to the modes of collection are quite well conformed to. Ketipay trees are hardwood, so collectors are naturally reluctant to fell young trees, which normally have less resin. The bekkay stems are climbing vines wrapped around other trees. Even if the collectors cut the stems, it is impossible to pull the stems down to pick the leaves. If they fell the main vine, it will cost more time and energy. The natural tendency in this case is to pick mature leaves on the lower part of the stem, which can be easily reached by climbing or from the ground.

Regarding the LMD dues, the collectors are only willing to pay it when they have obtained a successful harvest during their trip. In such a case, as the collectors put it, not only the LMD dues would be paid, but also 'the tenth for the Church'. The principles applied here are similar to those used in the sharing of game meat in hunting or in the sharing of fish in fishing activities. However, what exactly a big harvest is depends very much on the collectors' own evaluation at a particular time. Commercial forest products are mostly sold directly to the traders (buyers) in Long Pujungan or Long Alango, so it is hard to know precisely how much one has received in payment. When fellow villagers ask the collectors about the sale, they usually answer: un kedi'ut da ('only a little')! Another complicating factor is the bon system (credit, advance payment in kind). Even if a large quantity of products is sold, their profit will be much smaller after they have paid back their debts to the trader. 
Actually, the system of LMD dues was relatively simpler before 1990. The collection of commercial forest products, especially rattan, was done collectively and was directly organised by village authorities. The collection was done during the LT buka ulen (LU mesik olen) or 'open the restricted area' season, which usually took place after the rice harvest. The payment of LMD dues could be controlled, as it was directly deducted or paid from each collector's rattan harvest or from the proceeds of the sale. The principles applied in the collection were similar to those practiced in the sharing of game meat when people go hunting in groups during the wild pig swimming season, or in the sharing of fish when groups go fishing with poison for a village party.

\section{CONCLUSIONS AND POLICY IMPLICATIONS}

After examining the phenomena above, at individual level, I am inclined to see conformance or nonconformance to traditional rules and regulations as an 'adjustment process' (Bennet 1980: 252). Rules and regulations are coercive in nature. Response to such coerciveness may vary from one individual to the next, and from one situation to another. In the cases observed in Long Tebulo and Long Uli, it seems to depend mostly either on 'external group control and pressure' upon the individual (Keesing 1958: 305); or simply on 'pragmatic considerations of self-interest and expediency' in deciding whether to conform or not to the rules and regulations (Krech et al. 1967: 506; Beattie 1977: 168). Ethical motivations (awareness and responsibility) functioning as 'internal individual repressive control' (Keesing 1958: 305) could not be discerned in the cases observed.

At community level, I tend to see conformance or nonconformance as an ongoing process of retaining or modifying traditional rules and regulations to meet the community's persisting or changing circumstances and needs (Ostrom 1992: 62). As a process, at some points, it may, or may not, be well adaptive, in the sense that it may, or may not, lead to efficient and fair management of forest resources (Ostrom 1992: 47).

However, without pretending to blindly admire everything that is 'traditional', it is important to realise that traditional institutions and regulations still exist in various communities simply because of their greater long-term adaptive value (Bodley 1976: 52). Following this consideration, if adj ustments, changes, or substitutions are needed in the existing traditional rules and regulations, it is necessary to be able to identify which factors have played a role, in what conditions, and by what mechanisms, in allowing the institutions to function well or not function.

Information on such factors, conditions, and mechanisms is badly needed in order to design policies concerning adjustments, changes or substitution of traditional institutions, whether in terms of rules or in terms of regulations. Even when there is a significant gap between practices and associated rules and regulations, it is worth looking at whether the rules or regulations themselves need to be adjusted, changed or substituted; or whether the monitoring system and the sanctions need to be modified.

Various practices of use and management of forest resource by traditional communities, as seen in the Upper Bahau region, have some implications with regard to policy. One practical implication is the necessity of pluralism and flexibility in rules and regulations to accommodate as much as possible the needs of communities with different environmental, social, and institutional contexts. For this purpose, studies aimed at finding typologies of forest resource use and management by various communities living in and around forest areas are needed. By taking such typologies into consideration, it would be much easier for planners to design various policies 
adjusted to the various types of existing forest resource use and management, either regionally or nationwide.

In designing policies, the principles of traditional management regarding access to forest resources and control over their use should also be considered and accommodated. If not, the implementation of policies would face the same fate as the payment of LMD dues, which was simply neglected because it was not in accordance with traditional principles and common practices of forest resource use and management. 


\title{
9.
}

\section{A history of the Kenyah Leppo' Ké and Nyibun in Pujungan Subdistrict}

\author{
Njau Anau
}

\section{INTRODUCTION}

The Leppo' Ké and the Nyibun are two ethnic groups belonging to the larger group of the Kenyah, who are presently living in the subdistrict of Pujungan, specifically in the desa (administrative villages) of Apau Ping, Long Pengayan, Long Lat, Long Berini, Long Kemuat, Long Alango and Long Tebulo (see Table 9.1). Leppo' Ké and Nyibun are also found in the villages of Long Loreh and Gong Solok along the Malinau River, and in Long Banga' and Long Selaan, in the Baram area of Sarawak. The village of Apau Ping, the focus of this research, is the last settlement on the upper Bahau River, a very isolated area. The village of Apau Ping consists of four desa: Apau Ping proper, Long Lat, and Long Pengayan, inhabited by Leppo' Ké and Nyibun, and the desa of Long Tua, which has very few residents, from the Saben group (also known as Berau, see Table 9.2).

This research into the history of the Leppo' Ké and the Nyibun uses the ethnohistorical method and is based on interviews with people able to provide historical information. All interview results were crosschecked, and the historical events were then reconstructed accordingly. For accuracy of data, lepu' un (former sites of villages) and other historical sites were visited.

\section{Social Organisation of the Leppo' Ké and the Nyibun}

Even though Apau Ping is an isolated village, the values of modernity have begun to affect it. As in other traditional societies that have subsequently disappeared, these new values slowly but surely have begun to replace traditional values. 
Table 9.1 Leppo' Ké and Nyibun population in Pujungan Subdistrict

\begin{tabular}{lccl}
\hline Desa & \multicolumn{2}{c}{ Total } & Composition \\
\cline { 2 - 3 } & Families & Persons & \\
\hline Apau Ping & 20 & 108 & Leppo' Ké + Nyibun \\
Long Pengayan & 25 & 122 & Leppo' Ké + Nyibun \\
Long Lat & 4 & 16 & Leppo' Ké \\
Long Berini & 30 & 197 & Leppo' Ma' ut + Nyibun \\
Long Kemuat & 16 & 75 & Leppo' Ma' ut + Nyibun \\
Long Alango & 55 & 397 & Leppo' Ma' ut + Nyibun \\
Long Tebulo & 18 & 102 & Leppo' Ké \\
\hline TOTAL & 168 & 1017 & \\
\hline
\end{tabular}

Table 9.2 Population of the compound village of Apau Ping

\begin{tabular}{lccl}
\hline Desa & \multicolumn{2}{c}{ Total } & Composition \\
\cline { 2 - 3 } & Families & Persons & \\
\hline Apau Ping & 20 & 108 & Leppo' Ké + Nyibun \\
Long Pengayan & 25 & 122 & Leppo' Ké + Nyibun \\
Long Lat & 4 & 16 & Leppo' Ké + Nyibun \\
Long Tua & 3 & 11 & Berau (Saben) \\
\hline TOTAL & 52 & 257 & \\
\hline
\end{tabular}

Figure 9.1 A cluster of Leppo' Ké swidden fields near Apau Ping

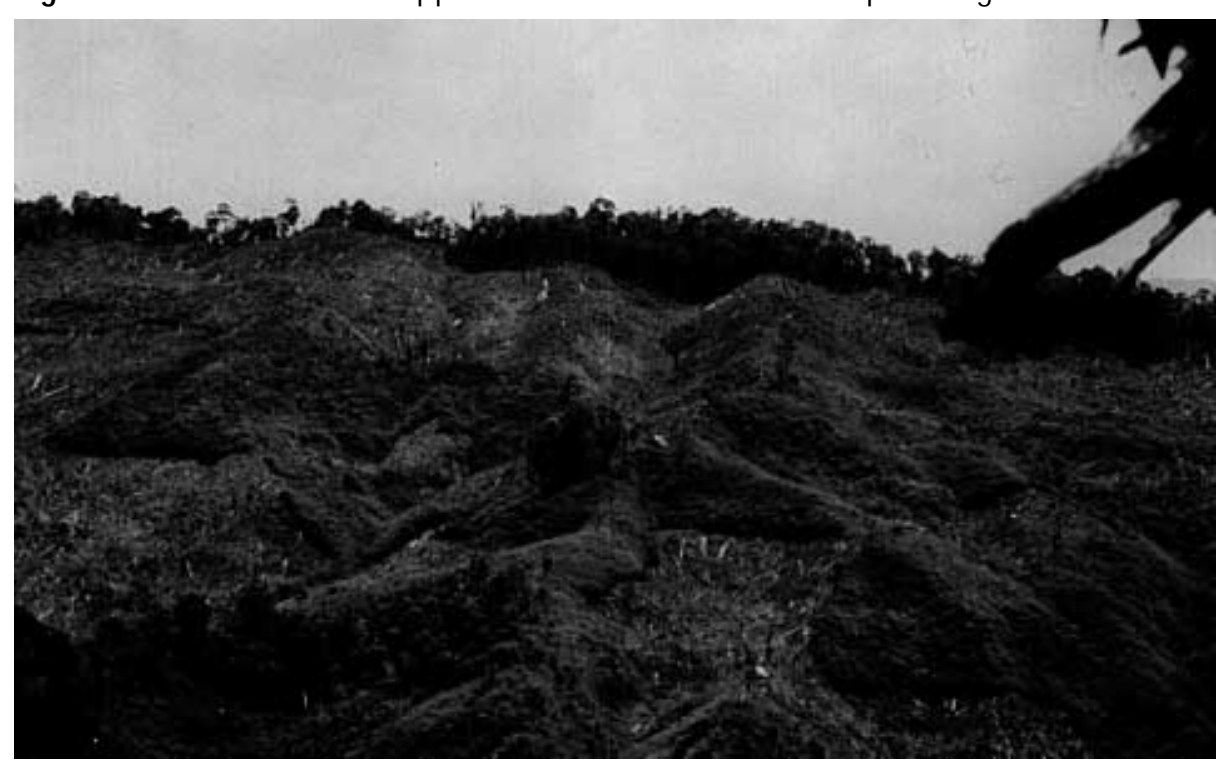


The first school was established in the settlement of the Leppo' Ké and Nyibun when they were still living in the village of Long Lat in 1964, with a teacher by the name of Pak Tasa. In 1978, an Inpres (Presidential instruction) school was established. As a result, the people in the seven villages of the Leppo' Ké and the Nyibun now have an elementary school level education. A junior high school (SLTP), however, is found only in the capital of the district, which is far away, and the senior high school (SMU) is even farther away downstream. Therefore, the present educational level in the village of Apau Ping is generally limited to elementary school level. There are also people who have never attended any school, and only a few people have gone on to institutions of higher learning in Samarinda.

The Leppo' Ké and the Nyibun as a whole have been Protestants for more than ten years, with half of them belonging to the GKPI church (Gereja Kristen Pemancar Injil) and half to the GKII church (Gereja Kemah Injil Indonesia), each church with its own separate building. The relationship between the two congregations is a friendly one and every month the two churches hold a joint service. Religious services take place on Sundays and on high holidays such as Christmas and Easter, and also on certain other occasions such as deaths, weddings, and baptisms.

\section{Economic Situation}

The economy of Apau Ping is based on agriculture, gardens, animal husbandry, hunting and fishing, gathering of forest products, and handicrafts. Agriculture is aimed primarily at meeting local needs for rice, which has been the staple food since former times. Rice is planted in wet and dry fields (Figure 9.1). The main crops in gardens are vegetables, such as string beans, bitter gourd, white and yellow squash, cucumbers, eggplants, amaranth, mustard greens and hot peppers. In addition, cassava, taro, sweet potatoes, pineapple, bananas and papaya are also planted.

Animal husbandry is also intended for own consumption and is limited to chickens and pigs. Their by-products (eggs) are sold only if a trader or other consumer from outside happens to be looking for them (for example, a researcher). The people have always been known as hunters of wild game and fish eaters. The preferred game are wild pigs, deer, barking deer, mouse deer and squirrels. The favourite fish are paked, selareng, baung and pasa. The animals hunted and the fish caught are intended for domestic consumption.

Forest products are collected to guarantee a source of additional income to be used for purchasing daily necessities that people cannot produce themselves. Forest products gathered are gaharu or eaglewood, resin, and various types of rattan, especially rattan sega. The main handicrafts produced are beadwork, rattan weaving, and sa' ung, a broad sun hat made of leaves and decorated with pieces of cloth. Among other handicrafts, iron tools are manufactured, such as decorative swords, shields, and hats decorated with bird feathers and used in traditional dances (kanjet).

Modern trade activities only began after the four villages joined together in Apau Ping, but these activities are still limited to one or two families that have enough capital to open small shops. Because access to outside markets by either river (Figure 9.2) or plane continues to be rather problematic, the shops often run out of trade goods. The commodities traded also remain limited to daily necessities, such as tobacco, cigarettes, kerosene, salt, granulated sugar, and some medicines. 
Figure 9.2 Up the Bahau River with 'Iong-tail' engine to reach Apau Ping

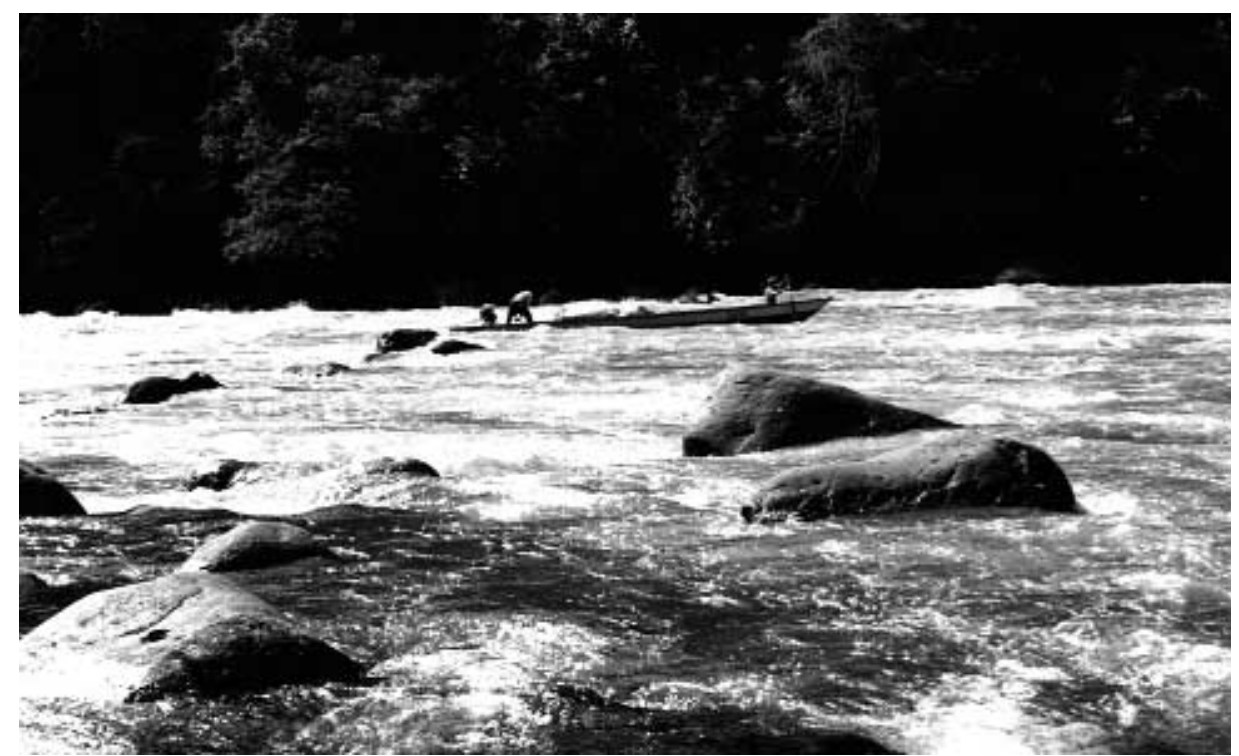

\section{Kinship System}

Three factors impinge upon the kinship system: lines of descent, the locality of a married couple, and the system of relationships and associated terminology. The Kenyah Leppo' Ké and the Nyibun recognise paternal lines of descent and use the father's name after the personal name. For example, if a man is called Njau and his father's name is Anau, he will be called Njau Anau. The wife usually resides with her husband's family, which is a practice locally known as ngiban. Recent developments have seen changes, however, because of the disappearance of the longhouses. The newly married pair now live in their own house, separated from either spouse's family, as agreed upon by all parties involved (see the map in Figure 9.3). The kinship system has always shown a tendency towards bilaterality, that is, both the paternal and the maternal families are part of the kinship environment. Names used for family members are from both the paternal and maternal side.

\section{Social Stratification}

Society, traditionally, was stratified. Formerly, the community within one village (leppo') was divided into groups based on residence in and affiliation to longhouses (uma') The people belonged to three social classes: the paren or nobility; the panyen or common people, subdivided into panyen tiga or prominent individuals, and panyen ngelayan or ordinary commoners; and the group of ula' or slaves. The paren were the power holders, both as paren leppo', village lords, or as paren uma', longhouse lords. Nobility status was by birth, based on paternal as well as maternal descent. The panyen tiga comprised the descendants of the intermarriage of nobility with commoners, or those commoners who had their social status upgraded because of some personal achievement. The slaves were generally descendants of prisoners of war or of people sentenced/punished. In recent times, the slave class has disappeared as a result of assimilation into the commoner class. 
Figure 9.3 Sketch map of the Apau Ping settlement in 1992

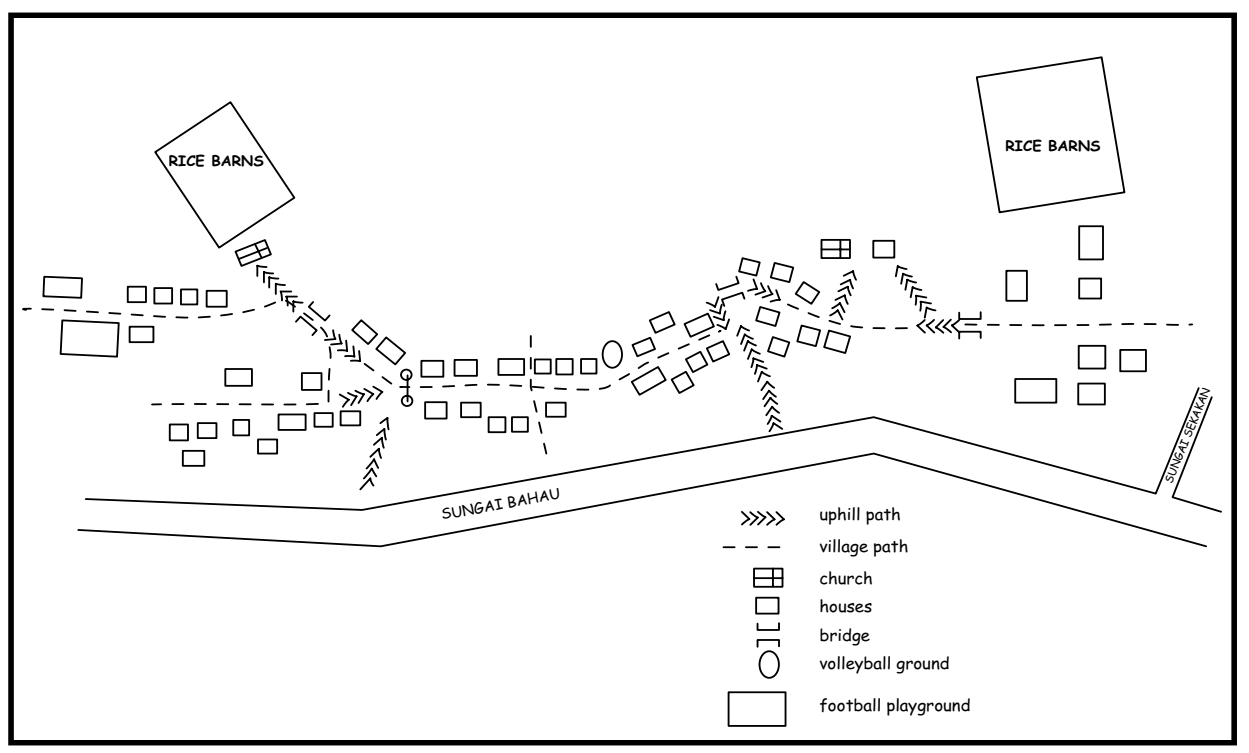

The other traditional social institution is the adat or customary organisation. In a village, there is a customary chief, a deputy chief, and their chosen assistants and staff (pegawa' and pengerak). The customary chief and his deputy are usually chosen from among those descendants of nobility who were considered most influential among all the longhouses in the village. They are in charge of maintaining order in the village according to customary law, and regulating and performing traditional adat ceremonies. They serve as village judges and act as advisors to the kepala desa (village head). Their assistants, pegawa', were chosen among trusted panyen tiga individuals from each of the longhouses by the customary chief, his deputy, and the people. They served as intermediaries between the customary chief and members of the community. As advisors to the customary chief, they were involved in decision making. The staff or pengerak ('mobilisers of the people') were selected from among the panyen tiga or the panyen ngelayan by the customary chief, his deputy, and their assistants. A staff member in that position must be able to talk well, must be popular with people, persuasive, and willing to obey orders. Any instructions from the customary chief or the head of the village were announced by the pengerak who walked from house to house delivering the message or the instruction with a clear voice. If necessary, he also mobilised the people to carry out the instructions. Above village level, there is a great customary chief (great adat chief) who is in charge of the entire customary land (Wilayah Adat) of Hulu Bahau and all the ethnic groups in it, including the Leppo' Ké, Nyibun, Leppo' Ma'ut, and Saben. The great customary chief (formerly referred to as highest nobility, or paren bio') has always been a member of the village nobility of the Leppo' Ma'ut, now settled in the village of Long Alango.

In addition to these two organisational structures based on social class and customary institutions, there are also other traditional organisations, such as that for implementing cooperative work and those based on age groups. There is also the official governmental apparatus, which will not be discussed here. 


\section{Social Institutions}

The formal institutions that maintain public order-dealing with the settlement of conflicts, the imposition of fines, and social control-are the customary institutions, the village government administration, and the head of the church congregation and its associated leaders. In addition, every elder, or every individual regarded as an elder because of his position in the family, informally becomes an administrator of social order in their respective families. Similarly, all villagers have the responsibility and the obligation to maintain social order within their own environment.

If conflicts occur, efforts are made to settle them within the family first. Only if they cannot be settled are the problems brought to a higher level, according to the nature of the conflict. In general, social order is well maintained because of, in the first place, the existence of institutions and mechanisms that represent and involve all societal organisations and groups, and, secondly, because order is supported by a system of fines that, by local standards, are heavy.

\section{HISTORY OF THE LEPPO' KÉ AND THE NYIBUN}

\section{Origins of the Kenyah}

Written sources on the history of the Leppo' Ké and the Nyibun are very rare and limited to foreign writers (Fischer and Gramberg 1910, van Walchren 1907). But much can be learned from local oral traditions, even though these often contain differences, depending on the memory of the informant. According to Oko' Bilung Lerang, an informant who is now approximately 75 years old, the ancestors of the Leppo' Ké lived in the Belaga river area in Sarawak and were led by a chief known as Apuy La'ing. From Apuy La' ing to Oko' Bilung Lerang, ten generations have passed, with the following

Figure 9.4 Elderly Leppo' Ké informant Bilung Lerang at Long Lat (Apau Ping)

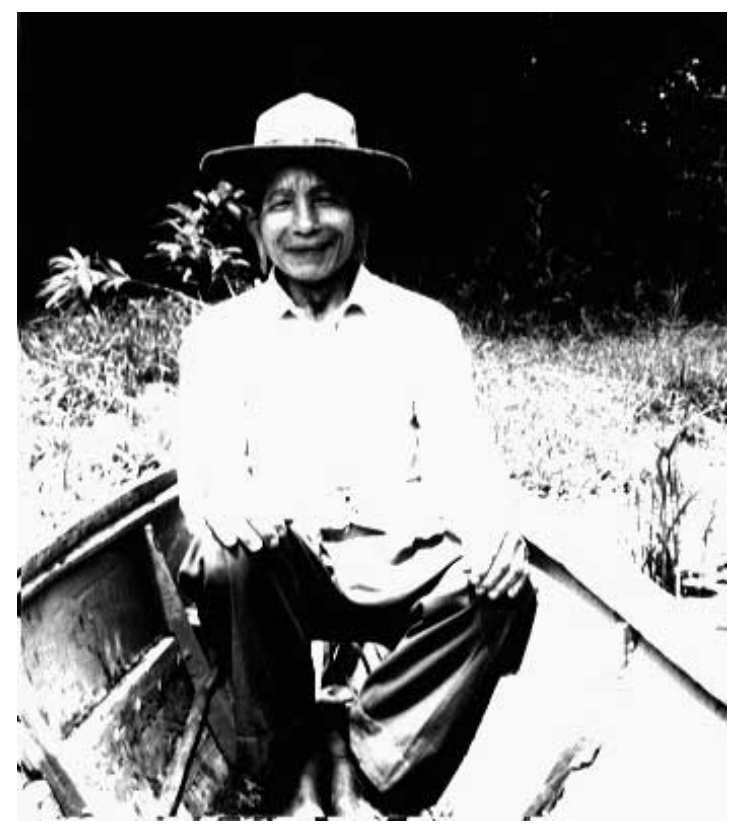

succession of leaders: La'ing, Apuy La'ing, Mahan Apuy, Apuy Mahan, Lian Apuy, Apuy Lian, La'ing Apuy, Apuy J alung, Lerang Apuy, and Bilung Lerang. Assuming an average of 25 years per generation, we can estimate that the ancestors of the Leppo' Ké lived along the Belaga River at the end of the 17th century (Figure 9.6).

Other sources indicate that, at that time, all the Kenyah groups were still together, and the Leppo' Ké had not yet separated from other Kenyah. From the upper reaches of the Belaga River, the Kenyah moved in the direction of the Iwan River and first settled at Apau Julun (c. 1700). The first split occurred as one group of Kenyah moved to the Lemeting River and eventually continued on the upper Iwan River, and another group remained in Apau 
Julan until today. The group that went to the Iwan River finally settled in a highland area known as Apau Data.

\section{On the Upper Iwan River (18th century)}

The upper reaches of the Iwan River were occupied by three successive waves of Dayak peoples from Telang Usan (a village on the Baram River, Sarawak). These were: the Modang and the Ga' ai; the Kayan and the Kayan Bahau; and the Kenyah. When the Kenyah arrived in that area, the other groups had already moved on southward to the Apau Kayan plateau. The Kenyah, initially one group, eventually split in several subgroups, including the Leppo' Ké and the Nyibun (see Henoch Merang, pp. 15-17). The Kenyah in Apau Data eventually broke up into several independent groups, each with its own separate longhouse, to areas that they considered suitable for settlement. The inhabitants of the various longhouses multiplied, so that the longhouse (uma') became a village (leppo') consisting of several longhouses. The name of the leppo' eventually became the name of the ethnic group, which often retained the name of the location of the village of origin. For example, the Kenyah Leppo' Ma' ut originated from the Ma' ut River.

The breakup in the Iwan River area was caused by frequent famines since the land in the area was not fertile for agriculture, and by frequent warfare between groups or longhouses. For example, according to informants, a power struggle between brothers led to a breakup. The younger brother, by the name of Lenjau, moved to the Akah River in Sarawak, taking many people with him. The elder brother, instead, remained on the upper Iwan River and continued to obstruct the departure of Lenjau. He went to the Akah River and brought back to the upper Iwan River a follower of the younger brother. In revenge, the younger brother came to the Iwan River and killed that person. Because he was under pressure from other groups, the older brother moved his group to Bawang Ipung (see below). In this manner, a number of groups moved to find other areas that were more secure or fertile. The following describes the sequence of moves that brought the Leppo' Ké to their present location (see maps and sketches).

\section{The Kenyah Leppo' Ké}

\section{Bawang Ipung (1780-1800)}

Bawang Ipung is located in the water divide area of the Iwan, Lurah, and Pujungan rivers. The move to Bawang Ipung was intended as an escape to a safer and more fertile area. In Bawang Ipung, the Leppo' Ké encountered the Nyibun for the first time. From there, they moved to Apau Urung.

\section{Apau Urung}

Apau Urung is located on the mountain ridge between the upper Lurah and Puj ungan rivers, on the upper Sa'an River. After they had settled in Apau Urung, the Leppo' Ké were attacked by the Kenyah Uma' Alim from the Pujungan River. A large war broke out, which led to subsequent feuds between the two groups (who thereafter were often at war). From Apau Urung the Leppo' Ké moved to Long Bena. 
Figure 9.5 Migrations of the Leppo' Ké and Nyibun (1)

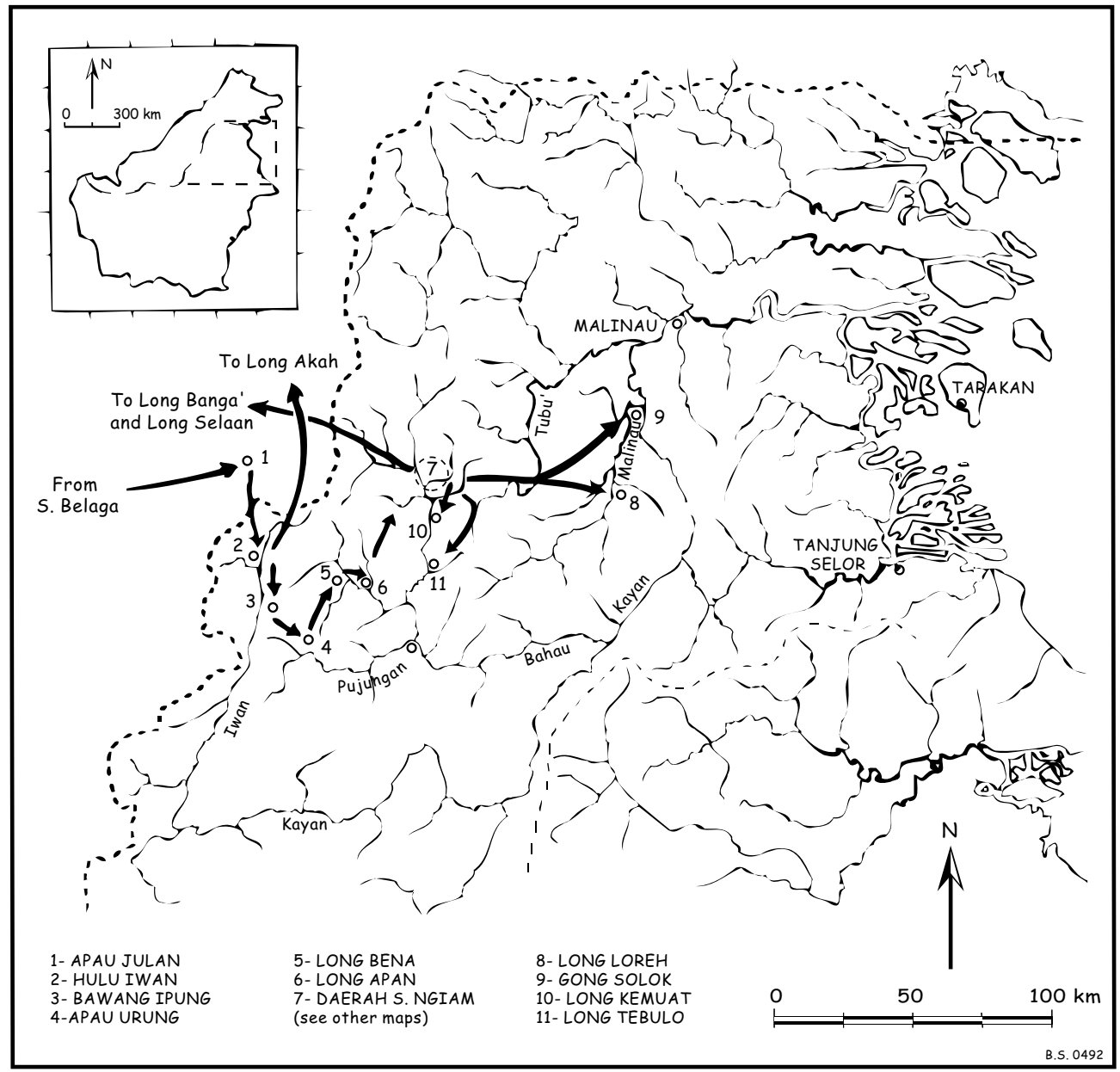

\section{The Lurah River: Long Bena and Long Apan (1810-1840)}

Long Bena is located on the upper reaches of the Lurah River. Not feeling safe in Long Bena because of continued attacks by the Uma' Alim, the Leppo' Ké finally moved downstream along the Lurah River to the area known as Long Apan (c. 1830) under the leadership of $\mathrm{Njau}$ Lian. Since there, too, they were not safe, they moved once again and left the Lurah River altogether.

\section{Sawa' Bio' (c. 1850)}

Sawa' Bio' is located on the upper Beraa River in the mountains between the Lurah and the Beraa rivers. While settled there, the Leppo' Ké were once again attacked by the Uma' Alim from the Pujungan River. After about five years, the Leppo' Ké moved down to Bawang Liong on the lower Beraa River. Initially, they established a settlement on a hilltop. Beginning to feel safer as they were further and further away from the base of the Uma' Alim, they moved to nearby locations on the banks of the Beraa River. 
Figure 9.6a Historical settlements of the Kenyah Leppo' Ké (1)

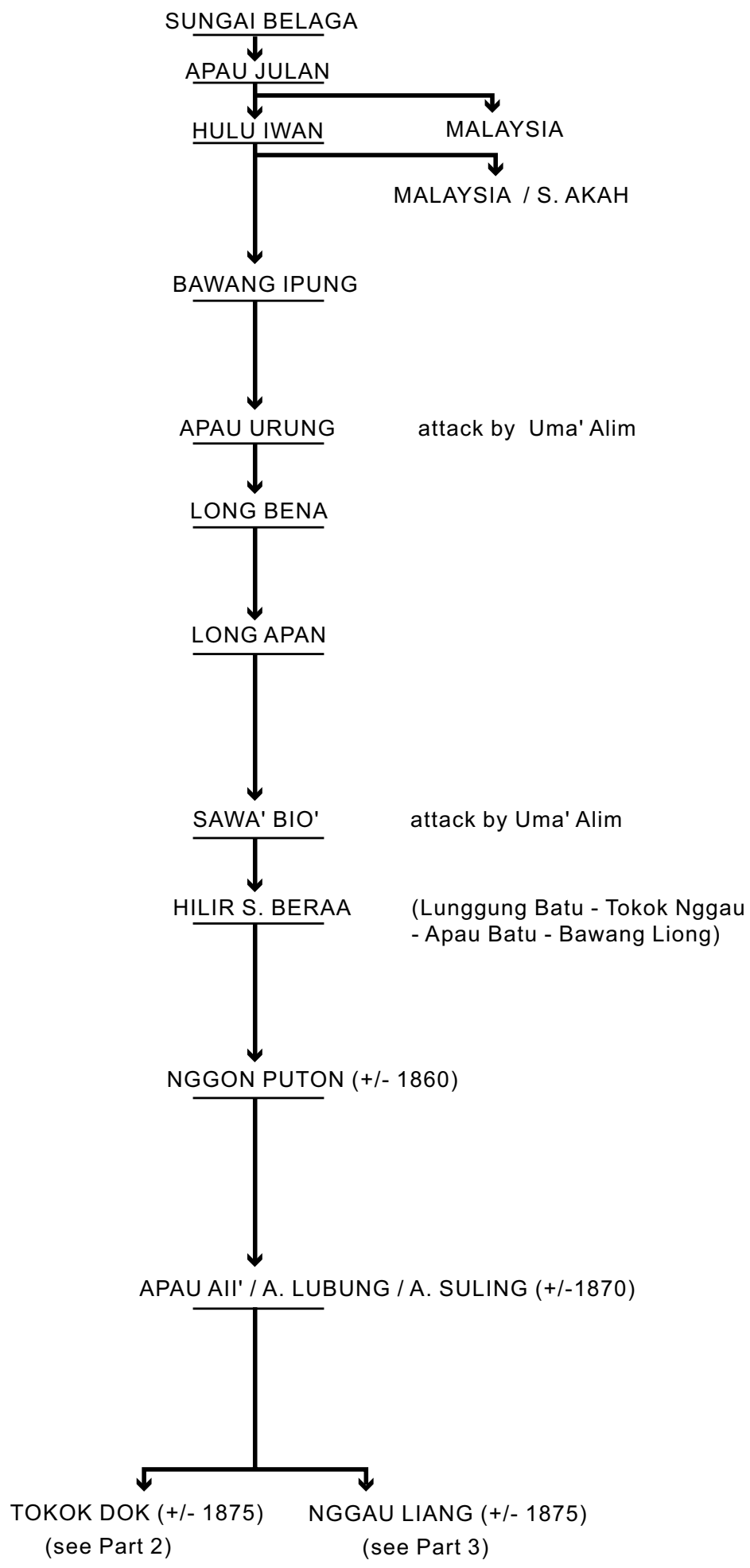


Figure 9.6b Historical settlements of the Kenyah Leppo' Ké (2)

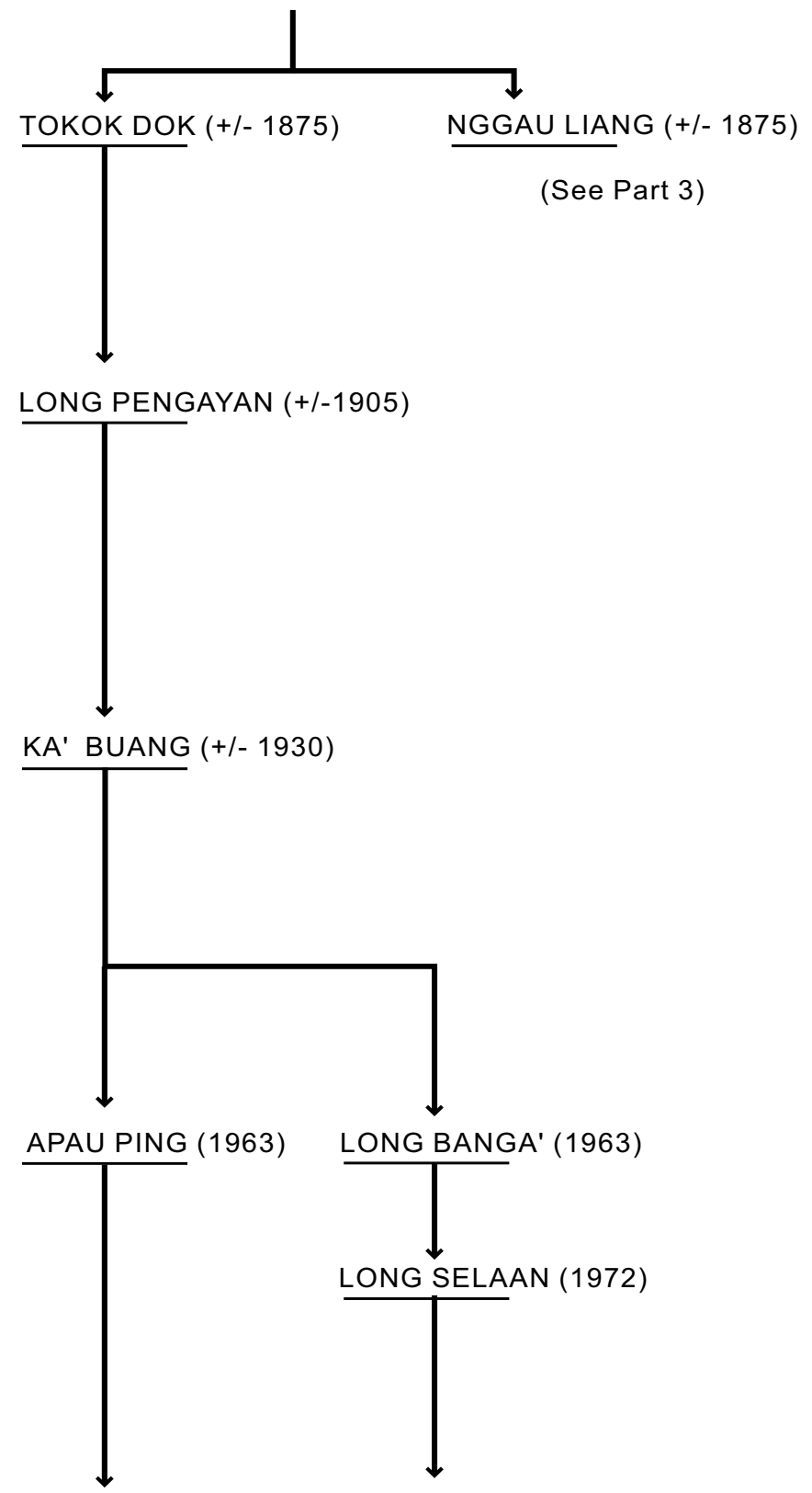


Figure 9.6c Historical settlements of the Kenyah Leppo' Ké (3)

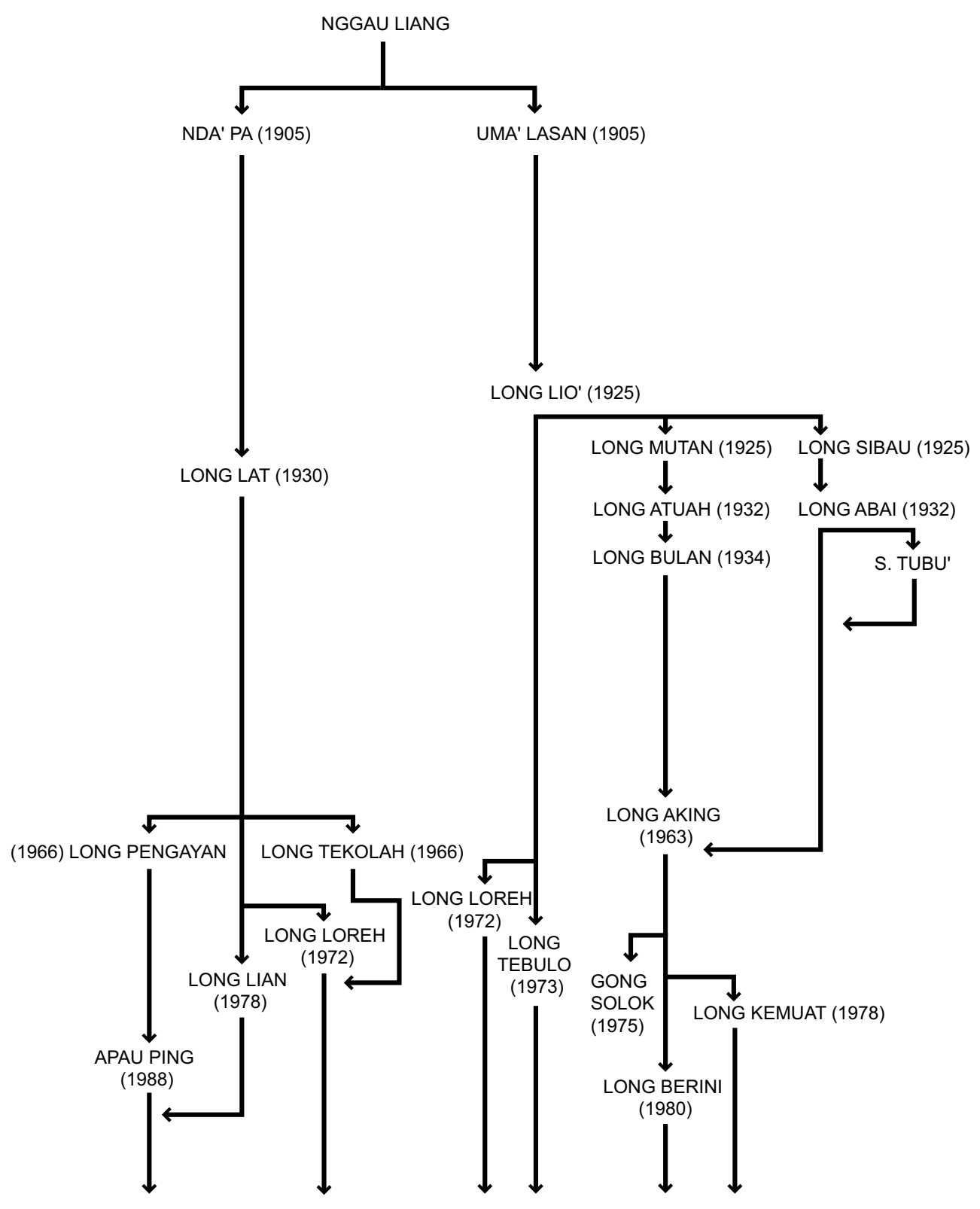




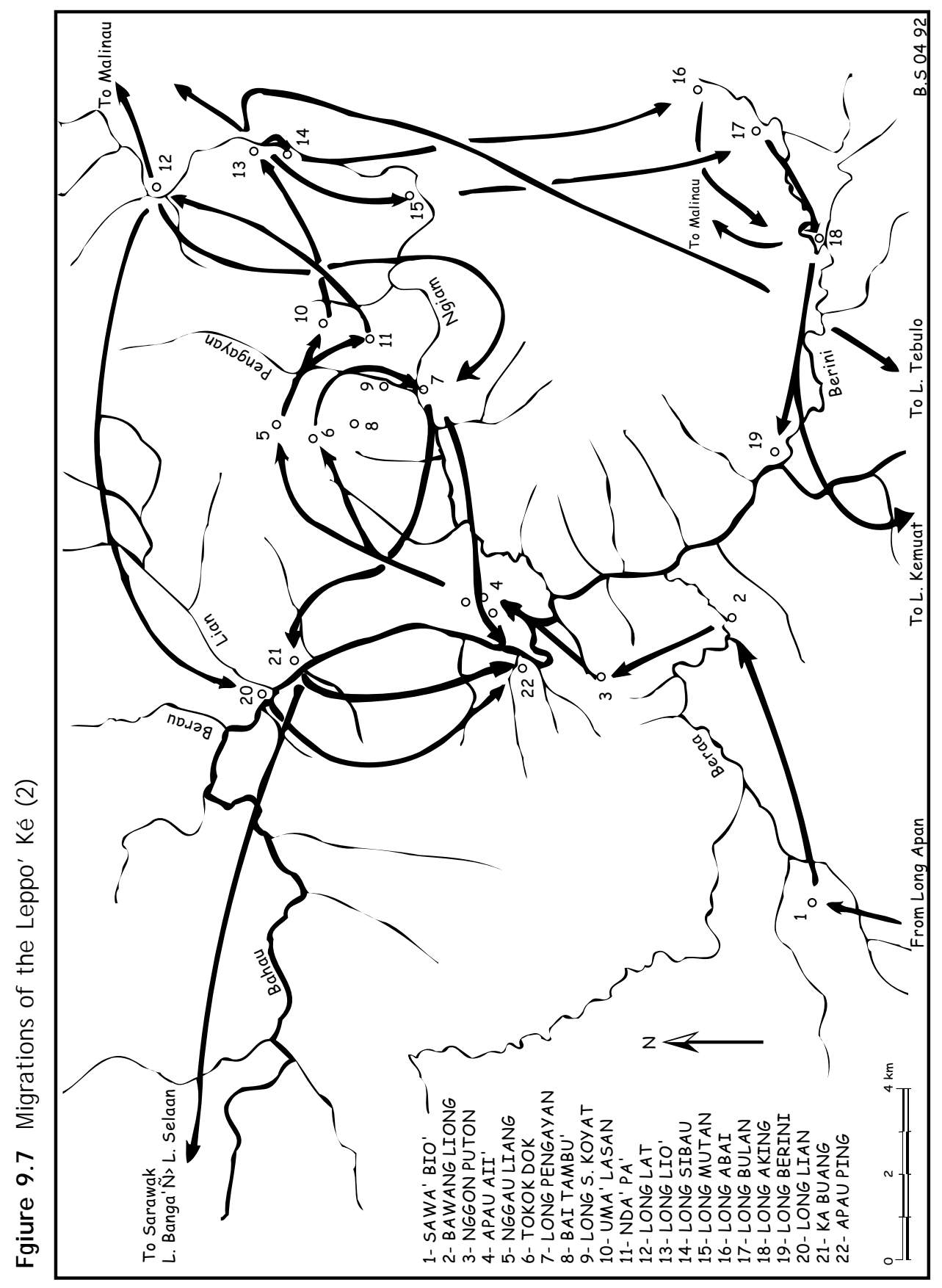


Nggon Puton (c. 1860)

The Leppo' Ké were once again forced to move from Bawang Liong and build a new village on a hilltop, at Nggon Puton, between the Bahau and the Semué rivers. The phrase nggon puton in the Ngorek language means 'interrupted ridge'. There are no remains at this site, except for fruit trees such as abong (a species of Nephelium), which are quite large. According to some accounts, the Leppo' Ké village consisted of 20 longhouses with roofs made of leaves. The threat from the Uma' Alim persisted even then, and after they had settled in Nggon Puton for some time, the Leppo' Ké moved to a location across the Bahau River.

\section{On the Upper Bahau: Apau Aii', Apau Lubung, and Apau Suling (1860-1870)}

These three sites are on the highlands between the Bahau and the Ngiam rivers. Apau Aii', Apau Lubung, and Apau Suling are located at a distance of only about $500 \mathrm{~m}$ from each other. The compound settlement consisted of 30 longhouses headed by the paren bio' Apuy Lian. Remains such as a ditch that once surrounded the village like moats for defensive purposes can still be seen. Subsequently, there was disagreement among the heads of the longhouses which led to the breakup of the settlement into two parts. The first part, consisting of 25 longhouses, moved to Nggau Liang, following their leader Lawing Usat La'ing. The five remaining longhouses moved to Tokok Dok under the leadership of J alung Irang.

\section{The Ngiam River: Nggau Liang and Tokok Dok (c. 1875)}

Nggau Liang was located on a mountaintop between the Salo' and the Pengayan rivers (a tributary of the Ngiam River), while Tokok Dok was located on a mountaintop between the Kuyat and the Salo' rivers (both tributaries of the Pengayan river). After the Leppo' Ké settled at Nggau Liang and Tokok Dok, war with the Uma' Alim broke out again. As a result of the extended feud, the Uma' Alim gathered their allies, the Kenyah Uma' Kulit, Leppo' Ndang, and Leppo' Ma'ut, to attack the villages of the Leppo' Ké and the Nyibun. They were defeated by the Leppo' Ké at Nggau Liang. At the beginning of the 20th century, the Leppo' Ké from Nggau Liang split into two parts, one part moving to Uma' Lasan, and the second part to $\mathrm{Nda}^{\prime} \mathrm{Pa}$ '. In the meantime, the Leppo' Ké of Tokok Dok had moved to Long Pengayan.

\section{The Nyibun}

We will leave the Kenyah Leppo' Ké temporarily to follow the movements of the Nyibun. According to informants among the Leppo' Ké, the Nyibun were living in Bawang Ipung before the Leppo' Ké (about 1780-1800), who only subsequently arrived in Bawang Ipung from the Iwan River. Their village was located close to that of the Nyibun. For security reasons the Leppo' Ké and the Nyibun moved together to the upper reaches of the Lurah River (Figures 9.5, 9.8 and 9.9).

\section{The Lurah River: Lepu' un J alung and Apau Angan (1810-1820)}

The Nyibun village site on the upper reaches of the Lurah River was known as Lepu' un Jalung and located very close to the village of the Leppo' Ké in Long Bena. It was located on the top of a hill and was very pleasant and clean. From there, the Nyibun 
Figure 9.8a The historical settlements of the Nyibun (1)

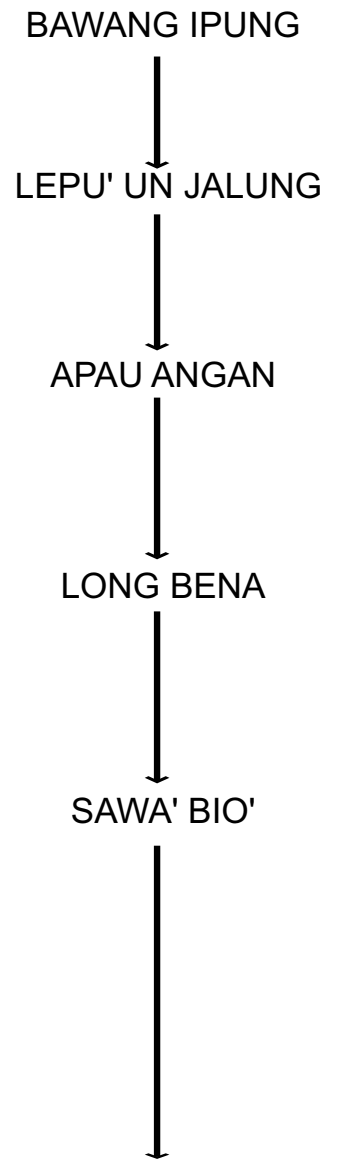

Figure 9.8b The historical settlements of the Nyibun (2)

TOKOK ISAU (1860) attack by U. Alim
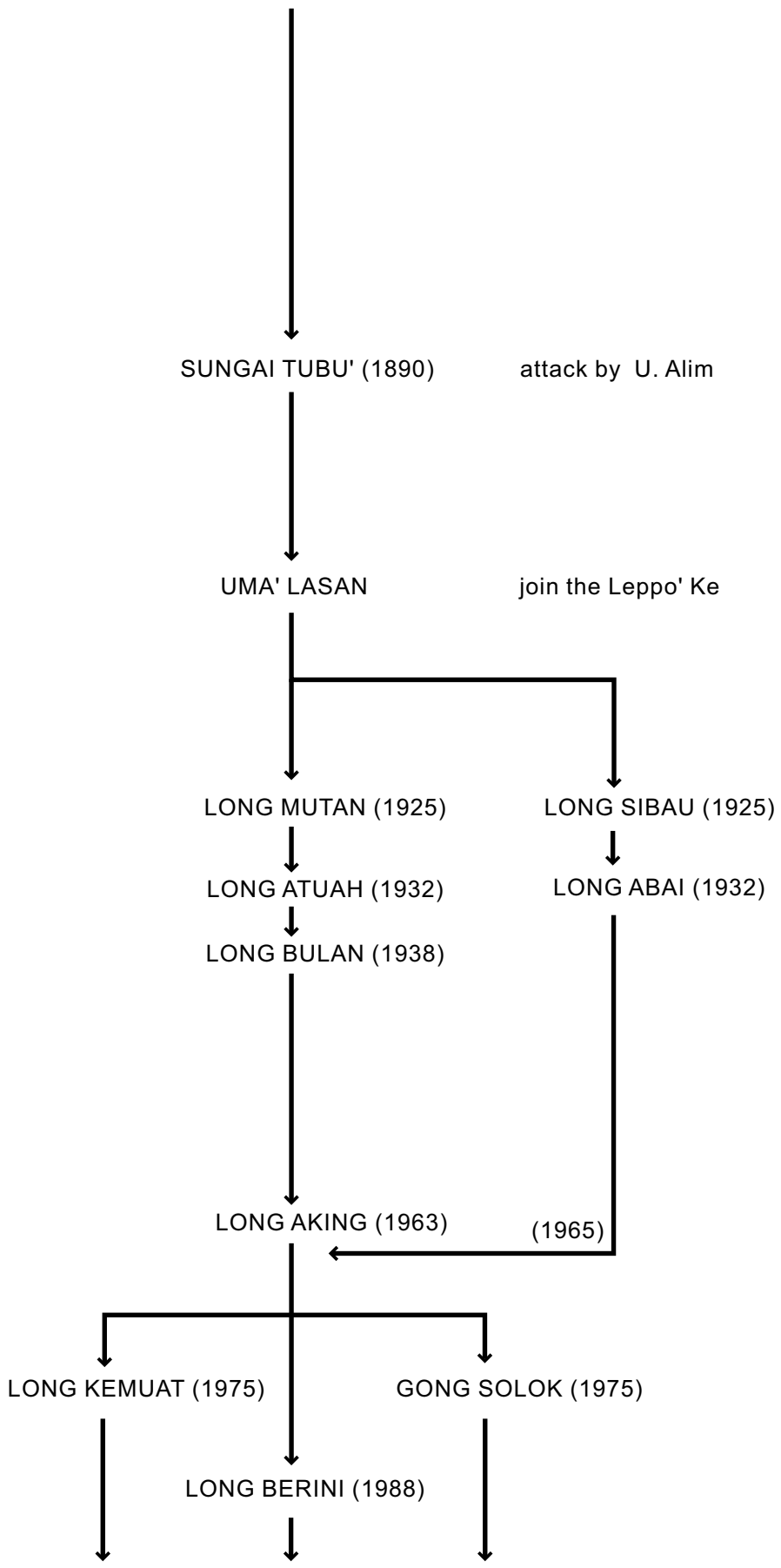
Figure 9.9 Migrations of the Nyibun (2)

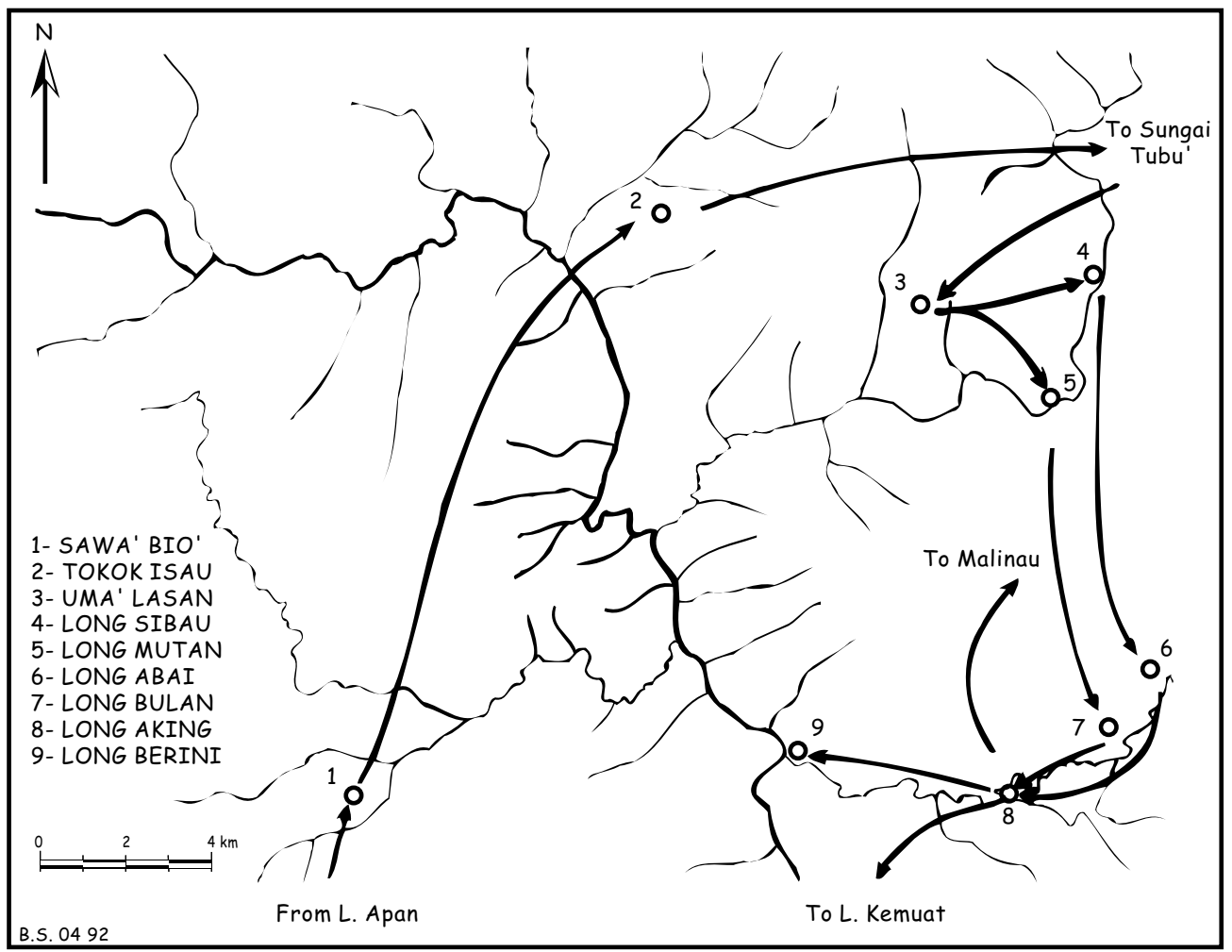

moved to nearby Apau Angan, which was also located on a hilltop. They remained there a long time because the area was a very effective stronghold.

\section{Long Bena (c. 1830)}

After remaining for some time at Apau Angan, the Nyibun no longer felt safe and decided to join the Leppo' Ké. For the first time, they lived on the bank of a river. Although the Leppo' Ké may have been about to move to Long Apan at that time, the Nyibun remained in Long Bena, also close to their allies, the Kenyah Leppo' Ma'ut, who lived at Long Sungai Ma'ut, thereby forming a strong defence network. But on the upper Lurah River, there were frequent attacks by the Uma' Alim and their allies, who were fierce warriors. In the end, the Nyibun felt under pressure and went in search of a safe and fertile area. They decided to follow in the steps of the Leppo' Ké who had moved from Long Apan to Sawa' Bio'.

\section{Sawa' Bio' (c. 1850)}

At Sawa' Bio' the Nyibun suffered a famine caused by an extended dry season, and people were forced to eat cassava in order to survive. Later they moved from Sawa' Bio' to Tokok Isau. 
The Upper Bahau: Tokok Isau (c. 1860)

Tokok Isau was located in the mountains on the upper reaches of the Lian River. At that time, the Nyibun were led by a high aristocrat by the name of Irang. When Irang died, his son Bilung Irang succeeded him, but the Nyibun were not happy with his leadership. Some of them decided to join the Leppo' Ma'ut, who had already moved from the upper Lurah River and settled in Long Nan, while other Nyibun joined the Leppo' Ké at Nggau Liang. While they were in Tokok Isau, the Nyibun were again attacked by the Uma' Alim and they asked for help from the Leppo' Ké. After the Uma' Alim were defeated by the Leppo' Ké at Nggau Liang, Bilung Irang moved with the rest of the people across the watershed, to the Tubu' River.

\section{The Tubu' River (c. 1890)}

After the Nyibun had been living on the Tubu' River for some years, the Uma' Alim realised that they were no longer living in proximity of the Leppo' Ké and they took the opportunity to attack them again (c. 1900-1905). Many Nyibun died in this attack, especially children and old people, and the Uma' Alim burned the Nyibun houses. The Leppo' Ké, who at that time were settled in Uma' Lasan and Nda' Pa', heard the news and, before the Uma' Alim could attack again, they sent young men to take the Nyibun survivors from the Tubu' River back to Uma Lasan and Nda' Pa' to join the Leppo' Ké. From that time on, the history of the Nyibun becomes one with that of the Leppo' Ké at Uma' Lasan.

\section{The Dutch Period to the Present}

\section{Uma' Lasan (1905)}

At Uma' Lasan, the Leppo' Ké and the Nyibun formed one settlement that consisted of three groups: Apau Kian (a group of Nyibun, led by Lenggang Ipuy), Apau Namam (with a majority of Leppo' Ké, led by Jalung Kiring), and Nda' Tilang (with a majority of Nyibun, led by Bilung Irang). In 1906, the Dutch colonial government sent a military unit under Captain Fischer to Uma' Lasan, with a plural assignment. They were supposed to forbid war among ethnic groups, ensure safety for the movements of the Dutch government in the interior, advise the people to move their settlements from the mountaintops to the river banks, and punish those who violated Dutch orders. In 1925, the Leppo' Ké and the Nyibun of Uma' Lasan finally moved to Long Lio', on the banks of the Ngiam River.

\section{Long Lio' (1925)}

After the area had become safe thanks to the Dutch government, the Leppo' Ké and the Nyibun scattered to various locations. Eight longhouses of Nyibun and Leppo' Ké led by J alung Lenggang moved to Long Lio'; two longhouses led by Apuy Bilung moved to Long Mutan; and one other longhouse, led by Dungau Bilung, moved to Long Sibau. After several years, the village of Long Lio' suffered an epidemic of cholera and many of its residents died. The entire village of Long Lio' burned down because of an old woman who was roasting a pig, and all its residents were forced to take refuge in their rice barns. In 1932, the group that had moved to Long Mutan moved to Long Atuah, on the Berini River. From there, it moved again to Lulou Bulan (or Long Bulan) in 1938, under the leadership of Apuy Bilung, and then once again back to Long Aking. 
In Long Lio', remains such as house and rice barn stilts, as well as fruit trees such as mango, coconut, and citrus, can still be found. Downstream from the village, four Nyibun graves can still be seen; they are made of hard lemelai wood, $5 \mathrm{~m}$ high, and hold jars containing human bones. According to Oko' Bilung Lerang, these are the graves of J alung Lenggang, Lerang Lenggang, Usat Bilung, and Bilung Usat.

\section{Long Aking (1963) and Long Tebulo (1973)}

The Nyibun living in Long Aking were led by J alung Apuy. During his period of leadership, the confrontation with Malaysia (1963-1965) took place. In 1975, Long Aking broke up into three parts: one part moved to Gong Solok (district of Malinau), under the leadership of Lawai Apuy; the second, led by Ingan Irang moved to Long Kemuat (1978); and the third remained at Long Aking, to later move to Long Berini under the leadership of J alung Apuy (1988). These groups have remained in these locations until today (see Figure 9.10).

Figure 9.10 Nyibun informant J alung Apui at Long Aking (Long Berini)

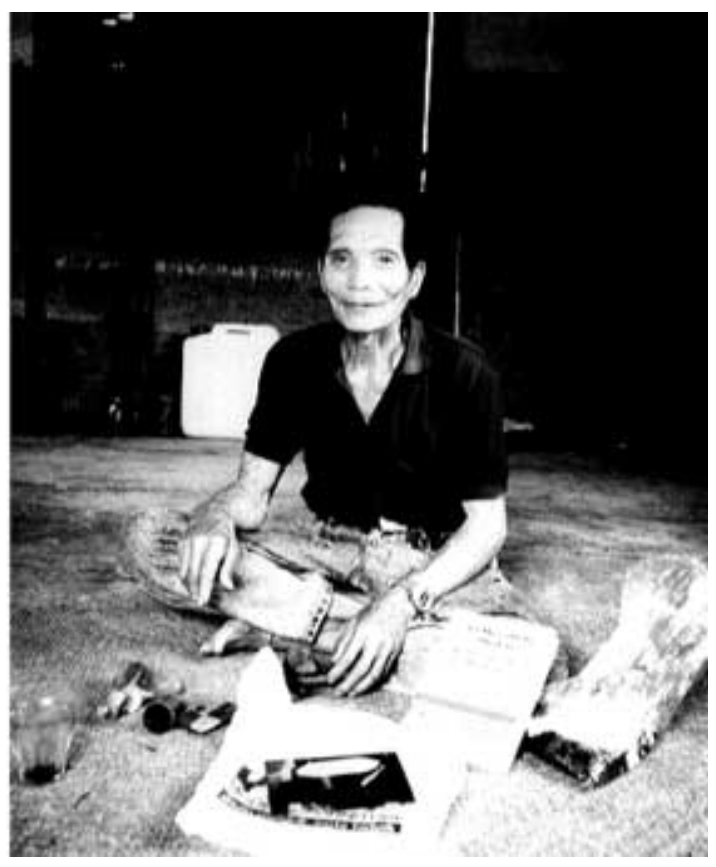

One longhouse that had moved from Long Lio' to Long Sibau under the leadership of Dungau Bilung moved again to Long Abai (1932), and then again to the Tubu' River. After several years in the Tubu' River area, the group returned to Long Abai, and then moved to Long Aking (1965). In 1972, part of the population of Long Lio' moved to Long Loreh (district of Malinau). Another part remained for a while in Long Lio', but later moved downriver to Long Tebulo (1973), on the Bahau River, under the leadership of Dan Awan, and has remained there until today. 


\section{Nda' Pa' (1905)}

Let us now return to the second splinter group under the leadership of Njuk Apuy, which moved from Nggau Liang to $\mathrm{Nda}^{\prime} \mathrm{Pa}^{\prime}$. $\mathrm{Nda}^{\prime} \mathrm{Pa}^{\prime}$ was located on a mountaintop between the Pengayan and the Ngiam rivers, and it was only about $500 \mathrm{~m}$ from the site of Uma' Lasan village. At Nda' Pa', the Leppo' Ké and the Nyibun lived together. After Njuk Apuy's death, the leadership was taken over by his younger brother, Lerang Apuy. It was at that time that the military unit under Captain Fischer arrived. In $\mathrm{Nda}^{\prime} \mathrm{Pa}^{\prime}$, the remains of a fortification and a $7 \mathrm{~m}$ wide ditch that surrounded the village are still visible. From there the group moved to Long Lat.

\section{Long Lat (1930)}

Around 1930, the village of $\mathrm{Nda}^{\prime} \mathrm{Pa}^{\prime}$ moved to Long Lat, on the banks of the Ngiam River. This village consisted of six longhouses under the leadership of Lerang Apuy. At that time, the interethnic wars (ngayau) had ceased, and the area could be described as safe. Lerang Apuy died and the leadership passed to Ging Apuy. In 1966, the village of Long Lat split into three parts: one part moved to Long Tekolah (district of Malinau); the second to Long Pengayan, under the leadership of Lenjau Lawing; and the third group remained in Long Lat.

Downstream from the village, one can still see four Nyibun graves with $4 \mathrm{~m}$ high poles made of jangin lapan wood, large jars containing human bones and sealed with gongs, and with stone slabs on top. According to the informants, these graves were erected to contain the bones of two women named Bai Lian and Bun Lawing, both in one jar; of their husbands Njau Irang Njau Cin, who died in 1960; of Lawing Dungau Usat Aran, a high aristocrat of the Nyibun who joined the Leppo' Ké in Long Lat, and died in 1930; and of Lian Bilung Njau Igau.

\section{Long Lian (1978)}

All the people who stayed put at Long Lat moved to Long Loreh (district of Malinau) in 1972-73, under the leadership of Laway Lerang, and live there until today, except for four families who remained at Long Lat under the leadership of Bilung Lerang. These four families eventually moved from Long Lat to Long Lian upon the advice of the government, and joined the multigroup settlement at Apau Ping in 1988. The group that moved from Long Lat to Long Pengayan also finally moved to Apau Ping in 1988 under the leadership of Lenjau Lawing, upon the advice of the government.

\section{Long Pengayan (c. 1905)}

We return to the five Ionghouses that had left Tokok Dok to settle in Long Pengayan around 1905 under the leadership of Lawing J alung. After the visit of the Dutch military unit, life there began to feel safer because the interethnic warfare had come to an end. From Long Pengayan, the Leppo' Ké then moved to Ka' Buang (1930) (Figure 9.11).

\section{Ka' Buang (1930)}

The move from Long Pengayan to Ka' Buang was led by J alung Lawing. At that time, Christian missionaries (KINGMI) began spreading Christian beliefs in the interior, where the old religion still prevailed. In 1931, the missionary Fisk baptised 221 people in the Bahau River area. The village of Ka' Buang was destroyed by a fire caused by a child. When J alung Lawing died, the leadership passed to his son Apuy J alung. The village of the Leppo' Ké then included seven longhouses. After Apuy J alung died and was succeeded by Njuk Anye', the village of Ka' Buang suffered a cholera epidemic, which caused 
Figure 9.11 Informant Oko' Ncuk Usat, with author, at Long Pengayan (Apau Ping)

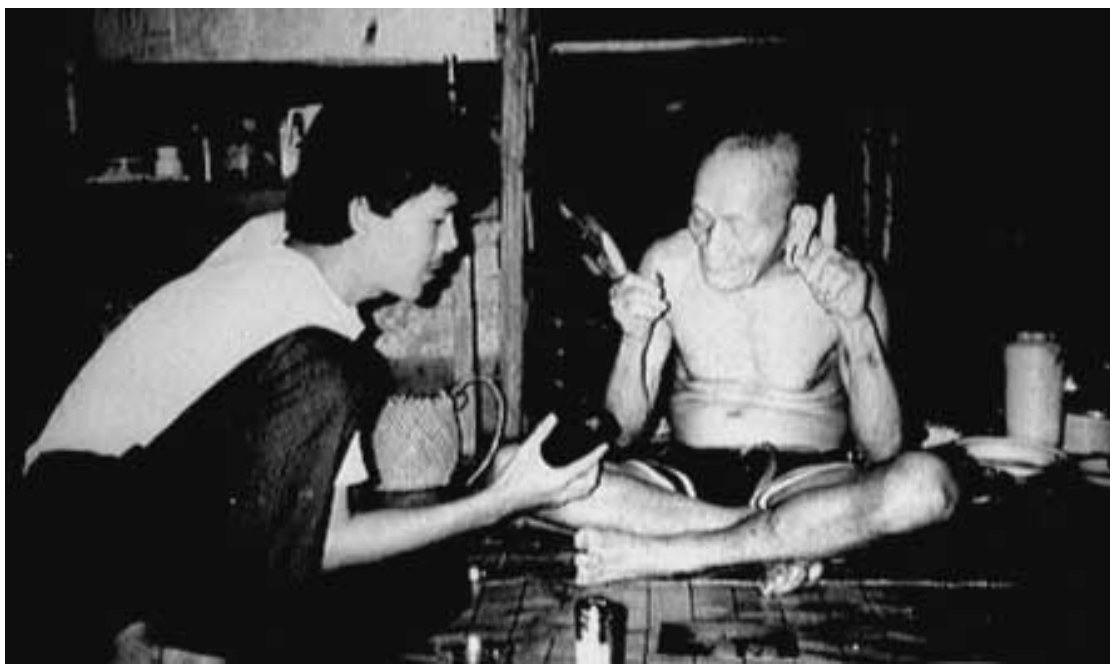

many deaths and prompted two longhouses to move to Long Banga', on the upper Baram River in Sarawak, under the leadership of Njau Asang.

\section{Apau Ping and Long Banga' (1963)}

The five longhouses that had remained in Ka' Buang later moved to Apau Ping under the leadership of Njuk Anye', and became the original village of Apau Ping. When they had newly settled in Apau Ping, the confrontation with Malaysia broke out and many people were involved as volunteers. In 1993, Apau Ping was led by the village chief Aran Lenggang. The people of the two longhouses that had moved to Long Banga' in the end split again: one longhouse moved to Long Selaan, while the other remained in Long Banga'.

\section{DISCUSSION}

The preceding analysis leads to the conclusion that, in the past, the frequent movements of groups of Kenyah Leppo' Ké and Nyibun-as well as other Kenyah groups-were generally caused by their search for better land. The selection of a location for settlement was based on the consideration of several important factors: the size of the area needed by the group, and in light of its population growth; soil fertility, which was crucial for meeting subsistence needs; security and defence, in order to avoid hostile attacks; and health to prevent outbreaks of diseases. In addition, there were frequent disagreements among the high aristocrats in a village which caused groups to break up. Generally, a group always had to negotiate among these factors and, in fact, security was given highest priority. A small and weak group, for example, first of all sought security, even though the surrounding soil might have not been sufficiently fertile. A large and strong group like the Leppo' Ké, whose population was estimated at about 3000, out of necessity left the fertile area of Long Bena in order to escape the attacks of the Uma' Alim and their allies. 
Security was also an important factor in the selection of village sites. Two types of sites were most common. First, hilltops and high plateaus. These could be easily defended because of their steep slopes, they were usually reinforced with fortifications made of tree trunks and sharpened bamboo, and surrounded by broad and deep ditches. The other type was a location along a river and usually also surrounded by fortifications. The first type of site was usually selected in a situation threatened with the outbreak of big interethnic wars or even attacks from hostile headhunters. This type of site was not most suitable for the wellbeing of the people, as they often suffered from water shortages, and made it necessary to dig a pond at the village site in order to collect rainwater. An example of such a pond can still be seen at the Uma' Lasan site. If conditions were safe, the second type of location was generally chosen for settlement.

A group could also maintain two settlements at both sites at the same time, one of them on the banks of a river, and the other on the top of a nearby hill. Most people would live in the village by the river and only retreat to the fortified village on the mountaintop for defence when getting news of enemies approaching the area. A twovillage situation is reported with regard to the Leppo' Ma' ut when they were settled on the lower Ngiam River. A similar arrangement may have existed among the Leppo' Ké when they were living in Bawang Liong.

Generally the history of settlement patterns shows that groups like the Leppo' Ké tried to prevent differences among the paren uma' aristocrats from causing the group to break up. If a group remained together or lived very close by, it could defeat its enemies, like, for example, the Leppo' Ké who succeeded in defeating the Uma' Alim and their allies at Nggau Liang. On the other hand, if they split up and settled far from each other, like the Nyibun when the moved to the Tubu' River, they could easily be attacked and destroyed by their enemies. Similarly, the history of the Leppo' Ké shows a pattern of mass movements (for security reasons), not movements of small groups. Even in the event the Leppo' Ké were forced to settle temporarily in locations that were less than suitable for their needs along their route movement-for example from the Lurah River to the upper Bahau River-they nevertheless remained together.

In time, especially under the Dutch government, movement and settlement patterns changed. One of the effects of the presence of the Dutch government became very noticeable after 1925: the formerly frequent interethnic wars started to disappear and the situation became safer. Settlements that were formerly one large village began to break up into several small villages; and settlements that had been located on hilltops began to move down to the river banks. The social structure began to change, too, because slavery was abolished by the Dutch government.

It must be mentioned that changes in settlement pattern were the result of the peaceful situation, which also triggered certain other effects: differences among the high aristocrats became increasingly obvious and could not be limited by considerations of security, and therefore breakups occurred. Also, the desire of the people for larger territories, for agricultural land, for hunting grounds and fishing, promoted the establishment of villages at a further distance from each other. The wish for fertile soil and improved welfare pushed the people to seek settlement areas near rivers. The shift to locations by the river banks was strongly supported by the Dutch government, which could thus control the inhabitants more easily. In fact, the Dutch government recommended that the people gather in large, easy-to-reach villages on the river banks, but this was not achieved during the colonial period.

After Indonesia achieved independence, three kinds of change occurred among the Leppo' Ké and the Nyibun. First, the Indonesian government required that the villages 
that were scattered and located in upstream areas of river tributaries join and move to the banks of the main Bahau River. This objective was finally achieved in the 1980s. Secondly, the effects of Christianisation led to changes in the settlement pattern because of the disappearance of the longhouses, which from the 1960s to the 1980s were gradually replaced by individual family dwellings. Thirdly, the establishment of the official village administration and the influence of Christianity gradually changed the traditional social structure, progressively weakening the role of the aristocrats. In addition, the changes in the social structure and the decline of the traditional religion were accompanied by the loss of a number of customs and traditional cultural features.

The most important event in the lives of the Leppo' Ké and the Nyibun in the last three decades, however, has been the mass movement out of the subdistrict of Pujungan, especially the move to the Baram River area in Sarawak, which took place during the Confrontation (Long Banga' village in 1963), and to what was then the neighbouring district of Malinau (the villages of Long Tekolah, Gong Solok, and Long Loreh, between 1966 to 1975). These mass movements originated in the people's desire to find easier and more pleasant living conditions than those prevailing in the very isolated area of the upper Bahau River, and conditions that would provide, among others, education, health, and access to market. Individual or family moves have also taken place to the coastal areas of the district of Bulungan (Tanjung Selor area) in an effort to seek work or pursue higher education; and to Sarawak, in search of waged work.

Figure 9.12 A Leppo' Ké or Nyibun carved stone on a hill in upper Ngiam area

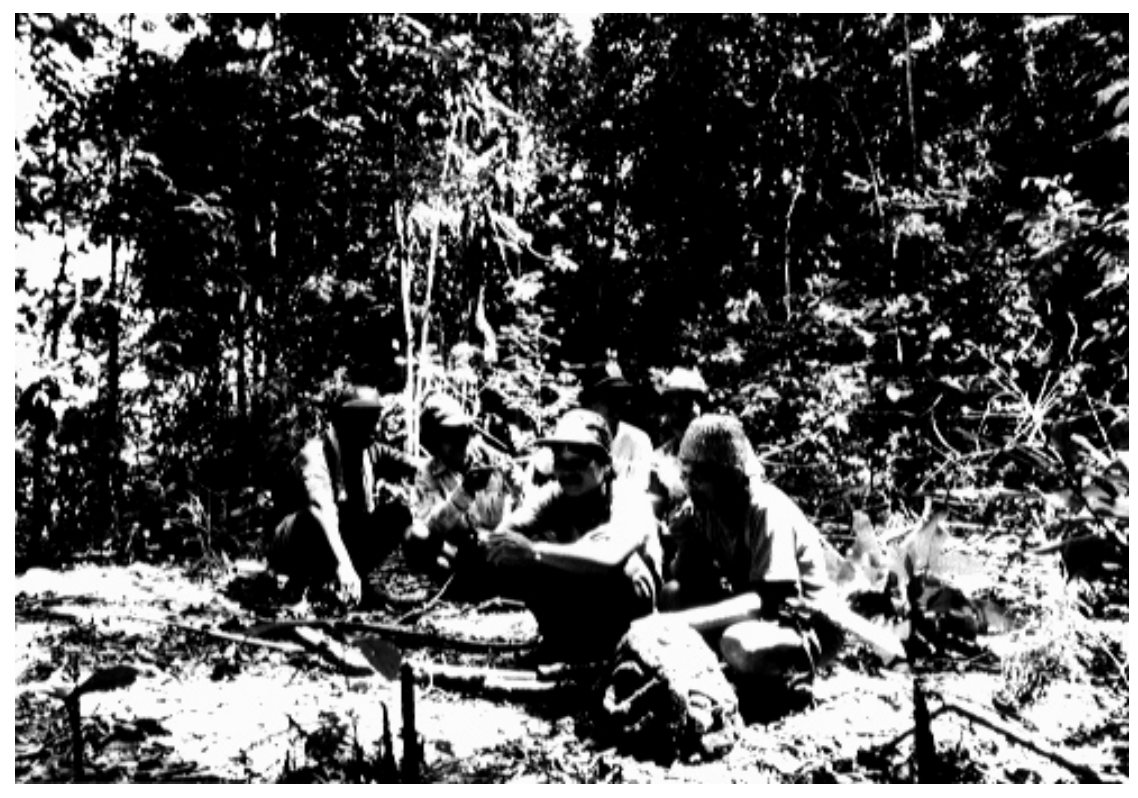


Figure 9.13 Stone barkcloth beaters excavated in Apau Ping

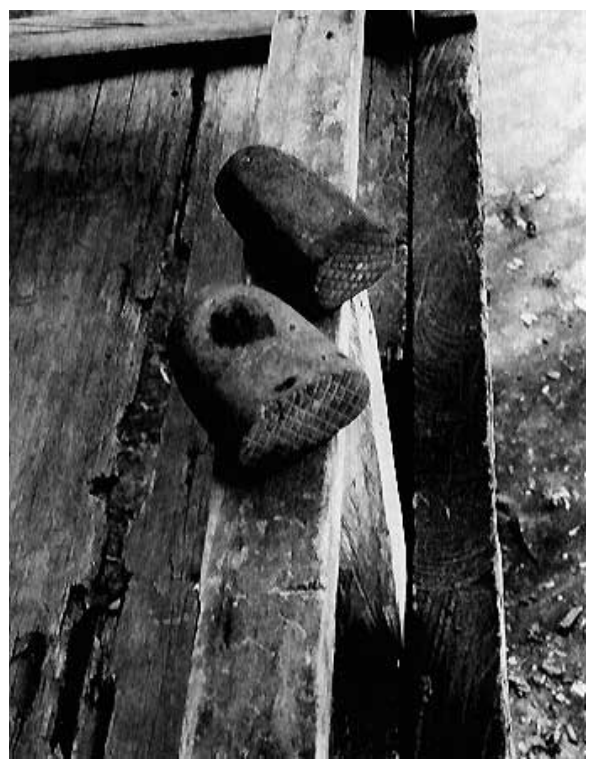

Figure 9.14 Author and ancient Nyibun funerary monuments at Long Lat site

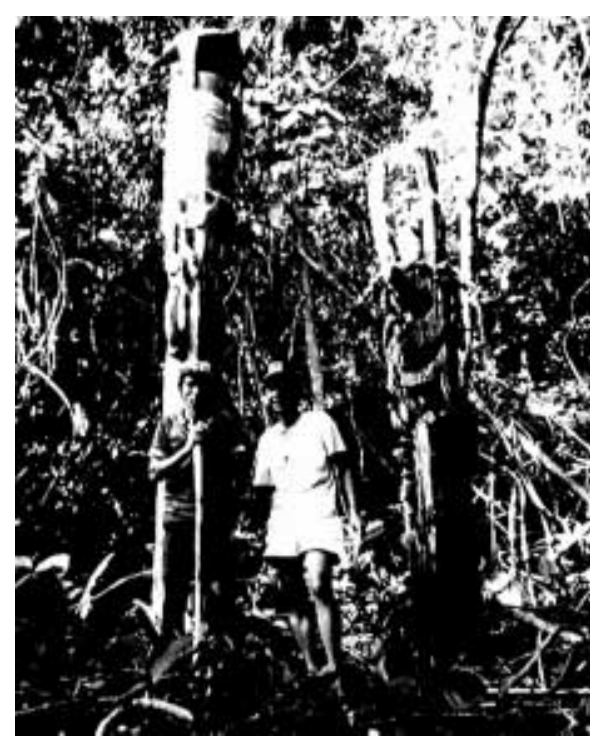

Figure 9.15 A Nyibun funerary monument in the upper Ngiam River area

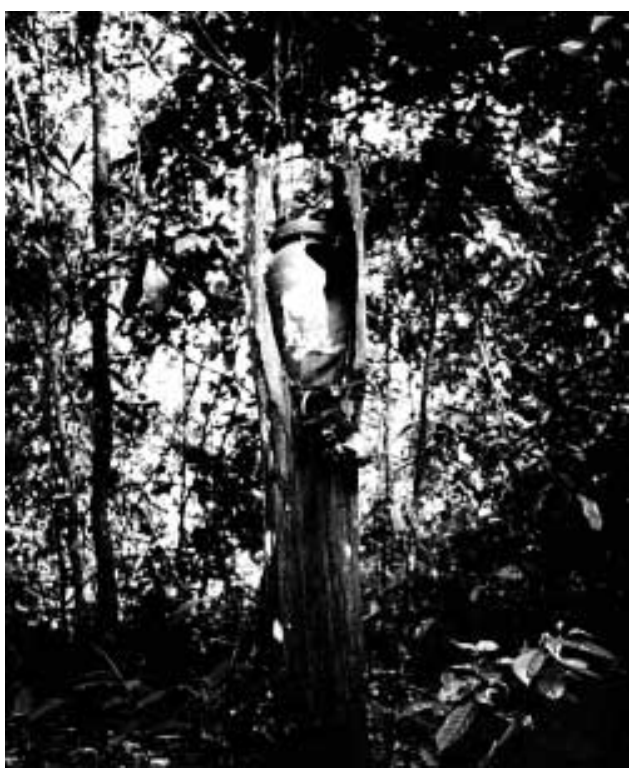




\title{
10. \\ A history of the Kenyah Leppo' Tau in Kayan Hulu Subdistrict, Apau Kayan
}

\author{
Liman Lawai
}

\section{INTRODUCTION}

The history of the Kenyah Leppo' Tau can be reconstructed on the basis of local oral traditions in combination with written records produced by officials of the Dutch colonial government, Kenyah leaders (such as Gun Kila), and several foreign researchers (such as $\mathrm{H}$. Whittier). These historical records also make it possible to analyse changes in the social structure through time.

It is known that the Kenyah initially lived in the mountainous area between what is now part of the Bahagian Belaga and Bahagian Baram in Sarawak and the Iwan River area in East Kalimantan. It is possible that they were still hunters and gatherers at that time and did not grow crops. Later, in the late 18th century, they moved to the Iwan River area. From there, some of them entered the Pujungan River drainage, others moved to the region of the Buram River, and yet others moved to the Apau Kayan highlands after the area had been abandoned by the Kayan people. The migration of the Kenyah to Apau Kayan seems to have occurred at the beginning of the 19th century. The first group to enter the Apau Kayan area were the Kenya Leppo' Timai, followed by the Leppo' Tau and other Kenyah groups. Although many Kenyah groups once lived in the Apau Kayan, which is very difficult to reach, at present many of them have moved out to other areas, primarily in the vicinity of urban areas where access to basic necessities such as salt and clothing is easier. 
The writer carried out field research from 1993 until January 1994. The aim of the research was to learn about the reasons for migrating, obtain information on the stopovers and settlements of the Kenyah Leppo' Tau as they moved from the Iwan River to Apau Kayan, and study the evolution in the forms of leadership from the past until today. Historical events and genealogies of leaders were compiled, and crosschecked, on the basis of interviews with informants according to historical accounts. In particular, the author collected the names of leaders at the time certain events occurred.

As a time frame, a standard scale of 20 to 25 years for a generation was adopted. The calculation then was as follows: Baya' Li' (the last generation in 1993) was 50 years old, so he was born in 1943, rounded off to 1940. Assuming a standard of 20 years per generation, 24 generations equal 480 years. Assuming a standard of 25 years, 24 generations equal 600 years. The birth of Pejulan Awang (24 generations before Baya' Li') thus is estimated to have taken place between 1350 and 1450 (rounded off). In compiling historical sequences in Borneo, this method may be used to calculate genealogies.

\section{GENERAL DESCRIPTION OF THE RESEARCH AREA}

The research location included all the villages inhabited by the Leppo' Tau in the Apau Kayan area: Long Nawang, Nawang Baru, Long Temuyat, Long Uro', and Lidung Payu. To obtain additional data, research was also carried out in several of the villages of the other Kenyah groups in Apau Kayan, such as Long Ampung (Kenyah Leppo' J alan group), Long Sungai Barang (Kenyah Leppo' Tukung), Long Payau and Metulang Baru (Kenyah Bakung). Historical reconstruction regarding these groups can be found in an earlier research report (Liman 1995).

The settlements of the Kenyah Leppo' Tau in the Apau Kayan area in the subdistrict of Kayan Hulu are (1993): Long Nawang (809 people), Nawang Baru (585), Long Temuyat (327), Long Uro' (303), Lidung Payau (351), and Long Lebusan (648). The total population of the Leppo' Tau amounts to 3023 (1993). The settlements of other Kenyah groups and of Punan in Apau Kayan (comprised in the subdistrict of Kayan Hulu) are: Long Betao' (Kenyah Badeng group, 111 people), Long Ampung (Kenyah Leppo' J alan, 454), Long Sungai Barang (Kenyah Leppo' Tukung, 369), Long Payau (Kenyah Bakung, 104), Long Top (Punan, 73), Long Metulang (Bakung, 82) Mahak Baru (Bakung, 378), and Dumu Mahak (Bakung, 242), with a total population of 1822 people.

\section{Education and Religion}

The formal educational level of most Kenyah in Apau Kayan is elementary school (SD), and many people have never attended any school. The first school was opened in Long Nawang during Dutch times. At that time, the people did not yet realise the importance of education and many parents prohibited their children from going to school. The first private SMP (junior high school) was established in Long Nawang in 1976 and its students came from two subdistricts, Kayan Hulu and Kayan Hilir. This SMP became state managed in 1990. At present many children attend school in Apau Kayan, even though many of them only graduate from SD. Unfortunately, the SMP is rather inadequate with regard to equipment and facilities for studying and teaching, and the students are often given days off. A low salary has forced teachers to find additional work outside the school. 
Almost all the Kenyah in Apau Kayan (96\%) became either Protestant or Catholic since the 1960s. In the village of Long Betao', two families (six persons) still follow the old religion (Adat Bungan) and thirteen newcomers are Moslems. In the subdistrict of Kayan Hulu, people are divided among the following congregations: Protestants of the GKII Church (2673), Protestants of the GPIB Church (1001), and Catholics (1143). Every village already has its own church. A mosque has been built in Long Nawang. The Adat Bungan community holds its ceremonies in their own houses, but ceremonies frequently held in the past, such as the mamat festival and the lemiwa ceremony, no longer receive much attention today. The relations between the religious congregations are good. For example, the building of a place of worship is done jointly regardless of church affiliation and Christmas and Easter are celebrated together. Some programs are arranged by the various church organisations separately, such as weekly services, wedding services, and baptisms, as well as funeral services.

\section{Economic Life}

Agricultural enterprises of the Kenyah are mainly intended to meet household needs and the main activity is cyclical (shifting) dry-field rice cultivation. Since olden times, the Kenyah have been planting beans and tubers in the old swidden (secondary forest) fields and today they cultivate plants such as onions, beans, eggplant, squash, mustard greens, red peppers, amaranth, pineapple, bananas, cassava and sweet potatoes. The people generally are not yet interested in perennial crops, because they have not yet mastered the cultivation methods, or lack marketing opportunities. Livestock (especially chicken and pigs) are also raised to meet household needs and they are only traded very rarely (there is no standard price). Hunting and fishing are very common. At present the people are beginning to trade the catch of their hunt or fishing, especially in the subdistrict capital.

Forest products currently exploited in Apau Kayan are eaglewood (Ind. gaharu, Kenyah sekau) and bezoar stones from monkeys and porcupines. Even though rattan and resin are still found abundantly in Apau Kayan, they are rarely collected today because the prices are very low and the people still do not have ways to process these raw materials into commercial products. Forest products are generally harvested to meet additional expenses like buying goods that the people cannot produce.

In 1993, the price of eaglewood in Apau Kayan has reached Rp 1000000 per kg for the best quality. Eaglewood traders (10 people) use local labour or import labour from outside the area (150 people, some of whom are stationed in Long Nawang). Traders with large capital use services and purchase their daily necessities, and they tend to monopolise the small airplanes, which are the only means for transporting staples (rice, sugar, salt, cooking oil and the like) from the coast to Apau Kayan. The supply of these goods is thus limited, the prices are very high and the local people, whose purchasing power is low, are often unable to obtain them.

Women often do handicraft work, such as beadwork, rattan weaving (baskets, mats, and baby carriers), and saong (a kind of broad sun hat with applications of multicoloured cloth). Old men make machete handles decorated with goat hair and carved from deer antlers.

Modern commerce only began when the airfield was opened in Long Ampung (located one-and-a-half hours away by ketinting (small motorised boat) from Long Nawang. Smallscale trade, which was formerly limited to the subdistrict employees, is expanding. Traders and villagers often import goods for local consumption from Sarawak along 
footpaths. These commodities, gasoline, kerosene, salt, and granulated sugar, sell quickly because their prices are competitive compared to those of goods brought in by plane. River transportation from Tanjung Selor is very risky because of the rapids and water levels. Other types of goods-cigarettes, cooking oil, soap, tea, coffee, monosodium glutamate, and medicines-are imported from Samarinda, because the prices for these items in Sarawak are much higher, but the supplies are very much dependent on the availability of air transportation.

\section{THE SOCIOCULTURAL SYSTEM OF THE LEPPO' TAU}

Various aspects of the social and cultural traditions and customs of the Leppo' Tau have influenced the history of their movements. Among these are their traditional class system, their leadership system and social institutions, the process of decision making and customary laws, as well as the peacemaking or petutung tradition.

\section{Social Classes}

In the language of the Leppo' Tau, the nobility is referred to as paren. The formation of the paren resembles the establishment of a kingdom when an individual who is much honoured and respected for having liberated his people from the enemy, especially on the battlefield, is elevated to kingship. The term paren first appeared when the Leppo' Tau lived in the area of Bawang Da'a (Apau Kayu Tau), and it is possible that it was derived from a similar Kayan word. At that time, an outstanding Kenyah leader was Suhu Batu, who was brave and strong and did not want to submit to any other group. On the contrary, he was the one who forced the other Kenyah groups to surrender and follow his leadership. In the period after Suhu Batu, Leppo' Tau people began to distinguish between the descendants of Suhu Batu and other families, which led to the formation of three social strata, i.e., the paren (nobility, descendants of Suhu Batu), the panyen (ordinary people), and the ula' (slaves).

Subsequently, society provided the paren class with the kind of recognition and honour that distinguished their position in society. In addition to playing an important role in the leadership of the society, both during a migration and in each successive settlement, the paren class also had special rights. Their apartments (amin) at the centre of the longhouse were taller and larger than the other apartments. To the right and left of their amin there were several amin of the panyen. The corvee labour system (mahap) required that the people work without compensation for one or two days for the nobility, especially in doing farm work. Before any decision was made in the community, the paren were always asked for guidance. The nobility was allowed to own valuable goods and objects of great symbolic significance and, to this day these items indicate the social status of the paren families. Among these items are objects such as tiger claws and skins, several types of expensive and ancient beads, large ceramic jars with raised dragon figures, and gongs. Some motifs (tigers and hornbills) and tattoos could only be used by the paren. In addition, the paren played an important ritual and ceremonial role in the ancient religion (Adat Puon) that pre-existed Adat Bungan (see below).

\section{Evolution}

From generation to generation, the paren families continued to grow in number, until they could no longer be accommodated in one amin. Some of the members of the 
original amin set up a new longhouse (uma') in the same village (referred to as leppo'), and some of the panyen were moved to the new uma', where the paren maintained their position as paren. Their amin was taller and larger and was located at the centre of the new longhouse, but they could not build it taller than the amin of the paren in the original longhouse, because the position of the leader of the new longhouse (paren uma') was inferior to that of the paren leppo', the leader of the original longhouse and-at the same time-of the whole village.

Informants claim that these aristocratic leaders were expected to have various praiseworthy characteristics, as well as the maren (noble) traits of Suhu Batu. They were expected to be courageous and strong (makang), sagacious and prudent (dena' kimet), and helpful ('un sahe'); to have a sense of compassion and social responsibility ('un lesau); to be polite when talking and to think rationally (tiga tira' ngan kenep); to be effective in uniting and advising the people (mencam pebeka' ngan mencam pekatok dulu ngeleppo'); to speak the truth and dislike lying (abe' uba' lemalo, ngan bang pisiu iya Ian); to have a broad perspective and an open mind ('un kenep iya dado'); to have a sense of shame ('un sae'); to not be hasty in action (abe' uba' basuk kenep), to keep from vilifying others (abe' uba' pejaat dulu); and, finally, to have great determination and a sense of responsibility in leadership (bawa'). This was the ideal leader who was respected by the panyen, and anyone chosen to be a leader had to understand and adhere to these principles of leadership.

\section{The Adat Puon}

In the ceremonies of the Adat Puon tradition, society was divided into the detau bio', or high nobility; the detau dumit, or low nobility; the panyen, consisting of panyen tiga, or the descendants of intermarriages of paren and panyen, and the panyen kelayan, or ordinary people; and the ula', or slaves. As soon as a ceremony was over, the paren category became one again, and was no longer divided into high and low nobility.

The Adat Puon tradition, the old beliefs of the Kenyah, occupied an important place in all social activities including choosing the location of settlements. Bird omens (amen-amen) were always used, and people did not hesitate to abandon a settlement if the signs were unfavourable, even if village construction was already almost completed. In the Adat Puon, the sound and the direction of the passage of several types of animals and birds-the isit bird and the pengulung (a type of owl), the deer, the Brahminy kite, the cobra, and others-were believed to influence human life and were interpreted as auspicious or inauspicious signs.

The Adat Puon had ceremonial aspects with definite and heavy requirements, which had a significant impact on social life, among others with regard to protection. For example, the mamat festival always involved human skulls (the result of headhunting, ngayau). If an epidemic spread to a village and left many people dead, it was necessary to hold the tepo ceremony, which required the use of blood of a murdered human being in order to protect the village.

\section{Adat Bungan and its Influence}

In 1947-50, a new religious current, Adat Bungan, appeared. The new belief, which was spread by J uk Apui, a man from Long Ampung (of the Kenyah Leppo' J alan group), was reportedly revealed to him in a dream. This belief was actually only a revised 
version of the Adat Puon. Certain requirements, such as animal sacrifice, were eliminated because they were a heavy burden on the people and several strict taboos were removed. In the Adat Bungan ceremonies, it was sufficient to pray directly to Bungan Malan Paselong Luan (the goddess of creation) and use a chicken egg as a intermediary that replaced all animal sacrifices. After the introduction of the Adat Bungan to Leppo' Tau society, the social stratification changed, resulting in the elimination of the distinction between high and low nobles or aristocrats. With regard to the panyen and the ula', no changes occurred.

The Leppo' Tau nobility initially was opposed to the Bungan cult, especially because it eliminated several hitherto essential ceremonial requirements. They feared for the safety of the people, because they were responsible to the gods. They opposed the principles of the Bungan cult and tried to prevent its growth and spread; finally, however, they had to accept it.

\section{The Influence of Christianity}

Christianity was introduced to the Leppo' Tau between 1952 and 1965, as its adherents spread. Christianity actually had already been introduced at the time of the Dutch presence in Apau Kayan, but it had not spread among the people. In the early 1950s, positions for and against the acceptance of Christianity were taken among the Leppo' Tau, and especially among the nobility in Long Nawang. Many of the residents of Long Nawang were strongly in favour of retaining the Adat Bungan; they separated from the village and established a new village at Nawang Baru, on the Nawang River (1952), while those who converted to Christianity have remained in Long Nawang until today. In approximately 1965, Christianity received a great opportunity, because the Indonesian government threatened that anyone still following the Adat Bungan or even the Adat Puon would be considered 'godless', and could thus be declared a Communist and be subject to punishment. The government apparatus forcibly disrupted and destroyed all places of worship of the adherents of the Adat Bungan.

The effects of Christianity are visible in the social stratification. The nobility became one single category. So did the class of ordinary people, as the distinction between panyen tiga and panyen kelayan also disappeared. The slave category was eliminated by the government, in line with the now dominant Christian ideas. Today the differences between the two remaining classes or strata are no longer striking for various reasons: Christian beliefs, educational progress, and economic factors. This means that the social classes are no longer functional, except in the selection of leaders: As of today, no panyen has ever been chosen to become village head, much less adat chief.

\section{The System of Leadership and Social Institutions}

The system of leadership of the Leppo' Tau is as follows: 1) at the level of the wilayah adat (a large customary domain, for example, a whole river basin, consisting of more than one ethnic group): the kepala adat besar (great adat chief) and his staff of notables or elders (pengelata' leppo'), his assistants (pegawa leppo'), and 'public relations' officers (pelawa'); 2) at the level of a settlement or single ethnic group: the village chief (kepala leppo' or paren leppo', today the village head), with his appointees, the pengelata' leppo' (community leaders), assistants (pegawa leppo'), and public relations officers (pelawa'); and 3) at the longhouse level: the longhouse 
chief (kepala uma' or paren uma'), his staff of pegawa uma' belonging to the panyen tiga category, and the publication relations officer, pelawa'.

\section{The Adat Chief}

The adat chief (or great adat chief) was chosen and appointed by all Kenyah groups occupying one given region (or one river basin) to lead and regulate social life. Some of the terms for the adat chief used through the ages are pengelata' (a respected person, notable), paren bio' (the great aristocrat), paren negen or paren mano' (direct descendants of high nobility), raja (king, after a relationship with the sultan of Kutai had developed), kepala suku besar (great tribal chief) or, for short, kepala suku (tribal chief, a phrase used during Dutch times), and finally, kepala adat or kepala adat besar (the phrase used under the Indonesian government).

A candidate for the position of kepala adat must meet a number of requirements (see the characteristics of an ideal leader above); he also must have broad influence; he must be appointed by the ordinary people; he must be able to talk well and influence the people; he must be honest and polite when talking; he must be able to receive the suggestions and opinions of others; in his service to the people, he may not distinguish between the nobility and the ordinary people.

In carrying out his duties, the kepala adat is assisted by the pengelata' leppo', notables from both the nobility and the ordinary people; the assistants of the village chief, pegawa leppo', chosen for their oratory skills from among the panyen tiga; and by public relations officers, pelawa', chosen from among the ordinary people. It is the task and function of the adat chief to make the decisions to be implemented by the people, to serve as an intermediary and as advisor if interethnic group conflicts develop, and to act as a leader in adat ceremonies. The village notables (pengelata' leppo') are respected individuals among the people who have been given 'elder' status. In every village (leppo'), these notables assist the village chief (kepala leppo') in the leadership of the village, but the notables of several villages also have an advisory role to the adat chief and to their respective village chiefs. In this respect, they also act as liaison between the great adat chief and the chiefs of each village.

The assistants to the village chief (pegawa leppo') are selected from among influential figures of the panyen tiga. The panyen tiga act as partners or assistants to the paren, and their apartments (amin) are always located to the right and left of the amin of the paren. The pegawa leppo' serve many functions: to assist in reaching decision together with the kepala adat; they assist him in all kinds of activities and can represent him; they give advice and present their opinions to him; they mediate if disagreement develops among the paren; they serve as leaders of village meetings or adat ceremonies; and they mobilise the people to carry out the decisions of the adat chief. The pegawa leppo' are not officially appointed, but are selected by the adat chief with the support of the public. These people must be able to speak well, communicate easily, and be loyal to the adat chief. The number of these assistants (pegawa leppo') varies; usually there are more than one, but rarely more than five.

The pelawa', or human relations officers, are usually chosen from among the common people. They are not officially appointed, but they are merely directly designated by the adat chief. Appointment to this position is a matter of pride for the person selected and for his family, who are viewed as trusted by the adat chief. The functions of the pelawa' are to convey news directly of any decision by the adat chief to the people; together with the kepala Ieppo', to mobilise the people to 
implement the decisions of the adat chief; and to serve as messengers of the adat chief whenever necessary.

\section{The Village Chief}

The village chief (kepala leppo', or also paren leppo') is selected and appointed from among the paren. In former times, it was often the case that one ethnic group was equated with only one village, so that the village head was simultaneously the chief of the group (kepala suku)-but this was not the case for the great chief (kepala suku besar). The village chief, then, was only the leader of his own group. The kepala leppo' from the various villages (or ethnic groups) in the area surrounding a given village also took part in the selection of that village's kepala leppo'. The kepala leppo' had to submit to and follow the decisions of the great adat chief; he implemented the decisions of the great adat chief in his village, and he was responsible to the great adat chief for the safety and security of the people of his own village. He reported to the great adat chief on any disputes in or among villages; and he was expected to settle disputes among the residents of his own village; he assisted the great adat chief in settling intergroup conflicts. Qualifications for becoming kepala leppo' did not differ from those that had to be met by an adat chief. The kepala leppo' is today referred to as 'village head', either kepala desa, kepala kampung, or petinggi (village mayor).

\section{The Longhouse Chief}

The chief of the longhouse, kepala uma' (also referred to as paren uma'), is always a member of the nobility and a descendent of the paren leppo'. Population growth led to the breakup of the original uma' (Ionghouse; see above) and led to the establishment of new longhouses. The paren who established them became their chiefs, paren uma'. In this way, a leppo' (village) could consist of several longhouses. If a paren moved to another area, he also became the new longhouse chief (kepala uma') in the new village. If the longhouse has been replaced with family homes, the kepala uma' is now the head of the 'block', or neighbourhood unit (RT, Rukun Tetangga), and is called Ketua RT.

The longhouse chief leads the people in the longhouse, and he may be selected to become village chief (paren leppo') or even great adat chief. If he is selected to become adat chief, then his apartment (amin) may be raised and enlarged to the size of that of the preceding adat chief.

The longhouse chief is charged with protecting and regulating life in the longhouse and with leading the people. In this, he is responsible to the adat chief. He also accompanies the adat chief on his visits to other groups. Within the longhouse environment, he settles conflicts and leads adat ceremonies. The longhouse chief is always accompanied by the pegawa uma', who act as his advisors in all decisions made. The pegawa uma' belong to the panyen tiga category, who live to the right and left of his amin and must be ready whenever called for without having to be assigned.

\section{The Process of Decision Making and the Customary Law}

Within the stratified Kenyah society, leadership has always been in the hands of the paren, who exercise power and make decisions. Nevertheless, the leaders rarely act dictatorially, because at times they only formalise decisions that have already been taken in a consultative meeting (musyawarah) and with advice from the notables 
(pengelata', pegawa leppo', and members of the panyen tiga). The system of leadership of the Leppo' Tau has always resembled a 'guided democracy', in which the paren make the final decision after holding meetings and consultations.

Tradition and customary law (adat) is highly honoured and respected. If offences against adat occur-such as elopements, sexual relations outside marriage and adultery, slander or insults of others, or pregnancy outside of marriage-the adat chief or the village chief will immediately call an adat meeting to take action by applying adat sanctions, punishments, or fines. Fines require the payment of a machete or the surrender of an heirloom item such as a gong, jar, or other, according to existing adat regulations. In addition to fines, sanctions such as banishment may also be imposed. For example, if a woman becomes pregnant without a known husband (temale' awah), she is banned from the village until she has given birth. She sets up a hut and food, and care can only be provided by her parents. After she has given birth, she may bring her child back to the village, but she still has to turn in what she was required to pay, which becomes the property of the village.

For crimes such as theft, fraud, robbery, murder of a fellow resident, there are no strict and definite sanctions, which may derive from the fact that such crimes hardly ever occur among the Kenyah. If a fellow resident is killed, it is usually unintentionally, as in a hunting accident. To cleanse the village from the evil effects of such accidents, it is necessary to hold a great adat ceremony, which is attended by all residents. The cost for the ceremony is charged to whoever was responsible for the accident. That person is also required to surrender heirloom items (such as a jar), which has mainly symbolic significance-it does not require a particular size or type of heirloom, nor does it pay excessive attention to its value. On the occasion of this ceremony, the notables, the adat chief, and the village chief offer words of advice and guidance aimed at preventing the recurrence of such accidents.

\section{Adat Petutung}

Petutung means 'to make peace' between two Dayak groups or villages by means of an alliance by marriage between children of the village chiefs (kepala leppo') of the two parties that have been in conflict, in the hope that the descendants of these marriages will eventually also become village chiefs and will play an important role as mediators if disputes or tension develop again between the two parties. This peacemaking can also occur through an exchange of symbolic objects, such as gongs (tawe'), tiger claws, spears, or shields, that is accompanied by an oath taken on these objects.

Petutung can also be used preventively, when signs of impending conflict between two groups appear and there is concern that these might lead to war. It is also used to improve unity among different groups living near each other in one region, even if there are no signs of hostility. Historically, the Leppo' Tau frequently used the latter approach to extend their power over other, smaller groups to force them to submit and recognise the leadership of the Leppo' Tau. Petutung involving such imposed intermarriage has resulted in the presence among the leaders of the other, less powerful groups of a Leppo' Tau paren, representing the power of the Leppo' Tau. Thus, once the child of this paren had become a leader, he could ensure the group's continuing loyalty to the Leppo' Tau. Thus, petutung was a frequent occurrence in the history of Kenyah society, and became an important political tool for the Leppo' Tau in its competition for power in the Apau Kayan area. 


\section{HISTORY OF THE KENYAH LEPPO' TAU}

\section{Origins of the Leppo' Tau}

Baya' Li' (a direct descendant of Leppo' Tau nobility) says that, according to legends, his ancestors came from across the sea and settled on the Baram River (Telang Usang), in Sarawak, where they remained for twelve generations (see Figures 10.1 and 10.2). Subsequently, they moved to the upper Iwan River area under the leadership of Suhu Batu. According to Baya' Li', the leadership of the Kenyah Leppo' Tau can be traced for 24 generations since they crossed the sea: 1) J ulan Awang (who came from across the sea), 2) Ubang Julan (who settled on the Baram River), 3) Kelawa Ubang, 4) Gela Kelawa, 5) Aka Gela, 6) Lurek Aka, 7) Apui Lurek, 8) Lencau Apui, 9) Masing Lencau, 10) La'ing Masing, 11) Batang La'ing, 12) Batu Batang, 13) Suhu Batu (who settled on the Iwan River), 14) Lencau Suhu, 15) Kajan Lencau, 16) Bungan Kajan, 17) Asa (or Tasa) Bungan (who moved to Ikeng Iwan), 18) Ngau Tau, 19) Anye' Ngau, *Ungau Kayang (who moved to Apau Kayan), *Usat Ngau, 20) Surang Anye' (who settled in Long Nawang), 21) Ingan Surang, 22) Lencau Ingan, 23) Li' Lencau, *Bit Ncuk, *Pare' La'ing (the Adat Chief of Apau Kayan in 1993), 24) Baya' Li'. The sequence indicates a straight line of descent from the first paren of the Leppo' Tau, except where the asterisk indicates the emergence of a leader from other paren families.

Calculations based on these 24 generations tentatively allow us to conclude that the ancestors of the Kenyah moved to Kalimantan around 1350 to 1450 AD. Five generations lie between Anye' Ngau and Baya' Li' (who is now 50-60 years old), this means that the Leppo' Tau entered the Apau Kayan area only 150-175 years ago (see historical maps).

Only after a number of Kenyah people had left the Baram River (Telang Usan) to settle in the upper Iwan River area (at Apau Kayu Tau, Bawang Da'a, and Apau Data) did the various names of the Kenyah subgroups appear in relation to certain specific characteristics of their settlements. For example, the name Leppo' Tau is derived from the kayu tau (tau tree), which was found in the yards of their longhouses.

\section{History of Leppo' Tau Settlement on the Upper Iwan River}

The Kenyah who eventually became known as the Leppo' Tau moved from the Baram River to the upper Iwan River under the leadership of Suhu Batu approximately twelve generations ago. At the same time, a number of other Kenyah groups also moved to the upper Iwan River. These groups settled close to one another in the highlands known as Apau Kayu Tau, Bawang Da'a, and Apau Data and their surroundings.

\section{Apau Kayu Tau and Bawang Da'a (c. 1700-1750?)}

Apau Kayu Tau is located in the mountainous area between the Baram River and the Iwan and Bahau rivers. The Leppo' Tau there were led by Suhu Batu. The name Leppo' Tau was derived from a wooden post or stick known as beraka' tau (or kayu tau), which was used to measure the sun's position in order to set the favourable date of the planting season.

Eventually the farming and hunting areas around Apau Kayu Tau became too small. Because of this and of the frequent intergroup wars, the various groups decided to split and move away, settling quite far from each other. The Leppo' Tau moved to Laleng Bawai, together with their allies, the Leppo' Tukung, Leppo' Bem, and Leppo' J alan. 
Figure 10.1 Hydrographic map of interior northern East Kalimantan

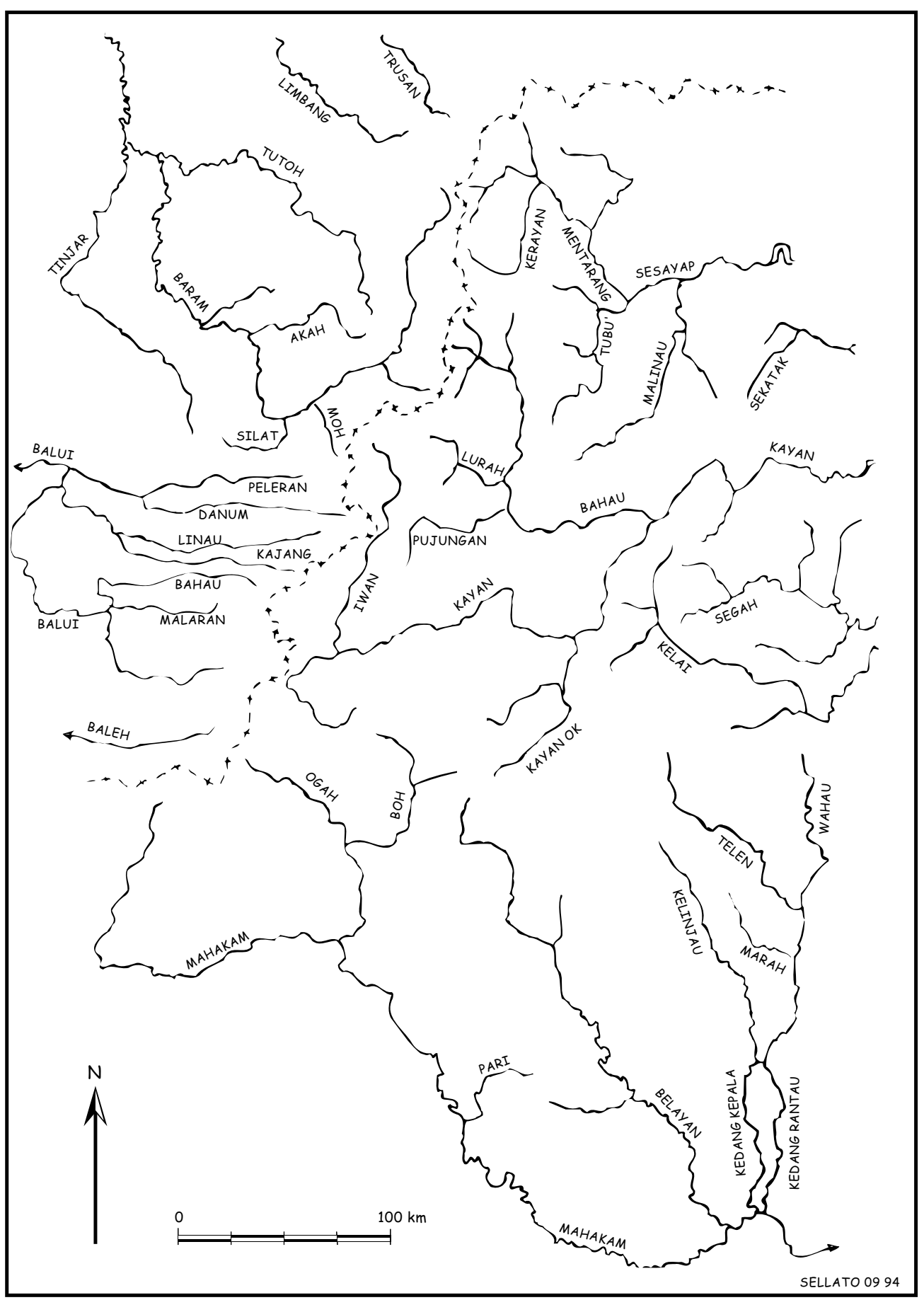


Figure 10.2 Migrations of the Kenyah Leppo' Tau (1)

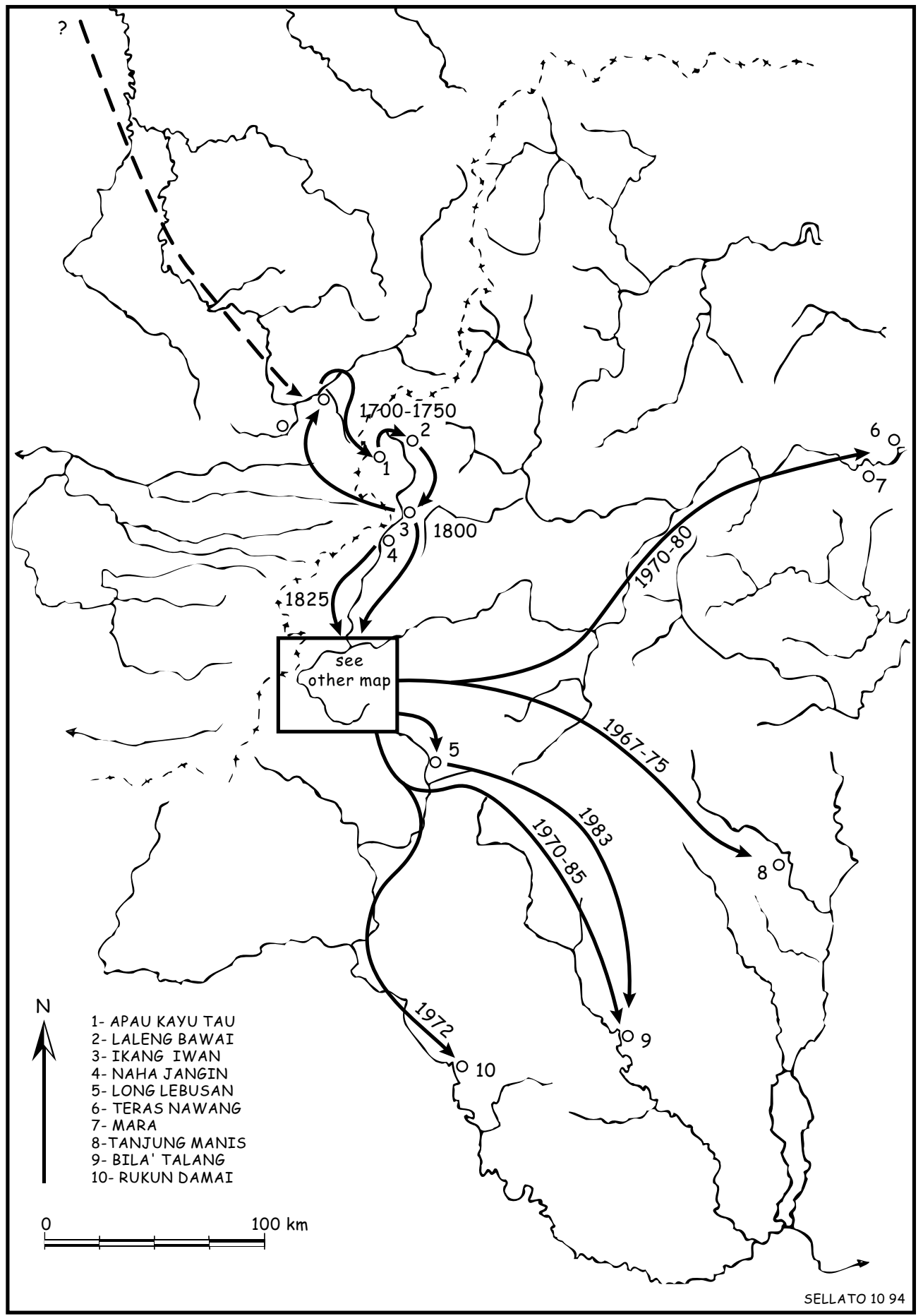


Since that time, the Leppo' Tau have attempted to keep their various allies united in order to guarantee their common safety. In every migration, the Leppo' Tau were always followed by these groups, who established settlements nearby.

\section{Laleng Bawai (c. 1730-1800?)}

Laleng Bawai was located on the upper lyung River, a tributary of the Iwan. The Leppo' Tau were led by Lencau Suhu. They remained in this area for three generations. In the third generation, as a result of war, no suitable leaders were left and a vacancy developed in the leadership. A young orphan, Uyau I' ut (the term means 'small orphan'), who had been raised among the Kenyah Uma' Alim, was appointed leader of the Leppo' Tau, who subsequently moved to Ikeng Iwan, joining other Kenyah groups which had settled there earlier.

\section{Ikeng Iwan (c. 1780-1820)}

Ikeng Iwan is located on the banks of the Iwan River. The Leppo' Tau were led by Palung Lawai, the son of Uyau l'ut. After his death, Palung was succeeded by Taman Bawe' Tului (whose original name was Tului Lawai). Under Tului's leadership, open war broke out between the Leppo' Tau and their Kenyah allies (Leppo' Tukung, Leppo' J alan, Leppo' Bem, and Bakung), on the one hand, and the Kenyah Uma' Alim, on the other. The Leppo' Tau lost and suffered many casualties. Several years later, Tului decided to move his group back to the Baram River, but the other leaders (paren) disagreed. Tului departed, taking with him a large number of people, that is, seven longhouses. This group initially settled at Lusung Laku (or Apau Paya), but they were attacked by the Iban. Then, they moved to Long Uheng, under the leadership of Ngulo Arang. Later, they moved again to Long Belian, and finally to Long Mu'u (Long Moh, Baram) and Lepu'un Sampi (Baram), under the leadership of Bilung Kuleh. In the meantime, only three longhouses had remained at Ikeng Iwan, led by Usat Ngau, Ungau Kayang, and Palung Tanyit, respectively. From these three longhouses derived all the Leppo' Tau who are settled in Apau Kayan today.

Not long after this, the Leppo' Timai allies of the Leppo' Tau, who had formerly settled on the upper Pujungan River, decided to move to Naha Jangin, not far from Ikeng Iwan. The Leppo' Tau invited the Leppo' Timai to join them to form a single settlement, but the Leppo' Timai preferred to survey the Kayan River area, with the intention of moving to Long Metun. At that time, many Kayan groups were still living in the Apau Kayan. Civil war broke out between two Kayan leaders, Ngau Wan Luhang and Kuleh Laleng Awang. After Kuleh was killed, Ngau swore to leave the Kayan River area altogether and, as a result, the Kayan people dispersed to various areas, including the Mahakam River region and the Balui River in Sarawak. This left the Apau Kayan region empty, and the Leppo' Timai moved from Naha Jangin to Long Metun, on the Kayan River. The Leppo' Timai, the largest and strongest among the Kenyah groups and the first to enter the upper Kayan River basin, were led by Ajang Ipui and J alung Ipui. Among all Kenyah groups in Ikeng Iwan, the Leppo' Timai were the most respected.

In the meantime, at Ikeng Iwan, the child of a member of the nobility of the Leppo' Tau, was killed, and this led to a split. Part of the Leppo' Tau moved with their paren, Ungau Kayang, to Naha J angin. New leaders were appointed by the bali dayung (spirits that possess religious leaders). Those appointed were Surang Anye' and Ngau Merang Anye', both orphans since early childhood (uyau i'ut), and the bali dayung 
blessed Surang and instructed the people: 'Take good care of this child, because he will become the leader of the Leppo' Tau in the future.'

\section{History of Leppo' Tau Settlement in the Apau Kayan}

After remaining for approximately one century in the upper Iwan River area, the Leppo' Tau moved downstream to the part of the Apau Kayan known today known as Kayan Hilir Subdistrict, following the Leppo' Timai, and settled on the lower Iwan River (see Figures 10.3 and 10.4).

\section{Naha J angin (c. 1820-1825)}

Some of the Leppo' Tau under Ungau Kayang had already settled in Naha J angin (on the banks of the Iwan River, downstream from Ikeng Iwan) when Surang Anye' and Ngau Merang Anye' joined Ungau Kayang, their adoptive father. At the same time, another paren, Palung Tanyit, and his followers also moved to Naha J angin, and from there the Leppo' Tau moved to Long Bullo'. In the meantime, Tubang Lusat and his followers remained at Ikeng Iwan.

Figure 10.3 Hydrographic map of Apau Kayan

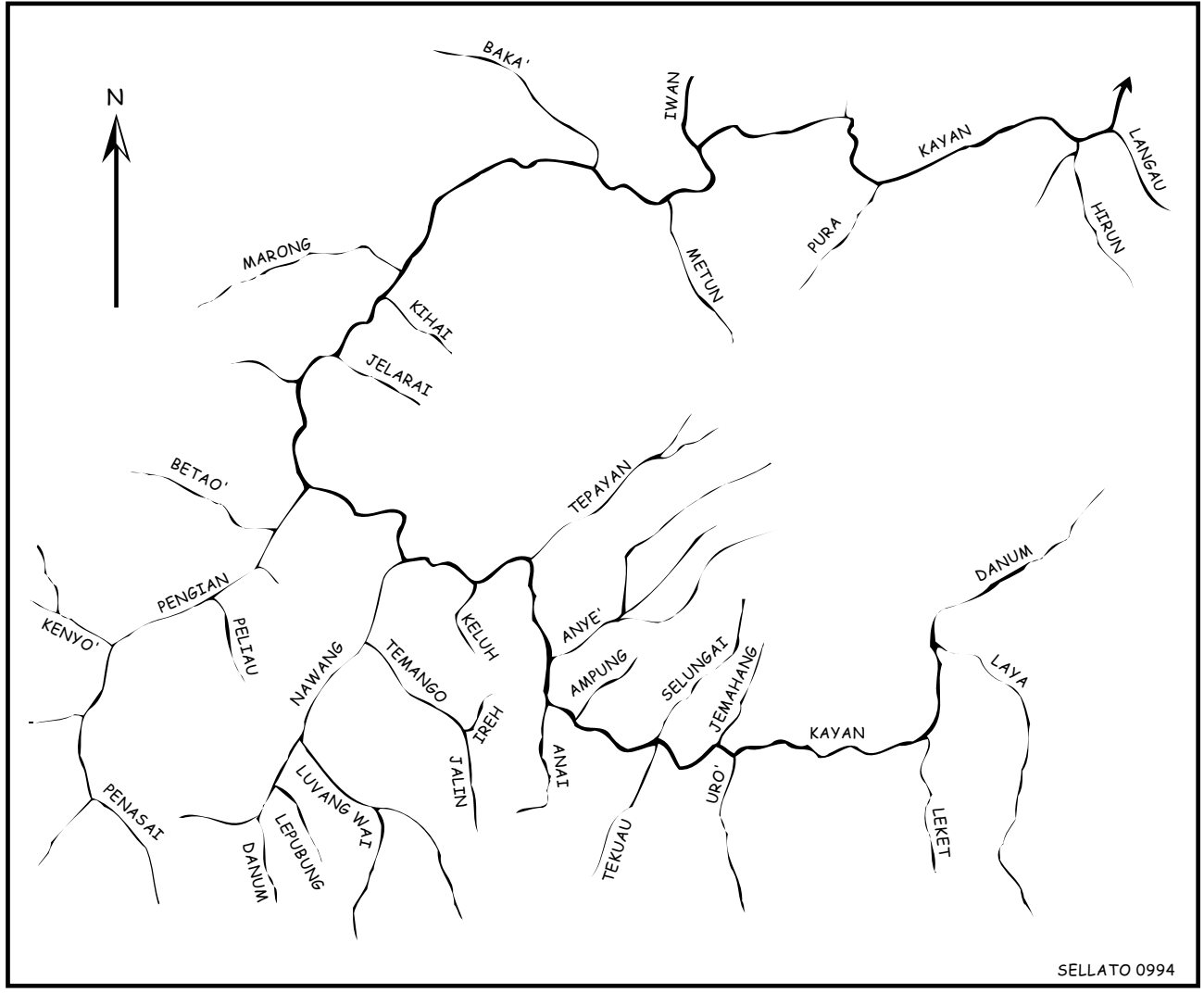


Figure 10.4 Migrations of the Kenyah Leppo' Tau (2)

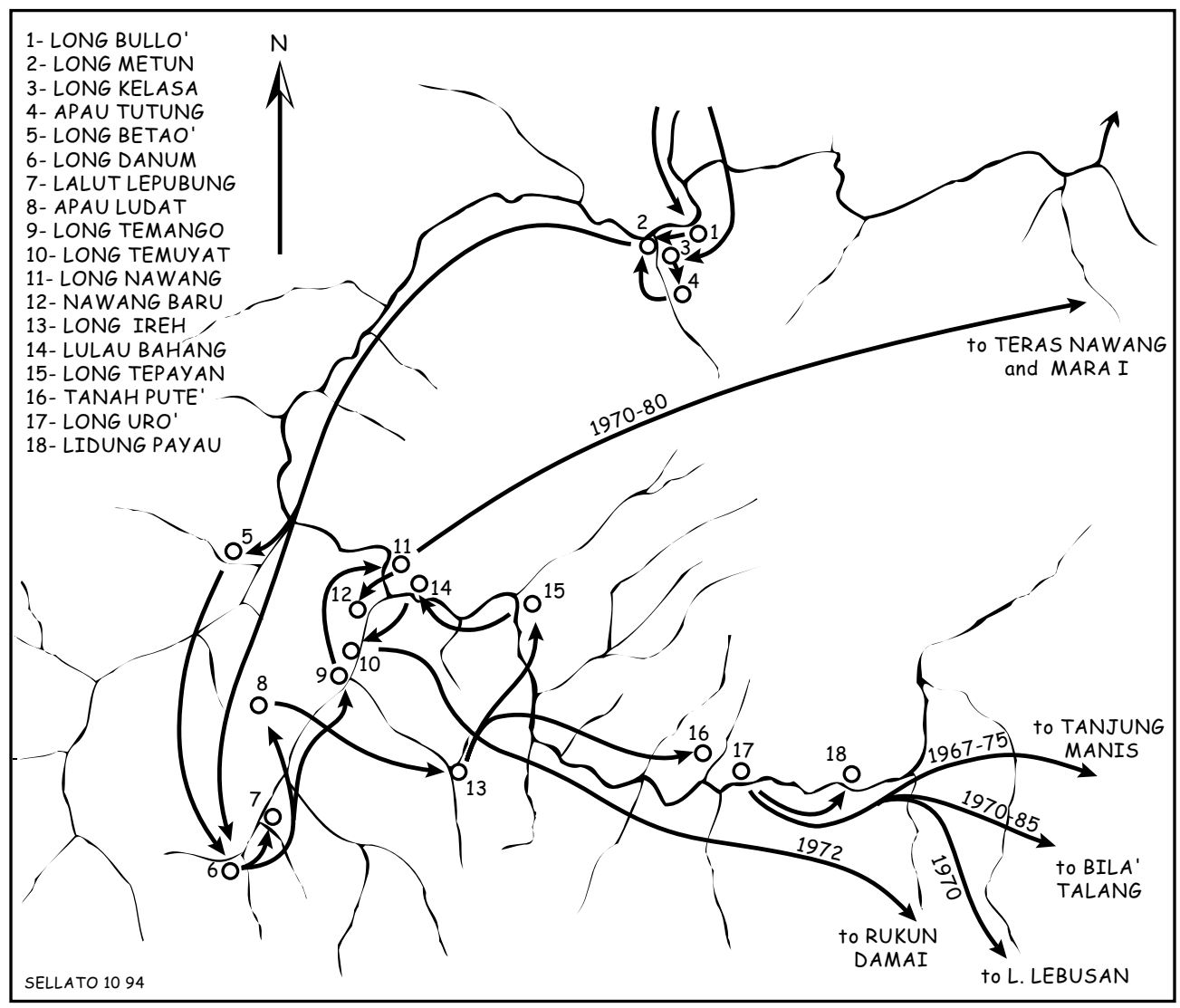

\section{Long Bullo' (c. 1825-1830)}

At Long Bullo', on the Kayan River, downstream from Long Metun, they remained only for a short time, because they felt too distant from the village of the Leppo' Timai at Long Metun. In the meantime, Surang Anye' and Ngau Merang were approaching adulthood and began to lead the Leppo' Tau. They invited Tubang Lusat and his followers in Ikeng Iwan to join them at Long Bullo', because the latter's small numbers at Ikeng Iwan did not guarantee their safety. After they arrived at the Kayan river, however, Tubang Lusat' s group decided to move on upriver along the Kayan River. They entered the Metun River and settled in Long Kelasa.

\section{Long Kelasa (c. 1825-1830)}

Long Kelasa is located on the Metun River, not far from the mouth of the river. The group of Leppo' Tau led by Tubang Lusat settled there for only a short time, moving again to an apau or highland area, not far from Long Kelasa and close to the village of the Leppo' Timai. Less than a year later, their longhouse burned down, and hence this location was named Apau Tutung ('burnt plateau'). The Leppo' Timai, notified of this disaster, picked up the people of Apau Tutung to join them in Long Metun. The Leppo' Tau who had lived at Long Bullo' also joined them in Long Metun. 


\section{Long Metun (c. 1825-1830)}

The Leppo' Tau remained only a short time at Long Metun with the Leppo' Timai, because the relationship between the two groups suddenly became tense when a Leppo' Tau woman was killed by a member of the Leppo' Timai. However, the leaders of the Leppo' Tau, Surang Anye' and Ngau Merang Anye', had to submit to the paren of the Leppo' Timai, Ajang Ipui and Kalung Ipui. As a consequence of this killing, the Leppo' Timai moved to the upper reaches of the Kayan River, and there they split into two groups, each group taking with them part of the Leppo' Tau. One group of Leppo' Timai, under Jalung Ipui, moved to the Tahap River (a tributary of the Pengian), and was soon followed by a group of Leppo' Tau under the leadership of Surang Anye' and Ngau Merang Anye', who established a village at Long Betao' (near the Tahap River). The second group of Leppo' Timai, led by Ajang Ipui, moved to the Lubang Wai River (a tributary of the Nawang river), and was followed by another group of the Leppo' Tau under the leadership of Tubang Lusat, who settled in Long Danum (on the Upper Nawang River). This left Long Metun empty.

\section{History of Leppo' Tau Settlement on the Upper Kayan River}

From Long Metun (today part of the subdistrict of Kayan Hilir), the Leppo' Tau moved across the Apau Kayan far upriver along the Kayan River (now part of the subdistrict of Kayan Hulu).

\section{Long Betao' (c. 1830-1835)}

Long Betao' is located on the banks of the Pengian River, not far from the mouth of the river and close to the Tahap River and the village of the Leppo' Timai. There, the Leppo' Timai and the Leppo' Tau remained only one year, because Tubang Lusat wanted to force the Leppo' Tau at Long Betao' to move to Long Danum. Tubang ordered the Leppo' Yibun (i.e., Nyibun; see Njau Anau in this volume), then living on the Iwan River, to attack Long Betao'. Surang Anye' and Ngau Merang fled the village of Long Betao' in order to avoid the burning of the village by the Nyibun, and they moved their group to Long Danum. The Leppo' Timai from the Tahap River moved to Apau Kuleh, upstream from Long Danum, while the Leppo' Timai from the Luban Wai River, under the leadership of Ajang Ipui, moved nearby, to Apau Kuleh.

\section{Long Danum (c. 1830-1835)}

The Danum River is located on the extreme upper reaches of the Nawang River. The Leppo' Tau remained there for four years, then they split again, because of leadership problems: Surang Anye' and Ngau Merang Anye' brought their followers to Lalut Lepubung (slightly upstream from Long Danum), while Mpui J ulang and Ingan Lusat led theirs to Apau Ludat (in the mountains between the Nawang and the Pengian rivers). At Apau Ludat, they remained for only about two years, because they were attacked by the Iban of Sarawak. Subsequently, they moved again to Long Ireh.

\section{Lalut Lepubung (c. 1835-1850)}

At Lalut Lepubung, the Leppo' Tau were still led by Surang Anye' and Ngau Merang Anye'. At this site two important events occurred between the Leppo' Tau and the 
Leppo' Timai, as well as one incident involving the Kenyah Leppo' Kulit. There, too, all the Kenyah groups of the Apau Kayan formed a union.

According to the old custom, during the rice-planting season, Kenyah people arranged the work schedule according to social stratification. The first day was used for people who took omens and observed a number of prohibitions on behalf of the entire community; the second day was reserved for the kepala leppo'; the third for the entire paren group; the fourth day for the panyen tiga, and so on. At that time, the village heads (kepala leppo') were Surang Anye' and Ngau Merang for the Leppo' Tau, and J alung Ipui and Ajang Ipui for the Leppo' Timai. Jalung Ipui and Ajang Ipui harshly prohibited Surang Anye' and Ngau Merang from planting on the second day, because the Leppo' Tau were considered of lower standing than the Leppo' Timai. The messengers from the Leppo' Timai were thrashed by the Leppo' Tau.

Another incident occurred as a result of an attack by the Kenyah Uma' Baka' on the Kenyah Uma' Kelep, who were allied with the Leppo' Timai. The Uma' Kelep believed their aggressors to be the Leppo' Tau, and reported this to the Leppo' Timai at Apau Kuleh. The Leppo' Timai responded by attacking the Leppo' J alan, who were allies of the Leppo' Tau. In response, the Leppo' Tau threatened to attack the Leppo' Timai village of Apau Kuleh but, in the end, an agreement was reached with the Leppo' Timai and the Leppo' Tau were satisfied with attacking only the Leppo' Kelep, a lowerranking group allied to the Leppo' Timai. After this event, the Leppo' Timai moved to Bawang Beliu (upriver from Long Ampung), and not long thereafter they moved again to Long Jemahang, and from there to the Tabang River area (a tributary of the Mahakam river). Since that time, there have been no Leppo' Timai in Apau Kayan, and the Leppo' Tau have remained as the most prominent and best known of the Kenyah groups in Apau Kayan.

After the Leppo' Timai had left the Apau Kayan, the Sultan of Kutai in Tenggarong inquired as to whom could be trusted to represent all Kenyah groups in Apau Kayan. The three kepala Ieppo', who were visiting Tenggarong, suggested that Surang Anye' of the Leppo' Tau be appointed as the leader of all the Kenyah groups in Apau Kayan. The Sultan sent to Surang Anye' symbols of his investiture, in the form of a spear named nyatap bujak and several pieces of cloth and royal clothing, with the message that he should maintain safety in the Apau Kayan area. Surang Anye' firmly refused these presents in consideration of the feelings of all the other Kenyah groups, and suggested that these symbols be sent around to all Kenyah groups in Apau Kayan. He invited the Kenyah leaders to Lalut Lepubung to discuss the problem of the sultan's gift or investiture. This meeting was attended by Lake' Langet (from the Kayan Uma' Lekan), Bilung Lusat (Kenyah Leppo' Bem), La'ing Imang (Kenyah Bakung, Taman Bo' Bilung (Kenyah Leppo' Tukung), Udau Ajang (aka Bo' Bulan, Kenyah Leppo' Kulit), Peng La'eng (Kenyah Leppo' Teppu), and Ngau Bilung (Kenyah Leppo' Jalan).

The meeting's outcome was that Surang Anye' was the most appropriate leader to retain the gifts of the Sultan. Surang was elevated to the position of leader of all the Kenyah groups of Apau Kayan, and he was given the title of Kepala Suku Besar se-Apau Kayan (equal to the term paren bio' in the Kenyah language). All ethnic groups of Apau Kayan were strictly forbidden from creating unrest or make war. A union symbolised by the hornbill was established. It was controlled by the leader of the all Kenyah groups in Apau Kayan. If this bird was sent out, its voice served as a call to all groups and had to be obeyed. If any one of these groups purposely committed crimes and destroyed the unity, action was to be taken by all the other groups together. After this, the leaders of the Leppo' Tau were responsible for travelling through the Apau 
Kayan area and visiting all the Kenyah groups to implement the petutung (peacemaking ceremonies).

These events were followed by the Long Peliau incident. Because a married Leppo' Tau woman had slept with a Leppo' Kulit man in Lalut Lepubung, a group of Leppo' Tau attacked the Leppo' Kulit near the village of Long Peliau. Because the weeding season was already over, they did not encounter anyone and to appease their anger, they cut down the paddy of the Leppo' Kulit. The Leppo' Kulit rushed to their fields and an uneven fight took place, in which the Leppo' Tau were outnumbered and exterminated, leaving only one survivor to carry the news back to Lalut Lepubung. The Leppo' Tau took revenge and many Leppo' Kulit fell victim. Thereupon the Leppo' Tau made peace (petutung) with the Leppo' Kulit, and soon after, moved to Long Temango.

\section{Long Temango (c. 1850-1865)}

In Long Temango, the Leppo' Tau were still led by Suran Anye' and Ngau Merang Anye'. After one year in that location, Ngau Merang died. While the Leppo' Tau lived in Long Temango, two important military events occurred.

The first, was a war with the Bakung, who did not want to adhere to the agreement reached at the meeting in Lalut Lepubung and who tended to kill anyone who came to their village at Tegeh. Surang Anye' met at Long Temango with all the kepala leppo' (village heads) of the Kenyah, and it was decided that the Bakung had to surrender a number of their people as slaves to all groups involved in order to replace the people whom they had killed. If this was not complied with, the allied Kenyah forces, coordinated by the Leppo' Tau, would attack the Bakung at Tegeh. The Bakung opted for war, and thus open war broke out with unevenly balanced forces and the Bakung suffered many casualties.

Then war broke out with the Uma' Baka', who often attacked the Leppo' Jalanthis resulted in the death of Ajang Apui, brother of Lawai Ingan (kepala leppo' of the Leppo' Tau at Long Ireh)-and with the Leppo' Tukung and the Leppo' Bem. Because of such extended feuds, the Leppo' Tau in Long Ireh asked Surang Anye' in Long Temango to plan a revenge. As head of all the Kenyah of Apau Kayan, Surang Anye' could not approve of this plan, but he appointed several of his men from Long Temango to accompany the forces of Long Ireh in their attack on Batu Aping (the village of the Uma' Baka'), with instructions not to chase people into their houses, because the Uma' Baka' were very few in number. The Uma' Baka' were unable to resist and suffered many casualties.

From Long Temango, Surang Anye' moved his group to Long Nawang. In the meantime, the group at Long Ireh, under the leadership of Mpui Jalan, split: Mpui Jalan himself and his followers moved to Tana' Pute (on the J emahang River), and the group led by Ingan Lusat moved to Long Tepayan (on the banks of the Kayan River). After several years at Tana' Pute, Mpui Jalan moved again to Long Uro', and this group still resides there today). In the meantime, Ingan Lusat moved to Lulau Bahang (across from the village of Long Nawang), but did not remain there long, moving again to Long Temuyat on the Nawang River).

\section{History of the Leppo' Tau at Long Nawang}

After their arrival in Long Nawang (c. 1865), the Leppo' Tau remained there, and are still there to this day. 


\section{The Times of Ingan Surang (c. 1865-1890)}

Surang Anye', the leader of the Leppo' Tau at Long Nawang, died after two years there, and by common agreement Ingan Surang was appointed to succeed his father as the leader of the Kenyah groups of all Apau Kayan. Under the leadership of Ingan Suran, several important events took place. The Kenyah from Malaysia threatened the Leppo' Kulit in Apau Kayan, and asked that the Leppo' Kulit send one of their own people to replace someone they had killed. So Ingan Surang, to keep the peace among the Kenyah groups in Apau Kayan and Sarawak, surrendered one slave. Sometime later, a Leppo' Tau killed several Kenyah in Sarawak, forcing Ingan Surang to surrender another slave. At the request of the leader of the Leppo' Timai in Tabang, Ingan Surang once more had to surrender a slave to the Leppo' Timai, as a sign that he controlled Apau Kayan. Throughout the period of his leadership, Ingan Surang tried to maintain peace in the Apau Kayan area, He strictly prohibited all attacks on anyone and in whatever form, so that gradually peace was brought about. This is the time when the Kenyah people of Apau Kayan began to travel freely and began to go on pelesai (go away to work) in Sarawak.

In the meantime, the government of Raja Brooke succeeded in extending its influence to the interior of Sarawak, that is, the upper reaches of the Balui and Baram rivers. A large-scale peace ceremony was held to stop war among Dayak groups. The ceremony was attended by all the village chiefs (kepala leppo') of the area. Ingan Surang, too, was invited to represent the Apau Kayan area. In his meeting with Raja Brooke, Ingan Surang made an agreement that he would maintain peace in his area, and Raj a Brooke presented Ingan Surang with a royal vest as a symbol of his power in Apau Kayan. Not long after Ingan Surang had returned home from Sarawak, the Dutch carried out their first survey of Apau Kayan. They entered the Apau Kayan area from the Berau region, and, as a result, became known as Tuan Berau. Ingan Surang died and was succeeded by his son, Lencau Ingan (also called Uyung Lencau), who by common agreement became the kepala suku besar (great adat chief) of all of Apau Kayan.

\section{The Times of Lencau Ingan, aka Uyung Lencau (c. 1893-1947)}

Some time after Uyung Lencau assumed the leadership, the Dutch came again to Apau Kayan, in approximately 1900 (Coomans 1980). They came to set up government, headed by Controleur Habbema (known as Tuan Habuma). Several war incidents occurred under the leadership of Uyung Lencau. The Kayan killed two members of the Leppo' Kulit on the Kihan River. The Leppo' Kulit took revenge and killed ten Kayan people on the Irun River. Later the Bakung, the Leppo' J alan, and the Leppo' Tau joined forces to attack the Leppo' Kulit on the Kihan River, and the attack was carried out at Long Kelasa (on the Metun River). The Bakung subsequently killed eight members of the Punan tribe on the Kelai River (Berau). The Punan on the Kelai River fought against the Punan Uho' (from the area of the Boh River).

Initially, the Dutch did not interfere in these conflicts, because they respected the authority of Uyung Lencau. Uyung Lencau settled all conflicts in accordance with adat law. This meant that the side that had done wrong had to replace the life taken by surrendering one of their own to become a slave to the group that had suffered the loss. After some time in Apau Kayan, the Dutch did begin to take power directly, without paying attention to the adat law that had always been followed by all Kenyah groups. At a certain time, Ingan Lencau (the son of Uyung Lencau) killed two persons who were in Dutch custody in Long Nawang. The Dutch captured Uyung Lencau, sentenced 
him to eight years in prison, and transported him to Samarinda to serve his sentence. In Apau Kayan, a leadership vacuum developed, which resulted in widespread uncertainty among the people with regard to the future. All the elders or kepala leppo' in Apau Kayan, gathered at a great meeting, suggested that the Dutch Resident of Samarinda visit the Apau Kayan to see for himself the conditions of the people who were now without a leader. When the resident arrived in Apau Kayan, he was earnestly asked to set Uyung Lencau free, and this request was met. As soon as Uyung Lencau returned, the kepala leppo' held a meeting to reappoint him as kepala suku besar of all Apau Kayan.

During Uyung Lencau's second period of leadership, other challenges developed. In 1913, Catholic and Protestant missionaries began to spread their religion in Apau Kayan. The Catholic mission opened a post at Laham, in the Mahakam region, but because of communication difficulties, the religious services in Apau Kayan were discontinued. The Protestant mission (KINGMI), in the meantime, was able to grow quickly, because its centre at Tanjung Selor had uninterrupted connections with Apau Kayan. The Kenyah groups that first converted to the KINGMI Christianity were the Uma' Baka' at Long Marong and Long Iron. This took place after the visit of the minister Dixon in 1934 (see Lewis 1987).

World War II and, later, the Indonesian war for independence put a complete stop to Christian missionary activities in Apau Kayan. Yet, Christian ideas had already taken root among the Kenyah and began automatically to shift the position of the old adat (Adat Puon). The Christian principles were firmly rejected by the paren in Long Nawang, who wanted to maintain their old adat and beliefs, and Christians were forbidden to enter the village of Long Nawang. At that time (1947), the adat of Bungan Malan Paselong Luan started being disseminated by a member of the Leppo' Jalan named Juk Apui to compete with Christianity. The Adat Bungan also was continuously challenged by the Leppo' Tau. J uk Apui was scolded publicly and was forced to stop his activities. In the public's view, Juk Apui would suffer an unfortunate fate because he had offended the old Adat Puon. In fact, however, he grew more prosperous, and in 1950 the Kenyah as a whole, as well as Kayan and Punan groups, turned to Adat Bungan, not only in the Apau Kayan area but even as far away as Sarawak.

Nevertheless, KINGMI was able to re-enter the Apau Kayan area and gained adherents among the Leppo' Tau in Long Nawang. In 1952 a split occurred in Long Nawang: some of the Leppo' Tau, who kept to the Adat Bungan, moved into the Nawang River, approximately $2 \mathrm{~km}$ from its mouth, while those who had already converted to Christianity remained at Long Nawang. In the midst of these upheavals occasioned by the acceptance or rejection of Christianity, Uyung Lencau died on 11 J une 1949. A meeting of all the groups chose Li' Lencau to succeed his father as great chief of the Kenyah of Apau Kayan.

\section{The Times of Li' Lencau (1949-1969)}

The appointment of $\mathrm{Li}^{\prime}$ Lencau as great chief of the Kenyah coincided with a time of transition from the old religion (Adat Puon) to the Bungan cult and then to Christianity. The process of conversion ran smoothly after 1965, because of the concern among the people that they would be considered communists if they did not have one of the religions officially recognised by the Indonesian government. Since the Bungan cult was not recognised, the Leppo' Tau people opted for the appropriate religion that would guarantee their life as one family; that is, Christianity. 
The title of Great Chief of the Kenyah groups of all Apau Kayan was changed to that of kepala adat besar (great customary chief, or simply kepala adat, customary chief) of all Apau Kayan, following the suggestion of the government. With the appearance of the government of the Republic of Indonesia in Apau Kayan, an opportunity opened for the introduction of cultural elements from outside, which brought about great changes into Kenyah society. Several Kenyah groups began to plan for a better way of life for their children and grandchildren in the future, to enable them to obtain more easily the staple goods that were so difficult to obtain in Apau Kayan. They made plans to move to the vicinity of towns in the lowlands.

During the period 1963-1970, many Kenyah from Apau Kayan moved out to several places, especially close to urban areas (see Liman 1995). In 1970, a group from the villages of Long Nawang and Nawang Baru moved to the village of Mara I, near Tanjung Selor (subdistrict of Tanjung Palas), under the leadership of Gun Bit. Even the great customary chief, Li' Lencau, also moved to Mara I in 1970. One group from Long Uro' moved to Bila' Talang and Tanjung Manis, in the Mahakam area, in 1967, followed by another group, which moved from Lidung Payau to Tanjung Manis. The movement from Apau Kayan is still continuing today, even though the government has made provisions to prohibit migrations, out of fear that the border area with Sarawak will become empty. After Li' Lencau had moved, a meeting of the Kenyah groups appointed Bit Ncuk to take his place as kepala adat of all the Kenyah in Apau Kayan.

\section{The Times of Bit Ncuk (1970-1981)}

Under the leadership of Bit Ncuk, the life of the people did not yet change much, although they were trying to overcome the alienation of isolated life far from the towns. The people voluntarily built an airstrip to enable the Cessna planes of the Protestant missionaries to land in the various villages, depending on field conditions. Airstrips of this type are today found in Long Nawang (350 m in length), Long Lebusan (700 m), Long Suleh (350 m), Long Sungai Barang (300 m, no longer in use because it is too short), Mahak Baru (350 m), Data Dian (350 m), and Long Ampung (750 m). The last airstrip is a government 'pioneer airfield', built directly by the government to better connect the city and the rural areas, and it can be used by Twin Otters of Merpati, Asahi, and Pelita Air Service.

During this period, the Leppo' Tau moved many times, both within the Apau Kayan area-among others, from Long Uro' to Lidung Payau and Long Lebusan (c. 1970)-and even outside Apau Kayan-from Long Uro' and Lidung Payau to the Mahakam area (in the 1960s); from Long Temuyat to Rukun Damai (Mahakam, 1972); from Long Nawang and Nawang Baru (the second group under the leadership of Baya' La'ing) to Mara I in 1972; and from Long Temuyat to Rukun Damai (Mahakam) under the leadership of Kihin Bit in 1972. In 1981, Bit Ncuk died and was succeeded by Pare' La'ing.

\section{The Times of Pare' La'ing (1981-1993)}

Till his death in 1993, Pare' La'ing held the position of kepala adat of all the Kenyah of Apau Kayan. A number of advances have already been made thanks to cooperation and participation between the Apau Kayan adat institutions and the local subdistrict governmental agencies, especially with regard to development. Upon the kepala adat's suggestion to the government, a path was opened across the border with Sarawak to facilitate the import of staple goods difficult to obtain in Apau Kayan. The provincial 
governor contributed televisions and parabolic antennas so that the Apau Kayan area would no longer be isolated from sources of information. Another suggestion made by the kepala adat, that the cultural values be preserved, was well received by the subdistrict government, and a building was constructed in which these values will be promoted. There are many other signs of the smooth cooperation between adat institutions and government agencies in efforts to encourage the development of Apau Kayan rural areas.

In the meantime, the Leppo' Tau in the Long Nawang area have increased in number: in 1993, Long Nawang had 809 inhabitants (399 men and 410 women), Nawang Baru 585 (294 men, 291 women), and Long Temuyat 327 (164 men and 163 women). This increase, the smooth process of development in the rural areas, and the presence of the pioneer airfields would appear as sufficient reasons for the local residents to forego a move to join their relatives in the lowlands. However, one group from Nawang Baru and Long Nawang, under the leadership of Ncuk Apui and Saging La'ing, moved to the village of Teras Nawang (subdistrict of Tanjung Palas) in 1980-81; and some of the residents of Long Lebusan moved in 1983-85 to the village of Bila' Talang (subdistrict of Tabang).

The trail to Sarawak can be used to carry staples needed by the people, so that Long Nawang has now become a strategic point for the economy of this cross-border region. It is hoped that the standard of living will improve and that dependence on government subsidies will decline. The latter often arrive late because they are transported by air and are thus very dependent on weather conditions. Despite the official policy aiming at preventing population depletion in the border areas, staples are still always in short supply in Apau Kayan. If relations between the rural areas and the cities are only maintained by air and if there are transportation problems at any time, even more Kenyah groups will move in pursuit of more advantageous locations.

\section{CONCLUDING NOTES}

Beginning with their departure from their region of origin in Sarawak until their arrival in Apau Kayan in the 18th century, the Kenyah groups often carried out mass movements and group movements. These movements had several causes:

\section{Security Reasons}

In former times, ayau (headhunting attacks) were carried out to fulfil the requirements of the Adat Puon, among others, fresh human heads for ritual purposes. So every leppo' was obliged to set up ayau expeditions against their neighbours in order to fulfil this need. The targets of the ayau were generally smaller groups with weak defences. For security reasons, people often moved their villages, travelling at night for fear that stronger groups would find them out. Certain groups, such as the Leppo' Kelep, left the Apau Kayan forever. For protection from hostile attacks, the weak groups often moved near to, and under the protection of, stronger groups with whom they were allied.

\section{Beliefs}

Beliefs could also be reasons for moving. In the traditional beliefs of the Adat Puon, the interpretation of unfavourable signs or omens (amen-amen) required the immediate 
abandonment of a settlement or fields. For example, when a grave or a belawing (ceremonial pole) was hit by lightning, when blood was shed in the village, or when a special omen bird as a messenger of the gods acted in a way that was thought to be a sign from the gods.

\section{Population Pressure}

If the total population or the number of members of a leppo' (or group living in the same village) increased, the farming and hunting area became increasingly limited and the people tended to move to try to find new, more suitable locations. This may have occurred when the Apau Kayan region was abandoned by the Kayan groups. In connection with this abandonment, the Kenyah groups that occupied the upper Iwan River quickly moved in and settled on the banks of the Kayan River.

\section{Competition Among Paren}

Among the Kenyah, leadership has always been in the hands of the paren category, whose history has been discussed above. Incidents, conflicts, or competition among the paren in one leppo' were common and could lead to the split of the village or the departure of one of the factions. If a difference of opinion developed between two related paren regarding a joint decision, e.g., whether to move villages or go to war, a village (leppo') would simply split into two groups. This same thing could happen in the case of a power struggle between two descent lines of paren of the same rank.

\section{Competition Among Groups}

Kenyah groups also competed for prestige. For example, after the Leppo' Timai first entered the Apau Kayan area, they were the most respected and powerful group in the area, and other groups had to recognise and accept their leadership. As the Leppo' Tau grew stronger and more daring, they confronted the Leppo' Timai and finally succeeded in forcing them to leave the Apau Kayan area. Then the Leppo' Tau emerged as the most powerful group, and their leaders were able to unite a number of smaller groups under their control. This struggle also had an effect on population movements, especially in the neighbouring settlement area.

\section{Interaction of the Kenyah with Other Groups}

Since early times, related Kenyah groups have tended to live near one another, because they were dependent on one another, particularly for defence against other Kenyah or non-Kenyah groups. Relations with unrelated Kenyah groups, however, such as the Leppo' Kulit, were relatively limited. This was also the case especially with regard to non-Kenyah groups, such as the Punan or the Kayan, and this situation was reinforced by religious beliefs that comprised many taboos vis-a-vis relations with the outside.

The groups that were of common stock-i.e., the Leppo' Tau, Leppo' Tukung, Leppo' Jalan, Leppo' Bem, Leppo' Timai, Bakung, and Badeng-maintained relations from the time they came to the Apau Kayan area together, as was demonstrated and confirmed by the meeting of the Kenyah from the entire Apau Kayan area for purposes of arranging a general peace (petutung). As a result of this peace, intermarriage among different Kenyah groups, formerly limited to a few members of the paren 
class, spread to the ordinary people. Loose relations also existed with Kenyah groups that did not come from the same stock and with non-Kenyah groups that had settled together with the Kenyah in the Apau Kayan area.

\section{Effect of Migrations}

Their frequent long-distance migrations have affected the Kenyah in various ways. For example, only rarely do they own historical objects (such as ancestral heirlooms), and there are few ancient historical sites. Furthermore, at times, people starved in their new settlements, because the rice supplies carried from their place of origin were only sufficient to meet food needs during the move, or the harvest in the new site failed. In this way, poverty developed, forcing people to work in the fields of other villages in exchange for rice and to make clothing from tree bark. Their attachment to their land of birth was weak because of their moves. Their way of life, with its frequent moves, left them always in a state of transition and obstructed efforts to improve their standard of living. This is still visible today among the new generation, which tends to move in search of better places closer to urban areas. 


\title{
11. \\ Archaeological survey and research in four subdistricts of interior East Kalimantan (Puj ungan, Kerayan, Malinau and Kayan Hulu)
}

\author{
Karina Arifin and Bernard Sellato ${ }^{1}$ \\ with reports by Aryandini Novita, Krisprihartini S., \\ Dody J ohanjaya, Anggara Yonathan \\ and Yoga Prima Subandono
}

\section{INTRODUCTION}

A number of megalithic structures are found on the upper reaches of the Bahau River and along its tributaries, in Pujungan Subdistrict. They consist primarily of urn-dolmen burial monuments. According to the Kenyah who now inhabit this area, these megalithic structures were erected by the Ngorek (see Sellato 1992b, 1995c). From historical reconstructions by Sellato, it is surmised that the Ngorek originally came from the upper Baram River in Sarawak. War with the Kelabit peoples finally forced some of the Ngorek to move to East Kalimantan in approximately 1700 AD. By about 1750, the Ngorek are believed to have occupied the area of the upper Lurah and upper Bahau rivers. By the middle of the 18th century, a coalition of Modang, Kayan, and Kenyah groups attacked the Ngorek. Some of the Ngorek were defeated and taken away by their conquerors far from their area of origin, and the rest fled and scattered. Today

\footnotetext{
${ }^{1}$ Karina Arifin compiled the sections titled 'Survey of Megalithic Sites in Four Districts' and 'Test Pits in Long Puj ungan Subdistrict' (on the basis of her own research), and 'Megalithic Graves: A Summary'; while Bernard Sellato contributed data from his survey in Kayan Hulu Subdistrict and rewrote the sections titled 'Inventory of Stone Grave Sites on the Upper Bahau' (based on a report by Dody J ohanj aya, Anggara Yonathan, and Yoga Prima Subandono) and 'Analysis of Artefacts Found in Apau Ping' (based on a report by Aryandini Novita and Krisprihartini). For more comprehensive data, see Karina Arifin 1995, Dody J ohanjaya et al. 1995, Aryandini Novita and Krisprihartini 1995.
} 
the entire area is occupied by various Kenyah groups. On the basis of this reconstruction, the history of these megalithic remains is believed to be traceable to the 17th century. The most recent structures, however, may date back to the beginning of the 19th century, and the current local inhabitants state that the carved urn-dolmen burial site at Long Pulung contains the bones of one Paran La'ing, a king of the Ngorek (Sellato 1995c).

The megalithic remains in the Long Puj ungan area were reported by Schneeberger, who visited Long Pulung and Long Berini in the course of a geological survey in the 1930s (Schneeberger 1979: 67-68). He referred to them as urn-dolmens, on the basis of the standard in their construction, i.e., a large stone urn placed on top of four river stones or two stone slabs, and protected by a large stone slab supported by two other stone slabs. Sometimes, this large stone slab is placed directly on top of the stone urn as a cover, without supporting slabs. Schneeberger also visited a number of megalithic sites in the Kerayan area and one site on the upper Malinau River. Explanations for these megalithic remains have also been offered by Martin Baier, in his discussion of various stone burial structures in the Long Pujungan area (Baier 1987, 1992). He also described a number of sarcophagi in the Apo Kayan area (Baier 1992), which had been mentioned earlier by Sierevelt (1929). These monuments have been grouped into two types, the urn-dolmen and the sarcophagus.

\section{ARCHAEOLOGICAL ACTIVITIES}

Research into the history of the Ngorek and their connection with the megalithic structures was started by Sellato in his first short survey in Pujungan Subdistrict in 1990.

\section{Previous Surveys and Research}

In 1991, Sellato carried out a more systematic survey in order to obtain some basic information. From ethnohistorical studies, in particular, it was possible to learn a little about the Ngorek who built the megalithic structures in the Long Pujungan area. In February and March of the following year (1992), a very short archaeological survey was undertaken in Apau Ping. Several sites were visited, among them a site thought to be a former settlement, as well as seven burial sites (Manguin 1995). It was also possible to record approximately 70 urn-dolmen burial sites and 15 settlement sites.

In addition, more than 100 stone tools were collected from local inhabitants. Of these, $90 \%$ originated in Apau Ping, while the remainder came from the surrounding area and from neighbouring villages. A test pit measuring $2 \times 1 \mathrm{~m}$ was opened and two scrapings were also dug in Apau Ping by Drs. Kiwok Rampai from the Regional Office of the Department of Education and Culture in Central Kalimantan. Their locations were chosen on the basis of the density of surface finds of stone tools and of the situation of the site's surface, slightly elevated above the surrounding area. Earthenware shards were found in abundance at every level and some of them shared similarities with the earthenware made in Apau Ping today. In 1992, all available information was combined in a report on the Ngorek (Sellato 1995c).

By early 1993, more than 100 Ngorek sites had been recorded in Pujungan Subdistrict, and about 250 stone implements had been collected from the people in Apau Ping. On the basis of this survey, further research was considered necessary in order to obtain more detailed information about the Ngorek groups. 


\section{Archaeological Research in 1993}

The archaeological research in 1993 consisted of several activities. The activities carried out in Jakarta concerned the analysis of a number of stone tools and earthenware shards from the Apau Ping location (Aryandini Novita and Krisprihartini). In the field, the activities included a survey of several urn-dolmen burial sites that could not be visited in the earlier surveys in Puj ungan Subdistrict (by Karina Arifin), as well as a first survey of sites in Kerayan Subdistrict and Malinau District (by Karina Arifin and Bernard Sellato) and Kayan Hulu Subdistrict (by Sellato); inventory and mapping of several sites already visited in the Apau Ping and Long Berini areas (by Dody J ohanjaya, Anggara Yonathan, and Yoga Prima Subandono); and the opening of test pits in several former settlement sites (by Karina Arifin).

The survey of archaeological sites in Pujungan Subdistrict aimed at obtaining a clearer picture of the range of variation of burial structures and their distribution, visiting Ngorek settlement sites, and searching for a stone extraction site or a stone tool workshop site. The districts of Kerayan and Malinau also were chosen for surveying because of the recorded existence of megalithic structures possibly related to the megalithic structures of Long Pujungan and for comparative purposes. It was thus hoped that this would produce additional information to assist the interpretation of the megalithic structures in the Long Pujungan area. The digging of several test pits in two former settlement sites in Apau Ping and Long Beraa was especially intended to clarify the existence of cultural strata which distinguished the remains of the Ngorek people from those of groups which occupied the same sites in later times, that is, the Kenyah Leppo' Ma' ut and the Leppo' Ké, and to improve understanding of the features of the life of the Ngorek people.

In addition, an ethnographic survey was carried out and data was collected on the burial customs of several ethnic groups now living in the three districts of Pujungan, Kerayan, and Malinau (see Karina Arifin, in Eghenter and Sellato 1999). Surface surveys were undertaken in Apau Ping, Long Beraa, and Long Berini (Pujungan Subdistrict), mainly, the collection of earthenware shards, for comparison with the finds in the test pits and with modern earthenware; and ethnographic information was collected on the manufacture of traditional earthenware (see Karina Arifin 1995; Karina and Sellato, in Eghenter and Sellato 1999).

\section{SURVEY OF MEGALITHIC SITES IN FOUR SUBDISTRICTS}

This survey was carried out in the subdistricts of Pujungan, Kerayan, Malinau, and Kayan Hulu. The age of the megalithic sites in Pujungan Subdistrict has been determined approximately on the basis of ethnohistorical research and it is thought that none postdate the early 19th century. Similarly, the remains found in Kayan Hulu Subdistrict are thought to date back to the 17th and 18th centuries. The age of the known sites in Kerayan Subdistrict is not yet known, and, in fact, for a large number of them, it is not yet clear which ethnic group established them.

Schneeberger (1979: Map III) reported on an urn-dolmen burial site on the upper Malinau River which resembles those on the upper Bahau River, leading to the expectation that similar structures would be found further downriver on the Malinau. So far, in the areas visited, no remains of stone structures have been found, and thus Malinau District will not be further mentioned in this part. A number of wooden burial structures have been discovered, which has been discussed by Karina Arifin (in Eghenter and Sellato 1999). 


\section{Pujungan Subdistrict}

Archaeological surveys were carried out in two areas (see Figure 11.1): on the upper Bahau River, including the vicinity of Apau Ping, where work was conducted by Karina Arifin and three young archaeologists (Dody J ohanjaya et al. 1995); and on the Lurah River, where Karina Arifin carried out work with the assistance of four local staff. A number of the upper Bahau sites reviewed in earlier surveys were visited again in order to obtain a clearer picture of the problem. Five of them were later mapped and documented in detail (Dody J ohanjaya et al. 1995; see below). Other sites that were

Figure 11.1 Archaeological sites in Pujungan Subdistrict

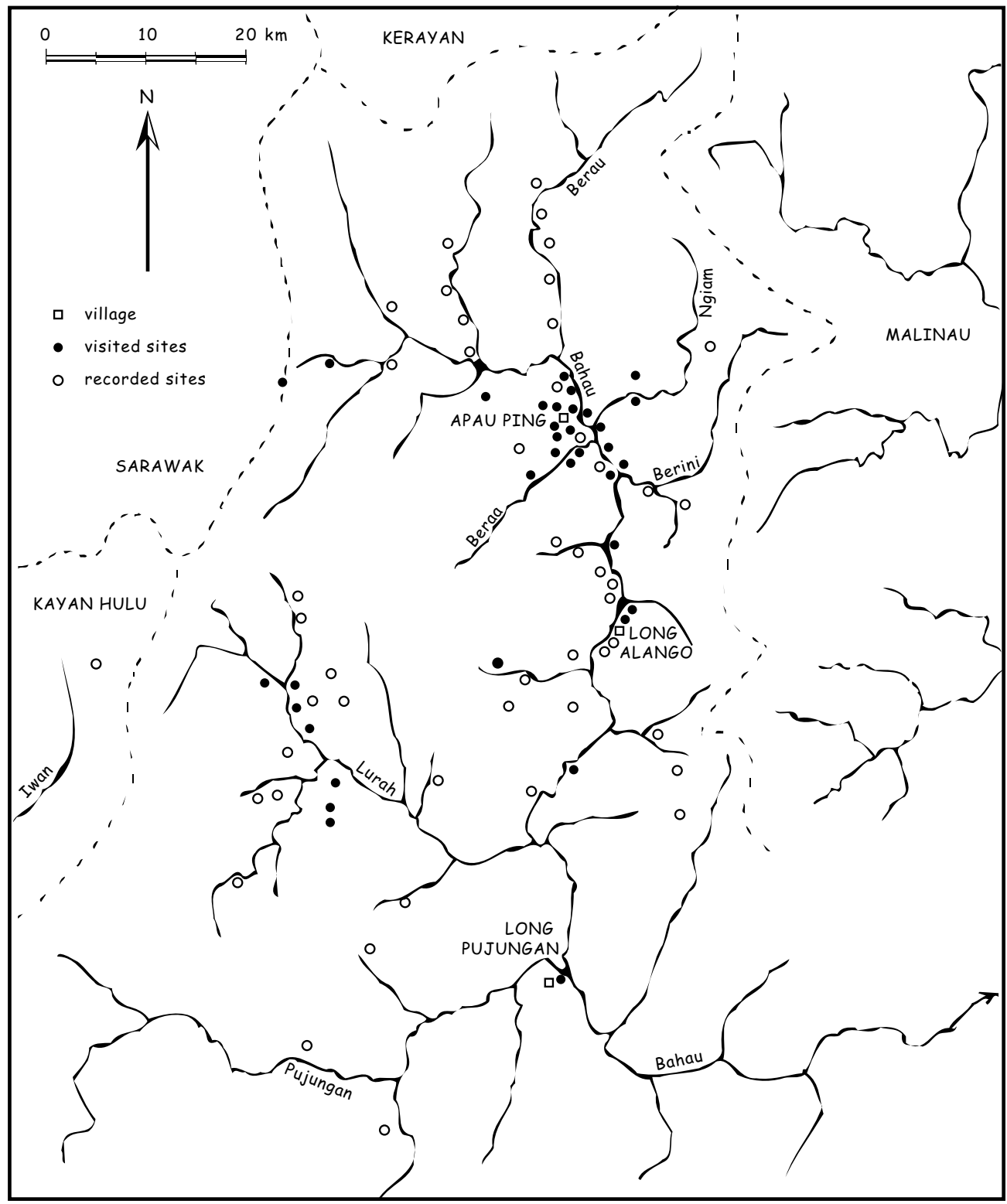


visited are described briefly here (for terminology relating to the parts of the burial structure, see Figure 11.2). The survey in the Lurah River area was intended to locate sites showing outcropping basalt, the material from which the stone implements found on the upper Bahau River were manufactured. In addition, other, new archaeological sites were visited. In a previous survey, Sellato had obtained information that a place called Leppo' Teranan, on the watershed between the Lurah and Iwan river basins, piles of worked stones could be found. This raised the possibility that the site may have been a workshop for the manufacture of stone implements. Leppo' Teranan was not visited, however, because the information was somewhat unclear, especially with regard to the time required in order to reach the site.

Figure 11.2 Terminology of the stone urn-dolmen

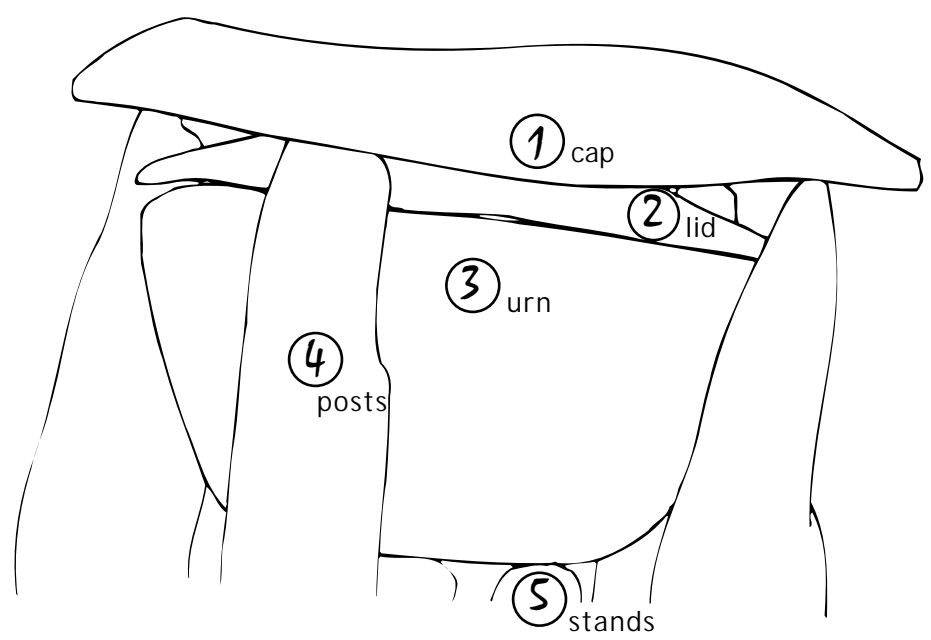

\section{The Apau Ping Area}

Seven sites were surveyed in this area. Some had been surveyed earlier, others were new sites, surveyed for the first time.

- Kiam Bio': 18 urn-dolmens, most of which have already collapsed, with their stone urns already opened. Urns are $60-70 \mathrm{~cm}$ high, round (diameter of the hole $45 \mathrm{~cm})$ or oval $(50 \times 30 \mathrm{~cm}$; depth of the hole $30 \mathrm{~cm})$. The pillars of the dolmen are oval river stones, or stone pieces resembling a curved board ('onion skin').

- Tanjung Ikeng: a large, intact stone urn-dolmen, partially covered with soil. The table (or roof) of the dolmen measures $225 \times 150 \mathrm{~cm}$, and the urn $95 \times 70$ $\mathrm{cm}$. Its height is not clear. Its five pillars are 'onion skin' stone pieces.

- Long Ngiam: a line of 13 stone urn-dolmens, oriented north-south, all of them already toppled over. There likely are others, covered by brush. The urns are either round or ovoid; one of them is very round (hole diameter $48 \mathrm{~cm}$, and 52 $\mathrm{cm}$ deep). The pillars are 'onion skin' stone pieces; the table's shape varies with the shape of the stone used. 
- Lubang Buka': a line of five or more urn-dolmens with a NW-SE orientation. All of them have toppled over and are scattered about. One is located on a steep cliff, its urn broken, and some of its pillars have tumbled to the foot of the cliff.

- Long Beraa: see the site description below. Surface finds of earthenware shards show similarities with finds in the test pit on this site. The shards are parts of a pot's body, except for one neck part. The temper is sand and crushed earthenware. On the basis of colour, this earthenware consists of at least three types.

- Long Berini: see the site description below. Surface finds of earthenware shards include 13 pieces (including two rims, and one neck), of a grey colour with a temper of crushed earthenware. Some show a residual layer of resin. Two shards show string decoration or incised decoration (Figure 11.3). Two tools for beating tree bark (to make clothing), made of sandstone, show a flat bottom part incised with cross lines (Figure 11.4).

- Apau Ping: Apau Ping was successively inhabited by the Ngorek, the Leppo' Ma'ut, and today the Leppo' Ké. Surface finds (see Figure 11.5) include an ovoid pounder with a flat base forming a $1.5 \mathrm{~cm}$ wide ring (see Sellato 1996); a sharpening tool made of sandstone of the same shape as that described below; and earthenware shards of several colours, generally of the same type as those found in the test pit, including shards of a round cooking pot and of a container thought to have been a plate (Figure 11.6). The earthenware shows string decoration and chequered decorations produced by a paddle carved with cross lines. The temper is sand and crushed earthenware. Shards of foreign stoneware with a grey paste and a brownish black glaze were also found.

Figure 11.3 Surface finds of decorated pottery shards from Long Berini

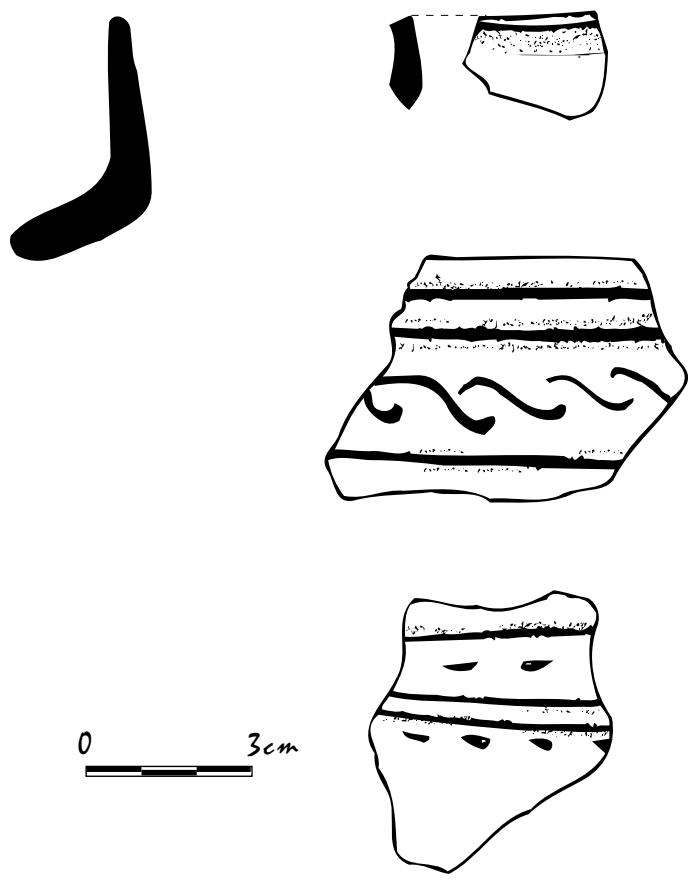


Figure 11.4 Two stone bark beaters as surface finds from Long Berini
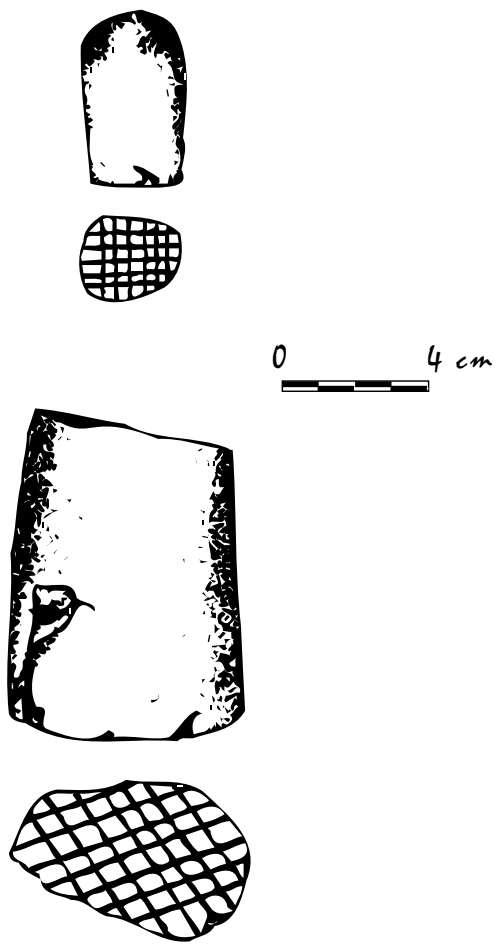

Figure 11.5 Surface finds from Apau Ping: sandstone pounder (top left), sharpening stone (top right), and earthenware neck with spout
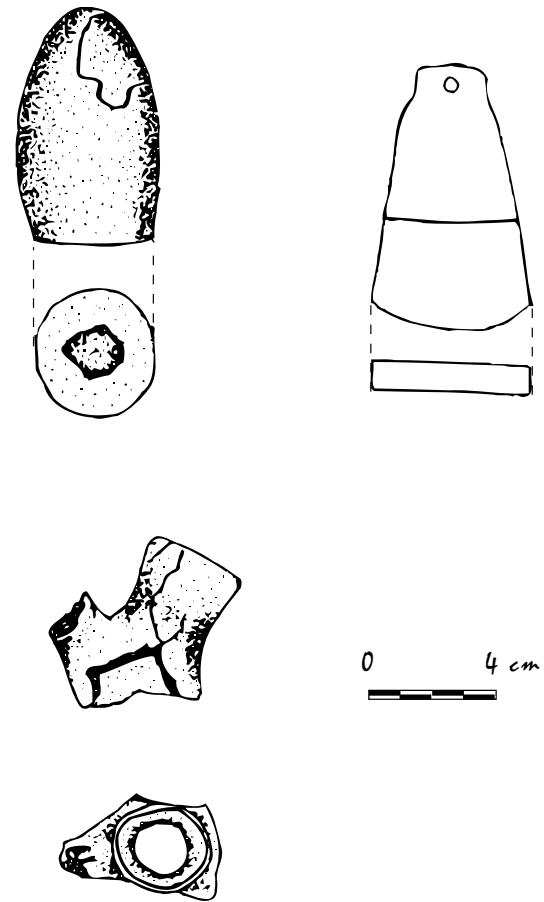

Figure 11.6 Surface finds of decorated pottery shards from Apau Ping
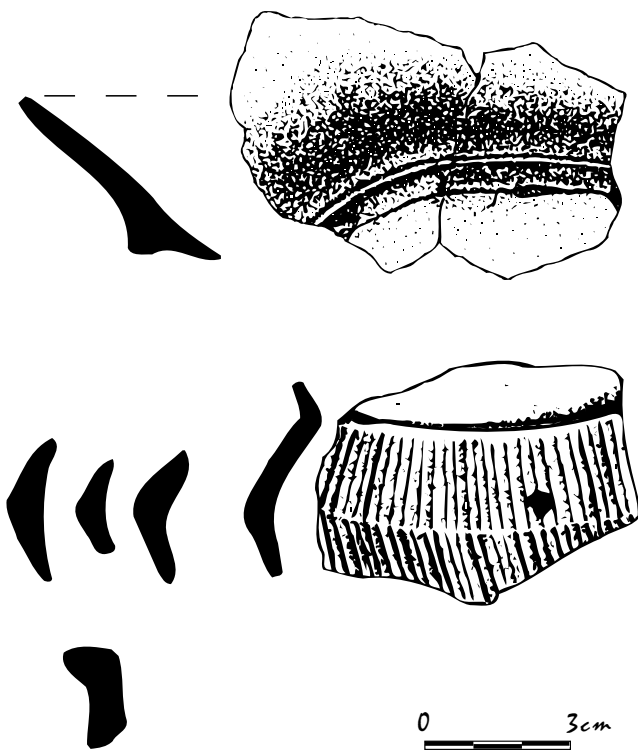


\section{The Lurah River Area}

Of the five sites visited, the first three on the upper Lurah River had been visited earlier by Sellato, and the remainder were surveyed by Karina Arifin on her travels to the left tributaries of the upper Lurah River with the help of information from Puri (1993).

- Long Lenjau Ca: two stone graves. One is rectangular (159 x $88 \mathrm{~cm}$; with 11 $\mathrm{cm}$ thick walls), with a narrower base. Its lid (140 cm long) was found nearby, along with a beam-shaped menhir $(80 \times 32 \times 20 \mathrm{~cm})$. The second grave is ovoid $(49 \times 33 \mathrm{~cm}$, wall thickness $6 \mathrm{~cm})$. Its lid $(105 \times 102 \mathrm{~cm})$ is lying nearby.

- Long Ping: a dolmen with a table $(165 \times 130 \mathrm{~cm})$ resting on stone pillars $50 \mathrm{~cm}$ high. The stone urn is not visible. Nearby are four rectangular columns or slabs measuring $105 \times 47 \times 10 \mathrm{~cm}$ and $75 \times 23 \times 20 \mathrm{~cm}$, and three standing menhirs, two of which resemble beams measuring $90 \times 34 \times 26 \mathrm{~cm}$ and $70 \times 34$ $x 27 \mathrm{~cm}$.

- Long Tela'u: two nearby sites. At one site are a dolmen with a table measuring $164 \times 164 \mathrm{~cm}$ and several menhirs, one of which resembles a long beam. In the second site, several menhirs are found standing around a pile of river stones.

- Lepu' un Nyibun: the site is located on a flat hilltop, where a line of Ficus trees stand. Four cylindrical stone urns range between 52 and $165 \mathrm{~cm}$ in height. One is ovoid (104 x $55 \mathrm{~cm}$ ) and rather squat, with urn walls $15-20 \mathrm{~cm}$ thick; the urn cover is lying nearby. Nearby, too, lies a takung or swampy pond.

- Lubang Lenjau: the site is on a flat hilltop. An artificial ditch $4 \mathrm{~m}$ wide is visible (formerly sharpened bamboos were stuck into the ground as a defence). One of several small clefts in the hill side, which can be entered for about 2 $\mathrm{m}$, contained four human skulls and various bones (limbs), already cemented into the cave sediments, as well as an old baby carrier, the remains of a wooden shield, and the sheath of a machete.

\section{Kerayan Subdistrict}

This survey was carried out to obtain some preliminary information on the district's inhabitants, their traditional burial practices, and related archaeological remains (Karina Arifin), and their languages, history, economy, and customs (Sellato). Archaeological information had been available only from written sources (Schneeberger 1979), which mention ten sites of menhirs and carved human figures. Only a few of these sites could be visited, but thanks to information obtained from the local people a large number of new sites was recorded (Figure 11.7) and some of these could be visited:

- Long Api, Kerayan Darat: Here is found a batu (battuh) terupun ('stone heap'), consisting of an accumulation of river stones on which a large dolmen of board-shaped pillars and table stand. At present, only two of these stone slab pillars $(220 \mathrm{~cm}$ high) and the collapsed table slab $(290 \times 195 \mathrm{~cm})$ remain. These stones are linked to the popular mythical figure of Yupai Semaring. A stone mortar, with a single deep cavity like a stone urn, is found in front of the elementary school. Only part of its square base remains, showing incisions around it and indentations scratched in. This stone is beaten during the dry season to bring on the rains.

- Bang Iluk, Long Bawan: One of a number of caves in the hills around Long Bawan, believed to contain archaeological remains. The cave walls are of coarse yellow sandstone permeated with water. At the end of the low, $50 \mathrm{~m}$ 
Figure 11.7 Archaeological sites in Kerayan Subdistrict

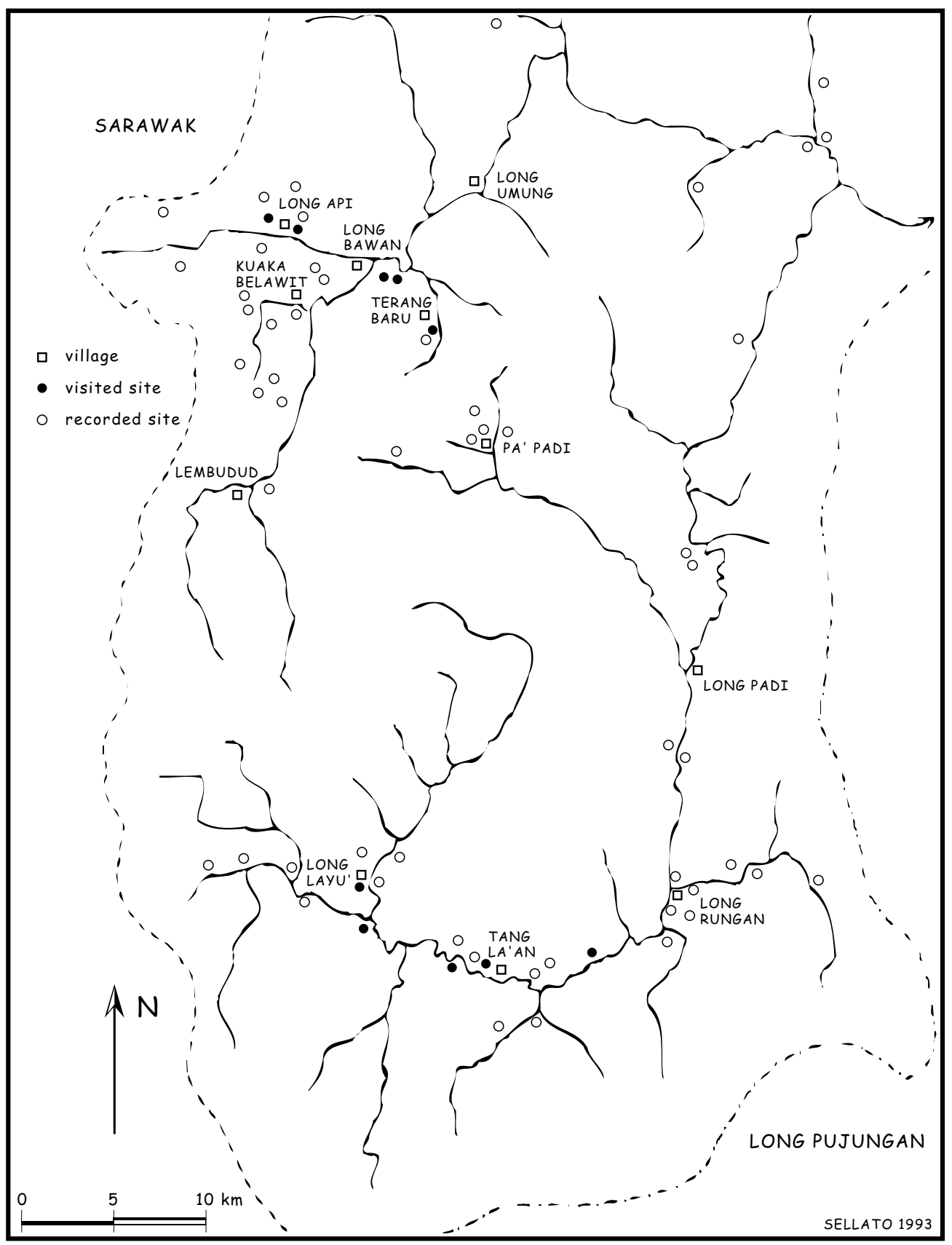


long passageway, there is a large and higher-roofed chamber where a stream flows. This place is often visited by people on outings. Yet, except for Coca Cola cans, there are no signs of use or habitation.

- Kuala Belawit, Kerayan Hilir: A stone slab, noted by Schneeberger (1979), is now erected near the church.

- Terang Baru, Kerayan Hilir: Three batu terupun are found in the grass fields, all already dismantled. Two were visited. The first is a heap of stones, on top of which stone slabs are still visible, some already broken. The other is a stone heap with a collapsed stone slab. In the village, several stone slabs, apparently transported from the batu terupun, have been erected to mark particular spots and the church.

- Sungai Bulu, Kerayan Hulu: Six rectangular stone graves are found, consisting of stone slabs forming a wall (the highest $115 \mathrm{~cm}$; and $80-120 \mathrm{~cm}$ wide). This burial complex has been dismantled, part has collapsed, the stone slab covers are broken, and skulls and bones are scattered around. Among the many ceramic shards found: pieces of brown stoneware jars, high-temperature porcelain jars, bowls, and plates. Also, the base of a stone urn and pieces of its walls. On the wall of one of the graves a carved human figure is visible.

- Sungai Kuyur, Kerayan Hulu: 12 or more stone graves, all dismantled, with their stone walls removed, broken up, and scattered, and the ceramic jars lost. One stone urn $(90 \mathrm{~cm}$ high; outer diameter of the mouth $31 \mathrm{~cm})$ shaped like a ceramic jar, complete with ears, is found below the grave, the walls of which are still standing. At Pa' Sing, this type of grave is called bupun.

- Upstream from Tang La' an, Kerayan Hulu: A batu (battuh) narit ('carved stone') was carved in low relief in the flat stones of the river bank, showing two human figures, one of them holding something (a shield?) in its right hand and standing on the other figure (Figure 11.8; see also Figure 11.9). Both are represented with their hands raised up, their legs open, with the heels of the feet protruding and forming a spiral. Their wide rectangular ears display some sort of ornament.

- Tang La' an, Kerayan Hulu: Several rectangular menhirs of hard sandstone are found in the village. Two of them were moved from the village of Pa' Upan. One is known as Battuh Sangui (Dragon Stone), the other has been set up in front of the elementary school (Figure 11.10). Another menhir has been transported from the village of $\mathrm{Pa}^{\prime}$ Ibang. Schneeberger (1979) saw these menhirs in their villages of origin. A pair of natural stones, also moved from Pa' Upan when the villagers settled in Tang La'an, are known as Battuh Berek (Pig Stone) and Battuh La'al (Chicken Stone).

\section{Kayan Hulu Subdistrict}

The current Kenyah population of Apo Kayan do not know the name Ngorek, but refer to all pre-Kenyah sites of former settlers in the area as 'Kayan'. In a very quick survey (six days) in Kayan Hulu Subdistrict, 45 such 'Kayan' sites were recorded from the local oral tradition (see Figure 11.11). Some of these can clearly be attributed to the Modang and not the Kayan. Of these 45 sites, 27 are located in Kayan Hulu Subdistrict and the remainder in Kayan Hilir Subdistrict. In at least 30 of the 45 sites, traces of a pre-Kenyah settlement are visible, 12 sites contain stone graves, and five show carved stones (some of these belonging to stone graves). A small number of the sites were visited by Sierevelt (1929), Tillema (1938), Harrisson (1959b), Whittier (1974), or 
Figure 11.8 Two anthropomorphic figures at Paru' Ating, Kerayan Hulu area of Kerayan Subdistrict

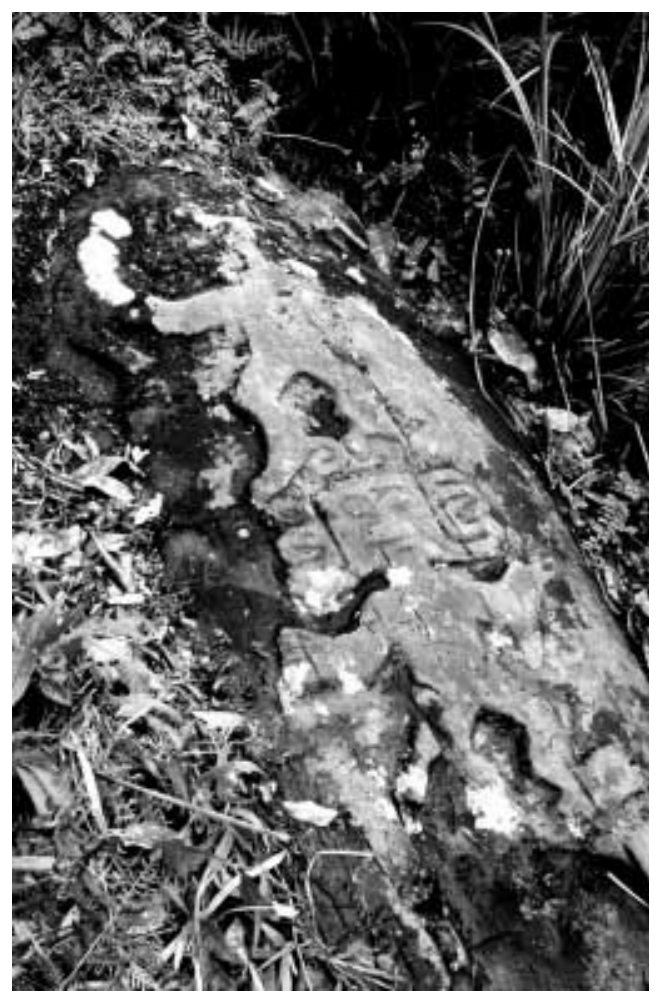

Figure 11.9 Anthropomorphic figure carved on a rock face by the river near Pa' Upan, Kerayan Subdistrict

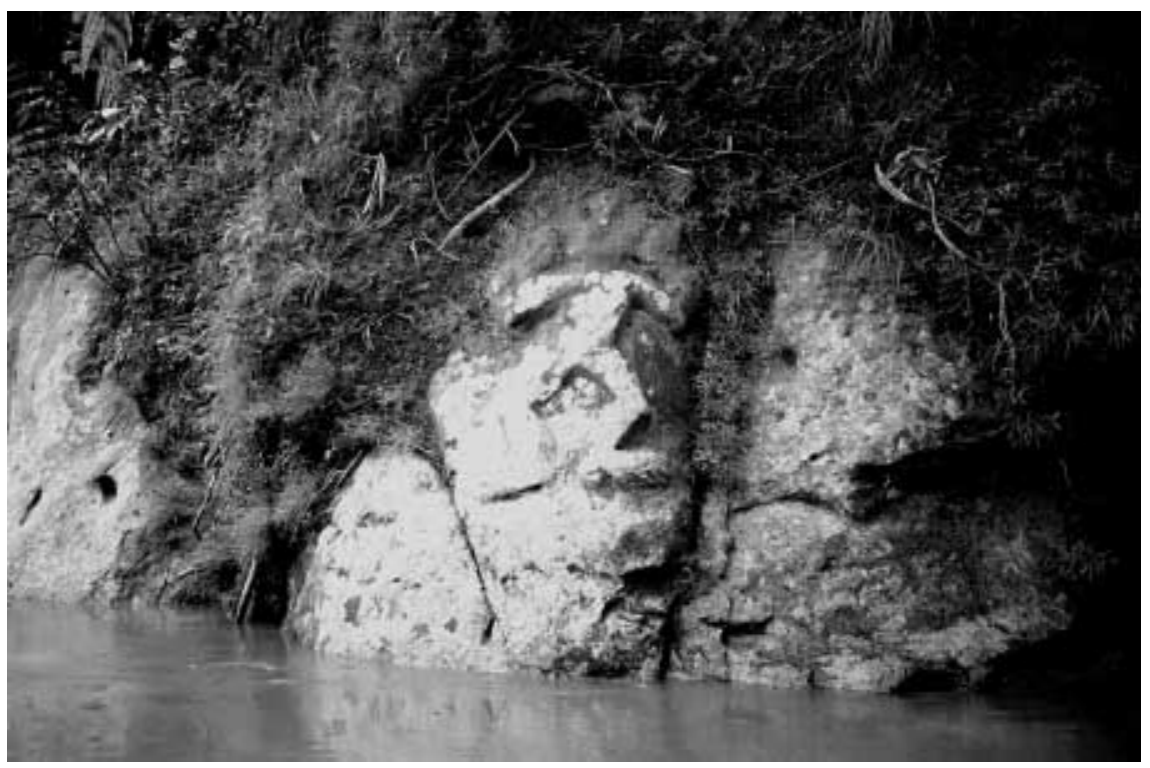


Figure 11.10 Two menhirs standing in front of the village school, Tang La'an, Kerayan Subdistrict

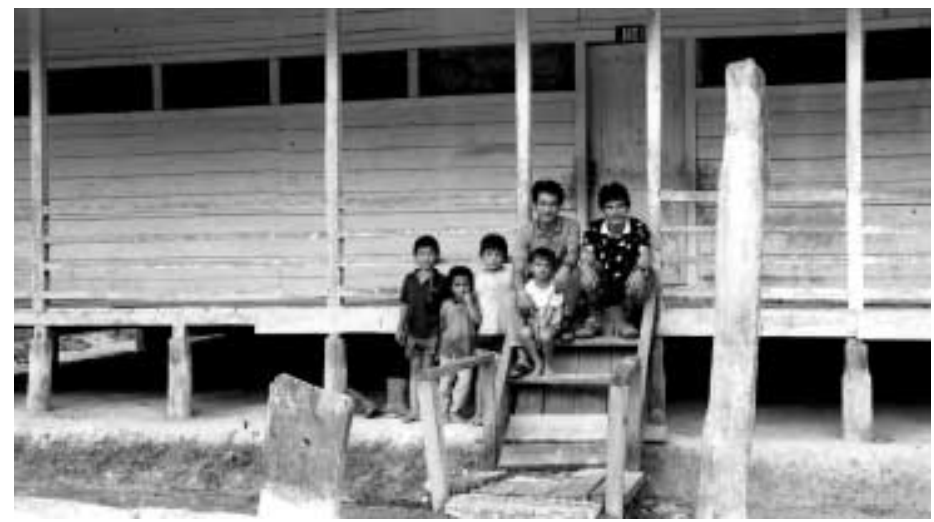

Figure 11.11 Archaeological sites in Kayan Hulu and Kayan Hilir Subdistricts, Apo Kayan

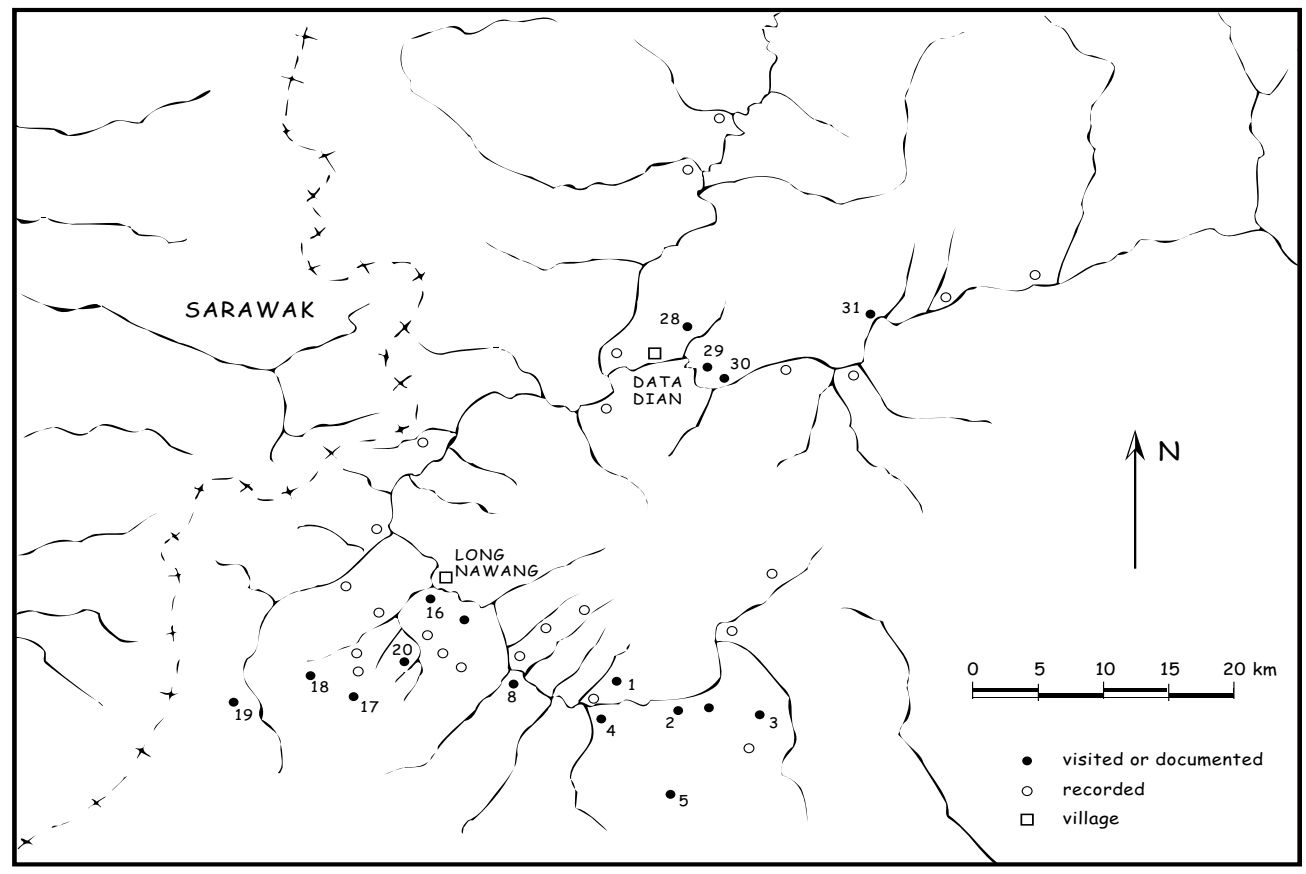

Baier (1992). Furthermore, at Long Ampung a tool (adze) made of basalt (13 cm long) was found, closely resembling the Apau Ping finds (see Figure 11.12; see also Figure 11.13).

Only two stone burial sites were visited, the easily accessible sites of Mudung Kerica at Long Uro' (see Figure 11.14) and J uman Nawang at Long Nawang (Figures 11.15 and 11.16). Information was obtained on the sites at Batu Tukung near Lidung Payau (J . Halapiry, pers. comm.; Figures 11.17 and 11.18) and Data Kanuyang near Data Dian (C. Eghenter, pers. comm.; Figure 11.19). The stone grave at Data Kanuyang is a large 
Figure 11.12 A basalt tool found at Long Ampung, Kayan Hulu Subdistrict

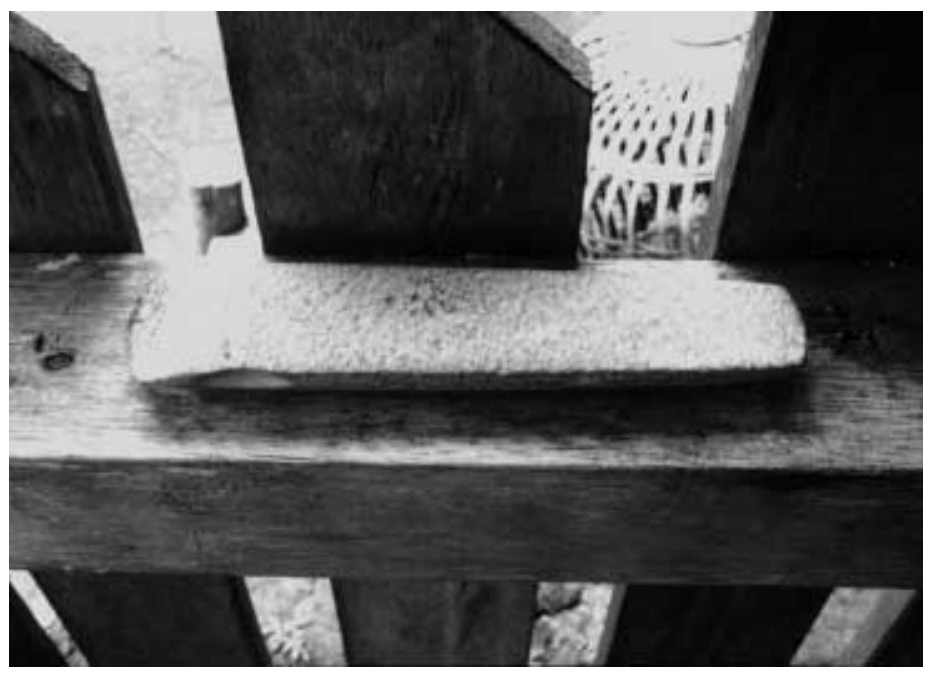

Figure 11.13 A basalt tool found in Mentarang Subdistrict

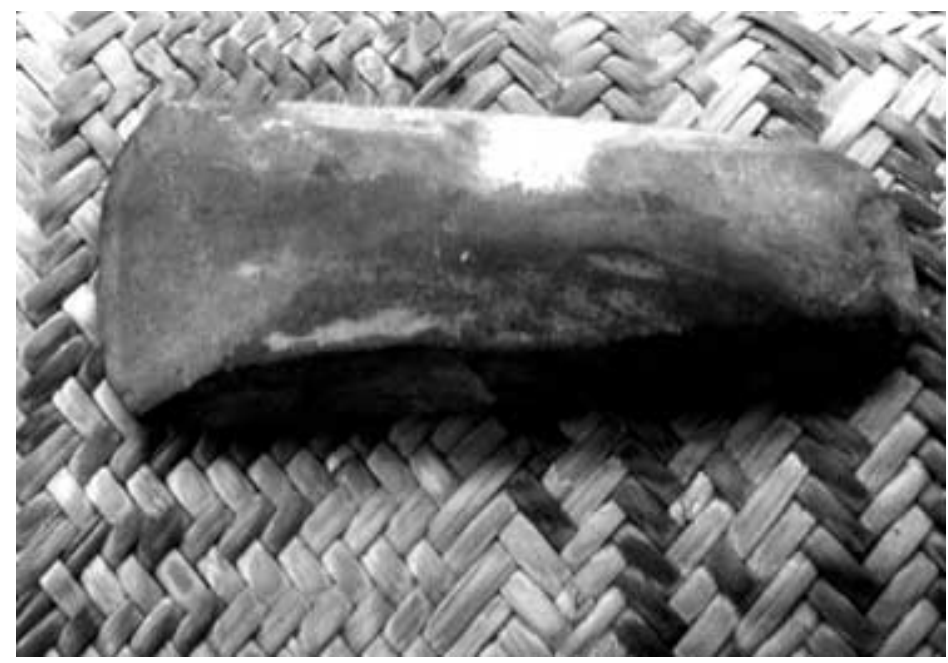

rectangular vat ( $1.8 \mathrm{~m}$ long and $1.2 \mathrm{~m}$ high) with four partially carved pillars and a stone slab cover. The graves at the three other sites are also vats, measuring 90-120 $\mathrm{cm}$ in length, $50-100 \mathrm{~cm}$ in width, and $25-55 \mathrm{~cm}$ in height (see Figures 11.20 to 11.22; also Figure 11.23). Information was also obtained on sites with carved stones, such as Long Sungan, Sawa' Angen, and Batu Kalung, in the vicinity of the village of Lidung Payau (J. Halapiry, pers. com.). The carved stones at the first two sites clearly were pillars for a stone vat. At Batu Kalung, however, a large boulder has been incised with motifs representing an aso' (dog-dragon; see Figure 11.24). 
Figure 11.14 Stone trough at Mudung Kerica, near Long Uro', Kayan Hulu Subdistrict

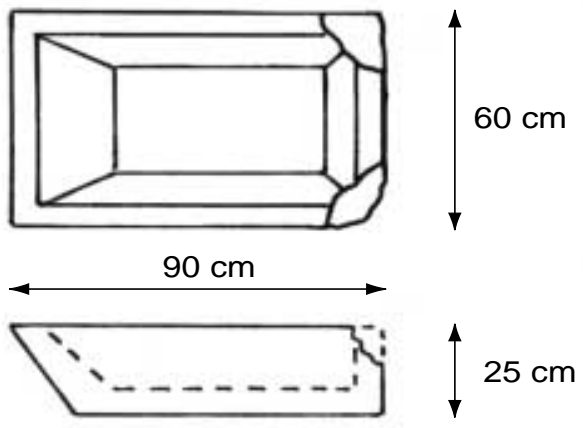

Figure 11.15 Stone trough at J uman Nawang, near Long Nawang, Kayan Hulu Subdistrict
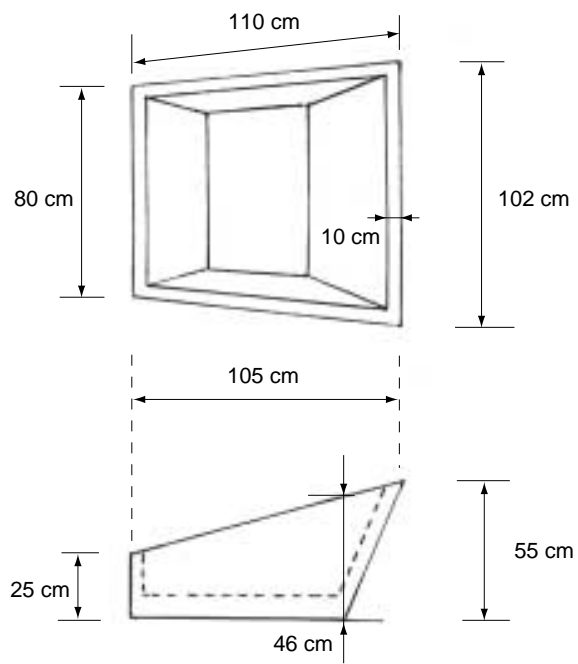

N $S$

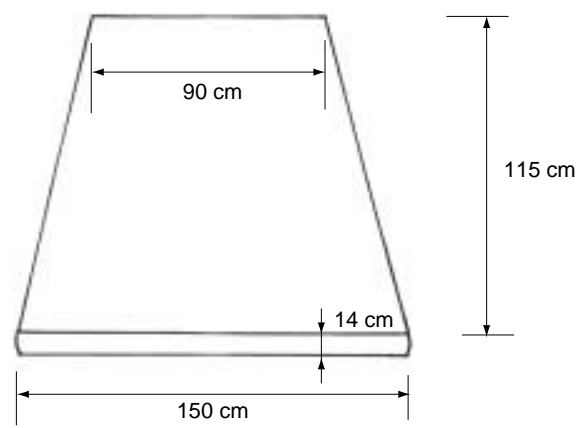


Figure 11.16 Stone trough at J uman Nawang, near Long Nawang, Kayan Hulu Subdistrict

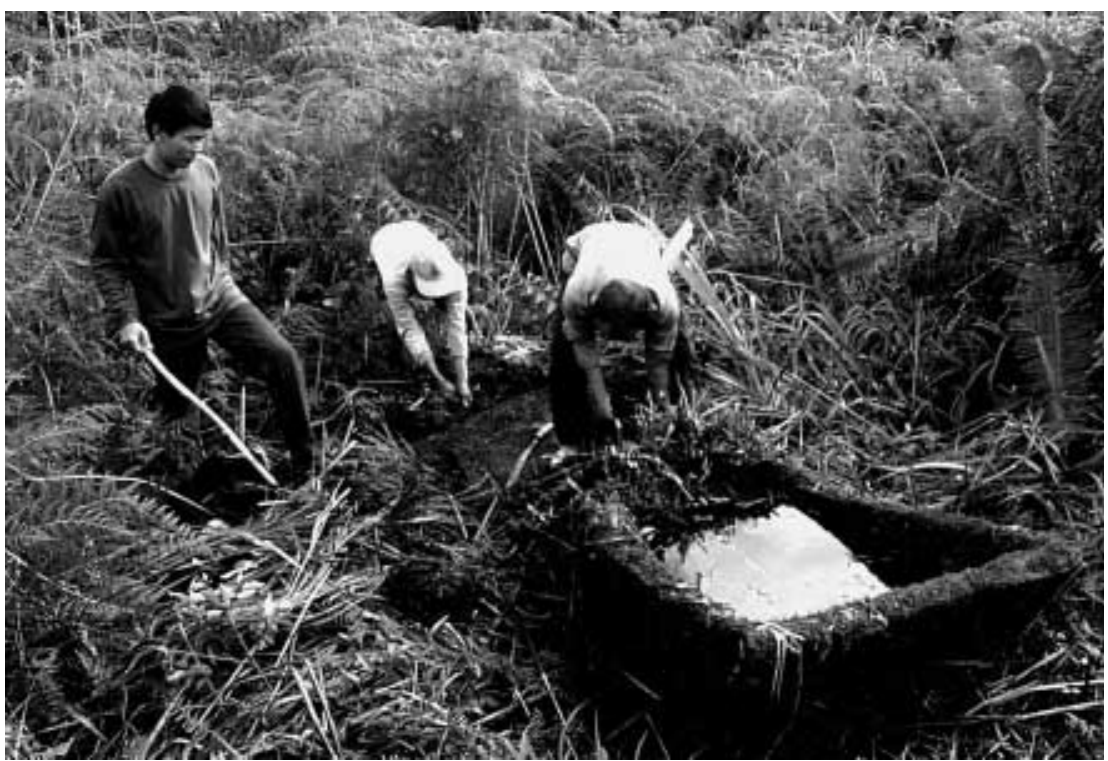

Figure 11.17 Rectangular stone trough at Batu Tukung, near Lidung Payau, Kayan Hulu Subdistrict

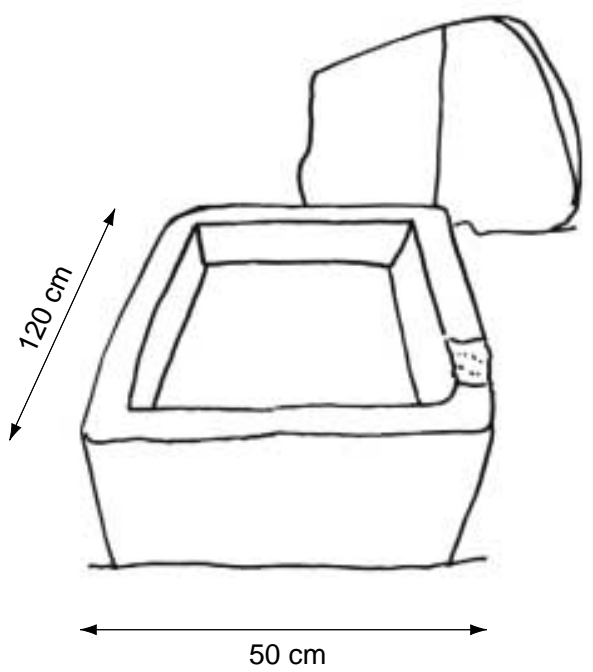


Figure 11.18 Rectangular stone vat at Batu Tukung, near Lidung Payau, Kayan Hulu Subdistrict

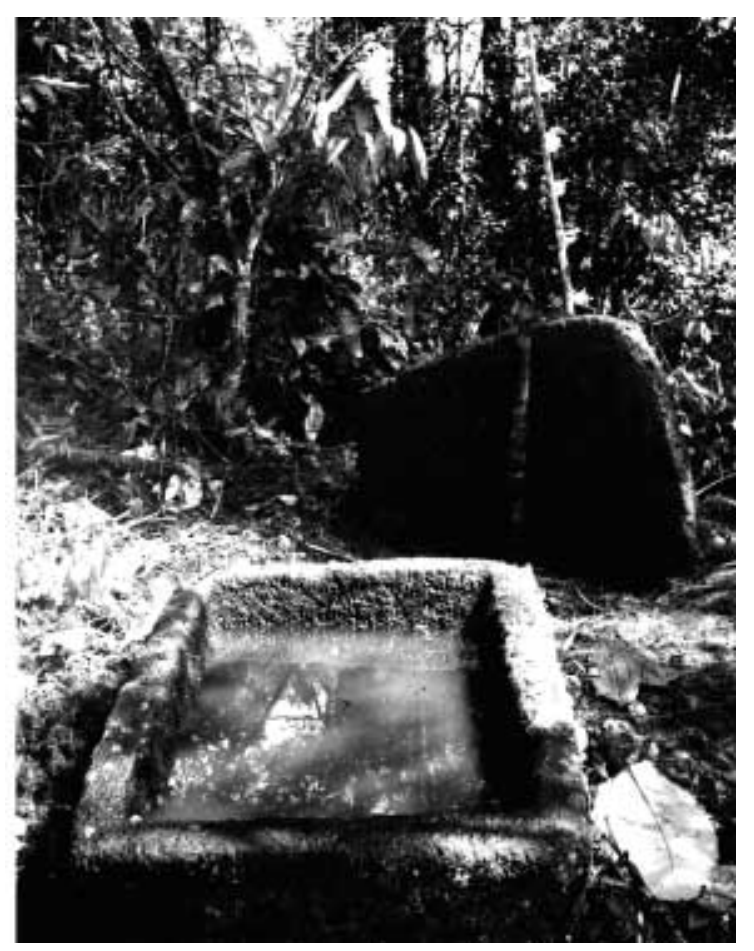

Figure 11.19 Large stone container with carved pillar at Data Kanuyang, Kayan Hilir Subdistrict

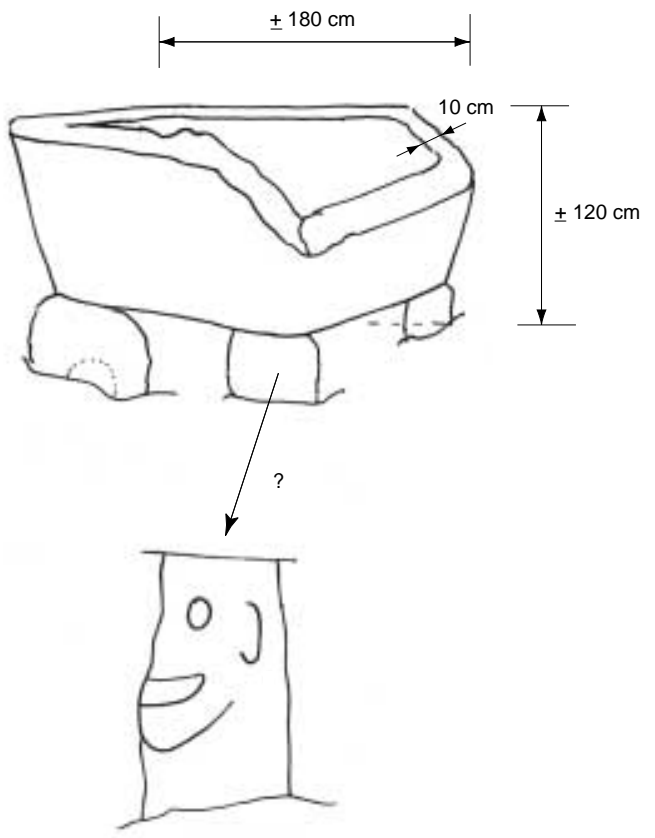


Figure 11.20 Anthropomorphic figure carved on a standing stone; Long Sungan, near Lidung Payau, Kayan Hulu Subdistrict

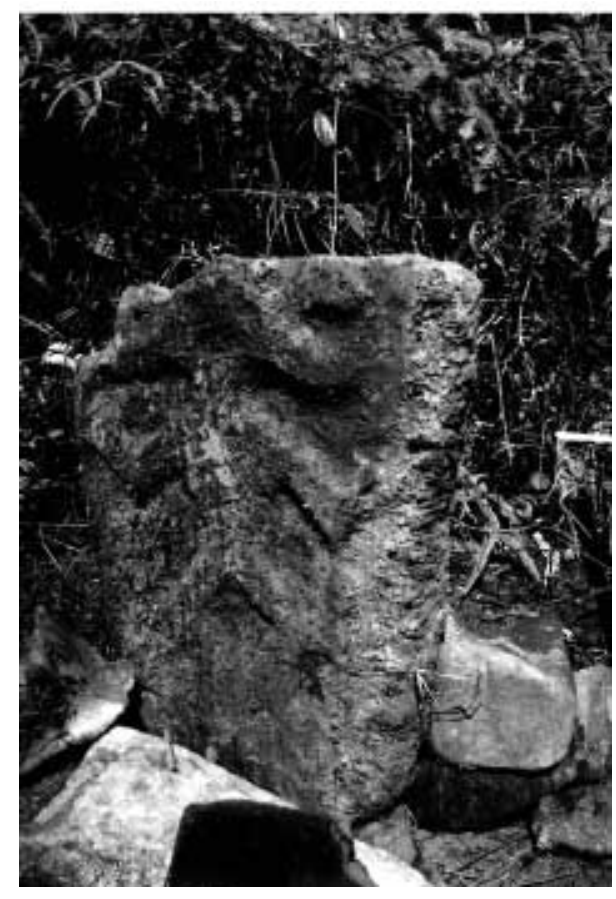

Figure 11.21 Carved stone pillars at Long Sungan, near Lidung Payau, Kayan Hulu Subdistrict
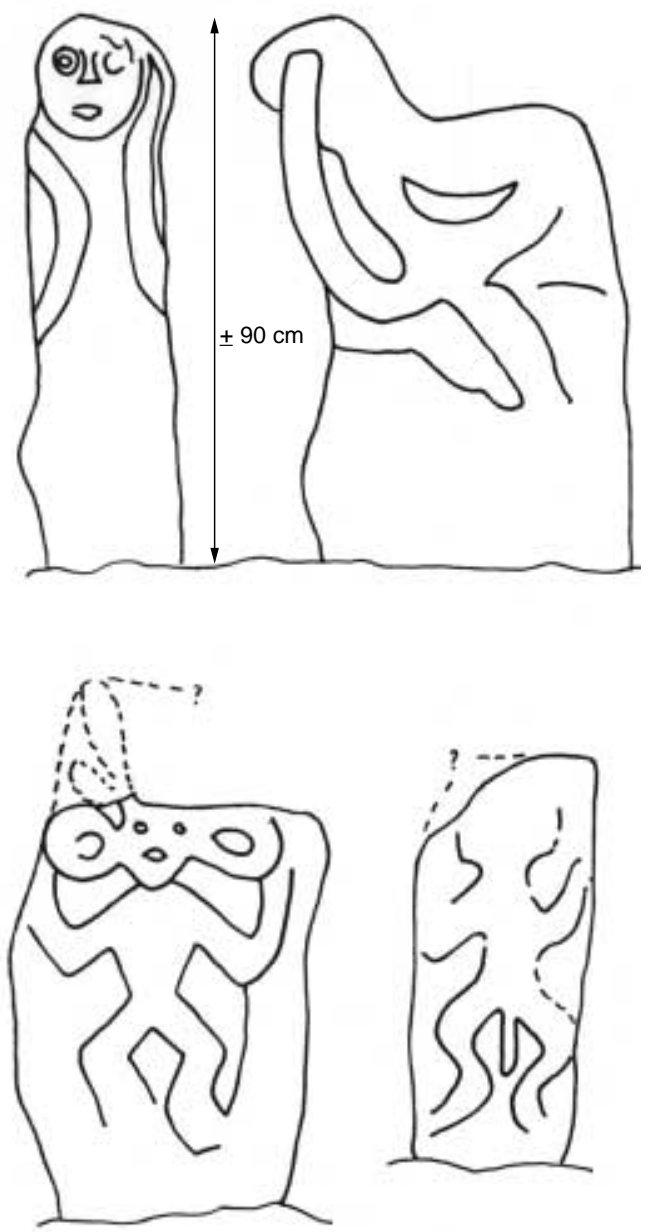
Figure 11.22 Carved stone pillar at Sawa' Angen, near Lidung Payau, Kayan Hulu Subdistrict

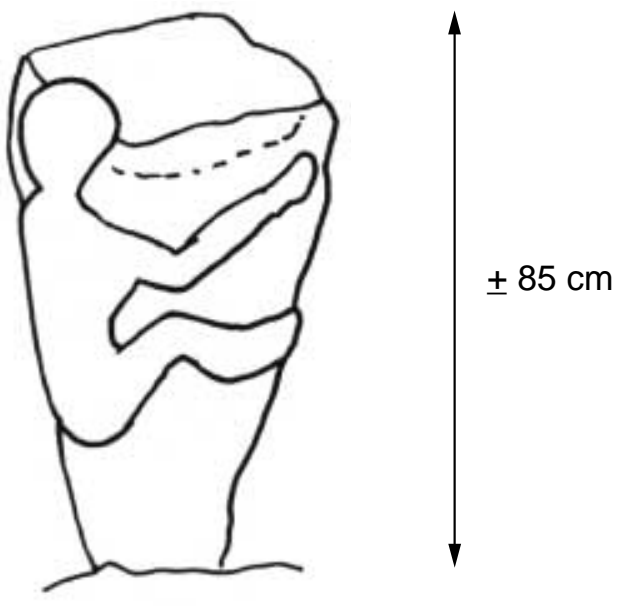

Figure 11.23 Anthropomorphic figure carved on a standing pillar at Long Poh, Kayan Hilir Subdistrict

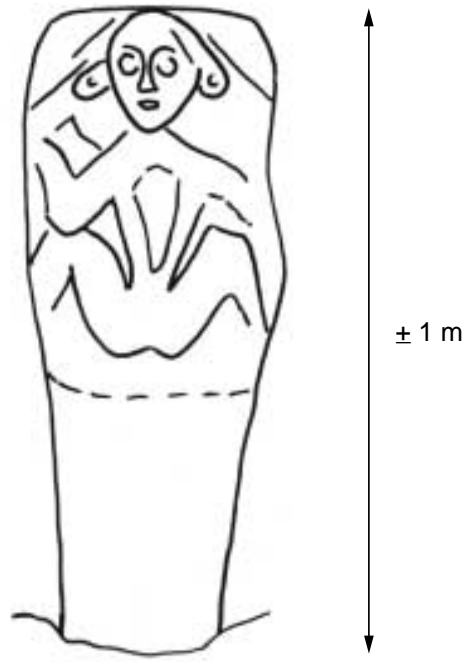


Figure 11.24 Batu Kalung, a large carved boulder, some way off Long Uro', Kayan Hulu Subdistrict

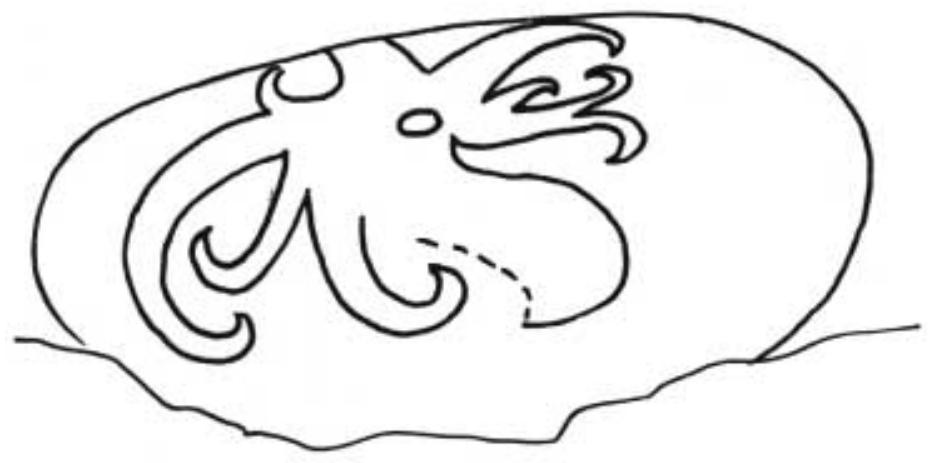

\section{INVENTORY OF STONE GRAVE SITES ON THE UPPER BAHAU}

A second visit was paid to several sites that had been surveyed earlier in order to determine which sites should be inventoried and mapped in detail. This decision was based on several criteria, including the location and size of the site and the number and variety of its stone structures, as well as their condition.

\section{Description of Findings}

A total of five sites were mapped (Figure 11.25). Urn-dolmen burial structures were drawn and photographed one by one, especially those still in good condition and representative of particular types (for types of urn-dolmen burials, see Figure 11.26).

\section{Long Berini}

The site looks clean of undergrowth and a number of urn-dolmen burials are still visible (see Figures 11.27 to 11.30). This site was once honoured with a visit from officials of the Regional Development Planning Office (Bappeda) of Bulungan District, who were kind enough to leave a souvenir in the form of writing in large letters 'BAPPEDA' with yellow paint on the burial structures. Of about 40 urn-dolmen structures, only eight are still intact and standing, complete with pillars, table, and stone urn, six have collapsed, and the remainder are heavily damaged. Many of the tables and pillars are of sandstone that tends to weather into 'onion skin' layers. A small number of pillars are rectangular slabs. The burial container is an urn dug of soft sandstone, or a ceramic jar (broken). The stone urns are bowl-shaped or rectangular, or ovoid with either a round or rectangular opening. They are from 40 to $100 \mathrm{~cm}$ in height and their walls are $5-16 \mathrm{~cm}$ thick.

Three graves of different sizes are found clustered, forming a complex grave. The largest contains a bowl-shaped stone urn that is still intact; the same was true of the next one; the third urn, however, is rectangular. Some graves have two containers under one roof, the main one a large stone urn, and the other a ceramic jar, inserted between a pillar of the dolmen and one of the stones supporting the urn. The only ceramic jar that was almost intact is decorated with protruding spirals, meanders, and pillars, and covered with a dark brown glaze. A cup of local earthenware $(8 \mathrm{~cm}$ high) was also found buried between the pillars of the dolmen, as were shards of earthenware pots (12 cm high). Several urns without lids were found full of dirt, 
Figure 11.25 Graveyard sites inventoried and test pits in Pujungan Subdistrict

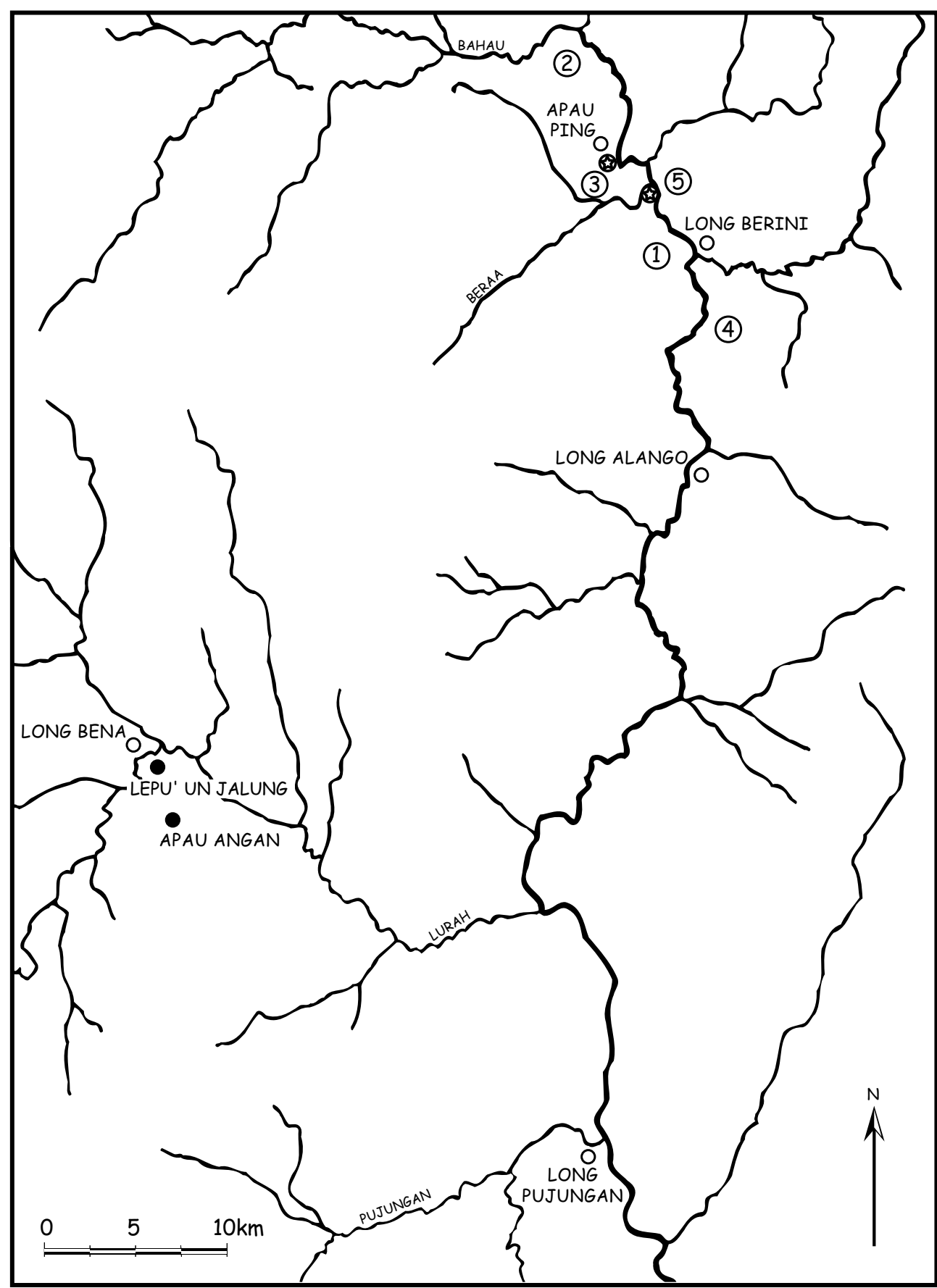

1. LONG BERINI

2. KA TEMPU

3. LONG KALE'

4. LONG PULUNG

5. LONG BERAA

(4) TEST-PITS 
Figure 11.26 Typology of stone containers: 1. rectangular with narrower base; 2. bowl-shaped; 3. rectangular 'bowl'; 4. cylinder; 5. ovoid with oval opening;

6. ovoid with rectangular opening; 7 . rectangular with rounded base

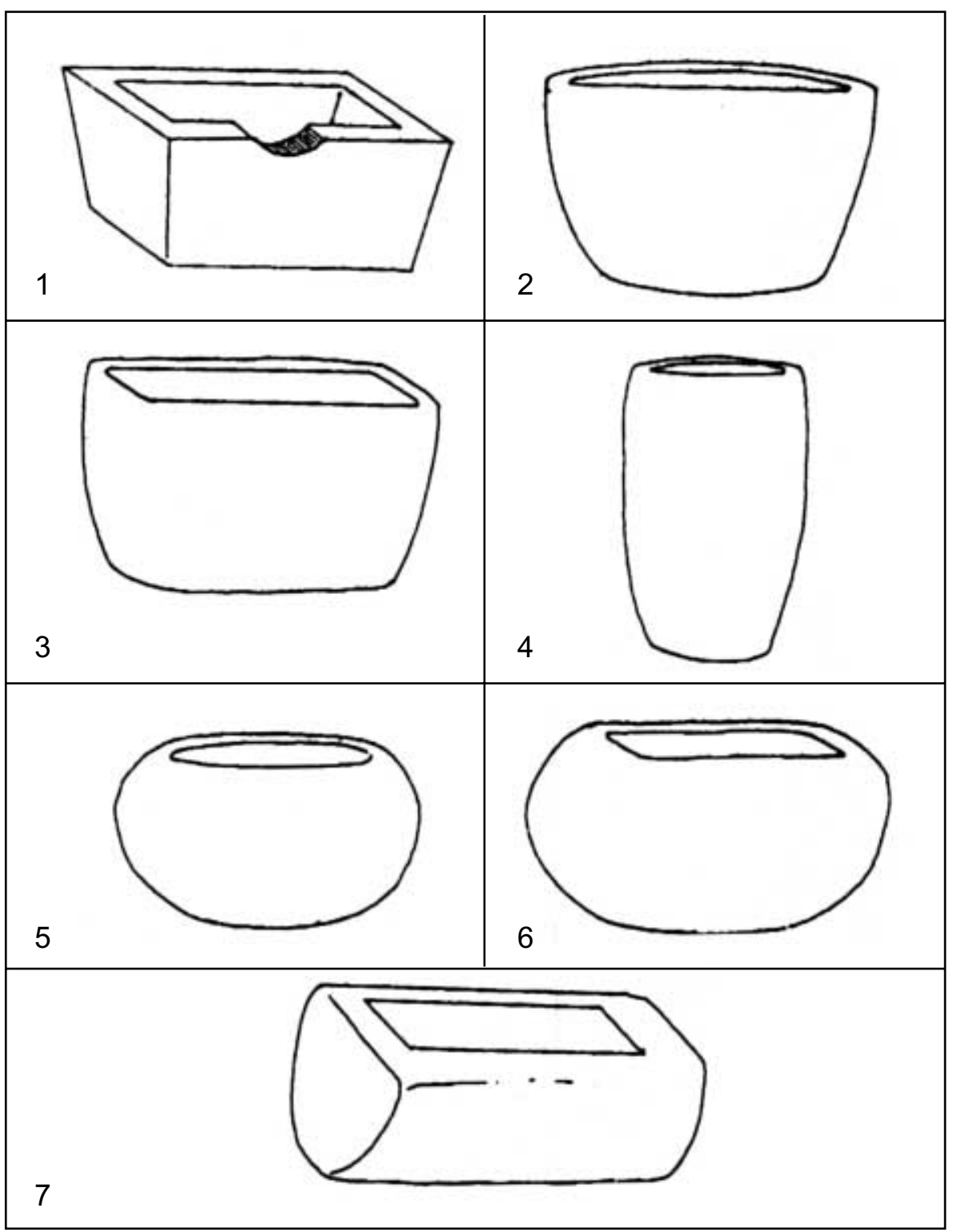


Figure 11.27 Urn-dolmen grave in Long Berini (No. 26)

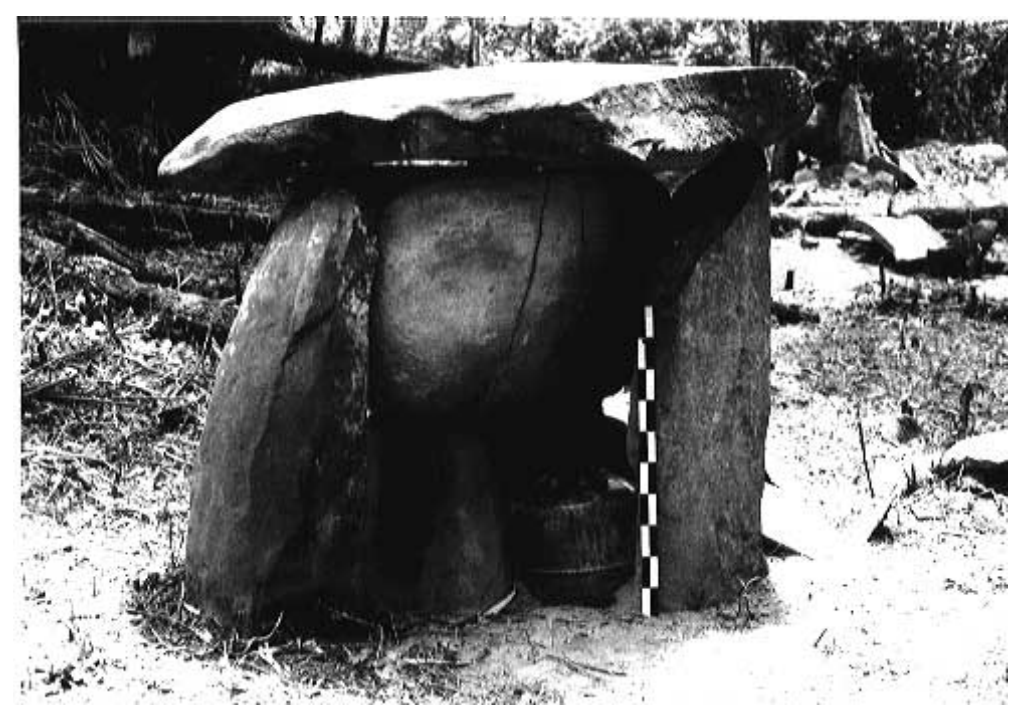

Figure 11.28 Urn-dolmen grave in Long Berini (No. 5)

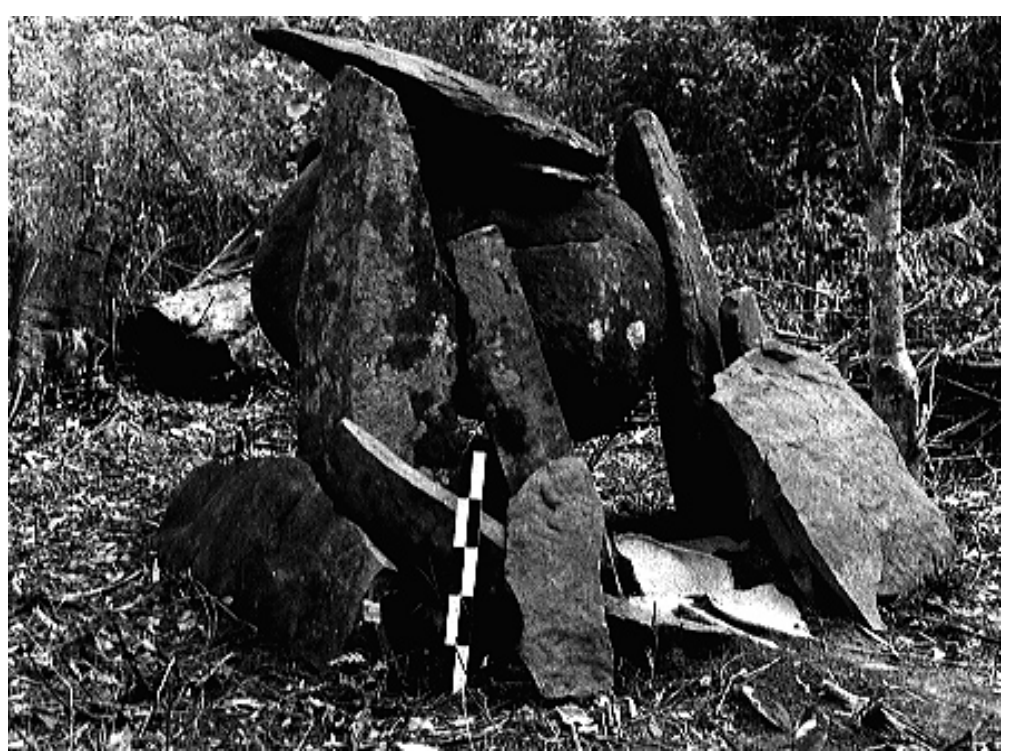


Figure 11.29 Urn-dolmen graves in Long Berini (Nos. 28, 29 and 32)

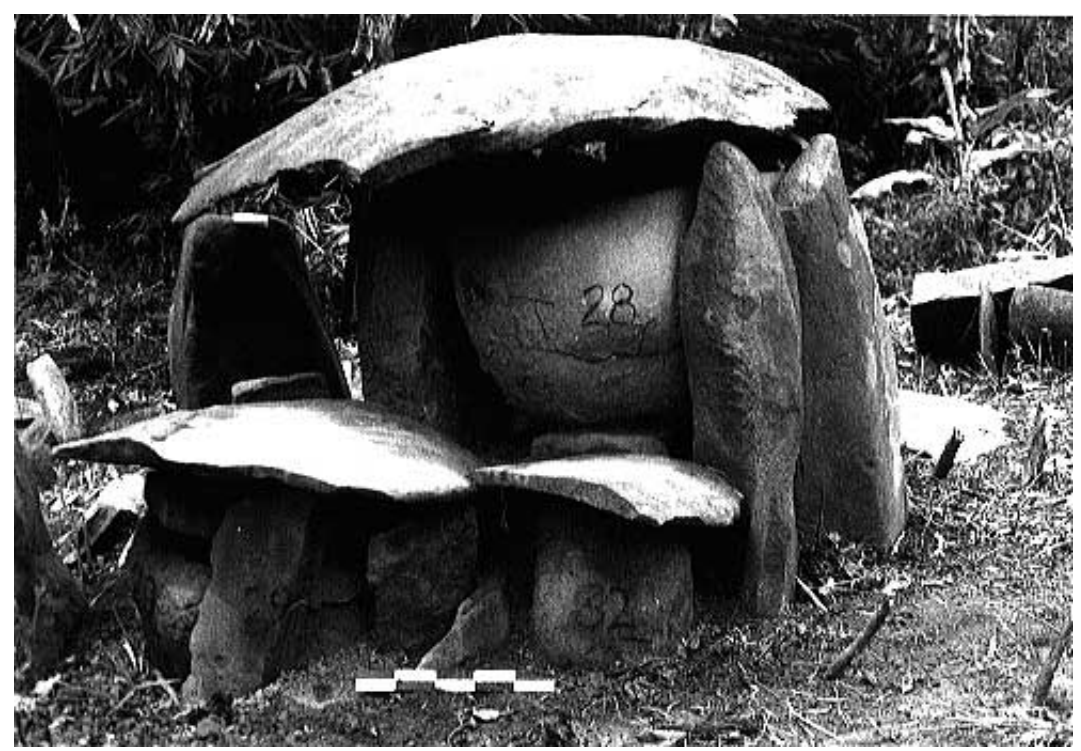

Figure 11.30 Urn-dolmen graves in Long Berini (Nos. 5 and 38)
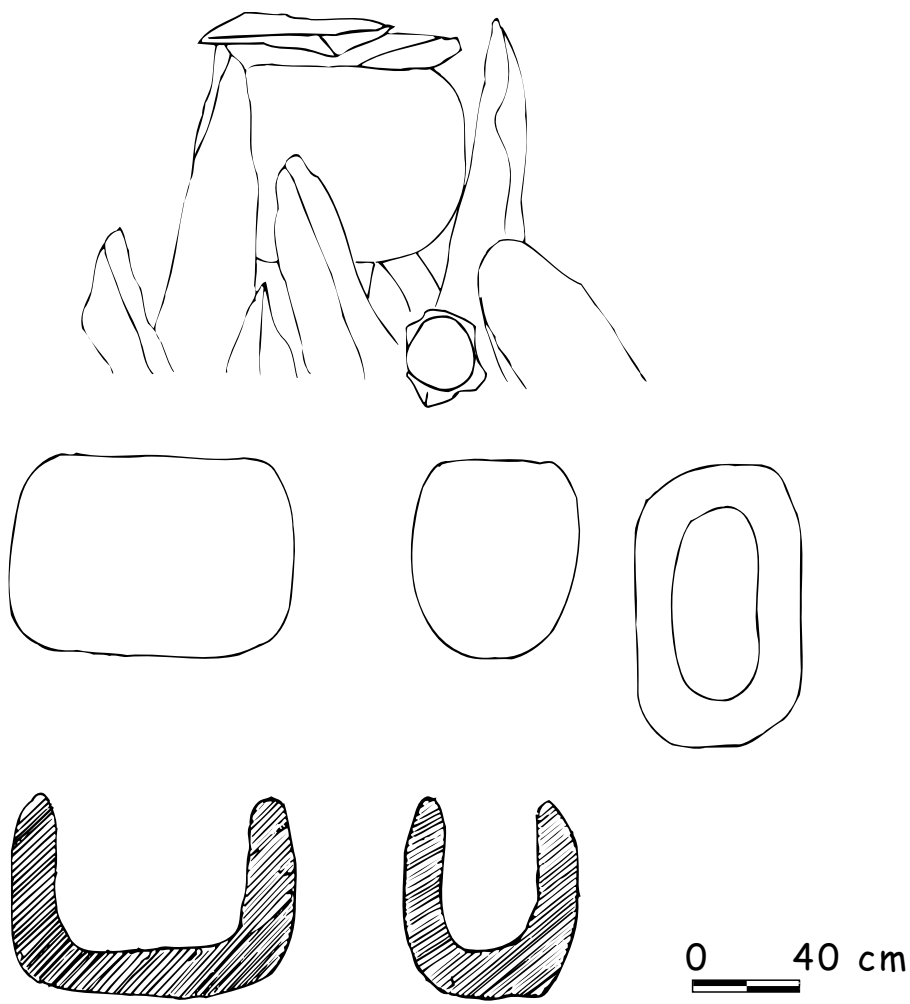
seeds, and pieces of bones. It was not possible to determine whether the few intact urns contained bones, because the space between the mouth of the urn and the roof of the dolmen was too small.

\section{Ka Tempu}

The site is covered with brush and trees and after it was cleared it became clear that trees and roots have already done considerable damage to the structures (see Figures 11.31 and 11.32). The graves are concentrated in the southeastern part of the site; in the northwest they are much fewer; and in between is an empty area. Several graves are also located on a steep slope, where some of the soil has already slid down. There is a total of about 80 graves of various sizes, types, and conditions, of which 6 are intact, 12 have collapsed, and the rest are heavily damaged. In several graves, a ceramic jar is found in place of the stone urn under the roof of the dolmen. One stone container is cylindrical and has toppled. One stone urn lid is carved in relief with a creature (a frog?) with hands and feet with five fingers/toes.

As at Long Berini, the burial containers are of soft sandstone, while the roof and pillars are of 'onion skin' stone, except for a few that have slab pillars. The urns are variously shaped: cylindrical, bowl-shaped, rectangular, or ovoid with either a round or rectangular opening. They range in height from $33.5 \mathrm{~cm}$ to $117 \mathrm{~cm}$, with walls $10-$ $12 \mathrm{~cm}$ thick. Two ceramic jars are of the same type as those found in Long Berini, broad and short and with a dark brown glaze.

Figure 11.31 Cylindrical stone container in Ka' Tempu (No. 17)

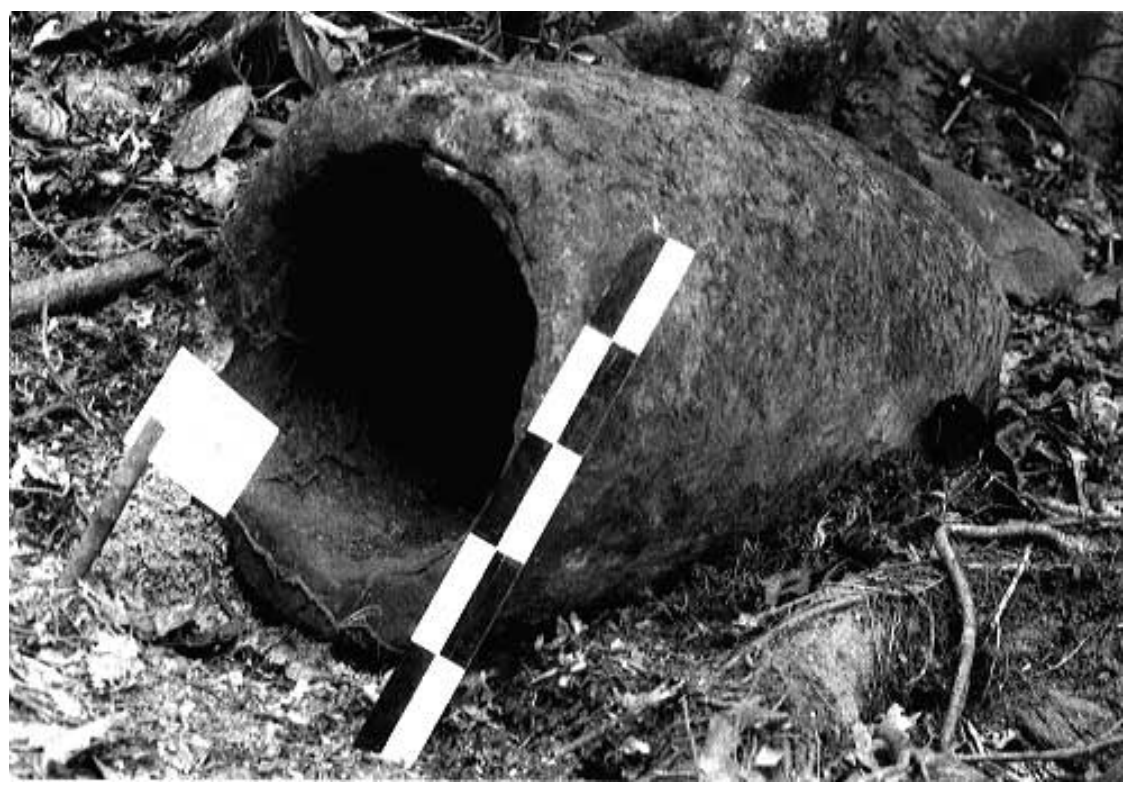


Figure 11.32 Ovoid stone container in $\mathrm{Ka}$ Tempu (No. 50)

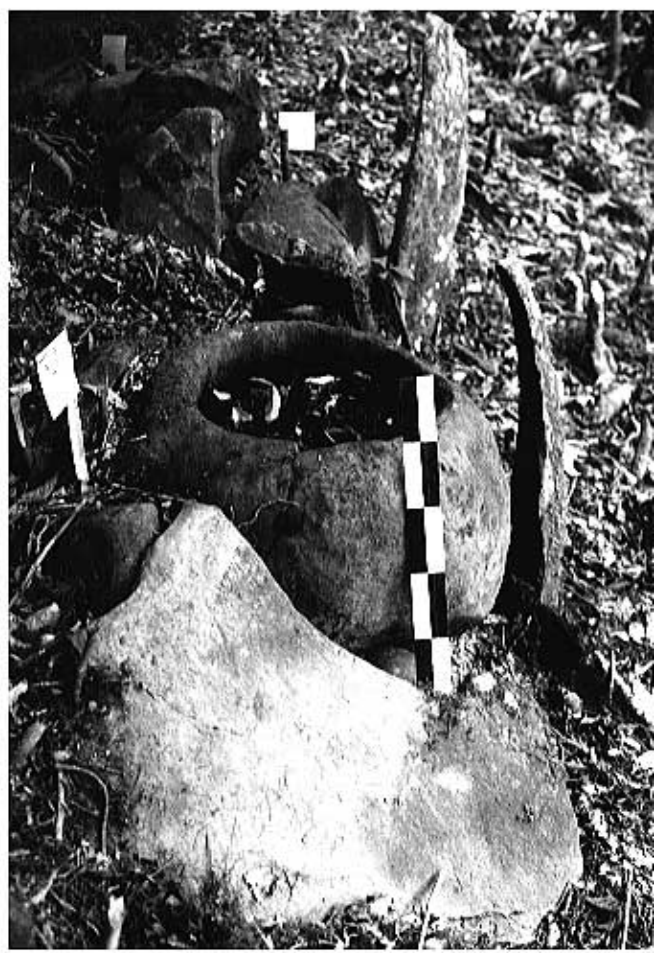

\section{Long Kale'}

This rather narrow site with an uneven ground surface was covered with brush and trees and needed clearing. None of the 18 graves stands intact, and only three are in fairly good condition, even though some parts have collapsed or disappeared. The other graves are broken, although in several of them the form of the urn is still recognisable. The pillars and roof of the dolmen are of 'onion skin' slabs of hard stone, while the containers are of soft stone. There is not much variation in urn shapes: cylindrical, bowl-shaped, and ovoid with rectangular opening. Not a single ceramic jar was found.

\section{Long Pulung}

The site is located on a gently sloping plain, in an old orchard, and looks clean and well maintained. This site, too, has been visited by staff from the Development Planning Office of Bulungan District, as indicated by the word 'BAPPEDA' in yellow paint on one of the monuments. It is enclosed by a $2 \mathrm{~m}$ high fence, already damaged, and by a lock on the gate. Of the dozen graves visible, only two remain intact, one still stands but has lost its urn, four have collapsed, and the remainder are nothing but broken pieces.

The dolmens have 'onion skin' pillars and roofs. Several of those stones look as if they have been worked to smoothen out both surfaces, and one has been processed 
into a slab. One rectangular stone container with a narrower base (palung or trough) has a dent cut at the mouth and a hole in the side. Another, partly broken, is cylindrical, with geometric decorations carved all over its surface (see Figure 11.33). Altogether, there are four urn shapes: cylindrical, rectangular with a narrower base, bowl-shaped, and ovoid with a round opening.

Figure 11.33 Carved stone urn in Long Pulung, upper Bahau

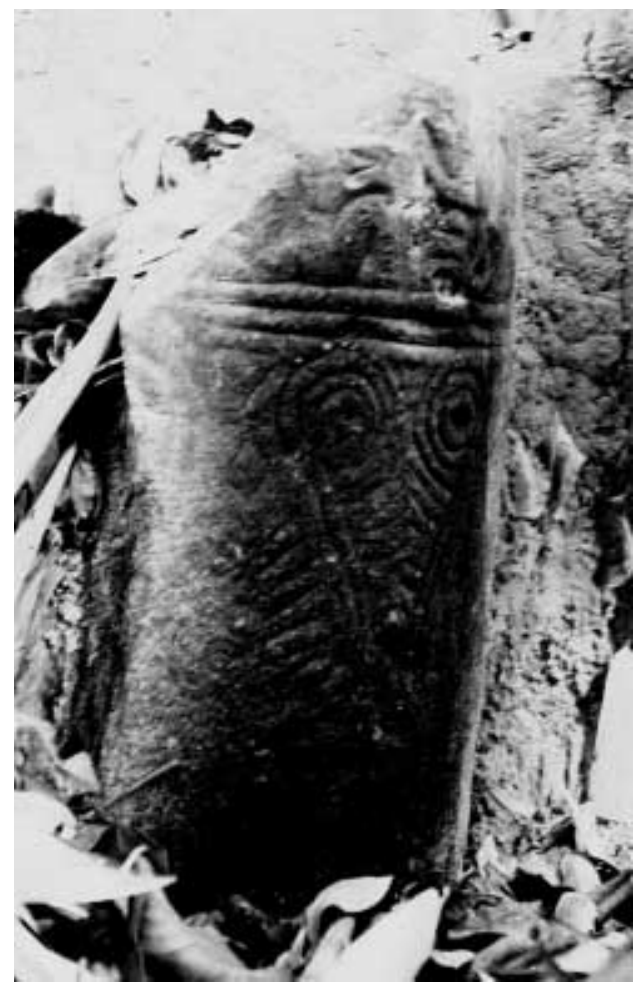

\section{Long Beraa}

This site is covered with dense brush and trees. Nyibun burial structures are located slightly below the megalithic graveyard. One big, Y-shaped wooden post still stands firmly and the ceramic jar at its top is intact. Another Nyibun post has rotted and collapsed, and scattered around and half buried are pieces of the ceramic jar with dragon motifs in relief, two gongs of different sizes, and a bent machete blade.

The stone grave complex is located on level land that was once cleared, and consists of five structures. Two intact monuments display stone containers with a rectangular opening and a rounded and narrower base. The pillars and roof are stone blocks, or slabs combined with coarse blocks. The containers are of softer stone. One container has a domed lid of 'onion skin' stone, underneath the dolmen roof. In one container (Figures 11.34 and 11.35), 12 human skulls and other bones (limbs and ribs) and a small rusty gong are found. Another grave contains a ceramic jar already broken. The remaining graves are heavily damaged. 
Figure 11.34 Stone monuments in Long Beraa (No.3)

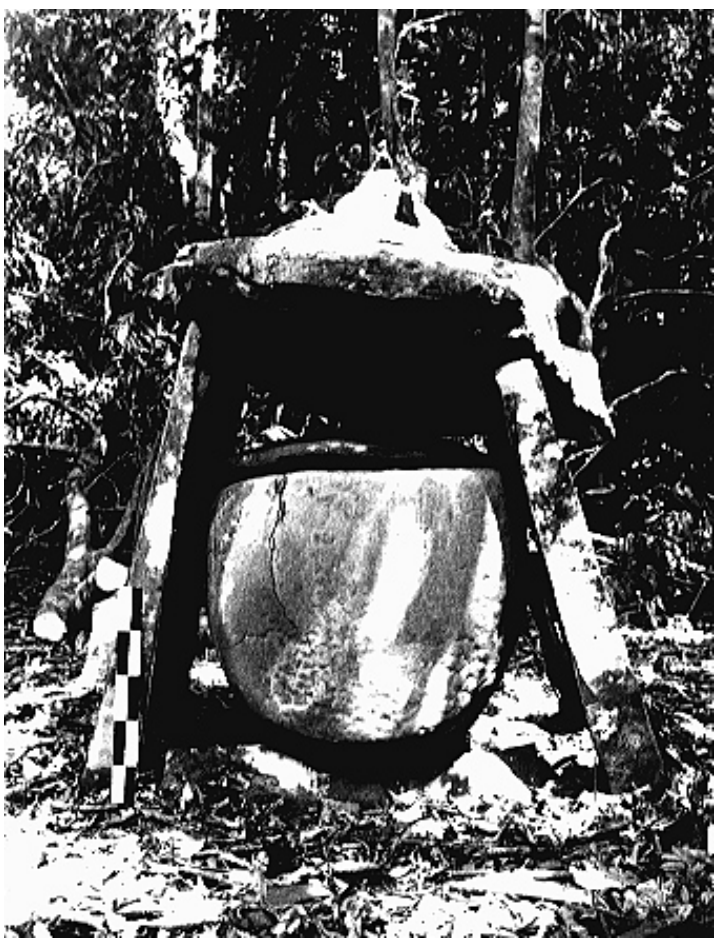

Figure 11.35 Skulls and bones from grave No. 3 in Long Beraa

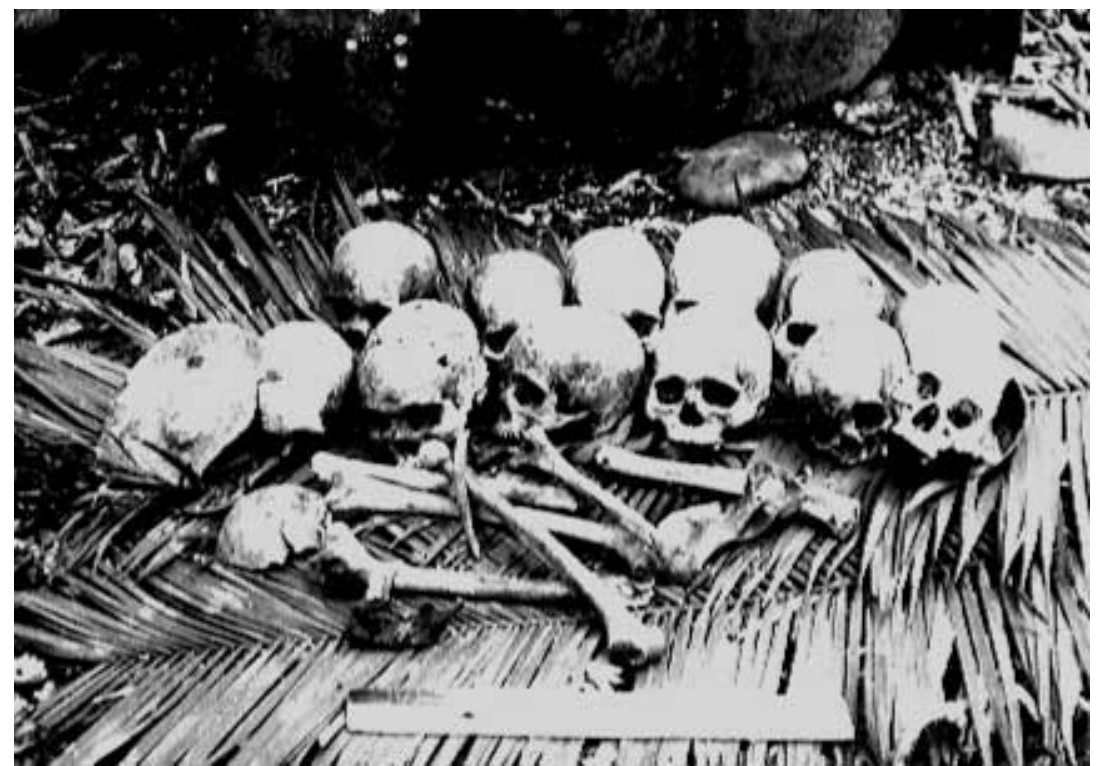




\section{Discussion}

The sites mapped cover an area ranging from 30 to $6000 \mathrm{~m}^{2}$ and are located from 5 to $20 \mathrm{~m}$ from the river. Generally, they extend parallel to the river (except at Long Beraa). At the five sites, a total of 155 graves were found, more than $50 \%$ of which are at Ka Tempu. On average, only $11.6 \%$ of the total number of graves are still intact. This fact is a matter for considerable concern, and even the sites in isolated areas have not escaped destruction. According to the local people, several sites have in fact been used for farming, one of the major causes of destruction, because the future field is burned. Destruction, however, can also be caused by the river (erosion of the banks), the growth of roots and trees, and the activities of animals, such as pigs, which like to root around in the ground. Of the five sites, only one (Long Pulung) shows any indication of an effort at preservation (fencing the site), since this location is very easy to visit.

For 80 graves $(51.6 \%)$, it was still possible to determine the original type and shape of the burial container (see Table 11.1). For example, at Long Berini (22 containers): 10 urns are ovoid with a round opening, 4 are bowl-shaped, 3 are rectangular, 2 are ovoid with a rectangular opening, and 3 more are ceramic jars. The overall most common container shape is the ovoid urn with a round opening (36 examples). One monument at Long Berini should be noted, because not only is it the highest monument recorded, but its stone urn is also the largest, with a diameter of $120 \mathrm{~cm}$, a height of $80 \mathrm{~cm}$, and $10 \mathrm{~cm}$ thick walls.

Table 11.1 Distribution of container shapes in the upper Bahau

\begin{tabular}{|c|c|c|c|c|c|c|c|c|c|}
\hline \multirow[b]{2}{*}{ SITE } & \multicolumn{9}{|c|}{ Shape of Stone Container } \\
\hline & $\begin{array}{l}\frac{\grave{d}}{0} \\
\frac{.}{\bar{d}}\end{array}$ & 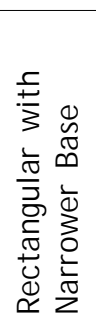 & 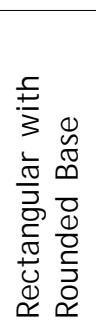 & $\begin{array}{l}\bar{d} \\
\frac{0}{0} \\
\frac{0}{n} \\
\bar{z} \\
\bar{\emptyset}\end{array}$ & 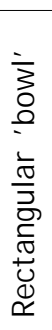 & 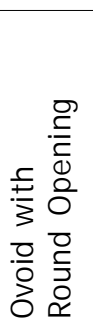 & 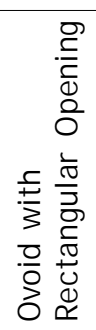 & 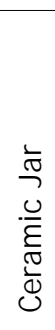 & $\begin{array}{l}\bar{\Gamma} \\
\stackrel{0}{\circ}\end{array}$ \\
\hline Long Berini & - & - & - & 4 & 3 & 10 & 2 & 3 & 22 \\
\hline Ka Tempu & 5 & - & - & 6 & 2 & 21 & 5 & 1 & 40 \\
\hline Long Kale & 1 & - & - & 2 & - & 4 & - & - & 7 \\
\hline Long Pulung & 1 & 1 & - & 4 & - & 1 & - & - & 7 \\
\hline Long Beraa & - & - & 1 & - & 1 & - & 1 & 1 & 4 \\
\hline Total & 7 & 1 & 1 & 16 & 6 & 36 & 8 & 5 & 80 \\
\hline
\end{tabular}

Little can be said about the structure of the graves because it varies considerably, following the types and shapes of their containers. At Long Beraa, for example, dolmen pillars are found only on the two sides of the grave, a consequence of the use of a rectangular container (sarcophagus). Likewise, supporting stones are used for the bowl- 
shaped stone urn, whereas cylindrical stone containers and ceramic jars are partly buried in the ground. The roof and pillars of the dolmen and the supporting stones of the container generally are not finely worked and of whatever form, and simply adjusted to the size of the container.

Furthermore, it is difficult to discover the relationship between sites, because there are many differences. From the similarities in the general shape of the monuments, however, it can be established that the people who built them had the same capabilities and technology, although with a different creativity. The burial containers may be filled with the bones of more than one individual, as at Long Beraa, making the container a collective grave. Small gongs or earthenware pots and cups, found in several graves, are believed to be grave goods.

The layout of the sites differs from one site to the next, except for the lining-up of the graves parallel to the river bank. At Ka Tempu, there are two separate concentrations of graves, believed to point to the existence of two distinct groups. According to the local inhabitants, the graves can be differentiated into those with carved containers (Ka Tempu and Long Pulung)-the graves of paren bio' (chiefs of ethnic group)-and those with plain containers. At Long Berini, the large monuments tend to be surrounded by smaller graves that seem to cling to them. The larger graves are believed to indicate a higher social position of the occupant. The differences in the features of a grave-shape, material of the container, size, presence of stone supports for the urn-seem to reflect differences in social status. These distinctions, however, may also result from the difference in the type of death suffered by the deceased (see Karina Arifin, in Eghenter and Sellato 1999).

\section{TEST PITS IN PUJ UNGAN SUBDISTRICT}

Three test pits were dug at the settlement site of Apau Ping and three more at the site of an abandoned settlement area (lepu'un) at Long Beraa (see Figure 11.25).

\section{Apau Ping}

The current village of Apau Ping is a settlement of the Kenyah Leppo' Ké. This site, however, was once occupied by the Ngorek, and later by the Kenyah Leppo' Ma'ut. Many polished stone adzes were found, which, according to the local people, were made by the Ngorek. Many earthenware shards were also found, part of Ngorek origin and part of Kenyah (Leppo' Ma' ut or Leppo' Ké) origin, although the differences between the two are still unclear. The test pits were meant to expose distinct cultural layers reflecting differences between the two ethnic groups and to identify types of artefacts characteristic of these groups, since the context of the many artefacts (stone adzes and earthenware) collected from the villagers' hands is not known. The test pits were expected to contribute more explicit preliminary information, both vertically and horizontally, regarding the Ngorek.

Three spots were selected. Test Pit I shows a structure of burnt clay resembling brick on the surface, which according to the villagers was made by the Ngorek. Test Pit II was dug in a spot where, according to the villagers, houses had stood since Ngorek times. Due to this spot's higher elevation, complete cultural layers could be exposed and numerous stone tools and earthenware shards were found nearby (for a terminology of the parts of earthenware containers, see Figure 11.36). The location of Test Pit III, at the highest ground elevation, has also once been occupied by the Ngorek, and 
earthenware and stone adzes were also found on the surface. During the 1992 survey, a test pit had been dug by Kiwok Rampai not far from Test Pit III, in the yard of a lower-lying house.

Figure 11.36 Pottery Terminology

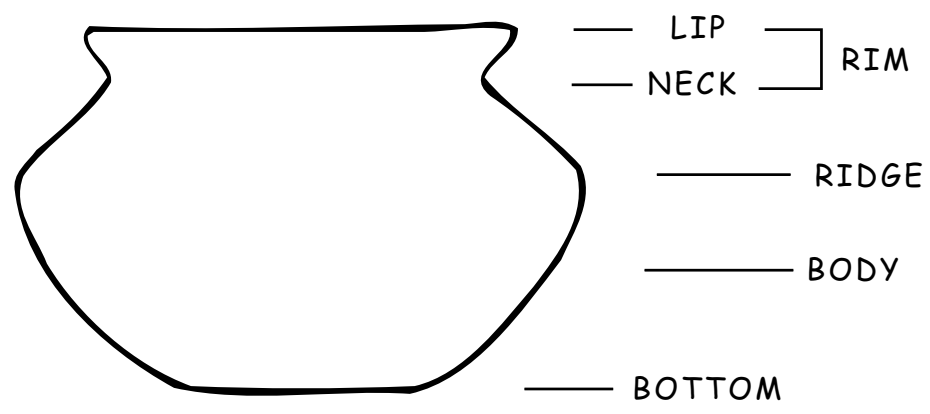

\section{Test Pit I}

The $1 \times 1 \mathrm{~m}$ test pit consists of five lots. It reveals a 'brick structure' forming two hollows of, respectively, $40 \times 30 \mathrm{~cm}$ (to the south) and $60 \times 30 \mathrm{~cm}$ (to the north). The bottom and sides consist of layers of hard brick. The outer walls are less hard and their colour shifts from bright red to brown and finally fades into the colour of the surrounding soil. In the hollows, river stones, charcoal particles, and earthenware shards were found. One of the river stones, of unclear function, has a round side covered by a layer of greenish yellow glaze. The base of the hollows is greenish brown and rippled and is impermeable to water, maybe the result of high temperatures at burning. Earthenware shards, all from the bodies of containers, are red, grey, and black, with a temper of crushed earthenware. One shows string decoration. No distinct soil layers or other artefacts were found that could be used as markers of cultural layers.

\section{Test Pit II}

Test Pit II is $1.5 \times 1.5 \mathrm{~m}$ and consists of three lots. Lot 1 consists of disturbed black soil containing stones and 68 pottery shards (including 1 ridge, 1 neck, and 1 rim). In Lot 2 , an earthenware artefact of unclear function, with a temper of coarse crushed pottery was found. The bottom of Lot 2 is a layer of dense yellow soil with black pellets and chunks of river stones, and one piece of dark grey pottery with a coarse temper. The bottom of Lot 3 ( $75 \mathrm{~cm}$ deep) displayed a sterile layer of yellow soil mixed with black pellets. Test Pit III, thus, shows a single cultural layer.

Lot 1 yielded $640 \mathrm{gr}$ of earthenware shards, generally rather small (less than 2 $\mathrm{cm})$, and Lot 2 only revealed one shard $(5 \mathrm{~cm})$. The thickness of the shards varies from 0.3 to $1.1 \mathrm{~cm}$. The temper is of crushed earthenware (from fine to coarse, with a maximum of $0.4 \mathrm{~cm}$ ), or sand with grains still visible, indicating a low firing temperature. The pottery is orange, reddish grey, or black. It does not always have an outside layer of resin, but occasionally the inside is covered by such a layer. One shard shows a straight rim, similar to the form manufactured by the villagers today. No decorated earthenware was found. 


\section{Test Pit III}

Test Pit III is $1.25 \times 1.25 \mathrm{~m}$ and consists of four lots. Lot 1 shows crumbly soil with chunks of river stones, 3 unpolished basalt adzes, small flakes of basalt, animal teeth, charcoal, and small pellets of batu bala (literally, red rocks, natural red ochre mixed with water and used for painting coffins, house walls, or shields). The earthenware ( 3 $\mathrm{kg}$ of small shards) includes 594 pieces of container bodies, 53 ridges, 65 necks, and 34 rims. Lot 2 yielded earthenware shards and chunks of river stone, batu bala, 2 flakes of basalt, and one polished basalt adze with one of its edges reworked. The earthenware $(1.6 \mathrm{~kg})$ consists of 286 pieces of container body, 53 ridges, 22 necks, and 23 rims. In Lot 3 , the dense brown soil contains basalt flakes, several chunks of yellow and red ochre, and small river stones. The earthenware (less than $1 \mathrm{~kg}$ ) consists of 216 pieces of the body, 30 ridges (Figures 11.37 and 11.38), 8 necks, and 6 rims (Figures 11.39 and 11.40). In Lot 4, the soil is still of the same type, and the earthenware $(0.5 \mathrm{~kg})$ consists of 87 pieces of the body, 19 ridges, 9 necks, and 4 rims, as well as pieces of white earthenware. Furthermore, two basalt adzes were found at a depth of $82 \mathrm{~cm}$. The test pit ended with a layer of sterile yellow soil at a depth of $94 \mathrm{~cm}$. Thus, a single cultural layer was found, which did not show any sublayers.

Figure 11.37 Ridges in earthenware (Apau Ping): (a to e) test pit III Lot 2; $(\mathrm{f}-\mathrm{g})$ test pit III Lot 4
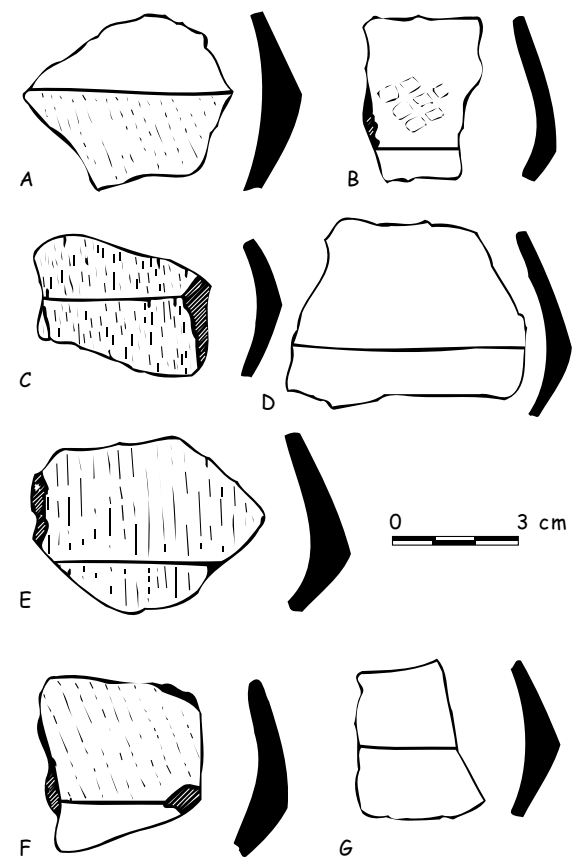

Figure 11.38 Ridges in earthenware from Apau Ping: test pit III Lot 3

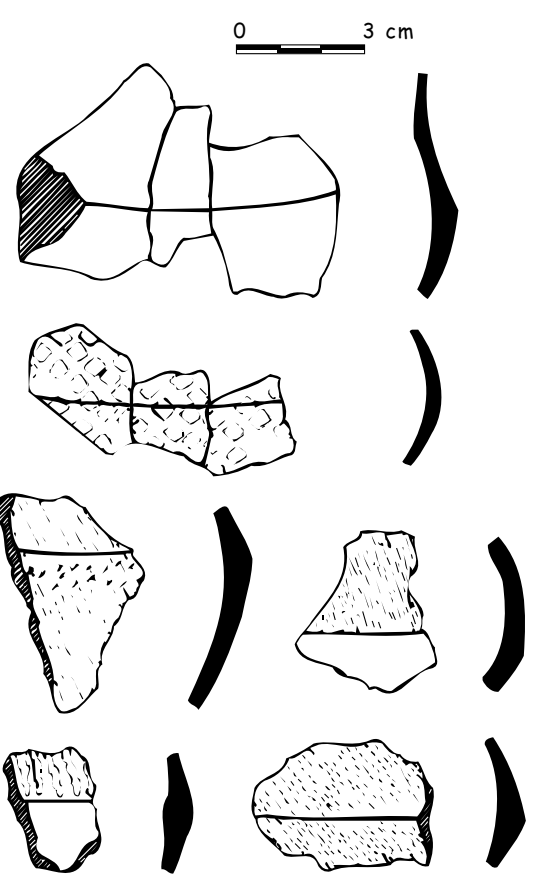


Figure 11.39 Rims in earthenware from Apau Ping: test pit III Lot 1

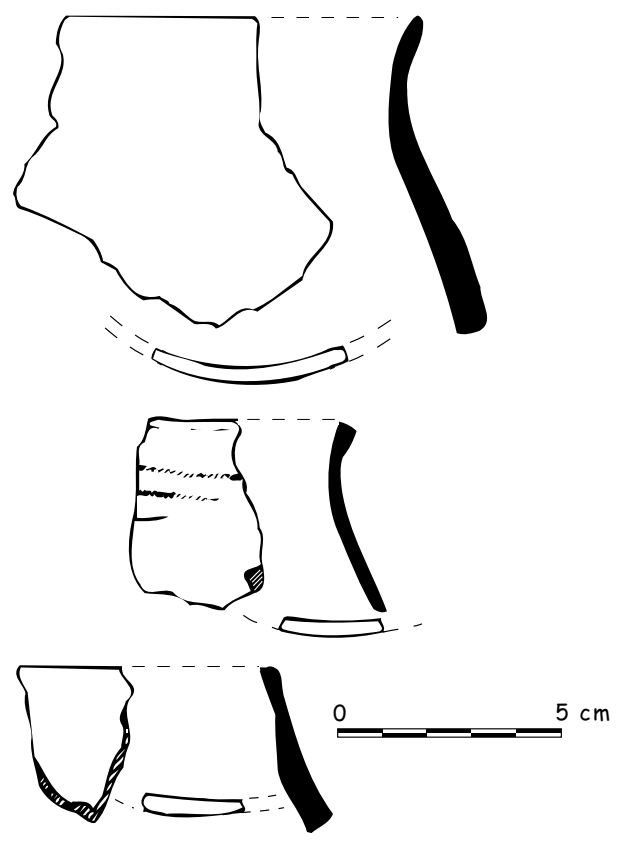

Figure 11.40 Rims in earthenware from Apau Ping: test pit III Lot 2

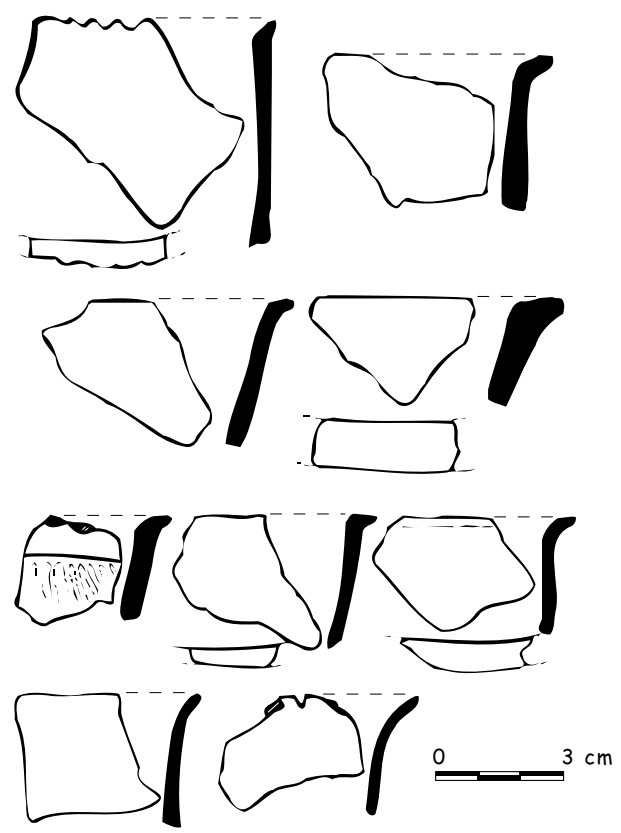

The pottery is red orange, grey, black or, most infrequently, pale yellow. A layer of resin is often found, either on the outside or the inside. Some pottery polished to a black shine was found, as well as another type, yellowish or greyish red on the outside and black on the inside. The temper generally consists of finely crushed pottery. Some pottery with a sand temper with quartz grains still visible indicates a low firing temperature. More than half the pottery is decorated, generally with a string pattern obtained by beating the pot with a paddle wrapped in string with varying diameter (see Figures 11.41 and 11.42). The straight rim of one container shows another technique of string decoration, made by impressing a string around the neck. A decorative pattern of boxes (squares or diamonds) is also found, made with a wooden paddle incised with crossed lines. The lip may be decorated with a motif of deep scratches around the edge. On the pot's body, decoration may be restricted to the bottom part, below the ridge, or to the part from the ridge to just below the rim. One of the pottery, showing a neck forming an angle, is decorated with a string pattern interrupted just below that angle.

\section{Long Beraa}

The Long Beraa site, located on the second terrace from the river bank, is an old Ngorek settlement site (lepu'un) and has been occupied again by the Kenyah Leppo' Ma' ut in the 1940s. This is an ideal location, because the flat is extensive, with a nearby hill suitable for defence. Many earthenware shards are found on the ground surface, as well as fruit trees (rambutan and candlenuts). Test pits were opened in three locations. 
Figure 11.41 Pattern made by thin string wrapped around a paddle

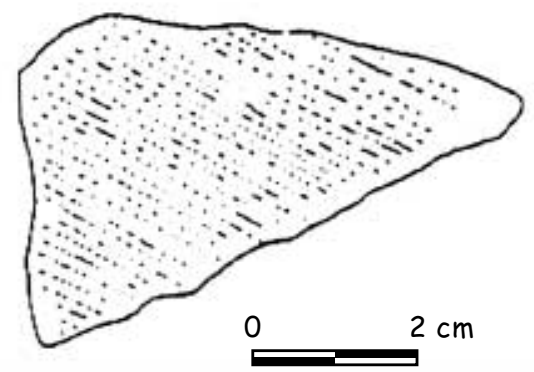

Figure 11.42 Pattern made by thick string wrapped around a paddle

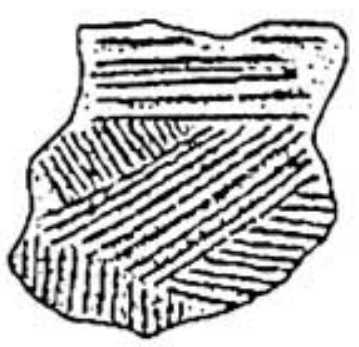

\section{Test Pit I}

Test Pit I, measuring $1 \times 1 \mathrm{~m}$, is located on a flat covered with grass and a few trees and consists of three lots. Lot 1 shows crumbly black soil mixed with roots, charcoal, shards of foreign ceramic, and earthenware shards (less than $0.5 \mathrm{~kg}$ ) consisting of 30 parts of container body, 3 necks, and 5 rims. There is also one pot bottom with a thickness of $2 \mathrm{~cm}$ (110 gr), thought to be part of a large container. The local people, however, claim that they have never seen one so thick. Batu bala is also present. In Lot 2, still denser yellow soil contains river stones, charcoal, and orange and grey pottery shards $(200 \mathrm{gr}$ ) consisting of 11 shards of body, 4 necks, and 1 rim, with a temper of crushed earthenware and very coarse sand $(0.5 \mathrm{~cm})$. In the upper part of Lot 3, a grey soil layer yielded one shard of a pot body and charcoal particles, and is gradually replaced with dense yellow soil. Lot 3 ends with a sterile yellow layer at a depth of $60 \mathrm{~cm}$.

\section{Test Pit II}

In a flat overgrown with ferns and dense tall Imperata grass, Test Pit II, measuring 1 x $1 \mathrm{~m}$, consists of 2 lots. In Lot 1 , crumbly black soil with charcoal particles yielded 7 chunks of batu bala (200 gr) and pottery consisting of 15 shards of container body, 4 necks, and 4 rims. Downward, the soil becomes sandy with fine grey soil pellets, and at the bottom of the lot it is mixed with yellow soil. Lot 2 was dug only $18 \mathrm{~cm}$ deep to check the underlying soil in the south of the square. At its bottom, the soil is still black and contains charcoal particles and earthenware $(200 \mathrm{gr}$ ) consisting of 11 shards of container body, 4 necks, and $1 \mathrm{rim}$. Small chunks of batu bala were also found. The yellow soil layer appears to be sterile.

\section{Test Pit III}

Test Pit III, measuring $1 \times 1 \mathrm{~m}$, is located at the end of a flat area overgrown with thick fern and it consists of three lots. In Lot 1 below the humus, a black sandy soil mixed with charcoal yielded earthenware shards (100 gr) comprising 15 shards of container body, 1 neck, and $1 \mathrm{rim}$, as well as pieces of glass and bottles, pieces of tin plates, river stones, and todan (a sort of resin). Lot 2 consists of dense yellow and brown soil with no charcoal or artefacts at all. Lot 3 was dug in the middle of the square to examine a spot of dark grey crumbly soil to a depth of $17 \mathrm{~cm}$, possibly the remains of 
a house stilt. The pottery is reddish orange and dark grey, some showing remains of a resin layer, and the temper is coarsely crushed pottery. Straight rims indicate a rather closed type of pot, like that still made by the local people today. Not a single shard of decorated pottery was found.

\section{Conclusion}

The two sites display similar features, i.e., a black upper layer containing charcoal and artefacts (primarily pottery), and a yellow, sterile substratum. In between are transition layers of black and yellow soils, frequently still containing artefacts. The upper layer does not show distinctive sublayers that could be viewed as representing two or more different cultural layers. It is thus difficult to identify or distinguish between the groups that manufactured the artefacts recovered. The Kenyah never manufactured basalt tools and always insist that these were made by the Ngorek, which leads to the conclusion that the stone tools in Test Pit III at Apau Ping were made by the Ngorek. The problem is different with regard to the pottery shards found everywhere. Without a clear differentiation of cultural layers, there is no indication to determine who made these pots. Although the people of Apau Ping tend to state that these shards are of Ngorek origin, they themselves, to this day, still produce earthenware (see Sellato 1997a).

\section{ANALYSIS OF ARTEFACTS FOUND IN APAU PING}

Research on the artefacts found in the Apau Ping area in 1991-92 was conducted in Jakarta. These artefacts consisted primarily of stone implements and pottery shards, and a few shards of foreign ceramic ware and pieces of iron.

\section{Stone tools}

The stone tools investigated totalled 205 pieces. They can be classified as adze, pounder, gouge, scraper, and sharpening stone. Adzes form the largest group (59 items)-to which should be added 42 unpolished adzes. A large number of broken basalt tools could not be classified.

\section{Adzes}

These adzes generally are elongated with a quadrangular cross section, and are finely polished all over (see Figure 11.43). A cutting edge is made by abrading the extremity of the tool, giving a sharper slant to the extremity of the lower surface. They vary in size from 4 to $25 \mathrm{~cm}$. They can be divided into eight types according to shape. It should be noted that this typology is essentially descriptive and does not carry implications regarding differences in the functions of the tools.

Type A (23 items; see Figure 11.44): the upper surface rises from a narrow butt towards the centre of the tool and broadens increasingly

Figure $\mathbf{1 1 . 4 3}$ Terminology of the adze: a) upper surface; b) longitudinal section; c) lower surface; 1) butt; 2) cutting edge

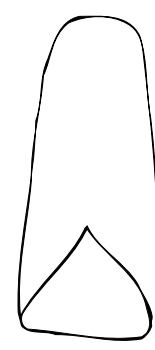

A

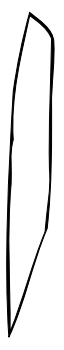

B

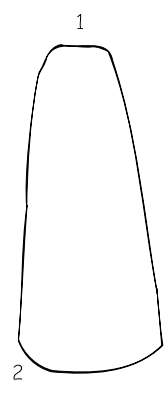

c 
Karina Arifin and Bernard Sellato

233

Figure 11.44 Typology of stone adzes from the upper Bahau, type A

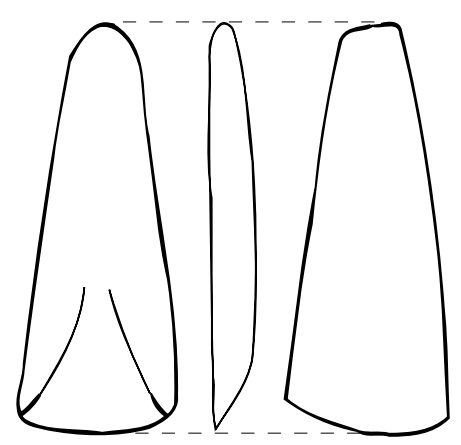

Type A

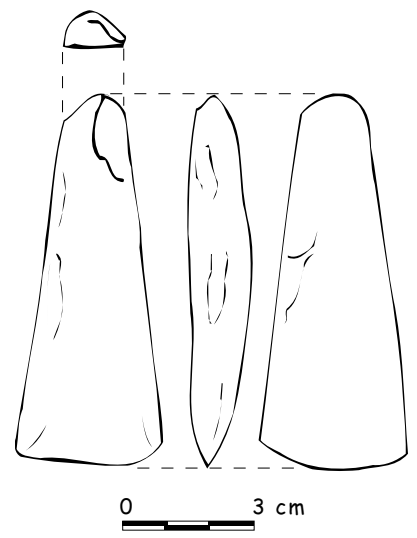

Subtype A2

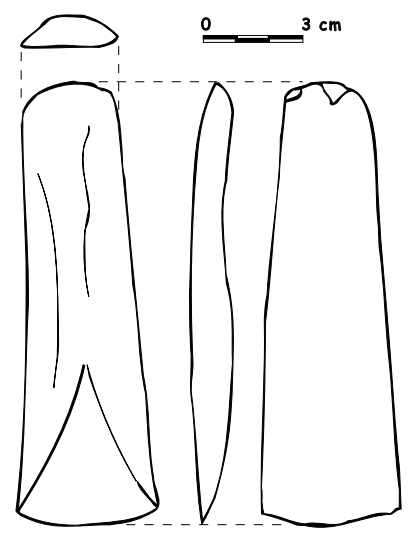

Subtype A4

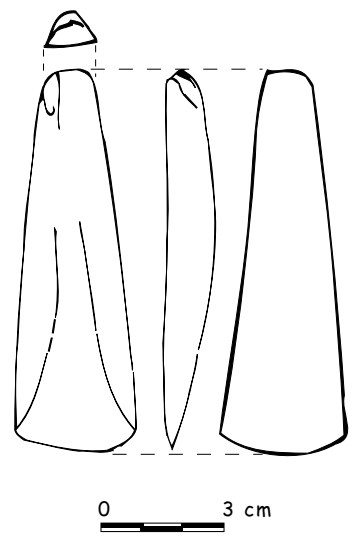

Subtype A1

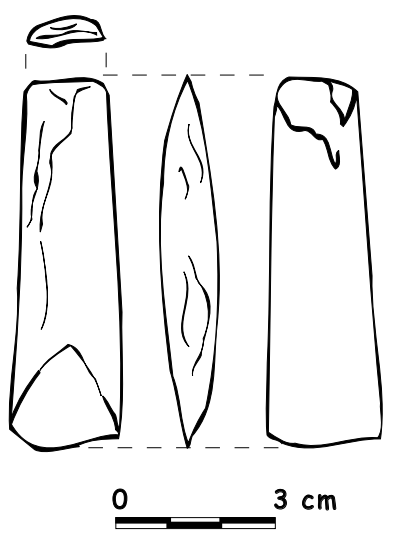

Subtype A3

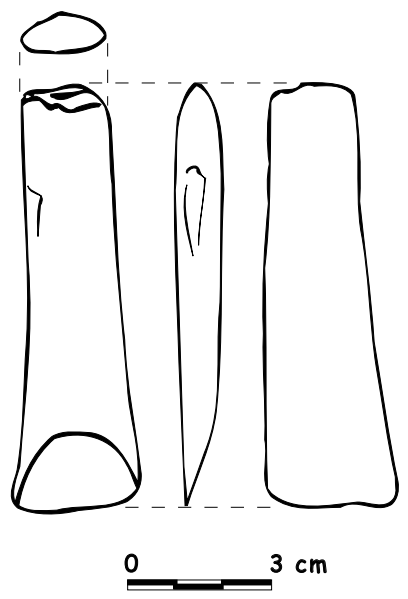

Subtype A5 
to form the cutting edge, which forms a convex triangle on the upper surface (see this type in Duff 1970). Type A adzes have been divided into five subtypes on the basis of their cutting edge and their section. Al (13 items; 5.3-12.6 cm long): the cutting edge is formed from the convex upper surface, whereas the lower surface is flat. The longitudinal section displays a flat lower surface and a convex upper surface $\underline{A 2}$ ( 7 items; $6.1-11.4 \mathrm{~cm}$ long): the longitudinal section is almost identical to that of $A 1$, but both surfaces have been abraded to form the cutting edge. $\underline{A} 3$ ( 1 item; $7.0 \mathrm{~cm}$ long): the butt does not much differ in width from the cutting edge, which was formed from the flat upper surface, whereas the lower surface is rather convex. A4 ( 1 item; 11.6 $\mathrm{cm}$ long): the cutting edge was formed by abrasion of both the lower and upper surfaces, which are both convex. $\underline{A} 5$ ( 1 item; $9.0 \mathrm{~cm}$ long): the cutting edge was formed from the upper surface, while the lower surface is rather convex.

Type B (21 items; see Figure 11.45): The upper surface is convex, whereas the lower surface, from which the cutting edge was formed, is flat. The butt is not significantly narrower than the edge (see this type in Duff 1970). According to variation in the cutting edge, four subcategories are distinguished. B1 (6 items; 7.8-11.2 cm long): the upper surface is convex while the lower surface is flat; the cutting edge is formed from the lower surface. B2 (8 items; $4.8-15.6 \mathrm{~cm}$ long): the cutting edge clearly shows a triangular shape. $\mathrm{B} 3$ (4 items; $10.1-14.7 \mathrm{~cm}$ long): the cutting edge is shorter and thus steeper. $\underline{B} 4$ ( 3 items; $8.5-9.5 \mathrm{~cm}$ long): the upper surface is rather convex and the lower surface is flat; the cutting edge is short.

Figure 11.45 Typology of stone adzes from the upper Bahau, type B

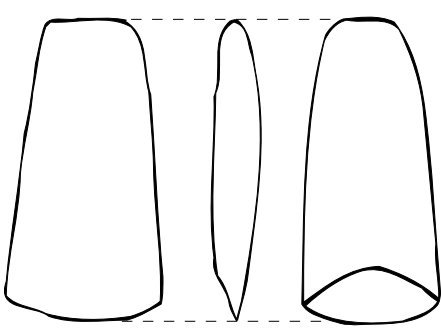

Type B

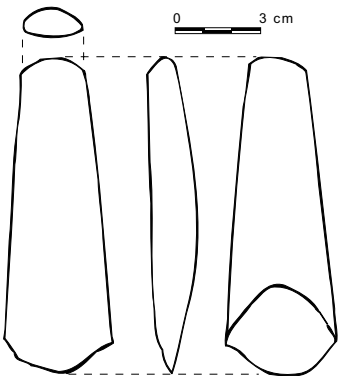

Subtype B1

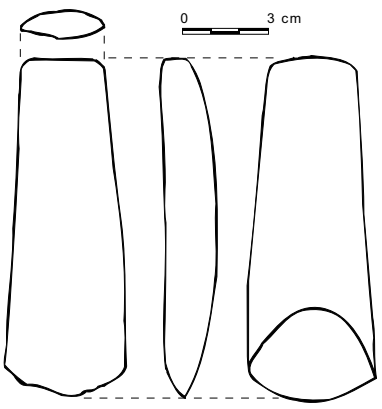

Subtype B2

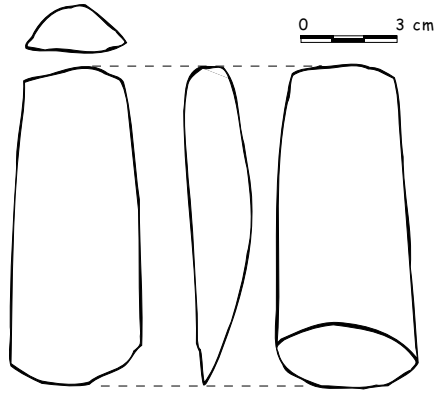

Subtype B3

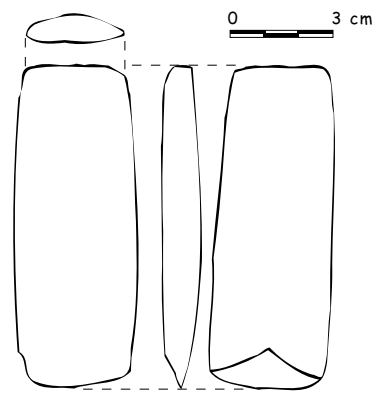

Subtype B4 
Other types (see Figure 11.46): Type C (7 items; 7.0-10.9 cm long): the upper surface is convex while the lower surface is flat. The cutting edge was formed from both the upper and lower surfaces. Type D (6 items; 7.7-10.6 cm long): the upper surface is convex while the lower surface is flat; the cutting edge was formed from the lower surface, and is narrower than the butt. Type $\mathrm{E}$ ( 2 items; $11.1-11.7 \mathrm{~cm}$ long): the lower surface is flat while the upper surface is slightly convex; the cutting edge was formed from the lower surface, and is wider than the butt; the sides of the tool are polished, and the butt is also polished to form a square. Type $F$ ( 3 items; 10.1 $13.8 \mathrm{~cm}$ long): the upper surface is convex, while the lower surface is flat; the cutting edge, formed from the lower surface, somewhat widens, while the butt is rounded. Type G ( 1 item; $15.4 \mathrm{~cm}$ long): both the upper and lower surfaces are convex; the butt is rounded and the cutting edge, formed from the lower surface, is slightly wider. Type H ( 1 item; $9.0 \mathrm{~cm}$ long): both the upper and lower surfaces are flat; the butt is smaller than the cutting edge, formed from both the upper and lower surfaces.

A total of 42 unpolished adzes $(4.3-21.5 \mathrm{~cm}$ long) were collected. Their features are in line with those of an adze, except that they remained unpolished.

Figure 11.46 Typology of stone adzes of the upper Bahau, $\mathrm{C}$ to $\mathrm{H}$

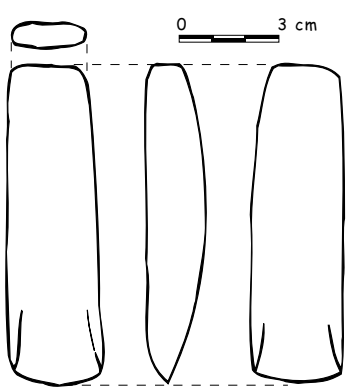

Type C

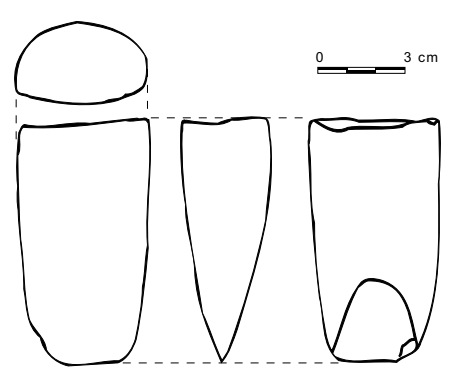

Type D

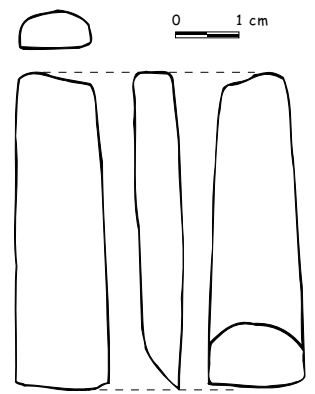

Type $\mathrm{E}$

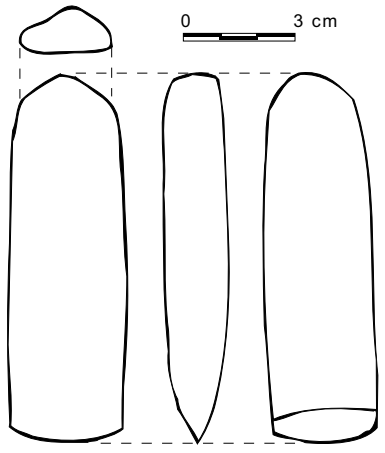

Type $\mathrm{F}$

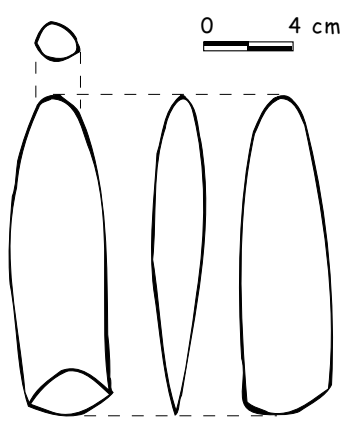

Type G

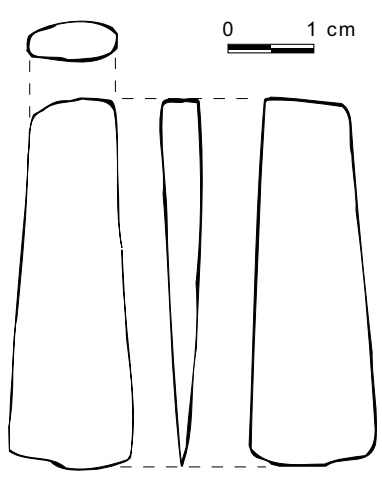

Type $\mathrm{H}$ 


\section{Other tools}

Gouges (2 items; $9.2-17.8 \mathrm{~cm}$ long; see Figure 11.47): the overall shape is elongated and rather convex, with the butt and cutting edge of the same width. The curved cutting edge is found on the lower part. Pounders (2 items; 12.2-14.1 cm long; see Figure 11.48): they are ovoid, with a butt smaller than the pounding end, which has a hollow centre and a rim forming a flat circle and is used for crushing (see Sellato 1996). Scraper (1 item, $7.5 \mathrm{~cm}$ long): it is rectangular with a thick butt and a pointed cutting edge, and both the upper and lower surfaces are flat. Sharpening stone (1 item; $9.1 \mathrm{~cm}$ long): it is thin and triangular, with a hole at the butt end. Unidentified (83 items; $2.6-13.8 \mathrm{~cm}$ long): various broken tools and pieces of worked basalt of unknown function and type.

\section{Pottery and Ceramics}

These finds are distinguished into local earthenware and foreign ceramics. The analysis is based on the analytical methods for pottery described by Wahyudi (1985).

\section{Local Earthenware}

The basic material is clay, but some pieces are made from clay mixed with lime. The clay, with a high iron content, is grey, black, or red. Low-temperature firing results in a coarse earthenware, whereas fine earthenware results from mediumtemperature firing. The tempers are sand and crushed earthenware. The technique used is hand modelling (for terminology, see Figure 11.36), and finger imprints are found on several earthenware shards.

At the end of the manufacturing process, a brushing technique was applied, which may have used straw, leaving fine lines visible on the pot's body. Pressure techniques of decoration were also used, employing paddles wrapped in string, resulting in lines whose width depended on the size of the string. Some very thick black shards of a container's body may have belonged to a metal-smelting container.
Figure 11.47 Stone gouge from the upper Bahau

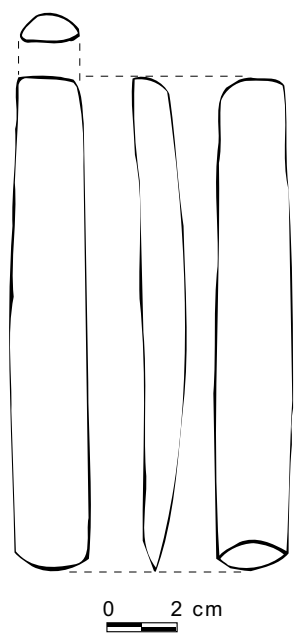

Figure 11.48 Stone pounder from the upper Bahau
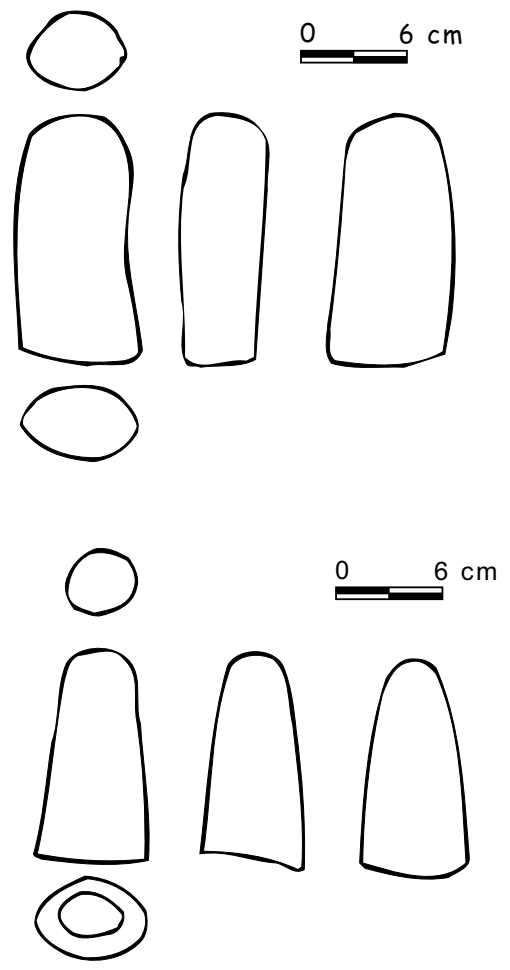
A total number of 676 shards included 7 pieces of black or grey, undecorated rims, with an open, straight, or closed angle, with a mouth diameter of 8 to $18 \mathrm{~cm}$; 1 piece of black ridge with line decoration, manufactured by the hand modelling technique; 182 pieces of grey, black, or red container body, plain or decorated with (thick or thin) lines made with a paddle wrapped with string (see Figures 11.41 and 11.42); 6 shards of smelting containers, black and undecorated; and 487 unidentified undecorated shards.

\section{Foreign Ceramics}

This category includes all shards of glazed, white or pale blue, kaolin base. From a total number of nine shards, 1 is a rim shard with a flower motif under the glaze, an open angle, and a probable diameter of $21 \mathrm{~cm}$ (possibly from a plate); 3 bottom shards, plain or decorated with floral motif under the glaze, one of which contains a factory mark which could not be clearly read (only a crown is visible); and 5 unidentified pieces with floral motif under the glaze.

\section{MEGALITHIC GRAVES: A SUMMARY}

The surveys that were carried out indicated differences in the form of the burial structures in the four subdistricts visited. In Long Pujungan, the graves generally consisted of stone urn-dolmens in various forms, but a few menhirs were also found, usually erected near graves. In Kerayan, two forms are known, the batu terupun (or perupun, pelepuun) and a type of urn-dolmen with a ceramic jar container, as well as a number of menhirs. So far, no stone burials have been found in Malinau where, instead, there are grave monuments made of wood and including ceramic jars. In Kayan Hulu, the most common burial container is a rectangular stone trough. This last subdistrict, however, will not be discussed in this summary.

\section{Pujungan Subdistrict}

The urn-dolmen burial structure (Figure 11.2) basically consists of a stone urn, standing on short stone pillars or blocks or directly on the ground, and covered with a flat stone (lid or cover). This container is protected by a dolmen consisting of several stone pillars supporting a large stone slab (the roof or table). The term urn-dolmen was coined by Schneeberger (1979). The materials used generally can be found in the vicinity of the grave, yet, in some cases they must have been carried from rather far away. The container and its lid, as well as a number of dome-shaped dolmen roofs, consist of medium-to-coarse-grained feldspatic sandstone of Cretaceous age. This rock formation is found in several locations, for example, on the Ngiam River and at Kiam Bio'. Many stone slabs which have been made into dolmen tables consist of Cretaceous siliceous siltstones or fine-grained sandstones, found along the length of the Bahau River. The pillars of the graves were made of whatever type of stone was available (Sellato 1995c).

The form of the structures varies significantly. For example, the cylindrical containers, found at Ka Tempu and Lepu'un Nyibun and reaching $1.5 \mathrm{~m}$ in height, apparently had not been protected by a dolmen, but only by a stone slab as a cover. The shape of the stone container also varies. Its mouth may be rectangular, oval, or circular, while its bottom is round. The rectangular containers found at Long Pulung 
and Long Lenjau Ca have a base smaller than their opening, so that their walls slope. The pillars may resemble a square beam, or be somewhat convex ('onion skin'), or just retain the natural shape of the stone used. There are also pillars of rectangular stone (e.g., at Long Tela'u), or made of carefully processed and shaped flat slabs (e.g., at Long Beraa). So far, only two carved stone graves have been found (Long Pulung and Ka Tempu).

The size of the graves, too, varies. The highest is $2 \mathrm{~m}$, with its container alone reaching $1 \mathrm{~m}$ in length. Yet, more commonly found are graves about $50 \mathrm{~cm}$ high. Near or attached to large structures are occasionally a number of smaller structures, seeming to form a cluster, as in Long Berini. Ceramic jars are also found, placed between the pillars of large stone urn-dolmens. The differences in the size and layout of the grave structures are thought to indicate status differences.

Ceramic jars were found at several sites, placed on the ground, or sometimes partly buried to prevent them from toppling. At Long Berini, a broken ceramic jar was located on the ground, enclosed by a ring of stone slabs slanting as if covering the $j$ ar. The various ceramic jars found as parts of stone burial structures in the Long Pujungan area still await identification with regard to their origins and age. Some have been identified as $18-19^{\text {th }}$ century Chinese jars, such as the rather common brown jars with dragon motif and the jars with four ears and two rows of protruding pegs underneath (Sellato 1995c). A number of jars with a red paste, coarse temper, and black lead glaze, originated from $15-17^{\text {th }}$ century Thailand or Burma (see Manguin 1995).

\section{Kerayan Subdistrict}

Here, too, a variety of burial structures are found. At Sungai Bulu and Sungai Kuyur, ceramic jars are often used as burial containers, and placed inside a square chamber of rectangular stone slabs with relatively straight edges and of even thickness; the chamber was covered with a stone slab. The only stone urn found was unique in that it had been carved to resemble a ceramic jar, complete with ears. At Sungai Bulu, a triangular stone pillar carved with a human form had been set up in one of the inside corners of the stone chamber $-a$ similar carving was found on the surface of a stone cropping out on the bank of the Kerayan River upstream from Tang La'an. The graves of Sungai Kuyur and Sungai Bulu seem to represent a specific form, which may be widespread in the Kerayan Hulu region. In the area of Kerayan Darat, the common grave structure is the batu terupun (or perupun, pelepuun), a large dolmen made of stone slabs reaching $2 \mathrm{~m}$ in length and $1 \mathrm{~m}$ in width, erected on a heap of river stones.

Several stones stand alone, both rectangular pillars (menhirs) and flat slabs. At Terang Baru, for example, several stone slabs had been erected in the ground as markers of the village, the church, or something else. Very likely, in the Kerayan Darat area, these slabs were formerly part of a dolmen structure. For example, one pillar of a batu terupun in Pa' Api has been moved to the edge of the football field to be erected as a village marker. In the Kerayan Hulu area (e.g., at Tang La'an), several tall menhirs clearly had not been part of a dolmen structure.

\section{Malinau District}

The grave structures here are made of large wooden beams, yet their construction and their function are reminiscent of the megalithic structures in other districts. The same is true of the burial structure of the Nyibun people-a large wooden post supporting 
a ceramic jar containing human bones-which seems to represent a sequel to the tradition of the stone structures. It may be guessed that the use of stone as construction material for graves does not only depend on the local traditions, but also on the availability of the materials. A shortage of stone of the right type does not mean, however, that a community must abandon its tradition of megalithic structures. In the Kerayan area, for example, the large stone slabs used in the batu terupun must have been brought there from a rather distant area. It must be asked why some people stopped building megalithic graves, even though the underlying ideas persisted. It is also possible that an important change in social structure caused the abandonment of the megalithic tradition, so that the stone burial structures were replaced with wooden ones.

\section{Further Research}

The test pits dug at two former Ngorek settlement sites (Apau Ping and Long Beraa) did not show distinct cultural layers. It was possible, however, to determine differences in the types of artefacts, especially with regard to the basalt tools and the earthenware. Further surveys of other settlement sites are needed to determine their size, characteristics, and environment, before selecting some for excavation. Further surveys should also focus on cave sites, to obtain a better picture of their types, morphology, and distribution, before test pits or true excavations begin. Extension work should be performed among the local people regarding the protection and preservation of archaeological remains in their regions, in order to protect the sites and prevent further destruction. This is also important for inducing pride and a feeling of ownership regarding these historic monuments among the villagers, who so far do not understand their significance. 


\title{
12. \\ Kenyah Bakung oral literature: An introduction
}

\author{
C. Yus Ngabut
}

\section{INTRODUCTION}

This contribution focuses on the Kenyah Bakung who are at present living in the village of Long Apan Baru (Long Aran) in the district of Puj ungan. These people originally came from Lasan Adie (Iwan River) and subsequently moved to Long Bakung on the Pujungan River (on the history of the Bakung, see Ngindra, in Eghenter and Sellato 1999, and Rousseau 1990). More recently, a group of Bakung living in Long Apan (on the Lurah River) finally moved to Long Aran in about 1969. Because they came from Long Apan, the village of Long Aran is better known as Long Apan Baru. From Long Aran, some of the people moved again to Sa'jau, while others moved to Long Bang on the lower Kayan River.

So far, the oral literature of the Bakung has been little documented. In 1992, Paternus Hanye was able to examine some examples of oral literature and made some cassette recordings (see Hanye 1995). Yet, it is almost certain that this literature will disappear if no efforts are made to preserve it. Today, only very few people remain who have mastered the literature, and they are generally already advanced in age. The younger generations appear to be uninterested in this heritage. Furthermore, the occasions for using the literature have decreased considerably as the traditional adat and religion have been abandoned by the Bakung themselves. Thus, it is clear that the oral literature of the Bakung must be studied and recorded and efforts be made to save it from extinction. It is hoped that this article will be of use in drawing attention to this rich and imperilled heritage. 
The research is intended to 1 ) inventory the types of oral literature in existence; 2) learn the position and the function of oral literature; 3) save the tekena' (folktales) of the Bakung from disappearance by recording, transcribing, and translating various types of tekena' into Indonesian; 4) analyse and describe basic themes and the characters and characterisation in the tekena'; 5) return the literary manuscripts to the Bakung in the form of printed books; and 6) stimulate interest among the Bakung themselves in taking over the preservation of their own oral literature. It is hoped that this article can contribute to the efforts of the Culture \& Conservation Program in preserving the oral literature of the Kenyah, and especially that the Kenyah themselves will eventually take over the preservation efforts. ${ }^{1}$

\section{The Body of Oral Literature}

Because of the short research time, the writer restricted himself to studying the prose known as tekena'. Nine texts were recorded, but as the writer's assistants were not much available and the writer himself had but a limited command of the Bakung language, not all of them have been transcribed. In addition to these recordings, the writer was also able to obtain two tekena' recorded by Hanye in 1991. The tekena' that could be transcribed and freely translated are Tekena' Laking Kuyang ngan Lenjau, Tekena' J alung Merang, and Tekena' Balan Tempau. Some tekena' were only transcribed and translated literally: Tekena' Tamen Burin Batu Tusan, Tekena' Sigau Belawan, and Tekena' Payau ngan Pelanuk. Other texts were only transcribed: Tekena' Uyau Apan, Tekena' Mering Belawan, and Tekena' Baya' ngan Lenjau. For one, the Tekena' Uyau Apan, an abstract had been made by Hanye (1995), and for two more, abstracts were made by the researcher and informants.

Some texts were not transcribed-Tekena' Sigau Belawan ngan Jalung Ila and Tekena' Mending Orang Sakit. The former, as its title resembles that of other texts already translated (Tekena' Sigau Belawan and Tekena' Balan Tempau), is believed to tell the same story as these two other texts, staging the same individual hero, J alung Ila. As for the latter, it is not a pure tekena', since its content describes the mending ceremony for treating the sick (see Ngindra 1995b and in Eghenter and Sellato 1999).

\section{Research Methodology}

The writer's informants were native speakers of the Bakung language, who lived in the village of Long Aran. The writer first sought information regarding potential informants, and the informants finally selected were a number of old people who could still tell the stories well, without difficulties in speaking. The writer visited the informants by appointment in the evenings to record them. To gather additional information regarding types of oral literature and the situation of the Bakung generally, informal interviews were conducted with informants while they were casually relaxing

\footnotetext{
${ }^{1}$ A large quantity of recordings of Bakung oral literature (and also of the literatures of other Kenyah subgroups in the area) were made during the years of the Culture $\&$ Conservation Program. A substantial part of them has been transcribed, at least cursorily, and some translated into Indonesian. One, at least, the story of Laking Kuyang ngan Lenjau, was published as an illustrated booklet (1997) with both the Bakung and Indonesian texts, for use in elementary schools in the area. Furthermore, in the framework of the $C \& C$ program, Stephanie Morgan produced a preliminary Bakung-Indonesian dictionary (1996), the only existing dictionary of a Kenyah language in Kalimantan to date.
} 
at home, planting in the fields, and on other occasions that did not interfere with the informants' activities. While interviewing, the researcher did not use any electronic recording equipment.

Data gathered through recordings were subsequently processed in three stages: transcription, translation, and analysis. The writer was assisted by four persons: one main assistant for transcription and translation, one person who helped transcribing only one tekena', and two others for literal translation. The free translation and the writing of the abstract were done by the writer. In this article, only the three tekena' that had passed through the stage of free translation are analysed (see the abstracts of these three tekena' in the Appendix). They are Tekena' Laking Kuyang ngan Lenjau (The Orangutan and the Tiger), Tekena' J alung Merang (The Story of J alung Merang), and Tekena' Balan Tempau (The Story of Balan Tempau).

After the transcription had been done solely by the writer's assistant, it was checked by the writer, who again listened to the cassette. For translation needs, the transcription was also used by the writer's colleagues, i.e., language specialists, in their studies of Bakung phonology, morphology, and syntax, and it represents a contribution to the vocabulary of the Bakung dictionary (see Sri Munawarah 1995, Morgan et al. 1996). The translation of the tekena' was done in two stages, beginning with a word-for-word literal translation, followed by a free translation. The literal translation was used as a step toward the final goal, a free translation acceptable to general readers. When the writer studied the literal translation of the tekena', it was clear that certain aspects-usually found at the beginning and simultaneously serving as an introduction-did not need to be retained. In the final transcription and translation, these aspects were omitted because they did not contribute to the completeness of the story, or facilitate enjoyment of the story. Nevertheless, this information was retained in the recording and in the early transcription and translation to document the process toward the final transcription and translation.

The following quotations from Tekena' Jalung Merang illustrate the process in which the data were treated. The first line is a transcription in the Bakung language, the second is a word-for-word translation, and the third line is the free translation in Indonesian (followed in the fourth line by the English translation).

(1) Aun ne dau Jalung Merang mudip kiang batu tusan

Adapun si J alung Merang hidup di tebing batu jurang

Jalung Merang hidup dan

J alung Merang lived and

(2) mudip kapau le' mande lepusut bunyau jangin nuyan

hidup di atas gunung kata mereka jeruk pegunungan tembaga buatan

tinggal di daratan sebuah pegunungan.

made his home on a flat in the mountainous highlands

(3) Uba' ketai umen selai mendang liran le mande

ingin pergi merantau melihat-lihat orang yang kata mereka

la ingin pergi merantau untuk melihat-lihat orang yang tinggal

He wanted to travel and visit the people who lived 
(4) $\mathrm{ri}^{\prime}$ ke daya alo Mara rene' kanan nde' mande. Nane

di hulu arus sungai Mara yang dipakai kata mereka. Itulah

di daerah hulu Sungai Mara. la

on the Upper Mara River. He

(5) dau katai pisu inai re nguleng jelai latung pudan.

pergi tanya namanya kalung jelai perhiasan badan.

menanyakan ibunya apakah ia diperbolehkan.

went and asked his mother for permission.

The analysis of the tekena' contents was aimed at finding themes, protagonists, and characterisations in the various stories. In addition, the analysis was also used to determine connections between the stories' content, themes, and protagonists and their titles and social and natural environmental conditions at present and in the past.

\section{ORAL LITERATURE OF THE BAKUNG}

The oral literature of the Bakung comprises those literary works of the Bakung speaking people, which are passed from mouth to mouth, spread orally and anonymously, and which describe the life of the Bakung in the past.

\section{Position and Function}

As a regional literature, the oral literature of the Bakung has four functions. First, it is a means of entertainment and is used to fill free time. The literature meant to meet this function usually is funny and humorous, such as is found in legends. Second, it serves as a means of education and of transmitting ancestral values. Stories serving this function are useful, not only for children but also for adults and old people. Stories of this type usually display positive values that are suitable for handing down, as well as undesirable values and attitudes that must eliminated. Third, it serves as a means of stating intentions and declaring wishes in connection with magical forces. For this, the oral literary forms used are mantra, used when fishing, taking honey, and treating the sick (mending ceremony). Fourth, it serves to tighten the relationship or acquaintance with a newcomer, which is usually done through singing (kendau or tiang).

\section{Genres of Oral Literature}

Among the genres in prose of the oral literature of the Bakung are tekena' (folktales), ngidau (lamenting the dead or saying a mantra when treating a patient), bon-bon usa talon (when taking honey from a tall tree), tuba la'it tuba sanit (when catching fish using tuba poison), and kelap ta' penyakit kini (to drive out evil spirits from the village; see Hanye 1995).

The tekena' that have been collected (see Figure 12.1) can be divided into two categories: heroic tekena' (epics) and regular, entertaining tekena'. Heroic tekena' in fact are neither myths nor legends, nor are they fairy tales. The titles of some heroic tekena' are Tamen Burin Batu Tusan, Mering Belawan, Balan Tempau, and Baya' ngan Lenjau; while the titles of entertaining tekena' are Sigau Belawan, J alung Merang, Laking Kuyang ngan Lenjau, and Payau ngan Pelanuk. Three tekena' seem to be fables, featuring animal characters: Laking Kuyau ngan Lenjau (The Orangutan and the Tiger), 
Payau ngan Pelanuk (The Deer and the Mouse Deer), and Baya' ngan Lenjau (The Crocodile and the Tiger). In fact, however, only the Tekena' Payau ngan Pelanuk is an animal story. In the case of the other two, the indications of the titles are not followed through in the content of the stories.

Figure 12.1 Pui PeAnye' Usat singing a tekena' in the usual lying position

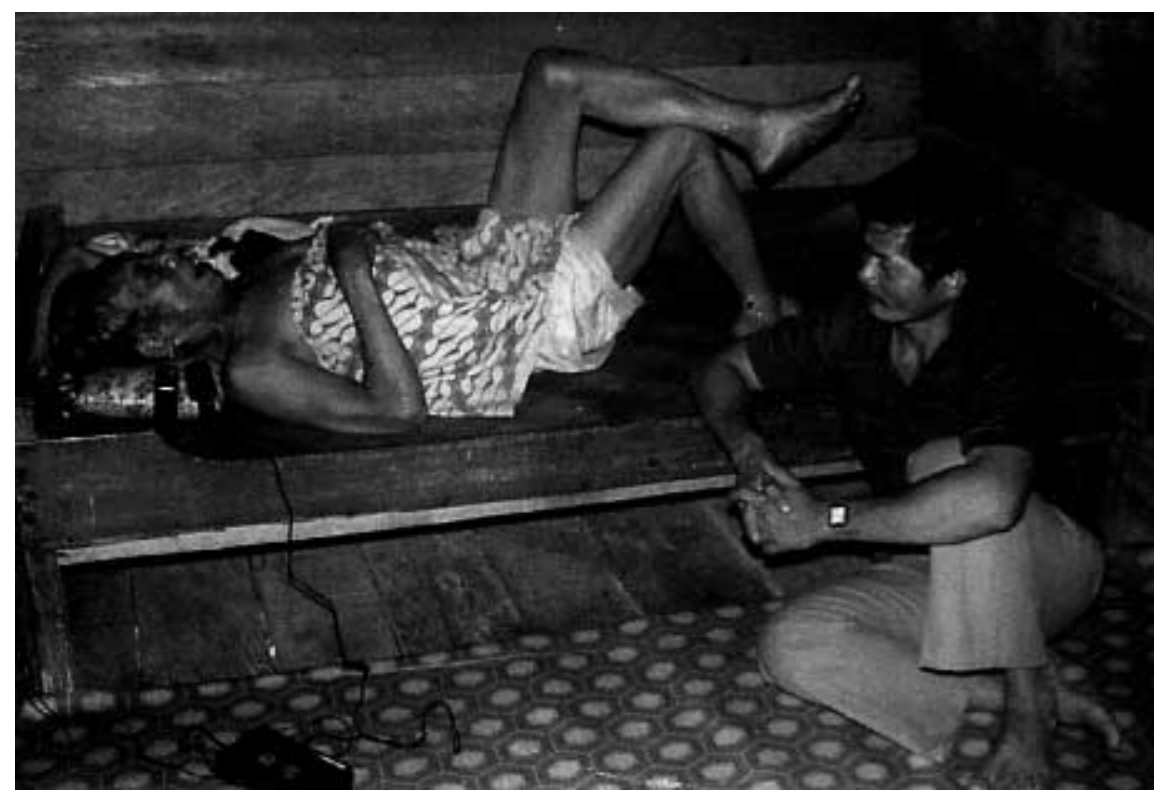

Poetry, as a literary form, can be divided into two categories, the kendau and the tiang (see Figure 12.2). Both forms are songs and are only distinguished according to the number of participants. If a song is performed by a solo singer, it is called kendau; if more than one singer is involved, it is a tiang. Both kendau and tiang are usually performed when receiving guests or as special performances when getting acquainted. Sometimes kendau are sung while people are relaxing. The content of kendau and tiang is generally fitted to the situation, including a focus on the person for whom the song is sung.

Tekena', as a lyrical genre, are prose that have been turned into song. Basically, all tekena' can be grouped into the two categories above, because the singers use songs and rhythm in telling a story, in an effort to beautify and add interest to the content of the story. In telling a tekena', singers tend to slip into silun, which are certain parts of the story especially made into songs. The telling of tekena' with song and rhythm as grouped according to these lyrics depends very much on the style and the abilities of the singer himself. The researcher's main informant, Aga La'ing (better known as PeNgang), who had a special secret for telling tekena', used songs and followed a beat from the beginning to the end of the story. 
Figure 12.2 A singer performing and recording a tiang or kendau song

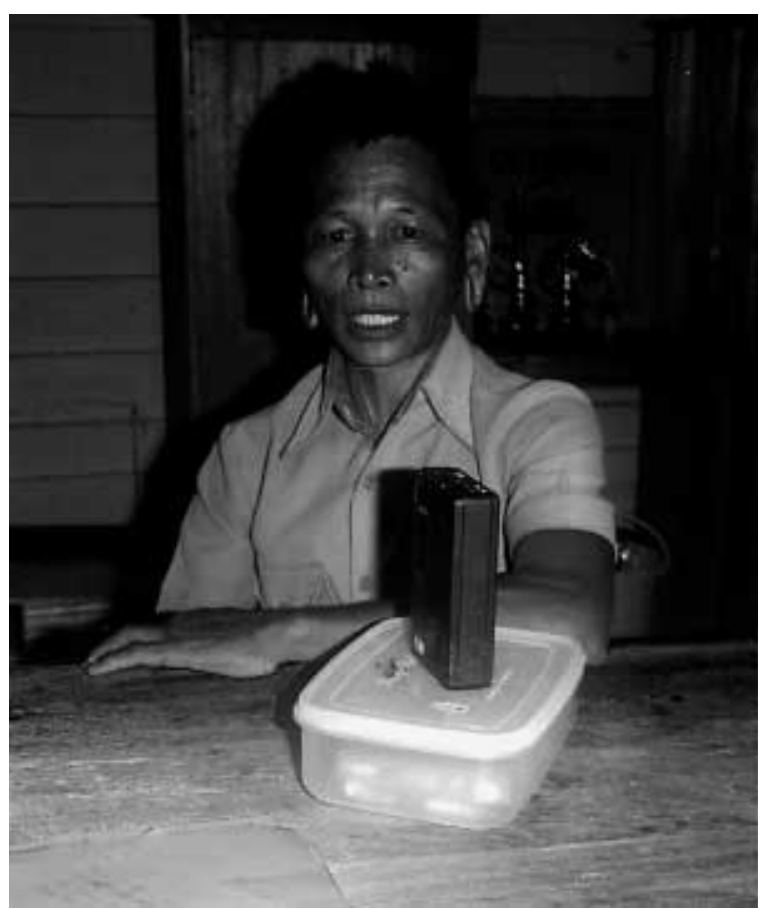

\section{ANALYSIS OF TEKENA' CONTENTS}

Below will be discussed the themes, the protagonists, and the characterisation, the relationship of the content of tekena' with tradition and social conditions in the past and at present, and, finally, the relationship of society to its natural environment. The full stories appear in the Appendix.

\section{Tekena' Themes}

The theme is a problem or an idea that the writer expresses through his literary work. A theme reflects the writer's view of life or his goals. Every tekena' has a basic theme that is supported by subthemes or secondary themes. The present analysis, then, will endeavour to describe the basic themes and the supporting themes of the three tekena' for which free translations were completed.

\section{Tekena' Laking Kuyang ngan Lenjau}

In this story of the Orangutan and the Tiger, the basic theme, 'A real effort will have the expected result', is evident in Belawan Lenjau's longing to meet his father, a goal pursued through persistent efforts to trace his father. He makes this effort because he has never known his father, who vanished while hunting for the feast to name his 
son, and because his friends ridiculed him as an illegitimate child. In the end, he meets his father and is appointed a paren (leader) of his father's longhouse by its inhabitants.

Secondary themes are 'Arrogance will bring disaster' and 'Unexpected benefits'. The first is expressed in the arrogance of Lenjau (Tiger), who considers Laking Kuyang (Orangutan) incapable of defeating him in a fight over the traditional territory of their ancestors. Orangutan repeatedly offers peace and says that war is not the best way to settle a problem. When they finally do go to war, Orangutan defeats Tiger by throwing him into the middle of the a great and deep river, where he immediately sinks to the bottom. Unexpectedly, Tiger lands on the veranda of the house of Baya' (Crocodile), who has a daughter named Bungan Baya'. This girl is amazed at the handsome Tiger and endeavours to make him her husband. In the end, they marry and have a child named Belawan Lenjau. These events represent the second subsidiary theme.

\section{Tekena' J alung Merang}

The basic theme, 'Friendship and restraint of feelings are more important than hostility', is expressed at the time of J alung Bilung's (J B) arrival. The hero from the mouth of the Mara Rian River stops at J alung Merang's (J M) village on his way to ask for the hand of the beautiful Urai Belawan on the upper Mara Rian. J M had previously asked his mother for permission to go and woo Urai Belawan, but his mother was not ready to allow this because she still needed his help for the farm work. When he hears the reason for J B's arrival, JM is very angry with his mother, and when JB asks him to come along, he refuses on the grounds that he $(J M)$ is busy. Although he is very angry and annoyed, JM does not say anything to JB. His hostility develops after J B and his friends leave next day, but JM does not say anything openly. With the help of his mother's magic powers, he changes himself into a hornbill and the rope of his machete into a tudo' bala pipa bala (a snake with a red tail and head), a very bad omen that forces J B to abort his journey. Starting on his own journey, J M flies upriver and asks for Urai Belawan's hand.

When J B finally reaches the upper Mara Rian River to ask for his beloved Urai Belawan, he develops feelings of hostility when he learns that J $M$ has already married her. J $B$ has no reason to be angry at J $M$, because he never clearly stated the goal of his journey. In the end, the latent hostility ends with feeling of friendship and the establishment of family ties when JB marries J M's sister.

The secondary theme, 'Marriage partners are determined by Fate', is expressed in the fact that we learn that the parents of Urai Belawan had already, since her childhood, promised her to J M's parents. So it was not by chance that J M, who assumed the shape of a hornbill, became their daughter's husband. If J B had succeeded in arriving first, the agreement already made with the parents of J M would necessarily have been violated.

\section{Tekena' Balan Tempau}

The basic theme of this story is 'If there is a will, there certainly will be a way.' It is expressed in the complications of the struggle and journey of Uyau Balan Tempau in search of the enemy who abducted his wife almost without leaving a trace, until he finally meets an old woman in a dream. She tells him that his wife's abductor came 
from the sky, and she orders him to make a blowgun with as many darts as possible. Failing repeatedly, because the darts cannot hit the sun, Balan Tempau finally remembers his wife's belongings and, among them, he finds three large needles. He makes these into arrows, which finally hit the sun. The three arrows are connected to the other arrows to form a ladder leading to the sky.

After he has managed to reach the sky and arrives at the sun, he meets Ulau Tau (the Protector of the Sun), who helps him by advising him to pursue J alung Ila. On his journey, he unexpectedly meets his older sister, who was abducted long ago by Kiring Jalung. His sister and brother-in-law then fix Balan Tempau with magic to enable him to defeat his enemy. He finally finds Mening Nyanding, his wife, whom J alung lla has not been able to convince to become his wife. Very determined, he then kills all the residents of J alung Ila's longhouse, and kills J alung lla himself by tying a rope around his neck. He and his wife return to earth, bringing along all valuables in a flying boat.

Secondary themes are 'Crime is repaid in like measure', 'Arrogance brings disaster', 'Negligence brings disaster', and 'Unexpected meetings'. The first is expressed in the defeat of Jalung Ila in his war with Balan Tempau. The second is evident in the arrogance of the father of Usun Garing Luran and Awing Liwen, who underestimates Uyau Balan Tempau's capabilities in claiming invincibility. In the end, however, he is killed by Uyau Balan Tempau. The third theme is expressed in the carelessness of Mening Nyanding, the wife of Uyau Balan Tempau, who mentions Uyau Mo's name when he pretends to be Uyau Balan Tempau. This carelessness revives the enemies' courage and they kill Uyau Mo' who was about to win the fight. The enemies actually were about to surrender or flee, because the power of Uyau Balan Tempau was already widely known. Because of this blunder, Uyau Mo' is killed and Mening Nyanding is carried off to the sky. The fourth theme is the unexpected meeting of Balan Tempau with his older sister. The two had never met before because she was kidnapped long before Balan Tempau was born. As a result of this meeting, Balan Tempau obtains special powers from his relatives and is able to deal with all challenges and enemies.

\section{Characters and Characterisation}

The characters in the tekena' stories of the Bakung are consistent with the titles, when these reflect the story's basic content. This analysis will discuss the protagonists, as well as the supporting characters.

\section{Tekena' Laking Kuyang ngan Lenj au}

The characters in this story, as indicated by the title, are Laking Kuyang (Orangutan) and Lenjau (Tiger), as well as others, such as Belawan Lenjau, the son of Lenjau. A supporting character is Bungan Baya', the mother of Belawan Lenjau.

Laking Kuyang is a character who is not arrogant because of his power, which is invisible to others. Instead, he is humble and maintains that he is not good in war. Continuously pressured by Lenjau to fight, he is finally forced to accept the challenge. He wins the fight by throwing Lenjau far out into a large river. Lenjau, on the other hand, feels that he is much stronger than Laking Kuyang and continues to challenge him to fight, until he is finally defeated. Lenjau is still lucky because when he is thrown into the river, he lands on the veranda of the house of Bungan Baya', daughter of the Crocodile, and falls in love with her. 
Belawan Lenjau, the son of Lenjau and Bungan Baya', is a strong and determined figure who searches for his father, whom he does not know. His search bears fruit, and he finally meets his father in his home village, where he is appointed leader of a longhouse. Bungan Baya' represents someone who unexpectedly meets her life partner. In the beginning, she is lucky but eventually she is abandoned by her husband while he is hunting to procure food for their child's naming ceremony. She is startled when her son asks who and where is father is and then sets out to find him.

\section{Tekena' J alung Merang}

The main characters in this story are J alung Merang, Jalung Bilung, and Urai Belawan, while J alung Merang's mother is a supporting character. Jalung Merang is strong and determined to woo Urai Belawan, who is famous for her beauty. He forces his mother to allow him to ask for Urai's hand, even though she has in fact already been promised to him since childhood. He has sufficient self-restraint and does not tell J alung Bilung that he also wants Urai Belawan. Taking the shape of a hornbill, he is able to defeat the purpose of J alung Bilung's journey to ask for her. He then flies to the upper Mara Rian and, in his bird form, he is captured by Urai Belawan and at once returns to his human form.

J alung Bilung is able to restrain his jealous feelings and nurtures great feelings of friendship. On his first journey to ask for Urai Belawan, he stops overnight in the house of J alung Merang and asks him to come along. When his journey is aborted by bad omens, he again stops, on his second trip, at J alung Merang's house. He shows restraint in not becoming angry immediately when he learns that Urai Belawan has already become the wife of Jalung Merang. His feelings of friendship return with his readiness to marry the younger sister of Jalung Merang. Urai Belawan is a pretty and polite girl. She is not aware of the competition between Jalung Merang and Jalung Bilung over her. Jalung Merang's mother is a woman who pays close attention to the interests of her son. She feels that she was wrong in delaying her son's departure to ask for the girl he loves. And so, she magically turns her son into a hornbill to enable him to fly after J alung Bilung. To defeat the purpose of J alung Bilung's trip and to smooth the road for her son, J alung Merang's mother tells her son to read a mantra to turn the string on his sword into a snake with a red head and tail. This type of snake is a sign that a journey cannot be continued.

\section{Tekena' Balan Tempau}

The main characters in this story are Uyau Balan Tempau, the father of Usun Garing Luran and Awing Liwen, Mening Nyanding, and J alung Ila. Supporting characters are Uyau Mo', Ulau Tau, Kirin Jalung, and his wife. Uyau Balan Tempau is a strong and confident figure, who is convinced that he will be able to persuade the father of Usun Garing Luran and Awing Liwen (and the murderer of his father) and to find the man who carried off his wife and that he will be able to kill them. The father of Usun Garing Luran and Awing Liwen (two girls living on a beran tree) tends to underestimate the strength of his enemies. He is convinced that he is invincible. Because of this attitude, he eventually loses the struggle with Uyau Balan Tempau.

Mening Nyanding, the wife of Balan Tempau is careless in the beginning, when she says: 'Never mind, Uyau Mo', let's run away', even though the enemy already has accepted his claim that he is Uyau Balan Tempau. This carelessness on the part of 
Mening Nyanding has a fatal outcome, i.e., Uyau Mo' is killed and Mening herself is carried off to the sky. She dares to defend her love for her husband and does not want to be touched by J alung Ila, and for approximately one year she remains on the veranda of J alung Ila's house until her husband arrives. Jalung lla does not understand why Mening Nyanding suddenly changes behaviour. He does not suspect that people from earth like Uyau Balan Tempau can pursue him up to the sky.

Uyau Mo' believes that people will waver before Uyau Balan Tempau. By claiming to be Uyau Balan Tempau, he confuses the enemies and fights them. He is almost able to defeat all the enemies, when his identity is revealed, and they no longer fear him. Ulau Tau, as the guardian of the sun, is a kind person and helps Balan Tempau, when he faints from the heat, by cooking porridge for him. After Balan Tempau regains his strength, Ulau Tau shows him the direction in which he must go.

It is appropriate for Kiring J alung and his wife to help her younger brother. J alung Kiring's wife, older sister of Balan Tempau, was kidnapped long ago and carried off to the sky. These two people do not want to let her brother leave until they are sure that he can defeat J alung lla. They give him special powers to enable him to defeat J alung and take his wife back home to earth.

\section{Relationship to Society in the Past}

Through the tekena' that have been handed down from generation to generation, the social conditions and traditions of the Bakung can be studied.

The name of a child is always followed by the name of his or her father. Thus, even though two Kenyah persons may have the same second name, they are not necessarily siblings. It is possible that two people have given their children the same name. In the past, the use of teknonyms, such as uko' (grandfather), tamen (father), tinen (mother), and of necronyms, such as uyau (orphan), was prevalent among the Bakung. Children were given names in a ceremony for which the basic food requirements (meat, fish, vegetables, and fruits) were gathered cooperatively (pengayeng) by the people. Pengayeng was used because the people did in fact live together in a longhouse. Marriages were arranged by parents when the children were still young, as was the case in the marriage of J alung Merang and Urai Belawan.

Interethnic wars were frequent. Wars were fought over land rights or settlements, or because of a wish to test the ability or defend the honour of a group, a wish for revenge, and so on. War, better known as mengayau, cannot be equated with savagery, as is often done by outsiders. The movement of people from one village to another resulted from the wishes of the paren to be leaders, from feelings of insecurity, from misfortune, or from defeat in war (in Tekena' Balan Tempau and Tekena' Tamen Burin Batu Tusan).

Ceremonies of meeting with or parting from a guest or outsiders were often accompanied by dances. Usually, the host first demonstrated his dancing ability, both in solo dances and in group dancing, and then gave the guest an opportunity to dance (see Figures 12.3 and 12.4). All present were expected to participate in these dancing activities. Invitations for wedding ceremonies, meeting guests, or other social activities were delivered orally. This task was carried out by Asang (a kind of assistant/ messenger). When calling for meetings to decide on important matters, such as war plans, the paren (leaders of the longhouse) beat a drum on a beat that the people recognised. 
Figure 12.3 An elderly Bakung chief, PeNcuk, in his warrior's attire, now used in dancing

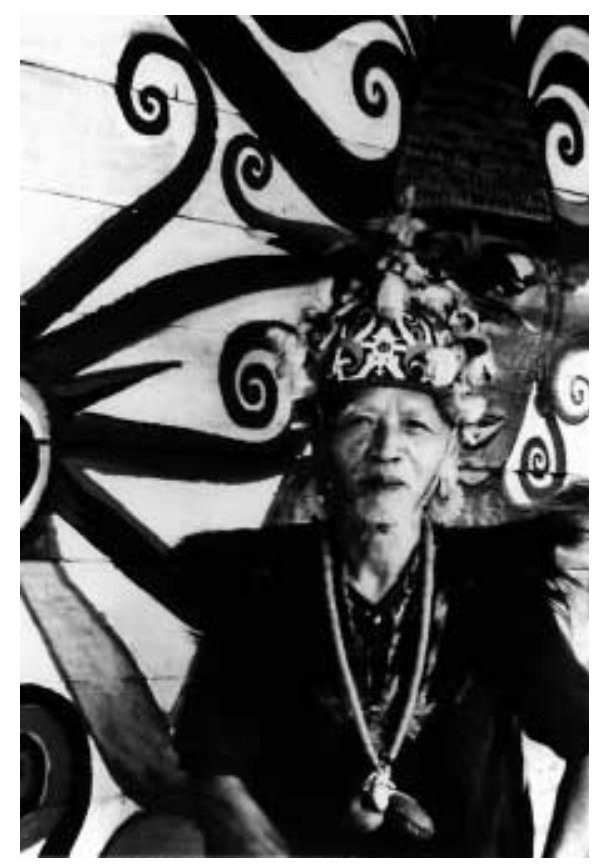

Figure 12.4 A Bakung girl in dancing attire, ready to perform

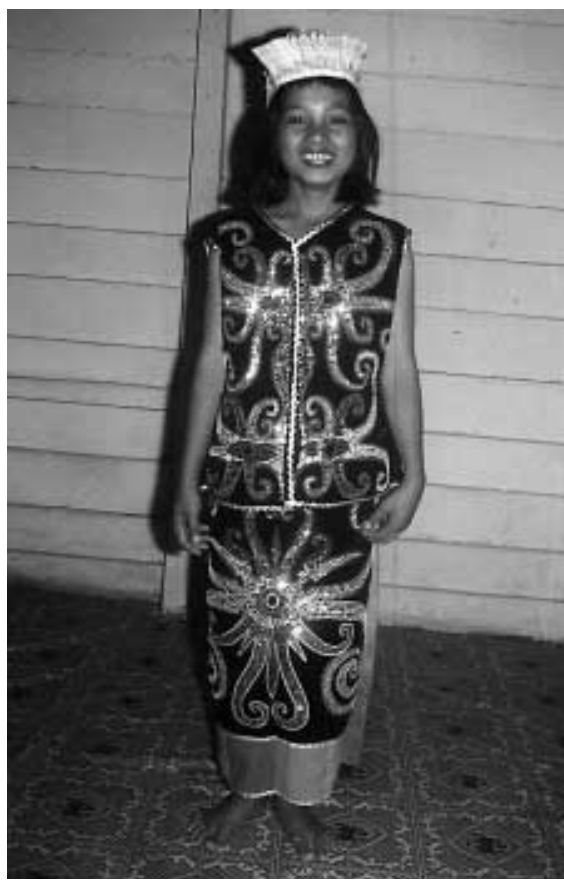

Tolerance or restraint and feelings of friendship were very strong within the community. The people joined in greeting and sending off guests. Problems between individuals were not mentioned directly to the person involved. In war, people who considered themselves invincible preferred that those who came to attack them abort their plans (cf. the father of Usun and Awing Liwen with regard to Uyau Balan Tempau and his group). Friendship and restraint were also expressed in the behaviour of characters toward people who had been killed, yet were not considered as having been wrong. These people who were not wrong were revived through magic by Balan Tempau and the father of Burin Batu Tusan.

Popular belief in omens (amen-amen) and dreams as guidelines for those involved was very strong. This was related to adat customs, like the calling of certain animals such as the kite (pelaki) and isit to ask for advice. Neglecting adat may have a fatal result for someone, as in the case of the death of Mering Belawan in the war against the father of Usun and Awing Liwen. The same was true for the popular belief in prohibitions or taboos. A journey had to be abandoned if the traveller met a snake with a red head and tail (tudo' bala pipa bala). If someone was departing for war, a white rooster was sacrificed and its blood rubbed on his arms to prevent sickness. Victory in war was always celebrated with a mamat festival (the greatest adat ceremony). When conditions were difficult, the people believed in mantras and in the readiness of the ancestors to help their descendants. For example, Balan Tempau in his effort to destroy the war gear of his enemy, the father of Usun and Awing Liwen, who has a glowing fire, calls on the ancestral spirits Uko' Baya (Grandfather or Grandmother Crocodile) and asks for wet clothing. 


\section{Relevance to Modern Social Conditions}

The social conditions and the traditions of the past still have an influence on modern social conditions. Several facts found in the tekena' still apply today.

The belief that the paren symbolically are the descendants of strong and powerful animals is still evident in the tendency of parents to name children Baya' (Crocodile), Lenjau (Tiger), and so on. A child's name is always followed by the name of his father, and there is as yet no effort to adopt one name as a family name. Similarly, teknonyms and necronyms are still used consistently.

Forms of cooperation such as village collective work (Indonesian gotong royong) are maintained in almost all aspects of social life, and the social awareness of the people is rather high. They join together to help if any member of the community needs assistance, as for example in building a house. This is also true for farming, hunting, and other activities. Even though the longhouse organisation no longer exists in Long Apan Baru, its basic characteristics endure. The villagers formerly were part of one longhouse, which eventually split up into three longhouses. Today these three longhouses are recognised in three blocks of individual houses (Block I, II, and III; the Block is an administrative unit on the same level as an RT, Rukun Tetangga, or neighbourhood unit).

Ceremonies introducing or seeing off guests with dancing are still found, but they have been brought in line with modern conditions. Invitations for village meetings are delivered orally by a messenger or pelawa, who runs through the whole village shouting the invitation. The pelawa who replaced the dignitary Asang in the tekena' is paid in kind.

Friendship is expressed by collectively seeing off someone about to depart, and gifts no matter how small are often given to acquaintances whom one may not meet again. Restraint and friendship are still cultivated among the people. A person who is thought to have violated adat and must be fined will not personally attend the meeting of the village officials. The decision of the meeting is delivered to the individual concerned by one or two messengers, while the meeting rests awaiting the response of the accused. Only after that does the meeting continue.

\section{Relationship to Nature in the Past and Today}

Several aspects of the relationship between society and the natural environment in the past can be seen in the tekena'. Nature provides various facilities for meeting the daily necessities of society, such as meat, fish, vegetables, fruits, and various other useful articles, which the people can obtain easily. The people use objects in space (the sun and the moon) to determine the farming schedule: for example, they set up a palan tau (gnomon, a pole to measure shadows at noon) to determine when to begin planting; and the phase of the moon is also observed.

The tekena' indicate a close and harmonious relationship between man and animals and among animals. Man and animals seem to speak the same language and are able to help each other. Because of this connection, land animals can live in harmony with river animals. They can even marry and have human offspring. Not surprisingly, in the tekena', human beings turning into animals and the reverse is common. Birds often help people to overcome the problems facing them. In several tekena', the kite, isit, hornbill, as well as the chicken, help or advise human beings about what they must do, even showing them how to reach the sky. The hornbill (temengang) is the best friend of human beings, as is often stated in the silun. 
The content of the tekena' shows that, today, nature still continues to provide various means for meeting social and individual needs. The harvest of the fields is always adequate as long as people make a satisfactory effort. The same is true for the product of the hunt, or other forest products. Even though all the residents of Long Aran have already abandoned the old beliefs, remnants of these beliefs are still found in present-day society, as for example in setting up a palan tau in front of the house of one of the residents to determine the beginning of the planting season. These beliefs clearly are related to the fertility of the soil and the eventual product of the harvest.

The same applies to the belief that the harvest will fail if a woman gives birth unexpectedly in the hut of another person. The offender must inform the village head and pay a fine of two machetes to the owner of the hut, in hopes of expunging the violation and thereby annulling its effect on the harvest.

\section{CONCLUSION}

The analysis of the tekena' contents above, in fact, only serves a subsidiary purpose. The main purpose of the research is to save the tekena' from extinction. The product of our work in recording, transcribing, and translating such oral texts will later be returned to the Bakung people. Further research must be done to seek more accurate and more precise information from informants through interviews or other promising techniques. This article, it is hoped, will stimulate the interest of members of the Bakung community themselves, to study and value more highly their own culture. Because the research team came from outside, it could not possibly remain very long at the location, and it would be a of great advantage if the collection and preservation of oral literature were done by people who are native speakers of the language of that literature. For this purpose, special training in collecting and preserving oral literature should be given to those interested parties who have helped so far to make the research a success, including, among others, Noh La'ing and Gun Upa.

\section{ACKNOWLEDGEMENTS}

The author wishes to express his gratitude to the tekena' performers (PeNgang, PeDate Upa, PeNjau Igau, and Pui PeDau La'ing), his assistants (Gun Upa, Yamos Ncuk, Hendri Lie, Imang Usat), and all the people of Long Apan Baru. 


\section{APPENDIX}

\section{Tekena' Laking Kuyang ngan Lenjau (Orangutan and Tiger), Abstract}

An orangutan and a tiger lived and worked for their livelihood in the area inherited from their ancestors. Each of them claimed the area belonged to him. The tiger invited the orangutan to fight for the area, but the orangutan refused on the grounds that he could not fight. The tiger continued to challenge him until he was forced to accept the challenge.

The two of them took their weapons and began to fight. They pursued each other, attacked, and evaded each other's hostile moves. After they had fought for a long time, they felt weak. Then suddenly the orangutan captured the tiger's hand, swung him, and threw him far out into a large and deep river. He sank and fell right into the yard of the house of Bungan Baya'. Bungan Baya' was attracted to the dashing tiger.

The mother of Bungan Baya', on first seeing the tiger, asked his name, but he was unwilling to reveal it. In the end, he did say that his name was Tiger. The parents of Bungan Baya' politely presented their guest with food and asked Tiger to remain with them in the river and marry their daughter.

In the evening Bungan Baya' asked Tiger to dance to get to know each other. They both expected to have a turn to dance. Bungan appeared to be very suitable as Tiger's future wife. This was the hope and opinion of her friends. In the afternoon, Baya' invited the village elders to discuss his daughter's marriage plans. The day for the wedding was set and the people helped to prepare the wedding by hunting and fishing. All villagers worked voluntarily.

Not long afterward, Bungan became pregnant and gave birth to her son, Belawan Lenjau. The naming had to be accompanied by a ceremony. For the needs of the ceremony, the villagers, including the child's father, Tiger, went hunting in the forest. Unfortunately, Tiger did not know how to return to the bottom of the river. In the end, he was forced to remain on land.

The child grew up and could already play with his friends, spinning tops and fighting cocks and young dogs. He always won because his top was made of metal, his chicken was a civet, and his dog a bear. Because they were annoyed at losing, the children called Belawan Lenjau an illegitimate child who did not have a father. When he came home, he asked his mother who his father really was. His mother explained what had happened to his father while hunting.

Belawan Lenjau then became determined to search for his father on the land, even though he had no idea where to go. He walked without any definite direction. Finally, he arrived at a high mountain, at the edge of a deep ravine. He was uncertain about how to climb the mountain. The only way was to climb the roots of the banyan tree to a cave. He climbed up and arrived at the cave. There he found a variety of animal skeletons and heard a frightening roar from inside the cave. That was the voice of Tiger. Belawan was very afraid, but he resigned himself to whatever was about to happen.

'Hey, stupid child, why did you come here?' 'I miss my father very much, Tiger!' he answered, 'That is why I came here.' 'What's your name?' Tiger asked again. 'Belawan Lenjau,' he answered, and Tiger realised that this was his own son. 
Tiger then took off his clothes and became human. Crying, he embraced his son. In fact, there were many people in the area and Belawan Lenjau then settled in the village and married his beloved Mening Nyanding. In the end he became a great leader of that village.

\section{Tekena' J alung Merang, Abstract}

Jalung Merang and his parents lived in the fertile mountainous area at the edge of the Mara Rian River. He wanted to ask for the hand of Urai Belawan on the upper reaches of the river, but his parents asked that he first help them with the farm work. J alung Merang grumbled to his mother: 'In that case, when am I going to get married?'

In the meantime, Jalung Bilung and his followers came from downstream. This nobleman from the mouth of the river stayed overnight in J alung Merang's house and informed them that the purpose of his journey was to see the beauty of Urai Belawan. When he heard this, Jalung Merang became very angry. Yet, he kept his anger in his heart, but when Jalung Bilung asked him to come along, he refused.

The next day J alung Bilung left. After that, J alung Merang told his mother of his annoyance. Feeling that she was in the wrong, she acceded to her son's request and endeavoured to abort J alung Bilung's j ourney. She changed J alung Merang into a hornbill bird, who then flew after the boat of J alung Bilung. He perched on the boat to obstruct their journey.

This attempt did not succeed. The hornbill then recited a mantra that changed the string of Jalung Bilung's machete into a snake with a red head and a red tail. Meeting with a snake of this type was a taboo or a sign that it was not good to continue the journey. For this reason, Jalung Bilung turned his boat around and went home. He was not aware that the obstacle was J alung Merang, who then flew straight to the village of Urai Belawan.

When he arrived in J alung Merang's village, J alung Bilung stayed overnight again. Of course, J alung Merang was not at home. J alung Bilung told J alung Merang's mother why they had returned. From his story, she learned that J alung Merang's efforts had been successful.

Still in the shape of hornbill, J alung Merang was captured by Urai Belawan. Only then did he change back to his human form. Urai Belawan accepted him as a suitor. Accompanied by a group of young people led by Sigau Belawan, Jalung Merang went home taking along his future wife.

The wedding was held immediately. After the wedding, Sigau Belawan and his group returned home. When they had just left, Jalung Bilung and his followers came again from downstream. He was surprised to hear that Urai Belawan had already married J alung Merang.

J alung Bilung was very angry, but he did not say anything directly to J alung Merang and his family. Restraining his anger, he remembered that he had never expressly stated that the purpose in his earlier journey had been to ask for the hand of Urai Belawan.

Aware of their fault, the family of J alung Merang tried to restore friendly relations with Jalung Bilung. In the end, Jalung Bilung married the younger sister of J alung Merang and took her to his home downriver. 


\section{Tekena' Balan Tempau, Abstract}

Long ago, Uyau Balan Tempau fought with the father of Awing Liwen and Usun Garing Liwen, whose weapon in war was a fiery flame. As was usual before fighting, the people held an adat ceremony to call the isit bird and the kite to ask whether they would win or lose. The advice was received by Balan Tempau.

During his journey to the place of Awing Liwen's father, he was confronted by the latter's defences, a mynah bird that pecked everyone who passed and sharpened bamboo that could walk on their own and pierce the body of the enemy. He was able to overcome these two obstacles by reciting mantras. After they had been fighting for a long time, they climbed up to a flat land and saw weapons shining on top of a beran tree. This was their destination.

They took turns climbing up, but failed. Then Balan Tempau, who in fact was the descendant of a tiger, tried to climb and succeeded. Everyone followed him like ants in a line, except for Pambo' Baat, who was fat.

At that time, the father of Awing Liwen was out hunting. His wife called him when she saw the enemy attacking her two children. Awing Liwen's father came home, but he did not immediately go to the house of his children because he used to underestimate all enemies. When he arrived at the beran tree, he met Pambo' Baat and attacked him. Pambo' lost because he was struck by the fiery flame. After climbing the tree, Awing Liwen's father said, 'Go on down, there's no need to fight with me, there is no chance that you will be able to defeat me!' Balan Tempau and his friends were determined and they started to fight. Everyone fell down, hit by the weapon of Awing Liwen's father, except for Balan Tempau and Balan Tiling, his brother-in-law.

Balan Tempau asked the spirit of his ancestors, the crocodile, to give him wet clothing, and the spirit fulfilled his request. The war continued, but the burning weapon could not harm Balan Tempau. Awing Liwen's father lost. In line with the instructions of Awing Liwen's father, Balan Tempau met the two children and asked for magic to revive his friends and then made the two girls smaller so that they could be taken back home.

When they arrived at their village, a victory celebration was held, which included spearing the head of Awing Liwen's father. During the night, Balan Tempau dreamed of a landslide as a sign that an enemy was about to attack. The celebration was postponed to be continued on the next night. Balan Tempau's wife, Mening Nyanding, and Uyau Mo' went to the upstream end of the village to cut sugarcane for the coming celebration. In a riverbed full of large stones, they saw a large group of enemies.

Uyau Mo', who claimed to be Balan Tempau, had almost won the fight, when Mening Nyanding mentioned his name. The enemy attacked again and defeated Uyau Mo'. Uyau Mo's body floated away in the boat, while Mening Nyanding was carried off to the sky.

Uyau Balan Tempau was very angry and tried to track down the people who had carried off his wife. He did not find any sign, until he met an old woman in his dream, who told him that his wife had been carried off to the sky and that he had to make a blowgun. He made the blowgun, but none of his arrows could hit the sun. Then Balan Tempau looked through his wife's things and found three large needles, which he made into arrows. He shot the first needle and it hit the sun. Then he shot with ordinary arrows and connected them all the way down. He did the same with the second needle, and the third. These connected arrows were then shaken until they became an iron ladder. With this ladder he was able to reach the sun. 
After reaching the sun, he fainted because of the heat. He was assisted by Ulau Tau, the guardian of the sun, who showed him the way to his elder sister's house, who had also been carried off to the sky long ago. His sister was very happy, and she and her husband gave him extraordinary powers to enable him to defeat J alung lla. After testing his strength, he was allowed to continue his journey.

He climbed a mountain and reached a stone wall that was his destination. There was no road leading further, except via the roots of a banyan tree, which was still rather small. He waited there a long time, until those roots had grown large enough and could be climbed. Below there was the house of J alung lla. Fortunately there was a gibbon. He jumped into the animal's mouth to be carried down. Mening Nyanding was sitting in front of the house, near the drying area. She was thin and very dirty. From inside the mouth of the gibbon Balan Tempau watched his wife.

Balan Tempau told his wife to do whatever she had been told to do by Jalung Ila, including inviting all residents to dance and entertain her. When they had all assembled for the dance, Balan Tempau called on his ancestral spirit to tell a white rooster to crow. When the rooster crowed, he immediately jumped into its mouth.

While people were dancing, Balan Tempau found a way to enable the rooster to fly to the upriver and downriver ends of J alung lla's longhouse. All those who were touched by the flapping wings died immediately, except for J alung Ila and Mening Nyanding. Uyau Balan Tempau emerged from the mouth of the rooster and pulled the hand of J alung lla to fight and test their respective levels of nobility. J alung lla used his weapons, while Balan Tempau was without any weapon. In the end, Balan Tempau won the fight and he tied a rope around the neck of J alung lla till he was dead.

Balan Tempau and his wife then gathered all the goods and valuable objects from the village storehouse and placed them into a flying ship. Then they flew home. The two of them were welcomed joyfully in their village because the evil deeds had been avenged. 


\title{
13. \\ Folk songs of the Kenyah \\ Leppo' Ma'ut: A study of text and music
}

\author{
Daniel Lawing
}

\section{INTRODUCTION}

Not surprisingly, traditional songs and music play a prominent role in the daily life of the Kenyah Leppo' Ma' ut. Demonstrably, almost every daily activity is accompanied by songs and musical performances. The importance of songs and music can also be measured by the great variety of songs and music of the Leppo' Ma' ut. Nevertheless, the traditional culture of the Leppo' Ma' ut is disappearing, and this includes their traditional songs and music. Thus, it is very important to document these and make as complete as possible an inventory and classify them according to the context in which they are used.

This article focuses on the village of Long Alango, in the district of Puj ungan. The maj ority of the village population (415 people or 60 family heads) belong to the Leppo' Ma'ut group. On several short visits to the villages of Long Kemuat and Long Berini, not far from Long Alango and also inhabited by Leppo' Ma' ut, the writer was able to obtain comparative materials. Research was carried out through interviews with old people well versed in the culture of the Leppo' Ma' ut and especially familiar with their oral literature, folk songs, and traditional musical instruments. These elderly experts included three individuals from Long Alango, ten from Kemuat, and nine from Long Berini. Some of the folk songs and music were recorded. 


\section{GENRES OF FOLK SONGS}

The Leppo' Ma'ut are familiar with nine types of folk songs, which can be classified into five categories (see Table 13.1). The songs and music use both the pentatonic scale (limited to 5-7 notes) and the diatonic scale (for songs using a full octave). The rhyme of Leppo' Ma'ut folk songs generally follows an A-A-B-B pattern. The five categories and their types are as follows: 1 ) belian songs include three types: belian kenai ndok, belian suket, and belian sakit; 2) silun songs consist of three types: silun tidau, silun ketena', and silun menjaeng; 3) londe'; 4) uyau along; and 5) melalo'.

\section{Belian Songs}

This category consists of three main song types. The belian kenai ndok are very highly valued because they can be used for nepet (declaring someone's personal character) and as katok (advice). The belian suket is reserved for healing ceremonies by a traditional healer, who in former times could be possessed by the belian spirits. The belian sakit or dayong is used in healing ceremonies of the Adat Bungan religion. In addition, there is the belian burak, which is sung when welcoming honoured guests at burak (rice wine) drinking ceremonies.

According to the informants, some of the belian songs originated in the adat customs of the Leppo' Ma' ut who have been living in the upper Bahau River area since the beginning of the 19th century. This is especially true of the songs sung at adat ceremonies and at burak drinking ceremonies. Other songs originated with the Kenyah who lived in Sarawak.

Figure 13.1 Oko' Dan Lawing performing the belian kenai ndok song

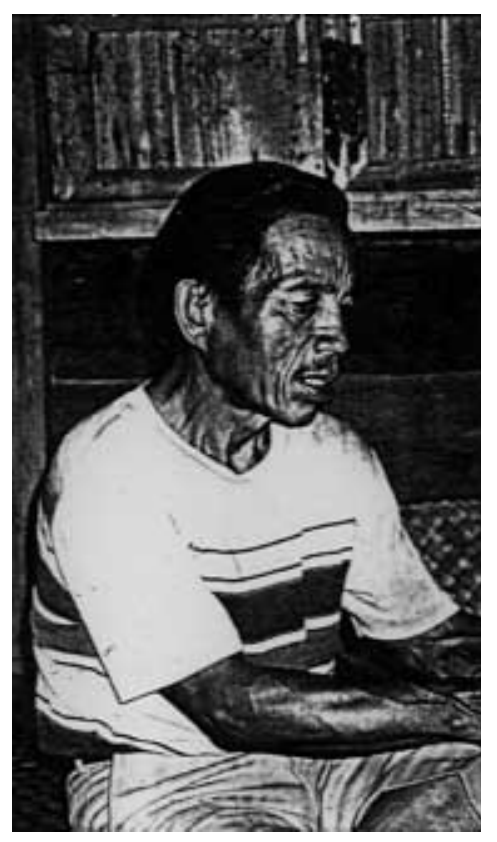

\section{Belian Kenai Ndok Songs}

The name kenai ndok means 'the firewood is coming' (Figure 13.1). These belian songs have two purposes: nepet and katok. The term nepet refers to a custom in which someone describes at length another person's personality (his/ her shortcomings, special characteristics, and outstanding qualities). The content of the songs can also give high praise to a person, often metaphorically, as in the words: Le pa aki' matai ka' nda' palat taket to' ia na iku' te' a ('I am ready to die under your foot if this makes you happy'). The term katok means 'advice'. The belian kenai ndok songs have always been used in speeches or sermons to advise other people, to admonish people to do positive things, and to prohibit negative things, for example, in the notong posa (child naming) ceremony. As a sign of respect, these songs may be used to praise a guest and ask guidance or advice from him.

The lyrics of the belian kenai ndok songs (as well as those of the belian burak songs) generally exhort and play on the emotions of the audience during certain social activities, such as inviting an honoured guest to drink burak. The text of these songs and 


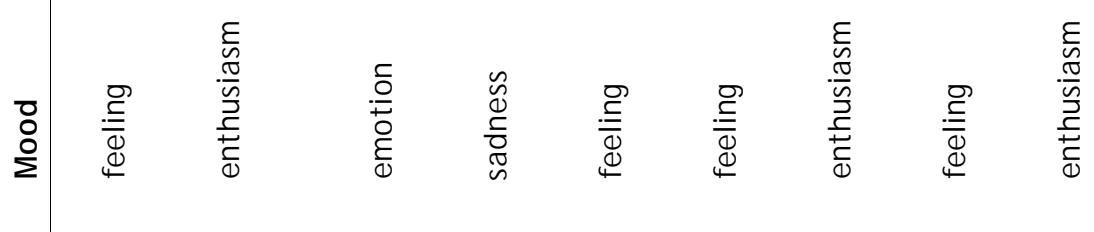

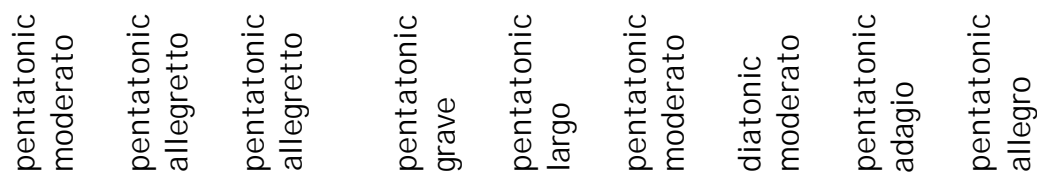

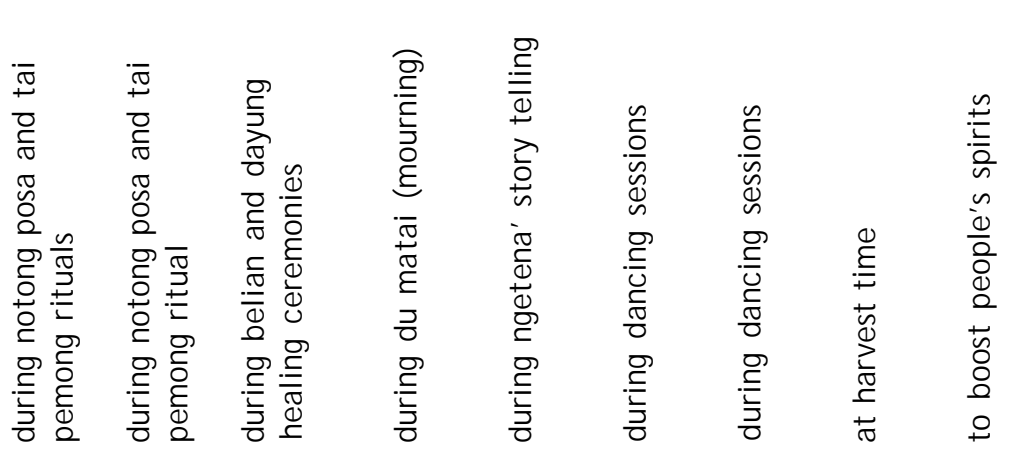

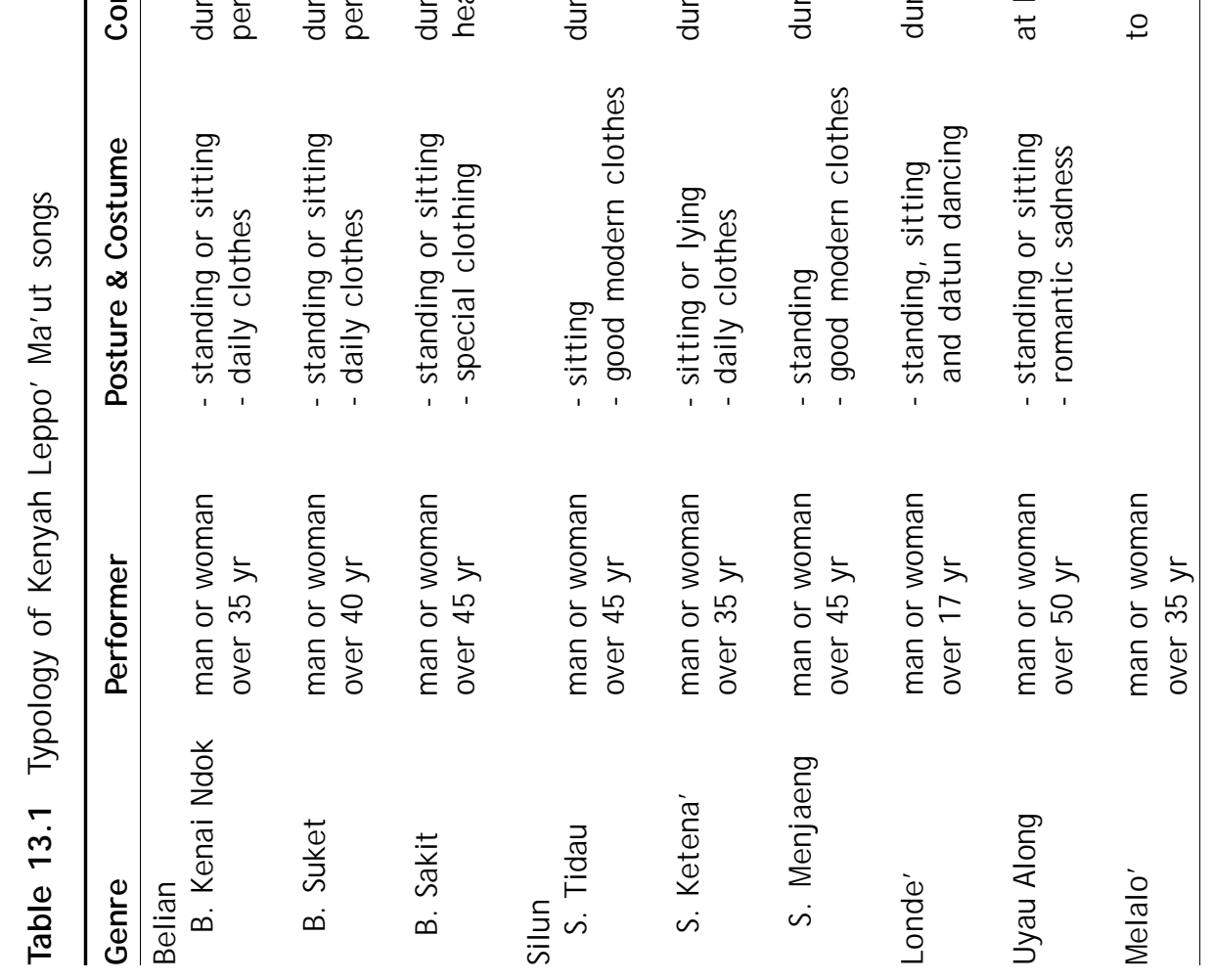

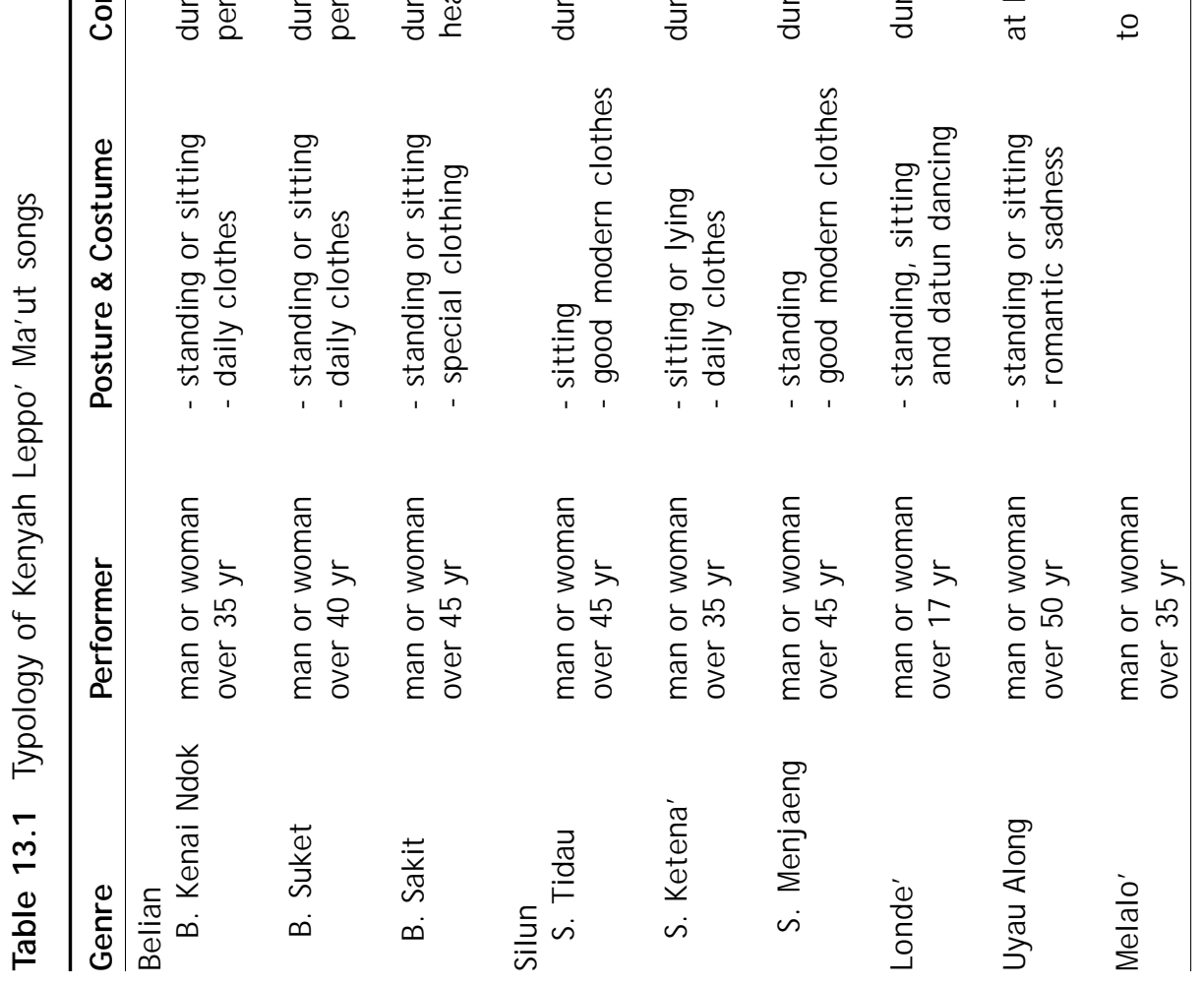

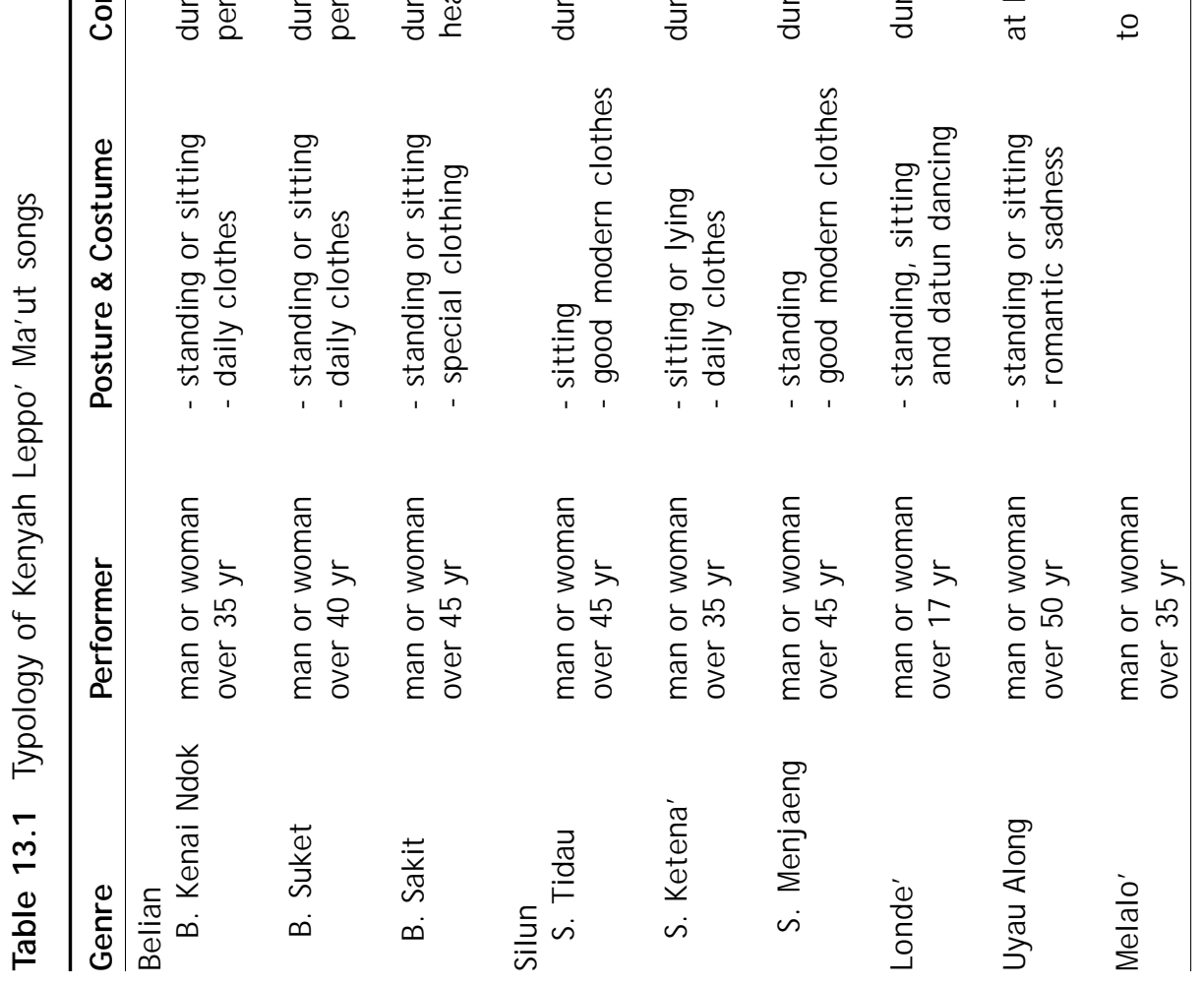

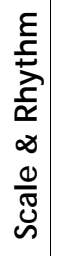


their rhythms are very short, while their solo voices are always chasing or answering the choir voices (ngendaeng). These songs have a rather even intonation or melody, and the choir only uses one note, namely 6 (la) low. A solo ends every part on the notes 1, 3, 6 (low). Example:

$$
\begin{array}{ll}
\text { Solo.... } 1 & \text { Solo..... } \\
\text { Choir...6 } & \text { Choir....6 } \\
\text { Solo....6 } & \\
\text { Choir...6 } &
\end{array}
$$

Figure 13.2 Oko' J angin performing

the belian suket song

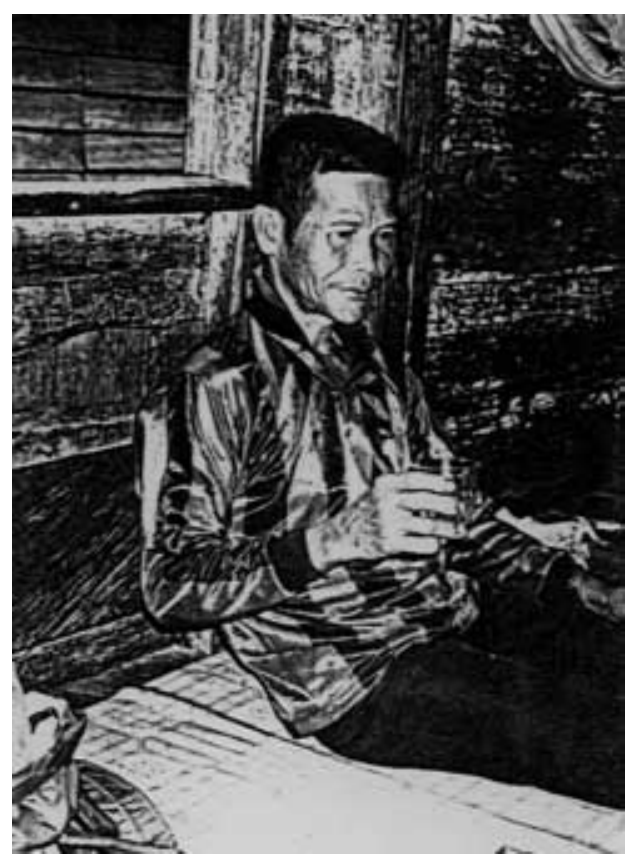

\section{Belian Suket Songs}

The belian suket songs (Figure 13.2) differ greatly from the belian kenai ndok. Formerly they were sung especially by a healer who was believed to have a bali belian (belian spirit helper) or to be susceptible to possession by such a spirit. Belian suket songs were performed in special rooms, such as the room of a patient's family, and were attended by several people who accompanied the solo of the belian suket song, which in the local language is called ngendaeng (accompaniment or choir). The meaning of suket is 'slowly', in the sense of doing something in a slow but orderly manner, as is described by this sentence of the song: Nisep ngan sain apan no' magat ('Drink slowly so that you will get well and full of energy'). The text of the belian suket songs is long. The solo voices and their choir are

like those of the belian kenai ndok, always chasing each other. These songs have a soft intonation that is rather drawn out. The solo voices end on two notes, a high 4 (fa) and a low 1 (do). The choir voices are also marked by two notes, a low 4 (fa) and a middle la (6). Example:

$$
\begin{array}{ll}
\text { Solo.....4 } & \text { Solo..... } 1 \\
\text { Choir....4 } & \text { Choir....6 }
\end{array}
$$

\section{Belian Sakit Songs}

These songs are reserved for sick people, and serve to mediate between the patient and Jalong Peselong (The Almighty in the Adat Bungan religion). According to popular belief, a variety of illnesses can be cured with the belian sakit ceremony. The text and the beat are not regular but depend on the preference of the singer (healer); they can be long or short. Furthermore, they are also adjusted to the instructions given by the bali (spirit) of the healer, or who is assigned to help the healer. Any requests made by the bali must be met by the healer and the patient, including words that must be uttered in 
the prayer song or the mantra. This song is preceded by a choir (ngendaeng) with a base note of 5 low (sol). After the solo has begun with note 2 (re), the choir follows with 4 ( $\mathrm{fa}$ ) low. The solo only uses 4 notes at the end of each sentence of the song, 2, 3, 4, 6; the choir, on the other hand, only uses one note to the end of the song, 4 ( $\mathrm{fa}$ ) low. Example:

$\begin{array}{ll}\text { Solo..... } & \text { Solo..... } \\ \text { Choir....4 } & \text { Choir....4 } \\ \text { Solo....4 } & \text { Solo....6 } \\ \text { Choir....4 } & \text { Choir....4 }\end{array}$

Before the solo voice begins to sing, it has to start with a rather long sound such as 'Aaa... Eee...', and exhale with a long 'Huss...', and then the song is started.

\section{Characteristics of the Belian Songs}

The belian songs is delivered in the following way: The song (vocal) begins with a solo part, which is then joined at the end of a certain sentence by a choir or ngendaeng. The singer either sits or stands, depending on the situation. For example: 1) while singing, a singer who is sitting holds a glass full of burak that will be offered to the guest or honoured person; the lyrics of the belian burak song are directed at the guest. After the song is finished, the glass of burak is offered to the guest to be drunk. 2) The singer faces the audience, and sings while dancing; the lyrics of the song are directed at the audience, both in the form of nepet or katok, and in the way in which he conveys his humility, e.g., Aki' uba' pakalai nyambet, li'i kunia lesau oban nem na' gelam maki ('I want to learn how to dance, since you have already given me a dancing costume and it would be a shame to waste it'). 3) In delivering the belian sakit song, the singer faces the audience and the patient, and he may be sitting or standing. The singer always sits when he is telling the story of the bali belian, but he stands when the sacrificial animals (chickens or pigs) are killed.

The language used in the lyrics of the belian songs is a highly metaphorical literary language, and not the language of everyday use. Today's young generation of Leppo' Ma'ut are no longer able to understand the meaning of these lyrics, e.g., kusun lilit sada langit anjan, which literally means 'above the circle of the sky and space', while its real meaning is 'the second world in human life other than earth'. Only a few people who are older than 35 can still understand this metaphorical language clearly. The metaphorical language of the belian songs takes many of its metaphors from the names of birds, animals, rivers, and forest plants. For example: the term suwi ta', which refers to a certain small bird that likes to sit on the tips of leaves or on fruit flowers is used metaphorically to refer to describe the panyen people (the commoner class); the term temenggang (the hornbill bird) is a metaphor for the paren (nobility); the phrase Lenjau Makang, 'Brave Tiger', describes heroes, especially those from among the paren; the phrase Kule Sip Mawe Poyan, 'Leopard with Sharpened Fangs', is a metaphor for a neat and strong individual, or someone strong and of a noble heart; the phrase Tanyit Lanya Enan, 'Smooth Tanyit-tree Trunk', is a metaphor for a tall person with smooth skin; or the phrase Sungai Limun Kanan, 'Domestic River Water', must be understood as the area of a river basin owned by a village. The names and characteristics of animals and plants that are closely tied to human life, have been used since olden times as metaphors in the lyrics of the Leppo' Ma' ut songs as a matter of pride.

Belian songs are a matter of pride for the singer, because not everyone can sing them. The belian songs are in the blood of the Leppo' Ma' ut, making them feel cheerful 
and spirited if someone is able to sing them at the time of an adat ceremony, and they do not feel very uplifted if a ceremony takes place without a belian song. Those attending feel that these songs have represented a special trait of Kenyah culture from olden times until today.

\section{Silun Songs}

Silun songs are sung when mourning a deceased person (nidau); when singing a historical or epic story (ngetena'); when lamenting, telling a story, or praising something or someone (menjaeng); and also at certain ceremonies such as collective dances, weddings, or births. According to stories, the silun songs were already known when the Leppo' Ma'ut were living at Tokong Julut (on the Iwan River), Data Pea (Iwan River), and Long Sungai Ma'ut (Lurah River), before they moved to the upper Bahau. They still use them today, but rather infrequently, and only for special ceremonies. Silun songs recall the past or one's youth, because formerly they were in fact sung by young people almost every evening, and not only at certain ceremonies.

\section{Silun Tidau Songs}

Silun tidau songs are laments and they are song at times of death. Their lyrics raise feelings of longing and sadness. They are sung to tell those present about the relationship of human beings to the Almighty (J along Peselong in the Bungan religion), and to tell them that after life in this world there is a second, better life in that other world. The silun stories are related to death, as is the one entitled Petapan ('Lament'), which talks about human beings who must meet their destiny, or Kusun Langit Tawang Deman, which describes another world beyond this earth. Silun tidau also tell the life stories of relatives who have already passed away and, at times, they mention the site of their graves on the upper Bahau and elsewhere. The beat of the silun tidau is short and rather monotonous.

\section{Silun Ketena' Songs}

Ketena' is a story, and ngetena' means to tell a story (see Figures 13.3 and 13.4). The stories generally are about the families of bali (spirits) who, according to local beliefs, live in the area of Long Berini or on the Berini River. The Berini River, which is called Alo Mararini Marani Kanan or Alo Mara Rian, is located between Apau Ping and Long Kemuat. Other stories are titled Ngayau ('Attacking the enemy'), Tai Ala' Letto ('Go to get your wife back'), Laki Muat ('The Champion Hero'), Nai Uli' Anak Da' Lingu ('The return of the lost child'), and Letto Mi' Nai Uli' ('The return of the lover'). The silun ketena' songs are pentatonic and have a rather long and slow beat.

Figure 13.3 Oko' Awing Lawing performing the silun ketena' song

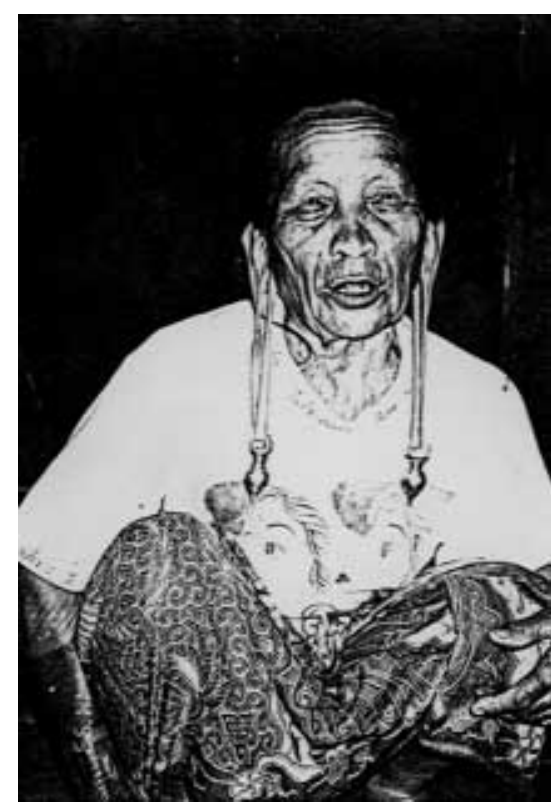


Figure 13.4 Atypical, comfortable posture for listening to a ketena' epic song

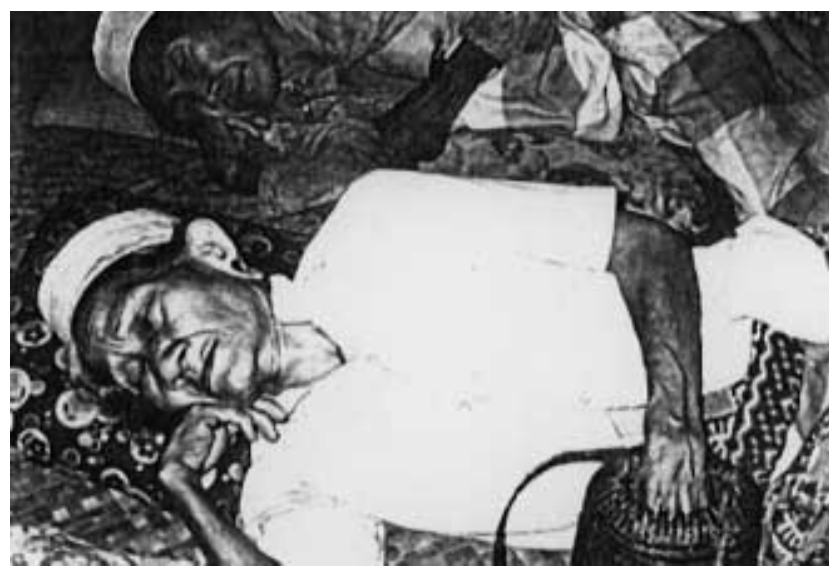

\section{Silun Menjaeng Songs}

Silun menjaeng are songs (Figure 13.5) sung especially to praise someone, for example, when he dances. The dancer is expected to be more spirited hearing himself praised by the singer (Figures 13.6 to 13.8). The beat or the melody of the silun menjaeng is of two kinds. In the menjaeng ayau, every sentence of the lyrics ends with the rhyme ' $a u$ ', and the song and beat are rather monotonous. Formerly, this type of song was sung in praise of someone who had been successful in ngayau (war). In the menjaeng silun, every sentence of the lyrics must end with the rhyme 'un', and this is taken from the word silun. This type of song has a slow long beat that rises and falls.

Figure 13.5 Oko' Asong performing the menjaeng song

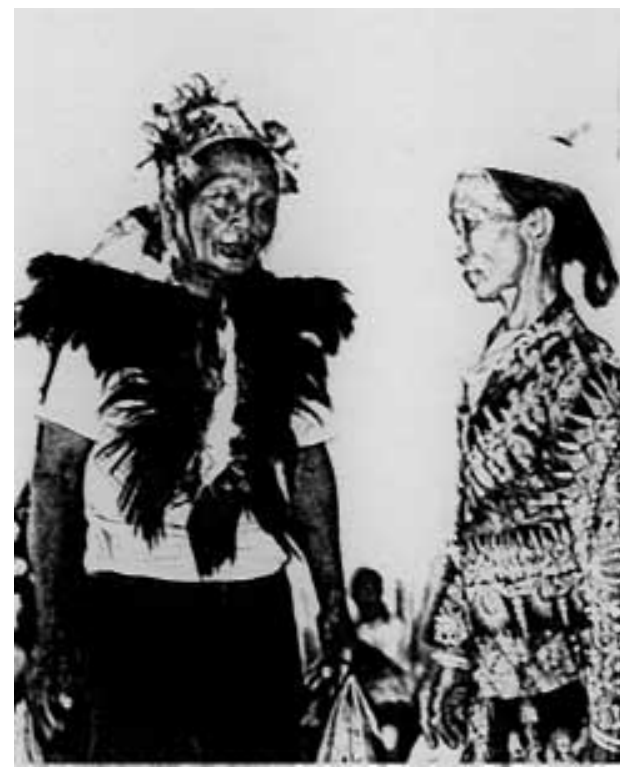

\section{Characteristics of the Silun Songs}

The silun songs generally are full of feeling because they are long and sung slowly by solo singers. In silun tidau and silun ketena', certain sentences are sung to introduce a story, while in silun menjaeng, entire stories are sung. The lyrics of the silun are often uncertain and depend on the singer. The silun songs are filled with metaphors only rarely used nowadays, except in certain ceremonies, such as du matai (a night wake), ngetena' (singing a historical epic), or menjaeng (praising someone or something). For example, uweng takin lareng esan, which is metaphorically a strong and well-loved young man.

The melody of the silun tidau is slow and sad. Its beat is repetitive and at the end of each verse the songs always subsides by using only one note, the low 
Figure 13.6 Woman performing traditional dance in Long Alango

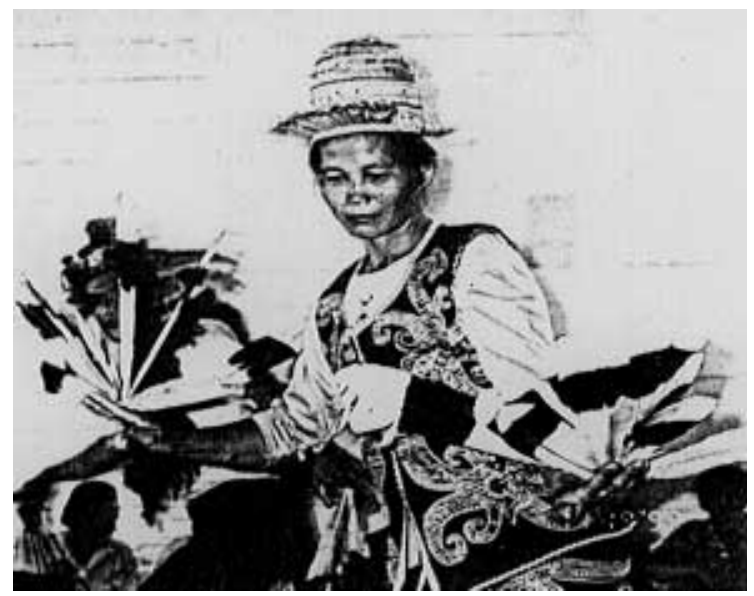

Figure 13.7 Man performing traditional dance in Long Alango

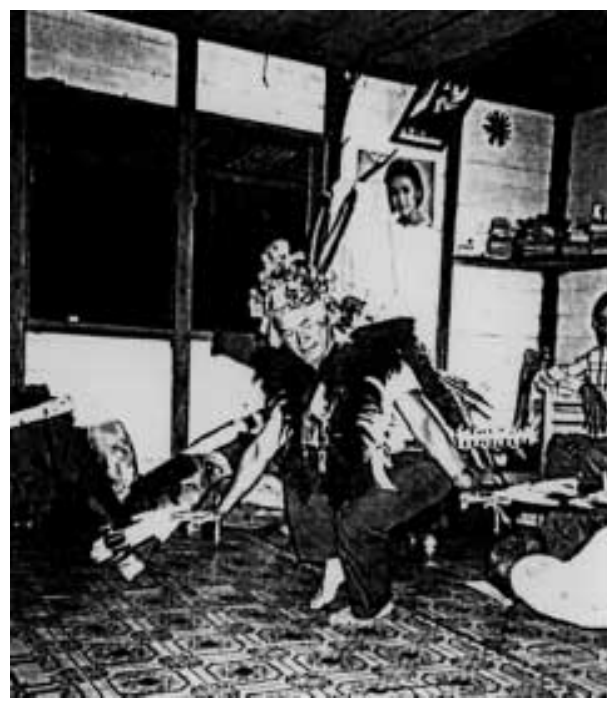

Figure 13.8 Author and friend in traditional Leppo' Ma'ut costume

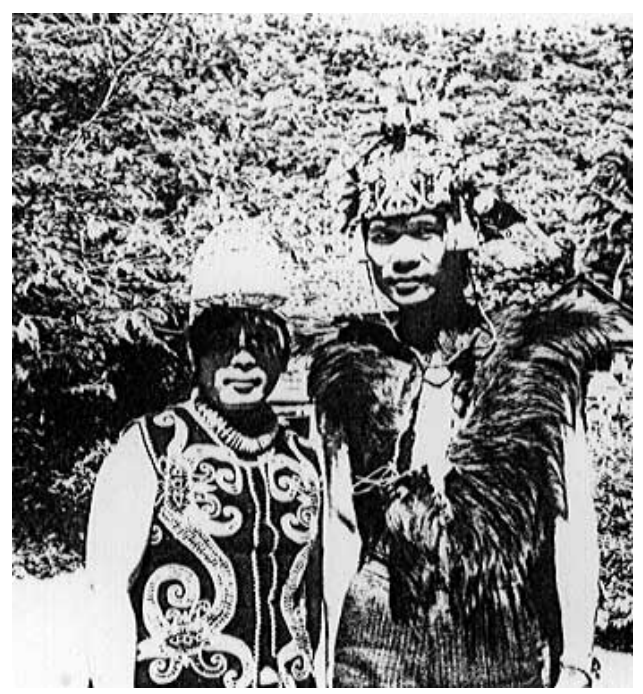


1 (do). The silun ketena' songs resemble the silun tidau, but in the second and third verses of some silun ketena' the notes rise higher than in the preceding verse. The silun menjaeng songs finish the first two verses with note $3(\mathrm{mi})$, but end the third verse with low 7 (si). Thereafter the song returns to the beginning note.

\section{Londe' Songs}

The term londe' carries the meaning of soft, gentle, and beautiful. Londe' songs are sung especially at dances and are intended to encourage those present to dance. Before the dancing begins, a datun dance is usually held by those organising the event, while awaiting further arrivals. The datun dance consists of a long stretchedout line of people who are walking and stomping their feet to the beat of the londe' (resembling a polonaise). Singing the londe' in the yard or on the veranda of a traditional house means that all residents are invited. This dancing event does not occur at any particular time, but is usually held in the evening; it may also take place in the daytime. The inviting group is usually composed of adults, both men and women. The londe' songs are still much sung and people aged 14 and over still know them very well.

Examples of londe' songs are Leleng and Kolong Ponai, which invite people to dance through their lyrics. Leleng means to turn or go around while dancing, in accordance with the general Dayak dance pattern of going around in a circle. Kolong Ponai means 'a pet pigeon', a metaphor for 'a loved one.' If after hearing a Kolong Ponai song, someone stands up and invites another to dance, the one asked will feel honoured because that one is seen as the kolong ponai or loved one of the one inviting. Londe' songs, like popular songs, are diatonic. For musical accompaniment, they use plucked or percussion instruments with many notes such as the sambi' and geng galeng. The londe' with free notes use a full octave or more, and are usually accompanied by guitars or other diatonic instruments.

\section{Uyau Along Songs}

The Uyau Along songs have an even beat, use a pentatonic scale, and are romantic in nature if sung in an answering manner, like traditional pantun (verses). When the senguyun (cooperative work) groups are planting rice together in the dry fields, Uyau Along may be sung by a couple (a man and a woman) in an answering manner. These songs can also be sung alone, by someone feeling sad or lonely, because, for example, s/ he misses a beloved or remember his/ her youth. The words Uyau Along are actually taken from a personal name: uyau is a term (necronym) for calling a boy whose father has died, while along means sad or lonely and is used as a boy's name. In the Uyau Along songs, the beginning of a verse is accompanied by two beats, and then the voice is drawn out to six beats, and only then does it proceed to the following parts of the song.

\section{Melalo' Songs}

Melalo' songs are connected to ngayau (war, headhunting), a frequent activity of men in former times, which involved attacking an enemy with the intention of taking and bringing home their heads. 


\section{Melalo' in Ancient Times}

The head was used as a protective agent (lewa) in the melewa ceremony (the collective cleansing of the village) held at the time of the mamat religious festival. It was meant to protect the residents from illness and danger. Human heads were also used if a member of the nobility (paren) died. During the mourning period, the people wear hats, shirts, and kuau (women's skirt), pants (for men; formerly, loincloths), which are all coloured light yellow with a dye made from clay. After taking a human head, the group of men who had gone headhunting returned to the village singing melalo' songs to dispel sadness, and they took off their mourning clothes. A pet lomo ('to discard mourning') ceremony was held, then the mourning clothes were thrown away, and a dancing ceremony was held to the singing of melalo' songs.

If a mamat festival was being held, or if a member of the nobility had died, when the successful headhunters arrived in their home village, they raised the head high in their left hand and, holding their swords in their right hand, they shouted their victory and joy. They were joined by the other members of their group and were answered by all the villagers together. These cries of victory and joy were formerly referred to as melalo'. This kind of joy was beyond earthly value, because only rarely was a man able to kill an enemy and cut off his head in a face-to-face confrontation. Only someone who was mayeng bali otong (able to endure trials that befall him, who was physically strong, and old enough) could win glory by ngayau or headhunting.

\section{Melalo' Today}

The melalo', songs to boost the spirit, are often sung when working together, as when carrying something heavy like a rice mortar or a large boat, or when setting up a belawing (a tall ritual pole). Before a singer begins a belian kenai ndok or belian suket song, he first sings a melalo' to boost the spirits of the choir members about to sing the belian songs. If anyone is going to dance, melalo' songs are also sung first by someone who is only sitting and watching. The melalo' songs really raise the spirits of those who are attending and can create a very emotional mood. They can also evoke memories of the mamat festival, which is no longer held today, and of the past glory of the Leppo' Ma'ut.

\section{Characteristics of the Melalo' Songs}

The melalo' songs use pentatonic notes and an even beat that is almost like regular speech. The songs are preceded by a solo that also resembles normal speech. When the solo is completed, it is answered by a choir of many voices following a beat. The lyrics at the beginning of every verse are sung by a solo voice that is joined by the choir at the end of the sentence. The first two verses consist of couplets introducing the story, while the second and third tell the content of the story. Melalo' can be delivered standing or sitting, but it seems that a sitting position is more common, when, for example, accompanying the feasting of a guest with burak. These songs also use a metaphorical language. For example, sadin mambin baya oban, which means 'younger sibling', while in ordinary language it is simply sadin or asri'. 


\section{MUSICAL INSTRUMENTS}

The Leppo' Ma'ut are also familiar with instrumental music as accompaniment to dances, which forces the dancers to coordinate their movements and steps with the beat of the musical instruments. Five types of instruments are known, and they belong to three categories (see Table 13.2): 1) plucked instruments, which include the sambi', lutung, and odeng talang jaran; 2) percussion instruments, such as geng galeng; 3) wind instruments, such as kediri' bulu', which is made of bamboo and used like a harmonica. The researcher did not obtain satisfactory information regarding the kediri' bulu', and therefore only the plucked and percussion instruments will be discussed below. The sambi', lutung, odeng talang jaran, and geng galeng are still used today.

Table 13.2 Typology of Kenyah Leppo' Ma'ut instruments

\begin{tabular}{|c|c|c|c|c|c|}
\hline Instrument & Performer & Posture \& & $\begin{array}{l}\text { Context } \\
\text { Costume }\end{array}$ & $\begin{array}{l}\text { Scale } \& \\
\text { Rhythm }\end{array}$ & Mood \\
\hline Sambi' & man over $18 \mathrm{yr}$ & $\begin{array}{l}\text { - sitting } \\
\text { - costume according } \\
\text { to context }\end{array}$ & $\begin{array}{l}\text { during dancing } \\
\text { sessions }\end{array}$ & $\begin{array}{l}\text { pentatonic } \\
\text { moderato }\end{array}$ & feeling \\
\hline Lutung & $\begin{array}{l}\text { man or woman } \\
\text { over } 40 \mathrm{yr}\end{array}$ & $\begin{array}{l}\text { - sitting } \\
\text { - costume according } \\
\text { to context }\end{array}$ & $\begin{array}{l}\text { during dancing } \\
\text { sessions and in quiet, } \\
\text { lonely times }\end{array}$ & $\begin{array}{l}\text { pentatonic } \\
\text { moderato }\end{array}$ & feeling \\
\hline $\begin{array}{l}\text { Odeng } \\
\text { talang jaran }\end{array}$ & $\begin{array}{l}\text { man or woman } \\
\text { over } 50 \mathrm{yr}\end{array}$ & - sitting or standing & $\begin{array}{l}\text { in quiet, lonely times } \\
\text { moderato }\end{array}$ & pentatonic & feeling \\
\hline $\begin{array}{l}\text { Geng } \\
\text { galeng }\end{array}$ & $\begin{array}{l}\text { man or woman } \\
\text { over } 40 \mathrm{yr}\end{array}$ & - sitting or standing & $\begin{array}{l}\text { in quiet, lonely times } \\
\text { moderato }\end{array}$ & pentatonic & feeling \\
\hline
\end{tabular}

\section{The Sambi'}

The sambi' is a type of kecapi (lute) with at least three strings (see Figures 13.9 and 13.10), but it may have up to four or five strings depending on its origins. In other Kenyah languages, it is known as sampe', and in Kayan it is called sape'. Before plastic and metal strings appeared, fibres from the iman tree (Arenga pinnata, sugar palm) were used as strings for the sambi'. Today, steel wire is much used, it is obtained from the wires of bicycle brakes or from guitar strings. Steel wire is preferred because it is strong, does not break easily, and has a soft but piercing sound. The first string or wire is used to play the melody. To set the notes, small pieces of rattan $(1 \mathrm{~cm}$ long and $3 \mathrm{~mm}$ wide) called nden are placed under the strings, and glued to the body of the sambi' with odep (a kind of resin). The sambi' is played by plucking like a guitar: while the left hand presses the strings in accordance with the notes of the song, the right hand plucks the strings. Two or more people may play the sambi' at the same time (Figure 13.11); the first one plays the melody, the second the accompaniment (рepa). The third and other players play variations of the melody and/or of the accompaniment (to embellish the presentation of the song). The sambi' can be tuned in different ways depending on whether it is to be played alone or to accompany dancing or singing; Figure 13.12). It can also be tuned to either the pentatonic or diatonic scale. 
Figure 13.9 Parts of the sambi' lute (viewed from the front): 1) kalong ulu, carved head; 2) poreng, pegs; 3) batuk, neck; 4) nden, nut made of rattan; 5) osa, body; 6) batek, soundboard; 7) nden, frets; 8) tali sambi', strings; 9) nden, frets; 10) pen, end part; 11) odep, spare resin to glue frets.

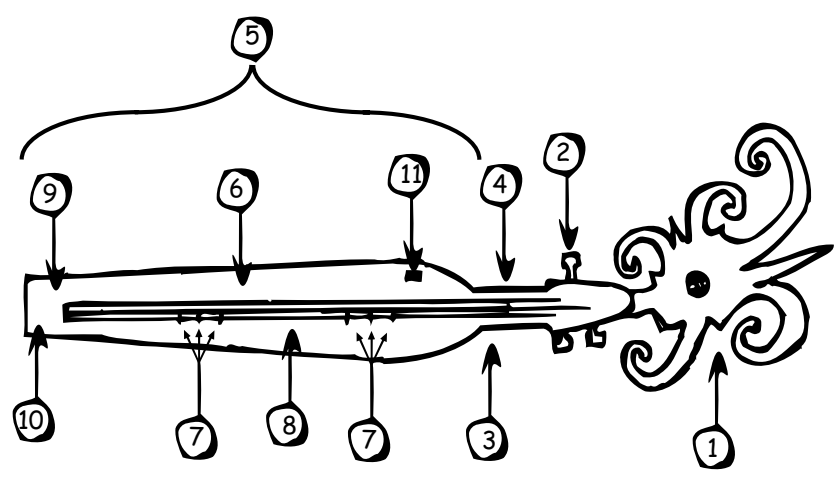

Figure 13.10 Young man playing the sambi' at Long Alango

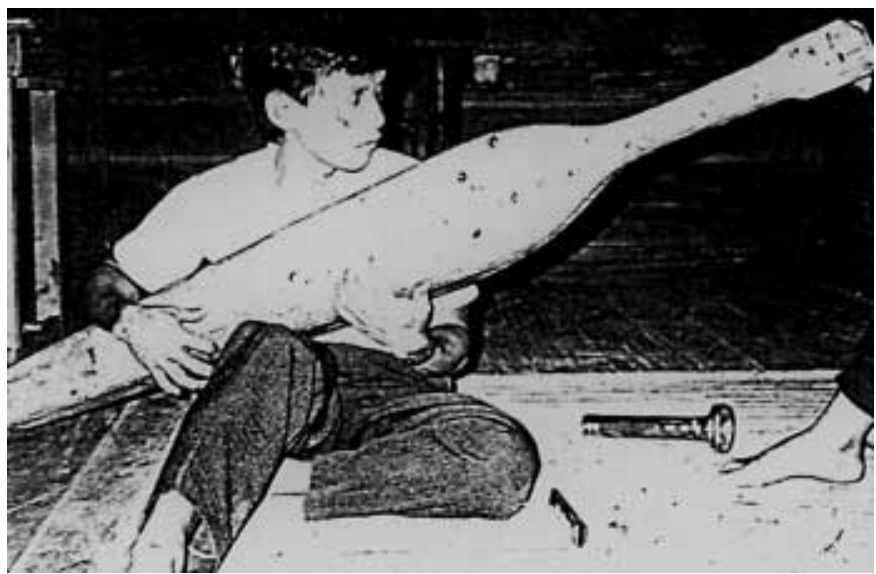

Figure 13.11 Recording Bakung lute music in Long Aran, 1992

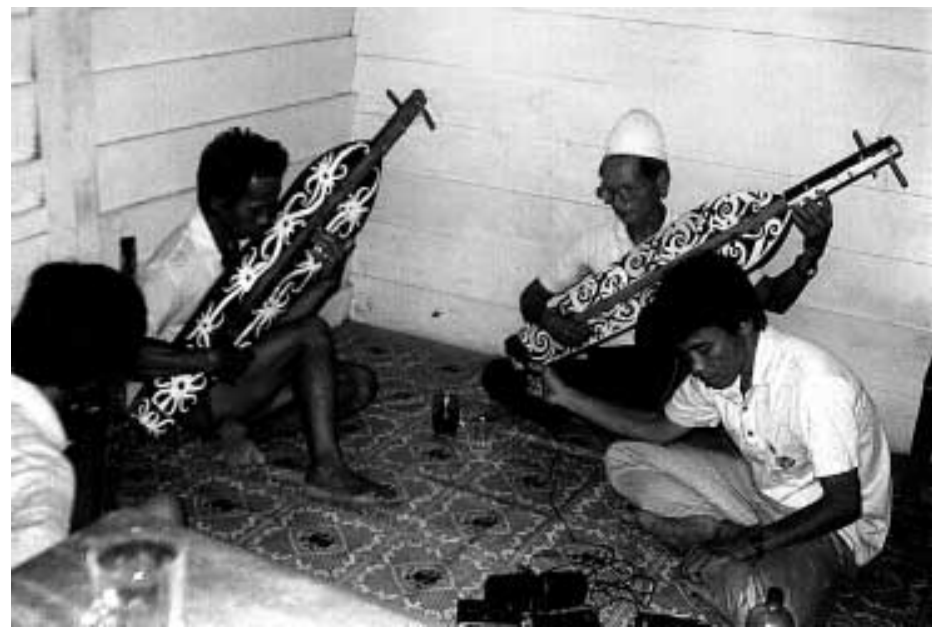


Figure 13.12 An example of sambi' tuning

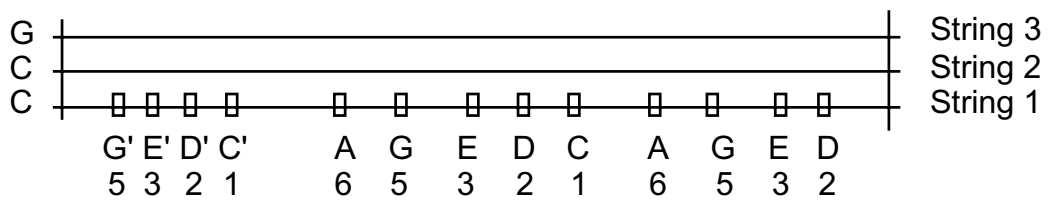

\section{The Lutung}

The lutung is also a plucked instrument, a zither. It has a five-cornered body and six strings on a pentatonic scale (Figures 13.13 and 13.14). Its size depends on the preference of the user (about $1.25 \mathrm{~m}$ long, $18 \mathrm{~cm}$ wide at the bottom, and $24 \mathrm{~cm}$ wide at the top). In the past, the lutung was cylindrical, because it was made from bamboo, and raised outer fibres of the bamboo were used for strings. Nowadays it is made from dried, lightweight boards and its strings are made from steel wire (from bicycle brakes). This simple instrument also accompanies dances or entertains the player himself when he is Ionely. The lutung are usually played by two or more people, with the first player playing the melody and the others the accompaniment (pepa). The scales of the lutung vary according to the songs played. The tuning is done by shifting the location of the nden (the frets or supports for the strings, which determine their notes).

Figure 13.13 Parts of the lutung zither: 1) ulu, head; 2) poreng, pegs; 3) nden, frets made of wood; 4) osa, body; 5) batek atau osok, soundboard; 6) tegaeng, sides; 7) laba, strings; 8) nden, nut made of rattan); 9) pen, end part; 10) likut, back.

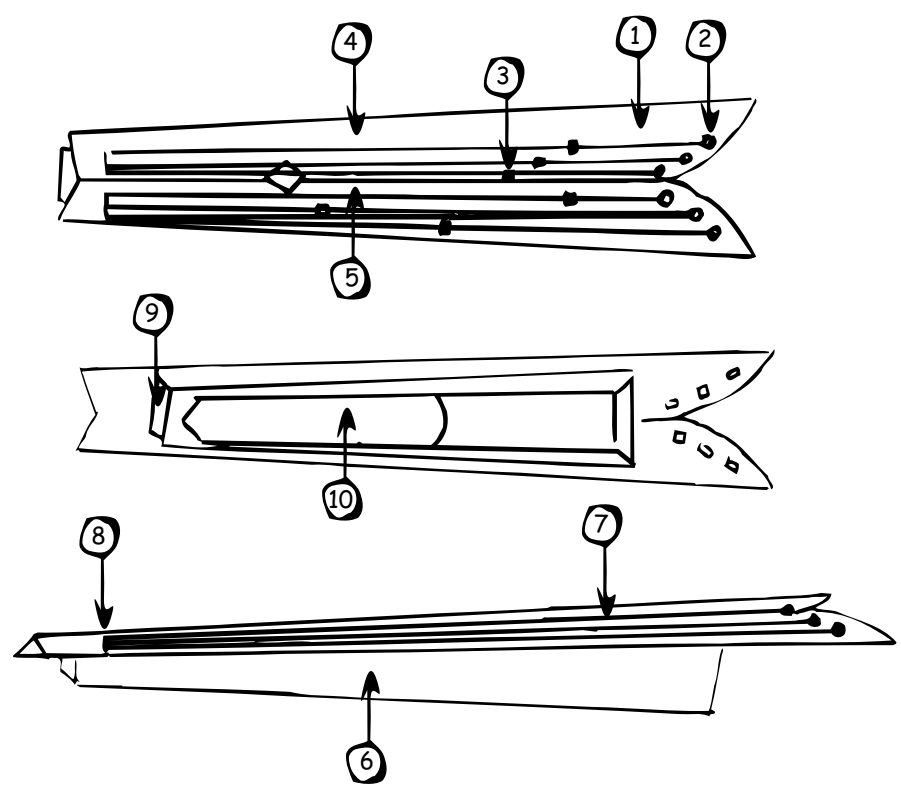


Figure 13.14 A lutung zither, played by a Bakung woman at Long Aran

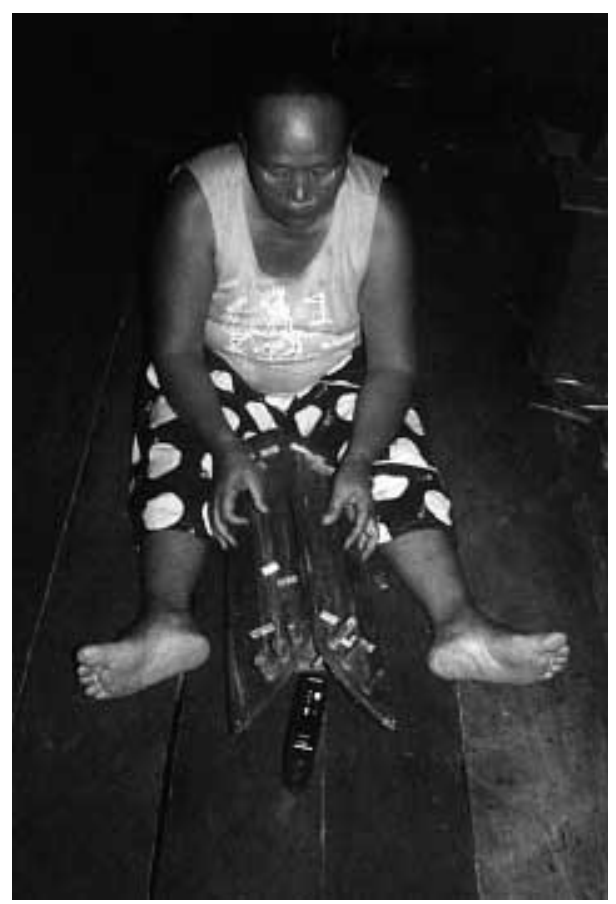

\section{The Odeng Talang J aran}

The odeng talang jaran, or jew's harp, is a plucked instrument made of bamboo that uses the mouth as a sound chamber. The sound produced resembles that of a frog. The shape is not very standardised according to definite measurements. It varies between 22 to $32 \mathrm{~cm}$ and can be changed according to preference and comfort of the instrument's fit to the mouth of the maker or user. There are two types of odeng, a short odeng and a long odeng (see Figure 13.15). This instrument is usually played by older people, both men and women, who are feeling lonely. The odeng talang jaran is usually played by two people, with one playing the melody and the second the accompaniment. The sharp tip of the odeng is plucked, the tail end is the handle, and the tongue part is placed in front of the mouth cavity. The sound produced is louder if the player is toothless, as the mouth cavity then is a more effective sound box.

Figure 13.15 Short (a) and long (b) odeng talang jaran jew's harp: 1) ulu, head; 2) jella', tongue; 3) batok, neck; 4) osa, body; 5) pen, end part.
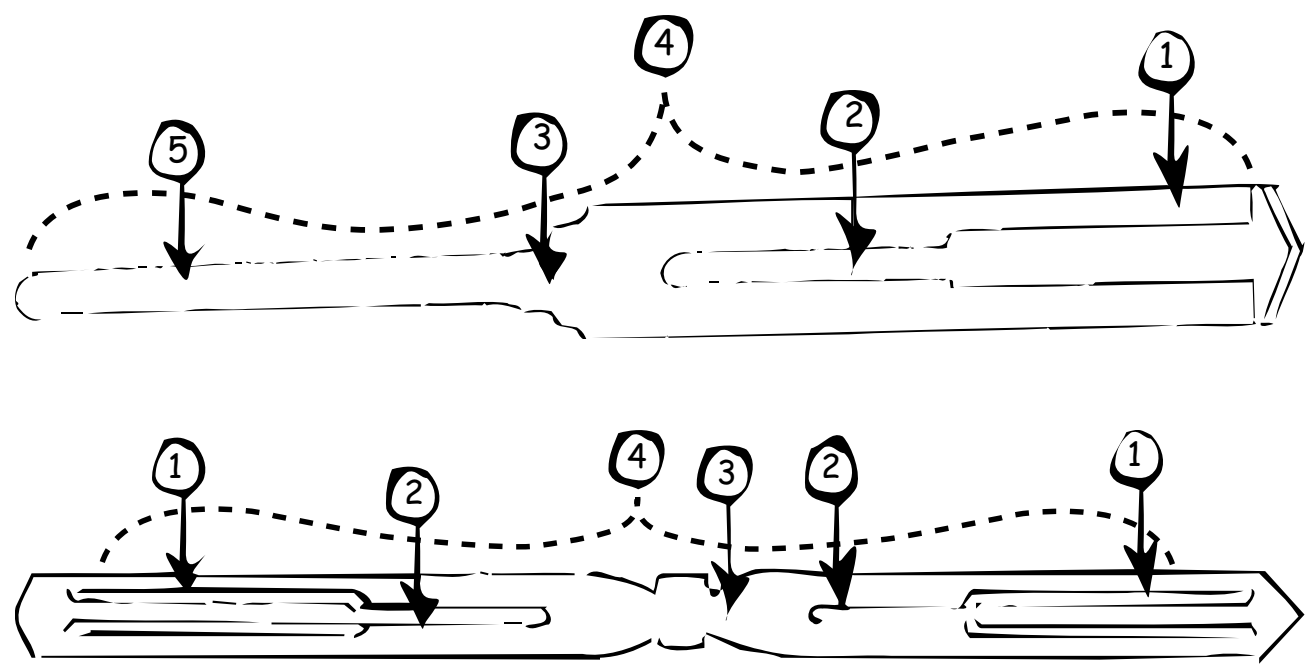


\section{The Geng Galeng}

The geng galeng is an instrument that resembles a xylophone. It has seven bars made of light wood and is approximately 20-50 cm long and 5-10 cm wide (see Figures 13.16 and 13.17). If two instruments are used, one geng galeng plays the melody and the other the accompaniment. It is also possible for two players to play the melody and the accompaniment alternately to give variation to the song. The geng galeng uses a pentatonic scale, but because their number can be increased, the geng galeng can also be used for playing songs with a diatonic scale. The geng galeng is played sitting on a bench that is $25 \mathrm{~cm}$ long and $7-10 \mathrm{~cm}$ high. The player's legs are crossed and his knees up as he faces the instrument. Both hands hold two round pieces of wood as beaters (tit), which are $20 \mathrm{~cm}$ long and $2-3 \mathrm{~cm}$ in diameter. Both hands are equally active.

Figure 13.16 The pentatonic geng galeng xylophone

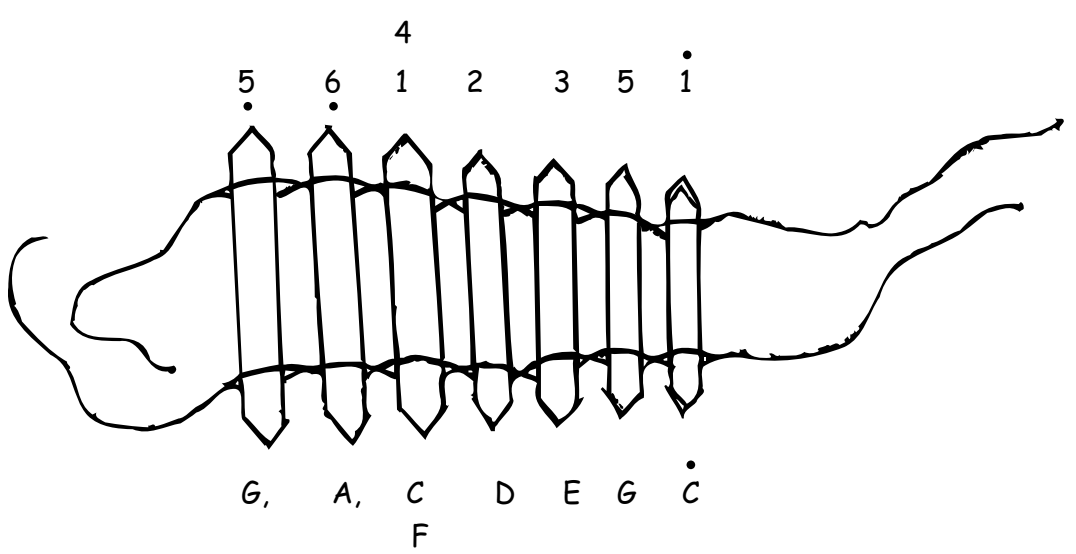

Figure 13.17 Leppo' Ma'ut musician Oko' Wak playing the geng galeng

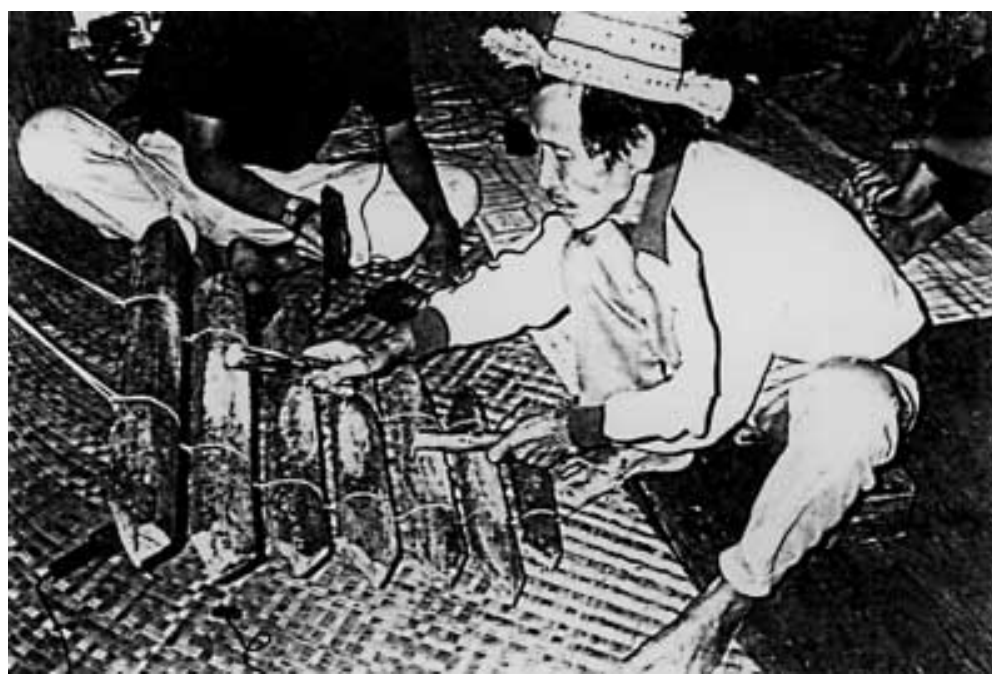


The music of the geng galeng is often heard during the planting season, from the time when the fields are burned until the end of the harvest. Since former times, this musical instrument has been made for playing during leisure time (initially it was not intended to accompany songs and dances); It was made from dry pieces of wood left over from the burning of the fields. It was usually played by men. Today, it is often used to accompany dancing or singing, along with the sambi'. It can even be combined with the sound of the guitar, of empty bottles, or of the ribs of palm leaves. The geng galeng can be used for entertaining people who are spending the night in the fields (referred to as todo), especially at weeding time and when harvesting. In the fields, the geng galeng is not only played for entertainment, but also to chase away pest animals (pigs, deer, monkeys, birds, and others) that threaten the crops. 


\section{References and selected literature}

Abdoellah, Oekan, et al. 1993 Communities and Forest Management in East Kalimantan: Pathway To Environmental Stability. International and Area Studies, Berkeley.

Abdurrahman, S.H. 1978 Kedudukan Hukum Adat dalam Rangka Pembangunan Nasional. Penerbit Alumni, Bandung.

Abdurrahman, S.H. 1984a Hukum Adat Menurut Peraturan Perundang-undangan Indonesia. Cendana Press, Jakarta.

Abdurrahman, S.H. 1984b Kedudukan Hukum Adat dalam Perundang-undangan Agraria Republik Indonesia. Akademika Pressindo, Jakarta.

Abdurrahman, S.H., M. H. 1990 Kedudukan Hukum Adat dalam Kerangka Hukum Nasional. Paper to Seminar Adat Masyarakat Dayak se-Kabupaten Kutai, Tenggarong, 9-11 November 1990.

Abidin, Z. 1987 Dasar Pengetahuan IImu Tanaman. Angkasa, Bandung.

Acciaioli, G. 1985 Culture as art: from practice to spectacle in Indonesia. Canberra Anthropology 8: (1-2): 148-172.

Adiwirata, S. 1983 Pengertian Hukum Adat Menurut Undang-undang Pokok Agraria. Penerbit Alumni, Bandung.

Alcorn, J. et al. 1990 Deforestation and What We Can Learn From Indians. American Anthropological Association, New Orleans.

Aliana, Z.A. et al. 1992 Sastra Lisan Bahasa Melayu Belitung. Pusat Pembinaan dan Pengembangan Bahasa, Departemen Pendidikan dan Kebudayaan, J akarta.

Alisjahbana, S. T. 1974 Values as Integrating Forces in Personality, Society and Culture: Essay of a New Anthropology. University of Malaya Press, Kuala Lumpur.

Aliza Diniasti 1986 Pola hias gores pada gerabah di beberapa situs paleometalik di Indonesia. In: Pertemuan IImiah Arkeologi IV 1986 vol. IIB, 83-88. Puslit Arkenas, Departemen Pendidikan dan Kebudayaan, Jakarta.

Angguk Lamis 1995 Penguasaan tanah berdasarkan hukum adat pada masyarakat Kenyah Leppo' Ma' ut di Long Alango. Report. Culture \& Conservation, Kayan Mentarang Conservation Project, WWF and Direktorat Jenderal Pelestarian Alam dan Perlindungan Hutan, Jakarta. 
Anonymous 1977 Population and Social Structure. Report No. 8. Transmigration Area Development Project, Samarinda.

Anonymous 1982 Pertanahan dalam Era Pembangunan Indonesia. Departemen Penerangan Republik Indonesia, J akarta.

Anonymous 1988 Hasil seminar Peranan Hukum Adat dalam Menunjang Pembangunan Menghadapi Era Tinggal Landas. Panitia, Seminar Peranan Hukum Adat, Fakultas Hukum, Universitas Tanjungpura, Pontianak.

Anonymous 1989 Proposal Pembangunan Wilayah Perbatasan Kalimantan Timur (Rencana Pembangunan dan Pemanfaatan Potensi Lahan Hutan Wilayah Perbatasan dalam Rangka Memperoleh Dana Bantuan Luar Negeri). Pemerintah Daerah Propinsi Tingkat I Kalimantan Timur, Samarinda.

Anonymous 1990a Bentuk-bentuk Peralatan Hiburan dan Kesenian. Balai Pustaka, J akarta.

Anonymous 1990b Kalimantan Timur Dalam Angka. Kantor Statistik Propinsi Kalimantan Timur, Samarinda.

Anonymous 1990c Pemanfaatan Hutan dan Pembangunan Pedesaan. Asosiasi Pengusaha Hutan Indonesia. Manggala Wanabakti, Jakarta.

Anonymous 1992 Penelitian Suku Terasing Kenyah Kalimantan Timur. Report. Direktorat Sej arah dan Nilai Tradisional, Direktorat J enderal Kebudayaan, Departemen Pendidikan dan Kebudayaan, Jakarta.

Apuy La'ing Kelong n.d. Sejarah Perpindahan Kenyah Badeng. Manuscript. Tanjung Selor. Ardans, H.M. 1993 Materi Ceramah Gubernur Kepala Daerah Tingkat I Kalimantan Timur. Pentaloka Dosen Kewiraan. Samarinda.

Arensberg, C. M. 1971 Introducing Social Change: A Manual for Community Development. Aldine-Altherton, Chicago.

Arman, Syamsuni 1989 Perladangan Berpindah dan Kedudukannya dalam Kebudayaan Suku-suku Dayak di Kalimantan Barat. Suara Almamater, Universitas Tanjungpura, Pontianak.

Aryandini Novita and Krisprihartini S. 1995 Analisis Temuan Alat Batu dan Gerabah dari Apau Ping 1991-1993. Report. Culture \& Conservation, Kayan Mentarang Conservation Project, WWF and Direktorat Jenderal Pelestarian Alam dan Perlindungan Hutan, J akarta.

Atan Hamju and Armilla Windawati 1978 Pengetahuan Seni Musik. Aries Lima, Seri Teori dan Lagu. J akarta.

Atmadja, N. B. 1993 Pengelolaan Hutan Wisata Kera Sangeh oleh Desa Adat Sangeh. Ekonesia 1 (1): 1-22.

Bachsan Mustafa, S.H. 1984 Hukum Agraria dalam Perspektif. Remaja Karya, Bandung.

Bahari Sindju, H. 1993 Konsep pemilikan tanah pada suku Dayak Kanayatan. Kalimantan Review 5: 13-18.

Baier, M. 1979 Zur Steinsetzung und Steinbearbeitung Innerborneos. Tribus 28: 70-82.

Baier, M. 1987 Megalithische Monumente des Bahau-Gebiets (Kecamatan Pujungan/ nordliches Zentralborneo). Tribus 36: 117-128.

Baier, M. 1992 Steinsarkophage und Urnendolmen. Tribus 41: 161-175.

Barbour, M.G., Burk, J.H. and Pitts, W.D. 1980 Terrestrial Plant Ecology. The Benjamin/ Cummings Publishing Company, Menlo Park, California.

Barne, K. 1958 Listening to the Orchestra. Dent and Sons, London. 
Barth, F. 1987 Cosmologies in the Making. Cambridge University Press, Cambridge.

Barth, F. 1989 The analysis of culture in complex societies. Ethnos 3-4: 120-142.

Beattie, J. 1977 Other Cultures: Aims, Methods and Achievements in Social Anthropology. Routledge and Kegan Paul, London.

Beer, J. de, and McDermott, M. 1989 The Economic Value of Non Timber Forest Products in Southeast Asia with Emphasis on Indonesia, Malaysia and Thailand. The Netherlands Committee for IUCN. Amsterdam.

Bellon, M.R. 1991 The ethnology of maize variety management: A case study from Mexico. Human Ecology 19: 389-418.

Benedict, R. 1966 Pola-pola Kebudayaan. Translated by Sumantri Martodipoero. Dian Rakyat, Bandung.

Bennett, J. W. 1976 The Ecological Transition: Cultural Anthropology and Human Adaptation. Pergamon Press, New York.

Bennett, J. W. 1980 Human ecology as human behavior: A normative anthropology of resource use and abuse. In: Altman, I. et al. (eds) Human Behavior and Environment: Advances in Theory and Research, 243-277. Plenum Press, New York.

Beratha, I.N. 1982 Masyarakat Desa dan Pembangunan Desa. Ghalia Indonesia, J akarta.

Berdichewsky, B. (ed.) 1979 Anthropology and Social Change in Rural Areas. Mouton, New York.

Berelson, B. 1971 Content Analysis in Communication Research. Hafner Publishing Company, New York.

Birkeland, P.W. 1974 Pedology, Weathering, and Geomorphological Research. Oxford University Press, Oxford.

Black, J. 1985 The Lastposten: Eastern Kalimantan and the Dutch in the nineteenth and early twentieth centuries. J ournal of Southeast Asian Studies 16 (2): 281-291.

Bloch, M. 1991 Language, anthropology and cognitive science. Man 26: 183-198.

Bloch, M. 1992 What Goes Without Saying. The Conceptualization of Zafimaniry Society. In: Kuper, A. (ed.) Conceptualizing Society, 127-146. Routledge, London.

Blust, R. A. 1972 Report of linguistic field work undertaken in Sarawak. Borneo Research Bulletin 4(1): 12-14.

Bodley, J.H. 1976 Anthropology and Contemporary Human Problems. Cummings, Menlo Park, CA.

Borofsky, R. 1987 Making History: Pukapukan and Anthropological Constructions of Knowledge. Cambridge University Press.

Boster, J.S. 1986 Exchange of varieties and information between Aguaruna manioc cultivators. American Anthropologist 88: 428-436.

Bourdelon, G. 1957 Les Dayak. 16-mm film.

Brechin, S.R., Wilshusen, P.R., Fortwangler, C.L. et al. 2002 Beyond the square wheel: toward a more comprehensive understanding of biodiversity conservation as social and political process. Society and Natural Resources 15 (1): 41-64.

Brookfield, H.C., Potter, L. and Byron, Y. 1995 In Place of the Forest: Environmental and Socio-Economic Transformation in Borneo and the Eastern Malay Peninsula. Tokyo: United Nations University Press.

Brosius, J .P. 1986 River, forest and mountain: the Penan Gang landscape. Sarawak Museum Journal 36(57): 173-184. 
Brosius, J.P. 1992 The Axiological Presence of Death Among the Penan Gang of Sarawak, Malaysia. Ph.D. dissertation in Anthropology, University of Michigan, Ann Arbor. University Dissertation Publications.

Brosius, P. 2001 Results of the Workshop on Conservation and Community. An Initiative of the Conservation and Community Working Group, Anthropology and Environment Section, American Anthropological Association. Unpublished manuscript.

Brosius, P., Lowenhaupt Tsing, A. and Zerner, C. 1998 Representing communities: histories and politics of community-based natural resource management. Society and Natural Resources 11: 157-168.

Brush, S., and Stabinsky, D. (eds.) 1995 Valuing Local Knowledge: Indigenous People and Intellectual Property Rights. Island Press, Washington, DC.

Budi Harsono, S.H. 1982 Hukum Agraria Indonesia. Himpunan Peraturan Perundangundangan Peraturan Hukum Tanah. Djambatan, Jakarta.

Bunde, Y. P. 1995 Pola Penguasaan Hak Atas Tanah pada Masyarakat Kenyah Bakung di Long Apan Baru. Report. Culture \& Conservation, Kayan Mentarang Conservation Project, WWF and Direktorat Jenderal Pelestarian Alam dan Perlindungan Hutan, J akarta.

Bushar Muhammad, S.H. 1981 Azas-Azas Hukum Adat (Suatu Pengantar). 3rd ed. Pradnya Paramita, Jakarta.

Bushar Muhammad, S.H. 1985 Pokok-pokok Hukum Adat. Pradnya Paramita, J akarta.

Caldecott, J.O. 1988 Hunting and Wildlife Management in Sarawak. IUCN, Cambridge.

Caldecott, J.O. 1990 Eruptions and migrations of bearded pig populations. Bongo 18: 212.

Catford, J.C. 1965 A Linguistic Theory of Translation. Oxford University Press, London.

Cense, A.A., and Ühlenbeck, E.M. 1958 Critical Survey of Studies on the Languages of Borneo. Martinus Nijhoff, Gravenhage.

Cernia, M. M. 1988 Unit-unit Alternatif Organisasi Sosial untuk Mendukung Strategi Penghutanan Kembali. In: Cernea, M.M. (ed.) Mengutamakan Manusia di dalam Pembangunan, 341-375. Translated by Basilius Bengo Teku. Penerbit Universitas Indonesia, Jakarta.

Chambers, R. 1994 The origins and practice of participatory rural appraisal. World Development 22(7): 953-969.

Chang, T.T., Sharma, S.D., Adair, C.R. and Perez, A.T. 1972 Manual for Field Collectors of Rice. International Rice Research Institute, Los Baños.

Charon, J oel M. 1979 Symbolic Interaction. Prentice Hall, New York.

Chartier, D. and Sellato, B. 1998 La Prise en Compte des Pratiques et des Usages Autochtones: Réalité Efficiente ou Construction Occidentale à Visée Néolibérale. Interférences Entre Chercheurs et Opérateurs/ Bailleurs de Fonds. Paper to Second Conference on 'Dynamiques Sociales et Environnement.' Bordeaux, France, September 1998.

Chartier, D. and Sellato, B. 2003 Les savoir-faire traditionnels sont-ils au service de la conservation de la nature ou au service des ONG internationales d'environnement? In: Rodary, E. (ed.) Dynamiques sociales et environnement. Karthala, Paris.

Chin, S.C. 1985 Agriculture and resource utilization in a lowland rainforest Kenyah community. Sarawak Museum J ournal Special Monograph No. 4.

Clayre, B. M. 1970 Focus: a preliminary survey of some languages of eastern Malaysia. Sarawak Museum Journal 18 (36-37): 193-219. 
Clayre, I.F.C.S 1970 Some notes on Sa'ban. Work in Progress 4: 112-119. Department of Linguistics, Edinburgh University.

Cohn, J. 1988 Culture and conservation. Bioscience 38 (7): 450-453.

Colfer, C. 1981 Women, men and time in the forests of East Kalimantan. Borneo Research Bulletin 13 (2): 75-85.

Colfer, C. 1983 Change and indigenous agroforestry in East Kalimantan. Borneo Research Bulletin 15 (1): 3-21.

Colfer, C. 1993 Shifting Cultivators of Indonesia: Marauders or Managers of the Forest? (with Dudley, R.G. and in collaboration with Hadikusumah, H., Rusydi, Sakuntaladewi, N. and Amblani). Community Forestry Case Study Series No. 6. Food and Agriculture Organization (FAO), Rome.

Colfer, C. et al. 1988 An indigenous agricultural model from West Sumatra: a source of scientific insight. Agricultural Systems 26: 191-209.

Colson, E. 1979 In good years and in bad: Food strategies of self-reliant societies. J ournal of Anthropological Research 35: 18-29.

Conklin, B. and Graham, L. 1995 The shifting middle ground: Amazonian Indians and eco-politics. American Anthropologist 97 (4): 695-710.

Conklin, H. 1957 Hanunoo Agriculture. Food and Agriculture Organization (FAO) United Nations, Rome.

Conley, W. W. 1973 The Kalimantan Kenyah: A Study of Tribal Conversion in Terms of Dynamic Cultural Themes. Presbyterian and Reformed Publishing Company, Nurley, New York.

Conley, W. W. 1974 Kenyah cultural themes and their interrelationships. Sarawak Museum J ournal 22 (43): 304-309.

Coomans, M. 1987 Manusia Daya, Dahulu, Sekarang, Masa Depan. Gramedia, Jakarta.

Crain, J.B. 1970 The Lun Dayeh of Sabah, East Malaysia: Aspects of Marriage and Social Exchange. Ph.D. thesis, Cornell University. University Microfilms International, Ann Arbor.

Crain, J.B. 1978 The Lun Dayeh. In: King, V.T. (ed.) Essays on Borneo Societies, 123142. Hull Monographs on South-East Asia, No. 7. Oxford University Press, London.

Damus, D. 1992 Pengetahuan tentang Varietas Padi dan Tipe Budidayanya pada Masyarakat Dayak Hulu Sungai Bahau, Kalimantan Timur. Paper to the Second Biennial International Conference of the Borneo Research Council, Kota Kinabalu, J uly 1992.

Damus, D. 1995 Pengetahuan tentang Varietas Padi dan Tipe Budidayanya pada Masyarakat Dayak Hulu Sungai Bahau. Report. Culture \& Conservation, Kayan Mentarang Conservation Project, WWF and Direktorat Jenderal Pelestarian Alam dan Perlindungan Hutan, J akarta.

Davis, K. 1949 Human Society. MacMillan, New York.

Davis, S. and Ebbe, K. (eds.) 1995 Traditional Knowledge and Sustainable Development. Proceedings of a conference held at the World Bank, Washington, D.C. September 27-28, 1993. The World Bank, ESD. Washington, D.C.

Devung, G. S. 1985 Laporan. Report.

Devung, G. S. 1993 Kelompok Suku Dayak Kenyah di Sungai Alan: Suatu Kasus Perubahan Kebudayaan. Report. Departemen Pendidikan dan Kebudayaan, Samarinda.

Devung, G. S. 1996 Praktik dan Pranata Tradisional Pemanfaatan dan Pengelolaan Sumber Daya Hutan di Daerah Sungai Bahau, Kalimantan Timur. Magister thesis, Program Studi Antropologi, Program Pasca Sarjana Universitas Indonesia, Jakarta. 
Devung, G. S. and Michael, S.E., M.S. 1990 Potensi Adat Masyarakat Dayak Bahau untuk Pengembangan Program Kepariwisataan dan Pembangunan Daerah. Paper to Seminar Adat Dayak Se-Kabupaten Kutai, Tenggarong, 9-11 November 1990.

Devung, G. S. et al. 1984-85 Penelitian Suku Terasing Kenyah Kalimantan Timur (Kelompok Suku Dayak Kenyah di Sungai Alan. Suatu Kasus Perubahan Kebudayaan). Report. Proyek Inventarisasi dan Dokumentasi Kebudayaan Daerah, Direktorat Sejarah dan Nilai Tradisional, Departemen Pendidikan dan Kebudayaan, J akarta.

Dixon, A., Roditi, H. and Siverman, L. 1991 From Forest To Market. A Feasibility Study of the Development of Selected Non Timber Forest Product from Borneo for the U.S. Market. Volume I: The Report. Project Borneo, Cambridge, Massachussetts.

Dody J ohanj aya, Anggara Yonathan, and Yoga Prima Subandono 1995 Inventorisasi Kuburan Tempayan Dolmen Di Daerah Hulu Sungai Bahau. Report. Culture \& Conservation, Kayan Mentarang Conservation Project, WWF and Direktorat J enderal Pelestarian Alam dan Perlindungan Hutan, J akarta.

Douglas, R.S. 1911 A comparative vocabulary of the Kayan, Kenyah and Kelabit dialects. Sarawak Museum J ournal 1 (1): 146-148.

Dove, M. 1985a Swidden Agriculture in Indonesia: The Subsistence Strategies of the Kalimantan Kantu. Mouton, Berlin.

Dove, M. R. (ed.) 1985b Peranan Kebudayaan Tradisional Indonesia dalam Modernisasi. Yayasan Obor Indonesia, Jakarta.

Dove, M. 1988a The Real and Imagined Role of Culture in Development. Case Studies from Indonesia. University of Hawaii Press, Honolulu.

Dove, M. R. 1988b Sistem Perladangan di Indonesia: Suatu Studi Kasus Dari Kalimantan Barat. Gadjah Mada University Press, Yogyakarta.

Dove, M. 1992 Foresters' beliefs about farmers: a priority for social science research in social forestry. Agroforestry Systems 17: 13-41.

Dove, M. R. 1993 Uncertainty, humility, and adaptation in the tropical forest: The agricultural augury of the Kantu'. Ethnology 40: 145-167.

Dove, M. and Kammen, D. 1997 The epistemology of sustainable resource use: Managing forest products, swiddens, and high-yielding variety crops. Human Organization 56 (1): 91-101.

Dove, M. and Tri Nugroho. 1994 Review of 'Culture and Conservation' 1991-1994. Report. A Subproj ect Funded by the Ford Foundation, World Wide Fund for Nature, Kayan Mentarang Nature Reserve Project in Kalimantan, Indonesia. Ford Foundation, Jakarta.

Dransfield, J. 1979 A manual of the rattans of the Malay Peninsula. Forestry Rec. 29. Forestry Dept., West Malaysia.

Dresden, S. 1952 Algemene Muziekleer. J.B. Wolters, Jakarta.

Duff, R. 1970 Stone Adzes of Southeast Asia. Canterbury Museum, Christchurch.

Dunsmore, S. 1985 Iban Pottery. Occasional Paper No. 5, Sarawak Museum, Kuching.

Eghenter, C. 1995 Knowledge, Action, and Planning: A Study of Long-distance Migrations among the Kayan and Kenyah of East Kalimantan, Indonesia. Ph.D. thesis, Rutgers University.

Eghenter, C. 1997 Cultural Dimensions of Forest Management in and around the Kayan Mentarang Conservation Area, East Kalimantan. Final Report on training, fieldwork, and dissemination activities of the Culture and Conservation program, 19951997. WWF and Ford Foundation. Jakarta. 
Eghenter, C. 1999a Research Strategies, Conservation Objectives, and Community Participation: The Third Phase of the Culture and Conservation Program, Kayan Mentarang Project, WWF-I. In: King, V.T. (ed.) Rural Development and Social Science Research: Cases from Borneo. Borneo Research Council Proceedings Series 6: 35-45. Williamsburg, VA.

Eghenter, C. 1999b Migrants' practical reasonings: the social, political, and environmental determinants of long-distance migrations among the Kayan and Kenyah of the interior of Borneo. Sojourn 14 (1): 1-33.

Eghenter, C. 2000a What is Tana Ulen good for? Considerations on indigenous forest management, conservation, and research in the Interior of Indonesian Borneo. Human Ecology 28 (3): 331-357.

Eghenter, C. 2000b Mapping Peoples' Forests: The Role of Mapping in Planning Communitybased Management of Conservation in Indonesia. Biodiversity Support Program. Washington DC.

Eghenter, C. 2000c Histories of Conservation or Exploitation? Case Studies from the Interior of Indonesian Borneo. Paper to IIAS/BRC International Seminar, Environmental Change in Native and Colonial Histories of Borneo: Lessons from the Past, Prospects for the Future. Leiden, The Netherlands, 11-12 August 2000.

Eghenter, C. 2001 Towards a causal history of a trade scenario in the interior of East Kalimantan, Indonesia, 1900-1999. Bijdragen Tot de Taal-, Land- en Volkenkunde 157 (4): 739-769.

Eghenter, C. 2002 Planning for Community-based Management of Conservation Areas: Indigenous Forest Management and Conservation of Biodiversity in the Kayan Mentarang National Park, East Kalimantan, Indonesia. In: Chatty, D. and Colchester, M. (eds.) Conservation and Mobile Indigenous Peoples. Displacement, Forced Settlement and Sustainable Development. Refugee Studies Programme. Berghahn Publishers, London.

Eghenter, C. and Sellato, B. (eds.) 1999 Kebudayaan dan Pelestarian Alam. Penelitian Interdisipliner di Pedalaman Kalimantan. World Wide Fund for Nature Indonesia, J akarta.

Ellen, R.F. 1986 What Black Elk left unsaid. On the illusory images of green primitivism. Anthropology Today 2 (6): 8-12.

Erd, Th. van den 1988 Ragi Cerita. BPK Gunung Mulia, J akarta.

Evans, I. H. N. 1955 Bajau pottery. Sarawak Museum J ournal 6 (5): 297-300.

Fischer, L.S. and Gramberg, H. 1910 Tochten naar Boven-Boeoloengan en de Apo-Kajan. Tij dschrift van het Koninklijk Ned. Aardrij kskundig Genootschap 27: 263-306.

Fisher, A.B. 1980 Small Group Decision Making. McGraw-Hill, New York.

Foster, G. M. 1962 Traditional Cultures and The Impact of Technological Change. Harper and Row, New York.

Fox, J. J. (ed.) 1992 The Heritage of Traditional Agriculture among the Western Austronesians. The Australian National University, Canberra.

Franz, J.F. von 1988 Population Development in East Kalimantan 1971-1987. Technical Cooperation for Area Development (TAD), Technical Report No. 88-10. Samarinda.

Freeman, D. 1970 Report on the Iban. London School of Economics Monographs on Social Anthropology. The Athlone Press, London.

Freeman, J.D. 1955 Iban Agriculture: A Report on the Shifting Cultivation of Hill Rice by the Iban of Sarawak. HMSO, London. 
Freeman, J. D. 1957 Iban pottery. Sarawak Museum J ournal 8 (10): 153-176.

Fujisaka, S. 1986 Pioneer shifting cultivation, farmer knowledge, and an upland ecosystem: Co-evolution and systems sustainability in Calminoe, Philippines. Philippine Quarterly of Culture and Society 14: 137-164.

Fuj isaka, S. 1987 Filipino upland farmers: informal ethnoscience for agricultural development research. Philippine Studies 35: 403-419.

Fujisaka, S., Elliot, P., Jayson, E. and Dapusala, A. 1992 Where There Has Been No 'Green Revolution': Farmers' Upland Rices and Related Knowledge In Mindanao, Philippines. Paper to the Sustainable Upland Agriculture Workshop, Baguio, Philippines, December 1992.

Galvin, A.D. 1967 Kenyah Vocabulary Lepo' Tau. Manuscript.

Galvin, A.D. 1975 Tribal authority among the Kenyahs. Sarawak Museum J ournal 23 (44): 91-94.

Guelke, L. 1982 Historical Understanding in Geography. Cambridge University Press, Cambridge.

Guerreiro, A.J . 1992 Some aspects of change among the Baluy Kayan. Sarawak Museum J ournal 43 (64): 47-105.

Guerreiro, A. and Sellato, B. 1984 Traditional migration in Borneo: the Kenyah case. Borneo Research Bulletin 16 (1): 12-28; 16 (2): 76-81.

Gun Kila 1949 Sebuah Cerita Mengenai Perjalanan Hidup Suku Kenyah Apau Kayan Pada Umumnya, Khususnya Lepo' Tau dan Lepo' Timai. Manuscript. Rewritten by Ului Tanyit (1969) and Lencau Ingkong (1988).

Gunadi Nh. [Nitihaminoto] 1983 Penelitian gerabah berhias pantai selatan J awa Tengah, J awa Timur. In: Rapat Evaluasi Hasil Penelitian Arkeologi I 1982, vol. IIA, 146-150. Puslit Arkenas, Departemen Pendidikan dan Kebudayaan, Jakarta.

Haar Bzn., B. ter 1980 Asas-asas dan Susunan Hukum Adat. 5th ed. Translated by K. Ng. Soebakti Poesponoto. Pradnya Paramita, Jakarta.

Hakim, N. et al. 1986 Dasar-dasar IImu Tanah. Universitas Lampung, Bandar Lampung.

Hanye, P. 1995 Sastra Lisan pada Masyarakat Kenyah Bakung di Long Apan Baru. Report. Culture \& Conservation, Kayan Mentarang Conservation Project, WWF and Direktorat J enderal Pelestarian Alam dan Perlindungan Hutan, Jakarta.

Hardjowigeno, S. 1993 Klasifikasi Tanah dan Pedogenesis. Akademika Pressindo, J akarta.

Harrisson, T. 1955 The distribution and general character of native pottery in Borneo. Sarawak Museum J ournal 6 (5): 301-306.

Harrisson, T. 1959a World Within. A Borneo Story. Cresset Press, London.

Harrisson, T. 1959b More 'megaliths' from inner Borneo. Sarawak Museum J ournal 9 (13-14): 14-20.

Harrisson, T. 1959c The Kelabits and Muruts. In: Harrisson, T. (ed.) The Peoples of Sarawak, 57-71. Gov. Printing Office, Kuching.

Harrisson, T., and O'Connor, S.J. 1970 Gold and Megalithic Activity in Prehistoric and Recent West Borneo. Data Paper No. 77. Southeast Asia Program, Department of Asian Studies, Cornell University, New York.

Headland, T. 1997 Revisionism in ecological anthropology. Current Anthropology 38 (4): 605-630.

Healy, K. 1994 The recovery of cultural resources for development. In: 1994 Festival of American Folklife Program, 14-19. Smithsonian Institution and National Park Service, Washington, D.C. 
Hein, A.R. 1890 Die Bildende Künste bei den Dajaks auf Borneo. Alfred Hölder, Vienna. Henoch Merang 1970 Sejarah Apo Kayan. Akademi Pemerintahan Dalam Negeri, Samarinda.

Hildebrand, H. K. 1982 Die Wildbeutergruppen Borneos. Münchner Ethnologische Abhandlungen, Vol. 2. Institut für Völkerkunde und Afrikanistik, Münchner Universitätsschriften. Minerva Publikation, München.

Hilman Hadikusuma, S.H. 1984 Ensiklopedi Hukum Adat dan Adat Budaya Indonesia. Penerbit Alumni, Bandung.

Hilman Hadikusuma, S.H. 1987 Hukum Kekerabatan Adat. Fajar Agung, Jakarta.

Hilman Hadikusuma, S.H. 1988 Hukum Waris Adat. 2nd ed. Penerbit Alumni, Bandung. Hoffman, C. F. 1985 Punan Liar di Kalimantan: Alasan Ekonomi. In: Dove, M.R. (ed.) Peranan Kebudayaan Tradisional Indonesia dalam Modernisasi, 123-162. Yayasan Obor, Jakarta.

Holsti, O. R. 1969 Content Analysis for the Social Sciences and Humanities. AddisonWesley Publishing Co., Reading, Massachussetts.

Hong, E. 1987 Natives of Sarawak. Survival in Borneo's Vanishing Forest. Institut Masyarakat Malaysia, Pulau Pinang.

Honigmann, D. 1959 The World of Man. Harper \& Row, New York and Evanston.

Hose, C. 1988 (1926) Natural Man. A Record of Borneo. Oxford University Press, Singapore.

Hose, C. and McDougall,W. 1966 (1912) The Pagan Tribes of Borneo. McMillan, London. 2 vols.

Hudson, A. B. 1978 Linguistic relations among Bornean peoples with special reference to Sarawak: An interim report. Studies in Thirld World Societies 3: 1-44.

Humardani, G. 1981 Masalah-masalah Dasar Pengembangan Seni Tradisionil. Aksi, Surakarta.

Iman Sudiyat 1981 Hukum Adat. Sketsa Azas. Liberty, Yogyakarta.

Iman Sudiyat 1982 Asas-asas Hukum Adat. Bekal Pengantar. Liberty, Yogyakarta.

Ingerson, A.E. 1997 Comment on T. Headland's 'Revisionism in ecological anthropology'. Current Anthropology 38 (4): 615-616.

Ipoi Datan 1989 A brief ethnography of the Lun Bawang of Sarawak. Sarawak Museum Journal 40 (61), Special Issue No. 4, Part III, pp. 143-156.

Irene A. Muslim, S.H. 1991 Peradilan Adat pada Masyarakat Daya di Kalimantan Barat. Speech (Pidato Pengukuhan Guru Besar), 15 J une 1991. Fakultas Hukum, Universitas Tanjungpura, Pontianak.

J acobus E. Frans L., S. 1988 Watas dan Hak Ulayat dan Hak-hak Serupa Itu dalam Pandangan Masyarakat Hukum Adat di Kalimantan Barat. Biro PSE, Keuskupan Agung Katolik, Pontianak.

Jacobus E. Frans L., S. 1995 Hak Milik Adat atas Tanah Pada Masyarakat Suku Bangsa Dayak Kenyah di Kecamatan Long Puj ungan. Report. Culture \& Conservation, Kayan Mentarang Conservation Project, WWF and Direktorat Jenderal Pelestarian Alam dan Perlindungan Hutan, Jakarta.

J essup, T. C. 1981 Why do Apo Kayan shifting cultivators move? Borneo Research Bulletin 13: $16-32$.

J essup, T. C. 1991 Keberlangsungan (Persistensi) dan Perubahan Dalam Kebiasaan Berladang di Apau Kayan, Kalimantan Timur. Unpublished report, Kayan Mentarang Conservation Project, WWF and Direktorat Jenderal Pelestarian Alam dan Perlindungan Hutan, Jakarta. 
Jessup, T.C. 1992 Persistence and change in the practice of shifting cultivation in the Apo Kayan, East Kalimantan, Indonesia. In: Fox, J.J. (ed.) The Heritage of Traditional Agriculture among the Western Austronesians, 21-32. Research School of Pacific Studies (Comparative Austronesian Project) and Department of Anthropology, Australian National University, Canberra.

J essup, T. C. 1993a Longhouses of East Kalimantan. Kalimantan Review II (3): 16-20.

J essup, T. C. 1993b The Kayan Mentarang Nature Reserve: nature conservation by and for the people in East Kalimantan. Conservation Indonesia 9 (3): 16-22.

J essup, T.C. n.d.1 Preliminary Report on Migration and Trading. Manuscript.

J essup, T.C. n.d.2 Appendix to Notes on Migration and Settlement. Manuscript.

J essup, T.C., and Mackie, C. 1984 A response to Guerreiro and Sellato on Kenyah migration. Borneo Research Bulletin 16 (2): 81-84.

J essup, T.C., and Peluso, N.L. 1986 Minor forest product as common property resources in East Kalimantan, Indonesia. In: Proceedings of the Conference on Common Property Resources Management, April 21-26, 1985, 505-531. National Academy Press, Washington, D.C.

J essup, T.C. and Sellato, B. 1990 Field Project in Oral Tradition and Social Forestry in East Kalimantan, Indonesia. A proposal to the Ford Foundation by the World Wide Fund for Nature (October). WWF-I, J akarta.

J essup, T.C. and Sellato, B. 1993 Culture and Conservation in East Kalimantan. Report on the First Phase of Training and Field Work, 1991-1992, in the Kayan Mentarang Nature Reserve and Vicinity. WWF/IP (February). WWF-I, J akarta.

Jessup, T.C. and Sellato, B. 1995 Cultural Dimensions of Forest Management In and Around the Kayan Mentarang Conservation Area, East Kalimantan, Indonesia. A proposal to the Ford Foundation from the World Wide Fund for Nature Indonesia Programme (J uly). WWF-I, J akarta.

J essup, T. C. , Soedj ito, H. and Kartawinata, K. 1993 Konsep Cagar Biosfir Kayan Mentarang: Pendekatan Baru Untuk Pengembangan Konservasi di Kalimantan Timur. Manuscript. WWF and Direktorat J enderal Pelestarian Alam dan Perlindungan Hutan, J akarta.

J iuhardi and Trivena 1990 Adat Suku Dayak Kenyah. Paper to Seminar Adat Dayak seKabupaten Kutai, Tenggarong, 9-11 November 1990.

J ohannes, R.E. 1981 Words of the Lagoon: Fishing and Marine Lore in the Palau District of Micronesia. University of California Press, Berkeley.

Johnson, A. 1974 Ethnoecology and planting practices in a swidden agricultural system. American Ethnologist 1: 87-101.

Kanyan, C. 1995 Pola Penguasaan Hak Atas Tanah pada Masyarakat Leppo' Ke di Apau Ping. Report. Culture \& Conservation, Kayan Mentarang Conservation Project, WWF and Direktorat J enderal Pelestarian Alam dan Perlindungan Hutan, Jakarta.

Karina Arifin 1994 Archaeological Remains in the Kayan Mentarang Area, East Kalimantan. Paper to the Indo-Pacific Prehistoric Association Meeting, Chiang Mai, Thailand.

Karina Arifin 1995 Etnoarkeologi di Kayan Mentarang: Hasil Survei Arkeologi dan Etnografi. Report, Culture \& Conservation, Kayan Mentarang Conservation Project, WWF and Direktorat J enderal Pelestarian Alam dan Perlindungan Hutan, J akarta.

Kartawinata, K., Jessup, T.C. and Soedjito, H. 1992 The Proposed Kayan Mentarang Biosphere Reserve: A New Approach to Conservation and Development in East Kalimantan. Paper to the Second Biennial International Conference of the Borneo Research Council, Kota Kinabalu, Sabah, Malaysia, 13-17 J uly 1992. 
Keesing, F. M. 1958 Cultural Anthropology: The Science of Custom. Rinehart and Co., New York.

King, V. T. (ed.) 1978 Essays on Borneo Societies. Hull Monographs on South-East Asia. No. 7. Oxford University Press, Oxford.

King, V. T. 1978 Revitalization movements in Kalimantan. Indonesia Circle 17: 14-27.

King, V. T. 1985 Kedudukan Sosial dan Perubahan Sosial di Kalangan Suku Maloh, Kalimantan Barat. In: Dove, M.R. (ed.) Peranan Kebudayaan Tradisional Indonesia Dalam Modernisasi, 241-286. Yayasan Obor Indonesia, Jakarta.

King, V. T. 1993 The Peoples of Borneo. Blackwell, Oxford.

King, V.T. 2002 Anthropology, Development and Borneo: A Problematic Relationship. Paper to the Seventh Biennial International Conference of the Borneo Research Council. Universiti Malaysia Sabah, Kota Kinabalu, 15-18 J uly 2002.

Kleymeyer, Charles 1994 Cultural traditions and community-based conservation. In: Western, D., Wright, R.M. and Strum.S. (eds.) Natural Connections: Perspectives in Community-Based Conservation, 323-346. Island Press, Washington, D. C.

Koentjaraningrat 1960 Beberapa Pokok Anthropologi Sosial. Yayasan Penerbit Fakultas Ekonomi Universitas Indonesia. Dian Rakyat, Jakarta.

Koentjaraningrat 1983 Metode-metode Penelitian Masyarakat. Gramedia, Jakarta.

Koentjaraningrat 1990 Metode-metode Penelitian Masyarakat. Gramedia Pustaka Utama, J akarta.

Koesnoe, Moh., S. H. 1988 Beberapa Masalah Adat yang Berhubungan dengan Pembebasan Hak Atas Tanah. Paper to Seminar Hukum Adat, Fakultas Hukum, Universitas Tanjungpura, Pontianak, 12-14 December 1988.

Kalimantan Resource Center (Pusat Kebudayaan dan Alam Kalimantan) 1997 Tekena' Laking Kuyang Ngan Lenjau. Kisah Orang-Hutan dan Harimau. Kalimantan Resource Center (Pusat Kebudayaan dan Alam Kalimantan)/ PKAK, Samarinda.

Krech, D. et al. 1967 Individual in Society. McGraw-Hill, San Francisco.

Kreps, C. 1998 Museum-making and indigenous curation in Central Kalimantan. Museum Anthropology 22 (1): 5-17.

Kroeber, A.L. 1948 Anthropology. Harcourt, Brace and World, New York and Burlingham.

Krohn, W. O. 1991 (1927) In Borneo Jungles. Among the Dyak Headhunters. Oxford University Press, Singapore.

Kusbini 1953 Seni Musik. Yayasan Pembangunan, Jakarta.

Lah Jau Uyo 1989 Kayan people of Sarawak. Sarawak Museum J ournal 40 (61): 57-87.

Lahjie, A.M. and Seibert, B. 1988 Prosiding Seminar Agroforestry untuk Pengembangan Daerah Pedesaan di Kalimantan Timur. Fakultas Kehutanan, Universitas Mulawarman, Samarinda, and GTZ.

Lambert, D.H. 1985 Swamp Rice Farming: The Indigenous Pahang Malay Agricultural System. Boulder and Westview Press, London.

LeBar, F.M. 1970 Note. Legend, culture history, and geomorphology in the KelabitKerayan Highland of north central Borneo. J ournal of the Royal Asiatic Society, Malaysian Branch 43 (1): 183-185.

LeBar, F. M. 1972 Kelabitic Murut. In: LeBar, F. M. (ed.) Ethnic Groups of Insular Southeast Asia, volume 1: Indonesia, Andaman Islands, and Madagascar, 158-163. HRAF Press, New Haven.

Lento 1980 Belajar Seni Musik Praktis. Aries Lima, Jakarta. 
Lewis, R. 1987 Ringkasan Sejarah Gereja Kemah Injil Indonesia 1928-1987. Kalam Hidup, Bandung.

Lieth, H. and Wegner, M.J.A. 1989 Tropical Rain Forest Ecosystem (Biogeographical And Ecological Studies). Ecosystems of the World No. 14B. Elsevier, New York.

Lightfoot, C. et al. 1991 Households, Agrosystems and Rural Resources Management - A Guidebook for Broadening the Concepts of Gender and Farming Systems. Bangladesh Agricultural Institute (BARI), Dhaka.

Liman Lawai 1995 Sejarah Suku-suku Kenyah di Apau Kayan dengan Perhatian Khusus pada Sejarah dan Struktur Masyarakat Suku Kenyah Leppo' Tau. Report. Culture $\&$ Conservation, Kayan Mentarang Conservation Project, WWF and Direktorat J enderal Pelestarian Alam dan Perlindungan Hutan, Jakarta.

Lumholtz, C. S. 1991 Through Central Borneo. Oxford University Press, Singapore. [First ed.: New York: Charles Scribner's Sons, 1920, 2 vols.]

Machlis, J. 1978 Introduction to Contemporary Music. Queens College, New York.

MacKinnon, J. and MacKinnon, K. 1990 Pengelolaan Kawasan Yang Dilindungi Di Daerah Tropik. Translated by Harry Harsono Amir. Gadj ah Mada University Press, Yogyakarta.

Manguin, P.Y. 1995 Report on a survey of archaeological sites, Sungai Bahau, FebruaryMarch 1992. In: Sellato, B. The Ngorek: Lithic and Megalithic Traditions in the Bahau Area and an interdisciplinary Sketch of Regional History, pp. 73-83. Culture $\&$ Conservation, Kayan Mentarang Conservation Project, WWF and Direktorat J enderal Pelestarian Alam dan Perlindungan Hutan, Jakarta.

Manguin, P.Y. and Sellato, B. 1997 The Last Traditional Potter of Borneo. 22-mm video film. Culture \& Conservation, Kayan Mentarang Conservation Project, WWF and Direktorat J enderal Pelestarian Alam dan Perlindungan Hutan, Jakarta and Institut de Recherche sur le Sud-Est Asiatique, Centre National de la Recherche Scientifique, Aix-en-Provence, France.

Martin Lenjau 1995 Keragaman Kerajinan Tangan Dari Rotan Serta Kegunaannya di Desa Long Alango. Report. Culture \& Conservation, Kayan Mentarang Conservation Proj ect, WWF and Direktorat J enderal Pelestarian Alam dan Perlindungan Hutan, Jakarta.

Martin, G. 1997 Editorial. People and Plants Handbook 3: 1-2.

Mayberry-Lewis, D. 1994 Forward: Culture and Development. In: Kleymeyer, C. (ed.) Cultural Expressions and Grassroots Development, ix-xvi. Lynne Reiner Publishers, Boulder.

McCay, B. and Vayda, A.P. 1992 A Question-Based Approach to Research in Ecological Anthropology: Lessons from Applied Research in Fisheries, Forestry, and Conservation. Paper to the Annual Meeting of the American Anthropological Association, San Francisco, December 1992.

McNeely, J. and Pitt, D. (eds.) 1985 Culture and Conservation: The Human Dimension in Environmental Planning. Croom Helm, London.

Mering Ngo, T.H.G. 1988 Luma' Umaa': Suatu Kajian Sistem Perladangan Ulang Alik Orang Kayan Di Desa Padua, Kecamatan Putussibau, Kabupaten Kapuas Hulu, Propinsi Kalimantan Barat. Unpublished BA thesis, Department of Anthropology, Universitas Indonesia.

Mering Ngo, T.H.G. 1989 Antara pemilik dan pemanfaat: kisah penguasaan lahan orang Kayan di Kalimantan Barat. Prisma 4: 73-86.

Mering Ngo, T.H.G. 1991 Ambiguity in property rights: lesson from the Kayan of Kalimantan. Antropologi Indonesia 49: 79-89. 
Misra, K.C. 1974 Manual of Plant Ecology. Oxford and IBH Publ. Co., New Delhi.

Momberg, F. 1992 Indigenous Knowledge Systems: Potentials for Social Forestry Development. Institute for Geography, Freie Universität, Berlin.

Momberg, F., Puri, R.K. and J essup, T.C. 1995 Gaharu Rush in the Kayan Mentarang: Supporting Local Tenure for Conservation. Manuscript.

Morgan, S.H., et al. 1996 Kamus Bahasa Kenyah Leppo' Bakung - Indonesia. Kalimantan Resource Center (Pusat Kebudayaan dan Alam Kalimantan)/ PKAK, Samarinda.

Morrison, A. 1955 Murut pottery. Sarawak Museum J ournal 6 (5): 295-296.

Mubyarto 1992 Mencari Model Penanganan Terpadu Kebijaksanaan Pemukiman Perambah Hutan. LP2IS, FISIP Universitas Indonesia, Jakarta.

Mubyarto, Sulistiyo, and San Afri Awang (eds.) 1992 Perekonomian Rakyat Kalimantan. Aditya Media, Yogyakarta.

Mubyarto et al. 1991a Prosiding Seminar Nasional Pengembangan Perekonomian Rakyat Kalimantan di Pontianak. Yayasan Agro Ekonomika, J akarta.

Mubyarto et al. 1991b Kajian Sosial Ekonomi Desa-Desa di Perbatasan Kalimantan Timur. Aditya Media, Yogyakarta.

Müller-Dombois, D. and Ellenberg, D.H. 1974 Aims and Methods of Vegetation Ecology. J ohn Wiley \& Sons, New York.

Muul, I. 1993 Tropical forests, Integrated Conservation Strategies and the Concept of Critical Mass. MAB Digest No 15. Division of Ecological Sciences, Man and the Biosphere, UNESCO, Paris.

Nazir Foead 1997 Ecology of the Upper Bahau Grasslands in East Kalimantan: A Traditional Ecosystem Management for Pest Control? In: Sørensen, K.W. and Morris, B. (eds.) People and Plants of Kayan Mentarang, 113-122. WWF and UNESCO, London.

Needham, R. 1972 Punan-Penan. In: LeBar, F.M. (ed.) Ethnic Groups of Insular Southeast Asia. Vol.1: Indonesia, Andaman Islands and Madagascar. Human Relations Area Files Press, New Haven.

Ngindra, F. 1995a Pemenuhan Kebutuhan Makanan pada Suku Dayak Kenyah Bakung. Report. Culture \& Conservation, Kayan Mentarang Conservation Project, WWF and Direktorat J enderal Pelestarian Alam dan Perlindungan Hutan, Jakarta.

Ngindra, F. 1995b Upacara Agama Bungan pada Suku Kenyah Bakung. Report. Culture \& Conservation, Kayan Mentarang Conservation Project, WWF and Direktorat J enderal Pelestarian Alam dan Perlindungan Hutan, Jakarta.

Nicolaisen, J. 1976 The Penan of the Seventh Division of Sarawak; past present and future. Sarawak Museum J ournal 24: 34-61.

Nida, Eugene A., and R. Taber 1969 The Theory and Practice of Translation. Leiden: E.J . Brill.

Nieuwenhuis, A.W. 1901 Mededeelingen over het vervolg der Commissiereis naar Centraal-Borneo. Tijdschrift van het Koninklijk Ned. Aardrijkskundig Genootschap 18: $1013-1073$.

Nieuwenhuis, A.W. 1904-1907 Quer durch Borneo. Brill, Leiden. 2 vols.

Njau Anau 1995 Sejarah Suku Kenyah Leppo' Ké dan Nyibun di Kecamatan Long Pujungan. Report. Culture \& Conservation, Kayan Mentarang Conservation Project, WWF and Direktorat J enderal Pelestarian Alam dan Perlindungan Hutan, J akarta.

Norman Edwin 1989 Cooking pots from Bakekau. Voice of Nature 72: 31-33. 
Oka, H.I. 1988 Origin of Cultivated Rice. Japan Scientific Societies Press, Tokyo.

Orlove, B.S. and Brush, S. 1996 Anthropology and the conservation of biodiversity. Annual Review of Anthropology 25: 329-352.

Ostrom, E. 1992 Crafting Institutions for Self-Governing Irrigation Systems. Institute for Contemporary Studies Press, San Francisco.

Padoch, C. 1988 Agriculture in interior Borneo: shifting cultivation and alternatives. Expedition 1: 18-28.

Padoch C. and Peluso, N.L. (eds.) 1996 Borneo in Transition. People, Forests, Conservation, and Development. Kuala Lumpur: Oxford University Press.

Parker, P. and King, T. 1990 Guidelines for Evaluating and Documenting Traditional Cultural Properties. National Register Bulletin No. 38. National Park Service, Department of the Interior, Washington, D.C.

Parlindungan, A.P., S.H. 1989 Pembebasan Tanah Menurut Versi U.U.P.A. dalam Pembangunan Daerah dan Nasional. Paper to Seminar Peranan Hukum Adat, Fakultas Hukum, Universitas Tanjungpura, Pontianak, 12-14 December 1989.

Parlindungan, A.P., S.H. 1991 Komentar atas Undang-undang Pokok Agraria. Mandar Maju, Bandung.

Payne, J unaidi, Francis, C. M. and Phillips, K. 1985 A Field Guide to The Mammals of Borneo. The Sabah Society with WWF Malaysia. K.L., Malaysia.

Pelkey, N. 1995 Please stop the PRA RRA Rah. OUT of the SHELL (Coastal Resources Research Network News) 5 (1): 17-24.

Peluso, N. 1995 Whose woods are these? Counter-mapping forest territories in Kalimantan, Indonesia. Antipodes 27 (4): 383-406.

Pemberton, J. 1994 On the Subject of 'Java'. Cornell University Press, Ithaca.

Persoon, G. and van Est, D. 1998 Co-Management of Natural Resources: The Concept and Aspects of Implementation. Paper to the IIAS/ NIAS Workshop on Comanagement of Natural Resources in Asia: a Comparative Perspective. Cabagan, Isabela (Philippines), 16-18 September 1998.

Pfeffer, P. 1959 Biologie et migrations du sanglier de Bornéo (Sus barbatus Muller 1869). Mammalia 23: 277-303.

Pfeffer, P. 1990 Bivouacs à Bornéo. [First ed. 1963] Flammarion, Paris.

Pfeffer, P. and Caldecott, J.0. 1986 The bearded pig (Sus barbatus) in East Kalimantan and Sarawak. J MBRAS 59: 81-100.

Piazzini, G. 1960 The Children of Lilith - A French exploration into the up-river country of Borneo. Hodder and Stoughton, London.

Pickett, S.T.A. and White, P.S. 1985 The Ecology of Natural Disturbances and Patch Dynamics. Academic Press.

Pimbert, M. and Pretty, J. 1994 Participation, People and the Management of National Parks and Protected Areas: Past Failures and Future Promises. Draft discussion paper. United Nations Research Institute, Social Development and International Institute for Environment and Development, and World Wide Fund for Nature (April).

Piper, J. M. 1992 Bamboo and Rattan Traditional Uses and Beliefs. Images of Asia, Oxford University Press, New York.

Poerwadarminta, W.J.S. 1966 Kamus Umum Bahasa Indonesia. Balai Pustaka, Jakarta.

Poffenberger, M. (ed.) 1990 Keepers of the Forest, Land Management Alternatives in Southeast Asia. Ateneo de Manila University Press, Manila. 
Poffenberger, M. et al. 1990 Community Participation for Conservation Area Management in The Cyclops Mountains, Irian J aya, Indonesia. In: Poffenberger M. (ed.) Keepers of the Forest, Land Management Alternatives in Southeast Asia, 237-252. Ateneo de Manila University Press, Manila.

Prain, G., Uribe, F. and Scheidegger, U. 1992 The friendly potato: Farmer selection of potato varieties for multiple uses. In: Moock, J.L. and Rhoades, R.B. (eds.) Diversity, Farmer Knowledge, and Sustainability, 52-68. Cornell University Press, Ithaca.

Prentice, D.J. 1970 The linguistic situation in northern Borneo. In: Wurm, S.A. and Laycock, D.C. (eds.) Pacific Linguistic Studies in Honour of Arthur Capell, 369-408. Pacific Linguistics Series C13.

Puri, R.K. 1992 Mammals and Hunting on the Lurah River: Recommendations for Management of Faunal Resources in the Cagar Alam Kayan-Mentarang. Preliminary report to Project Kayan-Mentarang. WWF Indonesia Programme, J akarta, Indonesia.

Puri, R.K. 1993 Three Burial Sites with Human Remains. Manuscript.

Puri, R.K. 1997 Hunting Knowledge of the Penan Benalui of East Kalimantan, Indonesia. A dissertation submitted to the Graduate Division of the University of Hawaii in partial fulfillment of the requirements for the Degree of Doctor of Philosophy in Anthropology. Unpublished Ph.D. Dissertation. University of Hawaii, Department of Anthropology.

Puri, R. K. 1998 Assessment of the Biodiversity of the Bulungan Research Forest in East Kalimantan: An Introduction to the Ethnoecology of the Punan Tubu'. Report, CIFOR, Bogor.

Puri, R. K. 2001 Bulungan Ethnobiology Handbook. Center for International Forestry Research (CIFOR), Bogor.

Puri, R.K., Damus, D. and Sirait, M. 1991 Report Survey Ulu Bahau untuk Proyek Cagar Alam Kayan Mentarang. Unpublished report. Kayan Mentarang Conservation Project, WWF and Direktorat J enderal Pelestarian Alam dan Perlindungan Hutan, Jakarta.

Ray, S.H. 1913 The languages of Borneo. Sarawak Museum Journal 1 (4).

Redford, K.H. 1991 The ecologically noble savage. Cultural Survival Quarterly 15 (1): 4648.

Redford, K. and Padoch, C. (eds.) 1992 Conservation of Neotropical Forests. Working from Traditional Resource Use. Columbia University Press, New York.

Richards, P. 1986 Coping with Hunger: Hazard and Experiment in an African Rice-Farming System. Allen and Unwin, London.

Richards, P. 1989 Agriculture as a Performance. In: Chambers, R., Pacey, A. and Thrupp, L.A. (eds.) Farmer First: Farmer Innovation and Agricultural Research, 39-43. Intermediate Technology Publications.

Richards, P. 1992a Rice Biodiversity Conservation and Plant Improvement in Sierra Leone. Paper to the CTA/IBPGR/ KARI/ UNEP Conference, Nairobi, October 1992.

Richards, P. 1992b Rural development and local knowledge: The case of rice in central Sierra Leone. Etnwicklungsethnologie 1: 26-40.

Richards, R.J. 1992 The structure of narrative explanation in history and biology. In: Nitecki, M. H. and Nitecki, D.V. (eds.) History and Evolution, 19-53. State University of New York Press, Albany.

Riwut, T. 1979 Kalimantan Membangun. Palangka Raya.

Rohadi, J . S. 1990 Relasi Sesama Ciptaan. Suatu Studi Mengenai Tingkah Laku Manusia Atas Hutan. Unpublished thesis, Sekolah Tinggi Teologia, Jakarta. 
Roodenburg, W.P. 1935 Memorie van Overgave van de Onderafdeling Apau Kajan. Manuscript.

Rosaldo, R. 1980a Doing oral history. Social Analysis 4: 89-99.

Rosaldo, R. 1980b Ilongot Headhunting 1883-1974: A Study in Society and History. Stanford University Press, Palo Alto.

Roth, H. L. 1968 (1896) The Natives of Sarawak and British North Borneo. University of Malaya Press, Singapore. 2 vols.

Rousseau, J. (ed.) 1974 The peoples of central Borneo. Sarawak Museum J ournal Special Issue No. 22.

Rousseau, J. 1979 Kayan stratification. Man 14: 215-236.

Rousseau, J. 1988 Central Borneo: A bibliography. Special Monograph, Sarawak Museum J ournal. Sarawak Museum, Kuching.

Rousseau, J. 1990 Central Borneo. Ethnic Identity and Social Life in a Stratified Society. Clarendon Press, Oxford.

Rudes, R.R. 1965 A General Description of Peoples and Places on the Kajan River of East Kalimantan, Indonesia. Manuscript, J uly 1965.

Rufinus, A. 1995 Sistem Kebahasaan Lepo' Bakung di Apan Baru, Long Pujungan. Report. Culture \& Conservation, Kayan Mentarang Conservation Project, WWF and Direktorat J enderal Pelestarian Alam dan Perlindungan Hutan, J akarta.

Saad, M. S. 1967 Catatan Kecil Sekitar Penelitian Kesusastraan: Penelitian Cerita Rekaan. In: Bahasa dan Kesustraan Indonesia Sebagai Cermin Manusia Indonesia Baru. Gunung Agung, J akarta.

Saleh Adiwinata, S.H. 1983 Pengertian Hukum Adat Menurut Undang-undang Pokok Agraria. Penerbit Alumni, Bandung.

Sandin, Benedict 1980 The Living Legends, Borneans Telling their Tales. Dewan Bahasa dan Pustaka Malaysia, Cawangan Sarawak, Kuching.

Santoso Sugondho 1983 Hasil penerapan metode analisis gerabah dalam penelitian arkeologi. In: Rapat Evaluasi Hasil Penelitian Arkeologi I 1982, vol. IIA, 126-145. Puslit Arkenas, Departemen Pendidikan dan Kebudayaan, Jakarta.

Sapardi 1992 Pengaruh Proyek Perusahaan Inti Rakyat Perkebunan Terhadap Ekonomi Rumah Tangga Peladang. Universitas Indonesia, Jakarta.

Sarbino 1992 Pedoman Praktikum Dasar-dasar Agronomi. Fakultas Pertanian, Universitas Tanjungpura, Pontianak.

Sarief, S.E. 1988 Konservasi Tanah dan Air. Pustaka Buana, Bandung.

Sather, C. 1972 Tidong. In: LeBar, F.M. (ed.) Ethnic Groups of Insular Southeast Asia, volume 1: Indonesia, Andaman Islands, and Madagascar, 167-168. HRAF Press, New Haven.

Sather, C. 1990 Trees and tree tenure in Paku Iban society: the management of secondary forest resources in a long-established Iban community. Borneo Review 1 (1): 16-40.

Scheffelaar, P.C.J . 1931 Memorie van Overgave van de Onderafd. Apau Kajan. Manuscript.

Schneeberger, W.F. 1979 Contributions to the ethnology of central northeast Borneo (Parts of Kalimantan, Sarawak and Sabah). Studia Ethnologica Bernensia, No. 2. The University of Bern, Bern.

Schrire, C. (ed.) 1984 Past and Present in Hunter-Gatherer Studies. Academic Press, London. 
Sejati Foundation 1994 Dayak and Biodiversity. Cultural Survival and Nature Conservation in Remote Interior Kalimantan. $16 \mathrm{~mm}$ film (transferred to Hi-8 video), 15 minutes. World Wide Fund for Nature, UNESCO, and Yayasan Sejati, J akarta.

Sellato, B. 1987 Note Préliminaire sur les Sociétés à Maison à Bornéo and Maisons et Organisation Sociale en Asie du Sud-Est. In: Macdonald, C. (ed.) De la Hutte au Palais, Sociétés à Maison en Asie du Sud-est Insulaire, 15-44, 195-207. Editions du CNRS, Paris.

Sellato, B. 1989a Proposal of guidelines for a project on oral traditions in Kalimantan, Indonesia, for the Ford Foundation, November. Jakarta.

Sellato, B. 1989b Hornbill and Dragon. Elf Aquitaine, Jakarta.

Sellato, B. 1990 Project on Oral Traditions in Kalimantan. Report to the Ford Foundation, April. Jakarta.

Sellato, B. 1992a Cultural community-development projects in Kayan Mentarang. Repopulation and ethno-cultural identity: Two major factors in communitydevelopment projects and nature conservation. Memo to WWF/IP, J akarta.

Sellato, B. 1992b A proposal for an interdisciplinary project in archaeology, ethnohistory, comparative linguistics, and palaeoecology in the upper Bahau river area, East Kalimantan. Paper to the Second Biennial International Conference of the Borneo Research Council, Kota Kinabalu, July 1992.

Sellato, B. 1993 Salt in Borneo. In: Le Roux, P. and Ivanoff, J. (eds.) Le Sel de la Vie en Asie du Sud-Est, 263-284. Grand Sud No. 4. Prince of Songkla University, Patani.

Sellato, B. 1994a The Culture and Conservation Program in the Kayan Mentarang Conservation Area. Borneo Research Bulletin 26: 54-68.

Sellato, B. 1994b Nomads of the Borneo Rainforest. The Economics, Politics, and Ideology of Settling Down. University of Hawai'i Press, Honolulu.

Sellato, B. 1994c Forêts tropicales et sociétés traditionnelles à Bornéo: Vers une histoire régionale 'en continu' de l'environnement et des systèmes de subsistance. Ecologie Humaine 12 (2): 3-22.

Sellato, B. 1994d Social Organization, Residence Patterns, and Ethnolinguistic Boundaries in East Kalimantan. Paper to the Third Biennial International Conference of the Borneo Research Council, Pontianak, July 1994.

Sellato, B. 1995a Four Upstream Kenyah Settlements in a Changing World, Long Puj ungan District: A Preliminary Social and Demographic Survey. Report. Culture \& Conservation, Kayan Mentarang Conservation Project, WWF \& Direktorat J enderal Pelestarian Alam dan Perlindungan Hutan, Jakarta.

Sellato, B. 1995b The Kenyah Dialects of Long Pujungan District: A Provisional Assessment. Report. Culture \& Conservation, Kayan Mentarang Conservation Project, WWF \& Direktorat J enderal Pelestarian Alam dan Perlindungan Hutan, J akarta.

Sellato, B. 1995c The Ngorek: Lithic and Megalithic Traditions in the Bahau Area and an Interdisciplinary Sketch of Regional History. Report. Culture \& Conservation, Kayan Mentarang Conservation Project, WWF \& Direktorat Jenderal Pelestarian Alam dan Perlindungan Hutan, Jakarta.

Sellato, B. 1995d Cultural Community Development Projects in Long Pujungan District, Kayan Mentarang. Report. Culture \& Conservation, Kayan Mentarang Conservation Project, WWF and Direktorat Jenderal Pelestarian Alam dan Perlindungan Hutan, J akarta. 
Sellato, B. 1995e (ed.) Culture \& Conservation in East Kalimantan, Jakarta: World Wide Fund for Nature Indonesia Programme. 5 vols.

Sellato, B. 1996a Culture and conservation in East Kalimantan. Indonesian Environmental History Newsletter 8: 11-12.

Sellato, B. 1996b Stone nutcrackers and other recent finds of lithic industry in interior northeastern Kalimantan. Sarawak Museum J ournal 50 (71): 39-65.

Sellato, B. 1997a The Last Traditional Potter's Dying Art in Long Pujungan District. In: Sörensen, K.W. and Morris, B. (eds.) People and Plants of Kayan Mentarang, 237240. WWF/IP and UNESCO, London.

Sellato, B. 1997b Dayak Kenyah Ritual Sunhats with Resist-dye Technique in Long Puj ungan District. In: Sörensen, K.W. and Morris, B. (eds.) People and Plants of Kayan Mentarang, 229-234. WWF/IP and UNESCO, London.

Sellato, B. 1997c Agricultural Practices, Social Organization, Settlement Patterns, and Ethnogenetic Processes in East Kalimantan. In: K.W. Sörensen and B. Morris (eds.) London: WWF/IP and UNESCO, pp. People and Plants of Kayan Mentarang, 27-58.

Sellato, B. 1999 L'Ethnologue entre l'Écologiste et le Bon Sauvage. De I'Usage de la Recherche en Sciences Humaines pour la Praxis des ONG et le Développement Durable. In: Bahuchet, S. et al., (eds.) L'Homme et la Forêt Tropicale, 89-98. Editions de Bergier, Chateauneuf-de-Grasse, France.

Sellato, B. 2001 Forest Resources and People in Bulungan. Elements for a History of Settlement, Trade, and Social Dynamics in Borneo, 1880-2000. Center for International Forestry Research (CIFOR), Bogor.

Sellato, B. 2002 Non-timber forest products and trade in eastern Borneo. Bois $\&$ forêts des tropiques 271: 37-50.

Sellato, B. in press 1 . Social organization, settlement patterns, and ethnolinguistic processes of group formation: The Kenyah and Putuk in East Kalimantan. In: Martin, P.W.(ed.) Language Issues in Borneo, 1-48. Borneo Research Council, Williamsburg, VA.

Sellato, B. in press 2 Culture, History, Politics and the Emergence of Provincial Identities in Kalimantan. In: Charras, M. (ed.) Beyond the State. Essays on Spatial Structuration in Insular Southeast Asia. CNRS, Paris.

Sellato, B., and J essup, T.C. 1994 Culture and Conservation in East Kalimantan. Report of Interim Activities [to the Ford Foundation] by the World Wide Fund for Nature Indonesia Programme, December. Jakarta.

Setyati, S. 1987 Dasar-dasar Agronomi. Swadaya, Jakarta.

Setyawati, I. 1991 Variasi Pengetahuan Pertanian dan Praktek Pengendalian Hama Padi di Kalangan Petani Pedesaan J awa. Unpublished BA Thesis, Fakultas IImu Sosial dan Ilmu Politik, Universitas Indonesia. Jakarta.

Setyawati, I. 1995 Knowledge and Use of Rice Varieties in Apau Ping, Long Pujungan District. Culture \& Conservation, Kayan Mentarang Conservation Project, WWF and Direktorat J enderal Pelestarian Alam dan Perlindungan Hutan, Jakarta.

Shipley, J. T. et al. 1962 Dictionary of World Literature. Littlefield, Adams and Co., Catterson, New J ersey.

Sierevelt, A.M. 1927 Memorie van Overgave van de Onderafd. Apau Kajan. Manuscript. Sierevelt, A.M. 1929 Oudheden in Apo-Kajan. Oudheidkundig Verslag 1929, 162-164. Sillitoe, P. 1998 The development of indigenous knowledge. Current Anthropology 39 (2): $223-252$. 
Sirait, M. et al. 1994 Mapping customary land in East Kalimantan, Indonesia: a tool for forest management. Ambio 23 (7): 411-417.

Sirait, M. T. 1995 Rotan, Pengelolaannya dan Kegunaannya pada Masyarakat Desa Long Uli. Report. Culture \& Conservation, Kayan Mentarang Conservation Project, WWF and Direktorat Jenderal Pelestarian Alam dan Perlindungan Hutan, Jakarta.

Siti Susiarti 1992 Pengetahuan Tumbuhan Obat and Racun di Desa Apau Ping dan Sekitarnya di Kecamatan Pujungan, Kalimantan Timur. Unpublished report. Balitbang Botani, Puslitbang Biologi, LIPI, Bogor.

Sloan, C. 1975 A study of the Punan Busang, III: Punan hunting methods. Malayan Nature Journal 28: 146-151.

Soedjito, H. and Kartawinata, K. 1994 Long-term Ecological Research: Top Priority for Achieving Sustainable Forest Management in Indonesia. Report. LIPI, Bogor, February 1994.

Soeharto, M. 1982 Belajar Notasi Balok. Gramedia, Jakarta.

Soemardjan, S. and Soelaiman Soemardi 1964 Setangkai Bunga Sosiologi. Yayasan Badan Penerbit Fakultas Ekonomi Universitas Indonesia.

Soemarwoto, 0. 1991a Indonesia dalam Kancah Isu Lingkungan Global. Gramedia Pustaka Utama, Jakarta.

Soemarwoto, O. 1991b Interaksi manusia dan lingkungan: Faktor kritis dalam pembangunan berkelanjutan. Prisma 1: 14-23.

Soerj ono Soekanto 1985 Meninjau Hukum Adat Indonesia. Suatu Pengantar untuk Mempelaj ari Hukum Adat. Edisi ke-3. Rajawali, Jakarta.

Soerjono Soekanto, Eddie T. Hendro, and Th. Sarjito 1984 Antropologi Hukum. Proses Pengembangan IImu Hukum Adat. Rajawali, Jakarta.

Soetardjo Kartohadikusumo 1953 Desa. Dian Rakyat, Jakarta.

Sörensen, W.K., and Morris, B. (eds.) 1997 People and Plants of Kayan Mentarang. WWF/ IP and UNESCO, London.

Soriente, A. 1999 Situasi Kebahasaan di Kecamatan Long Pujungan. In: Eghenter, C. and Sellato, B. (eds.) Kebudayaan dan Pelestarian Alam. Penelitian interdisipliner di pedalaman Kalimantan, 465-483. WWF/ IP, J akarta.

Soriente 2002 A Classification of Kenyah Variants in Sarawak and Kalimantan. Ph.D. thesis, Fakulti Sains Sosial dan Kemanusiaan, Universiti Kebangsaan Malaysia, Bangi, Malaysia.

Southwell, C. H. 1990 Kayan-English Dictionary. 2nd ed. Sarawak Literary Society, Kuching.

Sperling, L. 1992 Farmer Participation and the Development of Bean Varieties in Rwanda. In: Moock, J.L. and Rhoades, R.B. (eds.) Diversity, Farmer Knowledge, and Sustainability, 96-111. Cornell University Press, Ithaca.

Sponsel, L.E. 1997 Comment on T. Headland's 'Revisionism in ecological anthropology'. Current Anthropology 38 (4): 619-622.

Sponsel, L. Headland, T. and Bailey, R. 1996 Tropical Deforestation: The Human Dimension. Columbia University Press, New York.

Spradley, J. 1980 Participant Observation. Holt, Rinehart, and Winston, New York.

Sri Munawarah 1995 Struktur Kebahasaan Kenyah Bakung di Desa Long Apan Baru. Report. Culture \& Conservation, Kayan Mentarang Conservation Project, WWF and Direktorat J enderal Pelestarian Alam dan Perlindungan Hutan, Jakarta. 34p. 
Stockdale, M.C. 1992 People and Rattan in Upper Bahau Area. Unpublished report. Kayan Mentarang Conservation Project, WWF and Direktorat J enderal Pelestarian Alam dan Perlindungan Hutan, J akarta.

Stokhof, W.A.L. (ed.) 1983-86 Holle's Lists: Vocabularies in the Languages of Indonesia. Pacific Linguistics Series D, No. 69, vol. I and vol. VIII. Australian National University, Canberra.

Surojo Wignjopuro, S.H. 1982 Pengantar dan Azas-azas Hukum Adat. 4th ed. Gunung Agung, J akarta.

Suryawinata, Zuchridin 1989 Terjemahan: Pengantar Teori dan Praktek. Proyek Pengembangan Lembaga Pendidikan Tenaga Kependidikan, Direktorat Jenderal Pendidikan Tinggi, Departemen Pendidikan dan Kebudayaan, Jakarta.

Sutarman, G. 1993 Manajemen Lahan di Abad 21. Translated by Lal, R. and Force, R.J . In: Soil Management in the $21^{\text {st }}$ Century. Suara Almamater UNTAN, Pontianak.

Sutlive, V. H. J r. 1978 The Iban of Sarawak. AHM Publishing Corporation, Arlington Heights, Illinois.

Syahirsyah 1995 Suksesi Vegetasi, Perladangan Daur Ulang dan Pengetahuan Masyarakat Kenyah di Hulu Sungai Bahau. Report. Jakarta; Culture \& Conservation, Kayan Mentarang Conservation Project, WWF and Direktorat J enderal Pelestarian Alam dan Perlindungan Hutan.

Syahirsyah 1997 Local knowledge in relation to secondary forest land and the utilization of forest resources. In: Sörensen, W.K. and Morris, B. (eds.) People and Plants of Kayan Mentarang, 101-112. WWF/IP and UNESCO, London.

Sylado, R. 1989 Menuju Apresiasi Musik. Penerbit Angkasa, Bandung.

Tillema, H.F. 1937 Primitieve pottenbakers. Natuur en Techniek 7: 449-451.

Tillema, H.F. 1938 Apo-Kajan; Een filmreis naar en door Centraal-Borneo. Van Munster, Amsterdam.

Tillema, H.F. 1989 A J ourney among the Peoples of Central Borneo in Words and Pictures. King, V.T. (ed.). Oxford University Press, Singapore.

Tjitradjaja, I. 1993 Differential access to resources and conflict resolution in a forest concession in Irian Jaya. Ekonesia 1 (1): 58-69.

Tjitradjaja, I. et al. 1994 Kajian Pengembangan Institusi Masyarakat di Dalam dan Sekitar Hutan: Kasus Pengelolaan Hutan Damar di Krui, Lampung Barat. Program Studi Antropologi, Program Pasca Sarjana Universitas Indonesia, dan Administrator Pusat Perhutanan Sosial, Direktorat J enderal Pengusahaan Hutan, Departemen Kehutanan Republic of Indonesia, Jakarta.

Tonkin, E. 1992 Narrating Our Pasts. The Social Construction of Oral History. Cambridge University Press, Cambridge.

Tulung Anye' 1989 Mengenal: Suku Dayak Kenyah Menerima Pendidikan Agama dan Perkembangannya. Manuscript.

Ukur, F. 1971 Tantang Djawab Suku Dayak. BPK Gunung Mulia, J akarta.

Uluk, A., Sudana, M. and Wollenberg, E. 2001. Ketergantungan Masyarakat Dayak terhadap Hutan di Sekitar Taman Nasional Kayan Mentarang. CIFOR, Bogor.

Urquhart, I.A.N. 1950 Some notes on jungle Punans in Kapit District. Sarawak Museum Journal 5(3): 495-533.

Vansina, J. 1980 Memory and Oral Tradition. In: Miller, J. (ed.) The African Past Speaks, 262-279. Dawson-Archon, Folkestone, UK. 
Vansina, J. 1985 Oral Tradition as History. University of Wisconsin Press, Madison. Vaughan, D.A. 1980 Report of Trip to South and Central Kalimantan, 15 July-29 July 1978. Report.Genetic Resources Program, IRRI.

Vaughan, D.A. and Chang, T.T. 1992 In situ conservation of rice genetic resources. Economic Botany 46: 368-383.

Vayda, A.P. 1992 Report on Kayan Mentarang Consultancy, July-August 1992. Report. Kayan Mentarang Conservation Project, WWF and Direktorat J enderal Pelestarian Alam dan Perlindungan Hutan, Jakarta.

Vayda, A.P. 1993 Report on a Visit to the WWF Kayan Mentarang Project with Particular Reference to the Sub-Project on Culture and Conservation, J une-J uly 1993. Unpublished report. Kayan Mentarang Conservation Project, WWF and Direktorat J enderal Pelestarian Alam dan Perlindungan Hutan, Jakarta.

Vayda, A.P. 1997 Managing Forests and Improving the Livelihoods of Forest-Dependent People. Working Paper No. 16. CIFOR, Bogor.

Vayda, A.P., McCay, B.J. and Eghenter, C. 1991 Concepts of process in social science explanations. Philosophy of the Social Sciences 21 (3): 318-331.

Vollenhoven, C. van 1918-1933 Het Adatrecht van Nederlandsch Indië. Brill, Leiden. 3 vol.

Voss, J. 1992 Conserving and increasing on-farm genetic diversity: Farmer management of varietal bean mixture in Central Africa. In: Moock, J.L. and Rhoades, R.B. (eds.) Diversity, Farmer Knowledge, and Sustainability, 34-51. Cornell University Press, Ithaca.

Vredenbregt, J. 1978 Metode dan Teknik Penelitian Masyarakat. Gramedia, Jakarta.

Wadley, R. n.d. Ethics of Access, Boundary Keeping and Forest Resource Management in Indonesian Borneo: Potential Tools for Conservation Work among Mobile Peoples. Manuscript.

Wadley, R., Colfer, C. and Hood, I. 1997 Hunting primates and managing forests: the case of Iban forest farmers in Indonesian Borneo. Human Ecology 25 (2): 243271.

Wahyudi, W.R. 1985 Beberapa Metode Analisis Tembikar di Indonesia Berdasarkan Penelitian Tahun 1973-1983. Unpublished BA thesis, J urusan Arkeologi, Fakultas Sastra, Universitas Indonesia.

Wakijo Adiwijaya 1978 Seni Suara dan Teori Musik Praktis. Hasmar, Medan. 3 volumes.

Walchren, E.W.F. van, 1907 Eene reis naar de Bovenstreken van Boeloengan (middenBorneo). Tij dschrift van het Koninklijk Nederlandsch Aardrij kskundig Genootschap 24: $755-844$.

Wantjik Saleh, K. 1982 Hak Anda Atas Tanah. 4th ed. Ghalia Indonesia, Jakarta.

Warren, M., Slikkerveer, L. J. and Brokensha, D. 1995 The Cultural Dimensions of Development: Indigenous Knowledge Systems. Intermediate Technology Publications Ltd., London.

Watson, G.A. 1984 Utility of Rice Cropping Strategies in Semuda Kecil Village, Central Kalimantan, Indonesia. In: Workshop on Research Priorities in Tidal Swamp Rice, 49-67. International Rice Research Institute, Los Baños.

Wells, M. 1995 Biodiversity Conservation and Local Development Aspirations: New Priorities for the 1990s. In: Peerings, C.A. et al. (eds.) Biodiversity Conservation, 319-333. Kluwer Academic Publishers, Amsterdam. 
Wells, M. and Brandon, K. 1992 People and Parks. Linking Protected Area Management with Local Communities. World Bank, WWF, and USAID, Washington D.C.

Western, D., Wright, R.M. and Strum, S.C. (eds.) 1994 Natural Connections: Perspectives on Community-Based Conservation. Island Press, Washington, D.C.

Whitmore, T.C. 1972-84 Tree Flora of Malaya. Oxford University Press, London. 4 vols. Whitmore, T.C. 1984 Tropical Rain Forests of the Far East. Clarendon Press, Oxford. Whitmore, T.C. 1985 (1973) Palms of Malaya. Oxford University Press, London.

Whittier, H. L. 1973 Social Organization and Symbols of Social Differentiation: An Ethnographic Study of The Kenyah Dayak of East Kalimantan (Borneo). Unpublished Ph.D. dissertation, Michigan State University, East Lansing.

Whittier, H. L. 1978a The Kenyah. In: King, V.T. (ed.) Essays on Borneo Societies, 92122. Hull Monographs on South-East Asia No. 7. Oxford University Press, Oxford.

Whittier, H. L. 1978b Concepts of adat and cosmology among the Kenyah Dayak of Borneo. Sarawak Museum J ournal 26: 103-113.

Whittier, H.L. and Whittier, Patricia R. 1974 The Apo Kayan area of East Kalimantan. Sarawak Museum J ournal 22 (43): 5-15.

Whittier, Herbert L. 1974 Some Apo Kayan megaliths. In: The Peoples of Central Borneo. J. Rousseau (ed.) special issue of the Sarawak Museum Journal 22 (43): 369-381.

Whittier, P.R. 1981 Systems of Appellation among the Kenyah Dayak of Borneo. Unpublished Ph.D. dissertation, Michigan State University, East Lansing.

Widjaja, E.A., and Jessup, T.C. 1986 Short description of indigenous rice from East Kalimantan, Indonesia. FAO/IBPGR Plant Genetic Resources Newsletter 67: 44-45.

Williams, J.T., Zamora, A.B., Saxena, S., Dhawan, V., Banik, R.L., Ramanuja Rao, I.V., Lakshmana, A.C., Fu Maoyi, Watanabe, M., Wan Razali Mohd., Stockdale, Mary C. 1994. Constraints to Production of Bamboo and Rattan. Report of a Consultative Meeting held in Bangalore, India, 9-13 May 1994. International Network for Bamboo and Rattan (INBAR) Khoday Biotek.

Wilshusen, P.R., Brechin, S.R., Fortwangler, C.L. et al. 2002 Reinventing a square wheel: Critique of a resurgent 'protection paradigm' in international biodiversity conservation. Society and Natural Resources 15 (1): 17-40.

Wollenberg, E. 2001. Incentives for collecting gaharu (fungal-infected wood of Aquilaria spp.; Thymelaeaceae) in East Kalimantan. Economic Botany 55 (3): 444-456.

Wollenberg, E., Nawir, A.A., Uluk, A. and Pramono, H. 2001. Income is Not Enough: The Effect of Economic Incentives on Forest Product Conservation. CIFOR, Bogor.

Wong, M., and Manokraman, M. 1985 Proceedings of the Rattan Seminar, 2-4 October 1984, Kuala Lumpur, Malaysia. Rattan Information Centre, Forest Research Institute, Kepong, Malaysia.

World Bank 1996 The World Bank Participation Sourcebook. World Bank, ESD. Washington, D.C.

Wulffraat, S. and Samsu 2000 An Overview of the Biodiversity of Kayan Mentarang National Park. WWF Indonesia Kayan Mentarang Project, Samarinda.

Wurm, S.A., and S. Hattori (eds.) 1983 Language Atlas of the Pacific Area, Part II: J apan Area, Taiwan (Formosa), Philippines, Mainland and Insular South-East Asia. Pacific Linguistics, Series C, No. 67. Australian Academy of the Humanities, Canberra; The Japan Academy, Tokyo. 
WWF and Direktorat J enderal Pelestarian Alam dan Perlindungan Hutan 1992 Hasil Field Survey. Report. Kayan Mentarang Conservation Project, WWF and Direktorat J enderal Pelestarian Alam dan Perlindungan Hutan, J akarta.

WWF and Direktorat J enderal Pelestarian Alam dan Perlindungan Hutan 1995 Pemungutan Gaharu di Apau Kayan: Permasalahan dan Konteksnya. Report. Kayan Mentarang Conservation Project, WWF and Direktorat Jenderal Pelestarian Alam dan Perlindungan Hutan, J akarta.

WWF/I and WWF-D 1996 Conservation Management and Community Development in the Kayan Mentarang Nature Reserve, East Kalimantan, Indonesia. A proposal to the Danish Agency of Development Assistance (DANIDA). J akarta.

WWF-I 2000 Management Plan Kayan Mentarang National Park, East Kalimantan 20012025. Directorate of Forest Protection and Nature Conservation, Jakarta.

Yampolsky, P. 1995 Forces for Change in Regional Performing Arts in Indonesia. Bij dragen tot de Taal-, Land- en Volkenkunde 151: 700-725.

Young, P. V. 1965 Scientific Social Surveys and Research. Modern Asia Editions, Charles E. Tuttle. Tokyo.

Zach, P. (ed.) 1988 East Kalimantan. Times Editions, Singapore.

Zainie, C. 1969 Handcraft in Sarawak. Borneo Literature Bureau, Kuching.

Zen, M.T. 1992 Prakata. In: L.R. Brown (ed.) Hari yang Keduapuluh Sembilan, ix-xxv. Translated by Usica. Yayasan Obor Indonesia, Jakarta.

Zerner, C. 1994 Through a green lens: The construction of customary environmental law and community in Indonesia's Maluku Islands. Law and Society Review 28 (5): $1079-1121$. 


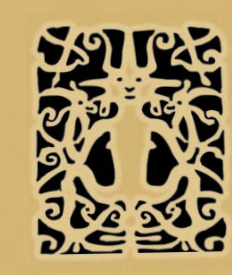

The Culture \& Conservation Research Program in Kayan Mentarang National Park, East Kalimantan, constituted a unique interdisciplinary engagement in central Borneo that lasted for six years (1991-97). Based on original ethnographic, ecological, and historical data, this volume comprehensively describes the people and the environment of this region and makes a rare contribution to the understanding of past and present interactions between people and forests in central Borneo. Kayan Mentarang has thus become one of the ethnographically best known protected areas in Southeast Asia. By pointing at the interface between research and forest management, this book offers tools for easing the antagonism between applied and scholarly research, and building much needed connections across fields of knowledge.

ISBN 979-3361-02-6

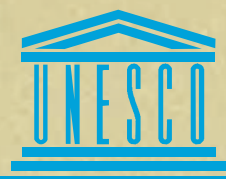

